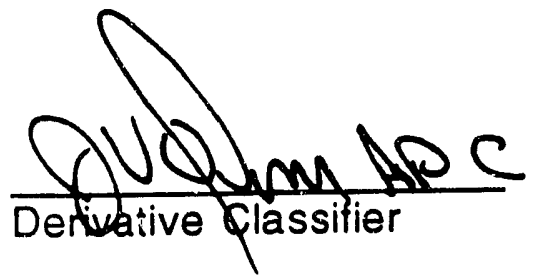

March 1993

ENVIRONMENTAL IMPLEMENTATION PLAN(U)

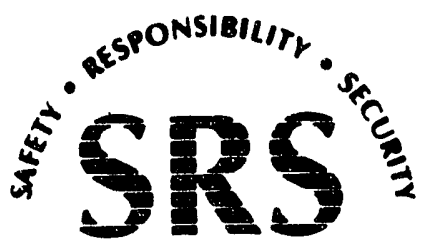

SAVANNAH RIVER SITE

Westinghouse Savannah River Company

Savannah River Technology Center

Aiken, SC 29808 


\section{WESTINGHOUSE SAVANNAH RIVER COMPANY \\ MEMORANDUM}

March 15, 1993

ENVIRONMENTAL IMPLEMENTATION PLAN (EIP) , WSRC-IM-93-17，(U)

The Environmental Implementation Plan (EIP) is a dynamic long-range environmental-protection plan for SRS. The EIP communicates the current and future (five year) environmental plans of individual organizations and divisions as well as site environmental initiatives which are designed to protect the environment and meet or exceed compliance with changing environmental/regulatory requirements. Communication among all site organizations is essential for making the site environmental planning process work.

I appreciate the "Partnership in Environmental Excellence" formed by the environmental coordinators and professionals who work daily toward our goal of environmental excellence and compliance.

I look forward to seeing continued success and improvement in our environmental protection programs through combined efforts of all site organizations to protect our employees, the public health, and the environment.

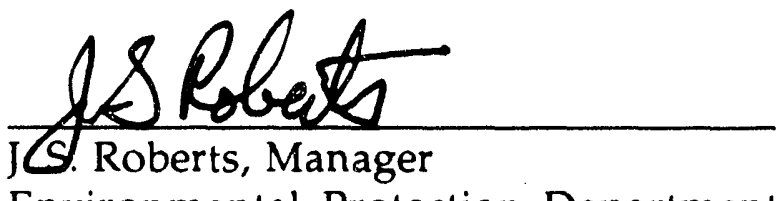

Environmental Protection Department 


\section{DISCLAIMER}

This report was prepared as an account of work sponsored by an agency of the United States Government. Neither the United States Government nor any agency thereof, nor any of their employees, makes any warranty, express or implied, or assumes any legal liability or responsibility for the accuracy, completeness, or usefulness of any information, apparatus. product, or process disclosed, or represents that its use would not infringe privately owned rights. Reference herein to any specific commercial product, process, or service by trade name, trademark, manufacturer, or otherwise does not necessarily constitute or imply its endorsement, recommendation, or favoring by the United States Government or any agency thereof. The views and opinions of authors expressed herein do not necessarily state or reflect those of the United States Government or any agency thereof.

This report has been reproduced directly from the best available copy.

Available to DOE and DOE contractors from the Office of Scientific and Technical Information, P.O. Box 62, Oak Ridge, TN 37831; prices available from (615) 576-8401, FTS 626-8401.

Available to the public from the National Technical Information Service, U.S. Department of Commerce, 5285 Port Royal Rd., Springfield, VA 22161. 


\section{Acknowledgments}

The Environmental Implementation Plan (EIP) is the product of the combined efforts of more than 100 Site professionals representing all Site organizations. Through a Partnership in Environmental Fxecllence, SRS environmental coordinators work daily toward our goal of Environmental Excellence and Compliance. The following additional recognition is given to the people and groups who helped develop this year's plan.

Acknowledgments are given to the members of the Central Environmental Committee Executive Committee (CECEC) for their vision, ideas, and continuing support to the EIP subcommittee, EIP Action Plan, and the EIP revision process.

A very special thanks to the EIP subcommittee members who volunteered to identify and incorporate customer expectations and expected benefits into the EIP revision process. Their teamwork and ideas produced the ElP Action Plan to revise the EIP in a way that develops program ownership, user value, and continuous improvement. The subcommittee members are as follows:

Bob Brookshire, Jennifer D'Orso, Steve Etheridge, Mark Kidd, Ken Lane, Steve Mertz, Sara Mundy, Greg Pelerson, Barbara Sly, Clarke Stanford, JoAnne Steingard, Beth Wheat, and Kathy Wolf.

Special support and guidance was provided to the EIP subcommittee by:

Jim Jackson, GCO

Todd Crawford, SRTC

\section{Steve Wright, DOE-SR \\ Dennis Ryan, DOE-SR}

Chris Thompson, CECEC Brenda Kelly, TQPD

A thank you is expressed to the environmental coordinators and professionals for their review and revisions to the March 1992 draft and/or the 1993 EIP:

Bill Austin, Al Boni, John Black, Doris Chavis, Todd Crawford, Phil Croll, Roger Duke, Allen Edenfield, Stephanie Fuller, Rooney Floyd, John Gladden, Dean Hayden, Nancy Halverson, Vivian Harper, Dawn Kaback, Joe Kato, Robyn McBeath, Mark Peters, Roger Pitts, Jim Riggsbee, Traci Richardson, Paul Rowan, Deb Moore-Shedrow, Stan Smith, Cary Stevens, Jim Sutherland, Bob Tarrant, and Nancy Turner.

Thank you to the EPD managers and environmental professionals for their continuing support of the EIP revision process and for your revisions to the March 1992 draft and the 1993 EIP. Their names are listed throughout the EIP.

Thank you to Ron Frontroth, Tom Gould, and Chris Noah for sharing planning information and ideas to integrate the EIP with other planning documents and to Doris Chavis and Terry Allen for sharing ideas and information from the Site Specific Plan and Waste Management Program Plan.

Thank you to Jeff Hammond, Shirley Hightower, Norene Powell, Richard Shipley, Diane Spitzer, Barbara Strack, Jeanne Sellers and their teams of professionals for their skills and efforts to make the EIP a quality document for our readers; and to the Print Shop team who provided timely support to the EIP.

$\Lambda$ very special thanks to the Environmental Advisory Committee, Environmental Management Team, and Natural Resources Coordinating Committee for their continuing support and input into the EIP planning process. 


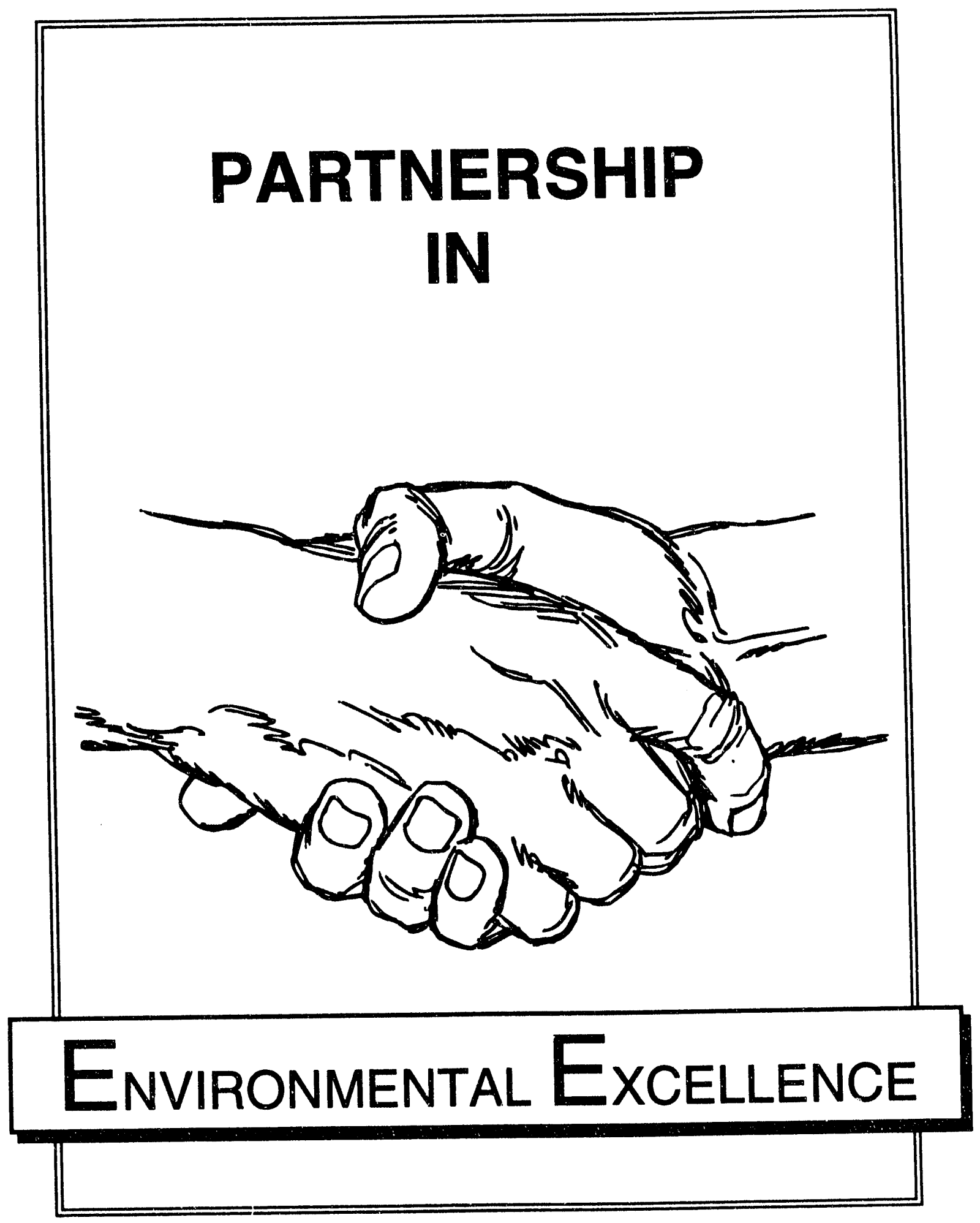




\section{CONTENTS}

Preface P-1

Background P-2

Document Organization P-3

How to Read the Plan P-4

Customer Survey C-1

Acronyms A-1

EIP Introduction $\mathbf{1 - 1}$

Reflections $1-9$

Sectional Revision 1-9

Integrated Planning 1-10

Strategic Plan for Environmental Compliance 2-1

Executive Summary (under development) 3-1

Environmental Monitoring 4-1

Sampling Program 4-12

Laboratory Programs 4-15

Monitoring Reports 4-18

Radiological Effluent Management 4-22

Chemical Management, Pollution Prevention and Other Compliance Programs 5-1

Toxic Substances Control Act 5-6

Polychlorinated Biphenyls (PCBs) 5-9

Federal Insecticide, Fungicide, \& Rodenticide Act (FIFRA) 5-13 
Emergency Planning and Community Right-To-Know Act (EPCRA) 5-16

Spill Prevention and Control Program 5-19

Safe Drinking Water Act (SDWA) $\quad 5-23$

National Environmental Policy Act (NEPA) 5-28

Natural Resource Protection 6-1

Land Use and Wildlife Protection 6-3

Land Use 6-15

Endangered Species 6-20

Other Wildlife 6-23

Wildlife Habitat $\quad 6-27$

Land Reclamation and Erosion Control 6-29

Surface Water and Wetlands Protection Site Program 6-32

Stream Management 6-42

Thermal Mitigation 6-46

NPDES: Wastewater 6-50

NPDES Storm Water Associated with Industrial Activity 6-58

NPDES Storm Water Associated with Construction Activity 6-63

Erosion Control 6-66

Waste Treatment Facilities 6-68

Wetlands 6-77

\section{Groundwater Protection 7-1}

Groundwater Consumption 7-11

Hydrogeological Regime Analysis 7-13

Groundwater Monitoring 7-18 
Water Conservation $\quad 7-26$

Contamination Prevention 7-29

Contamination Detection 7-35

Waste Management and Disposal 8-1

Waste Management $\quad 8-7$

Waste Minimization 8-10

Waste Handling, Treatment and Disposal Guidance 8-19

RCRA Permitting 8-25

\section{Atmospheric Protection Program 9.1}

Air Emissions Permitting 9-11

Air Emissions Inventory 9-16

Nonradioactive Emissions Management 9-24

Asbestos 9-24

Ozone Depleting Substances 9-26

Criteria Pollutants 9-35

Motor Vehicles 9-4()

Radioactive Air Emissions Management 9-43

Environmental Restoration 1()-1

Environmental Restoration Overview 10-3

Facility Transition Management 10-16

Decontamination and Decommissioning 10-16

RCRA Permitting $10-18$

\section{Employee Education 11-1}

Awareness 11-11

Training 11-14

DOE/Westinghouse School for Environmental Excellence 11-17 
Emergency Response, Environmental Occurrence Reporting, and Regulatory Notifications $\mathbf{1 2}-1$

Emergency Response $12-9$

Regulatory Response Required by EPCRA, CERCLA, and RCRA 12-13

National Contingency Plan 12-16

Environmental Permitting (under development) 13-1

Environmental Compliance Tracking and Data Management 14-1

Compliance/Commitment Tracking System 14-9

Review of DOE Orders 14-10

Data Management 14-11

Environmental Outreach $15-1$

Annual Savannah River Site Environmental Report 15-10

Environmental Outreach $15-11$

Environmental Appraisal and Surveillance Program 16-1

External Appraisals $16-12$

Internal Appraisals 16-14

External Surveillance 16-18

Internal Surveillance 16-20

Quality Assurance Program 17-1

\section{Site Organizations $\quad \mathbf{1 8 - 1}$}

Department of Energy-SR Organization and Responsibilities 18-7 SRS Contractor Organization and Responsibilities 18-12 WSRC Organization and Responsibility 18-13 


\section{Environmental Responsibility Summary $19-1$}

Department of Energy-Savannah River (DOE-SR)

Responsibilities $19-5$

Savannah River Site Contractor Responsibilities 19-6

SRS Environmental Programs Responsibility Summary 19-12

Environmental Monitoring 19-14

Chemical Management, Pollution Prevention, and Other

Compliance Programs 19-16

Natural Resource Protection 19-19

Surface Water and Wetlands Protection Site Program 19-22

Groundwater Protection Hydrogeological Program 19-25

Waste Management and Disposal 19-29

Atmospheric Protection Program 19-32

Environmental Restoration Program 19-36

Employee Education $\quad 19 \cdot 37$

Emergency Response, Environmental Occurrence Reporting, and Regulatory Notifications $19-38$

Division/Department Environmental Summary $\quad 20-1$

E \& PD

Construction Management 2()-6

ESH \& QA

Analytical Laboratory 20-14

NMPD

Reactor Materials 2()-16

Separations 2()-29

Tritium 2()-42

RRD

Reactor (RES\&HWD) 2()-51

SRTC

Savannah River Technology Center 20-58 


\section{SSD}

Central Services Works Engineering 20-71

Site Services Engineering 2()-78

WM\&ER

Defense Waste Processing Facility 20-84

Environmental Restoration 2()-95

Waste Management 20-102

Appendix 1 A1-1

Appendix 2 A2-1

Appendix 3 A3-1

Appendix 4 A4-1 


\section{Preface}

The purpose of the Environmental Implementation Plan (EIP) is to show the current and future (five years) environmental plans from individual site organizations and divisions, as well as site environmental programs and initiatives which are designed to protect the environment and meet or exceed changing environmental/regulatory requirements. Communicating with site organizations, departments, and committees is essential in making the site's environmental-planning process work. The EIP gives the site the what, when, how, and why for environmental requirements. Through teamwork and proactive planning, a partnership for environmental excellence is formed to achieve the site vision for SRS to become the recognized model for Environmental Excellence in the Department of Energy's Nuclear Weapons Complex.

The EIP consolidates the environmental plans and site environmental programs and initiatives of individual organizations and divisions to form a long-range environmental-protection plan for operating contractor organizations at SRS. This is required by DOE Order 5400.1 .

The EIP publicizes site environmental programs and goals from all SRS organizations to promote a common site vision and direction for natural-resource protection and share-savings from cost-effective compliance programs to meet regulatory requirements.

The $E I P$ is written primarily for operating-contractor management and environmental professionals. It also will be useful to the Department of Energy Savannah River Operations Office (DOE-SR) and to the environmental coordinators for other site contractors. The plan is designed to be a practical and useful document. The detail level is limited to that needed to describe environmental activities at the project and section program levels. The EIP references other site environmental-program plans, documents, and procedures for additional information and guidance. The plan will be updated annually. The EIP is designed to complement environmental planning efforts of DOE-SR and other site contractors.

The EIP revision process was improved by its subcommittee, a volunteer group of site environmental professionals from the Central Environmental Committee. The revision process develops the program ownership and user value so that the EIP will become a continuous planning and improvement process that incorporates total quality and is integrated with other environmental and budgetary plans.

As you read the EIP, your evaluations, questions, and suggestions for improvement are requested. Your feedback is an essential element to the revision process. Also, in order to understand your expected uses and benefits from a site environmental plan, a customer survey has been attached to the end of the preface. 


\section{Background}

The EIP, WSRC-RP-89-453, was revised and issued last on August 1, 1989. Since then, our site goal to protect the environment has not changed, but environmental laws, regulations, DOE orders, and site environmental programs and projects have continued to change. The March 15, 1993, EIP revision represents the combined efforts of site environmental coordinators and professionals to communicate environmental programs and plans. 


\section{Document Organization}

The revised EIP is one volume divided into five sections.

The first section, chapters $1-4$, contains an EIP overview, identifies the strategy for environmental compliance and excellence, summarizes significant environmental issues, and describes the environmental-monitoring programs.

The second section, chapters 5-10, contains the environmental-protection programs. These are the programs and plans that directly protect the environment from site operations.

The third section, chapters 11-17, contains the management and support programs. These programs respond to regulatory requirements in some cases, but also support good environmental practices.

The fourth section, chapters 18-20, describes site organizations, summarizes environmental responsibilities, and lists environmental plans submitted by SRS organizations.

The fifth section is an appendix of useful environmental information about documents, commitues, and other environmental resources. 


\section{How to Read the Plan}

The environmental protection programs, Section 2, are divided into media areas which include: chemical management, land use and wildlife, surface waters and wetlands, groundwater protection, waste management, atmospheric protection, and environmental restoration.

The management and support programs, Section 3, are divided into program areas which include: employee education, emergency response and reporting, community outreach planning relating to Superfund Amendments and Reauthorization Act (SARA) Title III, regulatory and DOE order compliance, appraisals and surveillance, and environmental quality assurance.

Each of the media and program areas in sections 2 and 3 are designed to follow the following similar format:

- Overview

- Policy

- Existing conditions

- Objectives

- Strategy

- Implementation programs

The first part is a brief summary of the media/program area. This is followed by a media policy statement or a program purpose statement. The third part defines the existing conditions of a media or state of a program. The fourth part contains the objectives that must be met to satisfy the policy/purpose statement. A brief strategy follows which highlights the basic approach for reaching the objectives.

The implementation program defines the major issues/topics within the media/program area. For each issue/topic, the justification, responsible organization, and major milestones are identified for the five-year planning period. For each implementation program, the format is as follows:

- Site program overview

- Five-year outlook

- Justification/regulatory requirements

- Organizational responsibility summary

- Site procedures and documents

- Programs

- Technical support programs

- One-year road map

- Five-year road map

The following is a brief description of each:

- Site program overview-provides the programmatic description of the site's environmental program 
- Five-year outlook-forecasts known regulatory commitment dates and projected site program milestones; discusses spending regulatory laws which may have significant impact to SRS operations/budget

- Justification/regulatory requirements-lists the major program drivers

- Organizational responsibility summary-describes organizational responsibilities for various implementation programs and services provided to the site

- Site procedures and documents-provides a list of reference documents which will provide more detailed information, guidance, and site proceciures

- Programs-describes WSRC and other SRS contractor programs which complement or support site program objectives

- Technical support programs-describes technical support by SRTC and other organizations for continued program development and improvement

- One-year road map-lists compliance deadlines, projected site program milestones, and facility program milestones (based on fiscal year)

- Five-year road map-same as one year, with a longer time line

In the fourth section, Chapter 18 describes site organizations. Chapter 19 summarizes environmental responsibilities for each program. The programs follow the order of EIP's table of contents. In Chapter 20, Division/Department Environmental Summary, environmental plans are arranged by divisions in alphabetical order. 


\section{EIP CUSTOMER SURVEY}

-What additional environmental information should be included in the EIP?

- What environmental information was not useful to you?

- How could the information be presented in a more user-friendly format?

- In order to optimize organizational resources for revising the EIP, list other Site documents or plans that provide environmental-planning information that should be referenced in the EIP.

-What are your expectations from a Site long-range-environmental plan?

- Any other comments, revisions, or suggestions?

By responding to the EIP Customer Survey, you will not only increase the customer value for the EIP, but you are taking an active role in our

"Partnership for Environmental Excellence"

With your participation and commitment to natural-resource protection and environmental compliance, we will achieve the following Site vision :

SRS to be the recognized model for Environmental Excellence in the DOE Nuclear Weapons Complex

Please fold and mail your customer survey, or send comments via All-in One to Greg Peterson. Your name and address is optional, but would be helpful. 
To: Greg Peterson

\author{
EIP Coordinator
}

742-A 


\section{Acronyms}

ACL

ADM

AEA

AIP

AITG

ALARA

ANSP

APETAR

ATSDR

BBC

BDAT

BMP

BRA

CAA

CAAA

CAP

CCWS

CEC

CECEC

CEQ

CERCLA

CFR

$\mathrm{Ci}$

CIF

CFC

CFR

CIF

CME

COE

CSWE

CWA

CX

D\&D

DETF

DNAPLS

DOE

DOE-HQ

DOE-SR

DOE-SR/EPB

DOE-SR/ECD

DWPF

EA

ECD

EH

EIP

EIS
Alternative Concentration Limit

Action Description Memorandums

Atomic Energy Act

Agreement-in-Principle

Aquatic Issues Task Group

As Low As Reasonably Achievable

Academy of Natural Sciences of Philadelphia

A-Area Powerhouse Effluent Treatment and Rerouting Facility

Agency for Toxic Substances and Disease Registry

Balanced Biological Community

Best Demonstrated Available Technology

Best Management Practices Plan

Baseline Risk Assessment

Clean Air Act

Clean Air Act Amendments

Corrective Action Plan

Comprehensive Cooling Water Study

Central Environmental Committee

Central Environmental Committee Executive Committee

Council on Environmental Quality

Comprehensive Environmental Response, Compensation, and Liability Act (the

Superfund Law)

Code of Federal Regulations

Curie

Consolidated Incineration Facility

Chloroflourocarbons

Code of Federal Regulations

Consolidated Incineration Facility

Comprehensive Monitoring Evaluation

U.S. Army Corps of Engineers

Central Shops Works Engineering

Clean Water Act

Categorical Exclusion

Decontamination and Decommissioning

Dilute Effluent Treatment Facility (M Area)

Dense Non-Aqueous Phase Liquid Substance

U.S. Department of Energy

DOE-Headquarters

DOE Savannah River Field Office

DOE-SR Environmental Policy Branch

DOE-SR Environmental Compliance Division

Defense Waste Processing Facility

Environmental Assessment

DOE Environmental Compliance Division

DOE Environment, Safety and Health

Environmental Implementation Plan

Environmental Impact Statement 


\begin{tabular}{|c|c|}
\hline $\begin{array}{l}\text { EM } \\
\text { EOC } \\
\text { EPA } \\
\text { EPB } \\
\text { EPCRA }\end{array}$ & $\begin{array}{l}\text { DOE Environmental Restoration and Waste Management } \\
\text { Emergency Operation Center } \\
\text { U.S. Environmental Protection Agency } \\
\text { DOE Environmental Policy Branch } \\
\text { Emergency Planning and Community Right-To-Know Act (Title III of SARA, } \\
\text { commonly called Right-To-Know or SARA Title III) }\end{array}$ \\
\hline ESA & Endangered Species Act \\
\hline ETF & Effluent Treatment Facility \\
\hline FFA & Federal Facility Agreement \\
\hline FFCA & Federal Facility Compliance Agreement \\
\hline FIFRA & Federal Insecticide, Fungicide, and Rodenticide Act \\
\hline FONSI & Finding of No Significant Impact \\
\hline FWS & U.S. Fish and Wildlife Service \\
\hline GDNR & Georgia Department of Natural Resources \\
\hline GEMA & Georgia Emergency Management Agency \\
\hline gpm & Gallons per minute \\
\hline HAZMAT & Hazardous Materials \\
\hline HEPA & High Efficiency Particulate Air \\
\hline HCFC & Hydrohloroflourocarbons \\
\hline HLW & High-Level Waste \\
\hline HP & Health Protection or Health Physics \\
\hline HWMF & Hazardous Waste Management Facility \\
\hline HW/MWDF & Hazardous Waste/ Mixed Waste Disposal Facility \\
\hline IAG & Interagency Agreement \\
\hline $\begin{array}{l}\text { IAPP } \\
\text { IMPACTS }\end{array}$ & $\begin{array}{l}\text { Interim Action Proprosed Plan } \\
\text { Issues Management Processing Action and Commitment Tracking System }\end{array}$ \\
\hline $\begin{array}{l}\text { IMPACTS } \\
\text { ITP }\end{array}$ & 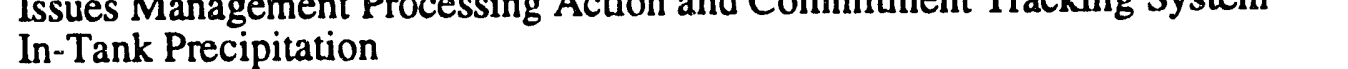 \\
\hline LDR & $\begin{array}{l}\text { In-1 ank Precipitauon } \\
\text { Land Disposal Restriction }\end{array}$ \\
\hline LEPC & Local Emergency Planning Committee \\
\hline LETF & Liquid Effluent Treatment Facility (M Area) \\
\hline $\mathrm{L}$ & Liter \\
\hline LLRWDF & Low-Level Radioactive Waste Disposal Facility \\
\hline MA.P & Mitigation Action Plan \\
\hline $\mathrm{mL}$ & Milliliter \\
\hline $\mathrm{M \& O}$ & Management and Operations \\
\hline MOA & Memorandum of Agreement \\
\hline MPSA & Marine Protection and Sanctuaries Act \\
\hline mrem & millirem \\
\hline MSDS & Material Safety Data Sheet \\
\hline MSWLF & Municipal Solid Waste Landfill \\
\hline MTF & Memorandum to File \\
\hline MWMF & Mixed Waste Management Facility (SRS RCRA Landfill) \\
\hline MWSB & Mixed Waste Storage Building \\
\hline NAPLS & Non-Aqueous Phase Liquid Substance \\
\hline $\mathrm{nCi}$ & Nanocuri \\
\hline NCP & National Contingency Plan \\
\hline NEPA & National Environmental Policy Act \\
\hline NERP & National Environmental Reseach Park \\
\hline NESHAP & National Emissions Standard for Hazardous Air Pollutants \\
\hline NHPA & National Historic Preservation Act \\
\hline NMFS & National Marine Fisheri \\
\hline
\end{tabular}




$\begin{array}{ll}\text { NOD } & \text { Notice of Deficiency } \\ \text { NOI } & \text { Notice of Intent } \\ \text { NOV } & \text { Notice of Violation } \\ \text { NOx } & \text { Oxides of Nitrogen } \\ \text { NPL } & \text { National Priorities List }\end{array}$

\begin{tabular}{|c|c|}
\hline NPDES & National Pollutant Discharge Elimination System \\
\hline NPR & New Production Reactor \\
\hline NRCF & Natural Resources Coordinating Committee \\
\hline NRDC & Natural Resources Defense Council \\
\hline OMB & U.S. Office of Management and Budget \\
\hline ORNL & Oak Ridge National Laboratories \\
\hline OSHA & Occupational Safety and Health Administration \\
\hline PCA & South Carolina Pollution Control Act \\
\hline PCB & Polychlorinated Biphenyls \\
\hline PCE & Perchloroethylene \\
\hline $\mathrm{pCi} / \mathrm{g}$ & Picocuries per gram \\
\hline PEIS & Programmatic Environmental Impact Statement \\
\hline $\mathrm{pH}$ & Potential of Hydrogen (a measure of acidity and alkalinity) \\
\hline PIP & Public Involvement Plan \\
\hline $\mathrm{ppb}$ & Parts per billion \\
\hline PRA & Probabilistic Risk Assessment \\
\hline psi & Pounds per square inch \\
\hline R\&HA & River and Harbor Act (COE Permitting Authority) \\
\hline RAFTS & Recommendations and Findings Tracking System \\
\hline $\mathrm{RCA}$ & Radiological Controlled Areas \\
\hline RCRA & Resource Conservation and Recovery Act \\
\hline rem & Roentgen \\
\hline RFI & RCRA Facility Investigation \\
\hline RFI/RI & RCRA Facility Investigation/ Remedial Investigation \\
\hline ROD & Record of Decision \\
\hline SARA & Superfund Amendments and Reauthorization Act of 1987 \\
\hline SC & South Carolina \\
\hline SCBCESO & South Carolina Board of Certification of Environmental Systems Operat \\
\hline SCDHEC & South Carolina Department of Health and Environmental Control \\
\hline SCEPC & South Carolina Emergency Planning Commission \\
\hline SCHWMR & South Carolina Hazardous Waste Management Regulations \\
\hline SCDWR & S. C. Drinking Water Regulations \\
\hline SCHWMR & S. C. Hazardous Waste Management Regulations \\
\hline SCPCA & S. C. Pollution Control Act \\
\hline SCWMRD & S. C. Wildlilfe and Marine Resources Department \\
\hline SCWRC & South Carolina Water Resources Commission \\
\hline SDWA & Safe Drinking Water Act \\
\hline SEA & Special Environmental Analysis \\
\hline SEFES & Southeastern Forest Experiment Station of the U. S. Forest Service \\
\hline SEIS & Supplemental Environmental Impact Statement \\
\hline SIRIM & Site Item Reportable Issue Management \\
\hline \multirow[t]{2}{*}{ SMARTS } & Specifications and Management Applications for \\
\hline & Regulated Tank Systems Program \\
\hline SPCC & Spill Prevention Control and Countermeasures Plan \\
\hline SR & U.S. Department of Energy, Savannah River Field Office \\
\hline
\end{tabular}


SREL

SRFS

SRL

SRP

SRS

SRTC

SW

SWDA

SWTP

TCE

TCLP

TDS

TNX

TRC

TRU

TSC

TSCA

TSD

TSS

TWF

UGA

UIC

U.S.C.

USDA

USFS

USGS

UST

UTRC

VOC

WSI

WSRC

WSRC-EAC

WSRC-EMT

WSRC-EPD

WSRC-ER

WWTP
Savannah River Ecology Laboratory (operated for DOE by University of Georgia) Savannah River Forest Station (of USFS)

Savannah River Laboratory (1992 changed to SR'.'C)

Savannah River Plant (4/1/89 changed to SRS)

Savannah River Site

Savannah River Technology Center

Solid Waste

Solid Waste Disposal Act

Sanitary Waste Treatment Plant

Trichloroethylene

Toxicity Characteristic Leachate Procedure

Total Dissolved Solids; Technical Data Summary

SRS Experimental Area

Total Residual Chlorine

Transuranic Waste

Technical Support Center

Toxic Substances Control Act

Treatment, Storage, and Disposal

Total Suspended Solids

Transuranic Waste Facility

University of Georgia

Underground Injection Control

U. S. Code of Laws

U.S. Department of Agriculture

U.S. Forest Service

U.S. Geological Survey

Underground Storage Tank

Upper Three Runs Creek

Volatile Organic Compound

Wackenhut Services, Incorporated (SRS Security Contractor)

Westinghouse Savannah River Company (SRS Operating Contractor)

Westinghouse Savannah River Company -Environmental Advisory Committee

Westinghouse Savannah River Company -Environmental Management Team

Westinghouse Savannah River Company -Environmental Protection Department

Westinghouse Savannah River Company -Environmental Restoration

Wastewater Treatment Plant 


\section{Chapter 1}

\section{EIP Introduction}

Chapte; was compiled and reviewed by Greg L. Peterson. 
Environmental Implementation Plan 


\section{Site Program Overview}

\section{Introduction}

Customer improvements and total quality are being incorporated into the Environmental Implementation Plan (EIP) revision process.

These achievements are due to the commitment and participation of more than 100 professionals from site environmental coordinators representing the following:

- Environmental Protection Department (EPD)

- General Counsel, Savannah River Technology Center (SRTC)

- ESH\&QA Division Quality Assurance, ESH\&QA Division Training

- Central Environmental Committee (CEC) and CEC Executive Committee (CECEC)

- Savannah River Ecology Laboratory (SREL)

- Savannah River Forest Station (SRFS)

- Natural Resources Coordinating Committee (NRCC)

- Environmental Advisory Committee (EAC)

- Department of Energy Savannah River (DOE-SR)

This effort was initiated by CECEC and developed and coordinated by the EIP subcommittee. This revision is the baseline for a continuous improvement cycle. Although the EIP is a Westinghouse Savannah River Company (WSRC) document, the environmental-planning process involves and will benefit all site contractors. Together, we are committed to a "Partnership in Environmental Excellence."

\section{Summary}

DOE and the managing contractor, WSRC, are committed to operating SRS in a manner that protects the public health and safety and the environment. This philosophy is contained in DOE Order 5400.1, General Environmental Protection Program, the SRS Strategic Environmental Plan, and in the SRS Mission, Vision. and Principles.

Compliance with environmental regulations and DOE orders relating to environmental protection is an important part of SRS's program. An overview of the strategy to reach our site goal of environmental excellence and compliance with new and existing environmental regulations and DOE orders is found in Chapter Two. Demonstrating environmental excellence is a high priority embodied in DOE and WSRC policy.

SRS is striving constantly to improve its standing as a leader in environmentalprotection activities. DOE-SR, WSRC, and other SRS contractors are committed to environmental excellence and compliance. Managing environmental programs is a major task. More than 1,000 people are devoted full-time to environmental activities at SRS. As the environmental laws, regulations, and DOE orders change, SRS 
environmental professionals work together not only to determine what actions are necessary for compliance, but to determine the most cost-effective actions which will meet or exceed compliance requirements and promote natural-resource protection.

The EIP is a long-range environmental-protection plan which describes: the strategy for environmental compliance and excellence; site environmental-protection programs; management and support programs; environmental responsibilities; and environmental programs and plans submitted from SRS organizations.

The EIP complies with DOE Order 5400.1 by providing a long-range environmentalprotection plan to give the site the what, when, how, and why for environmental requirements. Through the EIP planning process, which incorporates teamwork and proactive planning, a partnership in environmental excellence is formed.

To comply with DOE Order 5400.1 , the EIP programs identify environinental requirements, program goals for compliance and natural-resource protection, and reference site procedures and guidance documents. Environmental coordinators compare their facility operations against requirements and goals to identify needs. Through communications and teamwork, environmental coordinators establish strategies to meeting the needs, identify activities to implement the strategies, identify needed resources, and develop a schedule to accomplish those activities.

The EIP is written primarily for WSRC management and environmental professionals, but it also will be useful to the DOE-SR and to the environmental coordinators other site contractors. The $E I P$ is designed to complement the environmental planning efforts of DOE-SR and the other site contractors. The EIP publicizes site environmental programs and goals from all SRS organizations to promote a common site vision and direction for natural-resource protection and share-savings from costeffective compliance programs to meet regulatory requirements. By including the environmental programs, plans, and responsibilities from all SRS contractors, the EIP provides an holistic view of SRS environmental activities, the inter- and intrarelationships among the environmental media for natural resource protection, and the teamwork by all organizations and environmental committees to achieve our site vision for SRS to be the recognized model for Environmental Excellence in the DOE Nuclear Weapons Complex.

\section{Background}

Formal sitewide environmental planning at the SRS began in 1986 with the development and'adoption of the Strategic Environmental Plan. The Strategic Environmental Plan describes the philosophy, policy, and overall program direction of environmental programs at SRS. Input into the plan was obtained from a large number of operating contractor personnel, DOE, and the Environmental Advisory Committee. The document contains the following:

- philosophy and policy statements

- key planning assumptions

- visions for the future

- general objectives 
- management strategy

- legal requirements

- program strategies for protecting groundwater and soil

- jrogram strategies for protecting surface waters and wetlands

- program strategies for protecting the atmosphere

- program strategies for managing SRS land and wildlife

The Strategic Environmental Plan provided the basic for the EIP.

The EIP, WSRC-RP-89-453, was issued on August 1, 1989.

The Central Environmental Committee Executive Committee (CECEC) approved forming an EIP subcommittee in November 1991 to improve and facilitate the EIP revision process. The subcommittee members represent several site organizations. The subcommittee mission is to revise the EIP in a way that solicits and values CEC participation; optimizes the resource requirements for annual revisions; identifies and improves communicating environmental requirements and obligations; publicizes environmental activities, plans, and information; forecasts environmental changes and upcoming regulatory developments; meets or exceeds customers expectations; and combines ideas and perspectives of CEC members and EPD personnel.

A draft revision of the EIP was published in March 1992, which reflects the efforts by site environmental coordinators, CECEC, EPD, SRTC, and the EIP subcommittee.

In September 1992, the EIP Action Plan was developed to incorporate customer improvements and total quality into the EIP revision process.

The March 15, 1993, EIP revision represents the teamwork and commitment to environmental excellence by site environmental coordinators and professionals. 


\section{Objectives}

The objectives to support SRS environmental planning through the EIP are the following:

- meet the long-range environmental-protection plan requirements of DOE Order 5400.1

- improve the communication of environmental requirements, roles and responsibilities, and program goals

- promote common site solutions through teamwork which result in share-savings from cost-effective compliance programs that meet both regulatory requirements and natural-resource protection goals

- forecast environmental needs to promote innovative and cost-effective programs which will meet compliance requirements through applied technology development

- encourage continuous planning and program improvement

- incorporate total quality throughout the EIP planning process

- integrate $E I P$ with other environmental and budgetary plans

- complement environmental planning efforts of DOE-SR and the other site contractors

- meet customer expectations for a practical and useful long-range environmental plan 


\section{Strategy}

The following is strategy for reaching the EIP objectives:

- forecast five-year program vision and identify milestones to meet the program objectives

- identify and communicate regulatory and other environmental-protection initiatives and requirements

- identify environmental resources (documents, procedures), site environmental responsibilities, and goals of environmental committees

- involve all site organizations in environmental planning to meet site goals and policies

- include the planning information with other SRS organizations (SREL, USFS, WSI) to obtain holistic view of SRS environmental programs

- conduct quarterly "Reflections" to facilitate environmental planning and continuous improvements

- coordinate the EIP revision to incorporate plans consistent with the SRS integrated planning system (Site Development Plan, Mission Plans, Annual Operating Plans)

- revise the EIP individual chapters throughout the year to promote customer involvement to enable a more focused review of individual environmental media programs and their relationship with other environmental media (holistic view)

- request identification of national environmental directions and initiatives by the Environmental Advisory Committee which will promote SRS environmental excellence

- request the Natural Resources Coordinating Committee's assistance to evaluate EIP's site environmental programs for alignment with natural resource protection goals and to identify mile markers to evaluate SRS progress in achieving naturalresource protection goals

- implement the EIP Action Plan initiatives

- evaluate if customer expectations for EIP are met 
EIP: Partnership in Environmental Excellence

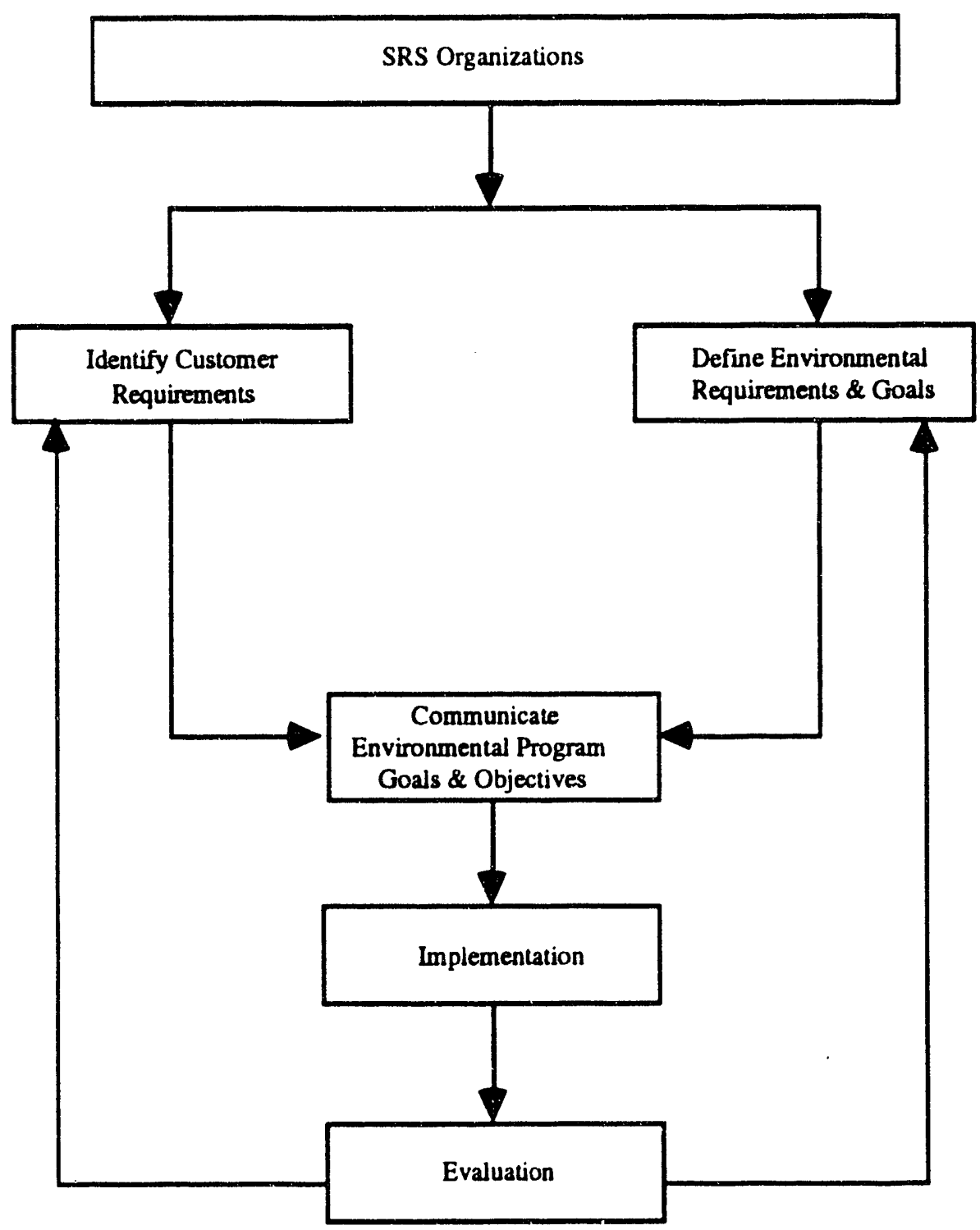

Fgure 1-1. EIP: Long-Range Environmental Protection Plan Strategy 


\section{Implementation}

Communicating with site organizations, departments, and committees is essential to making the site environmental-planning process work. The EIP planning process gives the site the what, when, how, and why for environmental requirements. Through teamwork and proactive planning, a partnership for environmental excellence is formed to achieve our site vision for SRS to become the recognized model for environmental excellence in the DOE Nuclear Weapons Complex.

Based on this partnership in environmental excellence, the EIP revision process is being improved by customer involvement and communication. The EIP Action Plan submitted by the EIP subcommittee recommends implementing three initiatives (reflections, sectional revision, integrated planning) in order for the EIP to become a continuous planning and improvement process that incorporates total quality and is integrated with other environmental and budgetary plans.

A brief description of each of the three EIP initiatives follows.

\section{Reflections}

\section{Sectional Revision}

Reflections is a planned review of an environmental program by the EPD program coordinator and facility environmental coordinators to develop joint program ownership and understanding, and facilitate planning which identifies areas for continuous improvement.

When changing environmental conditions (regulatory laws, site issues) are identified, communications with and early involvement by site organizations in developing implementation plans and procedures will optimize resources and minimize the impact on site organizations. Also, a planned review of environmental programs by EPD and facility environmental coordinators facilitates closed-loop communications to assess the goals and performance of existing plans. While developing joint program ownership and understanding, the reflections process identifies areas for continuous improvement.

Sectional revision will replace the annual revision of the entire EIP by updating different chapters throughout the year. Each chapter has several implementation programs that will need revision. This change is proposed to lessen the manpower for revision and enable a more concentrated and focused review of individual environmental programs by the environmental coordinators and EPD. This should encourage stakeholder participation and communication in assessing and developing revised goals, strategies, and objectives to meet identified environmental requirements and obligations. This also should improve the overall planning quality through increased program ownership. 
Integrated Planning

Integrated planning is a process that incorporates planning information in the EIP revision into other documents. Programs and projects required to meet environmental compliance goals will need to be integrated into the financial planning documents. Information obtained from EIP environmental program self-assessments during reflections can be integrated into the annual environmental self-assessments. Existing detailed planning and guidance documents will be referenced to prevent duplication and to ensure the information is accurate. 


\section{Chapter 2}

\section{Strategic Plan for Environmental Compliance}

Chapter was compiled and reviewed by Jay B. Hutchison. 


\section{Introduction}

The Strategic Plan for Environmental Compliance at the Savannah River Site (U), WSRC-IM-91-66, was developed by the Environmental Protection Department (EPD). Sections of this plan are presented to describe the processes EPD and site organizations have in place to meet environmental requirements. Flowcharts are utilized to describe processes designed to achieve environmental compliance.

\section{Timely Compliance with Department of Energy (DOE) Requirements}

EPD defines site environmental requirements by reviewing applicable state and federal environmental laws and regulations, by reviewing DOE orders, notices, and other requirements, and by considering other SRS initiatives. Developing requirements entails interacting with numerous site organizations, DOE, other government-owned contractor operated (GOCO) entities, and federal and state regulators.

These requirements are provided to SRS oversight and operating organizations. Environmental procedures have been developed to formalize the process of defining Westinghouse Savannah River Company (WSRC) responsibilities and requirements. These environmental procedures are contained in the Environmental Compliance Manual, Procedure Manual 3Q. EPD implemented a commitment-tracking system to track regulatory correspondence and required reports.

The site's general environmental compliance strategy is shown in Figures 1 and 2. The general process WSRC uses to ensure compliance with DOE requirements, as applicable (including DOE interactions with the site), is described in Figure 2. General descriptions are provided for key areas, along with examples of activity-specific systems that are in place (see Figure 2, for additional details). Specific references that document how WSRC conducts its environmental business are provided in Attachment 1.

A brief discussion of each process area follows.

\section{Excellence and Compliance}

Demonstrating environmental excellence is a high priority initiative incorporated in DOE and WSRC's site policy. Not only are environmental requirements to be achieved, but requirements are to be exceeded when possible. SRS is striving constantly to improve its standing as a leader in environmental-protection activities.

\section{Requirements Definition}

EPD and site organizations define site environmental requirements by reviewing applicable state and federal environmental laws and regulations, by reviewing the requirements of DOE orders, notices, and other requirements, and considering other 
site initiatives. Developing requirements entails interacting with numerous site organizations, DOE, other GOCO entities, and federal and state regulators.

\section{Planning}

Specific site environmental tasks are described in the Site Annual Operations Plan. Input into this plan takes into consideration issues developed or raised in the site's Environmental Implementation Plan (WSRC-RP-89-453), Five-Year Plan, Site Specific Plan, Implementation Plan for Establishing WSRC Lead with Environmental Regulatory Agencies (WSRC-RP-90-262), Strategic Plan for NEPA Documentation (WSRC-RP-91-199), and other planning activities.

\section{Process Definition}

Requirements are provided to SRS oversight and operating organizations. Environmental procedures have been developed to formalize the process of defining site responsibilities and requirements. These procedures are found in the Environmental Compliance Manual, Procedure Manual 3Q.

Under this procedural system, manuals are maintained which provide specific requirements to site organizations. These Environment, Safety, Health and Quality Assurance (ESH\&QA) Division Manuals (Specifications and Management Applications for Regulated Tank Systems (SMARTS), Hydrogeological Data Collection Methods, Procedures, and Specifications, Procedure Manual 3QS, Environmental Permitting Procedures "HOW" Manual, Waste Disposal Manual) specify detailed regulatory requirements which will help ensure full-regulatory compliance. Other site organizations are expected to develop additional procedures and manuals to manage the conduct of their day-to-day activities and to ensure environmental compliance. This will be the method used to ensure that site organizations are advised of all regulatory requirements.

\section{Implementation}

Once requirements are identified and distributed onsite, training is implemented by line management and site training organizations. Monitoring programs are implemented and bave procedures to ensure that proper sampling techniques and analytical methods are utilized. Permitting activities are initiated to address environmental needs, and the site's activities are reported through numerous mechanisms including the Environmental Implementation Plan. Site Specific Plan, Community Relations Plan, Annual Environmental Report, numerous community-outreach programs, and reports required by regulatory agencies (see Figure 2).

Emergency-response requirements are a separate procedural effort which encompass more than just environmental releases. A recent effort to update the Site Item Reportability and Issues Management (SIRIM) process has been completed and implemented. 
These activities address the requirements of DOE Order 5400.1, General Environmental Protection.Program, and the site's (developed by DOE) Environmental Protection Implementation Plan.

\section{Oversight}

EPD serves as the situ's internal environmental-oversight organization and coordinates numerous internal ar d external environmental-appraisal activities. The department also is charged with following up on findings and observations that result from internal and external appraisals, and maintaining a tracking system on the status of various appraisal activities.

\section{Communication}

Numerous feedback and communication mechanisms are in place including meetings (i.e., Central Environmental Committee (CEC) and its subcommittees, Central Environmental Committee's Executive Committee (CECEC), Environmental Management Team (EMT), Natural Resources Coordinating Committee (NRCC), Environmental Advisory Committee (EAC), organizational, regulatory agency, DOE, etc.), the review and comment resolution process associated with developing documents, and disseminating environmental updates and periodic reports. EPD and site organizations are striving constantly for communication improvements. 
Figure 1. Compliance Strategy 


\section{Figure 1. Compliance Strategy}

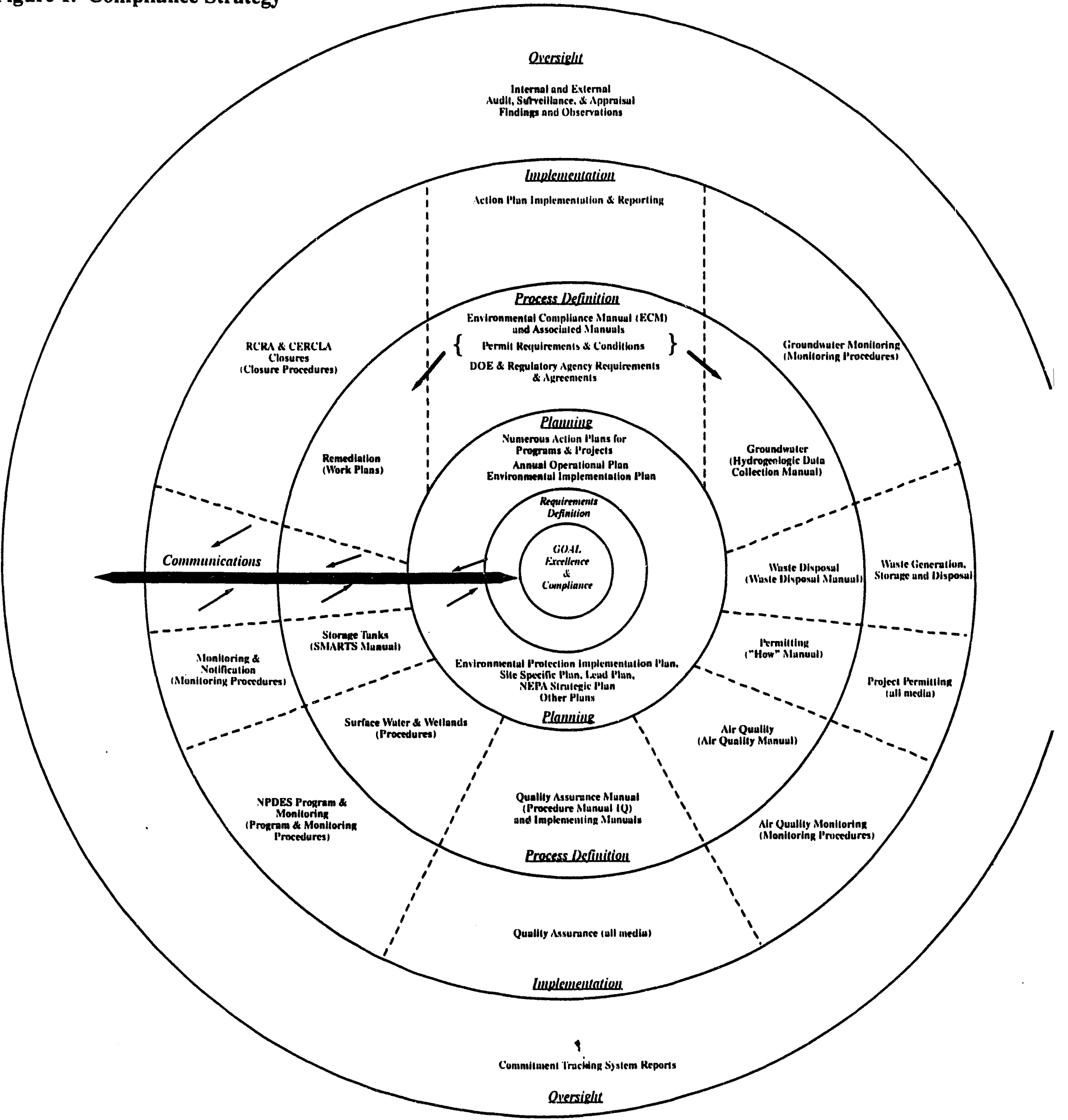


Figure 2. Timely Compliance with DOE Requirements Flowchart 
Figure 2. Additional Details (contd) 
Figure 2. Timely Compliance with DOE Requirements Flowchart

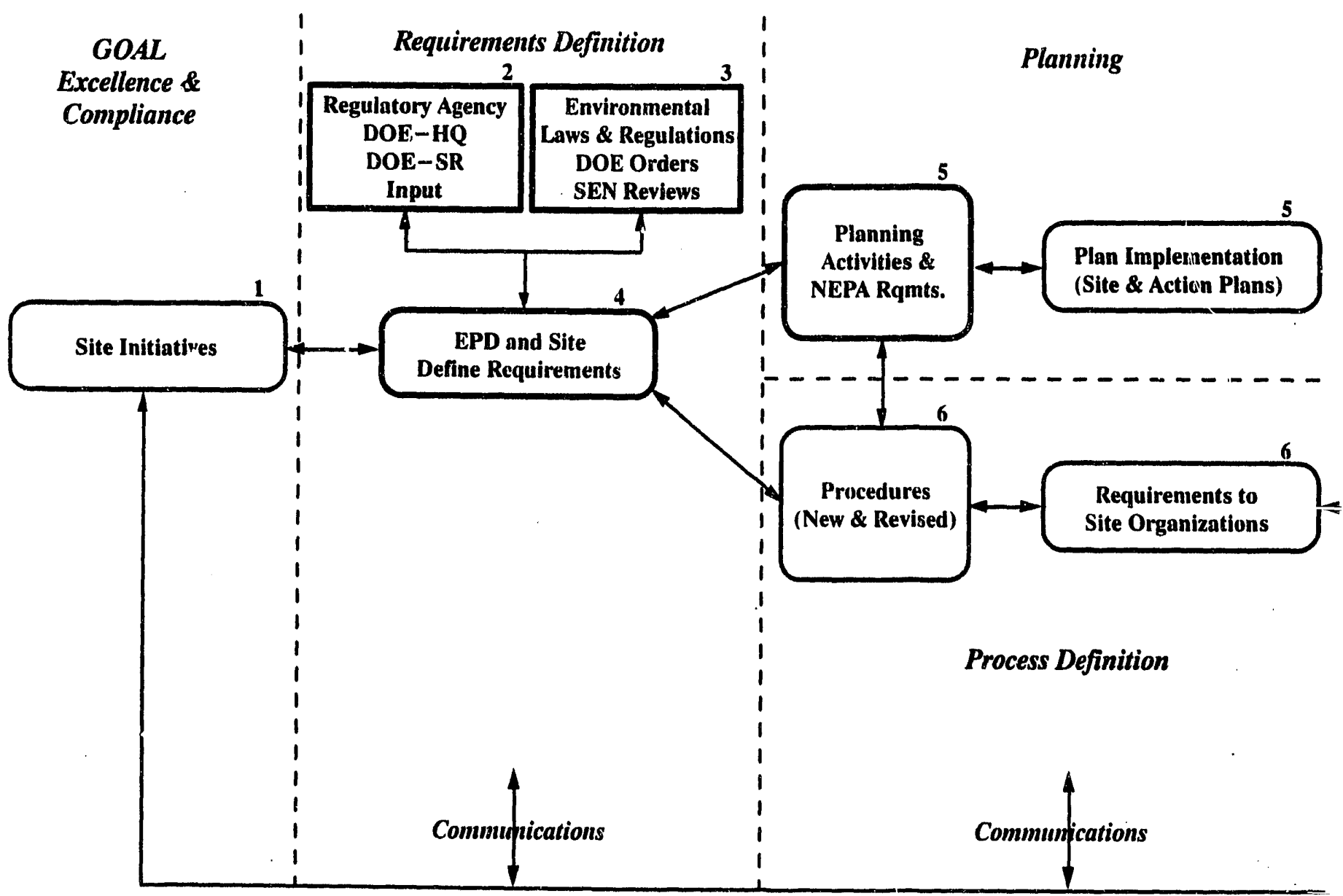




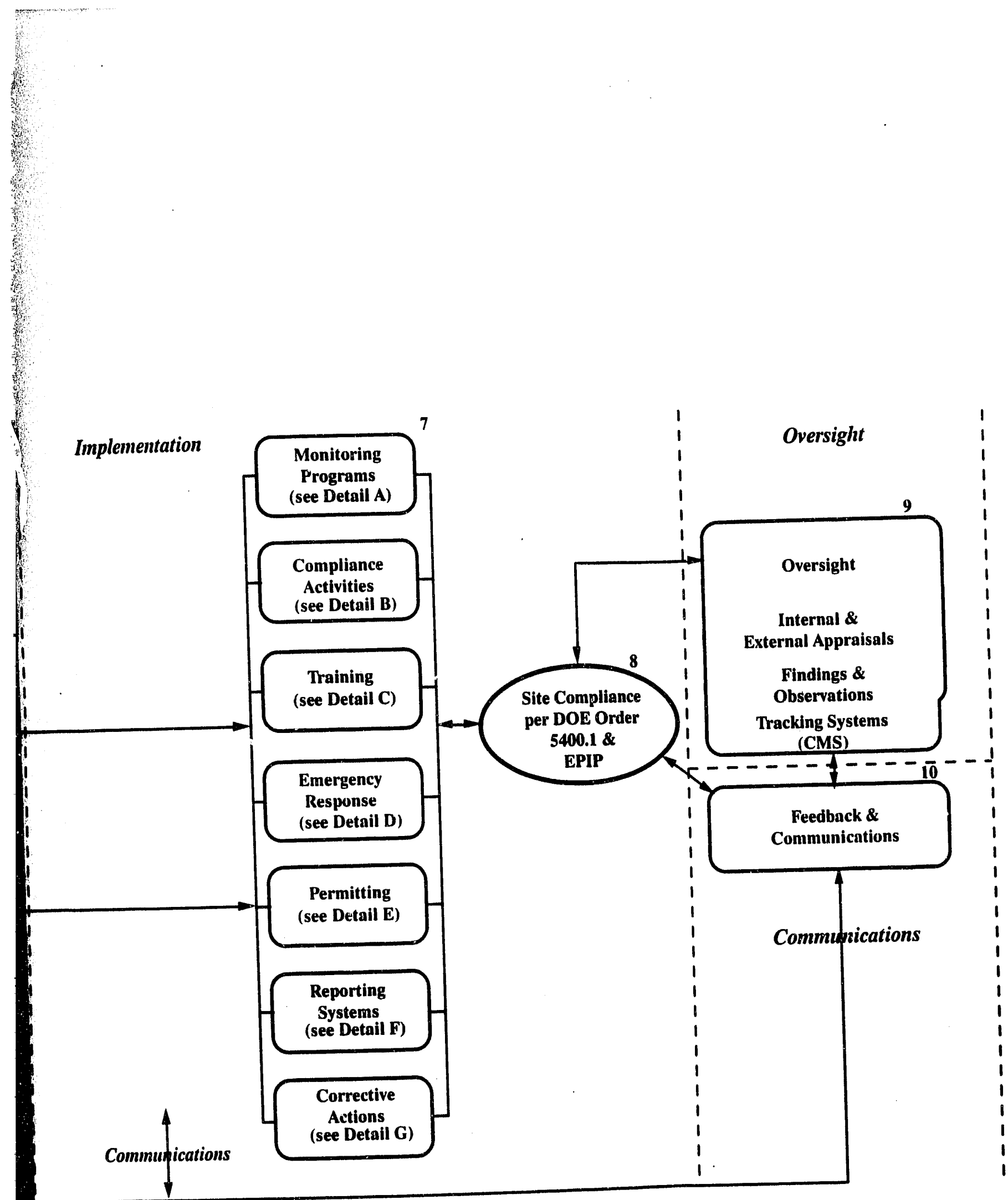




\section{Figure 2. Additional Details (contd)}

Flowchart is generalized for the compliance process; steps apply, as appropriate, with brief explanations provided below. In many instances, flow paths are bidirectional, to allow feedback as requirements are defined and implemented, and as additional issues are identified and factored into the process. The dashed lines also show that the division between major process areas is not discreet; depending upon the activity examined, several process areas may be ongoing at the same time.

1. Environmental excellence and compliance is a high priority site goal. The site is constıntly striving to improve its stunding as a leader in environmental protection activities.

2 - 4. EPD and site organizations define environmental requirements based on site initiatives, interaction with DOE-HQ, DOE-SR and site organizations, regulatory requirements (see Figure 3), and other factors.

5. Requirements are also defined through plans (site plans and action plans) and NEPA considerations. Plans may be developed by EPD or site organizations, depending upon the issue and organizutional responsibility.

6. Based on requirements definitions, requirements sre issued to site organizstions in the form of procedures and manuals.

7 - 8. Numerous procedures have been developed and issued. Refinements are ongoing in procedurul development. These include the Environmental Compliance Manual, Department Procedures, Iraining Procedures, Monitoring Requirements and Procedures, Eimergency Response Procedures, Project Procedures, and Reporting System Requirements and Procedures (see Attachment I for additional references). Adherence to site and department procedures results in excellent site compliance activities.

9. Oversight activities are underway, including external and internal appraisal activities. Findings and observations are entered into department and site tracking systems (CMS).

10. Feedback and communication are essential to maintain site compliance and define requirements. EPD and site organizations are constantly striving for communication improvement. The recent changes made to the Central Environmental Committee is an example of feedback and communications improvements. 
Additional level of detail for Figure 2.
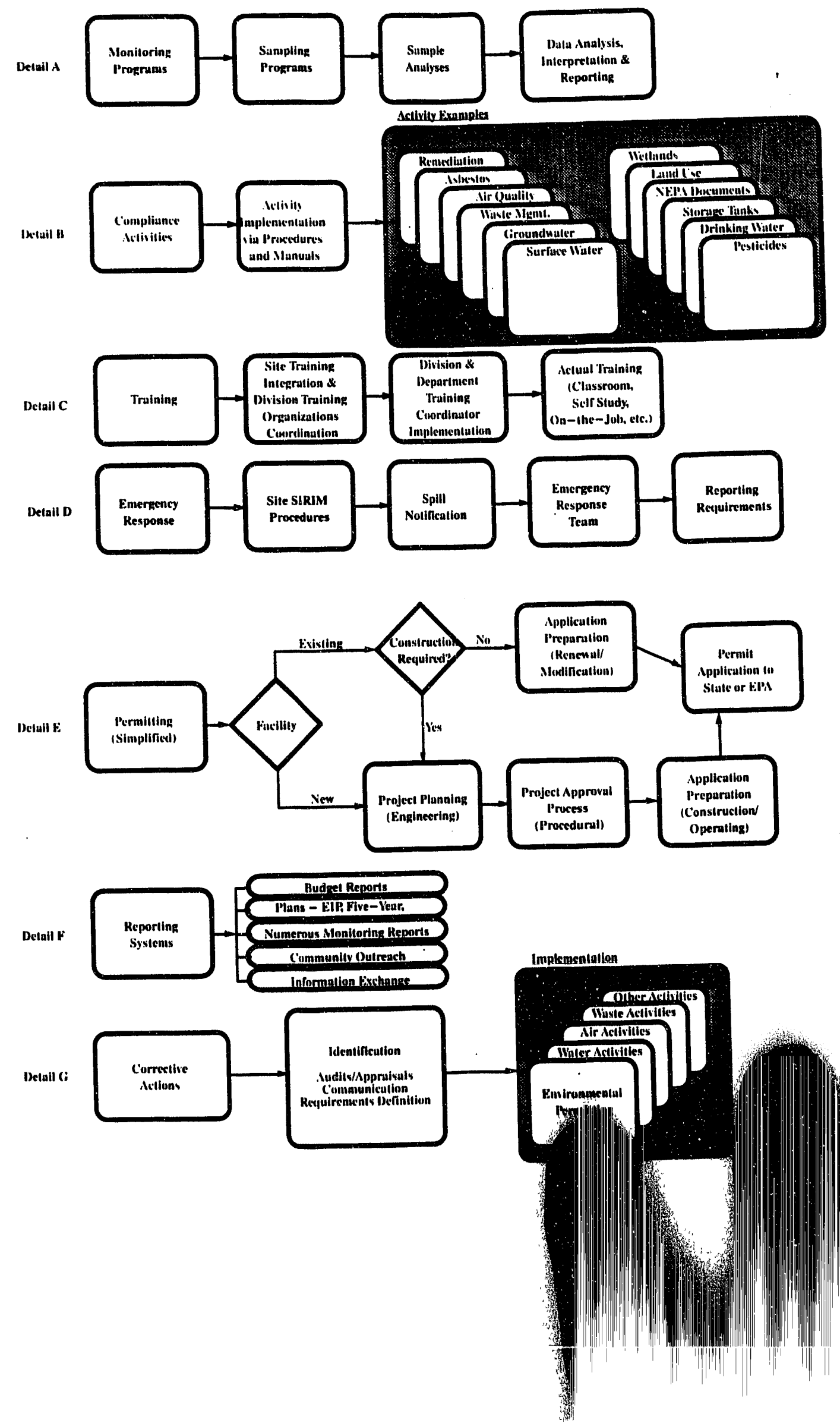
Attachment 1. Specific References for Timely Compliance with DOE Requirements Flowchart

\section{Monitoring Programs}

- Environmental Protection Implementation Plan

- Specified in the Environmental Compliance Manual (Procedure Manual 3Q) and procedures of other divisions

- Specified in Environmental Monitoring Section (EMS) procedures for sampling and analytical efforts, WSRC 3Q1-3

- EMS Quality Assurance and Quality Control (QAQC) Plan, WSRC 3Q1-2

- Descriptions provided in Environmental Implementation Plan (WSRC-RP-89. 453) and Site Specific Plans

- Quality Assurance specified by the Environmental Protection Department's Department Procedures Manual (Q-1-1-1) and EMS Procedures

- Quality Assurance Procedure Manual, Procedure Manual 1Q

\section{Compliance Activities}

- Procedure Manual 3Q, Environmental Compliance Manual (all) and associated reference manuals

- Environmental Permitting Procedures "HOW" Manual (IM-91-69)

- Hydrogeological Data Collection Methods, Procedures, and Specifications (Procedure Manual 3Q5)

- Specifications and Management Applications for Regulated Tank Systems, SRS "SMARTS" Program (WSRC-IM-90-90)

- Waste Disposal Manual (WSRC-IM-90-138)

- Site Quality Assurance Procedure (Procedure Manual 1Q, Quality Assurance) and associated division, department and section implementing procedures, (i.e., Department Procedures Manual (DPM) Q-1-1-1 for EPD), Environmental Monitoring Section Procedures (3Q1-7)

\section{EMS QAQC Plan}

- Environmental Monitoring Section, Quality Assurance Plan, WSRC 3Q1-2

\section{Training}

- $\quad$ SRS Environmental Training Plan, WSRC-RP-92-282

- Environmental Implementation Plan (WSRC-RP-89-453), Chapter 11, Employee Education

- Department Procedures Manual, Q-1-1-1, DPM-1101, Employee Indoctrination and Training

- Procedure Manual 3Q, Environmental Compliance Manual, ECM 14.1, Site Environmental Training Responsibilities, and ECM 14.2, RCRA/CERCLA Training Requirements 
- Site Training Requirements (Training Integration and Division Training Procedures)

\section{Emergency Response}

- Descriptions provided in Environmental Implementation Plan (WSRC-RP-89. 453)

- DOE Order 5000.3A, Occurrence Reporting and Processing of Operations Information

- SRS Management Requirements and Procedures Manual 1B, MRP 4.07 - 4.09 Events, Conditions, and Concerns - Identification, Determination, and Issue Management.

- Environment Protection Department Manual Q-1-1-1, DPM-301, Spills and Environmental Occurrence Response and Notification Procedure

- WSRC-IM-92-21, SRS Site Environmental Protection Handbook

- DOE-ECD Procedure, Occurrence Response and Notification Procedure

- WSRC SRS Emergency Plan, Procedure Manual $6 \mathrm{Q}$

- SRSOC Emergency Procedures Manual, 6Q15.4

- $\quad$ SRSOC Operating Procedures Manual, Q12

\section{Permitting}

- Procedure Manual 1B, Management Requirements and Procedures, MRP 3.24, Purchasing Requisitioning, MRP 3.28, Subcontract Administration), and MRP 3.29, Subcontract Formation

- Engineering and Projects Division (E\&PD) Procedures

- Environmental Compliance Manual

- Environmental Permitting Procedures "HOW" Manual (IM-91-69)

- Descriptions provided in Environmental Implementation Plan (WSRC-RP-89453) and Site Specific Plans

\section{Reporting Systems}

- Annual SRS Environmental Report

- Environmental Protection Implementation Plan

- Descriptions provided in Environmental Implementation Plan (WSRC-RP-89. 453) Oversight

Environmental Restoration and Waste Management Five-Year Plan Site Specific Plan

\section{Reporting Systems}

- Procedure Manual 1B, Management Requirements and Procedures, MRP 3.12, Commitment Management

- Procedure Manual 3Q, ECM 13.1, Environmental Compliance Internal Appraisals, ECM 13.2, Environmental Compliance External Appraisals, and ECM 13.3, RFI Program Appraisals, and ECM 13.4 Environmental Compliance Surveillance Program Administration 
- Commitment Management System - DOE letter tracking, Tiger Team action plan tracking, and NEPA commitment tracking

- Department Internal Appraisal Finding Tracking (EPD VAX Oracle application)

- IMPACTS for department commitment tracking 
Chapter 3

\section{Executive Summary}

Chapter is being developed. 


\section{Chapter 4}

\section{Environmental Monitoring}

Chapter was compiled and reviewed by Craig S. Hetrick. 
The Savannah River Site (SRS) occupies an area of approximately 300 square miles adjacent to the Savannah River, principally in Aiken and Barnwell counties in South Carolina.

The SRS environmental-monitoring program is conducted within a 30,000-squaremile area surrounding the government-owned facility, and includes regions in Georgia and South Carolina. Representative amples of food, drinking water, wildlife, soil, and vegetation are collected and analyzed for radioactive constituents. Nonradioactive monitoring also is performed on selected media, primarily surface water and groundwater samples. The selection of the sampling and analysis plans is a dynamic one, reflective of aite operating conditions and public concerns.

The Environmental Protection Department's (EPD) Environmental Monitoring Section was given the authority to monitor the environment at and around SRS. EMS has developed and maintains a routine monitoring program designed to characterize environmental conditions and identify any long- or short-term changes to these conditions. In addition, EMS responds to any nonroutine releases of pollutants with special sampling and analyses designed to measure the event's impact. Comprehensive surveys also are performed in areas affected by past releases, or in aress likely to be impected by future operations.

Other site operating grouph, including Health Protection Operations (HPO), Power Operation, the Savanah River Technoloyy Center (SRTC), and the Savannalı River Bcology Labontory (SREL), also participate in monitoring programs.

The SRS Environmental Monitoring Plan (EMP), published by EMS, provides a comprehensive look at enviroamental-monitoring rationale and technical basis. Updated annually and revised overy three years, the EMP shows the Department of Energy (DOE) and the public any changes, additions, and enhancements in environmental monitoring. The revision process forces a continuous cycle of evaluations and critiques on current monitoring practices in areas ranging from sampling and analyais to data evaluation and reporting.

The SRS Environmental Report provides the public and regulatory agencies an annual review of site monitoring results and compliance issues. The report includes the extimated ofiaite does from SRS operations, discuscions of environmental restoration and remediation, as well as other ieves of community concern relating to the site. The report is accompanied by a summary pamphlet deagigned to capsulize and highlight major environmental ieves.

Guidance and direction for enviroamental monitoring at SRS is contained in DOE Order S400.1. This order is supplemented by DOE/EH-0173T, Environmental Regulatory Guide for Radlological Efjluent Monitoring and Environmental Surveillance. Radiation andards for protectiog the public and environment are contained in DOE Onder 5400.5. Other applicable regulations are contained in the 
National Emission Standards for Hezardous Air Pollutants (NESHAP) and the National Pollution Discharge and Elimination System (NPDES). In addition, compliance is demonstrated against other standards set by the South Carolina Department of Health and Environmental Control (SCDHEC) and the Environmental Protection Agency (EPA).

\section{Summary}

Before construction and operations began at the SRS in the early 1950s, plans were developed and implemented for extensive environmental monitoring of the site and surrounding regions. From the operations-dominated 1950s and 1960s to the increased emphasis on enviroamental reatoration and waste management in the 1990s, the site monitoring plan has doveloped to reflect these changing conditions.

Environmental-monitoring programs at SRS serve two main purposes: to show compliance with foderal, atate, and local regulations as well as DOE orders, and to monitor any effects to onsite and offaite aatural resources. Effluent monitoring, which is performed at or near release points into the environment, serves compliance purposes and provides source terms for offsite dose calculations made by SRTC. Environmental surveillance, consisting of onsite and offsite samples at varying distances from effluent points, verifies doee calculations and monitors the impect from SRS releases.

In general, HPO and EMS share radiosctive effluent monitoring. HPO collects air and liquid samples from regulated areas and maintains monitoring equipment on stacks and some liquid effluents. EMS collects and analyzes most liquid effluent samples. Other than come stack radioisotope determinations, EMS analyzes all effluent-related samples in the EMS Counting Leboratory. All the data are collected and reported in monthly radiosetive release reports, and summarized in an Annual Radioactive Release Report a compilation of site releases since plant startup. Effluent data also are transmitted annually to the DOE databasea, the Effluent Information System (EIS) and the Onsite Discharge Information System (ODIS). These systems compile radioactive-waste effluent information from all DOE facilities in a centralized database, and aid DOE and contractors in managing of the continuing effluent-control and reduction systems and programs.

Nonadionctive sampling on li.juid efflueats generally is performed at NPDES outfalls at SRS, and reported in the Discharge Monitoring Repon (DMR). The report, compiled and authored by EPD, serves as a basis for evaluating the effectiveness of effluent-treatment control, as well as verifying compliance with federal, state, and local effluent regulations.

In addition to EMS, environmental surveillance is performed by SRTC and SREL. Air, surfece water, rainwater, groundwater, soils, sediments, and biots are monitored at - number of locations for radiological and nonnadiological constituents. Analytical reauls are used to measure environmental impects from SRS operations, to verify dose modela, and aseces regional background radiation to compare to site-measured levels. 
Data is gathered from the various SRS monitoring departmentis by EMS and published in the SRS Environmental Report. 


\section{Pollcy}

SRS's environmental-monitoring policy is to design and operate programs to aid in or assess dose, to determine trends in environmental radioactivity concentrations, and to address public and governmental concerns about site activities. 


\section{Existing Conditions}

To meet the criterion and objectives of SRS's environmental-monitoring program, approximately $\mathbf{5 0 , 0 0 0}$ samples are collected and analyzed annually for radioactive and nonradjoactive contaminants.

The basis for selecting samples often falls into one of the two following categories:

- Current operating conditions and environmental levels make the sample valuable in dose assessments and of fsite impact studies.

- Historical data at the sample location provide information for trending and longterm buildup of environmental contaminants.

Many sampling locations that once monitored process effluents now provide historical comparisons as SRS's mission changes from production to cleanup activities.

In addition, EMS uses its laboratory capabilities to support areas onsite that require special sampling and analytical results. These special sample requests are coordinated through the EMS Collections group, and require approval from the designated EMS manager.

Documents, reports, and technical papers containing monitoring results are distributed both onsite and offsite. Analytical results are verified in house by a comprehensive quality-assurance program, which sets flagging criteria in the preparations and counting laboratory, as well as in data management and evaluation. Published methods and results are available for review by technical organizations, as well as the public. 
The following objectives support the environmental-monitoring program:

- to ascess actual or potential exposures of radioactive and nonradioactive materials to critical groups and populations from normal site operations or from accidents

- to comply with authorized limits and regulatory requirements

- to verify the facility's adequacy in containing of radioactivity and its effectiveness in effluent control

- to notify proper officials of unusual or unforeseen conditions and, where appropriate, to activate a special environmental-monitoring program

- to communicate accurately and effectively monitoring program's results to the DOE, other government agencies, and the general public

- to maintain an accurate and continuous record of the effects of SRS operations on the environment

- to determine radioactive concentrations and nonradioactive consaminants in environmental media to assess the immediate and long-term consequences of normal and accidental releases

- to distinguish the contributions to environmental contamination and environmental effects of SRS operations from other sources' contributions

- to evaluate and revise the environmental-monitoring program in response to changing conditions in transfer pathways

- to provide site-specific data for risk assessment and uncertainty analyses for human populations near SRS

- to conduct scientific studies on the transfer pathways of radioactive and nonradioactive contaminants in the environment 
The strategy for reaching the environmental monitoring program objectives is the following:

- design a sampling program that meets both operator and regulatory requirements

- communicate the program to onsite groups who need to know the capabilities and purpose of environmental monitoring at SRS

- communicate the program to the public who need to know that the risk or perceived risk from SRS operations is being measured and evaluated

- critique and reaffirm the design basis for environmental monitoring on a continual basis 
The implementation section identifies issues and those responsible for actions to achieve defined objectives. The following programs are described in the implementation section:

- Sampling Programs (page 4-12)

- Laboratory Programs (page 4-15)

- Monitoring Reports (page 4-18)

- Radiological Effluent Management (page 4-22)

Figure 4-1 illustrates the interaction among the environmental-monitoring programs. 
Figure 4-1 Interaction among the environmental-monitoring programs.

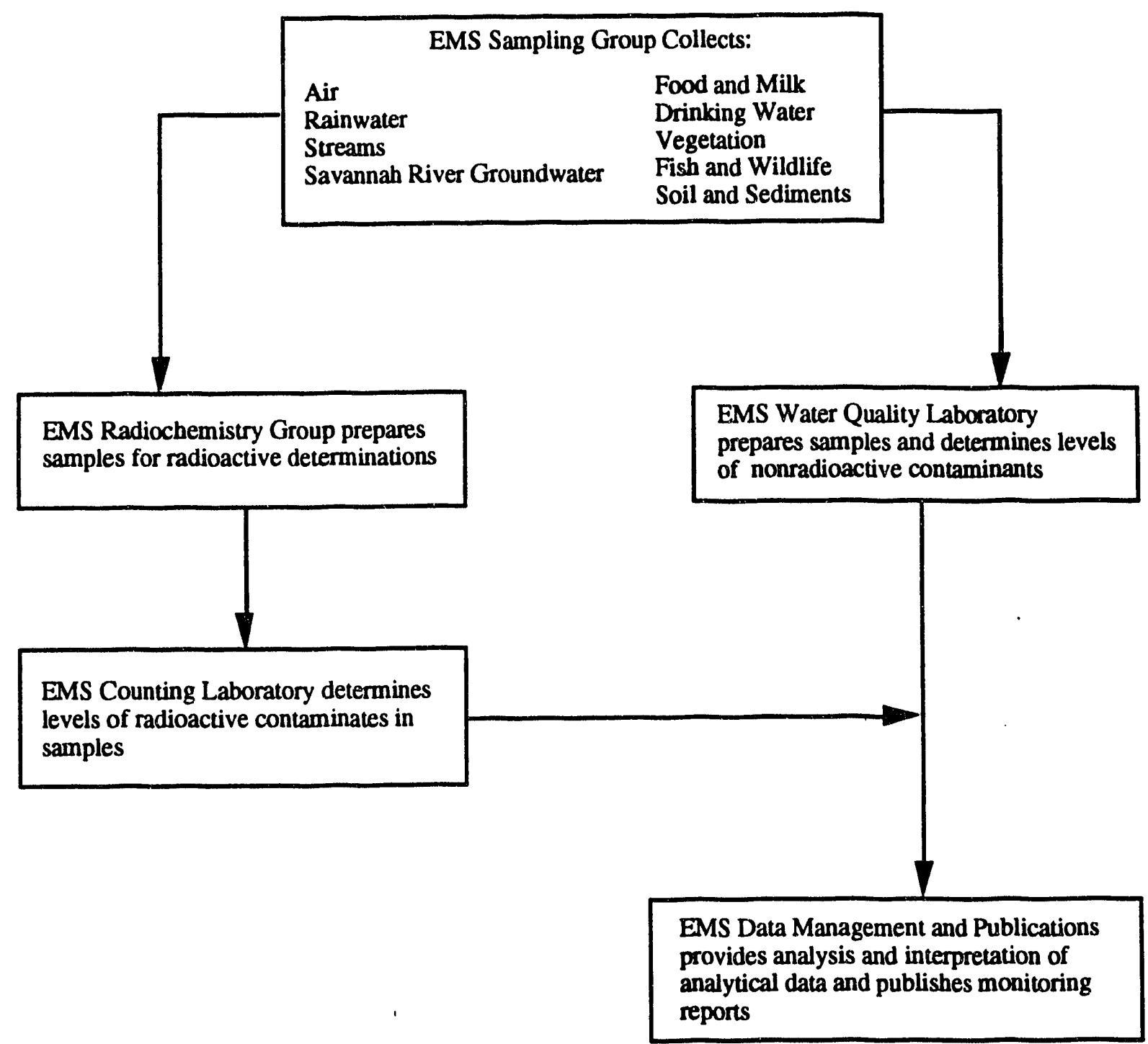




\section{Sampling Programs}

(Compiled and reviewed by Ted S. DeHart and Pete D. Fledderman)

\section{Site Program Overview}

The Environmental Monitoring Section's Sampling Group is responsible for collecting samples in various exposure pathways in and around SRS. These samples include air, water, soil, sediment, vegetation, milk, food, and wildlife. Sampling programs are balanced geographically in SRS's vicinity, with onsite, plant-perimeter, 25-mileradius, and 100-mile-radius collection points. The sampling frequency and location of collected media are developed in the Environmental Monitoring Plan, and are determined, in part, by potential and historical release points and pathways. EMS also responds to nonroutine occurrences and releases with a sampling program specific to the nature, content, and pathway of the released activity.

\section{Five-Year Outlook}

The EMS sampling program will expand in the next five years in the following ways with plans to address both public and regulatory concerns.

- A sampling program is planned for wells located across the Savannah River in Georgia.

- Increased nonradiological sampling will include biological surveys.

- Advances in instrumentation will allow developing programs such as underwater gamma spectroscopy in the field and surrounding community stations, providing current ambient gamma radiation levels.

\section{Justification/Regulatory Requirements}

Guidance and direction for sampling programs at SRS are contained in DOE Orders 5400.1 and 5400.5. These orders are supplemented by DOE/EH-0173T, Environmental Regulatory Guide for Radiological Effluent Monitoring and Environmental Surveillance.

\section{Organization Responsibility Summary}

EMS assumes responsibility for environmental sampling in and around SRS.

Other groups maintaining routine sampling programs include SREL (primarily streams, ponds, and Savannah River sampling), the SRTC (special studies, online effluent and environmental sampling), HPO (airborne and liquid effluent sampling), and the Power Department (drinking water sampling). 


\section{Site Procedures and Documents}

Procedures describing the EMS sampling programs are found in the following volume:

\section{- WSRC-3Q1-3 Environmental Sampling Procedures}

Further discussion and program overviews are contained in the Environmental Report and the Environmental Monitoring Plan. The Sampling Group also is bound by the EMS Quality Assurance Plan, WSRC-3Q1-2.

\section{Programs}

\section{Radiological Sampling}

Sampling for radioactive materials includes both effluent and environmental-surveillance sample collection. Media in both the atmospheric and aqueous pathways are collected and brought to EMS laboratories for sample preparation, counting, and reporting. Determining of radiological sampling sites is made with both historical and current release-pathway information, as well as public risk consideration.

\section{Nonradiological Sampling}

The Nonradiological Sampling Program primarily consists of samples collected in the liquid pathway, including SRS liquid effluents, site streams, the Savannah River, groundwater, drinking water, and fish. While some analytical measurements $(\mathrm{pH}$, temperature, dissolved oxygen, conductivity) are made by field sampling personnel, most samples are returned to EMS, another onsite laboratory, or a subcontracted offsite laboratory for specific analyses.

\section{Technical Support Programs}

\section{Health Protection Technology}

HPT works with EMS on the environmental thermoluminescent dosimeter (TLD) program, measuring penetrating radiation levels. HPT prepares the TLDs prior to sample placement, and analyzes the returned badges after the field cycle. EMS Sampling personnel place and collect the badges. EMS is responsible for data reduction and reporting. 
One-Year Road Map

Over the next year, EMS Sampling plans to do the following:

- upgrade instrumentation used in air-monitoring stations for environmental surveillance

- expand its foodstuff sampling program to the 50-mile radius stations, providing a more representative picture of the SRS environment

- continue complying with new and existing regulations including stormwater monitoring and toxicity testing

Five-Year Road Map

Over the next five years EMS plans to do the following:

- implement programs related to public and community concerns, including a Georgia well-sampling program near SRS

- improve monitoring capabilities and diversify sample collection as advances in sampling design and instrumentation are incorporated into the program

- modify and increase the sampling program to meet site, state, federal, and public expectations and regulations 


\section{Laboratory Programs}

(Compiled and reviewed by Robin H. Young)

Site Program Overview

Laboratory programs within EMS consist of an Environmental Counting Laboratory, a Water Quality Laboratory, and a Radiochemical Preparations and Analysis Section. The EMS Counting Laboratory determines radionuclide levels in samples prepared by the Radiochemical section. The Water Quality Laboratory prepares and analyzes samples for nonradioactive materials.

Five-Year Outlook

Advances in both instrumentation and method development should ensure that programs under the EMS laboratory section continue to improve and evolve in the following ways:

- As environmental levels of radioactivity decrease with the slowdown of production at SRS facilities, verification of dose models will require increased instrument and analytical sensitivity.

- A desire to bring more analysis work to EMS laboratories will decrease reliance on subcontractors, but provide a corresponding increase in sample preparation and counting.

- Cleanup and land-closure activities will require EMS support and experience to conduct low-level environmental measurements.

\section{Justification/Regulatory Requirements}

Guidance and direction for laboratory programs at the SRS is contained in DOE Order 5400.1 and DOE Order 5400.5. These orders are supplemented by DOE/EH-0173T, Environmental Regulatory Guide for Radiological Effluent Monitoring and Environmental Surveillance.

\section{Organization Responsibility Summary}

EMS assumes responsibility for routine monitoring in and around SRS. The majority of effluent and environmental measurements used to estimate annual offsite doses are made in the EMS laboratories. 
Other groups performing routine monitoring at the SRS include the following:

- $\quad$ SRTC - low-level counting, dosimetry of SRS operations, airborne and aqueous radionuclide effluent studies, activities to meet cnvironmental permits and other requirements, and enhancements of emergency-response capabilities

- SREL - independent environmental studies of SRS, surrounding streams and ponds, and Savannah River

- HPO - analysis of effluent samples and maintenance of online monitoring equipment

- Power Department - drinking water collection and analysis

\section{Site Procedures and Documents}

Procedures describing the EMS laboratory programs are found in the following volumes:

- WSRC-3Q1 4, Environmental Radiochemistry Procedures

- WSRC-3Q1-5, Environmental Chemistry Water Quality Procedures

- WSRC-3Q1-6, Environmental Counting Room Procedures

Further discussion and overview of programs are contained in the Environmental Report and the Environmental Monitoring Plan. The laboratory sections also are bound by the EMS Quality Assurance Plan, WSRC-3Q1-2.

\section{Programs}

\section{Environmental Counting Laboratory}

The EMS Counting Room employs a variety of detectors to measure the different types of radiation in the environment. Alpha and beta particles along with gamma rays are identified using sophisticated instrumentation and quantified using various software packages.

\section{Environmental Water Quality Laboratory}

Nonradiological surveillance at SRS began in 1951 with a water-quality monitoring program on the Savannah River. Today, the program has expanded to include monitoring for specific chemicals, metals, dissolved ions, and organic constituents in various SRS media.

\section{Environmental Radiochemistry Preparation}

Sample preparation to determine radionuclide concentrations is performed in the EMS Radiochemistry laboratories. Adhering to program design, the labs handle samples 
which represent the critical media through which radiological contaminants can be transported to the public and into the environment.

\section{Technical Support Programs}

\section{Savannah River Technology Center}

Although the EMS laboratories can identify and quantify very low levels of environmental radiation, the Environmental Technology Section (ETS) within SRTC specializes in ultra low-level isotopic determinations in its underground laboratory. ETS measures and provides EMS with information such as iodine-129 levels in effluent and environmental samples, and cesium-137 levels in the Savannah River.

\section{Analytical Laboratories}

Many effluent and process samples are handled by Analytical Laboratories because of their high activity levels. If measurements are below these labs' detection limits and a numerical determination is needed, samples frequently are forwarded to EMS or SRTC for further counting.

One-Year Road Map

In the coming year, EMS plans to upgrade and expand both sample preparation methodology and instrumentation by the following:

- developing procedures to identify more accurately low levels of radioactive materials in environmental media

- obtaining instrumentation that will allow the group to expand its nonradiological sample preparation and analysis program

Five-Year Road Map

In the next five years, EMS plans to do the following:

- prepare design documentation and begin lab renovation in Building 735-A

- upgrade laboratory procedures to maintain compliance with new and existing requirements of regulatory agencies, such as EPD and SCDHEC

- maintain a level of technical personnel and instrument sophistication to support the increasing environmental-monitoring mission at SRS 
Monitoring Reports

(Compiled and reviewed by Craig S. Hetrick)

Site Program Overview

Reports dealing with environmental monitoring at SRS have documented operations at the site since startup. The SRS Environmental Report, written for a public audience, summarizes environmental activities and environmental data annually. The Effluent Information System and Onsite Discharge Information System (EIS/ODIS) report lists effluent discharges for inclusion in a DOE effluent database. The Monthly Radioactive Release Report tracks the site's performance in radioactive effluent management to ALARA goals. An annual radioactive release report, Radioactive Releases at the Savannah River Site, chronicles effluent releases to the environment since plant startup in tabular and graphical form. Other reports dealing with monitoring are required by regulatory agencies, DOE, and oversight groups. Special sampling surveys, due to current conditions or previous releases, also require monitoring reports to communicate information.

Five-Year Outlook

The ability to communicate environmental activities to a better educated and responsive public will force environmental reports to balance detail and focus in the coming decade.

In the next five years, EMS is expecting the following to happen:

- The Environmental Report will continue to be an important vehicle of communication between SRS, regulatory agencies, and the public. The changing site mission, increased oversight, and greater public involvement will force the report to adapt to sometimes competing interests. More graphics and presenting technical information in an easily understood context are planned for the Environmental Report.

- Database management and report generation will have to be flexible in times of changing regulations and increasing requirements.

- The possibility of seepage basin closures and other land closings and remediation will be supported by historical records of early releases and contaminant levels. This information must be available in an accessible medium for quick and accurate retrieval.

- Monitoring reports and data will play an important role in reconstructing the site's environmental record for the SRS dose reconstruction project, which will continue into the 1990 s. 


\section{Justification/Regulatory Requirements}

DOE Orders 5400.1 and $1324.2 \mathrm{~A}$ contain the requirements for maintaining auditable records. DOE Orders 5400.1 and 5400.5 contain the requirements for reporting effluent-monitoring and environmental-surveillance activities. Other programs, including the NESHAP regulations and the Clean Water Act, require the following specific reporting conventions.

\section{Organization Responsibility Summary}

\section{Environmental Monitoring Section}

EMS compiles the Environmental Report, the Annual and Monthly Radioactive Release Reports, and the EIS/ODIS report. Other reports, including a quarterly Drinking Water Report sent to water treatment plants and a Nonradiological Water Quality Report, are distributed to interested personnel. Special sampling surveys and unusual occurrences also are the subject of EMS monitoring reports.

\section{Environmental Protection Department}

EPD has the lead responsibility for notifying appropriate officials of environmental occurrences at SRS. EPD also has the responsibility to ensure that reporting requirements to EPA, DOE, and other regulatory agencies are met within required time periods. Among others, these reports include the Annual Compliance Report as part of the NESHAP program (40 CFR 61, Subpart H), and the Liquid Discharge Monitoring Report per the Clean Water Act.

\section{Site Procedures and Documents}

Procedures describing the EMS monitoring reports are found in the following volume:

- WSRC-3Q1-7 Environmental Data and Reporting Procedures

\section{Programs}

\section{Environmental Report}

First distributed to the public in 1959, the SRS Environmental Report details the site's environmental-monitoring, environmental-research, and environmental-compliance programs. Since 1972, the report has provided radioactive-dose calculations for the offsite public from SRS releases. The report also summarizes significant environmental events, routine environmental-monitoring data, and laboratory quality-assurance practices and objectives. 
Emuent Information System and Onsite Discharge Information System (EIS/ODIS)

To comply with DOE Order 5400.1, EMS annually submits liquid and airborne releases into the environment to the EIS/ODIS management system, a DOE-wide database maintained at the Idaho National Engineering Laboratory. The EIS/ODIS database systems aid DOE-Headquarters and Field Offices in managing air and liquid effluents from DOE facilities.

\section{Radioactive Release Reports}

On a monthly basis, EMS compiles a radioactive-release report for distribution to site personnel. The report summarizes all effluent-release data at SRS, listing radionuclides released, quantities, and associated dose. ALARA goals are set by operating departments based on production schedules and planned emissions. Fach area's performance is monitored against the ALARA goal throughout the year. Adjustments to goals and incident investigations are performed accordingly.

All effluent data collected since plant startup is contained in the document, Radioactive Releases at the Savannah River Site. Releases are broken down by radionuclide and by year.

\section{Technical Support Programs}

\section{Savannah River Technology Center}

SRTC is in the process of compiling historical data on significant radionuclide releases at SRS. Each book concentrates on a specific nuclide, and provides an in-depth view on particular releases and historical information. These reports are being made available to the public.

\section{Savannah River Ecology Laboratory}

Since 1951, SREL has conducted independent environmental studies of SRS, surrounding streams and ponds, and the Savannah River. Operated by the University of Georgia under contract with DOE, SREL supports programs in biogeochemical ecology, wildlife ecology and toxicology, and wetlands ecology. Numerous books and research articles are published annually to communicate the laboratory's studies to the scientific community and the public.

\section{One-Year Road Map}

During the next year, EMS plans to do the following: 
- produce an Environmental Report that is responsive to concerns of site personnel, regulatory agencies, oversight groups, and the public.

- increase communication between EMS and recipients of monitoring reports

Five-Year Road Map

During the next five years, EMS plans to do the following:

- merge historical monitoring data into a single, accessible, and accurate database, maintaining the integrity of results and the limitations of historical information

- increased the interaction between Savannah River-area monitoring groups, including common sample locations, split sample studies, and data sharing 


\section{Radiological Effluent Management}

(Compiled and reviewed by Tim G. Jannik)

Site Program Overview

Since commencing operations, SRS has maintained a comprehensive history and inventory of radioactive releases into the environment from plant operations. In 1972, technical standards took an ALARA approach for environmental releases. This philosophy was applied to release guides assigned to operating facilities annually. In 1990, the AlARA program for radioactive effluent accountability placed new emphasis on the impact radioactive releases have on offsite dose rather than simply maintain an inventory of quantities released during the calendar year. The December 1991 release of liquid tritium from K Area into the Savannah River further focused efforts on effluent-release potential and control. The WSRC Environmental Release Prevention and Control Plan (ERP\&CP), which documented the characterization of SRS effluents and identified options, grew out of this effort.

Five-Year Outlook

The two effluent studies, the ERP\&CP and the Airborne Release Prevention and Control Plan (ARP\&CP) will be reviewed and, if necessary, revised annually to meet the challenges and conditions of a changing site. This review will provide the needed focus on radiological effluent management at SRS.

\section{Justification/Regulatory Requirements}

SRS is required to maintain radiation doses to the public within the limits specified in DOE Order 5400.5. In addition to meeting these limits, SRS also is required to ensure that doses to the public are as low as reasonably achievable (ALARA).

The ALARA program, an administrative system that emphasizes dose-based effluent accountability for all major discharge points, meets the requirement to minimize of fsite doses resulting from radioactive releases into the environment.

\section{Organization Responsibility Summary}

The various organizations and their responsibilities in radiological effluent management are outlined in the WSRC-3Q procedure, Radiological Effluent Monitoring, Reporting and ALARA Release Guides (ECM 18.2). Organizations assuming program responsibility include WSRC senior management, EMS, EPD, Operating Departments/Facility-Line Management, HPO, and ETS. 


\section{Site Procedures and Documents}

Options and alternatives for minimizing liquid releases are contained in the WSRC Environmental Release Prevention and Control Plan, which will be scheduled for release in 1993. The ALARA program and its administration is described in procedure ECM 18.2, Radiological Effluent Monitoring, Reporting and ALARA Release Guides (WSRC-3Q). The ALARA program is tracked throughout the calendar year in the Monthly Radioactive Release Report, listing all monitored site effluents and corresponding doses associated with environmental releases.

\section{Programs}

\section{Environmental ALARA Release Guides Committee}

This group is made up of operations and technical support personnel who review release guides and issues dealing with radiological effluent monitoring. EMS is responsible for assigning a representative to serve as acting chairperson of this committee and to make sure that all administrative guidelines are met.

\section{Technical Support Programs}

\section{Designated Operations Personnel}

Designated Operations personnel supply the Environmental ALARA Release Guides Committee the ALARA guidelines for the calendar year. These personnel, with help from environmental coordinators or other technical support, are responsible for incident investigations, any release guide revisions, and investigation of any potential release which may exceed ALARA guidelines.

\section{Health Protection Operations}

HPO maintains a sampling program at the ALARA airbome discharge points. HPO also supports on-line monitoring equipment needed for quick notification of potential releases which may exceed ALARA guidelines. 


\section{Environmental Technology Section (SRTC)}

ETS provides EMS with dose-conversion factors specific to SRS and used in the ALARA reports.

One-Year Road Map

Within the next calendar year, the Airborne Release Prevention and Control Plan (ARP \& CP) will be released, providing similar information for airborne effluents that the Environmental Release Prevention and Control Plan (ERP \& CP) documented for liquid effluents.

Five-Year Road Map

Both the airborne and liquid control plans will be updated annually and revised as necessary. The site will continue to adjust ALARA release guides triannually, reflecting the current operations. Increased analytical sensitivity also may make lower ALARA guides a reality as measurable environmental baselines decrease. 
Chapter 5

\section{Chemical Management, Pollution Prevention and Other Compliance Programs}

Chapter was compiled and reviewed by Greg L. Peterson. 


\section{Site Program Overview}

Compliance with environmental regulations and U. S. Department of Energy Orders (DOE) relating to environmental protection is an important part of SRS's program. Demonstrating environmental excellence is a high priority embodied in DOE and Westinghouse Savannah River Company (WSRC) policy. SRS constantly is striving to improve its standing as a leader in environmental-protection activities.

All activities at SRS are overseen by one or more regulators, such as the South Carolina Department of Health and Environmental Control (SCDHEC) and the Environmental Protection Agency (EPA).

Over the past few years, the number of environmental regulations bas increased. The strategy to comply with new and existing environmental regulations and DOE orders is described in chapter two.

In this chapter, the following environmental programs are described:

- Toxic Substances Control Act (TSCA):

- TSCA, Section 5(a), requires premanufacture notification to EPA 90 days prior to commercial manufacture, and Section 5(a)(2) requires reporting to EPA significant new uses of the existing purpose.

- TSCA, as amended in Section 6, prohibits using polychlorinated biphenyl (PCBs) except in a totally-enclosed manner. It also provides procedures required for handling, storing, and disposing of regulated PCBs and PCBcontaining materials.

- Federal Insecticide, Fungicide, and Rodenticide Act (FIFRA):

- FIFRA, as amended, and the S.C. Pesticide Control Act establish procedures for handling, storing, applying and disposing of pesticides.

- Emergency Planning and Community Right-to-Know Act (EPCRA):

- EPCRA contains four major provisions that impact site operations: planning for chemical emergencies; notifying emergency personnel of chemical accidents and releases; reporting hazardous chemical inventories; and reporting toxic-chemical releases.

- SPCC/BMP/Pollution Prevention Plans:

- These plans provide ways to mitigate the consequences of pollutants reaching the environment and contaminating the surface waters. 
- Safe Drinking Water Act (SDWA):

- The Safe Drinking Water. Act of 1974, as amended, and the South Carolina Primary Drinking Water Regulations require that applicable permits be obtained and that sample analyses and site inspections of public/industrial water supplies and drinking water sources be completed satifactorily.

- National Environmental Policy Act (NEPA):

- Compliance with and implementation of DOE Order 5440.1C and other DOE guidelines will evaluate potential environmental impacts of federal activities and alternatives. 


\section{Implementation}

The implementation section identifies issues and those responsible to achieve defined objectives. The following programs are described in this chapter:

- Toxic Substances Control Act (page 5-6)

- Polychlorinated Biphenyls (page 5-9)

- Federal Insecticide, Fungicide, and Rodenticide Act (page 5-13)

- Emergency Planning and Community Right-to-Know Act (page 5-15)

- Spill Prevention and Control Program (page 5-18)

- Safe Drinking Water (page 5-22)

- National Environmental Policy Act (page 5-27) 


\title{
Toxic Substances Control Act
}

\author{
15 U.S.C. 2601 , et seq.
}

(Compiled and reviewed by Steve D. Glover)

\section{Site Program Overview}

The Toxic Substances Control Act (TSCA) gives the U.S. Environmental Protection Agency (EPA) comprehensive authority to identify and control chemical substances that are manufactured, imported, processed or used. Reporting and record keeping is mandated for new chemicals and for chemicals that may present a substantial health or environmental risk. WSRC Environmental Protection Department (EPD) provides guidance for identifying TSCA-compliance requirements, and the Industrial Hygiene Section coordinates the process of recording allegations of significant adverse reactions to health or the environment. Managing and disposing of polychlorinated biphenyls are a major part of TSCA compliance and are described in a separate implementation program.

\section{Five-Year Outlook}

Over the next five years, emphasis will be on programs such as clean air and clean water. TSCA regulatory requirements are not expected to change substantially. The site will continue to monitor for new chemical developments and any allegations of significant chemical-related health or environmental risks.

\section{Justification/Regulatory Requirements}

TSCA of 1977, 15 U.S.C. 2604, Section 5, establishes procedures for manufacturers and importers to report new chemical substances. Chemicals not listed in TSCA's inventory are considered new chemicals and must undergo premanufacturing notification (PMN) to EPA 90 aays prior to commercial manufacture or importation.

Section 5(a)(2) EPA identifies significant new uses of chemical substances and specifies procedures for manufacturers, importers and processors to report those uses.

Section 8(c) requires chemical substance manufacturers, processors, and distributors to maintain records of employee allegations claiming that a substance or chemical causes significant adverse reactions to health or the environment.

Section 8(e) requires reporting information which reasonably supports the conclusion that a chemical substance or mixture presents a substantial health or environmental risk.

TSCA Section 6, (40 CFR 761) regulates PCBs, and these requirements are identified in the PCB implementation plan. 


\section{Organizational Responsibility Summary}

EPD provides general site guidance for TSCA compliance. EPD's TSCA coordinator is responsible for providing appropriate forms and submitting documentation for premanufacturing notification. The Industrial Hygiene Section coordinates recording allegations claiming that a chemical substance presents a health or environmental risk. EPD and the medical department bave the responsibility for reviewing allegations and determining if they are significant. Allegations are submitted to Westinghouse's corporate office and may be reported to EPA if the corporate office determines the information reasonably supports the allegations and should be reported under Section 8(e).

\section{Site Procedures and Documents}

The industrial hygiene section currently is drafting a procedure, "Records and Reports of Alleged Significant Adverse Reaction to Health and Environment", to be included in the $4 \mathrm{Q}$ procedures manual. This procedure will formalize recording allegations and reporting substantial risks required in sections 8(c) and 8(e) of TSCA. Procedure 3Q ECM 12.3 establizhes a site chemical inventory and supports the TSCA program.

\section{Programs}

Any employee, group or department that intends to manufacture or import a new chemical substance, which is not excluded by an exemption and is for a "commercial purpose", must submit PMN information to the TSCA coordinator in EPD. The requirement for a PMN review also includes certain bioengineered microorganisms which EPA regards as new chemical substances. TSCA, Section 8(c), requires maintaining records of allegations claiming that chemicals have caused previously unknown, significant adverse effects to buman bealth or the environment. Allegations may be made by anyone, including employees, families of employees and plant neighbors. The Industrial Hygiene Section of the Safety Division has the responsibility for providing assistance in completing allegation reports and routing them to the medical department or EPD.

TSCA, Section 8(e), requires reporting to EPA information that reasonably supports the conclusion that a chemical substance presents a substantial health or environmental risk. The Industrial Hygiene Section will coordinate reporting significant risk information, following review by the medical department or EPD. 
One-Year Road Map

Excmptions under TSCA eliminate some regulatory requirements for manufacturing nuclear source material and special nuclear material. These exemptions do not delineate clearly all requirements that are or are not applicable to GOCO operations, and therefore, interpreting the exemptions is an onguing process. Industrial Hygiene has a draft procedure under review which should be completed this year.

\section{Five-Year Road Map}

No major additions or changes are expected in the TSCA program over the next five years. 


\title{
Polychlorinated Biphenyls (PCBs)
}

\author{
(Compiled and reviewed by Vernon D. Osteen)
}

\section{Site Program Overview}

Since 1980, the Savannah River Site (SRS) has had an active program to remove and dispose of PCBs properly. In the past, the primary use of PCBs was in closed or semiclosed systems in electrical transformers, capacitors, heat-transfer systems, and hydraulic systems. At the present time, PCBs are found onsite in small capacitors (less than 3 pounds) used to raise and lower reactor-control rods, in ballasts in fluorescent light fixtures, and in several transformers. New purchases of hydraulic fluids, heattransfer systems, electrical transformers, capacitors, and other dielectric fluidcontaining materials are certified by the vendor to contain no PCBs.

Operations continue to remove all PCB fluids and materials from the site. SRS is going beyond regulations by shipping all PCB-containing (including unregulated, small capacitors and fluorescent light ballasts) materials offsite for disposal at an approved EPA facility. At the present time, there are two onsite locations for storing PCB-containing materials: Building 741-1N for non-radiological PCB-containing materials and Building 643-29E for radioactively-contaminated PCB-containing materials. Both of these facilities meet federal regulations for storing PCBs. Currently, there is not an approved facility for disposal of radioactively-contaminated PCBs.

\section{Five-Year Outlook}

The only major change in PCB regulations is an advanced notice of proposed rulemaking that will affect disposal of PCBs. The major impact to the site will be the storing and disposing of radioactive PCBs that are onsite.

Within five years, the site should bave removed all remaining PCBs onsite and have the PCB database that will confirm the concentrations in all transformers and oil-filled circuit breakers (OCB).

Regulatory Requirements

\section{Federal Low and Regulations}

Toxic Substances Control Act (TSCA) of 1977, as amended (15 U.S.C. 2601 et siq.), Section 6 (40 CFR 761) - The use of polychlorinated biphenyls (PCBs) are prohibited except in a totally-enclosed manner. DOE also is required to comply with listed procedures for handling, storing, and disposing of regulated PCBs and PCB-containing materials. 


\section{Organizational Responsibilities}

Materials Logistics and Inventory is responsible for the following:

- maintaining storage facilities at Building $741-1 \mathrm{~N}$ in compliance with regulatory requirements

- maintaining storage, inventory, and inspection records for Building 741-1N

- ensuring proper packaging and labeling of PCB-containing materials in Building $741-1 \mathrm{~N}$

- obtaining a contract for offsite disposal of PCBs

- ensuring PCBs are shipped offsite within the regulated time limitations.

Waste Management Operations is responsible for the following:

- maintaining the storage facilities at Building $643-29 \mathrm{E}$ in compliance with regulatory requirements

- maintaining storage, inventory and inspection records for Building 643-29E

- ensuring proper packaging and labeling of PCB-containing materials in Building 643-29E

The Environmental Protection Department (EPD) is responsible for the following:

- serving as an onsite PCB consultant

- coordinating the PCB-removal program

- interfacing with regulatory agencies on audits

Wealth Protection (HP) responsibilities are outlined in DPSOL 158-2-4161.

Custodial departments are responsible for the following:

- determining, by conducting a HP survey, if the potential for occupational exposure to PCBs exists

- instituting a personnel monitoring program to determine potential PCB occupational exposures

- notifying HP and EPD Spill Coordinator in the event of a spill

- notifying area HP when working on PCB-containing equipment

- ident fying any PCB-containing materials in the area

- ensuring proper labeling of PCB-containing materials

- transporting PCB-containing materials to proper storage facilities

- ensuring that employees are trained in handling PCBs and that training is documented 


\section{Site Procedures and Documents}

DPSOL 158-2-4161. Polychlorinated Biphenyls (Biphenyls)--PCBs

DPSOP 83. Polychlorinated Biphenyl Analysis in Transformer Oils

DPSOL S-9549, DPSOP 326. Control and Disposal of Polychlorinated Biphenyls (PCBs)

Polychlorinated Biphenyl (PCB) Management Manual for Savannah River Site (Draft)

\section{Auditing}

The following audits are to be performed at SRS for PCB-containing materials:

- DOE appraisal every three years

- EPA audit at infrequent intervals (PCB survey optional)

- SRS self audit at infrequent intervals (see Chapter 10, Environmental Auditing and Appraisal Program)

Compliance Action

Material Logistics and Inventory (ML\&I)

ML\&I manages the offsite disposal of all PCBs at the 741-N salvage yard. This is done by storing PCBs and making periodic shipments, per EPA regulations, to an approved offsite disposal vendor. The size of these shipments will continue to decrease as PCBs eventually are eliminated at SRS. The current storage facilities should be adequate for the next five years.

\section{Waste Management Operations (WMO)}

WMO presently is storing, one 85-gallon drum and eight 55-gallon drums of floor sweepings contaminated with PCBs in the mixed-waste storage building, 643-29E. WMO is developing a plan for disposal of these PCBs.

\section{Environmental Protection Department (EPD)}

EPD coordinates PC.B activities for the site and consults with the custodians on PCBrelated issues. EPD also prepares the annual inventory report and interfaces with the regulatory agencies or audits. EPD is continuing to verify and update the equipment database as a resource for the entire site. EPD also is consulting with the PCB task force to sample/analyze selected transformers onsite and reverify that they are nonPCB. EPD is finalizing a Polychlorinated Biphenyl Management Manual, which will aid the site in implementing regulations and corporate policies concerning PCBs. 


\section{Health Protection (HP)}

HP assists all other departments by implementing DPSOL 158-2-4161.

One-Year Road Map

In a effort to improve the PCB program at SRS, a number of items will be continued throughout the coming year. The draft PCB Management Manual will be finalized and distributed to the environmental coordinators to provide assistance and guidance in managing PCBs at their facilities. The sampling program to verify PCB concentrations in transformers will continue to demonstrate compliance with TSCA and SRS policies. The PCB database will continue to be updated and verified as the source for documenting PCBs at SRS. This effort will require the cooperation between all groups that have custody of transformers and oil-filled equipment.

The next year will see the beginning of negotiations of a Federal Facility Compliance Agreement (FFCA) between EPA, DOE, and WSRC on the radioactive PCB disposal issue. The waste is stored safely, but exceeds the one-year storage limit for PCBs.

Five-Year Road Map

The sampling program will continue until all the transformers and oil-filled equipment are sampled. The FFCA negotiations will be completed within this time period. Once these tasks are completed, there should be no major changes to the program. 


\title{
Federal insecticide, Fungicide, \& Rodenticide Act (FIFRA)
}

\author{
(Compiled and reviewed by Steve D. Glover)
}

\section{Site Program Overview}

SRS's pesticide program provides guidance for using pesticides. WSRC has a formalized process for evaluating pesticide programs which typically involves using insecticides, herbicides and rodenticides. Under this program's objectives, relative safety, potential effects on the environment and FIFRA regulatory requirements are assessed. The program's procedure defines responsibilities regarding pesticide selection, application and disposal.

Five-Year Outlook

No major changes are expected in regulating pesticide applications. EPA's requirement that manufacturers reregister existing products will reduce the number of different pesticides on the market, but it is not expected to have a significant effect on products used and applied by SRS. Proposed regulations for agricultural workers will need to be evaluated as information becomes available.

\section{Justification/Regulatory Requirements}

The Federal Insecticide, Fungicide and Rodenticide Act, as amended (7 U.S.C. 136, et seq.) and the South Carolina Pesticide Control Act (R. 27-1072 ff)-These statutes require SRS to comply with established procedures for handling, storing, applying and disposing of pesticides.

\section{Organizational Responsibility Summary}

WSRC has a Pesticide Use Task Group (PUTG) which is responsible for evaluating pesticide program applications. The group also responds to questions and communications concerning pesticide use at SRS and prepares reports or responses concerning pesticide activities. EPD's pesticide coordinator chairs the PUTG and provides general guidance for FIFRA compliance. PUTG is also represented by Central Services Works Engineering (CSWE), Industrial Hygiene, Forestry, Savannah River Ecology Laboratory (SREL), and the Savannah River Technology Center (SRTC).

WSRC pesticide programs go through the PUTG approval process to ensure compliance, and the forest service is guided by its environmental-impact staternent for the Coastal Plain/Piedmont.

WSRC applicators are required to be trained and licensed. Storage, use and disposal of pesticides is conducted according to regulatory, labeling and procedural requirements. WSRC's subcontract technical representative (STR) is responsible for contractor orientation with SRS's pesticide program. Contract specifications req :ire site-specific training, strict adherence to pesticide label instructions, observance of WSRC's 
pesticide procedures, and they specify that all unused pesticides and pesticide containers be removed from SRS daily.

Applicators licensed with CSWE apply herbicides to parking areas, road beds, fence lines and power line rights-of-way. CSWE also is the STR for the grounds maintenance contract. Waste Management applies herbicides to control weeds and brush in improved areas. Facilities and Services administers subcontracts for insect, termite, and rodent control. The transportation department manages subcontracts for weed control on railroad tracks and the Forest Service utilizes herbicides in its vegetation-management and reforestation programs.

\section{Site Procedures and Documents}

WSRC procedure ECM 8.1 establishes PUTG and program requirements including the requirement that applicators are state certified. Provisions in ECM 8.1 are based on regulatory requirements under FIFRA and the need to coordinate with other site activities that may be sensitive to pesticide applications.

\section{Programs}

Prior to initiating a pesticide program, the program originator, a representative of an SRS department that needs a pest-control program, is responsible for preparing a formal, written program plan for review and approval by PUTG. The pesticide program identifies the pest and describes the area, application method, and health and safety precautions. PUTG then reviews the application and determines if a site-use permit is required. Once approved, pesticides are applied on a routine basis and a pesticide-activity report is submitted to PUTG to maintain records of pest-control activities onsite.

\section{Technical Support}

Technical support is offered by the Forest Service for vegetation control. The Forest Service bas been instrumental in securing training for pest-control applicators to meet certification requirements.

\section{One-Year Road Map}

PUTG presettly is undergoing change. The original committee was enlarged to include representation from DOE, USFS and SREL. DOE's Natural Resources Coordinating Committee has adopted PUTG and is broadening the program. The goal for 1993 is to modify procedure 8.1 to account for the broader scope, institute site-use permitting where appropriate and create a database for data collected from pesticide activities reports.

\section{Five-Year Road Map}

The five-year outlook included trial utilization of low-volume application methods for power line vegetation management. An informal goal in power line vegetation 
management is to achieve control which will reduce herbicide applications to every other year or every two years. 


\section{Emergency Planning and Community Right-To-Know Act (EPCRA)}

(rompiled and reviewed by Steve D. Glover)

\section{Site Program Overview}

The Emergency Plansing and Community Right-to-Know Act (EPCRA), also known as Superfund Amendments Reauthorization Act (SARA) Title III, was devised to encourage and support emergency planning for chemical accidents and to provide local governments and the public information about possible chemical hazards in their communities. The law contains four major provisions that impact site operations: planning for chemical emergencies; notifying others of chemical accidents and releases; reporting hazardous chemical inventories; and reporting toxic chemical releases.

Five-Year Outlook

EICRA, being a popular and pervasive regulation, will continue to exert influence on other regulatory programs such as the air and water compliance programs. There also is political pressure to increase the size and scope of information-gathering provisions under EPCRA. An example of this is the "Right to Know More" bill that was introduced into Congress. The resources required to complete EPCRA-reporting requirements are expected to increase over the next five years, but generally, the compliance programs will be conducted similarly to moderate modifications.

\section{Justification/Regulatory Requirements}

The EPCRA of 1986, Title III of SARA, has the following four major sections. Sections 301-303 provide emergency planning. Section 304 requires a facility to notify the State Emergency Response Commission (SERC) and the Local Emergency Planning Committee (LEPC) of an offsite release in excess of reportable quantities. Section 312 requires facilities to submit chemical- inventory information to SERC, LEPC and local fire departments. Section 313 is the toxic-chemical release notification that is submitted to EPA and state agencies. The Pollution Prevention Act of 1990 adds reporting requirements on source reduction and recycling activities to the section 313 report.

\section{Organizational Responsibility Summary}

WSRC has the general sitewide responsibility for coordinating compliance activities under EPCRA. Section 302 requires facilities to assign a facility emergency coordinator to be a point of contact with LEPC. DOE-SR appointed the chief of the emergency management branch of the Radiation Protection and Emergency Management Division to be SRS's point of contact and to participate in emergency planning meetings.

Section 304 requires a facility to notify SERC and LEPC of an accidental release of a hazardous substance exceeding "reportable quantities" if the release leaves plant 
boundaries. A facility also must provide a written report on actions taken. WSRC has a well-defined program for reporting releases. This program is described in the Emergency Response, Environmental Occurrence Reporting and Regulatory Notifications Implementation Plan.

Section 312, "Hazardous Chemical Reporting", requires facilities to submit hazardouschemical inventory information to SERC, LEPC, and local fire departments. Due to overlapping requirements with OSHA's Hazard Communication Standard, the Industrial Hygiene Section (IHS) has the responsibility for sitewide inventory reporting and submitting material safety data sheets (MSD). Hazardous chemicals stored onsite in quantities greater than threshold planning quantities are reported annually by March 1 on an EPA Tier II form. IHS directs chemical coordinators representing SRS field organizations to provide MSD inventory information. A chemical information and inventory database (CIIS) was developed by WSRC to store the data from more than 13,000 MSDs onsite and to electronically generate the Tier II report.

Section 313, "Toxic Chemical Release Reporting", requires facilities to submit annual reports on toxic-chemical releases to SERC and EPA. EPD's environmental support section is responsible for coordinating and submitting data generated by various SRS organizations. Chemical releases into the air, on land, in water, and underground are reported by July 1 for aggregate quantities of regulated chemicals that exceed established threshold amounts. EPD organizes a task team representing WSRC field organizations and SRS coniuractors. Data gathering is delegated to task team members and data acquisition is aided by the CIIS inventory system. EPD's program coordinator provides training to task team members, distributes CIIS inventory information and assimilates the data. The EPA Form $R$ is used for data submittals, and the report is signed by WSRC's vice president of ESH \& QA.

\section{Site Procedures and Documents}

WSRC EPD has developed operating procedures for managing EPCRA programs. Procedure 3Q ECM 12.3 (Site Chemical Inventory) provides a chemical-substances inventory to support chemical reporting and establishes reporting requirements applicable to Section 312 of EPCRA. Procedure 3Q ECM 12.4 (MSDS Maintenance and Availability Requirements) establishes the requirements for the maintenance and availability of MSDs at SRS to comply with OSHA's Hazard Communication Standard, 29 CFR Part 1910.1200. Together these two procedures provide guidance for information gathering and Tier II reporting. These two procedures currently are being revised and transferred from EPD's $3 Q$ manual to Industrial Hygiene's $4 Q$ procedures manual.

Procediure 3Q ECM 10.3 (Preparation of Annual Toxic Chemical Release Report) establishes requirements and responsibilities for preparing the annual Toxic Chemical Release Report (Form R) for SRS as required by Section 313 of EPCRA. 
Programs

EPCRA, in addition to emergency planning and spill notification, mandates two separate chemical-inventory reporting programs. Both programs require participation from all contractors onsite that store or use chemicals that meet defined regulatory requirements. Chemical coordinators are assigned by each site organization to compile and maintain information on chemicals used by that organization. Chemical coordinators provide the information needed by IHS and EPD program coordinators to complete EPCRA reporting requirements. The Tier II report, completed by IHS, is submitted to the local fire departments, LEPC, and SERC by March 1. The Form R report, completed by EPD, is submitted to EPA and SCDHEC.

In June 1992, SRS reported that eight chemicals were released into the environment with quantities totaling 68,000 pounds. Source-reduction and recycling activities under the Pollution Prevention Act of 1990 were included in the reporting requirements.

One-Year Road Map

During 1992-1993, we will initiate transferring procedures 3Q 12.3 and 12.4 to the $4 Q$ procedures manual. Improvements continually are being made to the chemical inventory and information systems database which will improve reporting.

Five-Year Road Map

Inroads are being made to tie the chemical inventory and information system into procurement. This dramatically will improve the chemical-inventory system and also improve chemical reporting required by EPCRA. Source-reduction and recycling activities are expected to increase during this period and reporting under the Pollution Prevention Act should improve as tracking of these activities improves. 


\section{Spill Prevention and Control Program}

(Compiled and reviewed by Paul C. Carroll)

\section{Site Program Overview}

To mitigate the consequences of pollutants reaching the environment and contaminating the surface waters in South Carolina, SRS has implemented a comprehensive spill-prevention program.

In the area of spill response, SRS incorporates several levels of coverage to ensure that all spills are contained and cleaned up expeditiously. Primary, spill response lies with the individual organizations to maintain sufficient cleanup equipment and supplies to handle most small spill situations. If a facility can not cope with a spill/release, SRS's Hazardous Material (HAZMAT) Response Team is on duty 24-bours a day. When notified of a spill, the HAZMAT team is responsible for identifying, containing, isolating and properly turning over the incident to the Central Services Works Engineering (CSWE) department to cleanup the spill residue.

\section{Five Year Outlook}

On August 18, 1990, the Oil Pollution Act of 1990 (OPA) was signed and contains significant modifications to many provisions of section 311 of the Clean Water Act (CWA). As a result, the Oil Pollution Prevention Regulation, 40CFR 112, is being revised by EPA to reflect the changes required by the act. Some of the requirements that the site can anticipate are as follows:

- a revision of the sitewide SPCC plan to reflect the changes required by the regulation

- a notification to EPA within 60 days after publishing the final regulation, notification of the number, size and total above ground oil storage capacity

- an implementation of an annual integrity test for buried piping

\section{Justification/Regulatory Requirements}

\section{Executive Orders}

Executive Orders 11988 and 11990 - These executive orders obligate DOE to avoid, or minimize any short-and long-term adverse impacts to flood plains and wetlands.

\section{Federal Laws}

Federal Water Pollution Control Act (Clean Water Act of 1977) - The Code of Federal Registers (CFR), as authorized by Section 304 of the Clean Water Act, specifically addresses controlling runoff, spillage, and leakage of hazardous and toxic pollutants (40 CFR 125.100). Industries handling or discharging any toxic or hazardous 
pollutants are subject to requirements relating to all activities which may result in significant amounts of pollutants reaching surface waters in the United States. In addition, 40 CFR 125.103 states that a best management plan (BMP) shall be incorporated into a NPDES permit.

Oil Pollution Prevention Regulation (40 CFR 112) - The regulation establishes spillprevention procedures, methods, and equipment requirements for non-transportationrelated facilities with above-ground (non-buried) oil-storage capacity greater than 1,320 gallons (or greater than 660 gallons above ground in a single tank) or buried underground oil- storage capacity greater than 42,000 gallons.

The Oil Pollution Act of 1990 (OPA) - As a result of the Ashland Oil Company's 4 million-gallon diesel fuel spill January 2, 1988 in Floreffe, Pa. EPA amended the OPA requiring facilities to implement regulations to prevent discharges of oil or hazardous substances. In addition, OPA increases the type of damages facilities can be expected to incur and increases the penalties for violations resulting from discharges of oil or hazardous substances.

\section{Organizational Responsibilities Summary}

In response to the regulatory requirements and the NPDES permit, the site has prepared documentation that satisfies SPCC and BMP requirements. Each SRS facility custodian is responsible for implementing the requirements reflected in the Environmental Compliance Manual 3Q, procedures ECM 2.3 and ECM 2.4. How each facility custodian meets those requirements is described in the SPCC and BMP plans, either through documented administrative controls or via projects. In addition, each facility is responsible for the following:

- upgrading or adding containment systems in areas handling hazardous, toxic, oil or oil-related products

- achieving immediate spill response by storing spill-cleanup equipment and materials in strategic locations close to identified SPCC and BMP facilities

- providing spill/reporting training to pertinent personnel

- ensuring that spills are reported immediately through facility-specific administrative procedures

EPD is responsible for maintaining the SPCC and BMP plan manuals for the site and ensuring that the manuals are updated periodically as new facilities become operational. In addition, EPD serves as the primary point of contact, through the Emergency Operating Center, to ensure that timely notifications of significant spills are made to DOE, and any other outside regulatory authority (i.e., SCDHEC, EPA, National Response Center, Georgia Department of Natural Resources, etc.).

\section{Site Procedures and Documents}

Environmental Compliance Manual 3Q, ECM 2.4, "Spill Prevention Control and Countermeasures Plan Proceduren - This sitewide Level 1 procedure establishes the practices, procedures and identifies the resources necessary to prevent oil discharges 
into the environment. The procedure provides the guidance necessary to comply with the federal oil-pollution prevention regulation.

Environmental Compliance Manual 3Q, ECM 2.3, Best Management Practices Plan Procedure - This sitewide Level 1 procedure establishes the practices, procedures and resources necessary to comply with SRS's NPDES permit, to identify sources of hazardous and toxic substances, and to prevent their discharge into the environment.

WSRC-IM-90-48, "Spill Prevention Control and Countermeasures (SPCC) Plan" This identifies SRS's procedures, methods, equipment, and other requirements to prevent the discharge of petroleum products from site facilities into or upon navigable waters of the United States.

WSRC-IM-90-49, "Best Management Practices (BMP) Plan" - This identifies SRS's actions and procedures to prevent or minimize the potential releases of toxic or hazardous pollutants in significant amounts into surface waters. Sources identified in the plan include, but are not limited to, material storage areas; in-plant transfer, process and materials handling areas; loading and unloading operations; plant site runoff; and sludge and waste disposal areas. The BMP plan is an integral part of SRS's National Pollutant Discharge Elimination System (NPDES) permit.

MRP 4.08, WSRC Management Requirements and Procedures, "Events, Conditions, and Concerns Determinations" - This is a level one procedure that establishes a consistent reporting process sitewide, for reportability determination with respect to events, conditions, and concerns that may have safety, bealth, quality-assurance, security, operational or environmental implications.

\section{Programs}

\section{Environmental Monitoring Section (EMS).}

In the event of a radioactive or hazardous-material spill that would result in exposure to onsite personnel or have offsite consequences, EMS would collect samples from routine monitoring stations. These samples, along with special samples, would be analyzed to assess the impact of the spill or release on people and the environment.

\section{Spill Response Capability}

Each SRS facility custodian has placed supplies and/or hand tools in strategic locations near potential sources of spills and/or releases to minimize, control, and contain any release. These strategic supplies can include such items as shovels, buckets, sandbags, absorbent materials, and other materials necessary to contain any spill at that location. In addition, in the SPCC \& BMP plans, area sketches indicate facility locations and potential spill-flow pathways.

The Fire Department Spill Response Team and Central Services Works Engineering (CSWE) are two completely trained and equipped SRS teams that respond to environmental spills. Their role is to contain and cleanup accidental spills that have the 
potential to significantly impact the environment. Also, each facility or organization custodian is responsible for the cleanup of minor spills that occur within his respective areas.

The emergency-response personnel have received the training required by federal regulations. At a minimum, depending on the level of spill-response involvement, personnel receive the following:

- basic 40 -hour hazardous materials management response training required by SARA

- twenty-four hours of training in hazardous materials emergency-response duties

- a monthly four-hour training session on specific spill-response activities dealing with such topics as cleanup techniques, safety, communications, equipment operation etc.

- eight hours of annual refresher training

- three days of actual field cleanup experience under the supervision of trained personnel

The CSWE Spill Response Team is equipped with two trailers that contain oil booms, absorbent pads, Scott-air packs, rope, hand tools, Class A-response protective clothing, and various other specialized equipment. They also have one boat for access to spills that reach waterways and backup heavy equipment such as backhoes and dump trucks.

The fire department has support from its fire trucks and a special response van and trailer that is equipped with the same type of gear that the Spill Response Team has. Additiona'ly, the fire department is supported by a computer system that gives it onthe-spot guidance for any type of chemical spill.

\section{Technical Support Programs}

\section{SRTC - Environmental Technology Section (ETS)}

The SRTC-ETS has an aqueous model to assist in determining the consequences of a spill at SRS. The model is able to determine the primary pathway of a pollutant (down into the ground or surface runoff) and to which stream. Advanced models now are under development to take into account sediment transport involving radionuclides and subsequent depositions downstream and into the Savannah River.

\section{One-Year Road Map}

On October 22, 1991, EPA issued a proposed revision to the Oil Pollution Prevention Regulation, 40 CFR 112. It is anticipated that the final rule will be issued in mid-1993 by EPA. In addition, by January 1994, plans will be due for the three-year update, as required by res:lation. Plans are to coordinate the SPCC and BMP plan updates with the final versiorı of the Oil Pollution Prevention Regulation. 


\title{
Safe Drinking Water Act (SDWA)
}

\author{
(Compiled and reviewed by Jeffry A. Lintern)
}

\section{Site Program Overview and Summary}

SRS has domestic water-treatment facilities which are independent of the water systems in surrounding communities. The construction, modification, and operation of the site's domestic water supplies and wells are regulated by SCDHEC under the State Primary Drinking Water Regulations. SCDHEC has regulatory authority from EPA, and the state regulations meet federal requirements established under the Safe Drinking Water Act of 1974 (amended 1986). The regulations require the following:

- construction and operation permits for new systems or modifications to existing systems

- operation of existing facilities by certified operators of the proper grade

- periodic samples of finished water to verify proper treatment and portability

- monthly reports of certain water quality parameters to SCDHEC

In many cases, SRS goes beyond SCDHEC'S requirements to ensure the quality of the domestic water supplies. Annual chemical analyses are performed to verify compliance with SCDHEC contaminant limits for community water systems, even though SRS's systems qualify as less-regulated, non-transient, non-community systems.

\section{Existing Conditions}

SRS has 28 separate domestic water systems which supply drinking water to site personnel. Fourteen of these systems are considered by SCDHEC as "public" water systems. These systems supply water to facilities that range in size from the security barricades, with a small number of users, to the 300-M/700-A Area system, which supplies water to more than 5000 users. Treated well water supplies 27 of these systems. In D Area, treated water from the Savannah River is used for non-domestic service only. Currently, D-Area employees drink bottled water.

All domestic water supplies are chlorinated for bacteriological control. In the larger systems, the finished water is $\mathrm{pH}$ adjusted, and polyphosphate may be added to control water discoloration and piping corrosion.

In 1981, trace quantities (10 parts per billion) of chlorocarbons were detected in two of the domestic water wells in the 300-M/700-A Areas. As a precautionary measure, carbon bed filters were installed on-line until two new wells, 1.5 miles northeast of $A$ Area, were operational in 1986. The old wells were converted to process water use. 
Five-Year Outlook

The drinking water program will be impacted by new State Primary Drinking Water Regulations, currently out for public comment and due for release in 1993.

Lead/Copper Rule compliance monitoring begins in 1993 for SRS's 13 small public water systems.

SDWA Proposed/Anticipated Final Rules through 1995 include requirements for Radionuclides - 4/93, Disinfection / Disinfection By-Products (Phase VIA) - 6/95, and the balance of 25 contaminants from the Drinking Water Priority List (Phase VIB) $6 / 95$.

Developing methods to further improve permitting processes through "HOW" Manual and implementing material and construction standards will continue.

Project construction completion dates are committed to SCDHEC through 1997 (see Construction Projects Section). An independent engineering study to determine the feasibility of consolidating the major domestic v. ter distribution systems is near completion. The recommendations from this study could have an impact on the current project's scope and schedule.

\section{Regulatory Requirements}

FederalState Laws and Regulations

The Safe Drinking Water Act of 1974, as amended (42 U.S.C. 300f et seq.), and the South Carolina Primary Drinking Water Regulations (SCDHEC R.61-58) - These acts and regulations require DOE to obtain applicable permits and satisfactorily complete required sample analyses and site inspections of public water supplies and drinking water sources. EPA has authorized South Carolina to regulate both public water supplies and drinking water sources.

\section{Organizational Responsibilities}

\section{Environmental Protection Department (EPD)}

EPD evaluates regulatory requirements and compliance issues, reviews projects, assists with facility permitting and provides assistance with regulatory agency's facility audits and reporting. EPD also ensures that operator-certification requirements are met. EPD keeps the operating organization apprised of regulatory requirements and compliance issues related to the Safe Drinking Water Act, and facilitates information exchanges between SRS operating groups, DOE and outside regulatory groups. 


\section{Power Operations}

Power Operations has supervisors and operators that are certified by the South Carolina Environmental Certification Board to operate domestic-water facilities. While on the job, certified operators adjust chemical-feed rates, analyze water samples to verify proper $\mathrm{pH}$ and chlorine residuals, and collect bacteriological samples which are analyzed at the 772-D laboratory. Operators visit each facility at least once a day to perform these duties.

\section{Site Services Engineering}

Site Services Engineering prepares a monthly report which is submitted to SCDHEC through EPD. This report includes water-quality data relating to operating the D-Area surface water (Savannah River) treatment plant. Any positive bacteriological samples exceeding SCDHEC criteria also are detailed in this report.

\section{Defense Waste Processing Facility (DWPF)}

All DWPF production specialists are being SCDHEC certified to operate the DWPF Domestic Water System. This includes two domestic water wells and treatment by chlorination and neutralization. Operators will be required to adjust feed rates, sample water quality, and verify proper equipment operation daily. Facility operations on a temporary domestic water well began in March 1987. Operation of the primary domestic water deep wells began in June 1989 after approval by SCDHEC.

\section{SRL - TNX Operations}

The TNX Domestic Water Facility is operated jointly by TNX Operations and Power. TNX Operations take water samples every shift to check $\mathrm{pH}$ and residual chlorine. If the readings are outside the appropriate range, Power is called to make the necessary chemical adjustments. Power also takes daily samples to check pH and residual chlorine and makes chemical adjustments based on its results.

\section{Site Procedures and Documents}

WSRC-IM-91-69, SRS Environmental Permitting "HOW" Manual Environmental Compliance Manual (3Q)

Reference: R61-58, State of South Carolina Primary Drinking Water Regulations 


\section{Programs}

Modified Permitting Program (MPP) -EPD has the authority to issue construction and operating permits for domestic water-line installations up to 1500 feet in length. MPP is described in detail in WSRC-IM-91-69, SRS Environmental Permitting "HOW" Manual, Secticn 1.1.

Water Services Department (WSD) Cross-Connection Control Program. WSD provides support and guidance to identify and resolve public water system cross connections. This program is required by SCDHEC to maintain MPP.

\section{Technical Support Programs}

Site Services Engineering and the Water Services Department provide technical support for continued program development and improvement.

\section{Construction Projects}

Elevated Domestic Water Tanks - A, B, F, H, S Areas - Elevated domestic-water storage tanks will be constructed to meet SCDHEC sizing standards in A, B, F, H, and $S$ Areas. Milestones for construction completion are:

$\begin{array}{cc}\text { A } & 03 / 94 \\ \text { B } & 02 / 94 \\ \text { F } & 03 / 94 \\ \text { H } & 03 / 94 \\ \text { S } & 08 / 94\end{array}$

Reactor Areas Fire and Domestic Water Systems - Iron-removal systems, flow-paced chemical feed systems and buildings, elevated domestic-water storage tanks, and looped PVC piping systems will be installed in C, K, L, and P Areas. Milestones for construction completion are:

C

$\mathbf{K}$

L

$\mathbf{P}$
$07 / 94$

$05 / 93$

$09 / 97$

09/97 
D-Area Domestic Water System Upgrade - The D-Area domestic-water system will be converted from surface water to ground water. Two wells, distribution system piping, chemical-treatment equipment, and an elevated storage tank will be installed. Milestones are:

$$
\begin{array}{lr}
\text { Construction Start } & \text { Underway } \\
\text { Construction Complete } & 06 / 93
\end{array}
$$

Domestic Water Upgrade, Phase 1 - PVC piping systems for A, B, D, Central Shops, Forestry, and TNX Areas will be upgraded. Distribution system flushing hydrants, additional isolation valves, well-flow meters, well-failure alarms, chemical solution tank-level indicators and alarms in various areas, corrosion-control systems for forestry and railroad yard, hypochlorite system for B Area will be upgraded. Milestones are:

$$
\begin{array}{lr}
\text { Construction Complete } & 09 / 96 \\
\text { Construction Start } & 12 / 94
\end{array}
$$

Domestic Water Upgrade, Phase 2 - An elevated storage tank for Central Shops, corrosion-control and iron-removal systems for numerous facilities, color coding and labeling of chemical feed room piping, new hydropneumatic tanks and chemical-feed systems for small systems, flushing hydrants for branch lines, consolidation of D and TNX Areas will be constructed. Milestones are:

$$
\begin{array}{ll}
\text { Construction Start } & 01 / 96 \\
\text { Construction Complete } & 09 / 97
\end{array}
$$




\section{National Environmental Policy Act (NEPA)}

(Compled and reviewed by Jack Mayer)

\section{Site Program Overview and Summary}

The National Environmental Policy Act of 1969 (NEPA) established the national environmental policy and goals for protecting, maintaining, and enhancing the human environment of the United States. SRS's NEPA program was initiated in August 1982 at the request of DOE-SR to ensure that the NEPA requirements were met. This program is administered and coordinated for SRS by the WSRC NEPA Group within EPD of the Environment, Safety, Health and Quality Assurance Division. The program reflects the Council on Environmental Quality (CEQ) regulations, DOE orders and regulations which require considering environmental factors during the planning process for all major federal activities that significantly affect the quality of the environment.

The NEPA Group works with various SRS organizations in gathering information and preparing documentation necessary for NEPA compliance. The group also has an active NEPA training program for the department NEPA coordinators in implementing NEPA for site projects/activities and to inform employees of their obligations under the act.

Five-Year Outlook

Over the next five years, NEPA compliance is expected to result in two changes over the previous process. These changes include increased coverage of proposed SRS actions with environmental assessments; and more participation by line organizations (i.e., department NEPA coordinators) in the NEPA review and documentation process. Regulatory Requirements

\section{Federal Law}

National Environmental Policy Act (42 USC 4321-4327) - The purpose of NEPA is to establish a national policy to protect the environment and to promote a better understanding of the ecological systems and natural resources important to the nation. NEPA and CEQ regulations implementing NEPA (40 CFR 1500-1508) contain actionforcing provisions to ensure that federal agencies consider environmental information prior to making decisions on proposed actions. The NEPA process includes decision points at which the significance of environmental effects is assessed, project alternatives are evaluated, public input is obtained, and a Record of Decision is prepared publicly stating the alternative selected. 
DOE Orders/Regulations

Implementation of the National Environmental Policy Act (DOE Order 5440.1E) -This order established a DOE policy of complying fully with NEPA and describes the roles of various facilities within the DOE complex in implementing the act.

Secretary of Energy Notice (SEN) 15-90 - This notice was issued to implement the Secretary of Energy's announcement of a 10-point initiative to ensure that all DOE activities are carried out in full compliance with the letter and spirit of environmental statutes and regulations, as related to NEPA. SEN-15-90 directed significant changes in DOE policies and procedures for complying with NEPA, including revising the existing DOE NEPA guidelines.

DOE National Environmental Policy Act Implementing Procedures and Guidelines Revocation (10 CFR Part 1021) - These regulations replaced DOE NEPA guidelines revised the existing rule to implement CEQ regulations, and incor orated changes required by SEN-15-90. These regulations include public an affected state participation in the NEPA process, and a revised and expanded list of typical classes of actions, including categorical exclusions. SRS is required to integrate the NEPA process with other planning, as soon as possible, time for a proposed action to ensure that planning and decisions reflect environmental values. DOE and WSRC line managers are responsible for training, accountability, early implementation of NEPA, and project monitoring.

\section{Organizational Responsibilities}

The NEPA Group has the responsibility to prepare and/or manage all appropriate draft NEPA documentation for transmittal to DOE. The group's primary responsibility is to coordinate all activities of SRS organizations related to NEPA documentation for specific activities, and to train WSRC and other site organizations how to implement the NEPA process.

The NEPA Group receives approximately 300-350 Environmental Evaluation Checklists (EEC)s for site activities each year. Most activities require documentation, as Categorical Exclusions (CX) under the DOE proposed rule, with an average of 10 activities per year requiring preparation of an Environmental Assessment (EA) or Environmental Impact Statement (EIS). DOE and an independent subcontractor prepare all EISs for which the operating contractor provides technical information. Two programmatic EISs currently are being prepared; nuclear weapons complex reconfiguration and environmental restoration and waste management.

The project sponsor or EEC preparer is responsible for properly completing the checklist and providing any additional or follow-up information regarding the proposed action. 
The department NEPA coordinators are responsible for ensuring the implementation of NEPA provisions within their respective organizations. This responsibility is centered around the review, submittal, tracking and filing of the EEC. The department NEPA coordinators also function as a single focal point within the various organizations to transmit and coordinate EA/EIS review and approval by sponsoring organizations.

\section{Site Procedures and Documents}

DOF. Procedures Guide for NEPA Documentation for Savannah River Site - This document encompasses general guidelines for implementing the DOE-SR NEPA process, including a summary of NEPA laws and DOE orders, descriptions of various types of NEPA documentation, EIS preparation activities and procedures, and checklists for each NEPA activity related to an EIS.

DOE Guide for NEPA Coordinators at Savannah River Site - This guide was prepared for the DOE NEPA coordinators as a tool for implementing NEPA requirements at SRS. The guide provides an overview of NEPA, and explains how DOE has integrated the NEPA process into its program.

WSRC Q-1-1-1, Item DPM-306, Rev 1, "Implementation of the National Environmental Policy Act Final Rule 10 CFR Part 1021 at the Savannah River Site" This procedure defines the NEPA group's responsibilities within EPD and its activities and responsibilities in implementing the NEPA program at SRS.

WSRC 3Q, Procedure ECM 5.1, Rev 1, "Implementation of the National Environmental Policy Act" - This procedure establishes the responsibilities and requirements for implementing and complying with NEPA at SRS, as specified in 10 CFR Part 1021, DOE NEPA regulations. This procedure also establishes the responsibilities and requirements for preparing and using Environmental Evaluation Checklist, and is intended to ensure that the proper federal and state permits are identified (and subsequently obtained) for a proposed action.

Savannah River Site Plan for Implementation of NEPA Procedures 10 CFR Part 1021, WSRC-RP-92-770 - This plan provides a detailed strategy and process for implementing 10 CFR Part 1021 in order to fully comply with NEPA. This plan also defines DOE-SR and WSRC roles, responsibilities, and working arrangements to implement the NEPA process onsite.

WSRC Department NEPA Coordinator Handbook - This handbook/manual contains the materials/information used to train and qualify the designated site deparment NEPA coordinators to enable them to function in the role defined in WSRC-RP-92770. 
One-Year Road Map

The NEPA program will continue implementing the new DOE NEPA regulations (10 CFR Part 1021) during 1993. This process will establish a more significant role and responsibility within the site line organizations with respect to NEPA compliance and documentation. The primary position in this effort will be the department NEPA coordinators. These coordinators will be responsible for ensuring the implementation of the new NEPA provisions, the documentation/records and the maintenance within their respective organizations. The WSRC NEPA Groups also will increase, with responsibility and compliance support being extended to include all site organizations and contractors. A revised DOE Order 5400.1E is expected to be issued during 1993 to reflect regulatory/compliance changes established in 10 CFR Part 1021.

Five-Year Road Map

During the next five years, there will be earlier planning, increased training, and increased documentation of NEPA. This process will continue to be centered primarily around the team effort of the department NEPA coordinators within the site line organizations. No new NEPA regulations or guidelines are expected after the issuance of DOE Order 5400.1E. 


\section{Chapter 6}

\section{Natural Resource Protection}

- Land Use and Wildlife Protection

- Surface Water and Wetlands Protection

Chapter was compiled and reviewed by Keith W. Dyer. 
Environmental Implementation Plan 


\section{Introduction}

The United States Department of Energy (DOE) and the operating contractor are committed to operating the Savannah River Site (SRS) in a manner that protects the public health and safety, and the environment. This philosophy is contained in DOE Order 5400.1, General Environmental Protection Program, the SRS Strategic Environmental Plan (1986), and in the SRS Mission, Vision, and Principles.

The SRS Natural Resources Management Plan (NRMP), was approved on February 15, 1991. The NRMP encourages all SRS organizations involved in natural resource management to take an active role in environmental protection. The NRMP is consistent with the Secretary of Energy's 10-point initiative to move the department aggressively toward full accountability in the areas of environment, safety, and health. Specifically, the NRMP furthers the first initiative (resetting priorities) by providing a comprehensive plan for managing SRS's natural resources and establishing a mechanism (the Natural Resources Coordinatirig Committee) to provide DOE management with expert advice on natural-resources issues.

The Natural Resources Coordinating Committee (NRCC) was established in 1991 to enhance communication and understanding among SRS organizations concerning natural-resources management. The NRCC provides a forum to discuss onsite natural resources issues and provides technical advice to DOE and all site users to manage effectively SRS's natural resources. NRCC members are representatives from different site organizations with a Department of Energy Savannah River (DOE-SR) office member as chairperson. The following are some of the NRCC task groups:

- Aquatics Issues Task Group (AITG)

- Biodiversity Task Group

- Environmental and Technical Research/Monitoring Task Group

- Geographic Information System (GIS) Task Group

- Geoscience Task Group

- Pesticide Use Task Group (PUTG)

- Set-Aside Task Group

- Upper Three Runs Creek Task Group

- Wetlands Task Group

The requirements for preparing the NRMP and the Site Development and Facility Utilization Plan (SD\&FUP) are derived from DOE Order 4300.1B. The NRMP and the SD\&FUP are related, but the NRMP augments the SD\&FUP rather than flows from it. The SD\&FUP, while providing extensive information about onsite natural resources and the land-use approval process, is concerned primarily with facility planning.

The Strategic Environmental Plan (SEP), prepared by the operating contractor, is a similar augmentation of the SD\&FUP that addresses a specific mission- 
environmental compliance. The NRMP is a companion document to the SEP. Where they overlap, the policies and strategies in both plans will be consistent. Similarly, NRMP management-operation plans will be companions of the operating contractor's Environmental Implementation Plan (EIP).

Site environmental programs and plans from various site organizations represented in the EIP to enhance communication and alignment of site goals for natural-resource and environmental-protection programs, while meeting regulatory compliance requirements. These programs primarily are located in the following EIP chapters:

- Chapter 6 Land Use and Wildlife Protection; Surface Water and Wetlands Protection

- Chapter 7 Groundwater Protection

- Chapter 9 Atmospheric 


\section{Site Program Overview}

Less than 5 percent of SRS's land area is used for industrial purposes (buildings, roads, etc.). Most of the remaining land is managed as forest wildland. Other components of SRS's natural-resource management program include soil, water, and plant conservation; fish and wildlife management; preservation and study of historical and cultural sites; and land-use activities associated with the site's designation as a National Environmental Research Park (NERP). Although other organizations onsite are involved in natural-resource management, this section of the Environmental Implementation Plan (EIP) focuses on operating contractor activities for managing and protecting wildlife and land use.

The NRMP for strategic guidance was developed for SRS's natural-resources programs. The NRMP furthers SRS's mission by helping to ensure environmental protection and responsible stewardship of SRS's resources. The NRMP encourages all SRS organizations involved in natural-resource management to take an active role in environmental protection which is consistent with the SRS Mission, Vision, and Principles.

Authority and direction for land-use planning and managing natural resources is derived from DOE Order 4300.1B, Real Property and Site Development Planning. This order is augmented by supplemental DOE-SR correspondence which defines local responsibilities and procedures for planning development and using the site and facilities. Supplemental DOE-SR correspondence sets out the following responsibilities which have a direct bearing on the NRMP:

- assigns responsibility directing the tinber-management program, preparing a NRMP, and establishing a fish and wildlife management policy to the Environmental Division (ED) director.

- establishes the Savannah River Land Use Committee (SRLUC) and assigns the SRLUC responsibility for the following:

- approving or disapproving all general site land-use activities as established under Supplemental DOE-SR correspondence, Site Use Coordination

- approve the NRMP

- recommend SR land-use policies to the DOE-SR manager.

- address specific operational methods by developing various program operational plans as required in the NRMP

- Affected and involved contractors and operational departments will be asked for input in planning and tevelopment and will be given the opportunity to review and comment on draft operational plans as they are developed.

- Memoranda of Understanding (approved by DOE-SR and the operating contractor) will be written to define more clearly the areas of program responsibilities. 


\section{Summary}

SRS meets environmental regulations and site policies related to land use and wildlife protection. The operating contractor participates with other onsite contractors in a site-use coordination system to meet land-use requirements and to promote beneficial uses of site lands. SRS also participates in studies and management programs for protecting animal species that are classified as endangered, threatened, or species of special concern, under the Endangered Species AcL Principal activities involving other wildlife onsite include biological monitoring and population control. Land reclamation and erosion-control activities are underway to revegetate bare or disturbed areas.

The site-use coordination system, established by DOE-SR, ensures that land use at SRS is managed to meet mandated preservation requirements for endangered species and historical and cultural resources, to promote multiple, beneficial uses of the site, and does not interfere substantially with the SRS's mission. This system coordinates the review and approval of site-use requests for land not dedicated to production activities.

SRS provides a wide range of habitats for animal populations. More than $\mathbf{4 0 0}$ species of mammals, birds, fish, reptiles, and amphibians have been documented onsite. Four endangered animal species have been sighted at SRS.

SRS was designated the nation's first NERP in 1972 and has become one of the most extensively studied environments in this country. The NERP designation recognized the value of the environmental databases developed by previous Savannah River Technology Center (SRTC) and Savannah River Ecology Laboratory (SREL) research, as well as the protection provided to field research sites located onsite. Scientific investigators from universities and other research organizations are encouraged to use the NERP as an outdoor laboratory for environmental-impact studies.

The NRMP provides the strategy and assigns responsibilities for natural-resource management activities onsite within the framework of land use assigned by the site use coordination and approval system. The NRMP serves as the umbrella document for management-operation plans to be prepared under each management and research program. The NRMP provides policy direction for the management-operation plans. The NRMP fulfills the responsibility assigned to the ED director in supplemental DOE-SR correspondence to prepare a NRMP and the charge from the SRLUC to prepare a NRMP incorporating an increased role for the U.S. Forest Service Savannah River Forest Station (SRFS). Supplemental DOE-SR correspondence defines responsibilities of DOE-SR officials and establishes local procedures for site-use coordination and approval. This supplemental SR correspondence applies to all SRS organizations and contractors performing work for SRs which may affect the land, air, or surface water resources onsite. Thus, authority for assigning land uses rests with the SRLUC through this supplemental DOE-SR correspondence.

Natural-resource management is conducted principally by the SRFS with support from the operating contractor. Approximately 15 percent of the budget for land-use 
activities is spent to provide services such as maintaining equipment, buildings, and roads.

The principal activities in\%olving other wildlife at SRS are research studies and population control. The studies consist of biological monitoring and are described in the Surface Waters and Wetlands Protection Program. Public deer hunts are managed by the operating contractor with assistance from other onsite and of fsite contractors. Beaver and other nuisance animals are controlled by trapping.

Onsite land-reclamation activities began in 1974 with revegetation efforts by SRFS. Currently, both SRFS and the operating contractor have programs to revegetate bare or disturbed areas. 


\section{Policy}

SRS's land-use and wildlife-protection policy is to develop the site to meet operational requirements, restore impacted lands, and manage site lands and wildlife to satisfy regulatory and operating contractor requirements, while supporting DOE and other contractor programs.

\section{Background}

DOE and the operating contractor are committed to operating SRS in a manner that protects the public health and safety, and the environment. This philosophy is contained in DOE Order 5400.1, General Environmental Protection Program, and in the SRFS Strategic Environmental Plan (1986). Additional guidance for land use and wildlife protection at SRS is given in the following documents:

- Savannah River Operations Office (DOE-SR) Fish and Wildlife Management Policy for the Savannah River Plant (6-18-86)

- DOE Order 4300.1B, Real Property and Site Development Planning (7-1-87)

- SR Order SR-430X.1, Site Use Coordination and Approval (9-13-83)

- SRS Natural Resources Management Plan (NRMP), approved on February 15, 1991.

The SRS NRMP is consistent with the former Secretary of Energy's 10-point initiative to move the department aggressively toward full accountability in the areas of environment, safety, and health. Specifically, the NRMP furthers the first initiative (resetting of priorities) by providing a comprehensive plan for managing the natural resources at SRS and establishing a mechanism (the Natural Resources Coordinating Committee) to provide DOE management with expert advice on natural resources issues.

The requirements for preparing the NRMP and the Site Development and Facility Utilization Plan (SD\&FUP) are derived from DOE Order 4300.1B. The NRMP and the SD\&FUP are related, but the NRMP augments the SD\&FUP rather than flows from it. The SD\&FUP, while providing extensive information onsite natural resources and the land-use approval process, primarily is concerned with facility planning.

The Strategic Environmental Plan (SEP), prepared by the operating contractor, is a similar augmentation of the SD\&FUP that addresses a specific missionenvironmental compliance. The NRMP has been prepared as a companion document to the SEP. Where they overlap, the policies and strategies in both plans will be consistent. Similarly, NRMP management-operation plans will be companions of the operating contractor's EIP. Management activities carried out under the guidance provided by the NRMP will be consistent with the requirements of DOE Order 5400.1, General Environmental Protection. 


\section{Existing Conditions}

Current land use at SRS reflects the activities of the multiple site users. About 5 percent of the site is developed. Approximately 13 square kilometers are occupied by production, support, and waste-handling facilities and 29 square kilometers by transportation arteries and rights of way.

In 1951, when the 780-square-kilometer site was acquired, the land was approximately two-thirds forested and one-third cropland and pasture. Subsequently, the abandoned fields were planted with various species of pine trees or were allowed to pass through vegetational successional. Today, approximately 95 percent of the site is forested. Wetlands, creeks, floodplains, lakes, and the Savannah River Swamp account for approximately 160 square kilometers. The extensive wetlands and the prevalence of forest acreage gives the site a markedly different character than the surrounding agricultural and urban areas.

U.S. Forest Service is responsible for planning and implementing the wildlife, fisheries, and botany management program for SRS. This program is directed by the Savannah River Site Wildlife, Fisheries, and Botany Operation Plan.

During construction of facilities, roads, and dams, about 8 square kilometers of spoil piles and borrow pits were created. Initial attempts to revegetate these areas were not successful, and, in many cases, severe solid erosion occurred.

DOE's site use coordination system, established under Savannah River (SR) Order $430 \mathrm{X} .1$, ensures that land use at SRS meets mandated preservation requirements for endangered species (e.g., the Endangered Species Act of 1973) and historical and cultural resources (e.g., the National Historic Preservation Act of 1966) promotes multiple beneficial uses of the site (e.g., environmental/ecological research and forest management), and does not interfere substantially with SRS's mission.

In 1972, SRS was designated the first NERP and has become one of the most extensively studied environments in the country. The NERP designation recognized the value of the environmental databases developed by previous SRTC and SREL research and also the protection provided to field research sites located at SRS. Scientific investigators from universities and other research organizations are encouraged to use the NERP as an outdoor laboratory to study the impacts of man's activities on the environment. In 1986, ten research projects were conducted at the site under the NERP program.

SRS provides a wide range of habitats for animal populations. More than 400 species of mammals, birds, fish, reptiles, and amphibians have been documented onsite.

The ecosystems at SRS support many commercially- and recreationally-valuable game populations; however, DOE restricts recreational use to controlled hunts for white-tailed deer and feral hogs. Some species, such as the wood duck, bullfrog, and various species of turtles are mobile and migrate offsite where activities such as hunting are allowed. 
In addition to the NERP designation, 10 reserve sites onsite were selected by SREL to represent major site vegetational communities and formally were set aside in 1967 by DOE to promote ecological research. Two additional natural research areas are registered with the Society of American Foresters and also are protected from development. At DOE's request, the operating contractor and other contractors have identified examples of additional habitats appropriate for reserve status which are being considered for future designation.

Several endangered species inhabit the site. A nesting pair of bald eagles was located near Par Pond and raised two young birds in 1986 and two in 1987. From a recent census, the red-cockaded woodpecker was found in three colonies distributed in mature pine stands. In the Savannah River, larvae of the shortnose sturgeon were found. Evidence also indicates sturgeon spawning both upriver and downriver from the site. In swamps on and around the site, the wood stork has been observed feeding during the summer. The American alligator, another species protected under the Endangered Species Act, has a wide distribution in wetlands onsite. On June 4, 1987, the status of the alligator under the act was changed from threatened to threatened on the basis of similarity of appearance. Under this new classification, approval from the U.S. Fish and Wildlife Service (FWS) must be obtained before taking, moving, or killing alligators or destroying their nests.

The FWS has additional flora and fauna that are considered candidate species for the endangered and threatened species lists. Of these candidates, two insects, the American sand-burrowing mayfly and the blackwater sand-filtering mayfly, and approximately eight plants species are found at SRS. The latter are as follows: cypress stump sedge, Elliot's croton, smooth purple coneflower, bog-spice bush, swamp lobelia, loose water milfoil, Nestronia, and the awned meadow-beauty. Smooth purple coneflower now is listed in Federal Register as an endangered species.

The site complies with the requirements of the Endangered Species Act of 1973.

More than 800 prehistoric and historic archaeological sites are onsite. New sites are being located as intensive surveys by the South Carolina Institute of Archacology and Anthropology (SCIAA) continue. The operating contractor cooperates with SCIAA in implementing the National Preservation Act of 1966. 


\section{Objectives}

The objectives to support the Land Use and Wildlife Protection Program are the following:

- land regulations - comply with all applicable federal and state land preservation/management laws and regulations

- land use coordination - coordinate land-development plans with DOE and other contractor programs

- land reclamation - continue land-reclamation programs where practical

- wildlife regulations - comply with all applicable federal and state wildlife laws and regulations

- understanding impact - understand the effects of planned operations by quantifying the impacts to site lands and wildlife

- manage wildlife populations - manage wildlife populations to ensure employee safety and to protect SRS facilities

These objectives will be realized by effectively implementing SRS's NRMP approved for site use on February 15, 1991. Specific operational methods will be addressed by developing various program operational plans called for in the NRMP. Affected and involved contractors and operational departments will be asked for input in planning and development and will be given the opportunity to review and comment on draft operational plans as they are developed. Memoranda of understandings (MOUs between DOE-SR and the operating contractor) will be written to define more clearly the areas of program responsibilities. 


\section{Strategy}

The strategy for reaching the Land Use and Wildlife Protection Program objectives is the following:

- identify regulatory and other protection requirements

- promote innovative and cost-effective means to meet the requirements through research and development

- develop physical and administrative controls to protect wildlife and land by utilizing the knowledge gained from research and development

- implement physical and administrative controls

- evaluate the controls to ensure that protection requirements are met 
The strategy is illustrated in Figure 6-1.

The ESS Natural Resources Management directive is to support and endorse SRS's NRMP. The NRMP furthers the SRS mission by helping to ensure environmental protection and responsible stewardship of SRS resources. The NRMP encourages all SRS organizations involved in natural-resource management to take an active role in environmental protection. This is consistent with the SRS Mission, Vision, and Principles. Authority and direction for land-use planning and managing of natural resources is derived from DOE Order 4300.1B, Real Property and Site Development Planning. This order is augmented by supplemental DOE-SR correspondence which defines local responsibilities and procedures for planning the development and using the site and facilities. Supplemental SR correspondence sets out the following responsibilities: assigns responsibility for direction of the timber management program; prepares a NRMP, and establishes a fish and wildlife management policy; and establishes the SRS Land Use Committee. Preparation and content direction for the NRMP also comes from the Natural Resources Management Strategy Changes memorandum signed in October 1988. This memo requires that the NRMP include an increased role for SRFS.

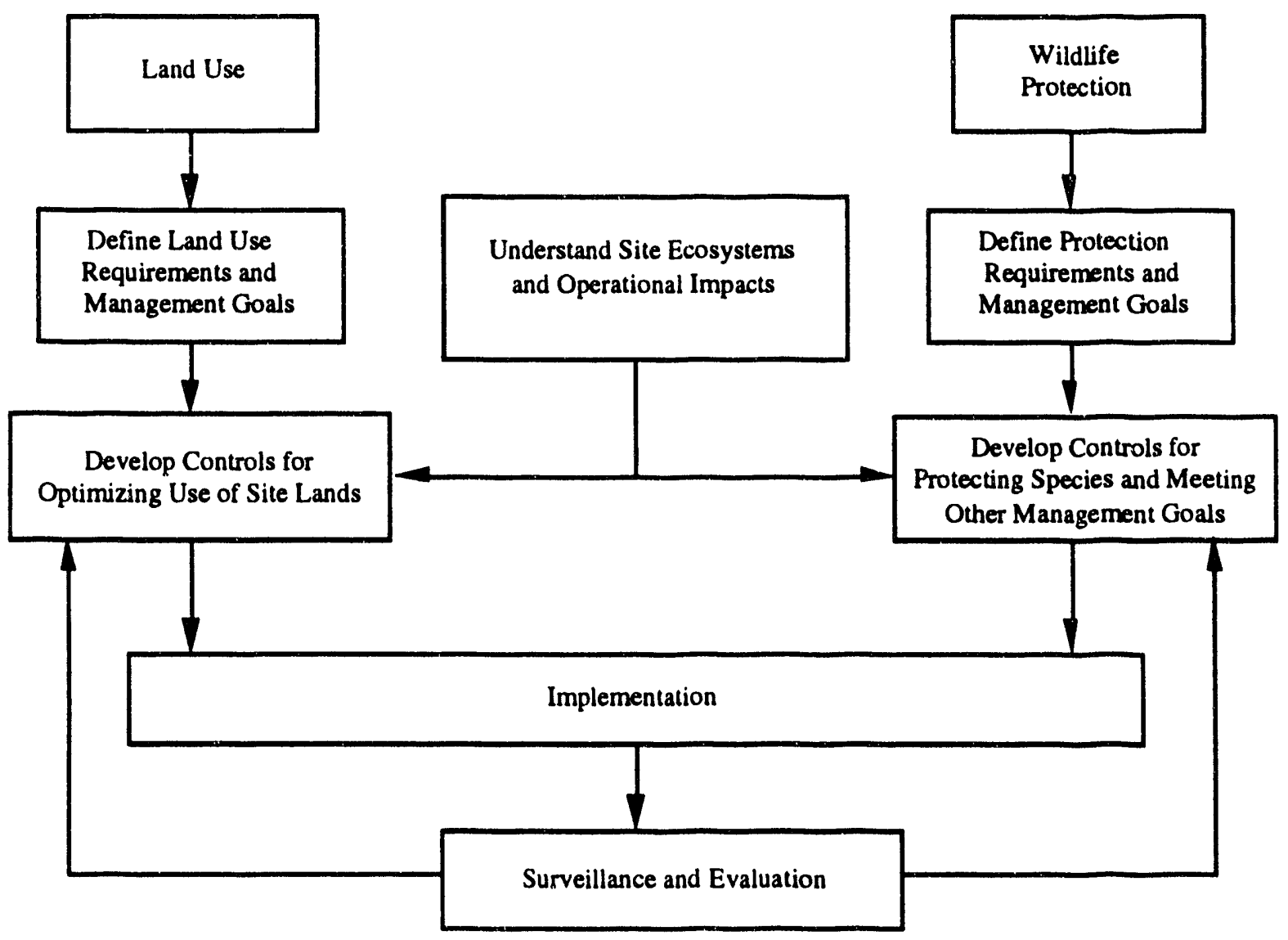

Figure 6-1. Land Use and Wildlife Protection Program Strategy 
The implementation section identifies issues and those responsible for actions to achieve defined objectives. Each environmental effort will require funding for one or more of the following: research and development, operations, programs, and construction/modification projects.

SRS's NRMP provides strategic guidance for SRS's natural-resource program. Specific operational methods will be addressed by developing various program operational plans called for in the NRMP. Affected and involved contractors and operational departments will be asked for input in planning and development and will be given the opportunity to review and comment on draft operational plans as they are developed. Memoranda of Understanding (approved by DOE-SR) will be written to define more clearly the areas of program responsibilities. The following programs are described in the implementation section:

- Land Use (page 6-15)

- Endangered Species (page 6-20)

- Other Wildlife (page 6-23)

- Wildlife Habitat (page 6-27)

- Land Reclamation and Erosion Control (page 6-29) 


\section{Land Use}

(Compiled and reviewed by Keith W. Dyer)

\section{Site Program Overview}

Activities to improve land use at SRS inclide research, site-use coordination, natural-resource management, and required supporting services. Ongoing research focuses on developing remote sensing technologies, evaluating databases to enhance the knowledge of natural processes and the effects of man's activities on them, and complying with regulatory requirements and commitments. About 20 percent of the National Environmental Research Park (NERP) budget for the site is managed by the operating contractor. These funds are currently used to support onsite research by university scientists.

Land-use activities outside of production area fences are coordinated under the DOE-SR site-use coordination system. The operating contractor and other onsite contractors paricipate through a site-use permit system.

Natural-resource management is conducted principally by SRFS. The SRFS is supported by the operating contractor. Approximately 15 percent of the budget for land-use activities is spent on services such as maintaining equipment, buildings, and roads.

\section{Justification/Regulatory Requirements}

SRS is managed by DOE-SR to meet the requirements of DOE Order 4300.1B, Real Property and Site Development Planning (7-1-87), and the objectives of the NERP program. Environmental objectives established for NERP sites include searching for new techniques to measure environmental changes, developing better tools to predict environmental response to human activities, and demonstrating methods to minimize adverse impacts.

The land-use program supports land regulations, land-use coordination, and the chapter objectives.

\section{Organizational Responsibilities Summary}

Land-use management is administered by DOE-SR and onsite contractors. The DOE-SR site-use coordination system governs the approval of land use not previously approved. Site contractors have land-use management responsibilities in the approved areas under the guidelines in the initial land-use approval. In addition, custodial departments of the operating contractor manage land use within the boundaries of the production areas and in cleared areas associated with various rights of way.

The major organizations conducting environmental research onsite are SRTC (primarily the Environmental Sciences and Environmental Technology Sections), SREL, and Southeastern Forest Experiment Station of the U. S. Forest Service 
(SEFES). These organizations conduct programs to provide information essential to achieving environmental goals and for evaluating the effects of operating nuclear production facilities.

Natural-resource management activities (e.g., forestry management) are conducted principally by SRFS under an interagency agreement with DOE.

\section{Programs}

\section{Site Development and Facility Utilization Plan}

Long Range Planning (LRP) - The Site Development and Facility Utilization Plan for the SRS was issued April 1, 1987. The plan will be maintained and kept current. Revisions will be distributed to plan holders at least annually, and the plan will be totally revised every five years.

\section{Site Use Coordination System}

Site coordination outside existing production area boundaries is governed by SR Order 430X.1, Site Use Coordination and Approval. The operating contractor manages land use within production areas and for cleared areas associated with various rights of way according to Projects Management Procedure 5.3 (formerly Memorandum B-23).

The Environmental Protection Department (EPD) currently coordinates the review of site-use permits regarding potential impacts on the environment.

Requests for changes to the site, initiated with the operating contractor and necessitating site clearance, removal of trees, or issuance of land-use permits are submitted to the Projects Management for authorization, as detailed in SRS Procedures Manual Item 1201. Other requests initiated by SRS are submitted directly to the DOE-SR for approval. Plant service groups are kept informed to ensure that their day-to-day activities do not jeopardize environmental and ecological research projects.

\section{Support to Land and Timber Management}

Central Services' Works Engineering (CSWE) provides support services such as maintaining building contracting outside vehicle and equipment maintenance with local vendors, furnishing fuel, issuing supplies, maintaining radios, and implementing road management plans.

\section{Boundary Management}

SRFS's forest manager manages SRS's boundary program that includes activities related to the administrative and physical location, marking, and maintenance of SRS's 
external boundaries, the acquisition of necessary rights of way, and the knowledge of adjacent owners and land uses under the administrative responsibility of the Engineering, Construction and Facilities Division of DOE-SR.

The boundary-management program supports the policy goals to protect the SRS at its perimeter and be a good neighbor to adjacent lands. It is concerned with all aspects of boundary location, fencing, clearing, signing, fire lanes, and maintenance, as well as information on adjacent lands and waterways. This program is limited to the physical maintenance of SRS's external boundaries. The security contractor is responsible for intrusion prevention.

A boundary-management operation plan (BMOP) will be developed to implement this program with input from the operations contractor's affected departments. An MOA was authorized May 20,1991, to define organizational responsibilities relative to boundary management.

Under the BMOP and in coordination with other NRMP programs and operation plans, the CSWE will perform boundary-maintenance activities under guidance from the forest manager.

\section{Secondary Road Management}

SRFS's forest manager manages SRS's secondary road program that includes the inventory, planning, construction, reconstruction, and maintenance of all SRS secondary roads under the administrative responsibility of the Engineering, Construction and Facilities Division of DOE-SR. Secondary roads are defired as all gravel and native surfaced roads except parking lots and roads within fenced compounds. Also included are 31 miles of low,-maintenance or abandoned, paved roads.

The secondary-road management program supports the site's objective to provide an effective network of roads that access SRS. It is vital to the success of the mission, as well as the natural-resource programs. It is important that this program be efficiently managed, environmentally acceptable, and comprehensive. It includes all the construction, reconstruction, and maintenance activities on existing and proposed segments of the entire secondary-road system.

A secondary-road management operation plan (SRMOP) will be developed to implement this program with input from the operations contractor's affected departments. An MOA was authorized May 20, 1991, to define organizational responsibilities relative to secondary-road management.

Under the SRSMOP and in coordination with other NRMP programs and operation plans, the CSWE will perform secondary-road maintenance activities under the guidance of the forest manager. 


\section{Programs by Other Onsite Contractors}

Forest management is performed almost exclusively by SRFS and includes such activities as timber harvesting, site preparation, reforestation, timber stand improvement, prescribed burning, wildlife management, soil reclamation, wetlands protection, secondary-roads mánagement, and research support.

Soil classification and mapping of SRS was completed by the Soil Conservation Service (SCS). A report, Soil Survey of Savannah River Plant Area, Parts of Aiken, Barnwell, ard Allendale Counties, South Carolina (June 1990), was generated as a result of this activity. Site-specific soil suitability and classification are provided on an as-needed basis by SCS. This information will be used in planining, managing, and harvesting woodland crops; locating and designing research plots; locating soil materials source of high density and low permeability; and locating and designing rnads, parking areas, buildings, and spray fields.

Technical Support

\section{Remote Sensing}

\section{SRTC Environmental Sciences Section (ESS)}

Data is being gathered from satellite and airborne sensor systems during SRS overflights to provide a database of those areas that are dificult to study on the ground. Evaluating these data will provide both a temporal and spatial assessment of the effects of SRS operations on terrestrial and aquatic environments onsite.

\section{National Environmental Research Park (NERP)}

The SRS is designated a NERP. This site is an outdoor laboratory set aside for ecological research on the environmental impacts of SRS operations and for informing the public of available environmental and land-use options. However, the research at the park is regional in approach, and activities are not limited to those environmental concerns and species native to SRS. In this regard, SRS lands are viewed as a national resource with the potential to contribute to a wide variety of environmental research issues.

The NERF program is conducted by SRTC, SREL, SRFS, and their contractors, and by scientists with outside funding who cooperate with one of these organizations. SRTC uses NERP program resources to support university research. At SREL, NERP program resources are used to support and facilitate applied research activities rather than actually to conduct such work. Support is provided for basic ecological studies and long-term baseline assess nents of the flora, fauna, and other important environmental factors. 
SRTC. Environmental Sciences Section (ESS)

In 1988 and 1989, the NERP provided seed support for studies on the microbiological components of the subsurface environment. In 1987, in excess of 1000 different organisms were found to a depth of 800 feet. This finding potentially has great significance to the fate of groundwater pollutants. Some of these organisms are new to science and may be very useful in biotechnology applications. The program is a cooperative one with universities and national laboratories (Florida State, Comell, Oklahoma, Penn State, Tennessee, PNL, and ORNL). The program provides essential information about bow the subsurface community influences nutrients and waste. It will provide important insight into the longevity of containers used to retain hazardous waste.

The NERP also supports a travel fund to permit well-known scientists to visit SRS. On their visits, they provide seminars to keep SRTC employees up-to-date with the latest approaches to environmental research. This program is extremely productive, providing our staff with insights that result in cost-effective alterations in our program areas and informing visiting scientists of research opportunities at the NERP. 


\section{Endangered Species}

(Compiled and reviewed by Keith W. Dyer)

\section{Site Program Overview}

Threatened and endangered species management and recovery efforts are under the responsibility of the SRFS. SRFS actively is involved in partnerships with the SREL, SEFES, and the SC Wildlife Marine Resource Division (SCWMRD) to accomplish habitat-improvement projects and population-monitoring projects. Potential impacts on endangered species from new activities are identified in the planning stage of each activity using a National Environmental Protection Act (NEPA) checklist and are addressed through consultations with federal and state agencies.

\section{Justification/Regulatory Requirements}

\section{Federal Law}

The Endangered Species Act of 1973 (16 USC 1531-1543) requires every federal agency to ensure that its actions and those of its contractors are not likely to jeopardize the continued existence of any endangered or threatened species or result in destroying or adversely modifying a critical habitat, unless an exemption as defined in Sections 1536(a)(2) and (b) has been granted by the Endangered Species Committee.

No permits are required to comply with the act. However, in the case of anadromous fish taxa, consultation with the U.S. Fish and Wildlife Service (FWS) or the National Marine Fisheries Service (NMFS) is required for a proposed project. A biological assessment may be required if the FWS or NMFS indicate that a threatened or endangered species might be found.

\section{State Law}

South Carolina Nongame and Endangered Species Act (Code of Laws of South Carolina, Title 50, Chapter 15) protects state, nongame species in need of management and species listed by the state as endangered. Consulting with the South Carolina Wildlife and Marine Resources Commission (SCWMRC) is required if a listed species is present in an area to be disturbed by construction or ongoing operation of a new facility.

The endangered species program supports the wildlife regulations objectives.

\section{Organizational Responsibilities Summary}

The NEMP directs SRFS to administer the threatened and endangered species program at SRS. 
When planning begins for an activity with a high potential for environmental impact, the operating contractor, department, or division initiating the activity must complete a NEPA Safety Analysis and Environmental Permit Checklist (OSR 14-347) that identifies whether or not an endangered species might be impacted by the proposed activity. If an endangered species might be impacted, DOE-SR contacts FWS'S Regional Field Station. If there is a potential for affecting endangered marine species, the NMFS's regional office also is contacted.

If it is found that an endangered species potentially could be affected, the DOE-SR will supervise the information-gathering necessary for a biological assessment of the impact on the species.

Management Programs

The following two SRFS programs for protecting endangered species are important enough to be noted:

- The Southern Bald Eagle Management Plan includes designating a territory management zone to provide additional protection for the species. Highly regarded offsite, this program serves as a model for USFS projects elsewhere.

- The Red-Cockaded Woodpecker Management Plan includes managing more than 400 square kilometers $(100,000$ acres) of forest, mostly pine, to benefit the woodpecker. Conditions favorable to the species are being established through longer rotations to allow pines to attain older age before harvest, and by controlled burning to remove understory species and maintain a more open pine forest.

Technical Support

Wood Stork

SRTC - ESS's technical working group is recommending research and management for the wood stork on SRS. Members of the group include the DOE, SREL, FWS, SCWMRD, SRTC, SRFS, and the National Audubon Society (NAS). The group meets annually to discuss the species' current status and the management of the NAS Kathwood Lake foraging site.

\section{Research/Studies by Other Onsite Contractors}

SREL currently is conducting several research projects on threatened or endangered species under their Stress and Wildlife Ecology Program. Among these projects are the following:

- studies on the ecology of alligators

- a population genetics study of the red-cockaded woodpecker to aid in introducing red-cockaded woodpeckers from other areas to SRS

- a study to evaluate the importance of the Savannah River Swamp System to the wood stork to determine its foraging requirements 
- surveys of rare and threatened plant species onsite to determine their presence, disuribution, and abundance.

- a study to clarify the taxonomic status of potentially rare and endangered freshwater mussels at SRS

- FWS DNA mapping

SEFES currently has a program for the re-establishment of the red-cockaded woodpecker at SRS. This program's objectives include recommending modifications to existing habitats, reintroducing red-cockaded woodpeckers to SRS from other offsite populations, and monitoring the reproductive and adaptive success of the existing and relocated populations. 


\section{Other Wildlife}

(Compiled and reviewed by Keith W. Dyer)

\section{Site Program Overview}

The principal activities involving other wildlife onsite are research studies and population control. The operating contractor's studies consist of biological monitoring and are described in the Surface Waters and Wetlands Protection Program. Public deer hunts are managed by the operating contractor with assistance from other onsite and offsite contractors. These hunts are significant operations as measured by the site area involved and extent of funding required. Beaver and other nuisance animals are controlled by collections and relocations. Funding for beaver and other nuisance animal control is relatively small.

Justification

\section{DOE Order}

Chapter VIII, Management of Natural Resources, of DOE Order 4300.1B, Real Property and Site Development Planning, states that all installations having suitable land and water areas will have programs for harvesting fish and wildife by the public, provided it does not interfere with the site's missions.

\section{DOE-SR Site Policy}

The Fish and Wildlife Management Policy for the Savannah River Plant (SR Announcement No. SR-86-35)-It is the DOE-SR's policy to manage effectively fish and wildlife resources at SRS to maintain their biological productivity and diversity. In addition, animals are hunted and trapped only to control safety hazards or excessive property damage.

The NRMP enhances SRS's mission by helping to ensure environmental protection and responsible stewardship of SRS resources.

Ongoing activities involving other wildlife support, help, and manage the wildlife populations objectives.

\section{Organizational Responsibilities Summary}

The main organizations conducting environmental research at SRS are the SRTC (primarily the Environmental Sciences and Environmental Technology Sections), SREL, and SEFES. These programs provide information essential to achieving environmental goals and for evaluating the effects of operating nuclear-production facilities. 
The Safeguards and Security Section, with support from EMS and CSWE, manages public hunts for deer and feral hogs at SRS to reduce animal/vehicle collisions. Nuisance beaver are controlled under a contract with a local vendor that is funded by SRFS and EMS and administered by EPD with guidance from SRFS. CSWE alerts SRFS to beaver activity.

SRFS's forest manager plans and directs a fish and wildlife management program that includes all habitat and animal survey and manipulation activities including those for threatened, endangered, and sensitive species under the administrative responsibility of the Environmental Division of DOE-SR. SRS's deer hunts and the special Crackemeck Area hunts are the responsibility of the Contracts and Property Division of DOE-SR. This program responsibility does not include fish- and wildlife-related research.

The fish and wildlife management program supports three general objectives; maintaining fish and wildlife diversity, rehabilitating endangered species populations, and controlling hazardous or nuisance animals. This program includes certain special management activities such as the wild turkey trapping program conducted by SCWMRD. SCWMRD has regulatory responsibilities which apply to the SRS and will be adhered to in conducting all activities under the fish and wildlife management program. These responsibilities include public hunts in the Crackerneck Area, scientific collecting permits, hunting licenses, and trapping permits. The fish and wildlife management program is committed to a cooperative working relationship with the SCWMRD in regard to the South Carolina Heritage Trust and the Nongame and Endangered Species Conservation Act, locally and statewide.

Management Program

\section{Management of Deer and Hog Hunting}

Animal hunts are conducted at SRS to control the resident deer and hog populations and to reduce animal-automobile accidents. The 1991 hunt at SRS yielded 1,092 deer and 126 feral hogs in 14 hunts. Approximately 3,086 hunters participated.

An overall success rate (animals harvested/hunter) of nearly 40 percent was recognized. The hunts are expected to be conducted and managed similarly for the next five years.

CSWE provides transportation for hunters from the plant's security gate entrances to designated hunting areas and back. CSWE also clears deer trails and repairs roads as directed by USFS.

EMS monitors all animals are monitored for radioactivity before they are released to the hunters.

Safeguards and Security plans and coordinates the hunts. Security and safety briefings are provided to the hunters before each hunt. 


\section{Control of Nuisance Animals}

Beaver activity (e.g., blocking culverts) frequently impounds surface water, which can kill valuable trees, undercut roadbed embankments, and inundate or prevent access to monitoring stations and research facilities. Other nuisance animals include dogs, cats, skunks, snakes, and rabbits that stray into operating areas of the SRS.

Environmental Protection Department (EPD) - EPD administers the contract for beaver control which is funded by USFS, EMS, and CSWE.

\section{Management by Other Onsite Contractors}

Under an interagency agreement with the DOE, wild turkeys formerly were netted onsite by SCWMRD to stock offsite areas. Although the need for transplanted birds currently does not exist, a new cooperative agreement between the two agencies provides for resuming the activity should the need arise.

\section{Technical Support}

\section{Plans to Mitigate Fish Kills}

A remedial action plan was developed and submitted to SCDHEC to reduce fish kills resulting from thermal discharges from $\mathrm{L}$ and $\mathrm{P}$ reactors. The plan's provisions were incorporated into the Fish Kill Settlement agreement between DOE and SCDHEC. Initial studies and design work have been completed to a point where all additional requirements can be implemented within three years. Work will resume if DOE announces that the $\mathrm{L}$ or $\mathrm{P}$ reactors will restart.

\section{Biological Monitoring}

SRTC's ESS conducted several studies to assess the cumulative effects of thermal discharges to onsite surface waters from SRS facilities. These studies were done to ensure that waters which receive thermal discharges maintain a balanced indigenous biological community. The studies include 316(a) studies of the K-Reactor cooling water system, the $\mathrm{D}$ Area powerbouse discharge, and the biological monitoring of L Lake and Steel Creek. A 316(a) demonstration was initiated in Beaver Dam Creek to determine if the stream supports a balanced biological community, following implementation of thermal mitigation in D Area. The ESS initiated a biological monitoring program in Pen Branch and Indian Grave Branch to document recovery of these ecosystems subsequent to the shutdown of K Reactor in April 1988.

ESS is participating in the SRS Biodiversity Program. This program is organized around a steering committee with representatives from DOE-SR, SRFS, WSRC, and SREL. The objectives are to assess the biodiversity of habitats onsite, and develop programs to enhance biodiversity. 
Studies by Other Onsite Contractors

SREL, operated by the University of Georgia, has several programs to develop an understanding of the impact of various energy technologies and management practices on the ecosystems of the southeastern United States. SREL research is conducted by interdisciplinary research teams organized under three major divisions: Biogeochemical Ecology; Wildlife Ecology and Toxicology; and Wetlands Ecology. Wildlife studies are included in the following SREL programs: Environmental Operational Support, Foraging and Breeding Ecology of the Wood Stork, Environmental Stress from SRS Operations, Environmental Toxicology, Biodiversity on the SRS, New Production Preoperational Studies, Defense Waste Processing Facility Study, New Production Reactor Preoperational Studies, and Par Pond Drawdown Studies. 


\section{Wildlife Habitat}

(Compiled and reviewed by Keith W. Dyer)

Site Program Overview

The effect of some SRS activities on wildlife habitat is assessed in support of NEPA documentation. This has included completing two Environmental Impact Statements (EIS): Waste Management Activities for Groundwater Protection at the Savannah River Plant, and Alternative Cooling Water Systems Savannah River Plant. In addition, SREL conducts wildlife-habitat studies under several ongoing programs.

\section{Justification/Regulatory Requirements}

NEPA directs federal agencies who propose actions significantly affecting the quality of the environment to evaluate the impact of the action on the environment. Preparing an EIS is required for major federal actions. Ongoing activities involving wildlife habitats support the wildlife-regulations and understanding-impacts objectives.

\section{Organizational Responsibilities Summary}

The major organizations conducting environmental research onsite are SRTC (primarily ESS and ETS), SREL, and SRFS. The programs conducted by these organizations provide information essential to achieving environmental goals and to evaluate the effects of operating nuclear production facilities. SRFS uses forest management to provide open areas and a diversity of forest habitats for wildlife.

Potential impacts on wildlife habitats from proposed new activities are identified in the planning stage by the operating contractor department or division initiating the activity. Potential impacts are assessed in a NEPA review and in a site-use permit review and mitigated as needed.

\section{Technical Support}

\section{Waste Management Activities for Groundwater Protection EIS Alternative Cooling Water Systems EIS}

The effect of certain SRS activities on wildlife habitats is described in two EISs. The EIS on waste management activities for groundwater protection discusses closing existing waste disposal sites, constructing new waste-management facilities for low-level radioactive and hazardous materials, and disposing of tritiated wastewater from reactor disassembly basins. The analysis considered the effect of hazardous substances reaching terrestrial and aquatic habitats by surface water runoff and the uptake by terrestrial vegetation or surface water by the passage of hazardous substances through the groundwater. The EIS on alternative cooling water systems evaluated the potential effects on receiving stream systems from the proposed cooling 
tower alternatives for $C$ and $K$ reactors and $D$ Powerhouse. The effects of operating of $K, L$, and $P$ reactors were considered in the continued Reactor Operation EIS.

\section{Studies by Other Onsite Contractors}

SREL, operated by the University of Georgia, conducts research that will develop an understanding of the impact of various energy technologies and management practices on the ecosystems of the southeastern United States. The titles of SREL wildlife habitat programs currently underway onsite include: Environmental Operational Support; Defense Waste Processing Facility-Ecological Effects of Construction; Environmental Stress from SRS Operations, Biodiversity on SRS; Wood Stork Foraging and Breeding Ecology; Environmental Toxicology, and New Production Reactor Preoperational Studies, Par Pond Drawdown Studies. 


\title{
Land Reclamation and Erosion Control
}

\author{
(Compiled and reviewed by Keith W. Dyer)
}

\section{Site Program Overview}

Onsite land-reclamation activities began in 1974 with revegetation efforts by SRFS. Currently, both SRFS and the operating contractor have programs to revegetate bare or altered areas.

Soils, water, and air-resource management ultimately is the responsibility of the organization that affects the given resource values. Accordingly, SRS contractors must try to use the special technical capabilities of the SRFS and the Soil Conservation Service (SCS) in soil and water conservation for construction areas, borrow pits, spoil piles, and waste site closures.

\section{Justification/Regulatory Requirements}

\section{South Carolina Standards}

South Carolina Water Classification standards (SCDHEC 61 68) require that all SRS navigable waters meet Class F Water-Quality Standards, which include limits on total suspended solids and $\mathrm{pH}$.

Ongoing and planned land-reclamation activities support the land-reclamation objectives.

\section{DOE Order}

DOE Order 4300.1B, Real Property and Site Development Planning (7-1-87) states that DOE will manage its real properties in a way that conserves soil, water, and plants.

\section{Organizational Responsibilities Summary}

SRFS's forest manager has the responsibility for planning and directing the soil-resource program which deals with the non-point source impacts from natural resource management activities. SCS is working with SRFS to provide onsite expert consultation and technical advice to SRFS and other SRS contractors on specific problems related to soil-resource conservation.

SRFS's forest manager is responsible for the water and air-resource program which deals with the non-point source impacts from natural-resource management activities. Program responsibilities include developing forest-management activities which protect ground and surface waters and the air resource, and providing 
recommendations to WSRC and other site users, as directed by DOE, concerning impacts on water and air from nonforest operations.

Several onsite organizations, including, SRFS, SCS, Bechtel, and WSRC, are developing plans to rehabilitate disturbed land onsite. Implementing these plans will extend the useful life of SRS facilities, while converting bare areas into more useful habitat for wildlife. SRFS has conducted soil-stabilization activities since 1974.

Erosion-control measures are the responsibility of Construction for construction projects, custodial departments for fenced areas, and CSWE for all areas outside the fences which are not controlled by other onsite contractors.

\section{Programs}

\section{Land Reclamation}

Site Utilities - Sanitary sludge from SRS wastewater-treatment facilities now is being applied to a SCDHEC-permitted borrow pit land-reclamation site in H Area. Borrow pits are sites where sand or gravel was removed during construction of plant facilities. These sites will benefit from sludge applications which act as soil conditioners and promote revegetation. The borrow pit was permitted to receive sludge until May 1992. A new permit has been requested to begin applying sanitary sludge on forested areas. The sludge will be used as a fertilizer and soil conditioner to enhance timber growth.

A similar program is being established for powerhouse ash disposal. Ash will be removed from existing ash basins to extend the basins' useful life. The ash will be used as a fill material to reclaim abandoned ash basins.

\section{Programs by Other Onsite Contractors}

In 1974, SRFS began soil-stabilization activities to control soil erosion. Since then, more than 2 square kilometers of bare area has been revegetated. In 1986, approximately 0.25 square kilometers were reshaped, subsoiled, and planted with legumes to provide wildlife food, while controlling erosion. 


\section{References}

Du Pont, 1986. Strategic Environmental Plan, DPW-86-102, E.I. du Pont de Nemours and Company, Wilmington, DE.

Natural Resources Management Plan, Strategic Guidance for the Savannah River Site's Natural Resources Programs was agreed to by WSRC, DOE-SR, and SRFS. WSRC approved the NRMP as the guidance document under which operation plans will be prepared for each management and research program described in the NRMP. (ESH-910003, 1/9/91) 


\section{Surface Water and Wetlands Protection Site Program Overview}

Large quantities of water are pumped from the Savannah River and site production wells to support SRS operations and subsequently are discharged to onsite streams and tributaries after use. SRS is crossed by six principal tributaries of the Savannah River: Beaver Dam Creek, Four Mile Branch, Pen Branch, Steel Creek, Upper Three Runs Creek, and Lower Three Runs Creek. Portions of the later two are classified as navigable waters of South Carolina. Additionally, surface water is held in more than 50 artificial impoundments with areas totaling more than 4000 acres. Par Pond is the largest, with an area of about 2700 acres, followed by L Lake, which has an area of about $\mathbf{1 0 0 0}$ acres. Water is retained intermittently in wetlands and in more than 200 natural impoundments, including some Carolina bays. A large swamp (about 10,000 acres) borders the Savannah River and is crossed by several streams. Some of the site streams, as well as L Lake and PAR Pond, receive treated industrial effluents, low-level concentrations of radiontclides, and heated water as a result of SRS operations.

Industrial and urban growth along the Savannah River above and below SRS is expected to expand and use more Savannah River water. The increasing demand for water will require continued exemplary stewardship of the river, wetlands, and onsite streams. The Surface Waters and Wetlands Protection Program establishes the overall management framework for protecting of this resource.

\section{Summary}

SRS operations meet environmental regulations and site policies related to protecting surface waters and wetlands except for thermal discharges from reactor operations presently regulated by a consent order with South Carolina. Extensive river monitoring demonstrates that the Savannah River generally is unaffected by plant operations.

The site is required by SCDHEC consent order to mitigate the heated water discharges from K Reactor. The Record of Decision issued February 12, 1988, selected a recirculating cooling system to mitigate heated effluents from $\mathrm{K}$ Reactor. The construction of this system was approved by South Carolina and an NPDES permit (No. SC0044903) was issued October 25, 1990, establishing effluent-quality limits for the cooling system subsequent to its completion by December 31, 1992. Heated-water from $P$ and $L$ reactors is discharged into Par Pond and $L$ Lake, respectively. Studies show that PAR Pond, built in the early 1950s, supports a balanced biological community, and L Lake, completed in 1985, is developing a balanced biological community. Concerns, however, that some fish mortalities have occurred in these receiving waters as result of recommencing reactor operations following extended outages prompted South Carolina to enter into a Settlement Agreement, requiring the site to eliminate these impacts by implementing an approved remedial-action plan. In February, 1991, DOE published a Record of Decision deferring indefinitely the restart of the $L$ and $P$ reactors by placing one in the warm standby mode and the other in the 
cold standby mode. Approval was received from SCDHEC December 10, 1991, effectively deferring any further implementation of the Fish Kill Remedial Action Plan pending a decision to restart either $L$ or $P$ reactors.

Nonradiological discharges are regulated by state-issued NPDES permits. The site has an effective NPDES program with more than a 99 percent compliance over the last five years. Although an application to renew the 1983 permit was submitted in June 1988, SCDHEC indicates a draft permit may not be issued until 1993 or beyond. A new permit covering five outfalls was issued in October 1991. The balance of site outfalls is covered by an administratively extended permit. Several issues may be associated with renewing this permit, including toxicity testing requirements, combining/eliminating outfalls, and using effluent-treatment facilities for treating additional waste streams.

Limits on residual chlorine could require installing dechlorination facilities at all sanitary-waste treatment plants and possibly other facilities, if included in the new permit. The potential for effluents to contravene water-quality standards is being investigated. A Toxicity Steering Committee has been formed to advise Operations on effluent toxicity concerns. An Aquatics Issues Task Group (AITG) further advises the site Natural Resources Coordinating Committee on water-quality concerns.

EPA has identified storm water runoff from industrial facilities as a major source of pollutants being discharged into U.S. waters. Therefore, as of October 1, 1992, storm-water point-source discharges associated with industrial or construction activities are regulated by the SCDHEC NPDES General Stormwater Permit for Industrial Facilities. The general permit targets specific industrial activities at SRS for storm-water discharge monitoring and reporting. The monitoring data will be used to develop and implement a facility-specific Pollution Prevention Plan (PPP) that wi: eliminate pollutants from being discharged with storm-water runoff.

The sitewide stream-management program will provide a comprehensive and. long-term approach to ensure that the quality of surface waters and wetlands is protected. A management policy will be developed for each onsite stream similar w. the existing Upper Three Runs Stream policy. These policies ivill be the basis for decisions related to installing and operating wastewater-treatment facilities and to siting and operating other facilities.

The Savannah River is monitored extensively for radiological and nonradiological constituents. Small concentrations of low-level radioactive (alpha-, beta-, and gamma-emitting radionuclides and tritium) and nonradioactive effluents reach the river from process discharges to onsite streams, but these do not have an impact on the aquatic biota or human health. A release of contaminated reactor cooling water in December 1991 brought into sharp focus the manner in which wastewaters are managed and monitored prior to discharge into the environment. SRS has since redoubled its efforts to minimize the potential for excursionary releases into the aquatic environment.

The wetland protection programs will become more fully integrated with the site-use and erosion-control programs, as SRS strives to fulfill former President Bush's goal of 
"no net loss" of wetlands. Specific regulatory interpretive guidance on full implementation has not been developed. In absence of promulgation, SRS will pursue a conservative, literal approach to program implementation. A Wetlands Task Group, chartered as a work group under the Natural Resources Coordinating Committee, enhances communication and understanding among onsite organizations concerning wetland-resource management. Wetland-restoration activities are exemplified by the Lost Lake cleanup project recently completed. Over the past 30 years, Lost Lake, a Carolina bay which was drained prior SRS's establishment, received M-Area effluents which included heavy metals. The cleanup of the bay and an associated settling basin was started in 1985. The bay officially has been closed as a waste site, and now, as a result of an extensive reconstruction effort which involved soil preparation and planting of more than 10,000 individual herbaceous plants, seeds, and soil plugs from other wetland areas, it is considered "a healthy wetland, teeming with plant life, insects, waterfowl and many species of reptiles and amphibians". SRS has committed to and has initiated restoration initiatives on parts of the cypress swamp bordering the site which previously were impacted by heated-effluent discharges into receiving streams.

The Clean Water Act was slated for Congressional reauthorization in 1992. In 1993 amendments likely are to be introduced that will require adjustments to site programs to meet challenges associated with complying with standards for protecting the site's surface water and wetland resources. 


\section{Policy}

SRS's Surface Waters and Wetlands Policy requires that site operations protect public health, preserve and maintain the quality of the site surface waters and associated wetlands, meet regulatory effluent limits, and comply with DOE and operating contractor requirements.

\section{Background}

DOE and the operating contractor are committed to protecting the public health and safety and the environment. These convictions are stated in DOE Order 5400.1, General Environmental Protection Program, and in the SRS Strategic Plan For Environmental Compliance at the Savannah River Site (WSRC-IM-91-66). Compliance with environmental regulations, DOE orders, and operating contractor policies form the basis for SRS's Surface Waters and Wetlands Policy. 


\section{Existing Conditions}

Large quantities of water are pumped from the Savannah River and site production wells for use as cooling and process water for SRS reactors and other processing facilities. The water then is returned to the surface streams that flow across the site into the Savannah River. SRS is crossed by six principal Savannah River tributaries: Beaver Dam Creek, Four Mile Creek, Pen Branch, Steel Creek, Upper Three Runs Creek, and Lower Three Runs Creek.

In addition, surface water is held in more than 50 artificial impoundments with areas totaling more than $\mathbf{4 0 0 0}$ acres. Par Pond is the largest, with an area of about 2700 acres, followed by L Lake, which has an area of about 1000 acres. Water is retained intermittently in wetlands and in more than 200 natural impoundments, including some Carolina bays. A large swamp (about 10,000 acres) borders the Savannah River and is crossed by several streams.

Some of the site streams, as well as L Lake and Par Pond, receive treated wastewater effluents containing typical industrial chemicals, small concentrations of radionuclides, and heated water as a result of SRS operations. Concentrations of radiological and nonradiological constituents are monitored to verify that permitted discharge limits are not exceeded.

The Savannah River, the principal tributaries, Par Pond, and L Lake are monitored extensively for radioactivity. Measurable concentrations of alpha-, beta-, and gamma-emitting radionuclides and tritium are released into these waters, but the concentrations do not have an impact on aquatic biota or buman health.

SRS complies with the Clean Water Act (CWA) and SCDHEC wastewater regulations for freshwater streams except for thermal effluents. Past thermal discharges currently are regulated by a consent order with South Carolina. Nonradioactive industrial effluents are monitored through a system of 81 currently permitted NPDES outfalls. Effluent-discharge limits are set to allow plant operation without an adverse impact on aquatic biota or water quality. The site operates more than $\mathbf{3 0}$ wastewater-ireatment facilities permitted by SCDHEC. NPDES discharge-permit compliance performance for the last eight years was as follows: $1985,98.8$ percent; 1986, 99.4 percent; 1987, 99.7 percent; 1988, 99.8 percent; 1989, 99.9 percent; 1990, 99.8 percent; 1991, 99.9 percent; and 1992, 99.9 percent.

Presently, 48 storm-water-only point sources are covered under the SCDHEC NPDES general permit for storm water associated with industrial activity. Of the 48 point sources, 10 representative outfalls have been selected for monitoring. These 10 outfalls represent a wide range of SRS activities, including facilities that store, use, or dispose of EPCRA section 313 chemicals, land disposal units, steam electric facilities, and chemical and allied product manufacturing. As required by the general permit, PPP is being developed for the identified storm-water outfalls. The PPP will identify facility areas where best management practices (BMP) and/or best available technology should be implemented to prevent or mitigate the release of pollutants into stormwater runoff. 
Storm-water discharges associated with land disturbances greater than 5 acres now are required to submit a notice of intent (NOI) to SCDHEC to be covered under the NPDES general permit for storm-water discharges associated with construction activities. The general permit requires that a PPP be developed and implemented prior to any land disturbance. No monitoring or reporting is required. Land-disturbance activities that require a NOI include new construction, environmental-restoration work, and/or any activity greater than 5 acres that would increase sediment runoff.

The majority of the Savannah River Swamp exhibits little visible change as a result of SRS operations. Some cypress-tupelo forest canopies in a portion of the river swamp have been eliminated due to elevated water temperatures, increased sedimentation, and flooding while at the same time, the aquatic habitat has increased. The loss of some tree canopies results in increased growth of herbaceous vegetation and algae.

In March 1991, an inspection of the Par Pond dam revealed a depression on the downstream face. A subsequent investigation revealed piping and erosion of fill materials within the dam. Although the investigation revealed no imminent potential for the dam to fail, precautionary measures were taken. To minimize the potential for failure and decrease the magnitude of associated flooding and spread of contaminants offsite, the reservoir was drawn down from some 19 feet in elevation to 181 feet mean sea level. More than 12 billion gallons of water was released into site streams during the draw down from July to November 1991. DOE currently is assessing three alternatives for managing the dam and reservoir.

The Savannah River generally is unaffected by SRS operations. The low levels of radionuclides have no demonstrated affect on aquatic biota or buman health. The concentrations of nonradioactive materials in the river are the same up-river and down-river from SRS. 


\section{Objectives}

The objectives to support the Surface Waters and Wetlands Protection Program are the following:

- to comply with the Clean Water Act, NEPA, SCDHEC's Wastewater Treatment Regulation 61-76, applicable federal and state regulations and orders, DOE orders, and operating contractor requirements related to allowable discharge limits, NEPA review, wetlands assessments, and accident-risk minimization

- to operate within discharge limits based on applicable effluent guidelines or site-specific water-quality criteria for selected radiological and nonradiological species that may pose an environmental hazard

- to control radionuclide discharges so that the Savannah River remains below the primary drinking water standards for radioactivity

- to monitor the quality of the Savannah River and inform the public and regulatory agencies of the results regularly

- maintain a spill response capability and a realtime emergency-tracking system that can respond rapidly to accidental releases into surface waters

- to minimize the loss of wetlands from existing operations and prevent any significant losses from future operations

- to develop a long-range land-use plan which adequately protects the site's surface water resources

- to minimize the impact of storm-water discharges into surface waters and wetlands 


\section{Strategy}

The strategy for reaching the Surface Waters and Wetlands Protection objectives includes the following:

- identifying regulatory and other protection requirements

- promoting innovative and cost-effective means of meeting requirements through research and development

- developing physical and administrative controls to protect surface waters and wetlands utilizing the knowledge gained from research and development efforts

- implementing physical and administrative controls

- evaluating the controls to ensure protection requirements are met

The strategy is illustrated in Figure 6-2. 


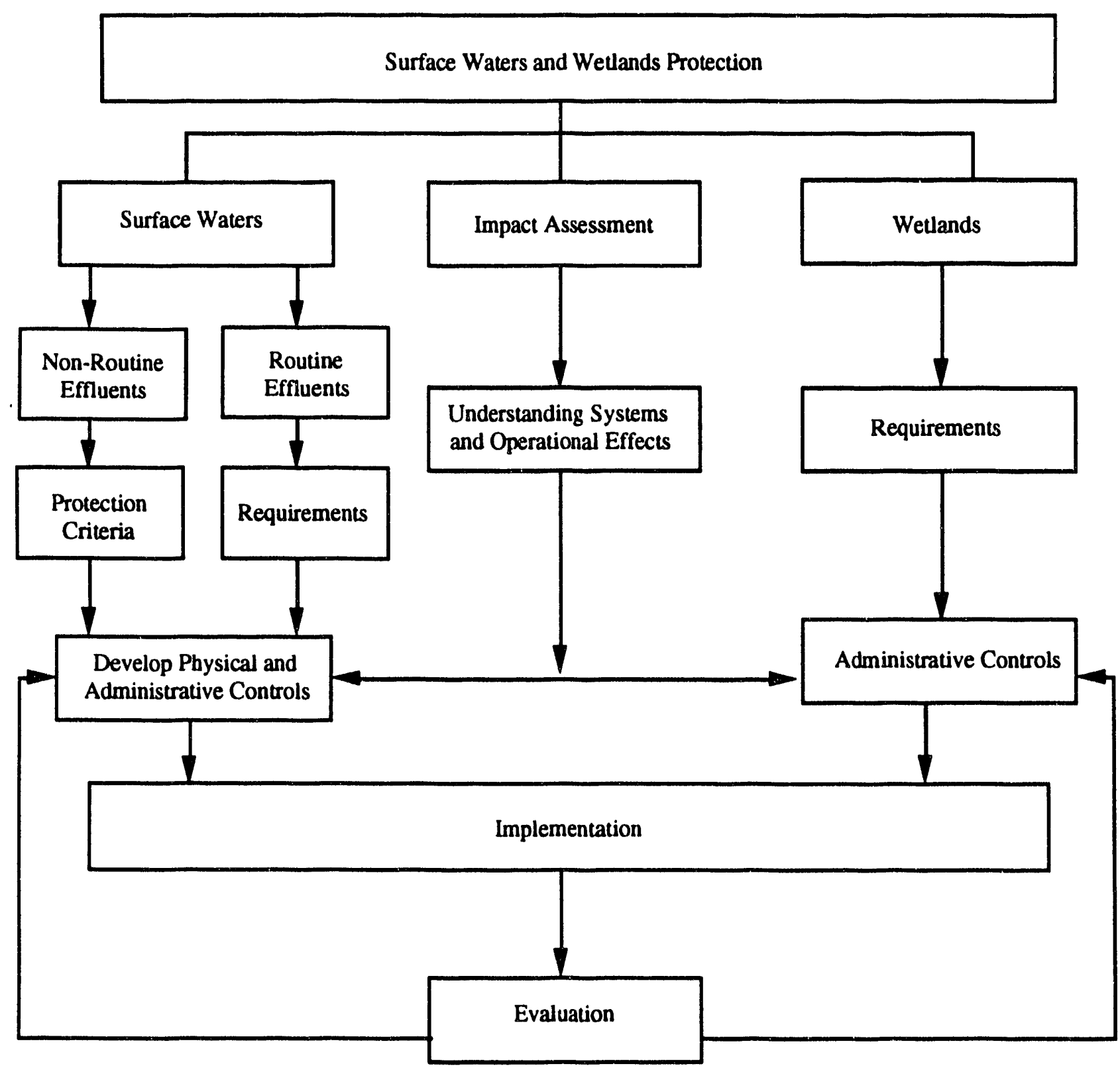

Figure 6-2. Surface Waters and Wetlands Protection Program Strategy 


\section{Implementation}

The implementation section identifies issues and those responsible for actions to achieve stated objectives. Each environmental effort will require funding for one or more of the following: research and development, operations, programs, and construction/modification projects. The following programs are found in the implementation section:

- Stream Management (page 6-42)

- Thermal Mitigation (page 6-46)

- NPDES Wastewater(page 6-50)

- NPDES Storm Water Associated with Industrial Activity (page 6-58)

- NPDES Storm Water Associated with Construction Activity (page 6-63)

- Erosion Control (page 6-66)

- Waste Treatment Facilities (page 6-68)

- Wetlands (page 6-77) 


\section{Stream Management}

(Compiled and reviewed by Keith W. Dyer)

\section{Site Program Overview}

SRS's stream-management policy is designed to protect human bealth, safety, and the environment by adhering to water-quality standards for fresh water streams in South Carolina. The water quality of each stream will continue to be determined through studies, modeling, and research to determine if the cumulative impacts of site operations have significant short- or long-term impacts on stream water quality and ecology. The results of this work are being used to develop stream management policies for each onsite stream. Decisions relative to the installation and operation of wastewater-treatment facilities and other operations discharges will be made by utilizing the stream-management policies to ensure minimal environmental impact.

In addition to routine sampling and special sampling during nonroutine environmental releases, radiological and nonradiological surveys are conducted onsite and of fsite by the EMS and other groups, including the SRTC, SREL, and the Academy of Natural Sciences of Philadelphia (ANSP). Both short- and long-term radiological and nonradiological surveys are used to monitor the effects of SRS effluents on the environment at and near SRS.

The Nonradiological Site-Specific Stream Guides program is a portion of SRS's stream-management effort to assess if point-source discharges are having any adverse impact on receiving-stream biota. Mathematical stream flow models will be developed along with biological toxicity studies to assess the impacts of present and future SRS wastewater discharges.

Under the direction of NRCC an AITG was formed. AITG consists of representatives from EPD, SRTC, DOE-SR/Environmental Division, DOE-SR/Environmental Restoration Division, UGA-SREL, SCS, and the USFS. The purpose of AITG is to facilitate the exchange of environmental information about surface waters among SRS organizations, to act as a forum for discussion on specific issues at SRS, to offer advice to DOE, to sponsor quarterly environmental user's group workshops, and to report to NRCC on aquatic issues. Two areas the group is evaluating are the use of chlorine at SRS treatment facilities and toxicity testing in SRS streams. Further studies of wastewater-plant effluents and their impact on streams are being designed. Studies on the effects of chlorination from others sources such as discharges from cooling towers, noncontact cooling water, domestic water systems, and sanitary wastewater-treatment facilities will continue. Total residual chlorine (TRC) concentrations in onsite streams are being evaluated in anticipation that TRC limits may be imposed in the renewed sitewide NPDES permit. Additional nonradiological constituents for assessment may be selected. 
Justification

To preserve the quality and character of SRS streams, the site must be concemed with the entire stream system rather than just regulatory compliance at point-source discharges. Although this approach requires a comprehensive knowledge of the site's surface waters, it is the only way to ensure proper utilization and protection of site streams.

The stream-management program supports the chapter objectives.

\section{Organizational Responsibilities Summary}

DOE has final approval on all stream-management issues and programs. EPD leads in developing the stream-management program. SRTC and SREL conduct basic and applied ecological research and provide expertise and assistance in making decisions regarding stream management. Operating departments assess their operational impacts on the streams and provide data from special studies related to surface-water concerns. The AITG is the focus group for aquatic issues under the NRCC.

Stream Policies

EPD, in cooperation with AITG and operating departments, will develop stream-management policies for each major SRS stream. These policies will provide guidelines for releasing effluents into each receiving stream and will establish a mechanism to obtain onsite approval for each release. The goal of these policies is to ensure that plant operations maintain the water quality of each stream and the associated aquatic community.

The Upper Three Runs Creek (UTRC) stream management policy states: The stream-management policy for discharging effluents into Upper Three Runs Creek delineates three regions of the creek. The stream management policy does not define land use adjacent to Upper Three Runs Creek and its tributaries. The regions are described as follows:

- Region 1 - Upper Three Runs Creek and its tributaries upstream of the mouth of Tinker Creek; also, Tinker Creek and its tributaries from the upstream bank of McQueen Branch to the source of Tinker Creek

- No effluents may be discharged into Region 1. This region is reserved for research purposes.

- Region 2 - Upper Three Runs Creek and its tributaries between the upstream banks of Tim's Branch and Tinker Creek; also, Tinker Creek and its tributaries between the upstream McQueen Branch and Upper Three Runs Creek

- Limited effluents may be discharged through tributaries to Region 2, within regulatory limits, provided that the collective impact on stream aquatic communities is insignificant and water quality is maintained within historic ranges. These discharges should not introduce into UTRC measurable quantities of potentially toxic chemicals not naturally-occurring in this stream. 
- Region 3 - Upper Three Runs Creek and its tributaries downstream of the mouth of Tim's Branch

- Additional low-impact effluents may be discharged to Region 3, within regulatory limits, provided that no significant adverse impact occurs to stream biota or water quality. The goal in managing Region 3 is to protect the aquatic community, while allowing limited and controlled plant use of this segment.

A stream-management policy for UTRC was submitted to DOE for review and approval in October 1987. This policy has been given to DOE with the recommendation that it be adopted for sitewide use by all SRS contractors. Prior to any new discharge to UTRC, the EPD must approve the discharge through AITG action that includes input from EPD, the custodial department proposing the discharge, and AITG. If AITG gives its approval, a program to assess the impact on the stream is developed. The DOE-ED reviews AITG recommendations and makes the final decision. This mechanism was used to obtain approval of the projected discharge of the F/H Area Effluent Treatment Facility (ETF) effluent into UTRC near F Area.

\section{Programs}

\section{Stream Management Program}

EPD is responsible for coordinating the stream-management program with the operating departments and SRTC. SRS's stream-management program supports a policy of using onsite streams, while maintaining water quality and ecological resources.

The goals of the program are the following:

- define existing stream quality and uses

- develop a management plan for each onsite stream considering existing and desired uses

- develop guidelines for assessing stream quality (chemical and biological)

- assess effects of point-source discharges on streams and the Savannah River

- optimize effluent discharges and associated processes to minimize impact on streams and the Savannah River and to protect desired uses

- develop a basis for negotiating NPDES permit limits (monitoring, modeling, etc.)

To meet these goals, available monitoring data to establish existing water quality in SRS streams has been surveyed. Further work will include developing guidelines for aquatic toxicity testing at the SRS and developing dilution and transport models for predicting outfall impacts on SRS streams.

ESS will continue to assist in decision-making on all proposed changes to the stream-management program. ESS also provides continued technical guidance and assessment on environmental-specific issues associated with onsite streams. Programmatic support of ESS in stream management will be provided in the future as required for chemical limnology, toxicology, and aquatic ecology. 
EPD has the lead in completing a chlorine data assessment of effluent wastewater from domestic water systems, reactor-effluent cooling water, cooling towers, sanitary-waste treatment plants, and other noncontact cooling water. Operations departments are continuing to develop treatment programs and options for managing chlorine, disinfectants, corrosion inhibitors, and biocides in their systems. A "feed forward-feed back" system is being implemented for chlorine control at the K-Reactor natural draft cooling tower. Additional outfall-specific program needs are being assessed and will be defined and implemented to address conditions in the renewed NPDES permit.

\section{Technical Support}

ESS is conducting toxicity studies (Toxicity Steering Committee) and chlorine/bromine research.

ESS has completed a study on the concentrations of residual chlorine in SRS streams related to the chlorination of effluents from the sanitary-waste treatment plants. Results from these studies indicate that chlorinating these effluents is not necessary and could be discontinued if proposed fecal coliform monitoring instream is approved by SCDHEC. These results were sent to SCDHEC for review. Considerations for reducing residual chlorine have been incorporated into the recirculating cooling tower design. Additional studies include the effects of process and nonprocess effluents on receiving waters. ESS chairs the SRS Toxicity Steering Committee that provides oversight and issue resolutions for discharge toxicity questions. In 1991, ESS completed a program to test SRS outfalls for acute and chronic toxicity.

ETS will continue to develop special equipment for sampling SRS streams and the river. Battery-powered remote water samplers are deployed in site streams and the Savannah River to monitor trace radionuclides in transport. An on-line tritium breakthrough monitor was developed and deployed at the K Reactor outfall. Advanced monitors are under development and will be placed in the field to monitor concentrations in the ETF and 400-D rework facility effluents. A large underwater Nal gamma detector has been installed at S. C. Highway 301 on the Savannah River. Data loggers that record data on water level and water quality are used in site streams. ETS provides near realtime flow in streams monitored by USGS, and additional data can be obtained from the wire services of the National Weather Service and the USGS.

ETS develops and uses stream/river transport models for estimating downstream/river concentrations of pollutants, both radiological and nonradiological, resulting from accidental releases. The same models have been used for assessments to determine if certain planned releases will exceed stream/river concentration guides. The models are a one-dimensional description of conservative stream transport and are verified using tracers in the streams. Stream transport coefficients recently were remeasured in 1991, and in the near future, an advanced stream/river transport model will be developed. 


\section{Thermal Mitigation}

(Compiled and reviewed by Keith W. Dyer)

\section{Site Program Overview}

The site is required by a SCDHEC consent order to mitigate the heated water discharges from K Reactor. The Record of Decision issued February 12, 1988, selected a recirculating cooling system for the mitigation of heated effluents from $K$ Reactor. The construction of this system was approved by South Carolina, and an NPDES permit (No. SC0044903) was issued October 25, 1990, establishing effluent-quality limits for the cooling system subsequent to its completion by December 31, 1992. A Clean Water Act Section 316(a) demonstration will be completed following commencement of the $\mathrm{K}$ Reactor cooling tower. The demonstration will be performed to validate a variance granted with South Carolina Water Quality Stream Standards for thermal discharges, which restricts the rise in receiving streams temperature to no more than 5 degrees Fahrenheit. Heated water from $P$ and $L$ reactors is discharged into Par Pond and $L$ Lake, respectively. Studies show that Par Pond, built in the early 1950s, supports a balanced biological community, and L Lake, completed in 1985, is developing a balanced biological community. Concerns, however, that some fish mortalities have occurred in these receiving waters, resulting from recommencing reactor operations following extended outages, prompted South Carolina to enter into a Settlement Agreement requiring the site to eliminate these impacts by implementing an approved remedial-action plan. In February, 1991, DOE published a Record of Decision deferring indefinitely the restart of the $\mathrm{L}$ and $\mathrm{P}$ reactors by placing one in the warm standby mode and the other in the cold standby mode. Approval was received from South Carolina December 10, 1991, effectively deferring any further implementation of the Fish Kill Remedial Action Plan, pending a decision to restart either $L$ or $P$ reactors. SRS has committed to and initiated restoration of parts of the cypress-tupelo swamp bordering the site which previously were impacted by heated-effluent discharges into site streams.

\section{Justification/Regulatory Requirements}

\section{Federal Laws}

The Federal Water Pollution Control Act (Water Quality Act of 1987) reauthorized and strengthened the Federal Water Pollution Control Act (commonly known as the Clean Water Act). The Water Pollution Control Act requires that discharges to navigable waters meet applicable thermal limitations or demonstrate a balanced indigenous, population.

Executive Order 12088 requires federal agencies to comply with applicable administrative and procedural p. Jllution-control standards established by federal laws. 


\section{South Carolina Standards}

South Carolina Water Classification and Standards (SCDHEC 61 68) require that all SRS navigable waters meet fresh-water quality standards. The standards require that discharges to receiving streams be $90^{\circ} \mathrm{F}$ or less, or not cause ambient temperatures to increase by more.

\section{State Consent Orders/Memorandum of Understanding}

CO-84-4-W (Thermal Mitigation) - In a consent order dated January 3, 1984, DOE and SCDHEC mutually agreed to supersede temporarily the NPDES temperature requirements. This agreement was amended in 1985, 1987, and 1988. The consent order also required DOE to assess the impact of SRS thermal discharges on site streams, lakes, and the Savannah River and to install facilities to mitigate thermal discharges from the $\mathrm{D}$ Area Powerhouse and the $\mathrm{C}$ and $\mathrm{K}$ reactors. The consent order was amended in August 1987 to exclude the shuidown C Reactor and to establish a new compliance schedule.

\section{Organizational Responsibilities Summary}

EPD is responsible for coordinatung compliance activities at the SRS for DOE. EPD stays abreast of thermal-mitigation studies and regulatory concerns, and facilitates communication between SCDHEC, DOE, research, and operating groups. EPD also is working with the operating groups to negotiate permits and achieve compliance for minor thermal (non-reactor) discharges.

ESS is respoussible for assessing the environmental effects of the intake and release of reactor and D-Area Powerhouse ccoling water on onsite stream systems and the Savannah River. This study was completed in 1990 and submitted to SCDHEC. A Comprehensive Cooling Water Study (CCWS), assessing the impacts of thermal effluents to site waters, was completed in early 1988. An L-Lake 316(a) demonstration study has been completed and submitted to SCDHEC to satisfy terms of the NPDES permit for L-Reactor thermal discharge. Predictive 316(a) information on the $\mathrm{C}$ and $\mathrm{K}$ reactor cooling water systems and powerhouse discharges was included in the ESROD. The ESS also is conducting an extensive monitoring program of biological and chemical constituents in L-Lake and Sieel Creek ecosystems. SCDHEC approved the K-reactor cooling tower 316(a) demonstration work plan developed by ESS; this program will be implemented following the initiation of cooling tower operations.

The ESS is the lead technical organization at the SRS in the development and use of remote sensing techniques.

ETS has developed systems capable of predicting the thermal effects of reactor cooling-water effluents on site surface waters. From LANDS multispectral data, thermal releases into bodies of water can be estimated accurately. 


\section{Power Operations}

An NPDES permit for powerhouse-condenser effluents limits the temperature of the water discharged to Beaver Dam Creek to $90^{\circ} \mathrm{F}$ and the temperature rise to $5^{\circ} \mathrm{F}$. The temperature limit may be exceeded by a few degrees during the summer months at the specified NPDES monitoring location. A consent order between DOE and SCDHEC has allowed D-Area powderhouse to continue to operate. An EIS has been prepared and a mitigation alternative selected.

The temperature of the discharge water can be maintained below $90^{\circ} \mathrm{F}$ by selectively increasing the river water flow pumped from the 681-5G pumphouse. This method of thermal mitigation has been approved by SCDHEC. No additional manpower requirements are needed to implement this thermal-mitigation procedure. No initial capital costs are involved.

A 316(a) demonstration study is being conducted in Beaver Dam Creek to verify that a temperature differential between the Savannah River and outfall D-001 in excess of $5^{\circ} \mathrm{F}$ will not jeopardize the biological balance in the Beaver Dam wetlands. The formation of a 1000-acre cooling pond in 1985 for L-Reactor startup was a condition of the Final Environmental Impact Statement, L Reactor Startup. L Lake receives the heated-effluent cooling water during reactor operation. The overflow from the L-Lake dam follows the Steel Creek channel into the Savannah River. The temperature limit of $90^{\circ} \mathrm{F}$ for Class B waters applies to 50 percent of the lake's surface area.

This criterion cannot be met during summer months in a cost-effective manner, considering the constraints the temperature limit places on reactor-power levels. During reactor operation, the reactor-power levels are lowered to prevent temperature noncompliances at $\mathrm{L}$ Lake. Production schedules call for $\mathrm{L}$ Reactor to be placed in a warm standby mode.

The current NPDES permit specifies that the temperature limit is enforceable in streams after mixing. Currently, temperatures are measured at the NPDES sample points, which often are far upstream from the mixing zones. Five power Department outfalls with minor thermal influence have had problems in the past meeting the NPDES temperature limit of $90^{\circ} \mathrm{F}$ at their NPDES sample points. These outfalls currently are being monitored at both the recognized sample points and downstream locations. With data obtained from this monitoring, alternative methods or locations for NPDES temperature sampling will be proposed to SCDHEC. In cases where there is insufficient data, additional time will be requested to study the effluent behavior.

\section{Reactors}

Reactors supplies $\mathrm{P}$ - and L- reactors operating data to SRTC for inclusion in thermal studies relating to L Lake and Par Pond. 


\section{Reactors}

Reactor Effluent Cooling Thermal Mitigation - Reactors, and SRTC implemented a thermal mitigation plan to maintain the $\mathrm{K}$-Reactor heated-water discharge temperatures below the $90^{\circ} \mathrm{F}$ NPDES permit requirements. A once-through, gravity-fed, natural-draft recirculating cooling tower was constructed. Construction was completed in December 1992.

The L Lake Secondary Supply project will provide a supply of water to L Lake independent of flow through the 105- $\mathrm{L}$ Building. This secondary supply's to enter $\mathrm{L}$ Lake separate from the normal flow from 105-L with a capacity to meet SCDHEC's minimum seasonal flow criteria for Steel Creek below L Lake and to maintain L-Lake level criteria during cooling-water outage in L Area.

\section{Technical Support}

\section{$K$ and D Area Studies}

ESS developed environmental information packages which include predictive 316(a) information to support the Alternative Cooling Water Systems EIS. The EIS addressed the thermal discharges from $\mathrm{K}$ Reactor and the D-Area powerhouse. This information is useful for determining what effects potential temperature exceptions will have on water quality and aquatic ecology of the receiving water. Simulated temperature models of onsite streams are being used to determine the effluent discharge temperatures following mitigation of the reactor and powerhouse heated effluent water. The EIS related to Beaver Dam Creek, Four Mile Creek, and Pen Branch has been completed. Predictive 316(a) data on the preferred altemative are included in the EIS. A complete predictive 316(a) demonstration for the K-Reactor recirculating cooling tower was submitted in 1989. A work plan for conducting the 316(a) demonstration for the cooling tower was approved by SCDHEC and will be implemented following initiation of cooling tower operations. 


\section{NPDES: Wastewater}

(Compiled and reviewed by Randy W. Weigel)

\section{Site Program Overview}

All operational effluents from SRS facilities discharge through point-source outfalls. Discharges from the outfalls are regulated by SCDHEC under NPDES. Currently, there are 76 permitted outfalls at SRS under NPDES Permit SC0000175 and 5 permitted outfalls under NPDES Permit SCO044903. The permit SCO000175 was issued on January 1, 1984, and a renewal application was submitted in June 1988. Permit renewal is pending action by SCDHEC. The permit SC 0044903 was issued on October 25, 1990, and expires on November 30, 1995. SCDHEC routinely does not issue duplicate permits to an individual permittee. SRS required the second permit to meet regulatory requirements for completing certain construction projects. Compliance performances for the last eight years were: $1985,98.8$ percent; 1986 , 99.4 percent; 1987, 99.7 percent; $1988,99.8$ percent; $1989,99.9$ percent; $1990,99.8$ percent; 1991, 99.9 percent; and 1992, 99.9 percent.

\section{Five-Year Outlook}

It is anticipated that SCDHEC will renew the $\$ C 0044903$ permit in 1993 to include all outfalis on permit SCO000175. Approximately 10 outfalls will be eliminated in the new permit since they are no longer discharging. Other outfalls will be combined to reduce the costs associated with monitoring requirements. The Clean Water Act was scheduled to be reauthorized in 1992; however, Congress decided to delay the Reauthorization Act until 1993. A draft reauthorization plan indicates that a pollution plan may be required to reduce toxic and hazardous constituents in wastewater, to reduce discharges into waters of the state either by reuse or alternative methods of treatment, and to establish zero discharge limits for certain substances. The NPDES self-monitoring program is administered by SRS personnel with analytical work done by a subcontractor lab. To reduce costs, EMS plans to do some of the analytical work. They plan to develop resources and capabilities in-house to request certification by South Carolina for a laboratory in Building 735-11A.

\section{Justification/Regulatory Requirement}

\section{Federal Laws}

Federal Water Pollution Control Act (Water Quality Act of 1987) requires DOE to obtain applicable permits before treating waste and discharging it into United States waters.

Under Section 402, a NPDES permit is required. EPA has granted this regulatory authority to South Carolina. 
In complying with the provisions of the NPDES permit, the site achieves the following objectives: compliance with SCDHEC Permit SC0000175 and SC0044903, and thus, with the Federal Water Pollution Control Act; and compliance with maintaining site stream-water quality criteria and/or stream-specific guides.

Based on 40 CFR 122, 123, 124 NPDES Permit Regulations for Storm Water Discharges, all SRS industrial-related facilities that discharge storm water through point sources were required to submit NPDES permit applications to SCDHEC by Octoher 1,1992 . The objective of the storm-water rule is to stop degrading of U.S. waters by applying best available technology and best management practices to control pollutants from entering storm-water runoff.

Once SCDHEC promulgates their own storm-water regulation, SRS will be required to comply, with possible additional permitting and monitoring.

Executive Order 12088 - see description in the implementation section on Thermal Mitigation.

\section{Organizational Responsibilities Summary}

\section{Environmental Protection Department}

The NPDES permit is administered on a sitewide basis by EPD/ESS. EPD provides support for permit applications, modifications, and compliance. EMS and Power Operations oversee compliance sampling and analysis. Each outfall has an assigned custodian who is responsible for ensuring that the outfall meets permit parameters. EMS and Power Operations are responsible for scheduling compliance sampling of outfalls as directed by EPD per NPDES permit requirements. State and EPA audit samples are taken on a less frequent basis. EMS takes parallel samples for comparison. EMS also oversees compliance sampling and analysis during the NPDES permit-renewal process. Outfall custodians are responsible for supplying EPD with information needed for permitting support.

\section{Site Procedures and Documents}

EPD/ESS maintains sitewide procedures for obtaining NPDES permits and modifications. The WSRC $3 Q$ Environmental Compliance Manual, Sections 2.1 and 2.6, currently under revision, outlines the permitting process and requirements related to construction or modification of wastewater-collection or treatment systems or NPDES discharges. The WSRC-IM-91-69 How Manual provides detailed instructions for preparing NPDES permit-application packages for new discharges or for modifying existing discharges. These procedures establish the permitting process and delineate responsibilities from the conceptual design phases of a project until the receipt of a NPDES permit for a wastewater discharge. EPD/EMS maintains a sitewide procedure for compliance sampling of NPDES outfalls. This procedure is contained in the WSRC-3Q1-3 Manual under Section 3340. This procedure provides instructions to Environmental Sampling personnel for NPDES outfall compliance monitoring. In 
addition to the procedures that EPD maintains, each SRS operating department maintains procedures which reflect requirements included in the NPDES permits.

\section{Permit Renewal}

A permit-renewal application was submitted to the SCDHEC in June 1988 for permit SC0000175. The new NPDES permit is expected to be issued in 1993. It is anticipated that SCDHEC will place the 76 outfalls from the SCO000175 permit into the SC0044903 permit.

\section{NPDES Permit Compliance Programs}

\section{Construction Management}

Construction Management has two outfalls, S-002 in Central Shops and DW-002 in $S$ Area. Construction Management plans to stop processing liquid waste through the oil/water separator and its subsequent discharge to DW-002 when DWPF construction is completed. SRS management will have to designate a custodian for the operation at that time. Construction Management administratively has closed the S-Area Batch Plant Pond (SCDHEC permit \#10,955 and also subsequently eliminates the adjoining outfall DW-001). These outfalls are sampled by EMS and analyzed for compliance parameters.

\section{Central Services Works Engineering (CSWE)}

CSWE has a program to monitor the A-005 outfall in according to DPSOL 7-1005.

\section{Defense Waste Processing Facility (DWPF)}

The DW-004 outfall is inspected daily, and effluent is sampled as needed. Nonroutine samples will be analyzed in-house. Compliance sampling and analysis will be done by EMS.

\section{Environmental Monitoring Section (EMS)}

EMS is responsible for collecting and analyzing monthly compliance samples from site NPDES outfalls. Collection procedures are outlined in WSRC 3Q 1-3. Currently, samples are collected by EMS and analyzed by an offsite, certified subcontractor and onsite laboratories. EMS maintains the site NPDES database and reports results to EPD in the format required by SCDHEC. In addition to routine compliance sampling, EMS collects parallel samples during SCDHEC compliance audits and has them analyzed. 
To consolidate NPDES activities onsite, the EMS recently has equipped laboratories in the newly constructed Building 735-11A. DPSOP 271-6 will document the analytical procedures for NPDES samples. A stepwise approach to state certification and onsite analysis is planned. The first phase, certification and testing for metals and solids, is planned for 1994. One additional analyst will be required for this effort.

The next phase will be certification and testing for parameters such as nitrate, sulfate. and oil and grease. This effort is planned for 1995 and will require additional personnel and funding. The final phase will be certification and testing for organic constituents. This phase also is planned for 1995 and will require additional personnel and funding.

\section{Environmental Protection Department (EPD)}

EPD has the administrative oversight responsibility for the NPDES permit. EPD monitors site performance under the permit, prepares required regulatory reports, assists the custodial departments with permit modifications, and is the operating contractor contact with DOE and SCDHEC.

\section{Power Operations}

Process-control sampling is performed to provide trend analysis data for all Power Operations outfalls. A minimum of two samples per week are taken from each permitted outfall. Data then is provided to outfall custodians on a monthly and bi-annual basis to perform trend analyses and characterize each discharge stream relative to area processes and discharge limits. Power Operations coordinates with EPD to prepare information for new permit applications and the justification to revise existing limits.

The historic 784-A powerhouse waste-stream effluents which used to flow to Outfall A-008 consisted of discharges from the wet ash scrubber, process cooling water, service and domestic water-tank overflows, well blow off, boiler blowdown, washdown water, and the coal unloading sump. The wet ash scrubber discharge and the washdown water contain high levels of suspended solids. These effluents were diverted and are being trucked to the D-Area ash basin. Domestic water-tank overflows temporarily are discharged to the Outfall A-008 until a treatment system employing a bag house can be installed. NPDES Permit SC0044903 includes two new outfalls for the powerhouse effluents. Outfall A-028 includes powerhouse wastewater, water from floor drains, cooling water and well-flush water. Outfall A-029 will discharge well-flush water and tank overflow water that currently is discharged to A-008. After completing this projech, no powerhouse effluents will discharge through Outfall A-008. 
Reactor Materials (RM)

The Reactor Materials Department releases effluent from the Dilute Effluent Treatment Facility (DETF) to Outfall M-004 and from the Project Air Stripper (PAS) to Outfall M-005. Both of these outfalls flow to Outfall A-014. Each process batch from DETF is sampled by RM and analyzed by SRTC prior to release to ensure compliance with NPDES permit limits. The outfalls (M-004, M-005, and A-014) also are sampled and analyzed weekly by EMS. Total mass for many of the constituents at the M-004 outfall are specified in the NPDES permit and are calculated based on the concentration analyses and measured flow rate. The PAS influent and effluent are monitored quarterly for all priority pollutants as a condition of the NPDES permit. The analytical results and mass calculations are compiled by WM\&ER and EPD, and issued as a portion of the monthly NPDES Discharge Monitoring Report.

An NPDES permit was granted to discharge treated groundwater through Outfall A-001A, the "prototype air stripper", located behind the SRTC complex. Another air stripper is planned for the area and will discharge through Outfall A-001B upstream of Outfall A-001.

\section{Reactors}

Reactor Department (RD) NPDES outfalls consist of storm-water runoff and in some cases heat exchanger cooling-water flow. Therefore, only monthly EMS compliance samples are analyzed routinely. Nonroutine discharges to the outfalls are analyzed prior to release. Records of all sample data are maintained in each reactor facility. RD personnel provide a visual inspection of the following items at each outfall at least monthly: grass cutting, headwall grating, flow weir, platform safety, and current signs. Construction of the K-Reactor natural-draft cooling tower was completed during Deceniber 1992, per the SCDHEC consent agreement.

\section{Separations}

The current Separations program includes daily $\mathrm{pH}$ monitoring for process control purposes by operations at the five Separations outfalls. EMS takes samples monthly for NPDES compliance. Data is analyzed for trends and process-control records are maintained by Separations.

\section{SRTC - Tech Area}

The Laboratory Services Section's effort to ensure compliance with Outfall A-001 NPDES permit limitations includes maintaining administrative controls on releases via written procedures, evaluating unusual discharges and submitting new permit applications to SCDHEC through EPD and DOE. EMS samples monthly for NPDES compliance. 


\section{SRTC.TNX}

TNX activities for ensuring compliance with the site NPDES permit currently consist of maintaining administrative controls on releases to the five active permitted outfalls (one from the sanitary treatment plant is under Power Department custodianship), evaluating unusual discharges, and submitting new permits and modifications to existing permits to SCDHEC via the EPD and DOE. Most sampling of TNX outfalls is performed by EMS.

Process-control samples are taken at the facility which generates the effluent to verify compliance. TNX is responsible for coordinating with EMS and EPD to ensure that testing is performed and analytical results are reviewed.

\section{Tritium}

The Tritium Department is responsible for ensuring that monthly compliance samples taken from NPDES Outfall $\mathrm{H}-002$ (by the EMS) comply with permit limits. A subcontractor takes weekly process-control samples for the Tritium Department and analyzes the samples for permit parameters. The process-control sampling program is a means of detecting trends leading to potential problems with the effluent waters from tritium facilities.

\section{Waste Management (WM)}

The WM Department has custodianship of seven outfalls. WM obtains periodic process-control samples for $\mathrm{pH}$, chlorine, and other parameters. Outfall $\mathrm{H}-006$ receives storm water and Outfall $\mathrm{H}-007$ receives cooling tower water and storm water. The outfalls are sampled monthly by EMS for NPDES compliance. The F/H ETF added five outfalls at the end of 1988 from the following:

- F Area retention basin/cooling water basin (F-012, F-013)

- H Area retention basin/cooling water basin (H-017, H-018)

- F/H ETF process water outfall to Upper Three Runs Creek (H-016) 


\section{Technical Support}

\section{Temperature and Flow Monitoring}

The United States Geological Survey (USGS) is responsible for maintaining 52 stream gauging stations which monitor flow and temperature for NPDES compliance. The USGS is under contract with DOE to provide state-certified data to SRS that is submitted to SCDHEC in the monthly Discharge Monitoring Reports. The monitoring stations are in locations representative of the discharges which occur from many NPDES outfalls.

\section{Outfall Characterization}

The EPD initiated an inventory to locate the influent sources, the location and condition, and the receiving waters of each outfall to validate the information in the NPDES permit application; to update the existing SRS Area Drainage Systems manual (DPSP-81-1045) to reflect new construction and other changes in the operational areas; and to develop a sampling program to comply with the requirements of the NPDES storm-water regulations. Each outfall was inspected and influent streams were traced physically to their sources. Available drawings provided guidance. Operations personnel assisted by providing personal process knowledge, attending the walkdowns, providing information not available on drawings, and referring the project members to other information sources. A.rea drainage maps are being entered into the Sight Configuration Control Map Atlas database and will be available for site use during 1993.

\section{Biological Monitoring, Assessment, and Reduction}

South Carolina Regulation 61-68, Stream Classifications and Standards, includes limits for toxic substances discharged into streams. SCDHEC has indicated that aquatic toxicity testing may be imposed in the renewed NPDES permit. Eighteen outfalis have been identified by SCDHEC for initial acute and chronic testing: A-001, A-003, A-011, A-014, A-015, B-007, C-004, CS-011, D-001, F-003, F-008, H-012, H-015, H-016, K-006, P-019, S-004, and X-008. EPD formed a Toxicity Steering Committee (TSC), consisting of representatives of operating organizations and SRTC. The committee was formed to gather input from SRS organizations to develop a wastewater toxicity-reduction program and to provide administrative assistance to sitewide organizations while working with the program. The committee is comprised of members knowledgeable in chemistry, toxicology, regulatory affairs, hazardous-waste management, waste minimization, and environmental management.

SCDHEC procedures also would stipulate that when a toxicity test failed, a Toxicity Identification Evaluation (TTE) would be initiated within 60 days to identify the cause and determine a corrective action. SRTC is responsible for administering a TIE subcontract for SRS. The $\$ 6$ million unit price subcontract will be made available to 
SRS organizations (anticipated to be in place by June 1993) to order to identify sources of effluent toxicity.

Other key elements in the toxic-control strategy will include using fewer toxicants. screening for alternatives, incorporating inventories of toxicants being used into purchasing to prevent these products from entering the site and later being discharged. reviewing their proper storage, identifying any waste eligible for recycling or closed-loop reuse systems, reviewing erosion-control programs to prevent the migration of toxic chemicals, training employees, educating commercial vendors on the proper use of products containing toxins (pesticides, fertilizers, cleaners, etc.), and discouraging illegal dumping of toxic chemicals into drains, sewers, or waterways.

An effective wastewater toxic-control strategy will ensure that SRS is meeting state water classifications and standards, reduce potential liabilities, protect public health and worker safety, reduce long-term liability and remediation costs from bioaccumulative toxic substances, and promote favorable public opinion toward SRS's mission.

The ESS has completed a study to determine the toxicological characteristics of surface water effluents discharged from site NPDES outfalls. Fifty-two of the 64 outfalls were surveyed at least once between March and October 1985. ESS repeated the toxicity screening in 1991.

Specific toxicity tests also have been conducted on the new M-Area effluent-treatment facility discharges. Similarly, a biotoxicity testing program has been completed for the effluent from the F/H-Area Effluent Treatment Facility (F/H ETF).

\section{One-Year Road Map}

During 1993, the NPDES outfalls will be retested for acute and chronic toxicity, starting with the 18 outfalls that SCDHEC anticipates required monitoring in the new permit. The wastestream characterizations also are scheduled for completion during 1993. The TIE subcontract is anticipated to be placed by mid-1993.

\section{Five-Year Road Map}

During the next five years, the toxicity-reduction program will be written formally and included in SRS's Best Management Plan. It may be required, instead, to be included in PPP when the Clean Water Act Reauthorization is finalized. The NPDES outfalls and other contributing wastewaters periodically will be retested for toxicity. EPD/ESS is planning on providing a program coordinator responsible for continued development and implementation. 


\section{NPDES Storm Water Associated with Industrial Activity}

(Compiled and reviewed by Joe K. Price)

\section{Site Program Overview}

The Clean Water Act says that storm-water discharges associated with industrial activity from a point source to United States water are prohibited, unless authorized by a NPDES permit.

During September 1992, SCDHEC was given authority by EPA to issue general permits. On September 9, 1992, EPA promulgated the NPDES General Permit Rule for Storm Water Discharges Associated with Industrial Activity. SCDHEC followed by promulgating their own NPDES general permit rule for industrial-related storm-water discharges.

The Environmental Protection Department (EPD) submitted a Notice of Intent (NOI) to be covered by the SCDHEC NPDES industrial general permit on September 28, 1992. Submittal of a NOI requested SCDHEC to include all industrial related storm-water discharges at SRS under the state's NPDES General Permit.

Five-Year Outlook

The NPDES general permitting program is fairly unique in that it gives the site the opportunity to address and solve potential storm-water pollution conditions with minimum state govermment involvement. SRS will continue to monitor storm-water discharges and implement best management practices (BMP) and best available technology (BAT) where needed to mitigate the impact of SRS's storm-water runoff. As long as the BMPs and BATs are effective, coverage under the general permit will continue. Where BMPs and BATs are ineffective, as indicated by water-quality problems, individual permits will be required. This will increase state government involvement in the sites storm-water management program.

\section{Justification/Regulatory Requirements}

The Federal Water Pollution Control Act (Water Quality Act of 1987) prohibits discharging any pollutant from a point source unless the discharge is authorized by a NPDES permit.

40 CFR 122, 123, 124 "NPDES Permit Regulations for Storm Water Discharges", says industrial-related facilities that discharge storm water through point sources must be covered by an NPDES permit.

The South Carolina Pollution Control Act (Title 48, Chapter 1) requires DOE to comply with applicable South Carolina environmental regulations. 
Under this act, SRS is required to permit storm-water discharges associated with industrial or construction activities. The enactment of the NPDES general permits allows SRS to be covered under the states generic permit for storm-water discharges.

\section{Organizational Responsibilities Summary}

The NPDES Storm Water Industrial General Permit is administered on a sitewide basis by ESS. ESS will provide guidance for storm-water discharges where BMPs and/or BATs are deemed necessary to meet water-quality standards. EPD is managing a subcontractor in developing industrial facility-specific PPPs. It is the facility custodian's responsibility to supply the subcontractor with all information requested for developing the PPP, ensuring its accuracy and implementing the plan. EMS will monitor selected outfalls, as required in the general permit. Facility custodians must maintain the outfall for collecting representative samples in accessible and safe locations. Once monitoring data is accumulated. EPD will supply the data to facility custodians to implement BMPs and/or BATs. EPD must submit discharge monitoring reports, as required by the permit.

\section{Site Procedures and Documents}

Site procedures or documents currently are being developed to ensure compliance with the new storm-water regulations.

\section{Programs}

General permit requirements include the following:

- Pollution Prevention Plan (PPP):

SRS must develop a PPP by April 1, 1993, and implement it by October 1, 1993. The PPP is intended to facilitate a process where the site evaluates potential pollution sources and selects and implements appropriate measures to prevent or control the pollutants discharged of in storm-water runoff. The plan must include the following: designation or identification of a pollution prevention team, identification of potential pollution sources, pollution prevention measures and controls, and a comprehensive site compliance evaluation.

The general permit establishes special requirements for facilities required to report under Section 313 of the Emergency Planning and Community Right to Know Act (EPCRA). Under the general permith Section 313 reporting facilities are required to identify the areas where these materials are stored, loaded, or used, and the structural and non-structural controls in place to prevent this material from being discharged with storm-water runoff.

Developing PPP will be a cooperative effort between EPD, facility custodians, and selected subcontractors. 
- Storm-Water Monitoring and Reporting:

The general permit targets specific industrial activities at SRS for monitoring as summarized in the following table.

GENERAL PERMIT MONITORING REQUIREMENT

\begin{tabular}{|c|c|c|c|c|}
\hline $\begin{array}{l}\text { Type of } \\
\text { Facility }\end{array}$ & $\begin{array}{l}\text { Type of Storm-Water } \\
\text { Discharge }\end{array}$ & Parameters & $\begin{array}{l}\text { Monitoring } \\
\text { Frequency }\end{array}$ & $\begin{array}{l}\text { Reporting } \\
\text { Frequency }\end{array}$ \\
\hline $\begin{array}{l}\text { EPCRA. Section } \\
313 \\
\text { Facilities Subject to } \\
\text { Reporting } \\
\text { Requirements for } \\
\text { Water Priority } \\
\text { Chemicals }\end{array}$ & $\begin{array}{l}\text { Storm-water discharges that come in } \\
\text { contact with any equipment, tank. } \\
\text { container, or other vessel or area used } \\
\text { for storage of a Section } 313 \text { water } \\
\text { priority chemical. or located at a } \\
\text { truck or rail car loading or unloading } \\
\text { area where a Section } 313 \text { water } \\
\text { priority chemical is handled }\end{array}$ & $\begin{array}{l}\text { Oil and Grease, BOD5, COD, TSS, } \\
\text { Total Kjeldahl Nitrogen, Total } \\
\text { Phosphorus, pH, acute Whole } \\
\text { Effluent Toxicity, any Section } 313 \\
\text { water priori.y chemical for which the } \\
\text { facility reports }\end{array}$ & $\begin{array}{l}\text { Semi- } \\
\text { annual }\end{array}$ & Annual \\
\hline $\begin{array}{l}\text { Land Disposal } \\
\text { Unitsi Incinerators/ } \\
\text { Boiler and Industria } \\
\text { Fumaces (BIFs) }\end{array}$ & $\begin{array}{l}\text { Storm water discharges from active } \\
\text { or inactive land disposal units } \\
\text { without a stabilized cover that have } \\
\text { received any waste from industrial } \\
\text { facilities other than construction } \\
\text { sites; and storm water discharges } \\
\text { from incinerators and BIFs that burn } \\
\text { bazardous waste }\end{array}$ & $\begin{array}{l}\text { Ammonia, Total Recoverable } \\
\text { Aagnesium, Magnesium (dissolved), } \\
\text { Total Kjeldahl Nitrogen, COD, TDS, } \\
\text { TOC. Oil and Grease, pH. Total } \\
\text { Recoverable Arsenic, Total } \\
\text { Recoverable Barium. Total } \\
\text { Recoverable Cadmium. Total } \\
\text { Rer sverable Chromium. Total } \\
\text { Cyanide. Total Recoverable Lead, } \\
\text { Total Mercury, Total Recoverable } \\
\text { Selenium. Total Recoverable Silver. } \\
\text { Acute Whole Effluent Toxicity }\end{array}$ & $\begin{array}{l}\text { Semi- } \\
\text { annual }\end{array}$ & Annual \\
\hline $\begin{array}{l}\text { Coal-fired Steam } \\
\text { Electric Facilities }\end{array}$ & $\begin{array}{l}\text { Storm water discharges from coal } \\
\text { handling sites (other than runoff from } \\
\text { coal piles which is not eligible for } \\
\text { coverage under this permit) }\end{array}$ & $\begin{array}{l}\text { Oil and Grease, pH, TSS, Total } \\
\text { Recoverable Copper, Total } \\
\text { Recoverable Nickel. Total } \\
\text { Recoverable Zinc }\end{array}$ & Annual & $\begin{array}{l}\text { Retain } \\
\text { onsite }\end{array}$ \\
\hline $\begin{array}{l}\text { Oil-fired } \\
\text { Steam Electric } \\
\text { Power Generating } \\
\text { Facilities }\end{array}$ & $\begin{array}{l}\text { Storm water discharges from oil } \\
\text { handling sites }\end{array}$ & $\begin{array}{l}\text { Oil and Grease, COD, TSS, pH, any } \\
\text { pollutant, anited in an effluent } \\
\text { guideline to which the facility is } \\
\text { subject }\end{array}$ & Annual & Retain onsite \\
\hline $\begin{array}{l}\text { Chemical and } \\
\text { Allied Troducts } \\
\text { Manufacturers SIC } \\
28\end{array}$ & $\begin{array}{l}\text { Storm water discharges that come } \\
\text { into contact with a material storage } \\
\text { area }\end{array}$ & $\begin{array}{l}\text { Oil and Grease, COD. TSS, pH, any } \\
\text { pollutant limited in an effluent } \\
\text { guideline to which the facility is } \\
\text { subject }\end{array}$ & Annual & $\begin{array}{l}\text { Retain } \\
\text { onsite }\end{array}$ \\
\hline $\begin{array}{l}\text { Oil fured Steam } \\
\text { Electric Power } \\
\text { Generating } \\
\text { Facilities }\end{array}$ & $\begin{array}{l}\text { Storm water discharges from oil } \\
\text { handling sites }\end{array}$ & $\begin{array}{l}\text { Oil and Grease. COD. TSS, pH, any } \\
\text { pollutant timited in an effluent } \\
\text { guideline to which the facility is } \\
\text { subject }\end{array}$ & Annual & $\begin{array}{l}\text { Retain } \\
\text { onsite }\end{array}$ \\
\hline
\end{tabular}

All samples must be collected from the discharge resulting from a significant storm event greater than 0.1 inches in magnitude and occurring at least 72 hours after the previous significant storm event. For all monitored discharges, data must 
be collected for both a grab sample taken during the first 30 minutes of discharge and a flow- or time-weighted composite. A composite is not required for discharges from a holding pond or impoundment with a retention period greater than 24 hours.

A discharge monitoring report shall be submitted to SCDHEC annually for SRS facilities required to monitor on a semiannual frequency.

The general permit allows permittees to group substantially identical outfalls to reduce the monitoring burden. However, facilities that choose this approach must include a written justification why one outfall is representative of others in the facility PPP.

EPD and the facility custodian will determine the outfalls and monitoring requirements that will necessitate monitoring under the general permit. EMS will monitor storm water discharges at selected outfalls.

- Monitoring Alternatives:

A facility that is required to monitor its effluent for whole effluent toxicity (WET) may chose to monitor for all pollutants that are known or it has reason to believe are present at the facility. Due to the cost, and the unpredictability of storm water monitoring, it is the EPD's opinion that SRS adopt this altermative.

Also, a facility is not subject to monitoring if that the facility manager writes a certification statement, on an annual basis, for a given outfall. Under penalty of law, material-handling equipment or activities, raw materials, intermediate products, final products, waste material, by-products, industrial machinery, operations or significant materials from past operation, are not exposed presently and will not be exposed to storm water during the certification period.

\section{Technical Support Programs}

Technical support programs will be developed where identified to support the storm-water program.

One-Year Road Map

Storm-water discharge monitoring reports (DMR) must be submitted to SCDHEC after October 1, 1993.

The PPP is required to be developed by April 1, 1993, and implemented by October 1 , 1993.

Five-Year Road Map

DMRs will continue to be submitted to SCDHEC, as required by the NPDES general permit. 
The facility PPP will be revised, as needed, to reflect implementation of BMPs and/or BATs, significant spills, changes to drainage pathways or every three years whichever comes furst. 


\title{
NPDES: Storm Water Associated with Construction Activity
}

\author{
(Compiled and reviewed by Joe K. Price)
}

\section{Site Program Overview}

As part of SCDHEC storm-water general permitting strategy, construction activities/land disturbances of 5 acres or greater now are required to submit a NOI to be covered by the SCDHEC NPDES general permit for "Storm Water Discharges from Construction Activities".

\section{Five-Year Outlook}

The South Carolina Land Resources Conservation Commission (SCLRCC) also has established a sedimentation and erosion-control and storm-water management program for construction sites (see Erosion Control Section). Its program is separate from the SCDHEC NPDES program. However, both programs have similar requirements such as developing PPP. SCLRCC requires the submission of the plan for approval, whereas DHEC has delegated approval to SCLRCC.

Some construction activities which are exempt under LRC's program that are not exempt under the NPDES program, such as environmental-restoration work. However, it would be in the best interest of SRS to consider all land disturbances greater than 5 acres under both programs. It is envisioned that the two programs will function in the following manner. First, a PPP for the site is prepared, ensuring it meets the requirements of both programs. The PPP then will be submitted to SCLRCC for approval. After approval by SCLRCC, the facility owner will submit NOI to SCDHEC for coverage under the general permit. Forty-eight (48) hours after the date the NOI is postmarked, construction may begin.

\section{Justification/Regulatory Requirements}

The Federal Water Pollution Control Act (Water Quality Act of 1987) prohibits discharging any pollutant from a point source unless the discharge is authorized by a NPDES permit.

40 CFR 122, 123, 124 "NPDES Permit Regulations for Storm Water Discharges", says industrial-related facilities that discharge storm water through point sources must be covered by an NPDES permit.

The South Carolina Pollution Control Act (Title 48, Chapter 1) requires DOE to comply with applicable South Carolina environmental regulations.

Under this act, SRS is required to permit storm-water discharges associated with industrial or construction activities. The enactment of the NPDES general permits allows SRS to be covered under the state's generic permit for storm-water discharges. 
Organizational Responsibilities Summary

The NPDES storm water Construction General Permit is administered on a site-wide basis by the Environmental Protection Department (EPD) Environmental Support Section (ESS). It is the facility custodian's responsibility to insure that PPP's are developed for land disturbances to mitigate/prevent erosion and sediment discharges. The facility custodian shall submit a Notice of Intent (NOI) to EPD at least 30 working days prior to work start. EPD shall submit the NOI to SCDHEC. The facility custodian will insure that all terms and conditions of the PPP and General Permit are carried out.

\section{Site Procedures and Documents}

Sile procedures or documents currently are being developed to ensure compliance with the new storm-water regulations.

\section{Programs}

The general permit requires each construction siee ( 5 acres or greater) to prepare a PPP. The plan must contain a site description, erosion and sediment and storm-water management controls, and other controls such as proper waste disposal and limiting vehicle tracking of sediments. The PPP will identify the best management practices to be implemented at the construction site that will prevent discharging pollutants into surface waters via storm water. The PPP also will contain post-storm-water management plans and controls for constructing industrial-related facilities.

The permit does not require storm-water monitoring but does require weekly inspections of storm-water management devices and an inspection 24 hours after each rainfall event of 0.5 inches or more.

\section{Technical Support Programs}

SCS and USFS will provide information and assistance with erosion and sediment controls. 
One-Year Road Map

SRS will develop and submit PPP's for land disturbances greater than 5 acres as necessary. 


\section{Erosion Control}

(Compiled and reviewed by Don W. Padgett)

\section{Site Program Overview}

Soil erosion to the Savannah River, site streams, Carolina bays, ponds, and lakes onsite can occur from storm-water runoff, improper maintenance of storm-water systems, and improperly maintained roads. The major erosion effects outside the site's operating areas occur along stream banks, secondary roads, and rights of way. Operating areas generally experience some soil erosion during and immediately after construction periods. On major construction projects, money is allocated for preventing the siltation/sedimentation of nearby streams. These preventative measures have included sedimentation basins, diversion of runoff water away from storm sewers to open fields, and filtration devices such as hay bales, cloth screening, and prompt re-establishment of vegetation.

\section{Five-Year Outlook}

SCLRCC has established a sedimentation and erosion-control and storm-water management program for construction sites. All projects disturbing two or more acres of land will require erosion-control plan approval by SCLRCC. SRS will apply to SCLRCC for a general permit to cover normal maintenance activities that are conducted on an annual or semi-annual basis. The effective date for this regulation (72-300 Standards for Storm Water Management and Sediment Reduction) on federal facilities is May 26, 1993.

\section{Justification/Regulatory Requirements}

Executive Orders 11988,11990 , and 12088 require that the DOE avoid or minimize to the extent practicable, any short-and long-term impacts to flood plains and wetlands. The site also must comply with S.C. Regulation $72-300$ "Standards for Storm Water Management and Sediment Reduction" by May 26, 1993.

\section{Organizational Responsibilities}

Each SRS area facility custodian is responsible for controlling or minimizing soil erosion caused by storm-water runoff or heavy construction. Immediately reporting significant erosion in an area contiguous to the facility falls within the domain of the area or facility custodian. The contiguous area, in many instances, is the secure area devoid of trees outside the perimeter fence.

SRFS conducts an annual road-condition survey of all general use and secondary roads in addition to power line and wood roads used in timber sales. SRFS manages the construction of new secondary roads, along with maintaining existing ones. Equipment, manpower, and materials to accomplish these tasks are provided by WSRC/CSWE. Soil erosion and land reclamation in all forested areas are SRFS's responsibility. 
Any erosion of the banks along the Savannah River that threatens SRS facilities, such as the river pump houses, is referred to the site office of the U.S. Army Corps of Engineers (COE) for site-specific action by the Charleston District CEO.

Sponsors for projects involving land disturbances of $1 / 2$ acre or more (includes $1 / 2$ acre or less if the slope is greater than $2 \%$ ) must have an approved erosion-control plan before any earth-disturbing activities begin. If the project involves an area 2 acres or greater, then the plan also must be submitted to SCLRCC for approval.

\section{Site Procedures and Documents}

Procedure ECM 12.2, Rev, Erosion and Sedimentation Control, is found in Procedure Manual $3 Q$. Environmental Compliance Manual. This procedure provides the necessary guidance for developing an erosion and sedimentation-control plan.

\section{Programs}

SRFS and SCS provide technical assistance and guidance to all onsite organizations for developing and implementing erosion- and sedimentation-control plans. WSRC/CSWE provides manpower and equipment under SRFS management for erosion-control areas throughout the site.

Construction management implements erosion-control measures as developed by the operating departments or design agencies for specific projects.

EPD currently reviews all erosion- and sedimentation-control plans developed for onsite projects. All plans must be reviewed and approved by EPD and SCS before submittal to SCLRCC.

\section{Technical Support}

SRTC/ETS makes special studies on stream sediment transport to support stream/river transport model development, because many pollutants are transported by sediment particles. These results will assist in determining the fate of stream-transported sediments. A study was completed in 1991 on the transport of Cs-137 from PAR Pond resulting from a postulated dam break, following the discovery of increased seepage and the discovery of soil depression. This study also was able to predict the resulting increases in Cs-137 in the Savannah River and at the drinking water plants downstream.

\section{One-Year Road Map}

SRS will develop and submit erosion-control plans as necessary. 


\title{
Waste Treatment Facilities
}

\author{
(Compiled and reviewed by Bill L. Payne)
}

\section{Site Program Overview}

SRS has more than 30 permitted wastewater treatment facilities currently in operation. These predominantly are package sanitary wastewater treatment plants (SWTPs). As SRS operations expand and environmental regulations increase in number, additional wastewater facilities will be constructed. Increased sanitary treatment capacity has been installed in several areas. SWTPs in all areas except D Area have equalization tanks to allow better control of peaks in hydraulic loading. Excess biological residuals from the sanitary treatment plants are reused beneficially through land application on DHEC permitted sites.

Physical/chemical treatment facilities recently permitted include DWPF, K-Reactor Cooling Tower, and the K-Area Emergency Retention Basin. Future facilities to receive WWTP permits include the Waste Management Tank Farm, In-Tank Precipitation, and a Centralized Sanitary Treatment Plant. These new wastewater-treatment facilities will require certified operators of the proper grade.

Five-Year Outlook

Several new wastewater-treatment facilities are being considered by site personnel for future. Examples include a Centralized Sanitary Wastewater Treatment Facility, an A-Area Powerhouse Wastewater Treatment Plant, and an SRTC Low-Level Radioactive Wastewater Treatment Facility.

EPD, in conjunction with Procurement, has initiated a blanket purchase agreement with an offsite publicly owned treatment works to accept and treat miscellaneous nonhazardous waste waters generated at SRS. This agreement will be active for the next five years and is intended to provide a reasonably-priced alternative for treating of these wastes.

Better planning and coordination of wastewater-treatment efforts will be one avenue receiving greater attention in the future. SRTC will fill a new position dedicated to providing treatability research for miscellaneous wastes generated site wide. This position will also evaluate the need for a centralized industrial wastewater-treatment facility and will assist in determining whether or not a specific department at SRS should take over the responsibility of managing all industrial wastewater. In addition to these proactive steps, a long-term committee comprised of sitewide wastewater treatment experts will be formed to assist the site in evaluating and finding solutions to large-scale wastewater-treatunent probleins. 


\section{Justification/Regulatory Requirements}

\section{Federal Laws}

The Federal Water Pollution Control Act (Water Quality Act of 1987) and its implementing regulations in $40 \mathrm{CFR}$ require DOE to obtain applicable permits before treating nonradioactive waste streams and discharging them into navigable waters.

Executive Order 12088

DOE Order 5400.5 releases guidelines for radionuclides.

\section{Code of Laws of South Carolina}

The South Carolina Pollution Control Act (Title 48, Cisapter 1) requires DOE to comply with applicable South Carolina environmental regulations.

Under this act, DOE-SR is required to obtain wastewater treatment facility construction permits to construct any wastewater-treatment facilities and sewers, including biosolids land application (South Carolina Regulation 61-9). After construction is completed, an operating permit must be obtained. In addition, an NPDES permit must be obtained for any liquid discharges into the environment.

The wastewater-treatment program achieves the following program objectives: compliance with regulatory requirements in the Clean Water Act and the South Carolina Pollution Control Act which require permitting prior to releasing wastewater into state navigable waters; compliance with DOE guidelines; compliance with requirements for reporting findings in the annual environmental report.

\section{Organizational Responsibilities Summary}

Custodians of permitted wastewater facilities are required to meet the permit limits for facility effluents and to operate the plants according to all NPDES permit conditions and state and federal regulations. Each custodian is required to have trained and licensed operators. Building custodians and project engineers are required to determine, in advance, the impact a large influx of operating or construction personnel would have on the local sanitary treatment system, and communicate with EPD and Power deparments regarding such an activity. 
Environmental Protection Department (EPD)

EPD helps custodians apply for permits and permit modifications, and provides guidance regarding general compliance and operational issues related to wastewater treatment and disposal. EPD facilitates the exchange of information between the regulatory groups and SRS operating groups. Department staff also coordinate environmental surveillance of all WWTPs to ensure compliance with permits and regulations. EPD is the sole contact with all regulatory authorities for all wastewater-treatment activities.

\section{Construction Management}

Construction Management currently has two permitted wastewater facilities. The oil/water separator facility in S Area is permitted to treat oily water generated at the equipment wash pad. The concrete batch plant, installed and permitted to facilitate the movement of concrete to the DWPF construction site, has been demobilized. When in use, dirty water from truck washing was clarified and $\mathrm{pH}$ adjusted in the treatment facility prior to release to a permitted NPDES outfall. Currently, the batch plant is under review for formal closure by WSRC ER and EPD.

Construction is considering installing a new oil/water separator in Central Shops to treat wastewater originating from the heavy equipment wash pad. This unit likely would recycle water and noi require a permit from SCDHEC.

\section{Reactor Materials (RM)}

RM operates one physical/chemical effluent treatment plant, the Liquid Effluent Treatment Facility (LETF). It provides treatrnent for all M-Area process wastewater and is operated under SCDHEC Permit No. 10,287. It comprises the Chemical Transfer Facility (CTF) and the Dilute Effluent Treatment Facility (DETF). Treated water is discharged to Tim's Branch via NPDES Outfall M-004, while dewatered sludge is managed as F-006 listed hazardous waste under the Resource Conservation and Recovery Act in the Interim TreamenuStorage Facility (ITSF).

M-Area personnel take a proactive approach to the characterization of their wastewaters. In addition, they continue to generate considerable data about the biotoxicity of their effluents through self-imposed biomonitoring.

Due to reductions in production requirements from $M$ Area, much of LETF is in the process of being "laid-up". Except for the slurry transfer tank, CTF has been cleaned and taken out of service. DETF primarily is used for treating supernate from ITSF tanks.

M-Area personnel are considering ways that the LETF may be used in the future to provide support to other departments in managing their wastewaters. 


\section{SRTC - TNX}

TNX Operations manages three permitted wastewater-treatment facilities.

The Ion Exchange Facility (IXF) removes mercury from wastewater generated by the Integrated DWPF Melter System (IDMS). Mercury is reduced to a concentration below $10 \mathrm{ppb}$, after which the wastewater is pumped into the Organic Removal Facility (ORF).

ORF utilizes carbon absorption to remove (primarily) phenol and benzene from wastewater generated at TNX research facilities. After treatment. wastewater from ORF is transferred to the Effluent Treatment Plant (ETP).

The TNX-ETP provides treatment for all liquid, nonsanitary effluents to ensure compliance with current regulations. The facility provides $\mathrm{pH}$ neutralization, effluent clarification and sludge dewatering.

TNX is a research area providing support for DWPF. As such, wastewaters generated there often change constituency and require frequent permit modifications by SCDHEC.

\section{SRTC - Tech Area}

Tech Area currently operates a waste-neutralization facility at Building 607-17A, serving the Environmental Monitoring Lab 735-11A. In this facility, wastewater $\mathrm{pH}$ is adjusted before release to Outfall A-001. This treatment piant currently is off-line due to mercury contamination. SRS entered into a settlement agreement with SCDHEC in 1991 relative to this contamination. The unit is expected to go back on-line in 1993.

SRTC. also owns a neutralization facility in B Area that treats wastewater generated in the 704-B laboratory complex. The system is small and is operated by personnel in the Site Utilities Department.

SRTC has constructed another small neutralization facility to treat wastewater generated in the Metallurgical Laboratory at 72.3-A. This unit is expected to go on-line in 1993 provided questions about the treatability of its influent can be answered.

SRTC is considering construction of a low level radioactive wastewater treatment facility for A-Area. If built, the plant would treat radioactive wastewater generated in building 773-A laboratories.

\section{Waste Management (WM)}

Waste Management owns and operates the F/H-Area Effluent Treatment Facility (ETF). The F/H-ETF was constructed to replace the F- and H-Area seepage basins, which received wastewater from Separations processes. Providing ultra filtration, $\mathrm{pH}$ adjustment, ion exchange, reverse osmosis, carbon absorption, and evaporation, the 
F/H-ETF is the most complex physical/chemical-treatment facility at SRS. Treated effluent is discharged through a permitted NPDES outfall $(\mathrm{H}-016)$ to Upper Three Runs Creek.

Considerable research and development activities greatly have reduced filtration problems that have plagued the ETF since startup. The addition of an aluminum/iron nitrate feed system (soon to be permitted by SCDHEC) has improved filter-feed rates by as much as 300 percent.

\section{Defense Waste Processing Facility (DWPF)}

The Vitrification Facility of DWPF recently received a permit to operate from SCDHEC. This wastewater-treatment plant will treat non-volatile radioactive waste by vitrifying it into a solid glass matrix. Volatile organics that are generated during treatment will be collected within an organic waste storage tank for incineration at a later date. Mercury will be reclaimed and purified for reuse at other SRS facilities, while residual radioactive wastewater remaining after treatment will be recycled through an inter-area transfer line back to the H-Area Tank Farm.

The Vitrification's Facility cold chemical runs (non-radioactive startup operations) will begin in early 1993. Wastewater generated during these runs will be disposed of offsite at a local POTW for approximately one year.

In addition to the Vitrification Facility, DWPF recently received a permit to operate the 980-S Chemical Waste Treatment Facility. This unit neutralizes acids and bases collected from the S-Area chemical waste collection system prior to discharge to a permitted NPDES outfall.

In Z-Area, the Saltstone Facility was designed and built to convert low-level radioactive liquid waste, stored in $\mathrm{H}$-Area, into a nonhazardous solid waste called Saltstone. Within this process, premix and salt solution are mixed to form a grout that is pumped into large concrete vaults where it solidifies. After the vaults are filled, they are capped with clean concrete to isolate the waste from rain and weathering.

\section{Reactor Operations}

The Reactor Department began operating of a new cooling tower servicing the $\mathrm{K}$ Reactor in late December 1992 . This facility has been permitted by SCDHEC as a physical/chemical-wastewater treatment facility. The tower itself will be operated by the Reactor Department; however, the chlorination/dechlorination system will be operated by Area Power and will require a D-Level operator-in-charge.

Reactor Operations also manages an emergency retention basin in $\mathrm{K}$ Area that has been issued a wastewater-treatment operating permit by SCDHEC. 


\section{Site Utilities}

The Site Utilities Department manages approximately 20 sanitary package wastewater-treatment facilities at SRS. These units are scattered around the site and are located near to populated areas. The plants utilize extended aeration-activated sludge to provide biological treatment of carbonaceous waste generated in restroom and cafeteria facilities. Under approval by SCDHEC, some of the facilities treat specific industrial waste (photographic wastewater, bioassay wastewater, scintillation cocktail, etc.), but greater than $99 \%$ of the wastewater is domestic in nature.

Site Utilities Department also is responsible for managing biosolids (waste-activated sludge generated during treatment of domestic wastewater). This byproduct is reused beneficially by land applying on specific SRS sites permitted by SCDHEC.

\section{Area Power}

Wastewater-neutralization facilities are associated with the water-treatment plants in $\mathrm{P}, \mathrm{D}, \mathrm{F}, \mathrm{H}$, and $\mathrm{K}$ areas. These plants adjust the $\mathrm{pH}$ of the wastewater produced during regeneration of ion-exchange units at the associated powerhouses before combining it with other area wastewaters and discharging it to NPDES permitted outfalls. Currently, the D-Area neutralization facility is being upgraded to increase its capacity.

\section{Site Procedures and Documents}

The following documents should be used for reference:

- WSRC Environmental Compliance Manual $3 Q$

- EPD Prucedure Manual Q-1-1-1

- WSRC Permitting "How" manual, WSRC $3 Q-2$

- WSRC Waste Disposal Manual (WSRC-IM-90-138)

- Area Procedure Manuals

\section{Programs}

\section{Operator Certification Training}

The 1976 Code of Laws of South Carolina, Chapter 23, Section 40-23-140, paragraph $B$, requires that all employees operating state-permitted water or wasiewater-treatment facilities must obtain state certification as a water or wastewater operator. The South Carolina Board of Certification of Environmental Systems Operators (SCBCESO) established rules and regulations for certifying operators. On July 1, 1987, SCBCESO reclassified wastewater-treatment plants and operations. They now require separate certifications for physical/chemical (P/C) and biological (sanitary) wastewatertreatment facilities. 
Each of tine four grade level of certification requires successful completion of an examination and at least one year of operating experience at levels. Higher levels of certification can be obtained only in sequential order beginning with level $D$ and followed by levels $\mathrm{C}, \mathrm{B}$, and $\mathrm{A}$. All operators also are required to receive pertinent continuing education, either in an educational institute, or through seminars, programs, workshops, in-house training, correspondence courses, or any combination of the above.

\section{Wastewgter Characterization}

During 1992-1993, SRS initiated a program to characterize all nonhazardous wastewaters disposed into "Waters of the State", either directly or after treatment. The purpose of this program is threefold:

- to comply with a DOE request

- to provide information for area environmental coordinators to use when updating their NPDES permit applications

- to eliminate toxic dischar ges prior to implementing a sitewide aquatic toxicity study

\section{Industrial Wastewater Treatment}

A program currently is being implemented to provide better management of industrial wastewaters generated at SRS. The three key aspects of this program are the following:

- forming a technical support group of wastewater-treatment experts who will provide guidance to sitewide personnel related to large-scale wastewater issues/problems

- creating a position in SRTC to perform treatability studies on nonroutinely-generated industrial wastewaters

- determining which SRS deparunent (if any) should assume responsibility for managing industrial wastewaters

\section{Wastewater Treatment Surveillance's}

All SRS areas participated in a Clean Water Act Permit Compliance Review in 1992. In addition, they receive formal surveillances regarding specific operational aspects of their wastewater-treatment facilities to ensure compliance with applicable environmental regulations. Surveillances normally are performed one or two times per monch. 


\section{Quarterly Meetings With SCDHEC}

Meetings are held approximately once per quarter at the SCDHEC's office in Aiken, SC. The purpose of these meetings is to provide the regulator with an overview of various wastewater-treament systems at SRS and to build relationships.

\section{Disposal of "Scavenger" Wastewaters}

EPD, in conjunction with Procurement, has initiated a blanket purchase agreement with an offsite publicly owned treatment works (Pots) to accept and treat miscellaneous, nonhazardous wastewaters generated at SRS. This agreement will be active for the next five years and is intended to provide a reasonably-priced alternative for treating these wastes.

\section{Technical Support Programs}

\section{SRTC Treatability Studies}

SRTC intends to fill a newly-created position to perform treatability studies on nonroutine industrial wastewaters. This position also will help determine the future of industrial wastewater treatment at SRS.

One-Yea: Road Map

The following regulations/permits are expected to be implemented within the next year:

- 40 CFR 503: Disposal of sewage sludge

- This regulation will affect the manner in which SRS manages its waste sludge from its sanitary treatment facilities.

- New SRS NPDES Permit

- The new permit may regulate discharging nitrates and aquatic toxicity in a manner which will require modifying certain wastewater-treatment facilities at SRS.

- Federal Facility Compliance Act

This new act, promulgated in Octcber, 1992, precludes disposal of hazardous wastes into federally-owned treatment works (FOTWs, SRS sanitary treatment plants). This could detrimentally affect disposal of bioassay wastewater at SRS and eliminate FOTWs as a future treatment option for certain waste. 
Five-Year Road Map

\section{SCDHEC Regulations}

In August 1992, SCDHEC published a draft notice in the state register stating that it likely will promulgate regulations for policy and guidance documents that have been used internally in the past when writing permits. If new regulations are promulgated. they likely will be issued within the state register periodically over the next one to three years. Some of these regulations may apply to wastewater treatment. 


\section{Wetlands}

(Compiled and reviewed by Don W. Padgett)

\section{Site Program Overview}

The sitewide program to address onsite wetlands protection is the Environmental Evaluation Checklist System. All SRS departments are required to submit a checklist (OSR Form 14-347) for any project that meets the site criteria. SREL and other onsite contractors are required to initiate similar documentation to DOE for any project that meets the site criteria. NEPA Activities group reviews each SRS-generated checklist and determines the significance of the environmental impact, including the impact on wetlands. If the impact on wetlands is not clearly insignificant, it may be determined that a wetlands assessment is necessary. The NEPA activities group coordinates the assessment and uses the results to prepare the required NEPA documentation.

Five-Year Outlook

SRS currenty is using the 1987 Corps of Engineers Wetlands Delineation Manual for delineating site wetlands. Any changes in federal or state regulations will be incorporated into site procedures.

\section{Justification/Regulatory Requirements}

Executive Order 12088 requires federal agencies to comply with applicable administrative and procedural pollution-control standards established by federal laws. Executive Order 11988 and 11990 obligate DOE to avoid, or minimize any short- and long-term adverse impacts to floodplains and wetlands.

The sitewide wetlands-protection program meets the following chapter obiectives: compliance with regulatory requirements, informing the public, and minimizing wetland losses from SRS operations.

\section{Organizational Responsibilities Summary}

EPD has the administrative oversight responsibility for the Wetland Protection Program. SRS's facility custodians are responsible for using the Environmental Evaluation Checklist System if any of their research, studies on, new installation waste streams have the potential to impact wetlands. Site-use permits are required by all SRS facilities that are enlarging their activities to include more land use. These permit applications are reviewed by EPD for any potential wetland impacts. Prior to any dredging or filling at navigable streams, a U.S. Army Corp of Engineers (COE) 
Section 404 Permit must be attached. EMS is responsible for performing periodic radioactivity surveys in the Savannah River Swamp in South Carolina. EMS also schedules comprehensive surveys of the swamp by the Academy of Natural Sciences of Philadelphia (ANSP) on a five-year frequency.

\section{Site Procedures and Documents}

Procedure ECM 12.1 Rev.1, Wetlands Protection, is found in Procedure Manual 3Q, Environmental Compliance Manual. This procedure describes the permitting process necessary to comply with federal and state wetland regulations.

\section{Programs}

EPD assists custodians with obtaining COE 404 Permits and coverage under nationwide permits. EPD plays an active role in wetlands protection by providing guidance, conducting field surveys and delineations, and serving actively on the Wetlands Task Group.

\section{Technical Support}

SRTC ESS provides the technical support for wetlands assessments and COE 404 Dredge and Fill investigations. ESS has developed GIS layers for wetland vegetation and soils. ESS in conjunction with SRFS, SCS, SREL, and DOE is developing a program to reforest portions of the wetlands damaged by heated effluents released by SRS production reactors and the D-Area powerhouse.

One-Year Road Map

SRS will apply for COE 404 Permits as necessary. 


\section{Chapter 7}

\section{Groundwater Protection}

Chapter was compiled and reviewed by Pamela B. Barnard. 


\section{Site Program Overview}

The Savannah River Site (SRS) uses large quantities of groundwater for drinking, processing, and non-contact cooling. Continued industrial and residential grow th along with additional agricultural irrigation in areas adjacent to SRS will increase the demand for groundwater. This increasing demand will require a comprehensive management system to ensure the needed quality and quantity of groundwater is available for all users. The Groundwater Protection and Waste-Management Program establishes the overall framework for protecting this resource.

Groundwater under SRS is monitored extensively for radiological, hazardous, and water quality constituents. Groundwater quality is known to have been affected at 33 onsite locations, but none of the contaminant plumes have migrated offsite. Onsite and offsite drinking water supplies are monitored to ensure they are not impacted. The site has more than $\mathbf{1 8 0 0}$ monitoring wells from which groundwater samples are analyzed for radiological and non-radiological constituents.

SRS is complying with all regulations and consent orders related to groundwater protection, waste treatment, and waste disposal. Consent-order requirements related to M-Area groundwater monitoring, the F- and H-Area Seepage Basins point-ofcompliance monitoring wells, and quarterly groundwater reports are being met. The existing waste-storage facilities are permitted or are being permitted. Existing hazardous- and mixed-waste storage facilities are being included in the site Resource Conservation and Recovery Act (RCRA) Part B Permit. Part B permitting has been initiated for many of the planned hazardous- and mixed-waste treatment and disposal facilities.

The Savannah River Technology Center (SRTC) has an extensive effort underway to define the regional hydrogeological system. Current programs include geological sampling, groundwater monitoring, and aquifer modeling efforts to further understand SRS's hydrogeological system. SRS also will conduct studies on the quantities of water removed from aquifers relative to the production capability of the formation.

To protect the groundwater from SRS-generated waste, the site has a comprehensive waste-management program. SRS's strategy requires that all waste be treated and disposed of onsite whenever practical. Facilities to treat and dispose of radioactive, hazardous, mixed (radioactive and hazardous), and non-hazardous waste either exist, are under construction, or are planned for the near future. The Defense Waste Processing Facility (DWPF) will convert the liquid, high-level waste into a permanent, solid-glass waste form for offsite, geological disposal. Low-level radioactive waste will be disposed of in the new Low-Level Radioactive Waste Disposal Facility (LLRWDF), which will stabilize and contain the radionuclides. The Consolidated Incineration Facility (CIF) will be constructed to reduce the volume of radioactive waste and to detoxify hazardous wastes. Treatment and disposal facilities for nonincinerable hazardous and mixed waste are planned. Facilities for retrieving and packaging stored TRU waste for shipment to offsite, geological storage also are planned. 
Increased waste-minimization activities began during FY 88 . These activities focused on improved process efficiency to reduce the amount of waste generated. The strategy was to conduct a site inventory of waste streams, identify candidate streams for costeffective reductions, and implement facility-specific reduction measures. The site will continue to reduce the amount and volume of low-level, radioactive waste going to the LLRWDF. Efforts to delist M-Area sludge from hazardous waste to nonhazardous waste will continue.

Activities toward closing 4 : many SRS waste units will continue to increase. The closure strategy is to close regulatory, required units first, units near the plant boundaries second, and finally the plant's interior units. RCRA-closure activities have been completed on the M-Area Settling Basin, Mixed Waste Management Facility (MWMF), the F- and H-Area Seepage Basins, the Metallurgical Laboratory, the SRTC Seepage Basin, and Tank 105C. In addition to waste closures, remediation activities are underway in $M$ Area to remove chlorocarbons from the groundwater to prevent the existing plume from spreading.

Systems to prevent and detect groundwater impacts on existing and future facilities are in place. Site specifications have been developed for underground storage tanks, diking systems, well installation, and well abandonment. 


\section{Policy}

SRS's groundwater-protection and waste-management policy requires that site operations protect the quantity and quality of the site groundwater, meet regulatory requirements, restore the resource where degradation has occurred when practical, and comply with applicable Department of Energy (DOE) and operating contractor requirements.

\section{Background}

DOE and operating contractors are committed to protecting the public health and safety, and the environment. These convictions are stated in DOE Order 5400.1, General Environmental Protection Program, and in SRS's Strategic Environmental Plan. Compliance with applicable environmental regulations, DOE orders, and operating contractor policies forms the basis for SRS's groundwater-protection and waste-management policy. 


\section{Existing Conditions}

SRS operations have not affected of fsite groundwater supplies. SRS uses large quantities of groundwater for drinking, processing, and non-contact cooling. After use and any necessary treatment, the groundwater is released to wastewater treatment facilities, surface streams or to seepage basins.

Although site operations have affected groundwater quality at several locations, no offsite drinking water supplies have contaminants in concentrations approaching regulatory limits resulting from SRS operations. The impacts on groundwater quality generally have been the result of using seepage basins for wastewater disposal, atmospheric tritium discharge throughout the site's history, and non-contained waste disposal at various units. Programs are underway to eliminate using seepage basins and to close all existing waste units. SRS operations have not affected the quantity of groundwater available to users adjacent to the site.

The increasing regional demand will require a comprehensive management system to ensure the needed quality and quantity of groundwater is available for all users. SRS has several programs and studies underway to define and understand the regional hydrogeological cycle. The site will continue current geologic sampling, groundwater monitoring, and aquifer modeling efforts to understand further SRS's hydrogeological system. The U.S. Geological Survey (USGS) currently is conducting a multi-year study to better characterize and quantify regional groundwater-flow conditions near the Savannah River. This study was funded by DOE.

SRS is in compliance with or has entered into compliance agreements related to groundwater-protection, waste-treatment, and waste-disposal regulations. SRS is meeting consent-order requirements for groundwater monitoring and cleanup at various units. Waste-treatment and disposal facilities are in compliance with federal and South Carolina regulations.

The site has a comprehensive waste-management and disposal strategy. The strategy requires that all waste be treated and disposed of onsite, whenever practical. Facilities for treating and disposing of radioactive, hazardous, mixed (radioactive and hazardous), nonradioactive, and nonhazardous waste currently either exist, are under construction, or are planned for the near future. The DWPF, currently under testing, will convert 34 million gallons of liquid high-level waste into a permanent, borosilicate-glass waste form for offsite, geological disposal. Low-level radioactive waste, currently disposed by shallow land burial, will be disposed of in the new LLWRF, which will stabilize and contain the radionuclides. The site currently has permitted storage facilities for hazardous and mixed wastes. An incinerator to reduce the volume of radioactive waste and to detoxify hazardous waste is planned. Treatment and disposal facilities for hazardous and mixed waste also are planned for nonincinerable waste.

The RCRA and RCRA Facilities Investigation/Remedial Investigation (RFI/RI) waste units, currenty listed in the Federal Facility Agreement (FFA) (Appendices $\mathrm{H}$ and $\mathrm{C}$, respectively), will be closed by the year 2020. RCRA-closure activities have been completed in the M-Area Settling Basin, MWMF, the F- and H-Area Seepage Basins, 
the Metallurgical Laboratory, the SRTC Seepage Basin, and Tank 105C. Other waste-unit closure activities are focused on characterizing the remaining waste units and developing the RFI/RI work required by the site RCRA permit.

Although operations have impacted the groundwater at 33 locations, current remediation activities have occurred at only one unit. Groundwater-remediation activities are being conducted to remove chlorocarbons in the $A / M$ Area. The chlorocarbons, used as degreasing agents in the M-Area fuel-fabrication facility, entered the groundwater principally through the $M$-Area Settling Basin and associated underground piping. The basin was closed under RCRA, and all other contaminant sources have been stopped or removed. The chlorocarbons primarily are confined in a shallow aquifer, but there are some isolated locations where the chlorocarbons have reached the deeper aquifer. The chlorocarbons are being removed from the shallow aquifer by a series of recovery wells installed in the plume onsite, which remove water from the formation. The water is pumped into two air-stripper columns which remove the chlorocarbons in the water. The water then is discharged to a permitted National Pollutant Discharge Elimination System (NPDES) outfall. The chlorocarbons are stripped in a carbon filter and the remaining air is vented into the atmosphere via a permitted stack. Approximately 270,000 pounds of chlorocarbons in the formation have been removed.

The small amounts of chlorocarbons in the deeper aquifer currently pose no threat to offsite drinking water systems. SRS monitors the aquifers under $A$ and $M$ Areas to track existing plumes and to detect other sources. Volatile organic compounds (VOCs) also have entered the groundwater from operations near the SRTC complex. Groundwater remediation in this area began in 1992, using an air-stripper column.

The site has developed special designs and procedures to protect the groundwater from current and future operations based on UST regulations. All new underground storage tanks must have double walls. New and existing underground tanks must have a rigorous inventory-reconciliation procedure capable of detecting leaks. Existing above-ground tanks are being retrofitted with diking systems to contain leaks. New facilities are constructed with dikes as part of the design.

Site specifications for production and monitoring wells were revised to ensure that the wells are constructed properly and not acting as conduits for contaminants to migrate vertically. In addition, the site's well-abandonment program is closing all wells not needed to remove any additional potential conduits for contamination migration. Monitoring wells are retrofitted into existing facilities where there is a potential for groundwater impact. New facilities are required to install monitoring wells prior to construction and startup. 


\section{Objectives}

The objectives supporting the Groundwater-Protection and Waste-Management Program are as follows:

- groundwater consumption - 10 protect the quantity and quality of groundwater resources by managing consumption for best resource utilization

- hydrogeologic understanding - to understand the natural conditions of hydrology and geology that exist near the site

- groundwater monitoring - to assess groundwater quality to determine any impacts from site operations

- groundwater conservation - to protect water resources by managing the quantity of water being used in comparison to the resources available

- waste-disposal requirements - to comply with applicable federal and state regulations, DOE orders, and operating contractor policies related to groundwater protection, waste treatment, and waste-disposal activities

- waste-disposal strategy - to provide a waste-disposal strategy consistent with applicable laws, DOE orders, and operating contractor policies for each waste stream, including a comprebensive waste-minimization strategy

- waste-unit closure - to close all inactive waste units according to applicable laws and regulations, DOE orders, and operating contractor policies

- groundwater remedial actions - to improve the quality of SRS degraded groundwater to limits agreed to with regulatory agencies

- operational guideline - to operate SRS facilities utilizing site groundwaterprotection designs and procedures 


\section{Strategy}

The strategy for reaching the groundwater-protection and waste-management objectives includes the following:

- identifying regulatory and other protection requirements

- understanding the hydrogeological system and promoting innovative, cost-effective means of meeting the requirements through research and development

- developing physical and administrative controls to protect groundwater, utilizing the knowledge gained from research and development

- implementing physical and administrative controls

- evaluating the controls to ensure protection requirements are met

The strategy is illustrated in Figure 7.1.

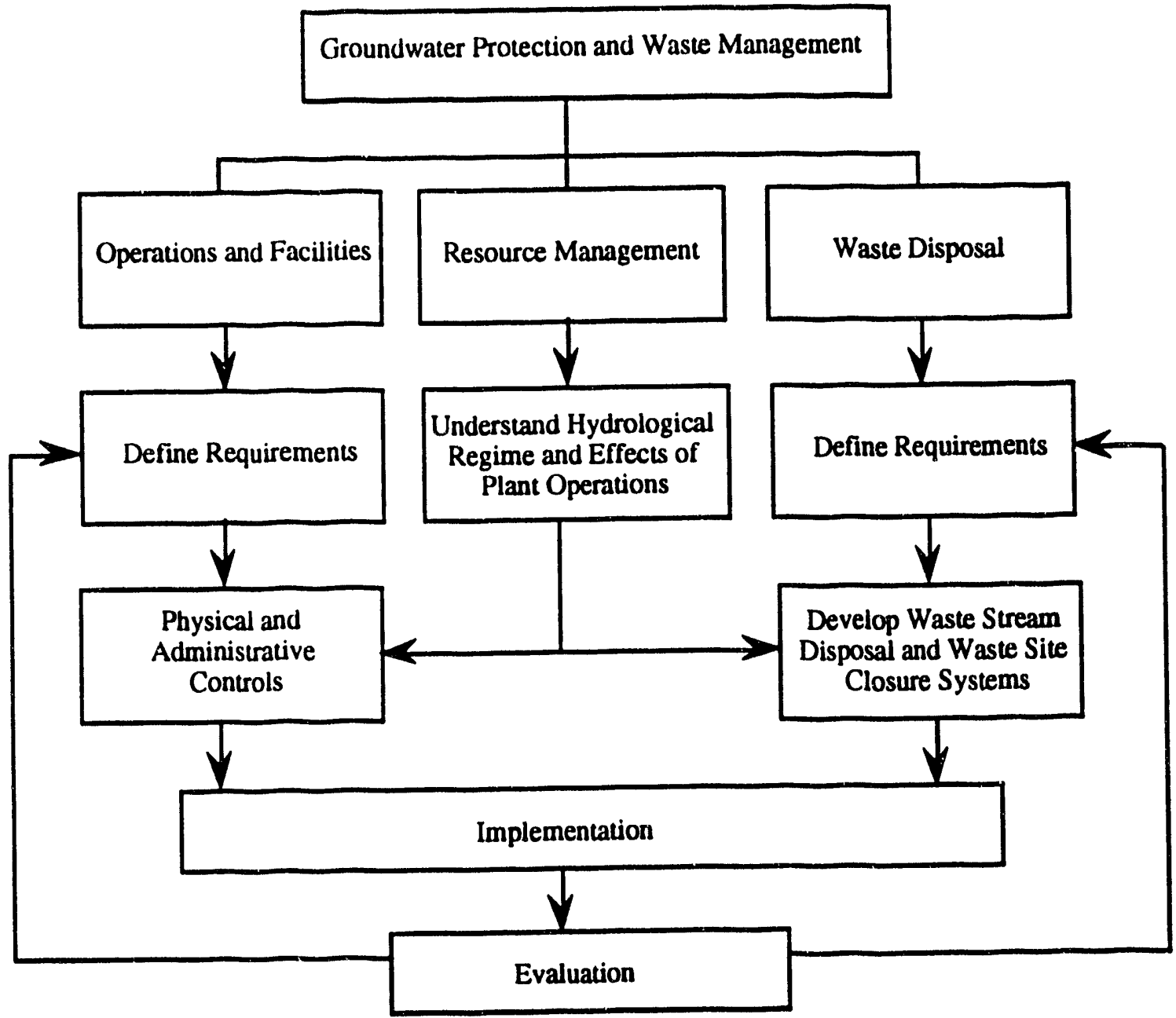

Figure 7.1. Groundwater Protection and Waste Management Strategy 
The implementation section identifies issues and those responsible for achieving defined objectives. Each environmental effort will require funding for one or more of the following: research and development, operations, programs, and construction/modification projects. The following prograns are discussed in the implementation section:

- Groundwater Consumption (page 7-11)

- Hydrogeological Regime Analysis (page 7-13)

- Groundwater Monitoring (page 7-18)

- Water Conservation (page 7-26)

- Contamination Prevention (page 7-29)

- Contamination Detection (page 7-35) 


\section{Groundwater Consumption}

(Compiled and reviewed by Pamela B. Barnard)

\section{Site Program Overview}

Managing groundwater consumption and understanding the effects of SRS groundwater consumption on the regional hydrogeological regime are essential to SRS's groundwater-protection program. A primary goal of SRS's groundwater-protection effort is to ensure that SRS groundwater consumption does not stress irreparably the yield of the underlying regional hydrogeological system.

Environmentally-sound management of groundwater-consumption practices is being done through various SRS efforts. Considerable evaluation of site hydrogeology through past and ongoing projects is allowing for refined delineation and predictive modeling of the regional hydrogeological regime. The Environmental Protection Department (EPD) is leading the development of a water resource plan for SRS which will ensure the protection, management, conservation, and monitoring of water quality and quantity. Other efforts are directed at enhancing the monitoring of groundwater consumption.

\section{Regulatory Requirements}

The South Carolina Water-Use Reporting and Coordination Act authorizes the South Carolina Water Resources Commission (SCWRC) to require the reporting of information relative to substantial use, withdrawal, or diversion of surface, underground, or other waters in quantities greater than 10,000 gallons per month. Required information includes locating the wells or facilities where water is used, withdrawn, or diverted; identifying the source and location of the water; and identifying the amount of water used, withdrawn, or diverted. The Safe Drinking Water Act (SDWA) imposes requirements on installing and maintaining drinkingwater wells.

South Carolina regulation R.61-71, Well Standards and Regulations, is applicable to most newly-constructed wells, including water-supply wells, monitoring wells, and piezometers. To satisfy this regulation, a water-well record form (HDI-977) for each well must be submitted to the South Carolina Department of Health and Environmental Control (SCDHEC) within 60 days of completing the well.

Groundwater-consumption management supports the groundwater-consumption objective.

\section{Organizational Rృsponsibilities}

Discussed below are those groups responsible for groundwater-consumption management. 


\section{Environmental Protection Department (EPD)}

The geological oversight group in EPD is responsible for coordinating all groundwater-protection activities. The group coordinates the technical and reporting aspects of groundwater consumption, preservation, remediation, and contaminant-monitoring activities. The group monitors the status of all ongoing groundwater projects, and maintains comprehensive documentation of project activities. All groundwater projects require approval from the manager of EPD's geological oversight group, or his designee. The geological oversight group's manager interacts with all custodial departments and environmental coordinators, and works with or is a member of all groundwater-related task forces.

EPD is responsible for the technical and regulatory review of all activities affecting groundwater-consumption. EPD also reviews groundwater-consumption activities to determine if site policies, objectives, and commitments are being met. The geological oversight group is responsible for coordinating all reporting activities relating to SRS groundwater consumption, e.g., EPD compiles and reports sitewide water-use data. EPD supports custodial efforts with regulatory expertise.

\section{Custodians}

Various custodial departments have personnel responsible for documenting water-use activities to ensure responsible use of water resources, and to compile data for the quarterly Water-Use Report submitted to the South Carolina Water Resource Commission.

\section{Programs}

Installing metering devices for all production wells (i.e., greater than $10 \mathrm{gpm}$ ) is necessary to comply with the South Carolina Water Use and Coordination Act's reporting requirements and to provide precise, baseline information for SRS's Water Conservation Program. Flow meters are installed for all new production wells.

\section{Monitoring and Compliance}

The South Carolina Water Use and Coordination Act requires SRS to report substantial use, withdrawal or diversion of surface, underground and other waters to the SCWRC. Specifically, this act requires all users of 10,000 gallons or more of water a day to report water use for each quarter. EPD presently completes the sitewide quarterly water-use reports from data collected from SRS custodians and submits them to SCWRC. USGS also receives copies of the reports to evaluate regional water resources. 


\title{
Hydrogeological Regime Analysis
}

\author{
(Compiled and reviewed by Pamela B. Barnard)
}

\section{Site Program Overview}

Describing the hydrogeological regime at SRS is an integral planning component of the groundwater-protection program. Analyzing both the natural systems and the effects of large-volume pumping centers are the two primary tasks of this effort.

Numerous wells have been installed onsite. Many of the deeper wells have been both cored and geophysically logged, which provides information on the vertical distribution of bulk, and the physical parameters affecting groundwater flow. Aquifer tests provide field estimates of groundwater-flow rates and directions, as well as the degree of confinement of an aquifer beneath a portion of the site. Special core sections have been acquired that are suitable for measuring both porosity and permeability.

Analyzing the field data includes correlating logs into stratigraphic cross-sections, comparing well logs with seismic cross-sections, piezometric and/or potentiometric surface maps, calculating groundwater-flow rates and directions, calculating vertical and lateral gradients, assessing leakage coefficients of regional aquitards, and many other efforts.

Numerical modeling of the aquifer system beneath SRS assesses both short- and longterm consequences of water withdrawals. The impact of regional droughts has been considered, but the primary modeling emphasis is on particle tracking to assess pathways of contaminant migration and assess the impact of large-volume pumping centers on groundwater-flow rates and directions.

Head-reversal studies assess both the lateral extent of and changes in the area beneath SRS in which there is an upward flow gradient between the uppermost Cretaceous aquifer and the overlying, uppermost aquifer. Additional data have added many control points for contouring the lateral extent of head reversal. The local influence of pumping centers in the general separations areas (GSA) has been the subject of several numerical modeling studies.

\section{Regulatory Requirements}

\section{Federal Laws}

Resource Conservation and Recovery Act (RCRA)-These regulations include requirements for groundwater monitoring (40 CFR 264 and 265). Many of these requirements imply a thorough description of the hydrogeological regime; particularly, defining the uppermost aquifer and determining groundwater-flow rates and directions. 
Comprehensive Environmental Response, Compensation and Liability Act (CERCLA)_CERCLA regulations govern the environmental restoration at facilities designated on the National Priorities List (NPL). SRS was included on the NPL in December 1989.

\section{State Regulations}

R.61-61-Solid-Waste Regulation-Post-closure monitoring requirements include using a monitoring well, which implies assessing the water table's location and determining the downgradient direction.

R.61-66-Industrial Solid-Waste Disposal Site Regulation-If hazardous waste is present. groundwater-monitoring requirements imply an assessment of the water table's location and a determination of the downgradient direction in the "uppermost" aquifer as defined by SCDHEC.

R.61-70-South Carolina Landfill Regulation-The requirement for monitoring wells implies an assessment of the location of the water table and a determination of the downgradient direction in the "uppermost" aquifer as defined by SCDHEC.

R.61-79.264 and 265 Hazardous Waste-Management RegulationsGroundwater-monitoring regulations require extensive knowledge of the hydrogeological regime.

\section{Consent Orders}

ACO 85-70-SW-DOE agreed to additional groundwater- assessment activities at and around the M-Area Settuing Basin and the F- and H-Area Seepage Basins, under the terms of an Administrative Consent Order signed November 7, 1985 and amended in 1988. These activities require a detailed understanding of the hydrogeological regime at each unit.

SA 87-52-SW-A settlement agreement signed November 12, 1987 also requires groundwater-quality assessments at several waste units.

SA 87-86-SW-A settlement agreement signed October 2, 1987 addresses installing piezometers at locations not approved by SCDHEC.

\section{DOE Orders}

5400.1 - General Environmental Protection Program-This DOE order requires the developing of groundwater-protection management and groundwater-monitoring programs for the site.

5480.2 - Hazardous and Radioactive Mixed Waste Management-This DOE order requires groundwater monitoring at all solid, hazardous, and mixed waste-management 
facilities to ensure that groundwater quality is not degraded. Assessing groundwater degradation requires knowledge of the hydrogeological regime.

5820.2A - Radioactive Waste Management-This DOE order requires that the wastemanagement plan for each facility describe groundwater-monitoring programs for both radioactive and nonradioactive constituents.

\section{Organizational Responsibilities}

All activities in geology, seismology and geotechnology at WSRC are integrated under the Site Chief Geotechnical Engineer who reports to the Site Chief Engineer (E\&PD). WSRC operating divisions (SSD, NMPD, WM\&ER, and RRD) have the responsibility for accomplishing their assigned missions and will provide E\&PD, SRTC and ESH\&QA with clear and concise technical support requirements.

A Memorandum of Understanding was signed October 30, 1992 which describes the responsibilities.

ESH\&QA will provide environmental, safety, health and quality-assurance support to all SRS organizations consistent with site policies. ESH\&QA will administer the sitewide drilling contract except for production well drilling. Construction Management's soil borings performed during foundation studies, road building, trenching, and other construction activities often provide useful hydrogeological information, such as the depth to the water table. Piezometers and dewatering wells often are installed during construction of large buildings.

ESH\&QA will conduct groundwater and soil sampling and laboratory analyses for regulatory oversight programs and, when requested, for well custodians. EMS hydrologists and geologists administer subcontracts for geophysical logging, monitor well drilling, pump and aquifer testing, and coring projects. Technical staff help characterize site aquifers and assist in interpreting groundwater-flow directions. This organization also is responsible for research related to groundwater sampling and analysis. ESH\&QA will also provide the regulatory oversight, regulatory interpretation and guidance, and interface with the regulators for environmental-protection activities. In its oversight role, EPD may suggest projects to SRTC or custodians, fund special studies, prepare policy and guidance statements, such as a water resource management plan, request acquisition of particular data, or conduct research of sitewide regulatory significance.

SRTC will conduct sitewide/regional hydrology, geology and seismology programs and technology development. SRTC will perform geology, seismology, geotechnical (GSG) integrated technology demonstrations, perform groundwater model analysis and groundwater model code developrnent, and approve groundwater codes. SRTC will develop the GSG/GIS data architecture, as specified by the Chief Geotechnical Engineer. SRTC will determine SRS seismic hazards, perform seismology analyses and faulting investigations, and maintain the seismic monitoring network. SRTC will perform risk analyses with guidance from ESH\&QA and WM\&ER to support environmental assessments. 
E\&PD will define and interpret engineering codes, standards, and practices for all GSG activities, manage a comprehensive GSG/GIS data base, and perform groundwater modeling with SRTC approved codes. E\&PD will provide field oversight of geotechnical, drilling, and soil/foundation/remediation construction activities. E\&PD will perform GSG studies necessary to support construction/facility activities including geotechnical characterization, soil mechanics studies, static and dynamic foundation analysis, embankment and dam stability analyses, and provide geotechnical pre-conceptual studies.

E\&PD and SRTC will review geological, seismological and geotechnical reports before incorporation into regulatory documents or before such information is released to the public. The site geotechnical engineer will represent or concur with WSRC representation on all GSG matters in meetings and presentations with the DOE, the public, oversight boards and regulators.

Programs

\section{SRTC-ESS}

All hydrogeologic regime analyses performed for research is directed by the ESS staff. These projects include the Baseline Hydrogeological Investigation, Aquifer Characterization Program, head reversal studies, and others. In addition, ESS works closely with Environmental Restoration Department (ERD) scientists to complete more site-specific bydrogeologic regime analyses. Examples include particle-tracking studies and groundwater-flow modeling in GSA, A/M Area. TNX, and groundwaterflow patterns near coal piles.

\section{Environmental Restoration}

ER also performs hydrogeological regime analysis. In these cases, the projects ordinarily involve groundwater monitoring of a waste unit or operating facility. Examples include the M-Area Settling Basin area and groundwater activities in GSA.

\section{Technical Support}

\section{Understanding the SRS Hydrologic Cycle}

Stratigraphic Definition of SRS-This study documents the geology, hydrology, and geohydrology of SRS. This is a geological study of the entire sedimentary column, with a goal to define aquifers underlying SRS, the interconnections, and the hydraulic properties. Aquifers will be delineated in both the regional and unit-specific geological framework.

Detailed Characterization of SRS Aquifer Systems-This program includes pumping tests and detailed chemical analysis of groundwater samples collected from wells installed as part of the Baseline Hydrogeologic Investigation. The groundwater 
chemistry portion of the program is being completed to provide a better estimate of groundwater-flow rates and paths. This information then will be used as input for groundwater-flow and transport models.

Seismology of SRS-This program maintains and upgrades four vertical, two horizontal, and three downhole sensing seismometers as part of SRS's seismological network. By the end of this year, six, three-component seismometers will be installed at locations offsite.

Geologic Map of SRS-This program calls for creating a geologic surface map of SRS. ESS scientists will work closely with geologists from the South Carolina Geologic Survey to complete this task. Maps of quadrangles surrounding SRS already have been completed.

Geophysical Studies-This study will develop an understanding of the threedimensional geologic structure beneath the site. Techniques used will be geomagnetic, seismic, and gravity surveys.

\section{Offsite Geological Investigations:}

South Carolina-SRS is coordinating a project with SCWRC to establish a permanent network of clustered wells offsite to study the hydrogeologic regime throughout South Carolina.

Georgia-DOE is funding a five-year study for the USGS to investigate groundwater flow, especially in the Cretaceous aquifers, across the Savannah River into Georgia. A better understanding of groundwater-flow directions and magnitudes in the area surrounding SRS is required. This study greatly will aid the existing knowledge base. 


\section{Groundwater Monitoring}

(Compiled and reviewed by Pamela B. Barnard)

\section{Site Program Overview}

Protecting the aquifers underneath SRS is a major component of the groundwaterprotection and waste-management program. EPD's office of the site groundwater coordinator is leading the organization responsible for aquifer protection through a comprehensive monitoring effort. Many groundwater-monitoring wells have been installed onsite. The data are being examined to monitor existing plumes and to identify any additional impacted locations.

\section{Regulatory Requirements}

\section{Federal Laws}

Resource Conservation and Recovery Act (RCRA)-RCRA regulations include explicit specifications for groundwater-monitoring requirements (40 CFR 264 and 265).

Comprehensive Environmental Response, Compensation and Liability Act (CERCLA)-CERCLA regulations govern restoring the environment at iacilities designated on the NPL. SRS was included on the NPL in December 1989.

Public Law 98-181-This law, passed in 1983, specified discontinuing the use of the settling basin in M Area by November 1985 and required the Department of EnergySavannah River (DOE-SR) to develop a plan for groundwater protection and submit it to Congress. The authorization to design and construct the $300 \mathrm{M}$-Area effluent treatment facility (ETF) is included in the law. SRS met the requirements of Public Law 98-181 by closing the M-Area Setuing Basin in July 1985 and by submitting a groundwater-protection plan to Congress in May 1984. The provisions in the plan represent ongoing cummitments.

\section{State Regulations}

R.61-61 - Solid Waste Regulation-This regulation specifies procedures for closing or abandoning solid-waste disposal units. The requirements include post-closure monitoring by at least one monitoring well with readings collected quarterly for submittal to the State Board of Health's Solid Waste Division.

R.61-66 - Industrial Solid Waste Disposal Site Regulation-This regulation requires a permit for operating any industrial, solid-waste system. If the system involves hazardous waste, then a groundwater-monitoring system must be developed into the unit plan. 
R.61-70 - South Carolina Landfill Regulation-The South Carolina Landfill regulation requires an owner or operator of a solid-waste disposal facility to obtain a permit to operate a sanitary-waste landfill. In addition, observation test wells that provide reliable data on groundwater contamination must be included in the unit design.

R.61-71 - Well Standards and Regulations-The South Carolina Well Standards and Regulations apply to any newly-constructed well, including water supply and monitoring wells. These regulations establish minimum standards for well construction and well locations. They require that a water-well record form (HDI 9-77) be submitted to SCDHEC within 60 days after completing any well or the abandonment of a well.

R.61-79.264 - Hazardous Waste Management Facilities Regulation-The hazardous-waste waste management regulation establishes minimum standards for managing hazardous waste for owners or operators of permitted hazardous-waste treatment, storage, and disposal facilities. The groundwater-protection standards, required by this regulation, will be met once SRS obtains its complete permit.

\section{Consent Orders}

DOE agreed to additional groundwater monitoring for basins in $M, F$, and $H$ Areas under a consent order (CO 85-70-SW) signed November 7, 1985. A settlement agreement (SA 87-52-SW), signed on June 20, 1986, requires periodic groundwater-quality assessments at several units and a biennial update of the Groundwater-Quality Protection Program's technical summary.

\section{DOE Orders}

5400.1 General Environmental-Protection Programs-This DOE order requires developing groundwater-monitoring programs at the site.

5480.2 Hazardous and Radioactive Mixed Waste Management-DOE Order 5480.2 establishes hazardous-waste management procedures for DOE facilities that generate, transport, treat, store, and/or dispose of hazardous waste. This order requires groundwater monitoring of all solid, hazardous, and mixed-waste management facilities to ensure that groundwater quality is not degraded.

5820.2A Radioactive Waste Management-DOE Order 5820.2A establishes policies and guidelines for DOE to manage its radioactive waste, waste byproducts, and radioactivity-contaminated surplus facilities. Under this order, the waste-management plan for each radioactive waste-management facility must include a section on the radioactive and nonradioactive monitoring programs, including groundwater monitoring.

The groundwater-monitoring program supports the hydrogeological regime objective. 


\section{Organizational Responsibilities}

Groups responsible for groundwater-monitoring activities are discussed below.

Custodians of facilities that have affected or are likely to affect groundwater are responsible for assessing the groundwater impact. This includes a significant effort to describe the site hydrogeology. These projects are performed by ESS, EPD, EMS, custodial staff, and consultants. The primary custodian role lies with ERD.

Operating organizations proposing hydrogeological-related efforts must complete and submit a general program plan for hydrogeologic work at SRS to EPD. Prior to commencing the project EPD and SRTC must approve the plan. EPD is responsible for coordinating all activities relating to the quantity and quality of groundwater, including program completeness, consistency, uniformity, and progress, and for reviewing data and reports prior to transmittal to the regulatory agencies.

Groundwater projects are carried out by the department with custodial responsibility for the geographical area where the project will occur. Most well drilling, soil boring and monitoring activities are centralized in EPD. The custodians are responsible for budgeting and planning groundwater projects, managing the projects, conducting data evaluations and preparing reports. EPD and SRTC support organizations have the expertise to conduct data evaluations and prepare reports. EPD administers most of the well-drilling contracts. SRTC has an independent drilling program.

EPD is responsible for administering subcontracts for groundwater well drilling, sampling, and analysis. EPD ensures that quality-assurance and quality-control requirements for sampling and analytical programs are met. Analytical results are sent directly to the appropriate custodian or through EPD. EPD maintains a computerized database containing well-construction records, well logs, cores, and analytical data.

EPD has established an extensive and comprehensive Groundwater Monitoring Program (GMP). The purpose of the GMP is to determine if any SRS facilities have influenced groundwater quality, and if they have, to quantify the influence. Facilities monitored include waste-disposal sites, spill sites, chemical-storage areas, process sewers, and cerain process buildings.

ERD has submitted a Contaminated Groundwater Management Plan to DOE.

Site Services Engineering is responsible for coordinating process and domestic water well construction, maintenance, and abandonment activities. 


\section{Programs}

\section{Oversight}

Custodial departments proposing hydrogeological-related efforts must complete and submit a general program plan for hydrogeologic work at SRS to EPD. Prior to commencing the project, EPD must approve the plan. EPD is responsible for coordinating all activities relating to the quantity and quality of groundwater, including program completeness, consistency, uniformity, and progress, and for reviewing data and reports prior to transmittal to regulatory agencies.

Procedure Manual 3Q5, Hydrogeologic Data Collection Methods, was developed to establish a single set of procedural methods for acceptable hydrogeological-investigation data collection and selected environmental testing protocols. The manual is organized so that updates require minimal effort. New sections may be added as activities requiring standardized procedures are identified.

\section{Groundwater Monitoring Program}

SRS has established an extensive and comprehensive Groundwater Monitoring Program (GWMP). The purpose of GWMP is to determine if any SRS facilities have influenced groundwater quality, and if they have, to quantify the influence. Facilities monitored include waste-disposal units, spill sites, chemical-storage areas, process sewers, and certain process buildings. EMS conducts all compliance groundwater monitoring at SRS. GWMP is composed of the following four subprograms:

- well drilling, maintenance, and abandonment

- water sampling

- sample analyses

- data management and reporting

The following are projects that support the GWMP described below:

- Well Drilling, Maintenance, and Abandonment-Monitoring wells are drilled and installed according to procedures and specifications described in 3Q5-Hydrogeologic Data Collection. A detailed protocol is mandated to ensure construction continuity. Such specifications conform to recently published SCDHEC guidelines. A monitoring-well installation report is completed and submitted with the general program plan for EPD review and approval. A final report is submitted to EPD upon completion of the well-installation process. The maintenance of all monitoring wells is done on a quarterly inspection by the sample-collection contractor. EPD has identified and located all monitoring wells within SRS that serve no present or future use and can be abandoned. The wellabandonment program is ongoing with PES and EPD in the lead. The $3 Q 5$ manual provides the procedures and specifications for abandoning groundwatermonitoring wells. The Production Well Standards Manual (WSRC-EPD-PED902581) provides specifications for abandoning production wells. The intent of 
these procedures and specifications is to return each aquifer and overlying sediments to as near the original state as possible. An abandonment-program plan is prepared for each well or group of wells to be abandoned. All proposed abandonment-program plans are reviewed and approved by EPD.

- Monitoring Well Surveying-This task involves subcontracts awarded to surveying firms so that new wells and soil cores accurately are placed and existing wells and soil cores may be located accurately, even after a long period of abandonment. Typically, surveying teams gather the well number, SRS grid coordinates, casing elevation, and ground-elevation information.

- Monitoring Well Drilling and Soil Coring-This task includes all monitoring-well and soil-core drilling, installing, and abandoning activities conducted by EMS. The actual well drilling and soil coring is subcontracted. Waste-unit custodians are responsible for transferring funds to EMS to pay for well installations, soilcore drilling and abandonment activities.

- Technical Oversight of GWMP-Qualified support is provided to oversee contractors working in EMS GWMP. An independent contractor provides an individual to oversee another contractor's activities. Additional support is provided as needed. This task supplements EMS by providing additional oversight of subcontractors. Activities that receive oversight from this project are well drilling and installation, soil coring, and well maintenance.

- Monitoring Well Maintenance-Well maintenance is the repair or replacement of malfunctioning electrical and mechanical equipment, in addition to routine maintenance. The objective of this task is to maintain the monitoring wells to minimize well contamination and failure and to comply with all state and federal regulatory requirements. Well-maintenance activities are conducted by a subcontractor.

\section{Environmental Protection Department}

In order to ensure that state and federal standards are met, EPD provides an independent contractor to oversee the drilling, installing, and abandoning of all monitoring and production wells. It is the contractor's responsibility to: conduct formal, written audits of the drilling subcontractor and technical oversight performance on individual well installation/abandonments; ensure that SRS wellinstallation/abandonment specifications are being followed by the drilling subcontractor; monitor the drilling subcontractor's overall performance; and monitor the quality of installation/abandonment. 


\section{Water Sampling}

Properly collecting groundwater samples is of prime importance in conducting a complete and defensible hydrogeologic investigation. The protocol used to ensure representative groundwater samples is: obtaining a sample that is representative of subsurface conditions; minimizing the potential for contaminating samples from sampling equipment, jars, etc.; proper logging, field testing, filtering, and preserving the samples; and proper documenting, including chain-of-custody records. A sampling program description form (3Q5-XI-1) must be completed and submitted along with the general program plan to EPD for review and approval prior to initiating a groundwater-sampling program. The sampling program must be developed using the specific field procedures described in Procedure Manual $3 Q 5$.

\section{Environmental Monitoring Section}

The well-sampling task ensures that groundwater samples follow accepted EPA sampling protocol, are collected on schedule, and are not subjected to outside contamination. Therefore, quality control is a very important aspect of the groundwater-sampling lask.

\section{Sample Analyses}

The analytical laboratories contracted to perform sample analyses adhere to the analytical methods and detection limits prescribed by EPA's sampling protacol SW-846 (3rd ed). The chemical constituents analyzed include: volatile organics; acid extractable and base neutral organics; pesticides and polychlorinated biphenyls (PCBs); inorganics; and radiological constituents. The accuracy and precision of the data generated by the contractor is determined through analyzing replicates, spiked samples, synthetic reference samples, and field or laboratory blanks submitted with each set of sampies.

\section{Environmental Monitoring Section}

Well Sample Analysis (Laboratory No. 1)-This task's purpose is to perform analyses on samples collected in the groundwater-monitoring program. These samples primarily are groundwater samples, but may include soil samples obtained through soil-coring operations. The primary analytical laboratory subcontractor is responsible for performing most of the analyses and can handle the needs of SRS's entire groundwater-monitoring program. This includes ensuring the quality of analytical results by rigorous quality-assurance procedures.

Well Sample Analysis (Laboratory No. 2)-This task's purpose is to provide a backup laboratory for any problems with the primary lab. Although the primary analytical laboratory has the responsibility of performing most of the analyses, circumstances may arise, due to equipment malfunction or sample load, where one laboratory may 
not be able to handle all analyses. Therefore, a secondary subcontractor laboratory that has the capacity to handle the sample-analysis and data-management needs of the entire groundwater-monitoring program will be named. This would include ensuring the quality of analytical results by rigorous quality-assurance procedures.

Well Sample Analysis (Laboratory No. 3)-This task's purpose is for a third subcontractor laboratory to perform $\mathrm{QA} / \mathrm{QC}$ work in order to check the results provided by the primary and secondary laboratories. The tertiary analytical laboratory is responsible for performing check analyses such as split-sample analyses. The results yielded by the check analyses are compared to the results obtained in the initial analyses by a simple statistical procedure. This comparison is the fundamental unit of the quality-assurance procedure. The tertiary laboratory does not have to perform all sample analyses and data-management work for the SRS's entire groundwatermonitoring program.

\section{Data Management and Reporting}

GWMP provides a data-management unit which receives, collates, and reviews data from various sources (laboratory, field personnel, drilling documentation, etc.); and organizes this data into a report-ready database. Data can be extracted from the database by personal computers connected to SRS's local area network. Monthly printouts highlighting flagged analyses are forwarded to the custodians and EPD. The flagged values do not necessarily have regulatory significance; they are intended to assist with data interpretation and scheduling. This printout provides the custodians and EPD preliminary data, allowing then to assist in the review process at the earliest possible point. Analyses are compiled in quarterly reports which are issued to the custodians and EPD. The custodians have the responsibility for data interpretation. The data-management element of GWMP is described in detail in DP-MS-87-109, The Organization and Operation of the Savannah River Site's Groundwater-Monitoring Program.

\section{Environmental Protection Department}

Well-construction data for approximately 2200 unit wells are located in a centralized database. The data provides information on well-construction details such as location, coring, drilling, geophysical logging, maintenance and abandonment. It provides the use with menu-driven searches by the following:

- well ID

- well coordinate

- distance (radius) from SRS coordinates

The well-construction data system is part of an effort to centralize data associated with the site's groundwater activities. 


\section{Environmental Monitoring Section}

Groundwater Monitoring Data Management and Report Preparation-This task's responsibility is to manage sample-analyses data received from the analytical laboratory, to schedule samples and to prepare reports. Data management is composed of: receiving laboratory results on a floppy disk; verifying these results by evaluating data from standards, blanks, duplicates, and previous analysis; entering the information into the computer; comparing the analytical results with flagging criteria; and formating the data for report preparation. Report production includes quarterly and annual nonradioactive groundwater-monitoring reports. 


\section{Water Conservation}

(Compiled and reviewed by Pamela B. Barnard)

\section{Site Program Overview}

Protecting the water resources (groundwater and surface water) by managing the quantity of water being used versus the amount available represents an important part of the SRS Groundwater-Protection and Waste-Management Program. Responsible use of SRS water resources also provides secondary benefits resulting in lower energy and wastewater treatment costs, while ensuring adequate water supplies for future SRS and neighboring activities.

Regional groundwater-assessment programs have documented the availability of adequate water supplies (DOE, 1987a). For more than 40 years, SRS operations in conjunction with other local industrial, agricultural, and municipal users have not affected adversely groundwater availability. The abundance of groundwater results in little direct economic benefits regarding to water conservation, but because of the potential for waste minimization, a water-conservation program is being developed. Water conservation has resulted indirectly from other environmental regulatory or economically driven programs.

\section{Regulatory Requirements/Justification}

\section{State Laws}

South Carolina Water Use and Coordination Act-This regulation requires SRS to report water use of more than 10,000 gallons, withdrawal or diversion of surface, underground and other waters in South Carolina to SCWRC.

In addition, South Carolina has drought-response regulations that can require consumption reductions at times.

The water-conservation program supports the groundwater conservation regime objective.

\section{Organizational Responsibilities}

Discussed below are those groups with the responsibility for the water-conservation program. 


\section{Environmental Protection Department}

EPD is responsible for the technical and regulatory review of all activities affecting groundwater and site geology. EPD provides the lead support for initiating water-conservation programs, conducts periodic surveys of water-use activities, and provides recommendations for specific conservation programs. Additionally, EPD will address water conservation in conjunction with related environmental audits and assessments in which it participates.

\section{Custodial Departments}

Various custodial departments have personnel responsible for documenting water-use activities to ensure the responsible use of water resources, and to compile data for the quarterly Water-Use Report submitted to the South Carolina Water Resource Commission. The personnel also are responsible for submitting appropriate water-conservation information, as required, to EPD for review and approval.

\section{Programs}

\section{Custodial Departments}

The custodial departments will submit an Annual Water-Conservation Assessment Report to EPD beginning in FY 93.

The Annual Water Conservation Assessment Report will address the following subjects:

- present fiscal year water use

- previous two fiscal years water use

- reason for increase or decrease

- proposed water conservation projects for next three fiscal years including:

- project description

- water savings as a percentage of total use

- affect on groundwater head reversal if any

- project cost

SRS has implemented a broad-based waste-management program which includes significant waste-minimization activities for the Waste Minimization Program. Although specifically designed to minimize waste stream quantity, many of these programs significantly reduce the quantity of process water use. A recent example of this secondary benefit type of water-conservation program is the M-Area wastewater reduction in the metal-fabrication operations program. Through careful analysis of existing processes, wastewater from 87 process effluents was reduced from 528 gallons per minute (gpm) to $20 \mathrm{gpm}$ (Martin et al., 1987). As similar analyses are performed, the water-conservation benefits should be reevaluated to justify the need for such programs. 


\section{Environmental Protection Department}

EPD provides the technical and regulatory review of all activities affecting groundwater and the lead support for initiating water-conservation programs. Periodic surveys of water-use activities, recommendations for specific conservation programs, and water conservation in conjunction with related environmental audits and assessments are ongoing activities.

\section{Site Services}

\section{Site Services Engineering}

Installing metering devices for all production wells (i.e., greater than $10 \mathrm{gpm}$ ) is necessary to report accurately sitewide groundwater use to the South Carolina Water Resources Commission on a quarterly basis and to provide precise baseline information for SRS's water-conservation program. Existing production wells will be retrofitted with flow meters by June 1996. 


\section{Contamination Prevention}

(Compiled and reviewed by Ross L. Fanning)

\section{Site Program Overview}

Systems to prevent groundwater contamination include all site diking systems and procedures, well design and installation specifications, and new underground storage tanks, associated equipment and piping systems. Diking systems prevent groundwater contamination by containing small leaks from above-ground facilities in addition to protecting surface waters from spill runoff. Well specifications and procedures in Procedure Manual $3 Q 5$ prevent contamination by ensuring all wells are installed properly to prevent cross contamination of aquifers, in addition to meeting regulatory construction requirements. All new tank systems containing hazardous substances as defined in the Comprehensive Environmental Response, Compensation and Liability Act (CERCLA), petroleum products, or hazardous waste provide groundwater protection with double-walled, steel construction with interstitial monitoring and cathodic protection.

Since the site diking program and well specifications are discussed in other sertions of the plan, this section deals almost exclusively with SRS's underground storage tank program.

Five-Year Outlook

Underground storage tank compliance over the next five years will require ongoing release detection for existing tanks and initiating projects to replace or upgrade tanks that don't meet new tank-performance criteria. Underground storage tanks installed before December 22, 1979, must comply with release detection requirements by December 22, 1992. Underground storage tanks installed between December 22, 1979 , and December 22, 1988, must comply with release-detection requirements by December 22, 1993. Underground storage tanks installed after December 22, 1988, must meet release-detection requirements upon installation.

All underground storage tank systems must meet the performance requirements of new systems by December 22, 1998. Existing tank systems may be replaced, upgraded, or closed.

\section{Regulatory Requirements}

The Hazardous and Solid Waste Amendments of 1984 (HSWA) expanded the RCRA in Subtitle I to include underground storage tanks. The final underground storage tank regulations (Subtitle I) were promulgated in 1988. DOE entered into negotiations with SCDHEC to include underground storage tanks in the existing Memorandum of Agreement (MOA). This gave SCDHEC control over tanks containing petroleum products at SRS under the existing SCDHEC underground storage tank regulations. 


\section{Federal Law}

Resource Conservation and Recovery Act (RCRA)-Permitting tanks regulated under RCRA Subtitle $C$ is a two-part process. The first part involves submitting a Part $A$ application, containing basic information describing the tank system. The second part involves submitting a Part B application, containing more detailed information of the tank system and a certified tank assessment. The hazardous-waste tank regulations require that all new tank systems have secondary containment with release detection, be built with material compatible with the waste type, and be protected from corrosion.

Regulations resulting from Subtitle I require EPA notification of all underground storage tanks in operation which contain petroleum products or a hazardous substance, as defined in CERCLA. SCDHEC was notified of all applicable tanks at SRS on May 8, 1986. All new tanks must have a release-detection system, corrosion protection, spill-and overfill-prevention devices, and be constructed with material compatible with the substances to be stored.

\section{State Regulations}

Underground Storage Tank Control Regulations (R.61-92)--These regulations require that all tanks installed after January 1, 1986, prevent releases due to corrosion, have a release-detection system, and maintain an inventory recordkeeping system. The regulations also include requirements for notifications, permitting, installations, general operations, corrective actions, and abandonment activities.

\section{Policy}

SRS's policy is to handle hazardous materials in pipelines and vessels above ground as long as it is safe and technically and economically feasible. When underground installations are appropriate, measures must be taken to ensure that such installations environmentally are sound. A comparative risk analysis must be performed to determine if the system may be installed underground. All new underground storage tanks which contain a hazardous substance or a petroleum product will be doublewalled steel with interstitial monitoring and cathodic protection.

Contamination-prevention systems support waste-disposal requirements and the operational guidelines objectives.

\section{Organizational Responsibilities}

\section{Environmental Protection Department (EPD)}

EPD is responsible for communicating applicable hazardous-waste and underground storage tank regulation requirements to the custodial departments. EPD also is the interface with DOE and SCDHEC, including permit transmittals. EPD also is 
responsible for sitewide consistency in information included in the hazardous-waste tank assessments.

EPD is responsible for overseeing the SMARTS program as it applies to underground-tank systems. This includes reviewing the comparative risk analysis, obtaining plant manager approval for tank installation, coordinating the permitting of new facilities, ensuring all departments have an active inventory program, and updating the SMARTS program when new regulations are promulgated. The SMARTS program also requires that all tanks subject to Subtitle I regulations have an inventory recordkeeping system. The program also provides plant policy on operating requirements, corrective-action responsibilities and abandonment practices.

\section{Custodians}

Custodians also are responsible for identifying the new tank systems required to meet the facility needs and for acquiring the funding for tank design, construction, and installation. Custodians also are responsible for providing the information required for the applicable permits. A listing of SRS's underground tanks by custodian is provided in Table 7.2. 
Table 7.2. Underground Storage Tanks

Qrganization

CSWE

Construction Management

DWPF

Power Operations

Reactor

Reactor Materials

Safeguards \& Security

SRTC

Wackenhut Security

Waste Management

Underground Hazardous Waste Tanks

Waste Management
TankDescription

Service Station Tanks (12)

Bulk Storage Tanks (2)

Heating Fuel Tanks (1)

Service Station Tanks (2)

Emergency Generator Feed Tanks (2)

Emergency Generator Feed Tanks (13)

Emergency Generator Feed Tanks (12)

Radioactive Waste Holding Tanks (2)

Extrusion Press Sump (1)

Emergency Generato Feed Tanks (2)

Fueling Tank (1)

Chemical Waste Storage Tanks (2)

Radioactive Waste Holding Tanks (10)

Fueling Tank (1)

Standby Generator Feed Tanks (2)

Radioactive Waste Holding Tanks (31)

Radioactive Waste Storage Tanks (52) 


\section{Site Procedures and Documents}

WSRC 3Q. Procedure ECM 6.6, Underground Storage Tank Management and Removal, outlines the requirements for proper management or closure of $\downarrow$. aderground storage tanks. WSRC-IM-90-90, Specifications and Management for Regulated Tank Systems, provides custodians comprehensive guidance concerning the proper operation, maintenance, installation, closure, and corrective action for regulated tank systems.

\section{Technical Support Programs}

The custodial departments' monitoring and surveillance systems are detailed in the next section, contamination detection.

\section{Diking Systems}

SRS's program is to retrofit existing above-ground storage areas with impervious diking systems to contain leaks and spills. All new site facilities are required to include containment structures as part of the original design. Although the primary justification for these systems is to protect surface water spills and leak runoffs, totally-contained dikes also provide groundwater protection by containing small leaks.

\section{Well Specifications}

SRS has standard well specifications for the design, construction, and operation of monitoring and production wells. These specifications ensure all new monitoring wells are installed according to RCRA requirements. Site procedures ensure these wells are sampled and analyzed according to EPA protocol standards. The monitoring-well specifications and sampling procedures are contained in Procedure Manual $3 Q 5$. Although these specifications and sampling procedures primarily were designed to comply with rigid, regulatory sampling requirements and health standards, these strict standards protect the groundwater by lowering the potential for an improperiy installed well to cross contaminate aquifers.

\section{One-Year Road Map}

Construction Management plans to replace four underground storage tanks by installing three above-ground fuel storage tanks at Central Shops. The total tank capacity is expected to be 60,000 gallons $(40,000$ diesel fuel, 20,000 gasoline).

Reactors will complete the closure of the 108-L and 108-P tank systems. The 108-K tank system will be maintained. CSWE is sponsoring a project to replace the 760-7G fuel tank at the Forestry Station. Power Operations will continue its ongoing project to replace all existing underground storage tanks. 


\section{Five-Year Road Map}

Projects should be initiated to replace or upgrade existing underground storage tanks that do not meet new tank-performance requirements. WM/ER also plans to abandon and decommission 31 underground holding tanks which contain radioactive waste. 


\section{Contamination Detection}

(Compiled and reviewed by Ross L. Fanning)

\section{Site Program Uverview}

Contamination detection includes the site monitoring-well program ald the underground storage tanks inventory systems. Monitoring wells are installed around existing facilities if there is an indication of impacted groundwater or if there is a high potential for future impacts. All major new facilities have monitoring wells installed during construction. All underground storage tanks containing hazardous materials, petroleum products, or hazardous waste have an inventory and leakage-detection system. These inventory systems are designed to meet regulatory requirements, as well as to protect the groundwater.

Since the monitoring-well program is discussed in another section of the plan. this section deals almost exclusively with SRS's underground storage tank inventory program.

Five-Year Outlook

Underground storage tank compliance over the next five years will require ongoing release detection for existing tanks and initiating projects to replace or upgrade tanks that don't meet new tank-performance criteria. Underground storage tanks installed before December 22, 1979, must comply with release-detection requirements by December 22, 1992. Underground storage tanks installed between December 22, 1979, and December 22, 1988, must comply with release-detection requirements by December 22, 1993. Underground storage tanks installed after December 22, 1988 , must meet release-detection requirements upon installation.

All underground storage tank systems must meet the performance requirements of new systems by December 22, 1998. Existing tank systems may be replaced, upgraded, or closed.

\section{Regulatory Requirements}

The Hazardous and Solid Waste Amendments of 1984 (HSWA) expanded RCRA in Subtitle I to include underground storage tanks. The final underground storage tank regulations (Subtitle I) were promulgated in 1988. DOE entered into negotiations with SCDHEC to include underground storage tanks in the existing Memorandum of Agreement (MOA). This gave SCDHEC control over tanks containing petroleum products at SRS under existing SCDHEC underground storage tank regulations.

\section{Federal Law}

Resource Conservation and Recovery Act-Permitting tanks regulated under RCRA Subtitle $\mathrm{C}$ is a two-part process. The first part involves submitting a Part $\mathrm{A}$ 
application, containing basic information describing the tank system. The second part involves submitting a Part B application, containing more detailed information of the tank system and a certified tank assessment. The hazardous-waste tank regulations require that all new tank systems have secondary containment with release detection, be built of a matertal compatible with the waste type, and be protected from corrosion. These regulations aiso require performing a tank assessment for all existing tanks which do not have a secondary containment system meeting the regulatory requirements. If a tank does not have a secondary containment system, it must be retrofitted with a secondary containment system which does or be ciosed.

Regulations resulting from Subtitle I require EPA notification of all underground storage tanks in operation which contain petroleum products or a hazardous substance, as defined in CERCLA. SCDHEC was notified of all applicable tanks at SRS on May $8,1986$.

All existing lanks must be retrofitted with leak-detection corrosion-protection and spill- and overfill- prevention devices within a 10-year period.

\section{State Regu'ations}

Underground Storage Tank Control Regulations (R.61-92)-These regulations require that all tanks installed after January 1, 1986, to prevent releases due to corrosion, have a release detectior system and maintain an inventory recordkeeping system. Under these regulations, each tank must have an inventory recordkeeping. system. The regulations also include requirements for notifications, permitting, installations, gesieral operations, corrective actions, and abandonment activities.

\section{Organizational Responsibilities}

\section{Environmental Protection Department (EPD)}

EPD is responsible for communicating applicable hazardous-waste and underground storage tank regulation requirements to the custodial departments. EPD also is the interface with the DOE anc SCDHEC, including permit transmittals. EPD also is responsible for sitewide consistency in information included in the hazardous-waste tank assessments.

EPD is responsible for overseeing the SMARTS program as it applies to underground tank systems. This includes reviewing the comparative risk analysis, obtaining plant manager approval for tanix installation, coordinating the permitting of new facilities, ensuring all deparunents have an active inventory program, and updating the SMARTS program when new regulations are promulgated. The SMARTS program also requires that all tanks subject to Subtitle I regulations have an inventory recordkeeping system. The program also provides plant policy on operating requirements, correcive-acion responsibiliti ss and abandonment practices. 


\section{Custodians}

The custodians are responsible for properly operating the underground tanks. The custodians also are responsible for developing and implementing the regulatory, required inventory systems. It is the custodial departments' responsibility to determine which tanks need to be replaced or upgraded and to acquire the funding necessary to meet applicable regulation requirements.

\section{Site Procedures and Documents}

WSRC 3Q, Procedure ECM 6.6, Underground Storage Tank Management and Removal, outlines the requirements for proper management or closure of underground storage tanks. WSRC-IM-90-90, Specifications and Management for Regulated Tank Systems, provides custodians comprehensive guidance concerning the proper operation, maintenance, installation, closure, and corrective action for regulated tank systems.

\section{Technical Support Programs}

A listing of SRS underground tanks by custodial deparument is provided in Table 7.2.

\section{Soil Gas and Geophysical Surveys}

SRTC - Environmental Sciences Section-Soil-gas analysis is a tool used at SRS to identify contaminant areas and to track shallow groundwater plumes. The technique has been successful in detecting chlorocarbon, oil, and mercury in groundwater at disposai and spill sites. Soil gas surveys are used as a screening technique in the preliminary characterization of a waste site. Shallow geophysical techniques such as ground-penetrating radar also are being used to characterize waste sites.

\section{Monitoring Well Requirements}

EPD—SRS has criteria for installing monitoring wells for early indications of groundwater impacts. Monitoring wells are installed around existing facilities if there are indications of impacted groundwater or if there is a bigh potential for future impacts. All major new facilities, such as the Defense Waste Processing Facility (DWPF), have monitoring wells installed during construction to obtain pre-startup data and to detect any impacts from operations.

\section{Monitoring/Surveillance/Testing}

All custodial departments are required to inventory and maintain inventory records on all underground storage tanks containing hazardous materials, petroleum products, or hazardous waste. 


\section{Central Services Works Engineering}

CSWE uses both a constant-level monitoring device and computerized automated fuel-pump dispensers at the service station tanks as part of the required inventory program. The level-monitoring device provides information on the number of inches of fuel in the tank, the number of gallons of fuel remaining in the tank, the number of inches of water in the tank, and the fuel's temperature. The automated fuel device provides information on the fuel transactions from a given tank. Manual tank inventory methods are performed once a week to verify the data obtained from the automated inventory devices.

\section{DWPF}

Two underground fuel-storage tanks were installed at DWPF in 1985. The tanks are a double-walled, steel design with continuous interstitial monitoring and sacrificial anodes for corrosion protection.

\section{Construction Management}

Construction Management uses manual monitoring devices to obtain in-tank liquid and water levels and metering devices to determine fuel transactions from a given tank. The net gains/losses are computed daily.

\section{Power Operations}

Power Operations uses manual monitoring devices to obtain in-tank liquid and water levels and metering devices to determine fuel transactions from a given tank. The net gains/lossf $s$ are computed daily.

\section{Reactor Materials}

Reactor Materials has a new underground oil sump which has full secondary containment and interstitial monitoring for leak detection. 


\section{Reactors}

Reactors uses manual monitoring devices to obtain in-tank liquid and water levels and metering devices to determine fuel transactions from a given tank. The net gains/losses are computed daily.

\section{Safeguards and Security}

Safeguards and Security uses manual monitoring devices to obtain in-tank liquid and water levels and metering devices to determine fuel transactions from a given tank. The net gains/losses are computed daily.

\section{SRTC-Technical Area}

SRTC uses in-tank monitoring devices to obtain liquid levels and to determine waste transactions from a given tank. Sump alarms, located within the secondary containment, serve as release detectors. The tank facility is operated under a RCRA IS Permit.

\section{Vaste Management}

Waste Management's underground high-level radioactive waste storage tanks each have an electrical reel tape to monitor liquid levels. Each reel tape is verified once a month by comparing readings between a steel tape manually lowered into the tank and the reel tape. Each tank also has a high-level conductivity probe.

Detailed procedures are in place to make material balances wher vaste is transferred between tanks. Tank-level readings are recorded each hour and a balance is made every four hours during the transfer. Each jacket is sloped to a low point where leak-detection equipment (conductivity probe) is located. Of the 51 tanks, 43 have an annulus. Each annulus has three conductivity probes and one pneumatic liquid-level bubbler. The other eight tanks are single-walled tanks.

Waste Management uses manual monitoring devices to obtain in-tank liquid and water levels in the nonradioactive underground tanks. The net gains/losses are computed daily.

One-Year Road Map

Construction Management plans to replace four underground storage tanks by installing three above-ground fuel storage tanks at Central Shops. The total tank capacity is expected to be 60,000 gallons (40,000 diesel fuel, 20,000 gasoline).

Reactors will complete the closure of the 108-L and 108-P tank systems. The 108-K tank system will be maintained. CSWE is sponsoring a project to replace the 760-7G 
fuel tank at the Forestry Station. Power Operations will continue its ongoing project to replace all existing underground storage tanks.

\section{Five-Year Road Map}

Projects should be initiated to replace or upgrade existing underground storage tanks that do not meet new tank-performance requirements. WM/ER also plans to abandon and decommission 31 underground holding tanks which contain radioactive wastes. 


\section{Chapter 8}

\section{Waste Management and Disposal}

Chapter was compiled and reviewed by Natalie D. Ferguson. 
Waste Management Operations Program Plan provides a strategy to comply with applicable federal and state regulations, Department of Energy (DOE) orders, and operating contractor policies related to groundwater protection, waste treatment, storage, and disposal activities. The plan covers disposal of all nonhazardous, hazardous, as defined by the Resource Conservation and Recovery Act (RCRA), radioactive, and RCRA hazardous radioactive (mixed) wastes.

The Savannah River Site's (SRS) waste-management plan is updated annually. Facilities for treating, storing, or disposing of the waste are detailed in the plan and include those that currently are operating in active design or construction, and those in the conceptual planning stage.

The SRS's Site Specific Plan (SSP) is produced annually to define sitewide environmental-restoration and waste-management activities identified by the DOE Waste Management and Environmental Restoration (WM/ER's) Five-Year Plan (FYP).

The FYP describes WM/ER's planning process, communicates WM/ER's philosophy and overall strategy for achieving its compliance and cleanup goals, summarizes multi-year program plans, and assesses progress made during the previous year. The FYP goal is to ensure that human health, safety, and environmental risks posed by the department's past, present, and future operations either are eliminated or reduced by the year 2019.

Sections and figures from the above three plans are presented to describe wastedisposal practices and waste-management. (Site Specific Plan. WSRC-RP-91-596 and Environmental Restoration and Waste Management Five-Year Plan FY 1993-1997). 


\section{Objectives}

SRS's waste-management objectives are to comply with applicable federal and state regulations. DOE orders and Westinghouse Savannah River Company (WSRC) policies to minimize effects on the environment and minimize waste generation as much as technically and economically practicable. Exceptions to onsite final disposal are PCBs, which must go to EPA-approved PCB disposal facilities; high-level waste and TRU waste, for which federal repositories are to be designated; some types of nonradioactive hazardous waste, which are sent offsite for incineration and disposal until onsite facilities are available; and chlorinated hydrocarbons, lead batteries and scrap metal, which are sold to commercial recyclers. SRS also maintains an excess and salvage sales operation which includes items such as miscellaneous electrical components, drums, paint, miscellaneous pipes, and weld rod stubs.

A waste-minimization program has been implemented as part of the overall wastemanagement objectives. The waste-minimization program is an organized, comprehensive, and continual effort to reduce waste generation systematically. The program meets regulatory and WSRC requirements and is designed to eliminate or minimize pollutant releases to all environmental media from all aspects of the site's operations. The site Waste Certification and Minimization (WCAM) group has been assigned the responsibility to coordinate the development, promotion, implementation, and reporting of waste-minimization activities.

The waste-minimization program implements specific waste-minimization techniques and technologies based upon current information on waste generation, waste characterization, and ultimate waste-disposal costs. The program will develop guidelines for collecting information, evaluating options, and identifying cost-effective waste-minimization techniques. Waste minimization is discussed in more detail in the implementation section. 


\section{Strategy}

The strategy for achieving SRS waste management objectives is the following:

ensure that there is a method to dispose of the waste before it is generated

- reduce/minimize waste generation

- recycle/reuse consumed waste in processes as much as practical

- segregate waste at the point of generation in a manner that prevents cross contamination

- segregate waste at the generating location for temporary storage in permitted facilities, as required

- incinerate to destroy hazardous waste and reduce waste volume

- treat waste to minimize mobility before final disposal

- dispose of generated waste in monitored repositories

- maintain integrity of disposal sites to ensure performance objectives are met 


\section{Implementation}

The implementation section identifies programs. issues, and those responsible for actions to achieve stated objectives. Each environmental effort will require funding for one or more of the following: research and development, operations; programs; and construction/modification projects. -The following programs are found in the implementation section:

- Waste Management (page 8-7)

- Waste Minimization (page 8-10)

- Waste Handling, Treatment, and Disposal Guidance (page 8-19)

- RCRA Permitting (page 8-25) 


\title{
Waste Management
}

\author{
(Compiled and reviewed by Natalie D. Ferguson)
}

Site Program Overview

Waste-management activities are defined as the management of all waste types (DOE 1989). Radioactive waste is categorized by its respective handling and management criteria according to standards established by EPA and DOE orders. High-level waste (HLW) requires considerable shielding, is long-lived and will be disposed of in a geologic repository. Low-level waste (LLW) is defined as radioactive waste that is not HLW or transuranic (TRU) waste. LLW normally is solid waste that is containerized according to its radioactivity and is disposed of onsite. The TRU waste generated onsite generally requires little shielding, is extremely long-lived, and also will be disposed of in a federal geologic repository.

Hazardous waste is defined by several environmental laws and managed according to requirements established by EPA and states. Mixed waste contains both radioactive and hazardous components. It is managed to meet requirements for its radioactive and hazardous components imposed by EPA,.states, and DOE. Sanitary waste, which neither is radioactive nor hazardous, also is within of the FYP's scope and is managed according to established federal and state regulations (DOE 1989a).

SRS's waste-management practices are regulated by DOE, EPA, and SCDHEC. RCRA, also known as the Solid Waste Disposal Act, as amended, provides a comprehensive EPA regulatory program for hazardous-waste management and a state regulatory program for non-hazardous waste. SCDHEC has been granted authority by EPA to conduct the RCRA hazardous-waste program in South Carolina. The basic framework for the managing hazardous waste, from generation to final disposal, is presented in 40 CFR $260-280$.

All hazardous-waste treatment, storage, and disposal facilities at SRS either are: fully permitted, have interim status, or have entered into settlement agreements or consent orders with SCDHEC. SRS is in compliance with or has entered into compliance agreements related to groundwater-protection, waste-treatment, and waste-disposal regulations. Some facilities needed for treating, storing or disposing of the waste currently are operating; others are in active design or construction; still others are in the conceptual planning stage.

\section{Regulatory Requirements}

The basic framework for assessing all waste-management units and developing closure, post-closure, and remedial-action plans is based on the requirements of RCRA, CERCLA, as amended, South Carolina Solid Waste Regulations (nonhazardous sites), and South Carolina Hazardous Waste Management Regulations (SCHWMR). Waste-management units at SRS are identified in the Federal Facility 
Agreeinent (FFA) and will be addressed under an integrated RCRA/CERCLA program. The RCRA requirements have been the primary regulatory driver for operating SRS waste-management units.

\section{Federal Requirements}

Resource Conservation and Recovery Act (RCRA) - South Carolina is authorized by EPA to administer RCRA. Permitting under RCRA is a two-pant process. The first part involves submitting a Part A permit application that contains certain basic facility information. The second part involves submitting a Part B permit application that contains detailed information about the individual hazardous-waste management facilities, including closure and post-closure activities. The SRS Part B permit was applied for in February 1985 and has been revised to incorporate additional facilities. A permit was issued in September 1987 to authorize closure and post-closure activities for the site.

CERCLA/Superfund Amendments and Reauthorization Act (SARA) (Superfund) CERCLA is administered by EPA. According to Section 102(a) of CERCLA, federal government agencies are subject procedurally and substantively to comply with this law. SRS was placed on the National Priorities List (NPL) in December 1989. DOE$S R$ has negotiated an FFA with the state and EPA Region IV.

\section{DOE Orders}

DOE Order 5400.4 - This order establishes instructions for implementing the DOE CERCLA program, defines actions to identify and evaluate inactive hazardous-waste sites at DOE installations, and directs the custodian to take remedial action where necessary to improve control of hazardous-substance migration from such sites.

DOE Order 5400.3 - This order establishes hazardous-waste management procedures for facilities operated under the Atomic Energy Act and provides instructions for implementing the RCRA.

\section{State Requirements}

SRS waste-management programs are developed according to the South Carolina Solid Waste Policy and Management Act and applicable state regulations. 
Organization Responsibilities

Solid Waste Management/Liquid Waste Management

Each waste-management department has the primary responsibility for selecting, permitung, constructing and operating waste-management facilities.

\section{Environmental Protection Department (EPD)}

EPD is responsible for coordinating and organizing the permitting of wastemanagement facilities. EPD also is responsible for reporting the status of wastemanagement compliance to DOE and SCDHEC.

\section{Custodial Departments}

The custodial departments are responsible for proper identification, characterization, and packaging of waste according to regulatory, DOE and applicable Department of Transportation (DOT) requirements.

Savannah River Technology Center (SRTC)

SRTC is responsible for the research and development (R\&D) supporting waste characterization, treatment, storage, and disposal.

\section{Site Procedures and Documents}

- Procedure Manual 3Q, Environmental Compliance Manual

- SRS Waste Acceptance Criteria Manual, 3.08, 2/28/92

- SRS Waste Management Operations Program Plan

- SRS Waste Disposal Manual

- Site Specific Plan, WSRC-RP-91-596 


\title{
Waste Minimizatio
}

\author{
(Compiled and reviewed by Natalie D. Ferguson)
}

\section{Site Program Overview}

SRS's Waste Minimization Program is designed to reduce the generation, volume and toxicity of hazardous, mixed, low-level radioactive and nonhazardous waste generated onsite in order to minimize any present or future threat to human health and the environment. The program meets regulatory and operating contractor requirements and supports the waste-minimization objectives of the Environmental Implementation Plan (EIP).

The WCAM group will manage the waste-minimization program. It is responsible for coordinating, developing, promoting, implementing, and reporting site-wide wastereduction activities. The EPD provides regulatory review, program oversight and supplemental program support for waste reciuction, while SRTC's Interim Waste Technology Section provides the necessary research and development support to achieve waste-minimization goals. The organizations interact and participate in the site program through the site Waste Action Team (WAT).

The site waste-minimization program is an organized, comprehensive effort designed to reduce waste generation systematically. The program is designed to eliminate or minimize pollutant releases to all environmental media from all aspects of site operations. Generating, handling, and disposing of classified waste is addressed specifically as part of this program. These eiforts are carried out in an economicallypractical and environmentally-responsible manner.

The order of priority for pollution prevention/waste minimization is:

- source reduction (reducing waste generation at the source)

- recycle/reuse (using materials so they do not become a waste)

- treatment (reducing volume, toxicity, and/or mobility of waste)

- disposal in an environmentally-safe and economical manner

This approack is designed to yield the following benefits:

- reduced waste-management and compliance costs

- improved product yields

- reduced inventories and releases of hazardous chemicals

- energy conservation and reduced raw material costs

- natural resource conservation

- reduced civil and criminal liabilities under environmental laws

- reduced health and safety risks to employees and the public

- improved public relations 


\section{Program Budget}

The development and implementation of facility-specific waste-reduction initiatives are funded from operating and capital funds within each operating facility's support organization. Budget details for each facility are contained in its Facility Specific Waste Minimization Plan. The WCAM budget provides for personnel, subcontracts, engineering work requests and miscellaneous expenses to support the program.

\section{Regulatory Requirements/Justification}

\section{Federal Laws}

1984 Resource Conservation and Recovery Act (RCRA) Amendments - The act requires the hazardous waste generator to have a program to reduce the volume or quantity and toxicity of waste to an economically practical degree and to use treatment, storage, or disposal methods which minimize the present and future threat to human health and the environment.

1990 Pollution Prevention Act (P2A) - The act sets source reduction as a national policy, directs EPA to create a clearing house for pollution-prevention information, and requires waste-disposal reports for pollution-prevention activities to be sent to EPA.

\section{DOE Orders}

DOE Order 5400.1, 5400.3, and 5820.2A - These orders mandate that operations be accomplished in a manner that minimizes waste generation. In addition, they establish requirements for waste-minimization plans as required by the RCRA, including the establishment of a Pollution Prevention Awareness program for the site, and program requirements and responsibilities for assuring compliance with environmental laws.

DOE Order 5820.2A specifically addresses requirements for managing high-level, TRU, low-level, and mixed radioactive wastes.

Policy

Waste Minimization Policy - The WSRC Environmental Assurance Policy (WSRC 101, MP 4.1) establishes waste-reduction philosophies and responsibilities. In general, the policy staits that the operating contractor shall manage radioactive and other hazardous materials in a manner that minimizes waste volumes and provides the maximum protection for the environment and human health.

Divisions will reduce or modify material, prored.'res, or processes which produce hazardous waste to a practicable extent. Waste-minimization programs should consider the following: 
- use of altemate raw materials to reduce or eliminate waste

- recovery, recycle or sale

- process and operational changes to eliminate or reduce the waste's volume, quantity and toxicity

Specific waste-minimization goals will bet set by individual operating departments and facilities as their waste-minimization programs are developed through the overall program. The following waste-minimization objectives are included in program development as applicable:

- reduce radionuclide releases on an ALARA (As Low As Reasonably Achievable) basis

- minimize the generation of low-level radioactive and hazardous waste

- destroy and immobilize unavoidably-generated hazardous wastes and residues prior to permanent disposal

- evaluate potential environmental impacts early in developing new processes and facilities to influence design in a way that reduces waste generation and environmental impacts

\section{Organizational Responsibilities}

The site has established a structure to support and implement the waste reduction programs effectively, as shown in Figure 8-1. WSRC has appointed WM/ER's vice president as the program's senior management sponsor to ensure that waste reduction receives proper management attention. A full-time manager and staff have been assigned the responsibility for coordinating the development, promotion, implementation, and reporting of the waste-minimization program and activities. A central WAT with representatives from the major operations, service, and staff groups has been established to identify issues and develop strategies for implementing wasteminimization program activities. Each major facility has assigned one or more waste coordinators to lead the implementation of waste reduction activities in its specific areas. 


\section{Waste Minimization Organization Interactions}

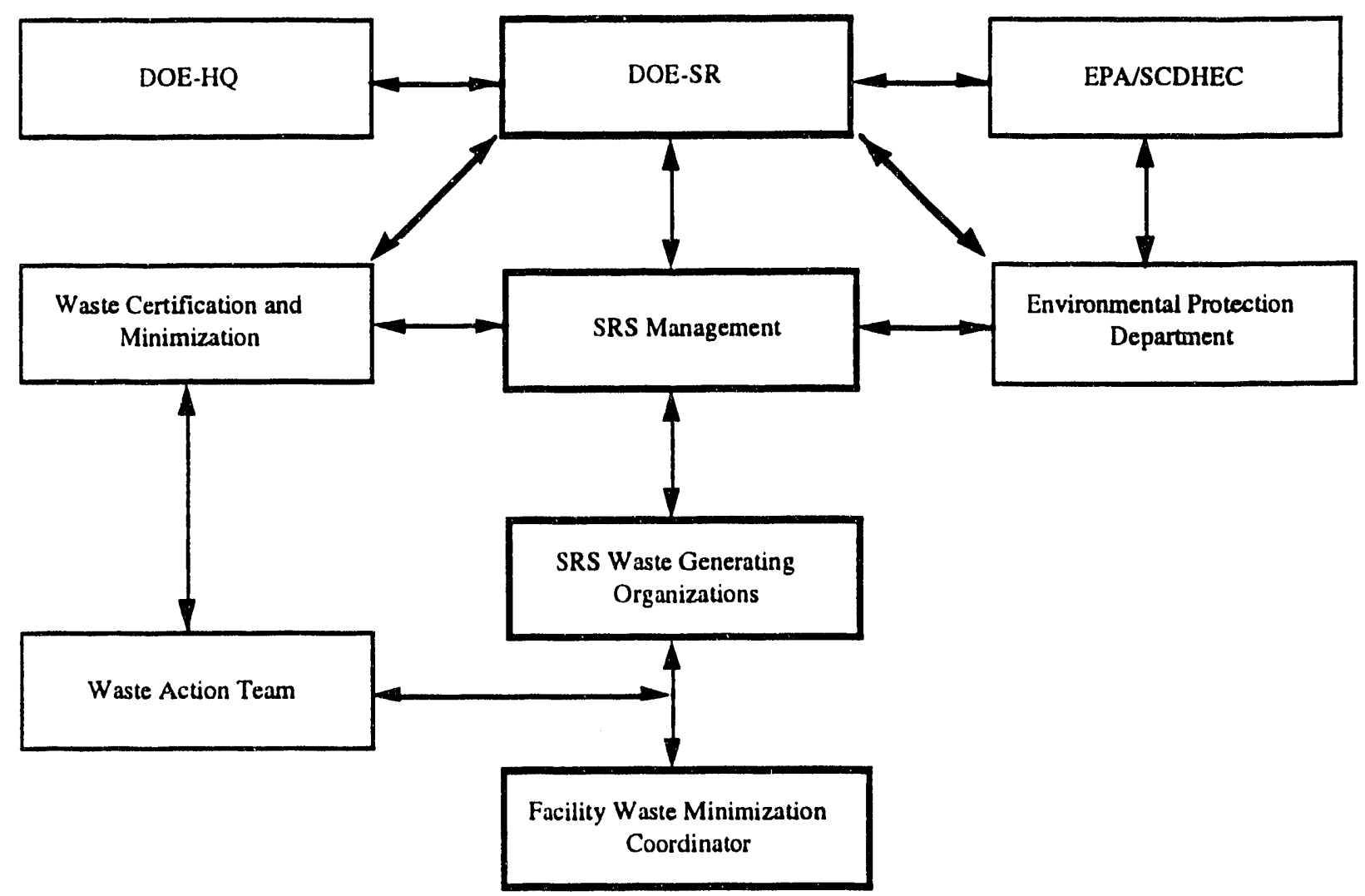

Figure 8-1. Waste Minimization Organization Interactions

\section{Waste Certification and Minimization Group (WCAM)}

The WSRC's WCAM group is responsible for developing the site waste-miniminimization program. Specific responsibilities are the following:

- establish the site's waste-minimization policy through appropriate site managers

- develop, issue, and update (annually as a minimum) the Site Waste Minimization Plan

- coordinate the development of site waste-reduction goals

- obtain management support for waste-reduction activities

- coordinate waste minimization/waste reduction/pollution prevention with DOE, including audits and award-fee activities 


\section{Environmental Protection Department (EPD)}

EPD has the following responsibilities in implementing the site's waste-minimization program:

- provide regulatory review and program oversight

- coordinate, prepare and submit official reports due to regulatory agencies such as EPA and SCDHEC

- interpret regulatory requirements and communicate necessary actions to SRS personnel

- coordinate specific waste-minimization projects as determined via WAT and ESH\&QA management

\section{Savannah River Technology Center (SRTC)}

SRTC provides the necessary research and development support to departments on such topics as process modifications, product/material substitutions, and recycling technologies.

\section{Waste Generating Organizations}

Typical managerial responsibilities are to develop waste-reduction goals and milestones, and track progress. Facility-specific waste-minimization plans must be developed by each waste-generating organization to address its respective strategy and program implementation plans for minimizing waste.

\section{Waste Action Team (WAT)}

Site organizations, including staff and support groups, that have a significant impact on waste generation, handling, storage, or treatment are represented on WAT. The responsibilities of this team are the following:

- identify current waste-minimization issues

- review and concur with Site Waste Minimization Plan and program objectives

- identify strategies for implementing waste-minimization objectives

- promote employee training and awareness programs

- identify opportunities for waste reduction including research program opportunities

- facilitate technology and program information exchange 


\section{Site Procedures and Documents}

- Procedure Manual 3Q, Environmental Compliance Manual

- Site Waste Minimization Plan. WER-SWM-92-0141, Revision 5 (11/92)

\section{Definitions}

The following definitions typically are used in SRS's Waste Minimization Program:

- waste minimization - the reduction of the amount of waste that is generated or that subsequenuly must be treated, stored, or disposed - it includes any sourcereduction or recycling activity that results in reducing the total volume or quantity of a waste and/or in reducing the toxicity or the toxicity classification of a waste. The reduction must be consistent with the goal of minimizing present and future threats to human health and the environment. Waste-minimization methods include waste reduction, substitution, volume reduction, waste treatment and stabilization, delisting, and reciassification

- waste reduction - the reduction of the total amount of waste that is generated and disposed by DOE operations through waste-minimization treatment activities

- substitution - the use of an alternative chemical in a process which results in producing a less toxic or nontoxic waste product

- volume reduction - any treatment, storage, or disposal method which reduces the volume of waste after generation

- waste treaunent and stabilization - the processing of a waste after initial generation to produce a less toxic and/or inert substance for storage or disposal

- delisting - the removal of a chemical from the RCRA hazardous chemical list by EPA - delisting reclassifies a waste by demonstrating that the waste is nonhazardous

\section{Strategy}

A hierarchical approach to waste reduction has been adopted and is applied to all types of waste including the following:

- source reduction (ieducing the waste generation at the source)

- recycle/reuse (using of materials so they do not become a waste)

- treatment (reducing the volume, toxicity, and/or mobility of waste)

- disposal in an environmentally-safe and economical manner

This waste reduction heirarchy is illustrated in Figure 8-2. 


\section{Waste Reduction Hierarchy}

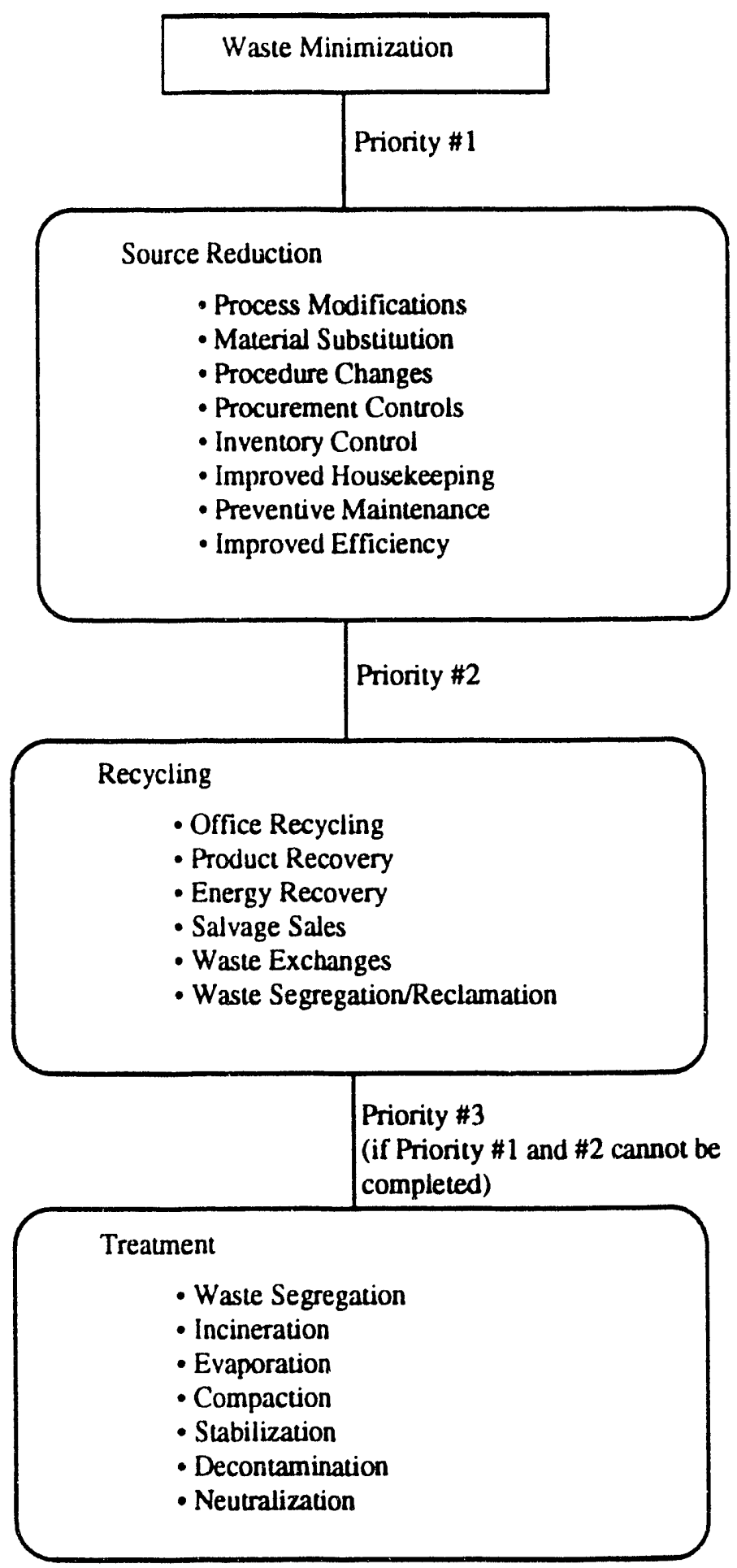

Figure 8-2. Waste Reduction Hierarchy 
Waste reduction will be accomplished by eliminating or minimizing the generation and/or toxicity of waste through source reduction. Those potential waste materials that cannot be eliminated or minimized will be recycled (i.e. used, reused or reclaimed) when teasible. Waste that is generated will be handled in accordance with existing environmental regulations to reduce volume, toxicity, or mobility prior to storage or disposal.

Establishing waste-minimization goals, developing waste-generation trend information, and a process for continual program evaluation are the program's primary elements. Various waste-minimization techniques will be implemented with the support of employee training and awareness programs to reduce waste, while still meeting safety, quality, productivity, and environmental-compliance requirements.

Waste-minimization approaches which currently are being followed include the following:

- process changes and material substitution - Nonhazardous (or less hazardous) materials are substituted for hazardous materials where possible. Processes also are reviewed for modifications that would eliminate or drastically reduce the waste-generation rate.

- process optimization - Process procedures strictly are followed or modified as necessary so that existing processes/facilities will operate more efficiently.

- segregation - Nontoxic substances are separated from waste mixtures when feasible.

- waste reuse and recycling - Waste is recycled either in the process that produced it, or by another onsite facility.

- detoxification techniques - After generation, the most cost-effective method of reducing waste toxicity that adequately protects human health and the environment is selected. Methods such as biological, chemical, or physical treatment and incineration currently are being utilized.

- delisting and reclassification - The toxicity category of a waste stream is lowered by delisting applicable hazardous-waste streams and reclassifying clean waste from regulated areas to nonhazardous and non-radioactive categories, respectively.

- awareness and training - Independent reviews of both new and existing processes by site waste-minimization committees help identify ways to reduce wastegeneration rates. Ongoing programs educate and train employees in wastegeneration opportunities. Additional awareness activities are planned to support the site waste minimization program. 
Each facility or group of facilities (as defined by each organization) which generate hazardous, radioactive, mixed, or industrial waste with a total life cycle cost in excess of $\$ 100,000 / y r$. and service organizations significantly impacting the site waste minimization program will prepare a facility-specific waste minimization plan (FSWMP). These plans will focus on the facility-specific waste-minimization programs and goals. These plans will be reviewed annually and revised by the responsible facility management.

A detailed description of the site waste-minimization program is contained in the Site Waste Minimization Plan. WER-SWM-92-0141, Revision 5 (11/92). 


\title{
Waste Handling, Treatment and Disposal Guidance
}

\author{
(Compiled and reviewed by Alex V. Guanlao)
}

\section{Site Program Overview}

SRS was constructed in the 1950's to produce nuclear materials for national defense. It is owned and operated by the DOE. WSRC operates the site for DOE which includes production and waste-management facilities, as well as numerous support facilities. Waste handling, treatment. storage, or disposal programs are conducted according to applicable federal and state environmental regulations and DOE orders.

Prior to waste generation, operating organizations must identify the facilities needed to provide adequate treatment for their waste before it is released into the environment (air, water, and land). Several waste-management facilities are operated and maintained by Waste Management Operations (WMO). These facilities include: treaument and disposal facilities for nonhazardous solid waste, radioactive and mixed wastes; storage facilities for nonradioactive hazardous and mixed wastes; and incineration facility for hazardous and mixed wastes. Although several facilities which process or treat hazardous waste are permitted or regulated under the state NPDES program, only those facilities which treat, store, or dispose of nonhazardous solid, hazardous, and radioactive mixed waste will be discussed here.

Waste treatuent, storage, or disposal facilities (TSDF) that are permitted under RCRA (Part B) or have interim status only can receive certain type of waste. Therefore, waste generators should plan ahead and inquire about the facility's capacity and wasteacceptance criteria by calling the facility owner (i.e., WMO) or the EPD hazardous/mixed wastes RCRA permit coordinator before generating waste or as soon as waste has been characterized. If treatment or disposal facilities have not been constructed, waste is shipped of fsite for treatment and disposal. WM coordinates offsite shipments of hazardous wastes; EPD coordinates nonhazardous and medical waste disposals offsite.

\section{Regulatory Requirements}

\section{RCRA Regulations}

Subtitle C of RCRA establishes the cradle-to-grave management of hazardous waste (from the point of generation until its disposal). EPA has promulgated regulations under 40 CFR 260-268 that regulates generators and transporters of hazardous wastes, as well as owners of treatment, storage, and disposal facilities. 


\section{Hazardous Material Transportation Act (HMTA) Regulations}

The generator requirements under EPA's 40 CFR 262. Subpart $C$, reference the applicable Department of Transportation (DOT) regulations, under 49 CFR 172.179. relative to hazardous-waste classifications, packaging, container labeling and marking, and vehicle placarding while waste is in transit. Container selection, labeling, and marking also are required (or recommended) by EPA, while the waste is being accumulated or stored before treatment or disposal.

\section{State Regulations}

South Carolina is authorized by EPA to implement the South Carolina Hazardous Waste Management Regulations (SCHWMR), R.61-79.260-79.280, in lieu of EPA regulations, 40 CFR 260-268. SCDHEC regulations also reference EPA and DOT regulations identified above.

\section{EPA vs SCDHEC Regulations}

Environmental regulations constantly are changing at the federal level.

New EPA regulations are effective in unauthorized states, but not in an authorized state unless adopted by state law. Waste generators should contact their environmental coordinator or EPD personnel for regulatory updates.

\section{DOE Orders}

DOE Orders 5400.1, 5400.3, 5400.4, 5480.1B, 5480.3, 5480.4, and 5820.2A - These orders set the DOE policies and programs, and implement environmental statutes for all its facilities and operations. A brief discussion of the orders follow:

- DOE 5400.1 sets out a policy for DOE to conduct all its operations in compliance with applicable environmental statutes, regulations, and standards.

- DOE 5400.3 deals with policies for managing hazardous and radioactive mixed waste under EPA and state hazardous-waste regulations, and for implementing waste-minimization plans under these regulations.

- DOE 5400.4 implements the CERCLA requirement relative to reporting hazardous-substance spills to the National Response Center, as appropriate, and assessing previous waste-disposal sites for possible listing under the National Priorities List (NPL).

- DOE 5480.1B establishes a DOE-wide ES\&H program for its operation.

- DOE 5480.3 establishes requirements for packaging and transporting hazardous materials (including radioactive), hazardous substances, and hazardous wastes. This order references applicable EPA and DOT regulations above.

- DOE 5480.4 sets a mandatory requirement for environmental protection, safety, and health standards to all DOE operations and DOE contractor operations. 
- DOE 5820.2A establishes DOE policies, guidelines, and requirements for managing its radioactive and mixed waste and contaminated facilities.

\section{Organizational Responsibility}

A waste generator is a person in charge or a facility custodian whose activity or operation produces a waste material which must be characterized, managed, or disposed of according to EPASCDHEC environmental regulations.

SRTC provides research and developmental support for SRS waste processes, treatment and disposals. It also provides analytical support to site personnel concerning radiometric screening of waste samples or materials prior to offsite shipments.

The Hazardous Material Transportation coordinator provides regulatory guidance to plant personnel relative to DOT issues. The coordinator approves the packaging, marking, and labeling of waste containers, and the placarding of vehicles prior to releasing an offsite shipment.

Health Protection provides physical radiometric screening of packages or containers of samples or waste prior to offsite shipments.

EPD provides technical and regulatory support to site personnel relative to environmental issues or regulations, and guidance on waste handling, treatment, or disposal. EPD reviews and approves hazardous waste manifests and land disposal restrictions (LDR) notification or certification forms for hazardous-waste shipments.

WM coordinates the offsite shipment of hazardous waste for treatment and disposal. It operates and maintains hazardous and radioactive mixed waste storage facilities.

\section{Site Procedures and Documents}

- Procedure Manual 3Q, Environmental Compliance Manual

- SRS Waste Acceptance Criteria Manual, 3.08, 2/28/92

- SRS Waste Disposal Manual

\section{Site Environmental Policies, Procedures, and Guidance}

Implementing various environmental statutes, laws or regulations emanate from Congress or through an executive order from the president (i.e., Executive Order 12088), at DOE sites and operations is by DOE orders or directives. These orders or directives (e.g., DOE 5400.1) set policies and define responsibilities for DOE site and field personnel and its contractor.

Under contract, WSRC complies with applicable environmental regulations by implementing DOE orders and by issuing policies, procedures, guidance manuals or, in some cases, a special procedure specific to a certain activity or operation. SRS's regulatory compliance strategy is illustrated in Figure 8-3. 


\section{SRS Regulatory Compliance Strategy}

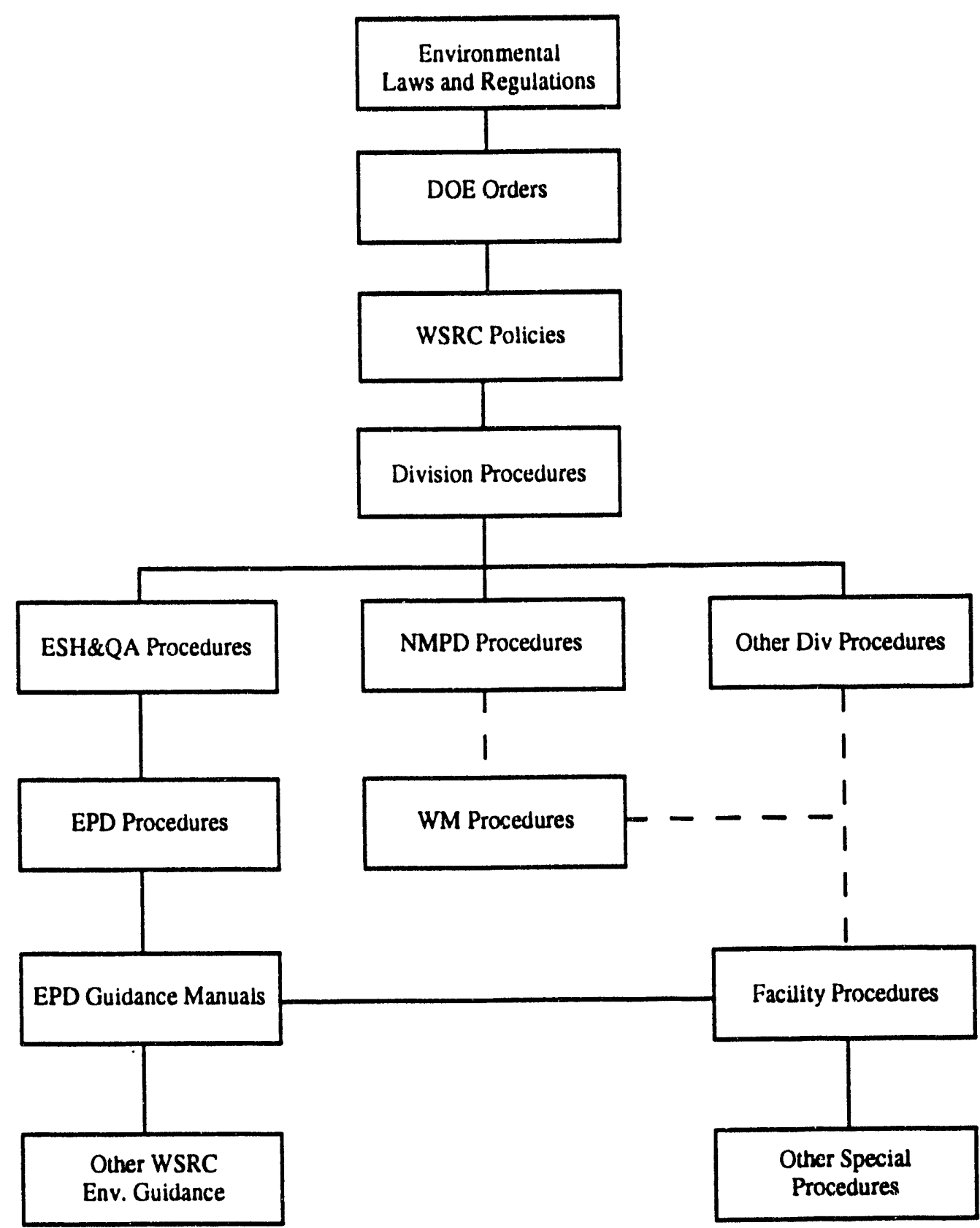

Figure 8-3. SRS Regulatory Compliance Strategy 
The following is additional information on the Procedure Manual 3Q and the Waste Disposal Manual.

Environmental Compliance Manual (ECM, 3Q) contains site procedures which should be consulted when dealing with hazardous and radioactive mixed waste. Some of the procedures and topic areas are as follows:

- ECM 6.1 Hazardous waste permit

- ECM 6.2 Waste accepted at the Sanitary Landfill

- ECM 6.3 Hazardous waste determination

- ECM 6.4 Used oil management

- ECM 6.5 Offsite disposal of nonhazardous wastes

- ECM 6.6 Underground tank management

- ECM 6.7 Hazardous waste tank program

- ECM 6.8 Hazardous waste quarterly reporting

- ECM 6.9 Hazardous waste satellite area

- ECM 6.10 Drum usage, handling, and disposal

- ECM 6.11 Waste minimization program

- ECM 6.12 Waste stream identification

- ECM 6.13 Disposal of unused chemicals

- ECM 6.14 Contingency plan for staging area

- ECM 6.15 Waste sampling under RCRA

WSRC Waste Disposal Manual

The Waste Disposal Manual was developed to provide a written guidance to SRS environmental personnel or waste generators to characterize, manage, store, treat, or dispose of such waste according to all regulatory requirements, WSRC policies and DOE orders. It provides a summary of EPA and SCDHEC regulations applicable to hazardous-waste determination, selection of compatible containers, management of containerized waste in accumulation areas and storage facilities, and preparation for shipment to onsite storage facilities or offsite TSDFs. Regulatory updates and specific regulatory guidance from EPD to site personnel are given when appropriate. This manual is to complement other sitewide procedures (e.g., SRS Waste Acceptance Criteria Manual, 3.08. 2/28/92) or other manuals developed and issued by EPD to site personnel. The Waste Disposal Manual contain sections describing the following:

- applicable federal and state hazardous waste management regulations, WSRC policies, and DOE orders

- a process to determine whether the waste material is a "solid waste" and a hazardous waste

- transportation requirements to onsite storage facilities or to offsite disposal facilities

- criteria for accepting waste to onsite TSDFs

- LDR requirements 
- treatment or disposal of nonhazardous wastes

- disposal guidance for generator of medical and other regulated wastes

- waste minimization program

- hazardous waste workers training requirements

- WSRC environmental guidance to site personnel 


\section{RCRA Permitting}

(Compiled and reviewed by Bill J. Maloney)

\section{Site Program Overview}

RCRA permit application, modification, and implementation is an ongoing process for treatment, storage or disposal facilities.

SRS submitted the first five volumes of its 1985 RCRA Part B permit application on February 6, 1985. This lead to the permi ing of several of these facilities in 1987. Since that time. SRS has submitted additional volumes of the Part B permit application for numerous other facilities, and SCDHEC has added several of them to the permit. At this time, the status of RCRA permitting activities at SRS pertaining to the 1985 RCRA permit application for waste-managing facilities (excluding facilities being closed which are addressed in the Environmental Restoration chapter) is as follows:

- RCRA permitted by 1987 permit

- Hazardous Waste Storage Facility, Bldgs 709-G,-2G,-4G, and 710-U

- Consolidated Incineration Facility

- 1985 Part B permit application volumes submittec/pending regulatory approval

- DWPF Organic Waste Storage Tank (12/88)

- M-Area Process Interim Treatmen/Storage Facility (07/88)

- Mixed Waste Storage Building 643-29E (08/80́)

- Hazardous Waste/Mixed W'

- Hazardous Waste Storage Facility, Solid Waste Storage Pad (SWSP) (12/88)

- Y-Area Saltstone (11/90) (on hold pending revision)

- 1985 Part B permit applications volumes to be submitted

The 1987 RCRA permit for SRS expired on September 3n. 1992. By iegulation, SRS is allowed to continue to operate the above listed normitted facilities according to the expired 1987 permit. This is because SRS submitted a new permit application (now called the 1992 RCRA Part B permit renewal application) at least 180 days prior to expiration, as required by the regulations. At this time, SCDHEC has not issued the renewal permit, therafore, SRS will continue to operate the above listed permitted facilities according to the expired 19.7 permit until SCDHEC does issue the renewal permit. At this time, the status of RCRA permitting activities at SRS pertaining to the 1992 RCRA permit renewal application for waste-managing facilities (excluding facilities being closed which are addressed in the Environmental Restoration chapter) is as follows:

- RCRA permitted by renewal permit

$$
\text { - None }
$$

- 1992 Part B permit renewal application volumes submitted/pending regulatory approval

- Hazardous Waste Storage Facility, Bldgs 709-G,-2G,-4G, 710-U, and the SWSP (3/92)

- DWPF Organic Waste Storage Tank (3/92)

- Mixed Waste Storage Builuing 643-29E, 643-43E, aint 
Waste Storage Pads 20-22 (5/92)

- M-Area Process Interim TreatmenuStorage Facility (9/92)

- 1992 Part B permit renewal application volumes to be submitted

- Consolidated Incineration Facility (note 1)

- Hazardous Waste/Mixed Waste Disposal Vaults (Note 2)

- Hazardous Waste/Mixed Waste Treatment Facility

- Low Activity Transuranic Waste Facility (LATF)

- Y-Area Saltstone

- TRU Pad 1 RCRA Storage Subpart X (Note 3)

- TRU Pads 2-5 RCRA Storage Subpart X (Note 7) (Note 3)

- TRU Pads 6-17 RCRA Storage (Note 3)

- Experimental TRU Waste Assay Facility/Waste Certification Facility (ETWAF/WCF) (Note 3)

- SRL Waste Storage Tanks (12/90) (Note 3)

- Mixed Waste Storage Shed, Bldg 316-M (Note 8)

- Waste Solvent Tanks 33 - 36 (Note 3)

- CIF Temporary Storage pads (Note 8)

- M Area Saltstone Temporary Storage pads (Note 8)

- DWPF Failed Equipment Storage Vaults (Note 3)

- Added TRU Waste Storage pads (Note 3)

- Added Mixed Waste Storage Bldg (Note 3)

There are a number of facilities which are "existing facilities" that either are operational or under construction, but are not Part B permitted. They currently are under interim status (IS). These facilities submitted Part A of the permit application, and it was approved by the regulatory agency to be added to IS. Many of these facilities were added as part of new rules (i.e. the byproduct rule, the TC rule, etc.). A few of them were added to IS as expansions according to 270.72. At this time, the status of RCRA IS activities at SRS for waste-managing facilities (excluding facilities being closed which are addressed in the Environmental Restoration chapter) is as follows:

- Interim Status Operating Facilities

- 643-29E Mixed Waste Storage Building

- 643-43E Mixed Waste Storage Building

- Waste Storage Pads 20-22

- Burial Ground Solvent Tanks S23 - 30 (Note 5)

- Transuranic (TRU) Pads (1-5)

- Transuranic (TRU) Pads (6-17)

- Experimental TRU Waste Assay Facility/Waste Cerification Facility (ETWAF/WCF)

- M Area Process Waste Interim Treatmen/Storage Facility

- F/H High-Level Waste Tank Farms (Note 6)

- Hazardous Waste Storage Facility, Solid Waste Storage Pad

- SRL Waste Storage Tanks

- Mixed Waste Storage Shed, Bldg 316-M Facilities under construction

- DWPF Organic Waste Storage Tank (Note 4) Part A submitted/pending regulatory approval

- Waste Solvent Tanks 33 - 36 (8/92) Part A to be Submitted 
- CIF Temporary Storage pads

- M Area Saltstone Temporary Storage pads

- DWPF Failed Equipment Storage Vaults (Note 9)

- Hazardous Waste/Mixed Waste Treatment Facility (Note 9)

- Low Activity Transuranic Waste Facility (LATF) (Note 9)

Note 1 SRS did not submit the CIF Part B permit renewal application 180 days prior to the 1987 permit application. This is because, at that time, the CIF was not permitted. The CIF was not added to the 1987 permit until September 30, 1992. Per agreement with SCDHEC, SRS needed to submit the CIF Part B permit renewal application by May 2, 1993.

Note 2 SRS anticipates submitting shortly after SCDHEC issues the Notice of Deficiency (NOD) \#1 based on its review of the 1985 Part B permit application submitted in November 1988. SRS will not revise the 1985 Part B permit application, but will respond to the NOD by submitting the 1992 Part B permit renewal application with SCDHEC comments incorporated.

Note 3 SRS anticipates submitting within 180 days of SCDHEC requesting the submittal of a Part B permit application for that facility.

Note 4 It is currently under construction. With an anticipated start of operation in 1993.

Note 5 A Closure Plan has been submitted for this facility. As soon as replacement capacity becomes available, the closure of Burial Ground Solvent Tanks 2330 will begin.

Note 6 A Waste Water Treatment Permit (WWT) application currently is under review with SCDHEC. As soon as the WWT permit is issued, this facility will be removed from IS.

Note 7 SRS anticipates starting the effort to retrieve and repackage the containers of waste in 1995. After repackaging, the waste would be stored back onto pads, but would not be recovered with soil. As such, the Part B would be for a Subpart I container storage unit.

Note 8 SRS anticipates closing this facility before Part B is to be submitted.

Note 9 SRS anticipates this to be added as a result of the new debris rule which created the new containment building unit.

\section{Site Procedures and Documents}

Procedure Manual 3Q, Environmental Compliance Manual 


\section{Chapter 9}

\section{Atmospheric Protection Program}

Chapter was compiled and reviewed by John E. Harris. 


\section{Site Program Overview}

The Atmospheric Protection Program (APP) describes the overall framework for minimizing offsite impacts of operations at the Savannah River Site (SRS) and includes a comprehensive monitoring program to evaluate potential impacts of emissions from site operations. Data show that atmospheric impacts of SRS operations are minimal. The Clean Air Act Amendments of 1990 (CAAA) mandate several major new air initiatives. The APP will be revised to ensure compliance with these initiates as regulations are issued by the U. S. Environmental Protection Agency (U.S. EPA). Because of projected changes at SRS and continued local, urban and industrial growth in the Central Savannah River Area, exemplary stewardship of this resource is required. 


\section{Summary}

SRS operations meet current federal and state standards and site policies related to protecting air resources, except for occasional high-opacity results from coal-fired boilers. Atmospheric emissions of sulfur dioxide from powerhouse stacks are determined from coal analyses.

The CAAA requires that 189 hazardous air pollutants be regulated and that industry install maximum achievable control technology to reduce the impact of these pollutants over the next 10 years. In addition, South Carolina has promulgated an air standard regulating emissions of 259 air pollutants. To ensure compliance with these requirements, SRS has initiated a project to identify and characterize systematically all point and fugitive emission areas.

Some radioactivity is released from SRS facilities during normal operations. This radioactivity is monitored at atmospheric-release points. SRS's policy is that radioactive emissions be as low as reasonably achievable. Radioactivity levels are monitored throughout the site, at the site boundary and at various locations offsite. A comprehensive review of radioactivity monitoring has been completed, and improvements needed to demonstrate compliance with EPA's radioactive emissions standard have been identified. 


\section{Policy}

SRS's atmospheric protection policy is to conduct plant operations in a manner that protects human health and safety, meets regulatory emissions requirements, reduces emissions below regulatory limits, and complies with applicable Department of Energy (DOE) requirements.

\section{Background}

DOE and WSRC are committed to protecting public health, safety, and the environment. This commitment is stated in DOE Order 5400.1, General Environmental Protection Program, and in SRS's Strategic Environmental Plan (Du Pont, 1986a). Compliance with applicable environmental regulations, DOE orders, and site policies forms the basis for SRS APP. 


\section{Existing Conditions}

SRS's atmospheric-protection program includes a comprehensive air-monitoring program to evaluate the impact of site operations. Long-term activities include monitoring for nonradioactive pollutants and radionuclides at onsite and offsite locations. In addition, special air surveys are initiated to understand specific impacts to air quality during normal and abnormal conditions.

\section{Toxic Air Pollutants}

Ambient levels of toxic and other pollutants are not measured routinely at SRS, except for asbestos which is monitored during building renovation and/or demolition. Concentrations of toxic air pollutants can be calculated from emission-source estimates using a dispersion model which predicts downwind concentrations.

Monitoring programs for toxic air pollutants will be necessary to comply with regulations that the revised Clean Air Act requires EPA to issue over the next 10 years. Hazardous and toxic emissions data will be required to permit the Consolidated Incineration Facility for onsite disposal of hazardous waste.

\section{Radionuclide Emissions}

The long-term SRS monitoring program, which conforms with DOE Order 5480.1B, has shown that ambient air concentrations of radionuclides around SRS are within guidelines set by DOE and EPA ( 40 CFR 61, Subpan $\mathrm{H}$ ) to limit radiation doses to the whole body and critical organs.

Radiation dose from SRS operations is small in comparison to the background from natural radioactivity (cosmic, terrestrial, radon in homes), which averages $288 \mathrm{mrem}$ per year for the area within $80 \mathrm{~km}$ of SRS.

The effects of SRS operations on the environment is reported annually in the Savannah River Site Environmental Report.

\section{Site-Specific Air Contaminant Problems}

Emissions from some SRS operations can be reduced. Improvements either are planned or under study for the following operations.

Site

A systematic air-emissions inventory is being conducted to generate data needed to model the site boundary concentrations for 259 air pollutants regulated by SCDHEC Air Standard No. 8. If boundary concentrations exceed levels specified in the standard, remedial action will be necessary to reduce emissions. This data also is needed to apply for air permits required by the revised CAA. 
M Area

Degreasers in 321-M use CFC-113 which is being banned under the Montreal Protocol. An evaluation of alternate degreasing systems to replace the solvent degreasers is underway. 


\section{Objectives}

The objectives supporting the APP are the following:

- requirements to comply with the Federal Clean Air Act, SCDHEC Regulation 61 62 , and other applicable federal and state regulations. DOE orders, and site policies related to accident risk minimization and allowable emissions rates

- operational guidelines to strive to maintain emission of radioactive, nonradiological, and toxic air pollutants per unit of production at or below current levels

- impact assessment to quantify sitewide air-pollutant emission levels, understand the transport and interaction mechanisms of pollutants, and evaluate the impact on human health and the environment.

- release response to maintain a realtime emergency-response system at SRS that has both onsite and two-state of site capabilities

- cost benefit to utilize a cosvbenefit method for evaluating air-emission initiatives. 


\section{Strategy}

The strategy for reaching the APP objectives includes the following:

- identifying regulatory and other protection requirements

- promoting innovative and more cost-effective means of meeting requirements through research and development

- developing physical and administrative controls to protect the atmosphere utilizing the knowledge gained from the research and development efforts

- implementing physical and administrative controls

- evaluating and upgrading controls, as needed, to meet protection requirements

This strategy is illustrated in Figure 9-1. Programmatic details are presented in the implementation section.

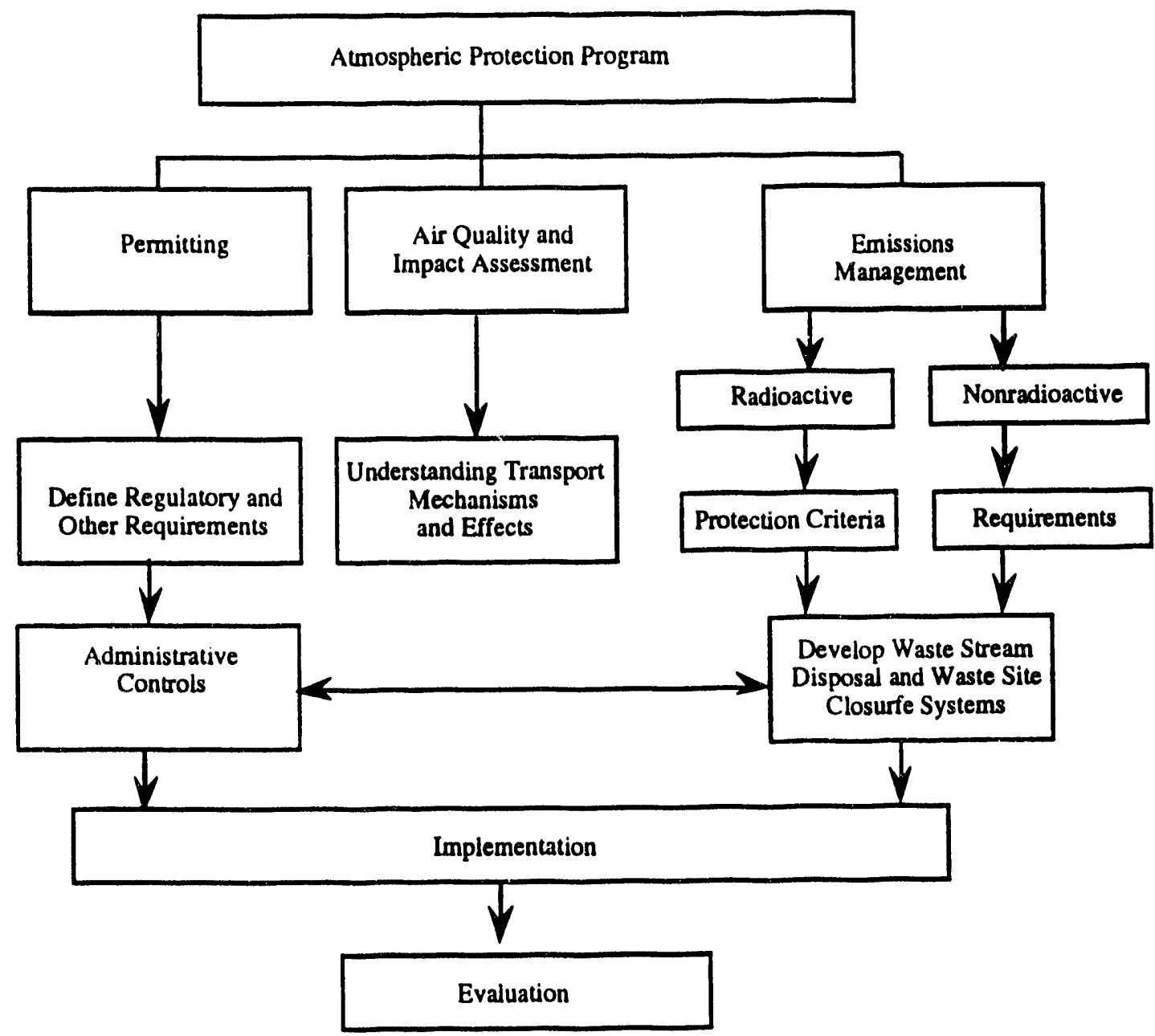

Figure 9-1. Atmospheric Protection Program Strategy 
The following programs have been implemented to meet the Atmospheric Protection Program objectives:

- Air Emissions Permitting (page 9-11)

- $\quad$ Air Emissions Management (page 9-16)

- Nonradioactive Emissions Management (page 9-24)

- Asbestos (page 9-24)

- Ozone Depleting Substances (page 9-26)

- Criteria Pollutants (page 9-35)

- Motor Vehicles (page 9-40)

- Radioactive Emissions Management (page 9-43) 


\section{Air Emissions Permitting}

(Compiled and reviewed by Carl M. Cook)

SRS's air-emissions permitting program is designed to ensure that radiological, nonradiological, and toxic air pollutants emitted from SRS facilities are within levels not detrimental to human health and welfare, and that all federal and state regulatory requirements are met.

Air-emission permits may be required from one or more governmental agency for the construction or modification, and operation of a facility. This section summarizes the types of permits, approvals and notifications which are required by EPA and SCDHEC.

\section{Site Program Overview}

Currently, SRS holds operating permits from SCDHEC which regulate nonradioactive emissions from approximately 120 point sources, several of which have specific emission limitations. SRS has submitted several permit applications to SCDHEC and is proceeding with coi-structing several new facilities under authorized construction permits. If required, a list of permitted SRS sources can be obtained by contacting the Environmental Protection Department (EPD).

Five-Year Outlook

Significant changes were made to the Clean Air Act (CAA) by the 1990 annendments which may impact SRS. The major changes that affect permitting SRS sources are as fo!' Jws:

- Title III of CAA involves Hazardous Air Pollutants (HAPs) and has increased the number of regulased HAPs to 189 toxic pollutanis and identified additional source categories. As regulations for HAPs and source categories are promulgated between now and the year 2000, SRS will be required to permit sources which were not permitted previously. Also, the new regulations will require SRS to install new control technolc, y for many existing sources.

- Title V of CAA involves permitting air-emission sources by EPA and paying operating and rermit-application fees. SRS will be required to submit new permit applications to SCDHEC for all sources by November 1995, requiring a major work effort by EPD. The new permit fees will range from $\$ 11$ per ton of emitted pollutants in 1992 (based on 1991 emissions) to \$25 per ton after 1995. Application fees for new facilities and permit modifications also will be levied by the new state and federal regulations.

Regulatory Requirements

Air emissions from SRS facilities are regulated by EPA and SCDHEC. SRS operations àso must be conducted in a manner which complies with DOE orders and site policies. 
Clean Air Act

DOE facilities are required to comply with EPA's Clean Air Act (Title 42 U.S.C. 7401, et seq.) regulations which include the following:

- The National Primary and Secondary Ambient Air Quality Standards (NAAQS, 40 CFR 50) set primary and secondary standards for criteria pollutants, and reference methods for determining criteria pollutants in ambient air.

- The Prevention of Significant Deterioration rules (PSD, 40 CFR 52) require preconstruction monitoring and permits for major, new stationary sources of air pollutants.

- The Standards of Performance for New Stationary Sources (NSPS, 40CFR 60) set allowable emission limitations for new sources.

- The National Emission Standards For Hazardous Air Pollutants (NESHAP, 40 CFR 61) has delegated regulating hazardous air pollutants to South Carolina, except for sources which release radionuclides. Construction or modification of a radionuclide source requires approval from EPA, as specified in the applicable subpart of 40 CFR 61 .

South Carolina has an approved State Implementation Plan (SIP). Authority to regulate air programs for sources within the state is delegated to SCDHEC with the exception of regulating radionuclides under NESHAP.

\section{South Carolina Pollution Control Act}

DOE facilities are required to somply with SCDHEC's South Carolina Pollution Control Act (SC Code of Laws, Title 48, Chapter 1) regulations which include the following:

- South Carolina Air Pollution Control Regulations (SCDHEC 61-62), which set standard requirements for construction and operation permits and for permit renewals, require complying and updating emissions inventory annually, regulating open burning, and that emergency-action plans deal with releases of hazardous air pollutants.

- South Carolina Ambient Air Quality Standards (SCDHEC 61-62.5) set standards for visibie emissions and requirements for opacity monitoring and source tests. These regulations also set emission limitations for certain source types, PSD requirements, and toxic-air pollutants.

\section{DOE Orders}

The following DOE order applies to permitting activities at SRS:

- 5400.1. General Environmental Protection Program, November 9, 1988 - This order sets the requirements for reporting and notification including compiling of an annual site environmental report. 
- $\quad 5480.1 B$. Environment, Safety, and Health Program for Department of Energy Operations, adopted September 23, 1986 - This order sets environmental, safety, and health $(\mathrm{ES} \& \mathrm{H})$ requirements for all DOE or DOE-controlled operations.

\section{Organizational Responsibilities}

EPD is responsible for the administrative oversight of air permitting. EPD monitors site performance required by permits; assists custodians in preparing permit applications; transmits permit applications and regulatory reports to SCDHEC; and maintains contact with SCDHEC for WSRC.

Each facility custodian is responsible for completing a National Environmental Policy Act (NEPA) checklist and preparing required permit applications prior to any construction or facility modification. The custodians are responsible for ensuring that facilities are constructed and operated in accordance with permit requirements.

The Savannah River Technology Center (SRTC) is responsible for conducting air modeling that may be required to support permit applications.

\section{Site Procedures and Documents}

- Procedure Manual 3Q, Environmental Compliance Manual

- Environmental Permitting Procedures "HOW" Manual (Procedure Manual 3Q2)

- Clean Air Act Compliance Manual (Vols. 1, 2, 3) (Procedure Manual 3Q3)

\section{Programs}

\section{NEPA Checklist Review}

Environmental Protection Department - Facility custodians prepare an environmental checklist per site procedure ECM 5.1 in the WSRC-3Q manual. EPD reviews environmental evaluation (formerly NEPA, Safety Analysis and Permits) checklists prepared by facility custodians. EPD advises facility custodians of permit requirements and timing needed to obtain permits. Custodians then complete permit applications with EPD assistance. EPD submits permit applications to SCDHEC, arranges any necessary meetings with SCDHEC, and notifies custodians when permits are issued.

\section{Permitting Support}

Environmental Protection Department - EPD provides permitting support to custodial departments. This includes reviewing and submitting air-permit applications for new or modified facilities, overseeing permitted facilities to ensure compliance with permit conditions, submitting required reports, and coordinating inspections and source tests. 
Custodial Departments - It is the responsibility of each custodial department to prepare an environmental evaluation checklist, complete permit applications and compile supporting information. Custodial departments must ensure that facilities are constructed and operated in accordance with permit requirements and that any change in design modifications will not violate permit conditions.

Custodial departments are responsible for submitting information required for permit renewal or modification to EPD.

Costs to complete the environmental evaluation checklist and to prepare permit applications are included in the cost of each project.

Technical Support

\section{Emission Impact Modeling}

SRTC - Environmental Technology Section (ETS) - ETS has obtained and developed the capability to use the AIRDOS-EPA code to calculate the impact of air emissions. AIRDOS will be used to evaluate compliance with radionuclide NESHAP standards. ETS also uses EPA's Industrial Source Complex - Short Term (ISCST) computer model to calculate concentrations of air toxics at SRS's boundary in support of air-permit applications.

\section{One-Year Road Map}

Because SRS has been identified as a major source as defined by the CAA, SCDHEC bas changed the operating permit identification numbering scheme for all SRS sources. When issued, new operating permits will have the same overall permit number with individual area designations being the distinction between areas rather than individual numbers. Each source within any area still will have a point ID number.

The current operating permits for S Area and TNX will be due for renewal in the third quarter of FY 93. SCDHEC will issue these permits and will include any new sources that have been placed into operation over the last few years.

Permitting new facilities and equipment is an ongoing process with several air permits being received each year. During FY 93, SRS is expected to receive construction permits for the following new facilities:

\section{Environmental Restoration (ER)}

Vadose Zone Vapor Exaraction Units (SVE) - Four Vadose Zone ground remediation SVEs will be installed in the $A$ and $M$ Areas to remove trichloroethylene, tetrachloroethylene, and trichloroethane from contaminated soils. These solvents, which are listed on SCDHEC's Toxic Air Pollutants list, are in the soil as a result of 
reactor-components production in M-Area facilities. SVEs will treat the solvents through catalytic oxidation and will emit hydrochloric acid into the atmosphere. Permitting is expected during FY 93.

\section{Waste Management (WM)}

Consolidated Incineration Facility (CIF) - The CIF will be installed in $\mathrm{H}$ Area to burn low-level, hazardous, and mixed wastes to minimize waste disposal as required by the Resource Conservation and Recovery Act (RCRA). It also is being done to meet land ban and SRS volume/cost reduction goals. The facility will include design provisions to minimize chemical and radiological air emissions, using such techniques as offgas scrubbers and HEPA filters. Milestones include the following:

$$
\begin{array}{ll}
\text { obtain air and RCRA permits } & \text { FY } 93 \\
\text { construction start } & \text { FY } 93 \\
\text { construction completion } & \text { FY } 95 \\
\text { trial burn } & \text { FY } 95 \\
\text { operating permit and startup } & \text { FY } 95
\end{array}
$$

Five-Year Road Map

The current operating permits for the following areas will be due for renewal in FY 94: A, C, D, F, H, K, L, M, P, and Z. Any new sources placed into operation over the past few years will be added to the new permits. 


\title{
Air Emissions Inventory
}

\author{
(Compiled and reviewed by $\operatorname{Tim}$ A. Faugl)
}

\section{Site Program Overview}

The goal of SRS's Air Emissions Inventory program is to conduct and maintain a comprehensive inventory of radiological and non-radiological emission data.

The inventory will contain annual emission data beginning in 1985. Information is being compiled on approximately 22,000 identified emission sources. This information includes actual and potential emission data, material balance, stack parameters, building characteristics, control devices, computer-aided digitized design drawings (CADD), monitoring and sampling systems, process-flow diagrams, and emission calculations. The information is collected and stored on air emission inventory (AEI) data forms (hard copy) and in a computer database, using Oracle software. The air inventory reporting system (AIRS) database was designed for WSRC, using CASE tools and is capable of interfacing with other databases and downloading to dispersion models.

Each operating department is responsible for reviewing and submitting annual updates to EPD for identifying air-emission sources under its jurisdiction. EPD is responsible for updating and maintaining the database and submitting required information to regulatory authorities by March 31 of each even-calendar year. Emission data are utilized to demonstrate compliance with SCDHEC's Bureau of Air Quality Control (BAQC) Standard No. 8 Air Toxics, and to support other permitting and compliance activities.

Five-Year Overview

\section{Annual Update}

Custodial departments, Bechtel Construction and other DOE onsite subcontractors are responsible for reviewing and submituing annual updates to EPD for their identified air-emission sources. EPD is responsible for circulating the latest revision of AEI data forms. Revision eight, now in use, will be updated to make it more user friendly, and to increase information collected concerning building configurations. EPD also is responsible for updating and maintaining the $\mathrm{CADD}$ layers assigned for emission points.

\section{AIRS Enhancements}

EPD custodians for the AIRS database will develop two interfaces with the site GIS system, and internal enhancements to demonstrate compliance with current SCDHEC air-quality control operating permits. 
The first interface enhancement will permit a graphic representation of the dispersion model results. showing concentrations in two dimensions. The possibility of three-dimensional representation is being studied. This task is projected to be completed by May 1993, allowing visual results to be submitted with the dispersionmodeling data due to SCDHEC by June 1993.

The second enhancement will permit an annual data dump from AIRS into the site's $\mathrm{CADD}$ system. This read-only file will give field auditors and compliance inspectors the ability to query all emission points and to process and build data by utilizing visual land references on the CADD system. This will alleviate the need to carry large volumes of data into the field during audits and appraisals. This task is projected to be completed prior to SCDHEC's annual compliance inspection for CY 94.

A VAX version of EPA's Industrial Source Complex - Short Term II, currently out in beta version, will be installed into AIRS. This will permit Design Engineering and Operations to perform dispersion models for new and modified processes, using actual site data. This enhancement will assist in designing control devices and stack characteristics, and in estimating of fsite impacts during the conceptual design phase.

\section{Air Toxic/Hazardous Air Pollutants}

SCDHEC Air Standard No. 8 for air toxics requires that any facility which emits or has the potential to emit any of the 257 listed air toxics must demonstrate compliance with this health-based regulation at the site boundary. WSRC must demonstrate compliance by June 28, 1993. To satisfy this requirement, the Environmental Technology Section-Environmental Transport Group, will determine the maximum possible ambient air concentration at the site boundary for identified air toxics by utilizing site meteorological data, the AIRS potential to emit emission data, and EPA's Industrial Source Complex - Short Term II dispersion model. EPD will compile the data and submit the modeling results to SCDHEC.

Clean Air Act Amendments 1990. Title III, requires that the states develop a SIP to implement federal standards for hazardous air pollutants. This regulation is technology based, and requires facilities which emit 10 tons per year or more of any one hazardous air pollutant, or $\mathbf{2 5}$ tons per year or more of any combination of hazardous air pollutants to meet the Maximum Achievable Control Technology (MACT) standard for new and existing sources once a standard is established. This standard will be established and implemented over a 10-year period. EPD will identify MACT standards which custodial departments will be required to comply with as they are proposed and promulgated.

\section{SARA 313}

The AIRS database will provide input to the annual EPLRA section report for those chemicals of interest being emitted into the atmosphere. 


\section{SCDHEC BAQC Air Emission Inventory}

The AIRS database will be used to prepare SRS's air-emission inventory required by SCDHEC Regulation 62.1 Section III. The emission inventory will be supplied to SCDHEC in both hard copy and on ASCII file by March 31 of each even-calendar year.

\section{Air Emissions Permitting Program}

The AIRS database will be used to support the Air Emissions Permitting Program.

\section{Compliance Tracking}

The AIRS database will be used to support and generate reports required under Title $V$ of the Clean Air Act. The level of effort is unknown due to the current status of developing regulations.

\section{Emission Credits and Emission}

The AIRS database will support Prevention of Significant Deterioration (PSD) permitting, netting, bubbling and other related activities. AIRS will calculate a five-year rolling average for actual emissions. These credits may be utilized for major construction activities, i.e., NPR or Complex 21 , or be transferred across the DOE complex or sold on the open market.

\section{Justification/Regulatory Requirements}

\section{Clean Air Act Amendment of 1990}

The Clean Air Act Amendment of 1990 Title III, Hazardous Air Pollutants, requires certain facilities to meet MACT. Once a MACT standard is promulgated, the AIRS database will be able to report on all applicable emission sources and current monitoring systems, and control devices associated with that process. Custodial departments will notify EPD of any new construction or process modifications that may be required. EPD will update the AIRS database to reflect these changes and determine compliance with applicable MACT standards.

The Clean Air Act Amendment of 1990 Title V, Permits, requires states to develop a permitting strategy and program including public review. The permitting program will be funded by an annual fee to be assessed per ton of pollutant. The AIRS database can be used to develop information about site emissions to refute any disagreement. Current proposed regulations will assess a fee based on potential to emit, with the possibility of a switch to actual emissions at a later date. The AlRS database will be able to deliver both sets of data for all pollutants being emitted if requested by the regulators. 
40 CFR 60 requires specified monitoring equipment for certain pollutants. The AIRS database will be able to report on all monitoring systems installed at SRS emission points.

\section{SCDHEC Air Standard No. 8}

Air Standard No. 8, Air Toxics, requires facilities that install a source with potential to emit an air toxic to submit a dispersion model of the offsite ambient air concentration. SRTC will pertorm dispersion modeling for any air-toxic pollutants and submit the data to EPD for inclusion in any new construction or process-modification permit application.

SCDHEC also requires all major facilities to maintain, review and update various emission parameters annually. The state may request a current inventory at any time in order to determine the compliance status.

\section{DOE Order 5400.1}

DOE Order 5400.1 requires all contractors to comply with all environmental regulations.

\section{Westinghouse Corp. Management Directive MD-E55}

Westinghouse Corp. Management Directive MD-E55 is similar to DOE Order 5400.1 in that it states that all Westinghouse facilities must comply with all applicable environmental regulations.

\section{Organizational Responsibility Summary}

\section{AIRS Database}

EPD will be responsible for access authorization. Custodial access will be limited to end-user reporting tools.

Data entry will be accomplished by trained EPD personnel. These people also will be training on the CADD system and will be responsible for maintaining the two layers containing the point and area-emission points.

AIRS enhancements that further complement site activities are: additional validation tables (synonym table for pollutants, pollutant parameters); site air permit limits and conditions; and VAX versions of dispersion models (ISC-STTI, SCREEN, CAP88 and AIRDOS). 
The Facilities and Services/Site Permitting Section will be responsible for maintaining the site mapping and addressing building-coordinate and shape/size issues developed during AEI's data collection.

Custodial departments will be issued an AIRS Users Guide and training on available reporting tools. Operating departments may desire to access the CADD portion of the AIRS system; if so, that deparment will be responsible for procuring a work station and the necessary training.

Information Systems Engineering will develop the requested enhancements to the AIRS database and publish updates to the AIRS Users Guide.

\section{AEI Data Collection Forms}

EPD will update the data-collection forms to reflect any new data required to comply with new regulations. Revision No. 9 will be used in CY 93 with procedures to permit easy field use and data entry. A site standard-calculations manual with software will be issued to assist in emission calculations.

Custodial departments, Bechtel Construction and other DOE onsite contractors will be responsible for data collection, emission calculations, and submitting data forms annually, no later than February 28 for in-service sources which emit a regulated pollutant. New or modified emission points/sources must have initial data, a process sketch, and CADD information submitted prior to placing that new or modified source into service. The information submitted must be the original and must be cleared by an Authorized Derivative Classifier before submittal to EPD. A copy of all data must be maintained within a department's field file for annual or as needed reference.

\section{AEI Procedures}

EPD will write site procedures addressing the AEI. These procedures will be located in the Procedures Manual 3Q. ECM4.7.

Custodial departments, Bechtel Construction and other DOE onsite contractors will write procedures tiered from the ECM4.7 manual as deemed necessary.

\section{Original Data and Regulatory Agencies}

EPD will be responsible for submitting to Central Files the official copy of AEI data. EPD will process the new/modified source data and annual updates from the custodians of emission sources. Once entered into AIRS, EPD will submit the original copy to Central Files for long-term storage. 


\section{CADD Drawings}

EPD will be responsible for maintaining the CADD drawing. This will occur when any new source is established or an existing source is relocated.

\section{Dispersion Modeling}

SRTC will be responsible for performing dispersion modeling for regulatory compliance. Custodial and design departments will perform dispersion models for internal and design use only.

\section{Site Procedures and Documents}

The Air-Emission Data Folder consists of two major components and supporting documents. Each emission folder must have a copy of the CADD-plan view of the emission point as it is referenced to a building or an area onsite, and at a minimum. data sheet 1 of the $1-7$ form, containing building and emission-point data. Depending on the type of emission point, data sheets 2 through 7 of the 1 through 7 form and other data sheets will be enclosed. The emission calculations and assumptions must follow the data sheets. This constitutes a complete emission data folder.

Procedures Manual $30, E C M 4.7$ requires that custodial departments submit an annual update for all existing emission points or modified emission-point data to EPD before placing the source into operation. EPD will update the procedure to reflect the latest data revision.

Air Users Guide provides a system overview and operating instructions. This manual will be maintained by ISE and updated each time a significant enhancement or modification has been made. EPD will monitor the aumber of copies in circulation and distribute errata sheets as required.

Savannah River Site Air-Emission Inventory-Calculation Procedures Manual will be compiled and distributed to the air coordinators once completed by EPD. The site manual will promote uniformity for emission calculations. This manual will incorporate EPA emission factors, manufacture data for common processes, and specify SRS's derived emission factors for specialized processes. This manual also will have guidelines on completing the AEI data forms.

\section{Program}

The SRS Air-Emission Inventory is a compilation of data required to permit, monitor and perform dispersion models for air emissions. The AEI identifies and locates every roof-emission point, volume source and area source of significance, validating that all potential sources are accounted for. This includes sanitary sewer vents, stove hoods, and roof ventilators. 
Information collected

Custodians of emission sources annually review the data collected and submit changes required. The data-collection effort involves numerous procurement line organizations, stores, site use, records management, and operations personnel. The type of information generated consists of the following:

- building data: ID number, SRS grid coordinates northeast comer, length, width, height, custodian, and phone number

- emission data: type of emission (point. volume, area), SRS grid coordinates and UTM, height above ground, height above structure, area, exit velocity, exit temperature, and stack configuration

- source sampling: sample ports available to meet regulator requirements, continuous or periodic sampling, and sampled pollutants

- fan data: make, model, serial number, break horsepower, capacity and rating curve

- source data: ID number, responsible organization, operating schedule, seasonal average, make, model, serial number where applicable. SIC code and brief description

- pollutants emitted: source ID which generated the pollutant, CAS number, chemical name, and emission rates (maximum design, actual, before and after control devices) by calendar year

- material balance: raw materials used in the process, product produced, byproducts, gaseous, solid waste, and liquid wastes generated

- emission monitors: make, model, serial number, continuous or periujic, calibration frequency, pollutant monitored (with sensitivity range), and line-loss factor

- source specific: comments, assumptions and calculations

- For repetitive sources commonly permitted, additional specific data is collected. These sources are abrasive cleaning, ash disposal, concrete batch plants, coal crushing, degreasing/cleaning, external combustion, fuel dispensing, fuel loading, incineration, internal combustion, open burning, process and production, storage tanks, solvent recovery, and surface coating and printing. Specific abatement-device data is collected for absorbers, adsorbers, condensers, cyclonic separators, electric static precipitators, HEPA and fabric filters, flares, sand filters, selective catalytic reduction, and thermal oxidation.

- process sketch: a brief flow diagram of the process to show the relationship between the source, control devices, fans, monitors, stack height, and building penetration

\section{Technical Support Programs}

SRTC supports the AEI by collecting meteorological data and performing the dispersion modeling submitted for regulatory compliance. SRTC performs the necessary QAVQC checks, ensures the proper model was utilized to meet the regulatory agency requirement, and develops the supporting documents generated for the dispersion model. 
ISE supports the AEI by developing and installing requested enhancements and updating the AIRS Users Manual.

Subcontractors will support the AEI, as needed, to develop emission data or other related requirements.

\section{One-Year Road Map}

\section{Dispersion Model of Air Toxics}

To comply with AIRS Standard No. \#8, WSRC must submit to SCDHEC a dispersion model demonstrating the offsite ambient air concentration for each air toxic generated by onsite activities conducted.

Five-Year Road Map

- develop the WSRC Emissions Calculation Workbook

- perform additional QAVQC checks on the data collected and conver all data to the most recent version of the AEI data-collection forms

- develop the AIRS enhancements/interfaces with the GIS system

- procure the VAX versions of the dispersion models utilized onsite for compliance

- develop additional building data to assist in downwash characteristics and resolve discrepancies concerning building locations and sizes using a global positioning system 


\section{Nonradioactive Emissions Management}

(Compiled and reviewed by Rick Wilson)

Asbestos

SRS's nonradioactive emissions management program is conducted to achieve the chapter objectives, to meet all SCDHEC permit conditions, and to reduce emissions per unit of production.

\section{Site Program Overview}

Each operating department is responsible for ensuring that air emissions from its facilities comply with SCHDEC permits and all applicable state and federal air standards. EPD provides regulatory oversight and assistance to the operating departments.

\section{Regulatory Requirements}

South Carolina bas an approved State Implementation Plan (SIP). Authority to regulate air programs for sources within the state is delegated to SCDHEC with the exception of regulating radionuclides under the NESHAP. The South Carolina Pollution Control Act requires DOE facilities to comply with regulations issued by SCDHEC in S.C. Code of Laws, Title 48, Chapter 1 which include the following:

- South Carolina Standards of Performance for Asbestos Removal Operations (SCDHEC 61-86.1) - a set of requirements for removing and handling asbestos when a facility is either renovated or dismantled

Air emissions from SRS operations must comply with applicable regulations, DOE orders and all conditions specified within SCDHEC construction andior operation permits.

\section{Organizational Responsibilities Summary}

Operating departments are responsible for controlling air emissions from their facilities. Facilities must be operated such that all permit conditions are met. Programmatic regulatory support is provided by EPD to achieve current and future regulatory requirements.

SRTC is responsible for special studies and predictive air assessments. 


\section{Site Procedures and Documents}

\section{Programs}

The following programs have either been proposed or undertaken to better understand processes and their environmental impacts. These programs have specific immediate or near-term objectives.

\section{Asbestos Removal Control}

EPD is the leading organization responsible for regulatory compliance concerning asbestos oversight for WSRC and serves as the interface between other WSRC organizations and SCDHEC. The EPD asbestos coordinator for WSRC is responsible for all interactions between WSRC and the regulators (SCDHEC, EPA ? id OSHA) pertaining to the asbestos-abatement projects scheduled at SRS. NESHAP-size projects are reported on a project-by-project basis. Minor/small projects, which involve less then 160 square feet or 260 linear feet, per state regulation 61-86.1 section $\mathrm{V}$ part $\mathrm{B} 1$, can be reported on a quarterly basis. This quarterly log may be inspected by SCDHEC at any time.

The EPD asbestos coordinator oversees medical records to ensure people who remove asbestos at WSRC medically are fit for the job. The coordinator also maintains records on respirator-fit tests, issues purmits to perform asbestos-abatement projects, coordinates asbestos training for supervisors and workers, and maintains records of certificate to verify personnel are qualified to perform the asbestos job. This oversight requires knowledge of regulations for asbestos-abatement projects.

The EPD asbestos coordinator issues permits for Bechtel (Construction) to handle NESHAP-size projects and some smaller jobs. WSRC personnel handle minor/small abatement projects. The Medical Department oversees medical records and Industrial Hygiene does all air sampling and clearance monitoring.

Monitoring

\section{Industrial Hygiene Section (IHS)}

The Industrial Hygiene Section monitor: asbestos levels according to DPSOL 40-5102 during all building renovations or demolitions involving asbestos. 


\section{Nonradioactive Emissions Management}

(Compiled and reviewed by Dick Reynolds)

Ozone Depleting Eubstances

Title VI of CAAA is intended to address the destruction of the stratospheric ozone layer. This law includes a phase-out schedule for ozone-depleting substances (ODS).

\section{Site Program Overview}

Each custodial department is responsible for ensuring that use, recycling and the emission of ozone-depleting substances from its facility comply with all applicable state and federal air standards. EPD yrovides regulatory oversight and assistance to the custodial departments.

Five-Year Outlook

Although the CAAA calls for a phase-out of the production and consumption of Class I compounds (chlorofluorocarbons - CFCs) by the year 2000, a February 11, 1992 presidential order calls for an accelerated phase-out by December 31, 1995. Consumption could continue until the year 2000, but only for recycled products. The progressive tax, required by Title VI of the CAAA, on these substances will make CFCs very expensive after 1995; thus, strongly encouraging the search for CFC substitutes. The Class II compounds (hydrochlorofluorocartons - HCFCs) currently are scheduled to be phased out between 2015 and 2030; bowever, it is anticipated that these dates may be shortened. The draft site program milestones are outlined in the following subsections.

\section{Fire Suppression}

The anticipated schedule for the initial evaluation for alternatives is September 1993.

\section{Cooling}

The anticipated schedule for cooling is as follows:

- for all site organizations except Bechtel Construction-December 31, 1999

- Bechtel Construction - one year from date of full funding 


\section{Cleaning}

The anticipated schedule for cleaning is as follows:

- reactor materials - December 31, 1994

- tritium operations - TBD

- tritium construction - December 31, 1993

\section{Propellants}

The schedule for propellants will be determined by market forces.

\section{Laboratory}

The anticipated schedule for implementing supercritical fluid extraction is as follows:

- method approval - January 1994

- budget submission - March 1994 (subject to EPA's approval schedule)

- authorization to purchase - October 1994 (subject to DOE's budget cycle approval for purchasing capital equipment )

- procure and install - January 1995

- begin routine use - January 1995

\section{Regulatory Requirements}

Title VI of CAAA is intended to address the destruction of the stratospheric ozone layer. This law includes a phase-out schedule for ozone-depleting substances. Section 608 (National Emission Reduction Program) addresses prohibiting the venting of class VII substances (CFCs/HCFCs) from refrigeration and air conditioning equipment. The law requires EPA to generate regulations addressing the recovery, recycle, reclaim. and disposal of these substances. Although EPA has not promulgated these regulations, it has provided guidance.

Section 609 (Servicing of Motor Vehicle Air Conditioners) addresses servicing motor vehicle air conditioners, and the requirement that after January 1, 1992, persons repairing/servicing such vehicles must be certified in refrigerant recovery and recycling and must use approved equipment. EPA promulgated the final rule on July 14, 1992. The major impacts at SRS involve the following: Halons used in firesuppression systems, refrigerants used in site vehicle and facility air conditioning systems, degreasing and cleaning applications, propellants used for a wide variety of consumer-type products, and solvents used in laboratory analyses. 
Organizational Responsibilities Summary

Custodial departments are responsible for controlling ODS air emissions and for capturing and recycling ODS before servicing or discarding ODS-containing refrigeration or fire-suppression equipment.

Although no single organization has been assigned the responsibility for the phase-out of CFCs and HCFCs onsite, the following plan has been recommended:

- assign a site focus group (champion)

- develop a plan/schedule for each of the five CFC categories

- identify funding needs

- perform an inventory of current CFC uses, equipment affected

- perform more R\&D, as needed

- change local specifications/procedures, as needed

- review impact on national specifications

\section{Site Procedures and Documents}

Site documents addressing Section 608 of Title VI (National Emission Reduction Program) are as follows:

- Memorandum, J. S. Roberts to Site Managers, 6/25/92, ESH-ENV-920175, "Clean Air Act Amendments - New Requirement Prohibiting the Venting of CFCs to the Environment - Effective July 1, 1992"

- Memorandurn, C. C. Zeigler to Distribution, 8/7/92, ESH-ESS-920452, "Guidance on Reporting of Unplanned Releases of CFCs and HCFCs"

- Memorandum, R. W. Reynolds to Distribution, 10/7/92, ESH-ESS-920564, "Clean Air Act - CFCs Vented from Air Conditioners - Meeting Announcennent Updated EPA Guidance"

Documents addressing Section 609 of Tile VI (Servicing of Motor Vehicle Air Conditioners) are as follows:

- September 4, 1991, 56 FR 43842 - 40 CFR Part 82, Protection of Stratospheric Ozone, EPA, proposed rule

- Tursday, July 4, 1992, 57 FR 31242-40-CFR Part 82, Protection of Stratospheric Ozone, EPA, Final rule Programs

\section{Programs}

The following programs either have been proposed or undertaken to better understand processes and their environmental impacts. These programs have specific immediate or near-term objectives. 
For convenience, the activities involving CFCs at SRS are broken into the following broad usage categories:

- fire suppression (Halons)

- refrigeration (A/C, chillers, freezers, drinking fountains, etc.)

- cleaning (degreasing)

- propellants (paints, aerosols, white-out, etc.)

- laboratories (extractions)

\section{Fire Suppression}

DOE-HQ requested a list of "essential" Halon applications at SRS, justification for their use, and the impacts if they are not used. SRS has assumed that "essential" means those systems required to protect the public, to prevent unacceptable programmatic delays or large monetary losses, or where other means of fire suppression are not available immediately. SRS is including only those Halon systems in custodial facilities which handle nuclear materials or in which a fire may cause unacceptable programmatic delays.

This criteria defines 297 of the 331 Halon systems as being "essential". There are 34 Halon systems defined as non-essential. Eleven Halon systems considered essential have other forms of fire suppression nearby, but they either are not hooked up or are not directly accessible to the Halon-protected areas.

A review of the existing Halon systems to define acceptable replacement alternatives will be performed by March 1993 for systems in facilities covered by the Project Review Board (PRB). The non-PRB facilities will be evaluated by September 1993.

DOE-HQ also requested each site to provide its plan for recovering and storing Halon. SRS has a current process description available. Further plans for disposal of Halon 1211 still are being developed. Procedures for recovering and storing Halon have been developed.

\section{Refrigeration}

The following items have been initiated:

- SRS implemented the CAAA, Title VI, Section 608 (National Recycling and Emission Reduction Program - 7/1/92) and Section 609 (Servicing of Motor Vehicle Air Conditioners - 1/1/92).

- Du Pont personnel gave a seminar to the site's maintenance personnel (10/9/92) about CFC teplacements.

- Discussions on establishing a sitewide inventory of cooling equipment are just beginning. 
Information on the feasibility and cost of safe alternatives is not readily available due to the extent and variety of air conditioning, cooling and chilling equipment at SRS (i.e., hundreds of vehicles, thousands of air conditioners/chillers). This pertains to all site organizations except Bechtel. The site is proposing the following actions (completion date):

- develop a plan/schedule (12/31/92)

- perform walkdown inventory for essential equipment data (12/31/93)

- evaluate feasibility of refrigerant substitution, equipment modifications, equipment replacements, and initiate projecis: budget process (12/31/95)

- project completions (12/31/99)

The real costs of retrofitting and replacing equipment could not be determined until the evaluation phase. Some of the equipment replacement would be a part of the normal replacement process due to equipment obsolescence. while others may be driven by the required change in refrigerants. The estimated cost for planning, scheduling, and inventory will be developed during the planning process.

- Bechtel (construction activities include vehicles and air conditioners, coolers, freezers, etc.)

- automotive/heavy equipment - estimated costs to generate data, labor, and parts is $\$ 316,200$

- maintenance (A/C, coolers, freezers, etc.) - estimated costs to generate data, labor, and parts is $\$ 98,225$

This would include retrofitting all existing equipment.

\section{Cleaning}

SRS has formed a number of CFC-reduction task teams.

Examples of success in specific areas are as follows:

Tritium Operators

- substitution efforts were made in tritium facilities (maintenance).

- In 1989, maintenance activities in radiologically controlled areas (RCAs) that required CFCs were stopped. Dry-wiping for all pipe and flange cleaning replaced wiping with a solvent rag, which created a mixed waste. Currently, the only cleaning activities that use CFCs are outside of RCAs.

- SRTC performed a study in 1991 to look at alternatives to CFC-113 for cleaning stainless steel. This study is documented in WSRC-TR-90-536. No substitutes have been used in tritium facilities yet.

Tritium facilities have a number of applications for CFCs that involve cleaning/degreasing and some maintenance-equipment cooling. Due to the variety and complexity in specifications, a plan and schedule will be developed for generating 
substitutes for each application. This plan and schedule will be completed by December 31, 1992. The schedule may span several years, and more detailed cost data will be available for the first annual report to DOE-HQ on December 31, 1993.

\section{Tritium Construction: Phase-Out of Ozone-Depleting Substances}

Site standards used for installing Halon and $\mathrm{CO}_{2}$-piping systems required using $\mathrm{CFC}$ 113 for cleaning the piping's interior before final installation. Field Engineering requested a substitute cleaning method, so Design Engineering deleted CFC-113 from site standards and made high-pressure air the method for cleaning these types of piping systems.

CFC-113 was used routinely by construction personnel for cleaning metal surfaces before welding and for cleaning sheet metal before installing insulation. This activity was halted by training and supplying the craftsmen with a substitute cleaner (nonCFC).

Tritium Site Specification 6995 requires using $\mathrm{CFC}-113$ for cleaning tritium-process piping before installation. A substitute cleaner has been identified and currently is being tested $a$ the field to ensure compliance with the site's quality standards.

Several sols: nts have been studied to determine the most probable substitute for the CFC-113 solvent currently being used in the cleaning/degreasing the piping in tritium facilities. The choice of solvents has been narrowed down to three. These solvents will require the procurement of new equipment currently not onsite. The initial cost of this equipment is $\$ 25,000$. Considering the laboratory analyses that must be performed to ensure compliance with the tritium-facilities requirements for the cleanliness of tritium piping, it is estimated that by December 1993, the new cleaning/degreasing solvent will be in full use, eliminating the need for CFC-113.

\section{Reactor Materials: ODS-Elimination Activities In M Area}

M Area has had an active program to eliminate using ODS in operations since 1988. Task teams composed of production, SRTC, engineering and technical personnel have been evaluating and testing alternatives for a number of ODS applications in M-Area operations.

The major operations using ODS in $M$ Area are deluge coolant/lubricant for machining activities, ultrasonic bath cleaning, and vapor-solvent degreasing. The highvolume uses are in the machining and degreasing operations.

Field tests on surrogate machining products with alternate materials successfully were conducted on cutting operations in 1991.

Functional performance requirements were initiated for a project to replace the existing solvent degreaser in 1992 with an aqueous and thermal degreaser process. 
All ODS-degreaser elimination programs are on hold due to the lay-up and deinventory of M-Area facilities scheduled to start in FY 93, and the inability to schedule final-product validation testing on the proposed alternatives.

Our task team identified five use areas and recommended alternatives for those areas. All the alternatives are feasible, and the cost to implement them ranges from approximately $\$ 100$ to $\$: 70,000$. However, M Area may go into a lay-up mode, so the task team does not plan to implement the altematives. However, the task team is considering implementing two minor alternatives to support defueling better (costing less than $\$ 20,000$ ). It probably will be implemented by the end of 1994 .

\section{Propellants/Carriers}

In 1988, SRS formed the Site Waste Action Team (WAT), which includes representatives from all deparments, to promote waste-minimization programs. Some of its goals are driven by RCRA and DOE requirements, while others are independent initiatives. The group has had some success in promoting the replacement of ODS, for example, it did the following:

- replaced CRACK CHECK and MAGNAFLUX with non-ODS products

- replaced many paints containing ODS with water-based paints.

- replaced some degreasing activities with non-ODS solvents or other technologies

The expectation is that market forces ultimately will drive ODS replacement in the myriad of consumer products used onsite.

Since most applications using ODS as prupellents or solvents are within consumertype products such as paints, aerosol sprays, liquid paper, etc., external mar..et forces (i.e., manufacturers) primarily will be responsible for replacing the ODS in their products, which may or may not drive the cost of these products higher. The experience, to date, with finding alternate products on the market has indicated that the alternatives probably will be more expensive.

\section{Laboratory}

Currently, SRTC uses CFC-113 as a scoping method for total petroleum hydrocarbon in soil and for oil and grease in wastewater. Another group, Analytical Laboratories (AL), uses a substitute chlorofluorocarbon, Flon, in similar analytical operations.

The procedures measure soil and water against environmental regulatory standards, and although we are not performing certified analyses, it is important that these results be comparable directly to the regulatory method. EPA SW-846 procedure 9073 and Methods for the Chemical Analysis of Water and Wastes, method 418.1 are the referenced methods. 
A new method has been issued which will provide adequate data for these two procedures, and we do anticipate that EPA will approve the procedure within two years. Considerable pressure is being placed on EPA to approve and implement the new procedure quickly, as driven by the Montreal Protocol.

The new method uses supercritical fluid extraction (SFE) with carbon dioxide as the supercritical fluid at about $10,000 \mathrm{psi}$ to extract petroleum residue from the samples.

The cost of the SFE device will be abrut $\$ 30,000$ and will require budget-cycle approval for capital purchases. After implementing the SFE, no ODS will be used for either TPH or oil and grease analyses.

Implementation in AL will follow approximately the same table as SRTC, but AL has one primary and four satellite laboratories that will require independent SFE devices. This will increase capital-budget requirements for implementation by about $\$ 150,000$ for a total of $\$ 180,000$ for SRTC, plus the five AL labs.

General Initiatives

Additional initiatives are as follows:

\section{Environmental Evaluation Checklist}

This checklist is used when initiating any project or modification onsite. It already contains a section requesting the project engineer to consider air impacts. Currently, a group of NEPA coordinators representing all organizations onsite is being trained to use and screen these environmental evaluation checklists. By December 31, 1992, these coordinators will have received special training regarding ODS concerns and will be prepared to direct all new/modification projects to be sure to design and procure them with ODS substitutes in mind. No cost is anticipated for this initiative.

Chemical Inventory and Information System Database (CIIs):

This site database maintains information about chemicals that are inventoried to comply with SARA Title III, EPCRA 312, requirements. The database can locate and describe ODS uses onsite and serves as a valuable resource in that capacity.

This sitewide database maintains information about all materials onsite that require an MSDS (Material Safety Data Sheet). There is an initiative under consideration that eventually will allow chemicals tracking (probably only selected chemicals) from purchase to use. This would allow tracking the types, locations, and quantities of designated chemicals, including CFCs, HCFCs, etc. With this system, we could exercise better control over a variety of chemicals purchased/used onsite. This project has no schedule at the moment. 
One-Year Road Map

Activity

Initial Evaluation for Halon Alternatives

Develop Plan/Schedule for A/C CFC Walkdown

Conduct A/C CFC Walkdown

Compile Annual Report to DOE-HQ

Conduct CFC Surveillances

Develop Plan/Schedule for CFC Phase-Out

Implement CFC Substitute for Pipe Cleaning
EPD

EPD

$12 / 93$

Group Date

Fire Department $09 / 93$

CSWE/SSD

$12 / 92$

$12 / 93$

Tritium Operations

$12 / 92$

Tritium Operations

Five-Year Road Map

Refer to "Five-Year Outlook" for dates. 


\title{
Nonradioactive Emissions Management
}

\author{
Criteria Pollutants \\ (Compiled and reviewed by Carl M. Cook)
}

\section{Site Program Overview}

The majority of SRS air-emission sources are permitted primarily for criteria pollutants, i.e., particulate matter $(\mathrm{PM})$, sulfur dioxide $\left(\mathrm{SO}_{2}\right)$ nitrogen oxides $\left(\mathrm{NO}_{\mathbf{x}}\right)$, carbon monoxide (CO), and volatile organic compounds (VOCs). Each custodian is responsible for ensuring that air emissions from its facilities comply with SCDHEC permits and all applicable state and federal air standards. EPD provides regulatory oversight and assistance to the operating departments.

Five-Year Outlook

Significant changes were made to the CAA by the Amendments of 1990 which may impact SRS. The major changes dealing with criteria pollutants are as follows:

- Title IV of CAA entitled "Acid Deposition Control" involves reducing $\mathrm{SO}_{2}$ emissions from high-emitting utility units beginning in June 1995, and other utility units beginning January 2000 . It also involves reducing $\mathrm{NO}_{\mathbf{x}}$ emissions; monitoring, reporting and record keeping practices; clean coal technology requirements; and emission allowances and trading rules. These regulations may affect SRS coal-fired boilers after the year 2000.

- Title $V$ of CAA allows state regulatory agencies to collect operating permit fees based on emitted pollutants. SRS was required to pay permit fees starting at \$11 per ton of emitted pollutants in 1992 (based on 1991 emissions) up to $\$ 25$ per ton after 1995.

- The potential impact of CAA amendments involves new provisions for enforcing state and federal regulations. One new provision allows for a Field Citation Program in which SRS could be fined up to $\$ 5,000$ per day, for any violation found during routine or annual inspections. With the number of sources at SRS, the potential for fines is high. Another provision provides for rewarding individuals up to $\$ 10,000$ for the reporting of and subsequent conviction of plant operators for environmental violations.

Regulatory Requirements

Air emissions from SRS operations must comply with applicable regulations, DOE orders, and all conditions specified in SCDHEC construction and/or operating permits. 


\section{Organizational Responsibilities Summary}

Custodial departments are responsible for controlling air emissions from their facilities. Facilities must be operated so that all permit conditions are met. Programmatic regulatory support is provided by EPD to achieve current and future regulatory requirements.

SRTC is responsible for modeling special studies and predictive air assessments.

\section{Site Procedures and Documents}

- Procedure Manual 3Q, Environmental Compliance Manual

- Environmental Permitting Procedures "HOW" Manual (Procedure Manual 3Q2)

- Clean Air Act Compliance Manual (Vols. 1, 2, 3) (Procedure Manual 3Q3)

\section{Programs}

The following programs either have been proposed or undertaken to better understand processes and their environmental impacts. These programs have specific immediate or near-term objectives.

\section{Site Services Power Engineering (SSPE)}

Boiler Control Optimization and Performance Testing - SSE is conducting studies to optimize the boiler combustion control systems' performance testing. This study should improve boiler efficiency and reduce particulate emissions.

\section{Reactor Materials (RM)}

Elimination of Solvent Degreasers - RM created a task team to identify, test and implement chemical substitutes and/or new production methods which will eliminate using solvent degreasers in $M$ Area. It is anticipated that the solvent degreasers will be replaced with detergent degreasers and "thermal" degreasing. (Thermal degreasing uses heat to degrade residues and polymerized oils.)

In 1987, $M$ Area replaced 1,1,1-trichloroethane with Freon ${ }^{T M}$ TF, a more environmentally suitable substitute. SRTC only has had limited success in identifying an alternatives to Freon ${ }^{T M}$ TF. The ability to meet the outlined milestones is dependent upon the results of additional testing and whether identified alternatives feasibly can be implemented into M-Area processes. 
The task milestones are as follows:

$12 / 91$

$1 / 92-4 / 92$

$5 / 92-5 / 93$

$6 / 93 \cdot 9 / 94$ identify viable altematives

compare, select, and study alternatives

study and demonstrate alternatives

implement alternatives into full-scale use

Facility Operations

\section{Power Operations}

Control of Boiler Emission - The coal-fired boilers at SRS are equipped with mechanical dust collectors or electrostatic precipitators to meet SCDHEC permit conditions and ambient air-quality standards. Opacity meters are installed in the boiler stacks to measure emissions continuously. Routine operations include maintaining the dust collectors, calibrating and repairing the opacity meters, coal-quality , araalyzing, and generating required environmental operating records.

Reactor Materials (RM)

Control of M Arec Emissions - SCDHEC's air permit limits chlorinated solvent emissions from the M-Area groundwater stripper, and emissions from two metal-cleaning processes. Routine operations include determining and recording the amount of solvents emitted from the stripper by analyzing of inlet and outlet water from the cleaning processes that can be controlled using scrubbers or tank controls.

\section{Custodial Departments}

Diesel Engine Powered Equipment Operations - SCDHEC permits for diesel engine powered equipment, i.e., emergency diesel-power generators, diesel air compressors, fire water pumps, etc.. contain specified emission levels and limitations on the number of operating hours. Custodians must keep operation records and make them available to SCDHEC on request.

\section{SRI - TNX}

TNX Pilot Operations Emissions - The SCDHEC air permit for TNX sets emission limits for the Precipitate Hydrolysis Experimente: Facility (PHEF). The Integrated DWPF Melter System (IDMS) is exempt from SCDHEC regulations. Air emissions from PHEF must be controlled to meet permit and exemption limits. 
Benzene emissions from PHEF are controlled with a refrigerated condenser. SCDHEC requires a temperature gauge which has been connected to an audible alarm. If a temperature excursion occurs. the facility is shut down. In addition, a portable benzene-vapor monitor is used intermittently to detect and correct fugitive emissions from flanges, seals and valves.

Emissions from IDMS are controlled using several systems including a refrigerated formic-acid condenser to remove mercury vapor, an offgas quencher, an ejector venturi gas scrubber for particulates, high-efficiency mist eliminators, and HEPA filters.

\section{Technical Support}

\section{SRTC - Environmental Technology Section (ETS)}

Identification of Trace Level Organic Emissions - ETS has initiated a research study to identify and characterize trace-level emissions of organic compounds used in production processes or formed as radiation-degradation products. Air emissions from SRS facilities are sampled and analyzed, using ultra-sensitive mass spectrometry developed in ETS/SRTC laboratories.

\section{Monitoring}

\section{Power Operations}

Boiler Compliance Testing - SCDHEC permits require that the nine coal-fired boilers at SRS be tested every two years to verify compliance with particulate-emission limits. The tests are conducted by a certified vendor with a SCHDEC observer present.

\section{Separations}

Canyon Stack Testing - SCDHEC permits for the F- and H-Area canyon stacks require that compliance testing be conducted as part of the permit-renewal process. Stack testing may be required in 1994.

\section{Defense Waste Processing Facility (DWPF)}

DWPF Stack Monitoring - A continuous stack-monitoring program will be initiated when DWPF starts up. Benzene, mercury and $\mathrm{NO}_{\mathrm{x}}$ will be monitored in $\mathrm{S} Z$ Zone 1 and mercury in S Zone 2 . Opacity will be monitored routinely in $Z$ Area. This program will provide essential operating data and information on air emissions. 
One-Year Road Map

\section{Power Operations}

Improved Soot Blowing Equipment - 484-D-The soot-blowing equipment at the 484-D powerhouse has been in service for more than 30 years. New equipment will increase boiler efficiency and reduce stack opacity. Project completion is expected in the first quarter of FY 93.

Reduction of Boiler Excess Air - 484-D-The 484-D powerhouse has operators maintaining a high volume of excess air in the combustion chamber as a method of decreasing boiler opacity. While decreasing boiler opacity, excess combustion air also decreases boiler efficiency. A program will be implemented in FY 93 to improve boiler efficiency by reducing the excess air in the combustion chamber.

Boiler Efficiency Optimization - 484-D-The operating efficiency of the 484-D powerhouse boilers has been evaluated, and identified aging combustion-control equipment as a major cause of inefficient operations. A project to refurbish various powerhouse controls currently is being planned and will be submitted for review sometime during FY 93.

Five-Year Road Map

Dust Abatement Systems - A, H, K and P Areas-Significant quantities of dust are generated by handling coal at the powerhouses. This FY 91 project to control fugitive coal-dust emissions will reduce a potential employee health hazard and improve SRS air quality.

Project completion will be in FY 95. 


\title{
Nonradioactive Emissions Management
}

\author{
Motor Vehicles
}

(Compiled and reviewed by Carl M. Cook)

\section{Site Program Overview}

Currently, SRS does not have a site environmental program for motor vehicles because its motor vehicle fleet is not regulated by any state or federal environmental regulations other than routine vehicle-inspection requirements. A plan for meeting new regulatory requirements has been developed and submitted to DOE and is awaiting approval. This plan, if approved, will establish the basic program for SRS motor vehicles.

\section{Five-Year Outlook}

Title II of CAA, involving Emission Standards for Moving Sources, has established several new requirements for emissions from motor vehicles, vehicle fuels, and cleanfueled vehicles. Although most of these standards affect areas of non-attainment and commercial vehicle fleets, SRS may be impacted by the new standards as follows:

- SCDHEC has proposed revising Air Pollution Contro! Regulation 61-62 to establish regulations addressing the inspection and maintenance of motor vehicle emission-control equipment in accordance with CAA. CAA requirements primarily are for non-attainment areas: however, if the proposed revision specifies, and is approved for the entire state, SRS will be required to establish emission-control inspection and maintenance programs.

- Executive Order 12759, entitled The Federal Energy Management Program, requires federal agencies to meet CAA requirements primarily designed for commercial fleets, i.e., for conversion to and/or purchase of alternate-fueled vehicles (AFV). Implementing this order will require SRS to acquire several alternate-fueled vehicles and clean-fuel dispensing facilities in FY 93. Another aspect of the program is to reduce fuel consumption for federal fleets by $10 \%$ between now and 1995 .

\section{Regulatory Requiroments}

Clean Air Act - DOE facilities are being required to comply with the Emission Standards for Moving Sources, Tile II of CAA, as a result of Executive Order 12759, entitled The Federal Energy Management Program. These standards set the requirements for purchasing and converting to AFVs reducing air emissions from vehicle fleets, and implementing emission-control inspection and maintenance programs. 


\section{Organizational Responsibilities Summary}

The SRS Transportation Department, Fleet Management, was required to meet the requirements of Executive Order 12759. With the assistance of Central Services Works Engineering (CSWE), Fleet Management has developed the plan outlining how SRS will comply. If approved, Fleet Management will have the overall responsibility for implementing and managing this program.

The CSWE Vehicle-Maintenance Department will be responsible for installing alternate fuel-conversion kits onto site vehicles and subsequent maintenance of the converted and new AFVs.

The Site Services and Safety Deparment procedure groups will be responsible for developing and maintaining procedures and safety rules for maintaining and operating the AFVs and fuel stations.

\section{Programs}

The following programs have been proposed and are awaiting approval and funding by DOE:

\section{Transportation Department, Fleet Management}

Compressed Natural Gas Vehicles - The conversion of some SRS vehicles to and the purchase of new compressed natural gas (CNG) vehicles has been recommended as a means to comply with new CAA regulations and Executive Order 12759. Hydrocarbon and air-toxic emissions from CNG vehicles are reduced from $80 \%$ to $93 \%$, and carbon-dioxide emissions are reduced by $24 \%$, compared to gasoline-engine emissions.

Compressed Natural Gas Fuel Supply - SRS will negotiate a gas supply contract with SCE\&G which will include installing, maintaining, and operating a natural gas supply line and natural gas compressor (fill) station. Emissions from natural gas-powered compressors will be much lower than diesel or gas-powered compressors.

Fuel Reduction Plan - Fuel consumption at SRS will be reduced by $10 \%$ between now and 1995 by training site personnel on proper driving techniques; improving vehicle maintenance and gas station practices such as monthly inspections, scheduled tune-ups and air/oil dispensers at stations; using private vehicle vs. shuttle; and alternate-fueled vehicles. 
Technical Support

Site Services Engineering (SSE) and CSWE

Development of site infrastructure for CNG fuel supply - The SSE and CSWE are assisting developing the site's infrastructure to provide a fuel-supply system for CNGfueled vehicles. This includes acquiring land-use permits and easements for constructing the natural gas pipeline through SRS to A Area: contracting the design and installing the fuel fill station in A Area; contracting with SCE\&G to provide and operate the gas line, fill station, and natural gas supply; and permitting the fuel fill station.

One-Year Road Map

Transportation Department, Fleet Management

The proposed program for complying with the motor vehicle regulations and fuelreduction programs has the followi9

ng milestones:

fuel supply contract-fill station, utility and site work $\quad$ FY 93

$\begin{array}{ll}\text { site education and training } & \text { FY } 93\end{array}$

$\begin{array}{ll}\text { vehicle conversions/purchase } & \text { FY } 93\end{array}$

Five-Year Road Map

Transportation Department, Fleet Management

$\begin{array}{ll}\text { vehicle conversions/purchase } & \text { FY } 94\end{array}$

$\begin{array}{ll}\text { vehicle conversions/purchase } & \text { FY } 95\end{array}$

$\begin{array}{ll}\text { vehicle conversions/purchase } & \text { FY } 96\end{array}$

$\begin{array}{ll}\text { vehicle conversions/purchase } & \text { FY } 97\end{array}$ 


\title{
Radioactive Air Emissions Management
}

\author{
(Compiled and reviewed by Brent $C$. Blunt)
}

SRS's radioactive-emissions management program is conducted to achieve the Atmospheric Protection Program objectives, to meet the as low as reasonably achievable (ALARA) goals, and to identify ways to reduce emissions per unit of production.

\section{Site Program Overview}

SRS's radioactive-emissions management program is based on the ALARA principle. To achieve the lowest emission rates, annual dose-based radiological release guides are set for the site and each operating facility. These guides are based on past performance, projected production rates, and planned improvements in emission control. Progress is measured against these guides monthly, and appropriate action is initiated if emissions approach or exceed prorated goals.

The Environmental Monitoring Section (EMS) and the Health-Protection Operations Section (HPO) conduct extensive routine monitoring programs to measure emissions of radioactivity from individual facilities and operating areas, and to measure environmental concentration at selected onsite, perimeter, and offsite locations. These data are used to measure the success in meeting release guides and to calculate radiation doses. The Environmental Technology Section (ETS) of SRTC conducts special monitoring of $\mathrm{F}$ - and $\mathrm{H}$-Canyun stacks to determine emissions of radionuclides that are difficult to measure. Calculated emissions are determined each year for diffuse sources, unplanned emissions and low-level sources without monitoring or sampling capabilities. Monitoring results along with the calculated emissions are included in the annual SRS Environmental Monitoring Report and the annual radionuclide NESHAP report.

Several operating departments have proposed projects to either install new or to upgrade existing equipment to improve monitoring capabilities and accuracy, and to reduce radioactive emissions.

Five-Year Outlook

Radionuclide NESHAP compliance over the next five years is expected to include upgrades to existing monitoring systems to meet regulatory requirements. Many of these upgrades are and will continue to be tracked in the Radionuclide Federal Facility Compliance Agreement. Other changes will include a more structured approach to evaluating new facilities and changes or modifications to existing facilities, and incorporating NESHAP requirements into the D\&D and environmental-restoration processes as routine evaluations. The impact from CAAA cannot be determined for radionuclide emissions. 


\section{Regulatory Requirements}

Constructing new facilities and modifying existing facilities are subject to NESHAP regulations promulgated by EPA under Section 112 of CAA. Routine emissions are subject to NESHAP emission standards and the requirements of DOE Orders 5400.1 and 5400.5 . These requirements include dose limits recommended by the International Committee on Radiation Protection (ICRP) and included in NESHAP, 40 CFR 61, Subpart H, National Emission Standard for Radionuclide Emissions from DOE Facilities.

\section{Organizational Responsibilities Summary}

Custodial departments are responsible for the radioactive air emissions from their facilities. Facilities must be operated to maintain radioactive emissions based on the ALARA principle and meet applicable radiological release guides. Raw Materials, Reactors and Separations set guidelines for their operating areas based on planned improvements, past performances and projected production rates. Site guidelines are set annually by a committee of operating representatives and EMS. Since the radionuclide NESHAP defines the entire site as a facility, EPD monitors compliance with radionuclide NESHAP and prepares the annual NESHAP report. EPD also monitors the progress of compliance with the Radionuclide NESHAP Federal Facility Compliance Agreement (FFCA) and prepares monthly reports required by FFCA.

\section{Site Procedures and Documents}

Savannah River Site Potential Emissions Evaluation With Area Specific Dose Factors For Determination Of Monitoring Requirements For the Radionuclide National Emission Standards For Hazardous Air Pollutants, August 1992 - This document provides the latest evaluation of monitoring requirements for SRS facilities monitoring. Evaluation is based on WSRC/EPA-approved methodology as required in the Radionuclide NESHAP.

Savannah River Site Unmonitored Source Evaluation and Schedule For Confirmatory Measurements, ESH-ESG-910667 - This document evaluates all known diffuse sources and unmonitored point sources to determine monitoring requirements.

Savannah River Site Alternative Methods Information For Demonstrating Compliance With 40 CFR 61, ESH-ESG-910156 - This document provides a comprehensive look at the monitoring programs across the site.

Savannah River Site Radioactive Air Emissions Monitoring, ESH-EMS-910039 - This document provides generalized drawings and descriptions of each point source at SRS.

Radionuclide NESHAP Federal Facility Compliance Agreement (FFCA), October 31, 1992 - This document allows continued operations at SRS while upgrades and evaluations are being completed to ensure compliance with 40 CFR 61, Subpart H. A milestone listing and associated schedule ilso is included in the document as Appendix A. 
Environmental Regulatory Guide for Radiological Effluent Monitoring and Environmental Surveillance, DOE/EH-0173T - This is the DOE guidance document to support implementing of DOE Orders 5400.1 and 5400.5.

DRAFT National Emissions Standards for Hazardous Air Pollutants Quality Assurance Plan, WSRC-IM-91-60 - This document serves as a road map to outline how the SRS complies with the quality assurance requirements in Method 114 of 40 CFR 61. The document does not impose requirements, but simply lists or describes existing site procedures and programs which are part of the complex SRS quality assurance effort for radionuclide air emissions.

Savannah River Site Radionuclide Annual Report For National Emissions Standards For Hazardous Air Pollutants, WSRC-IM-92-49 - This report is required by 40 CFR 61, Subpart H. It summarizes the emissions from SRS during CY 1991.

Environmental Monitoring Plan, 5Q1-2 Section 1100 - This plan is required by a DOE order and contains information about the overall site monitoring and sampling program. Descriptions of each source also are included.

\section{Programs}

Custodial departments at SRS either have proposed or undertaken the following programs to better understand processes and their environmental impacts. These programs have specific immediate or near-term objectives.

\section{Air Emissions Inventory}

EPD has initiated a program to identify and characterize all point and fugitiveemission sources at SRS, which include both radioactive and non-radioactive emissions.

\section{Annual Radiological Release Guides}

Annual site release guides for radionuclides are authorized by the vice president, Environmental, Safety, Health and Quality Assurance (ESH \& QA) based on recommendations by the site Release Practices ALARA guides, and Monitoring Committee. Approved guides are documented in 5Q, Section 11. The guides are based on operations and production experience and are set to the lowest practical level. EMS is responsible for a comprehensive monitoring program to measure releases of radionuclides to all media. Any abnormal condition or guide exception is reported to the appropriate operating department which will initiate appropriate action to reduce emissions. 
RM evaluates the type and quantity of reactor components to be produced and their impact on radionuclide releases in developing annual release guides. Recommended guides are sent to EMS for final review and inclusion in 5Q, Section 11. RM is responsible for issuing notifications for all radioactive releases in excess of their annual guides.

A Reactors ad hoc committee develops annual ALARA release guides based on production rates, production subcycles and fuel cycies. The recommended guides are reviewed by the 160 Area environmental committee before submission to EMS for final review and inclusion in $5 Q$, Section 11. Reactors is responsible for issuing notifications for all radioactive releases in excess of their annual ALARA guides.

The Separations environmental coordinator chairs the 200-Area release-guide committee which develops annual radioactive-release guides based on production rates, irradiation time and age of targets or fuel elements processed, and past experiences. The recommended release guides are submitted to EMS for final review and inclusion in 5Q, Section 11. Separations is responsible for getting responsible departments to issue notifications for radioactive releases in excess of their annual guides in the 200 Area.

\section{Technical Support}

\section{SRTC- Environmental Technology Section (ETS)}

Noble Gas and Tritium Forms Study - The Tracking Radioactive Atmospheric Contamination (TRAC) mobile laboratory is used to study and plot the distribution of tritium and argon-41 (Ar-41) in plumes downwind of reprocessing and reactor facilities when in operation. Routine sampling and analysis for $A r-41$ is difficult because of its short half-life (1.83 hours); however, with the TRAC laboratory, Ar-41 can be measured at distances up to $50 \mathrm{~km}$. Results are used to verify dispersion modeling and dose estimates.

SRTC Monitoring of Separations Stacks - SRTC monitors certain radionuclide emissions from process stacks in the $\mathrm{F}$ and $\mathrm{H}$ Areas that can not be monitored by online equipment or routine laboratory procedures. ETS uses special collection and analytical procedures to measure carbon-14 (C-14), technetium-99 (Tc-99), iodine-129 (I-129), neptunium-237 (Np-237) and other isotopes. Weekly samples are collected from the canyon stacks and radioassayed using the Ultra-Low Level Counting Facility for C-14 and I-129 concentrations. The program has been expanded to measure Tc-99 and $\mathrm{Np}-237$ in canyon emissions and I-129 and C-14 in reactor emissions.

\section{Environmental Monitoring Section (EMS)}

Ambient Radiological Monitoring Program - EMS is responsible for complying with the radiological monitoring and reporting requirements of DOE Orders 5400.1 and 5484.1. An extensive radiological monitoring network has been established with measurements taken at 6 onsite locations, an additional 12 stations at the site 
perimeter, and 13 stations at a 25 -miles away from SRS. The stations at the site perimeter and 25 mile radius are located to permit continuing sampling within each 30-degree sector around SRS. The system currently is being expanded 15 perimeter monitors. An additional 4 monitoring locations have been established 100 miles from SRS near high-population centers. Sampling procedures are covered by DPSOP 271-1.

Tritium, which accounts for more than $75 \%$ of the of fsite population dose from atmospheric releases, is the only radionuclide of SRS origin that routinely can be detected offsite. Ambient levels of particulate alpha and beta/gamma emitters are determined by direct count of nilter-paper samples, using a high-purity germanium detector. The filter papers and other samples are analyzed further for strontium-89, strontium-90, iodine-131, plutonium-238, and plutonium-239. Analytical requirements are set forth in DPSOP 271-5.

Gross gamma radiation is measured continuously onsite and offsite, using thermoluminescent dosimeters at approximately 340 locations, covering an area of 800 square miles. This network will be used to distinguish between SRS emissions and future emissions from Plant Vogtle, which is directly across the Savannain River from SRS.

\section{One-Year Road Map}

The following are milestones related to the Radionuclide NESHAP Program at SRS. Some are plinned $(P)$ and others are regulatory commitments (C). With the modification of the FFCA and the startup of various facilities this list will change.

\begin{tabular}{lll}
\hline P & issue final quality assurance project plan & $1 / 15 / 93$ \\
P & complete modification to FFCA to include five new stacks & $1 / 15 / 93$ \\
P & complete unmonitored source calculations & $3 / 1 / 93$ \\
P & complete Clean Air Act Manual (Rad NESHAP Vol) & $6 / 30 / 93$ \\
& & \\
C & complete quarterly hot wire testing in K Reactor & $12 / 31 / 93$ \\
C & submit report on K-Reactor bot wire testing to epa & $1 / 31 / 93$ \\
C & complete construction on 291-F \& H upgrades & $3 / 1 / 93$ \\
C & complete quarterly hot wire testing in K Reactor & $3 / 31 / 93$ \\
C & submit report on K-Reactor hot wire testing to EPA & $4 / 30 / 93$ \\
C & submit demonstration report for 291-F \& H upgrade & $4 / 30 / 93$ \\
C & complete construction on 772-F upgrade (cold startup) & $4 / 30 / 93$ \\
C & complete annual NESHAP report & $6 / 30 / 93$ \\
C & complete quarterly hot wire testing (K,F \&H) & $6 / 30 / 93$
\end{tabular}


C submit report on hot wire testing to EPA (K,F\&H) $7 / 31 / 93$

C complete ORR for 772-F Upgrade $7 / 31 / 93$

C submit demonstration report for $772-\mathrm{F}$ upgrade

9/30/93

C complete quarterly hot wire testing (K,F \&H)

$9 / 30 / 93$

C submit report on hot wire testing to EPA (K,F\&H)

$10 / 31 / 93$

C complete quarterly hot wire testing (K,F \&H)

$12 / 31 / 93$

C submit report on hot wire testing to EPA (K,F\&H)

$1 / 31 / 94$

\section{Five-Year Road Map}

Other than routine reports, there are no firm milestones over the next five years, outside of those listed above. With the modification of the Radionuclide NESHAP and the startup of several facilities, there will be milestones, but at this time they can not be listed. 


\section{Chapter 10}

\section{Environmental Restoration}

Chapter was compiled and reviewed by Beth Wheat and Mary Flora. 


\section{Sitewide Program Overview}

The Savannah River Site's (SRS) Site Specific Plan (SSP) is produced annually to define sitewide environmental-restoration and waste-management activities identified by the Department of Energy's (DOE) Environmental Restoration and Waste Management Five-Year Plan (FYP).

The FYP describes the environmental-restoration and waste-management (ER/WM) planning process, communicates ER/WM's philosophy and overall strategy for achieving its compliance and cleanup goals, summarizes multi-year program plans, and assesses progress made during the previous year. The FYP goal is to ensure that human health, safety, and environmental risks posed by the department's past, present, and future operations either are eliminated or reduced to safer levels by the year 2019.

Sections from the above plans are presented to describe the following remedial actions and decontamination and decommissioning (D\&D) programs (Site Specific Plan, WSRC-RP-91-596 and Environmental Restoration and Waste Management Five-Year Plan FY 93-97).

\section{Environmental Restoration Overview}

The Westinghouse Envirulumental Restoration (ER) Department was formed in F $Y 91$ to consolidate ER activities at SRS. ER is responsible for all aspects of assessing and cleaning up sites and facilities that are no longer operating, but are contaminated with various quantities of hazardous, radioactive, or mixed waste materials. ER also is responsible for inactive waste sites which are nonhazardous and nonradioactive. ER performs two sets of activities; remedial actions, and decontamination and decommissioning (D\&D). The remedial action tasks encompass site characterization, analysis of cleanup alternatives, and selection of remedy; cleanup and site closure; and site compliance monitoring. D\&D is concerned with the safe caretaking of inactive nuclear facilities, and either their decontamination or their complete dismantling and removal.

The following overview is summarized from the Environmental Restoration and Waste Management Five-Year Plan (FYP). 


\section{Summary}

The primary objective of SRS's ER program is to identify, characterize, and remediate all inactive waste sites. The program is designed to comply with all applicable regulations to minimize or mitigate effects on the environment. SRS has an active ER program that addresses issues in the following areas:

- identification of waste sites

- investigation to confirm and quantify contamination

- technology development and demonstration to conduct cleanup

- installation of post-closure environmental monitoring

- remedial design and cleanup to restore natural resources

- decontamination and decommissioning (D\&D) of surplus facilities

Between 1984 and $19 \%, \$ 10$ million was spent at SRS for the Groundwater Protection Environmental Impact Statement (EIS) to evaluate, by technical and environmental-risk analysis, the magnitide and potential risk of most waste sites. This evaluation included radioactive-, hazardous-, and mixed-waste sites at SRS and also included remediation needs. Additional waste sites will be evaluated in a supplement to the EIS.

A total of 262 waste-management units currently are in the ER program at SRS. The type of waste units range from nonhazardous waste units to waste units containing both hazardous and radioactive waste. The waste units have been categorized into 5 groundwater units, 3 burial grounds, 6 reactor cooling/purge basins, 12 sanitary sludge sites, 3 process sewer lines, 1 storage tank, 1 sanitary landfill, 9 erosion control sites, 27 spill sites, 15 ash piles, 58 seepage/settling basins, 17 surface water units, and 105 disposal piles/pits. Some waste units include the contamination of surrounding subsurface soils and groundwater. The contaminants identified at various waste units include volatile organic compounds, heavy metais, pesticides, and radionuclides.

Since the formation of ER in October 1990, six RCRA facilities have been closed according to the South Carolina Department of Environmental Control's (SCDHEC) approved closure plans. They are the Mixed Waste Management Facility, F- H- and M-Area Hazardous Waste Facilities, Tank 105-C, and the Metallurgical Laboratory Basin. In addition, A- and M-Area groundwater :emediation is continuing. If left untreated, this area poses a potential threat to human health and the environment. The other waste area groups are broken down by RCRA waste-site closure, the consent order settling of the Natural Resources Defense Council lawsuit, investigations, and potential CERCLA activities.

RCRA has been the primary regulatory driver at SRS. A large number of waste sites either will undergo RCRA closures or are in the RCRA Facilities Investigation Program. However, SRS was placed on the National Priority List in December 1989, and signed the Federal Facilities Agreement with the state and EPA Region IV in January 1993. The FFA integrates the requirements of RCRA and CERLA at SRS waste units. 
The D\&D program potentially includes 14 facilities. Progress on D\&D activities has been slow because of past funding constraints. Surveillance and maintenance at the Heavy Water Component Test Reactor have been accomplished. The project plan outline has been completed for the D\&D of two experimental separations facilities, (SED I and SED II).

Outyear efforts include completing the Mixed Waste Management Facility's groundwater-remediation facility during FY 97 and completing the F- and H-Area groundwater-remediation facility during FY 95.

Justification

\section{Regulatory Requirements}

The basic framework for assessing all waste units and developing closure, post-closure, and remedial-action plans is based on the hazardous-waste requirements of RCRA, CERCLA as amended, the South Carolina Solid Waste Regulations (nonhazardous sites), and the South Carolina Hazardous Waste Management Regulations (SCHWMR). Waste units at SRS are identified in the draft FFA and will be addressed under an integrated RCRA/CERCLA program. The RCRA requirements have been the primary regulatory driver at SRS waste units.

\section{Federal Requirements}

Resource Conservation and Recovery Act (RCRA)-South Carolina is authorized by EPA to administer RCRA. Permitting under RCRA is a two-part process. The first part involves submitting a Part A permit application that contains certain basic facility information. The second part involves submitting a Part B permit application that contains detailed information about the individual hazardous-waste management facilities, including closure and post-closure activities. SRS's Part B permit was applied for in February 1985 and has been revised to incorporate additional facilities. A permit was issued in September 1987 to authorize closure and post-closure activities for the site.

CERCLA/Superfund Amendments and Reauthorization Act (SARA) (Superfund)CERCLA is administered by EPA. According to Section 102(a) of CERCLA, federal government agencies are subject procedurally and substantively to comply with this law. SRS was placed on the National Priorities List (NPL) in December 1989. DOE-SR currently is in the process of negotiating an FFA with the state and EPA-IV.

\section{DOE Orders}

DOE Order 5400.4-This order establishes instructions for implementing the DOE CERCLA program and defines actions to identify and evaluate inactive hazardous-waste sites at DOE installations. It also directs the custodian to take 
remedial action where necessary, to improve control of hazardous-substance migration from such sites.

DOE Order 5400.3-This order establishes hazardous-waste management procedures for facilities operating under the Atomic Energy Act and provides instructions for implementing the RCRA.

\section{State Requirements}

State requirements include the following:

- R.61-58 State Primary Drinking Water Regulations

- R.61-60 Solid Waste Regulation

- R.61-61 Solid Waste Regulation

- R.61-66 Industrial Solid Waste Disposal Site Regulation

- R.61-68 Water Classification and Standards

- R.61-69 Classified Waters

- R.61-70 South Carolina Landfill Regulations

- R.61-71 Well Standards and Regulations

- R.61-79 SC Hazardous Waste Management Regulations (SCHWMR)

- R.61-87 Underground Injection Control Regulations

- R.61-92 South Carolina Underground Storage Tank Control Regulations

In addition, other state regulations may apply to the format or other aspects of closure plans. Until the investigations are complete, it is not known which regulations may apply.

\section{Strategy}

\section{Closure/Environmental Restoration Strategy}

Closure options for the waste units vary and will be determined on a unit-specific basis. Options for remediation include waste stabilization, site capping, waste removal, and grading. No action may be required at some waste sites, in which case, documentation supporting this option will be provided in a report to the regulators. In EIS's preliminary analysis, "Waste Management Activities for Groundwater Protection at the Savannah River Plant," DOE/EIS-0120D (DOE 1987c), the current plans propose waste removal at the old F-Area seepage basin and at six R-Area seepage basins. The final closure strategy for all waste sites, however, will depend on the information developed during characterization and assessment.

Groundwater remediation currently is underway in $A$ and $M$ Areas where volatile organic carbons are removed from the groundwater by air stripping. Groundwater corrective-action plans currently are being developed for the TNX and F and $\mathrm{H}$ Areas. Groundwater remedial actions will be performed, as needed, to comply with groundwater-protection requirements resulting from negotiated agreements with regulatory agencies. Corrective actions are complex and depend on many variables, 
which are often unit specific. Remedial actions include in situ treatment, groundwater extraction with surface treatment, and containment or diversion. An effective design often combines two or more actions.

\section{RCRA Part B/RFI Activities}

There are 15 waste sites that currently are subject to RCRA permiting and compliance actions by SCDHEC under the authorized state hazardous-waste program. Six of these waste sites have undergone closure under approved RCRA closure plans. Closure plans for four sites currently are under regulatory review.

In September 1989, SRS received regulatory approval for the RCRA Facility Investigation (RFI) program. Unit-specific work plans will be developed for these units to determine the nature and extent of potential hazardous-substance releases and the necessity for corrective actions. The RFI program has integrated CERCLA requirements and now is known as the RFI/Remedial Investigation (RI) program.

Programs

Waste-site closure activities include many phases, such as characterization, assessment, closure plan development, site closure, and remedial activities (see Figure 10-1). 


\section{Savannah River Site Waste Site Closure Pathway}

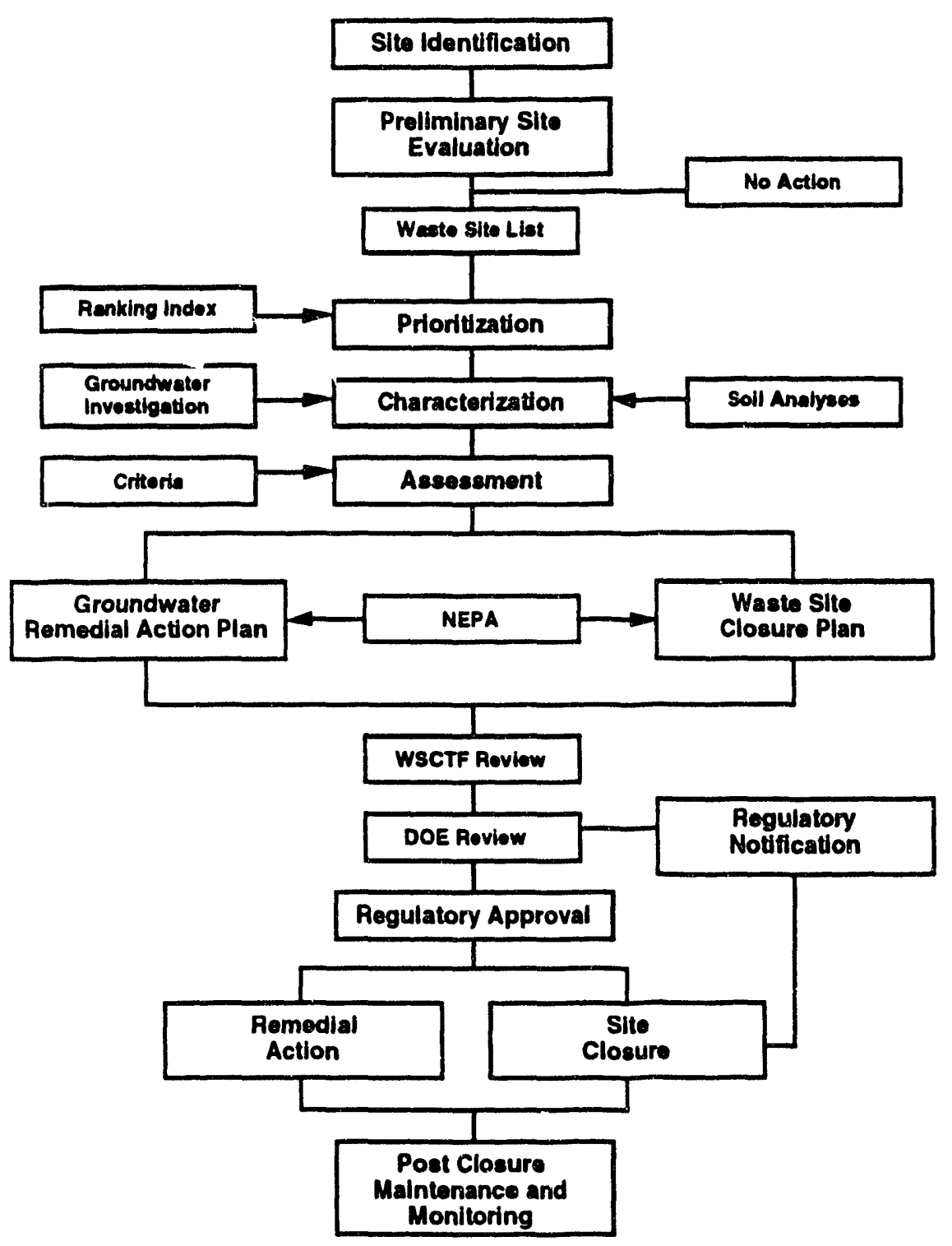

Figure 10-1. Savannah River Site Waste Site Closure Pathway

Funding estimates for most of the waste sites assume the waste will be left in place by applying closure techniques, such as capping. However, the final closure option is dependent upon site-specific conditions, regulatory requirements, and approval.

The characterization of SRS waste units addresses the following:

- compiling all available data

- identifying data gaps

- gathering additional information such as soil gas surveys, soil borings, well installations, and groundwater analysis 
SRS waste units are assessed as follows:

- compiling and interpreting data collected during the characterization plase

- identifying applicable regulations

- developing closure plans

Site-specific assessments include the following:

- establishing the properties of the known contaminants, if any

- determining the sources

- ascertaining the rate and extent of contamination

- identifying the groundwater-flow directions and elevations

Based on this information, one or more closure options is recommended.

Site Closure Criteria-Procedures and criteria for characterizing, remediating, and closing the inactive waste sites are controlled by federal and state regulations and DOE orders. There is a minimum amount of information that must be developed for each site. A different activity level is required at each waste site due to the type of waste deposited and the different regulations. The definition of the unit-specific closure criteria is developed during the characterization and assessment of phases of closure for each site.

Closure Plan Development and Approval-The closure plans for all SRS waste sites will be developed to minimize or eliminate the contaminants' migration. This plan may be obtained by immobilizing or extracting the contaminant or by capping the waste site without contaminant removal. Closure plans address the following:

- obtaining agreement on closure performance standards

- establishing a detailed waste inventory

- determining waste-removal, treatment, and disposal requirements

- determining sampling and analysis needs

- defining backfill requisements

- identifying cover systems

- decontaminating equipment

- controlling surface water

- establishing closure schedules

Postclosure/Remedial Action Plan Development-An integral part of each waste-site closure plan is the post-closure maintenance and monitoring activities that ensure the integrity and security of the closed waste site. Post-closure plans include the following:

- developing inspection checklists

- defining inspection frequency

Post-closure/remedial-action plans for specific waste sites must be reviewed and approved by the appropriate regulatory agencies.

Closure for Large Sites-The major portion of work outlined in the closure plan will be performed by subcontractors. The waste-site custodian is responsible for managing 
the subcontractor(s) and ensuring that the contractor is following the approved closure plan. Closure of small sites, such as the Met Lab Basin, may be performed by onsite resources.

Postclosure Activities/Remedial Action-ER is responsible for ensuring the implementation of activities specified in the approved Postclosure/Remedial Action Plan. Postclosure inspection, maintenance, and monitoring may be required in order to ensure the integrity and security of the closed waste site. The effectiveness of any required remedial action is verified through post-closure monitoring. The scope of these activities will vary from site to site, depending on the type and amount of waste, waste residue, or residual contamination remaining after site closure.

\section{Milestones}

The following major milestones for ER were listed in the Environmental Restoration and Waste Management Five Year Plan, FY 93-97:

- submit closure plan for the low-level waste burial ground 1Q FY 93

- start construction at F- and H-groundwater remediation 3Q FY 95

- submit closure plan for the current sanitary landfill $1 Q F Y$

Technical Support

\section{Savannah River Technology Center}

Subsurface environmental research at SRS primarily is conducted by the Environmental Sciences Section (ESS) and the Interim Waste Technology Section (IWTS). The programs related to the subsurface can be divided roughly into the following three categories: waste constituent transport rate/mechanisms; engineered cleanup technologies; and geology/geohydrology. The objectives of the transport rate/mechanism studies are to define the rate of waste constituent migration (using field techniques such as soil gas surveys, groundwater analyses, lysimeters, and lab studies such as column and batch sorption experiments) and to elucidate the mechanisms of transport. These activities will facilitate accurate modeling and help identify new treatment technologies. The objective of the engineered cleanup technology study is to determine the applicability of emerging remediation technologies for waste constituents at SRS. The objective of the geology/geohydrology programs is to develop a fundamental understanding of SRS's strata (depositional environments and history, stratigraphy, tectonic history, seismic environment, etc.) and to develop methods to describe subsurface processes. 
A description of subsurface research programs follows:

Transport Rates and Mechanisms

Title

Facilitated Transport Study

SRS Waste Lysimeters

Tenth-Scale Saltcrete Lysimeters

Groundwater Modeling

Tank 24 Saltstone Lysimeters

\section{Description}

This study evaluates the detailed mechanisms for waste transport through porous media, using laboratory column studies, geochemical models, and field studies. Initial results suggest that the association of waste constituents with mobile colloids and various ligands can play a significant role distributing these materials. The feasibility of minimizing the transport of waste constituents by modifying the geochemical environment will be evaluated.

This provides technical support for improved management of shallow-buried waste, using lysimeters. This project uses $\mathbf{4 2}$ lysimeters to test different SRS wastes, representing the types buried in the SRS burial ground from 1953 to 1984. These lysimeters were installed in the burial ground and sampled monthly to monitor the release and migration of radionuclides.

This evaluates economical shallow-land disposal of low-level waste by testing a 1982 formulation of nonradioactive saltstone. The lysimeter is sampled monthly to evaluate the retention of soluble constituents.

This provides technical support for site-specific groundwater modeling such as supporting remedial-action programs. Current projects involve modeling the $\mathrm{A} / \mathrm{M}$ Area groundwater-remediation program and the $\mathrm{F}$ - and $\mathrm{H}$-Area groundwater plume, assessing the effect of capping waste sites on groundwater flow, and stochastic modeling to help locate monitoring wells at waste sites.

This is to evaluate on a larger scale with actual waste. Three lysimeters are sampled monthly to determine retention of soluble constituents. 
Transport Rates and Mechanisms (Contd)

Alpha Source Mini Lysimeters

This evaluates leaching from five chemical forms of plutonium and americium, and from alpha-containing glass, ash, and sludge. The 11 lysimeters are in the burial ground and are sampled quarterly.

Environmental Saltstone

Lysimeters

Special Waste Form

SRL Tree Plots

TRU Waste Assessment

Organic and Inorganic Coal Pile Constituents
This measures radioactive releases from saltstone that are a potential path for transport to the surface by vegetation.

This evaluates five different types of commercial lysimeters with nuclear power plant wastes. These 10 lysimeters are located in the burial ground and are sampled monthly. The lysimeters allow horizontal coring.

This determines uptake of radionuclides from a burial ground low-level alpha waste trench by vegetation.

This reviews procedures for managing transuranic wastes at SRS, including historical monitoring data, isotopes in the groundwater, and modeling projections on potential effects of the waste in the biosphere.

This collects and analyzes groundwater data from the coal piles and coal pile runoff basins at SRS. The objective is to protect the groundwater through improved management and utilization strategies for coal piles. 
Engineered Cleanup Technologies

Vacuum extraction

In Situ Air Stripping

In Situ Bioremediation

Horizontal Wells
This evaluates the feasibility of using vacuum technology to remediate organic solvents at SRS. A successful pilot study was performed with one vertical extraction well and two pressure measurement wells. Fifteen hundred pounds of solvents were removed in 21 days. A full-scale system will be installed at four locations across $M$ Area to remediate the unsaturated zone near sources.

This evaluates the effectiveness of an in situ air stripper to remove organics from the groundwater. The in situ air stripping, air injection below the water table combined with vacuum extraction in the vadose zone, were demonstrated successfully in 1990, using horizontal wells. Sixteen thousand pounds of solvents were removed during the 20-week test.

A full-scale in situ bioremediation demonstration now is underway using the same horizontal wells as in the in situ air stripping demonstration. The demonstration, consisting of injecting methane plus air below the water table and vacuum extraction above the water table, will last for one year.

A number of horizontal drilling technologies have been and will be demonstrated as part of the Office of Technology Development's integrated demonstration. The objective is to develop new methods for improving access to the subsurface in a cost-effective manner. Technologies modified from the petroleum and river crossing industries have been demonstrated at SRS. Utility industry technologies will be demonstrated in the near future. Other supporting technologies that involve characterization and monitoring for remediations have been demonstrated as part of the integrated demonstration. Several developed at SRS include depth discrete sampling of soils and groundwater, a new analytical method, and three-dimensional modeling of environmental data. 
$\because$

Engineered Cleanup Technologies (Contd)

TCE Biodegradation

Demonstration

Waste Disposal Cover

Other Biotechnology Programs

Biobartiers for Sites
This program provides direct application of biotechnology for remediation of wastes and waste sites at the SRS. One task nvolves designing anci demonstrating above-ground bioreactors to remediate trichloroethylenecontaminated groundwater. A microorganism that degrades trichloroethylene has been discovered and a patent has been submitted. Three different bioreactors will be tested as part of this program, which is being conducted in cooperation with the Gas Research Institute. This program's second task involves testing different types of vegetation that can encourage microorganisms to degrade richlorethylene in shallow, contaminated soils. Greenhouse experiments, conducted in conjunction with scientists from the Oak Ridge National Laboratory, have shown that pines encourage microorganisms with TCE degrading abilities.

This develops new technologies for closing waste disposal facilities. Currenty, this involves developing new materials and implementing techniques for geomembranes, currently required for closing waste sites.

From a basic understanding of biotechnology, this develops applications related to product recovery, waste disposal, and process replacement. Design and construction of a facility to treat oil-contaminated soils is underway. Using biotechnology to treat waste sites contaminated with oil products is under consideration. An investigation of the potential for microalgae to treat waters contaminated with metals has been initiated.

This field tests a system of an encapsulated slow-release herbicide bonded to a geo-fabric. When the system is placed below the soil zone. over a closed waste facility, the system is designed to eliminate root penetration for more than 100 years. 


\section{Engineered Cleanup Technologies (Contd)}

Environmental Radionuclide

Waste Site Remediation Studies
The Environmental Technology and Environmental Sciences sections have initiated a long-term study to assess the status of radionuclides released from in-stream, wetland, and terrestrial areas on and near SRS. The studies are a joint effort with the Environmental Monitoring and Environmental Protection sections and are oriented toward evaluating the long-term risks associated with radionuclides released by aquatic and atmospheric pathways, and deposited beyond SRS facility boundaries.

The Environmental Sciences Section has initiated projects in conjunction with the Interim Waste Technology Section and plant custodial organizations to examine the biological effects of historical waste-disposal practices. These studies are to determine what, if any, biological effects are detectable, and to develop methods for remediating the effects to above-ground biological communities. 


\section{Facility Transition Management}

\section{Site Program Overview}

In 1992, a new office was formed within EM. The Office of Facility Transition and Management (EM-60) has the responsibility to act as an intermediary between existing program offices and the rest of EM in the disposition of surplus facilities. At SRS, an interdepartmental coordination committee was established to deal with facility transition matters. The Planning Integration Department will oversee the coordination of transition planning with site mission, land use, and long-term plans. The Environmental Restoration Department will provide the management expertise for transitional facilities. This will include surveying and maintaining surplus facilities awaiting disposition by EM, and program management for deactivation and characterization of EM-60 facilities.

Milestones

No milestones for facility transition were listed in the Environmental Restoration and Waste Management Five Year Plan, FY 93-97.

Objectives

Near-term objectives to be reached in FY 93 are the following:

- investigate and document the condition of facilities identified as surplus candidates for transition in FY 93

- identify additional candidate facilities for transition in FY 94

- establish protocols for turnover of responsibility of surplus facilities for Defense Programs to EM

- establish organizational relationships and policy for transition activities

\section{Decontamination and Decommissioning (D\&D)}

\section{Site Program Overview}

The D\&D Program at SRS continues to be restrained by limited funding. Characterization of the Separations Equipment Development (SED) facility has been initiated. Surveillance and maintenance at the Heavy Water Components Test Reactor facility continues. Planning activities include investigating conditions at potential D\&D program facilities, generating a program-management plan, and coordinating D\&D program planning with other long-range plans.

Milestones

No milestones for decontamination and decommissioning were listed in the Environmental Restoration and Waste Management Five Year Plan, FY 93-97. 
Objectives

Near-term objectives to be reached in FY 93 are the following:

- prepare a D\&D Program Management Plan

- gather information about facility conditions and expand the facility database for potential D\&D projects

- compiete ciaracterization of the SED facility and start preliminary engineering activities

- prepare an annual revision of the D\&D Thirty-Year Facilities Plan 


\section{RCRA Permitting}

(Compiled and reviewed by Bill J. Maloney)

RCRA permit application, modification, and implementation is an ongoing process for post-closure care (PCC) facilities.

SRS submitted the first five volumes of its 1985 RCRA Part B permit application on February 6, 1985. This led to the permitting of several of these facilities in 1987. Since that time, SRS has submitted additional volumes of the application for numerous other facilities and SCDHEC has added several of them to the permit. At this time, the status of RCRA permitting activities at SRS, pertaining to the 1985 RCRA permit application for environmental-restoration (ER) facilities (excluding operating facilities which are addressed in the waste management chapter), is as follows:

- RCRA permitted by 1987 permit

- M-Area Hazardous Waste Management Facility (HWMF)

- F-Area HWMF

- H-Area HWMF

- 1985 Part B permit application volumes submitted/pending regulatory approval

- Mixed Waste Management Facility (MWMF)

- Metallurgical Laboratory HWMF

- 1985 Part B permit applications volumes to be submitted

- none

The 1987 RCRA permit for SRS expired on September 30, 1992. By regulation, SRS is allowed to continue to manage the above listed permitted facilities in accordance with the expired 1987 permit. This is because SRS submitted a new permit application (the 1992 RCRA Part B permit renewal application) at least 180 days prior to the expiration. At this time, SCDHEC has not issued the renewal permit, therefore, SRS will continue to manage the above listed permitted facilities in accordance with the expired 1987 permit until SCDHEC issues the renewal permit. At this time, the status of RCRA permitting activities at SRS, pertaining to the 1992 RCRA permit renewal application for environmental-restoration (ER) facilities (excluding operating facilities which are addressed in the waste management chapter), is as follows:

- RCRA permitted by renewal permit

- none

- 1992 Part B permit renewal application volumes submitted/pending regulatory approval

- M-Area Hazardous Waste Management Facility (HWMF) (3/92)

- Mixed Waste Management Facility (MWMF) (11/92)

- Metallurgical Laboratory HWMF (9/92) 
- 1992 Part B Permit Renewal Application Volumes to be Submitted

- F-Area HWMF (8/93) (Note 1)

- H-Area HWMF (8/93) (Note 1)

- Sanitary Landfill HWMF (3/93)

- Acid/Caustic HWMF (Note 2)

There are a number of facilities which are "existing facilities" that are not yet Part B permitted. They currently are under interim status (IS). These facilities submitted Part A of the permit application, and it was approved by the regulatory agency to be added to IS. Many of these facilities were added as part of settlement agreements. At this time, the status of RCRA IS activities at SRS for environmental restoration (ER) facilities (excluding operating facilities which are addressed in the waste management chapter) is as follows:

- IS facilities no longer receiving hazardous waste

- $\quad$ Mixed Waste Management Facility (MWMF) (Note 3)

- Sanitary Landfill HWMF (Note 4)

- facilities under construction

- none

- Part A submitied/pending regulatory/approval

- none

- Part A to be submitted

- none

Note 1 SRS did not submit the F/H HWMF Part B permit renewal application 180 days prior to the 1987 permit expiration. This is because, at that time, the F/H HWMF was not permitted. The F/H HWMF was not added to the 1987 permit until September 30, 1992. Per the September 30, 1992 permit modification, SRS needs to submit the F/H HWMF Part B permit renewal application by August 2, 1993.

Note 2 It is not clear whether Part B is required for any or all of the acid/caustic basins. SRS has requested approval to perform a "Hybrid Closure" in the basins and is waiting for a decision. A schedule for preparing and submitting the Part B permit application for any basin that SCDHEC decides can not be "Hybrid Closed" will be prepared at that time.

Note 3 For the most parh, the MWMF has been certified closed. That portion of the facility which was added as part of the solvent rag settement agreement (Low Level Radioactive Disposal Facility (LLRDF) is not closed. A closure plan is being prepared. The MWMF does not receive waste, therefore, it is not operational.

Note 4 The Sanitary Landfill HWMF does not receive hazardous waste, but still accepts non-hazardous waste as part of its domestic-waste permit. The facility was added as part of the solvent rag settlement agreement and is not closed. A closure plan is being prepared. 


\section{Chapter 11}

\section{Employee Education}

Chapter was compiled and reviewed by Patricia J. West. 


\section{Site Program Overview}

\section{Introduction}

The Savannah River Site (SRS) environmental-awareness and training programs are documented as Employee Education. These programs facilitate reaching environmental goals at SRS and meeting the objectives of the Environmental Implementation Plan (EIP).

\section{Summary}

Employee education is enhanced through awareness and training. The awareness program is designed to communicate site environmental philosophy and policy (goals) to employees. A formal awareness program was implemented in FY 88. The site's environmental-awareness programs are coordinated by the Environmental Protection Department (EPD). Leadership and financial support for sitewide environmentalawareness programs are provided by EPD.

The training program is designed to identify training activities needed to teach jobspecific skills that protect the environment and satisfy regulatory training requirements. The Savannah River Site (SRS) Environmental Training Plan, WSRC$R P$-92-282, issued February 1992, is a documented framework for implementing and managing an integrated environmental-training system. 


\section{Policy}

SRS's environmental-awareness and training programs are designed to communicate site environmental goals, comply with regulatory requirements for environmental training, and support the EIP objectives.

\section{Background}

The operating contractor is responsible for protecting human health, the environment, and other natural resources. At a minimum, this responsibility includes full compliance with applicable regulations. DOE orders, and operating-contractor policy. Therefore, site environmental goals must be linked closely to safety, quality, and production goals, and employees must be committed to protecting the environment.

An acceptable level of commitment can be realized, if employees understand what the site environmental goals are, what actions/procedures are required to reach these goals, and what the consequences (to both the environment and to continued, successful operations at SRS) are if these goals are not met. Understanding comes through knowledge, and knowledge comes through education. The site environmental goals can be reached through effective employee education and support of every employee. 


\section{Existing Conditions}

In April 1988. the SRS Environmental Awareness Program was initiated when EPD issued the awareness-program booklet. The objectives of the sitewide program were to: publicize goals and contacts; provide information; and coordinate sitewide awareness activities.

In August 1988, the first onsite Environmental Awareness Day was beld. The theme was "Savannah River Plant: Protecting the Future", and several thousand employees participated. A gathering of 300 and 700-Area employees featured speakers, pamphlets, posters, videotapes, and displays which included the Tracking Radioactive Atmospheric Contamination (TRAC) van, spill-response equipment and trailer, and the Environmental Monitoring Section's (EMS) monitoring equipment. Similar activities were held concurrently in other areas sitewide. In addition, environmental-outreach tours and information-sharing sessions were provided for local and state officials in September. These activities focused on SRS's impact on the environment and included discussions of waste-management practices and environmental-protection performances/initiatives. Representatives from DOE, Savannah River Ecology Laboratory (SREL), SRS, and the U. S. Forest Service (USFS) spoke on a variety of topics. In December, the fire department's Hazardous Materials (HAZMAT) Response Team and Central Services Work Engineering (CSWE) Spill Busters Team displayed new equipment and promoted environmental awareness.

EPD and ESH\&QA Division Training continued to assist line management by providing and developing the following environmental-awareness and training programs:

- An environmental-protection orientation is provided to persons through the Upgraded First Line Supervisor Training Program, the Contract Administration Workshop, and the Subcontractor Orientation Program. About 75 percent of the participants were newcomers to the site. Feedback from these presentations affirmed improved employee awareness of potential environmental impacts.

- Specialized courses are conducted for environmental professionals onsite. These include the following: Fundamentals of RCRA, OSHA 1910.120 Overview, and Regulatory Training for Management of Hazardous Waste.

- RCRA training coordinators were provided a site-specific videotape (Hazardous Waste Training) and background materials for initial training and annual retraining of personnel handling hazardous waste/mixed waste at SRS staging areas.

- A central Waste Action Team (WAT) coordinates a comprehensive wasteminimization program for the site. WA'T provides input on program development, implementation, and employee-training and awareness activities. Each site department is represented on the team by a designated waste coordinator.

- A training video on environmental awareness was developed for the SRS general employee training program (GET). Although environmental training is not a GET program requirement, this video was written and developed by EPD to further enhance awareness of environmental issues and site environmental goals. 
- The National Environmental Policy Act (NEPA) orientation is provided by the EPD NEPA coordinator annually.

- Orientation courses are conducted by EPD to present and publicize site environmental manuais to site personnel. The Environmental Compliance Manual, Procedure Manual $3 Q$, orientation course can be arranged by contacting EPD.

- The Savannah River Site (SRS) Environmental Training Plan, WSRC-RP-92-282 was issued in February 1992 as a documented framework for implementing and managing an integrated environmental-training system. 


\section{Objectives}

Employee-education objectives include the following:

- a commitment to implement a site awareness program to communicate site environmental goals to employees and to enhance employee commitment to environmental protection

- a requirement to provide environmental training that meets federal and state regulatory requirements, including cerification and emergency response 


\section{Strategy}

The employee education strategy, as illustrated in Figure 11-1, distinguishes between awareness and training programs.

The awareness program is designed to communicate site environmental goals and to enhance employee commitment to protecting the environment. The strategy for this program is to do the following:

- develop a pilot awareness program plan (completed FY 88)

- implement an awareness program using public-relations techniques

The training program is designed to assist line management in identifying training activities needed to teach job-specific skills that protect the environment and satisfy regulatory training requirements. The following is the strategy for this program:

- identify site training needs (continuing)

- develop site training program plan. Savannah River Site (SRS) Environmental Training Plan. WSRC-RP.92-282 was issued February 1992

- develop specific training modules (continuing) 


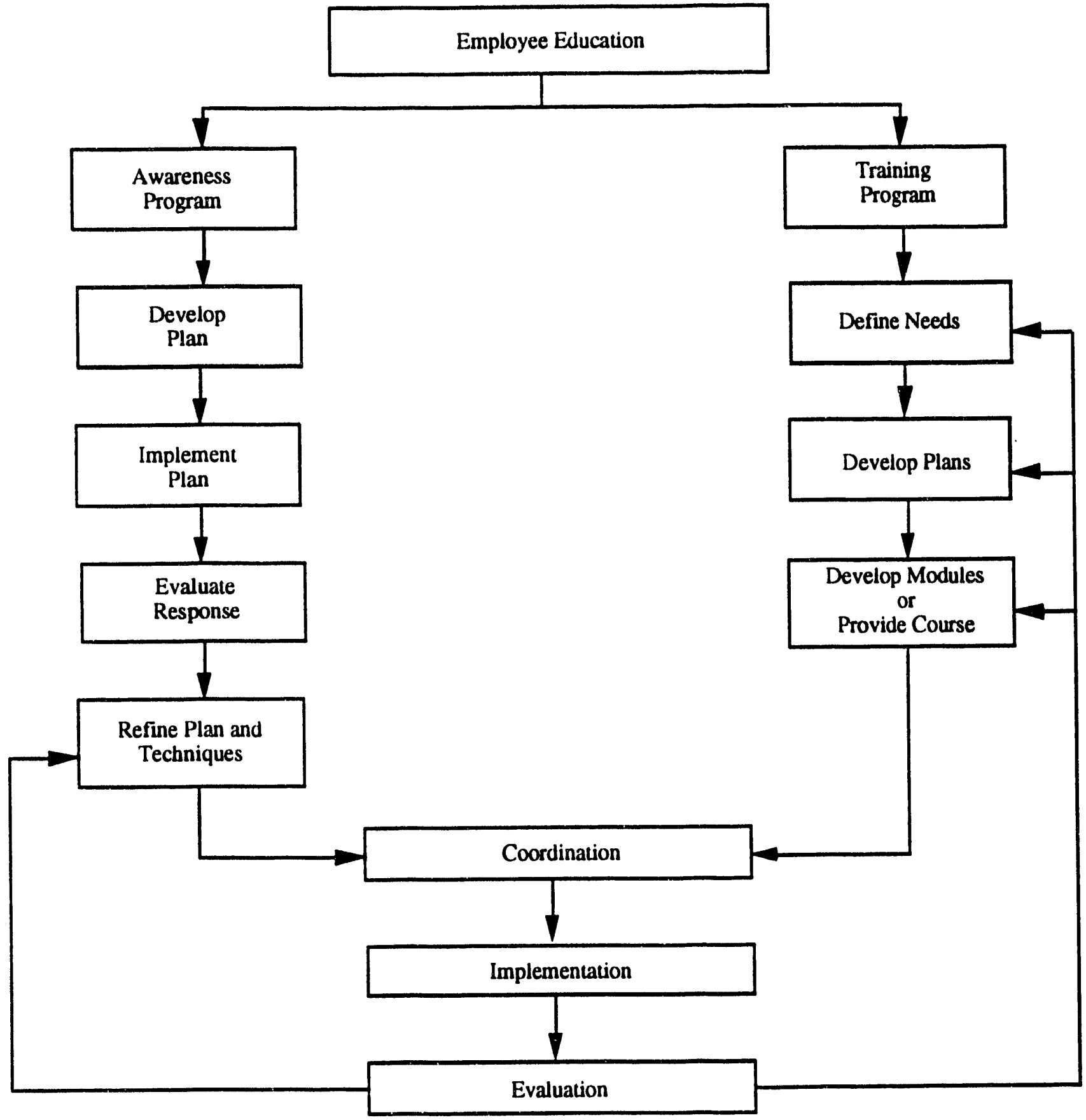

Figure 11-1. Employee Education Program Strategy 


\section{Implementation}

This section provides details of the site environmental awareness and training programs and identifies organizations that are responsible for achieving objectives. Employee education requires funding for programs and studies.

The following programs are discussed in the Implementation Section.

- Awareness (page 11-11)

- Training (page 11-14)

- DOENWestinghouse School for Environmental Excellence (page 11-17) 


\section{Awareness}

(Compiled and reviewed by Patricia J. West)

\section{Site Program Overview}

The formal awareness program was developed in FY 88. The purpose of this program is to provide employees with appropriate, basic knowledge of site environmental goals and to enhance their commitment to protecting the environment.

Justification

In January 1987, General Staff at SRS and the Savannah River Technology Center (SRTC) endorsed a proposal to develop a site environmental-awareness program. In addition, a pollution-prevention awareness program now is required by DOE Order 5400.1, General Environmental Protection Program. SRS environmental-awareness programs support the commitment objective.

\section{Organizational Responsibilities}

EPD is responsible for developing the site environmental-awareness program.

Employee-awareness and training activities supporting the waste-minimization program are developed by WAT.

EPD provides leadership and resources to support the activities of WAT.

ESH\&QA Division Training provides documented, formal awareness training courses.

\section{Site Program}

The site's environmental-awareness program is a coordinated effort to increase employee understanding of site environmental goals. Every employee's support is required to meet these goals.

\section{Environmental Protection Department (EPD)}

EPD has taken the leading in coordinating and implementing the site environmentalawareness program.

The awareness program includes several important components designed to enhance employees' understanding of the site's environmental goals. These include the following:

- A monthly newsletter, Environmental Exchange, is published for site environmental personnel. The newsletter focuses on timely environmental issues, 
as well as regulatory updates. This newsletter is published by the Facility Support Section of EPD.

- An annual Environmental Awareness Day for all site employees is organized. The event coincides with the nation's celebration of Earth Day and includes participation in community Earth Day activities. The site event includes speakers, displays and opportunities to discuss environmental issues with environmental personnel from Westinghouse Savannah River Company, SREL, Savannah River Forest Station and other organizations.

- Articles focusing on environmental topics are published monthly in the SRS News. The articles focus on ecology, as well as waste-minimization topics.

- Update, the monthly video program is used to promote environmental issues at SRS.

- A quarterly SRS environmental video update is produced. This video is produced for regulators, as well as for senior SRS management and site environmental professionals. The update is written by EPD's Facility Support Section and produced with Video Services.

- Orientation courses to promote environmental manuals at SRS are provided.

- The National Environmental Policy Act (NEPA) orientation is provided annually by the EPD NEPA coordinator.

\section{Central Environmental Committee (CEC)}

The CEC provides support to the site environmental-awareness program. The committee plays a key role in activities such as Environmental Awareness Day and aricles for the Environmental Exchange.

\section{Site Waste Minimization}

The Site Waste Minimization organization is responsible for coordinating the development, promotion, implementation, and reporting of site waste-reduction activities.

The site's waste-minimization program has been developed to include employee training, awareness, incentives and awards, as required by the Pollution-Prevention Awareness Program in DOE Order 5400.1. The program's focus is to reduce or eliminate the generation of solid waste at SRS. Employee-education and awareness activities will promote source reduction and recycling techniques as the top priorities for achieving this goal. Further information on the site's waste minimization program is found in the Savannah River Site Waste-Minimization Plan, WER-SWM-92-0141 Revision 5 (11/92).

\section{ESH\&QA Division Training}

ESH\&QA Division Training provides documented, formal awareness training courses. 


\section{Facility Programs}

Any formal facility-specific awareness programs should be documented in a later version of the EIP. Facility custodians are encouraged to communicate environmental matters to their employees and to EPD or CEC in order to facilitate coordinating the site environmental-awareness program.

Monitoring

A study may be undertaken to determine a valid method to measure changes in employee awareness, and thus, to evaluate the effectiveness of the site environmentai awareness program. 


\section{Training}

(Compiled and reviewed by James $M$. Sutherland)

\section{Site Program Overview}

The purpose of this program is to ensure that training activities needed to teach jobspecific skills and to protect the environment are identified, and that regulatory training requirements are met.

In an effort to focus and centralize "Environmental Training" at SRS, the ESH\&QA Division Training has developed the WSRC Environmental Training Plan (WSRCRP-92-282). This plan addresses the SRS's current position on environmental training and identifies actions needed to validate and evaluate existing training and to develop needed training. These actions will be accomplished between the plans effective date of March 3, 1992 and the end of 1994. The plan will be revised and updated periodically.

Justification

Specific environmental-training requirements are cited in most federal and state environmental laws/regulations, in DOE orders, and in operating contractor policy.

\section{Organizational Responsibilities}

Employee training is a responsibility of its management. Line management ensures that training, which meets the needs of its organization and employees, is provided.

ESH\&QA Division Training will assist line management in developing, instructing, maintaining, and documenting environmental training.

Specific issues directly relating to an area or facility will be handled by the appropriate division training organization with oversight by ESH\&QA Division Training. All training activities will be coordinated by ESH\&QA Division Training.

\section{Site Program}

The Savannah River Site (SRS) Environmental Training Plan, WSRC-RP-92-282, issued in February 1992, is a documented framework for implementing and managing an integrated environmental-training system at SRS. The following information describes the plan.

During the past 20 years, the nation has responded to environmental changes in an evolutionary fashion, i.e., pollution control has led to waste management, waste minimization, and finally pollution prevention. The environmental area is a dynamic 
one, as new laws and regulations constantly add increased regulatory pressures to both industrial and federal facilities. Meeting these requirements is a tremendous training challenge to help employees master the technology and requirements of their jobs.

Both Westinghouse Corporate Directives (MD-E60), in regard to Govermment-Owned, Contractor-Operated (GOCO) facilities, and DOE orders indicate that WSRC will comply with all applicable state and federal laws, and regulations pertaining to the protection of the environment and the health and safety of employees and the general public. Consequently, careful attention must be paid to ensure that SRS complies with these laws, regulations, orders, and policies. To meet both present and future regulatory challenges, SRS needs to ensure that a sound environmental program is in place, including -- and of primary importance -- continual employee training.

To date, environmental training at SRS has been implemented primarily ai the department and facility level. These activities have met with limited success and have generated numerous programs, some of which are inconsistent with requirements, costly, and redundant. In order to ensure compliance, to eliminate inconsistencies, and to maximize SRS's effort, a centralized total quality approach to environmental training is being pursued. Issues that have sitewide implication will be dealt with by ESH\&QA Division Training. Specific issues directly relating to an area or facility will be handled by the appropriate division training organization with oversight by ESH\&QA Division Training. All training activities will be coordinated by ESH\&QA Division Training.

As part of this training initiative, this plan addresses each of the 10 current federal environmental regulations focusing on required training programs and recommended education courses for workers, supervisors, and managers who are involved with environmental oversight, hazardous materials, and waste management at SRS. These training programs will include formal delivery (classroom, self-paced, computerbased, etc.), as well as documented, supervised on-the-job experience, when appropriate. All training activities will be documented. Programmatic records, as well as individual records. will be maintained.

To implement the program, the following actions will be taken to evaluate the condition and cost-effectiveness of the present training, develop and implement needed training, and assist line management in identifying SRS employees who need training:

- A regulatory needs assessment will be completed. ESH\&QA Division Training will assess and validate the level of compliance with applicable regulations for each program identified.

- ESH\&QA Division Training will complete a "vendor supplied versus Westinghouse" analysis for each subcontracted course currently offered. The division training will produce an approved course list for SRS employees.

- A tickler system will be established with procurement to route all future purchase requisitions for ESH\&QA-related training to the ESH\&QA Division Training manager for review and approval.

- The 29 CFR 1910.120 course identified in this plan will be developed and implemented. 
- The 40 CFR 262.34 course identified in this plan will be developed and implemented.

- ESH\&QA Division Training will develop environmental-training decision flow diagrams to enable line management to identify personnel that are required to complete environmental training.

- Line management will identify employees requiring environmental training and report this information to the ESH\&QA Division Training manager. ESH\&QA Division Training will provide assistance in this effort as requested.

- ESH\&QA Division Training will maintain and enhance relations with other GOCO facilities to facilitate the exchange of environmental-training courses and programs that can be adapted to meet SRS environmental-training needs.

WSRC is committed, as a matter of policy, to maintain its facilities and conduct its operations in full compliance with all applicable laws and regulations to protect the environment, the health and safety of employees and the general public.

This training plan represents a centralized total quality approach to environmental training. The primary objectives are to train employees to participate actively as "Partners in Environmental Excellence".

Facility Programs

Many varied training activities that meet regulatory requirements currently are provided by line management. Examples of these activities are: radiation selfmonitoring; respirator use; fire extinguisher use; proper techniques for handling asbestos; and emergency-response exercises. In addition, specialized teams, such as the Spill Team led by the Central Services Works Engineering organization, receive formal training in areas of needed experise.

\section{Monitoring}

Compliance with environmental-training requirements is assessed through site internal-appraisal programs, as well as through technical reviews by external agencies. 


\title{
DOE/Westinghouse School for Environmental Excellence
}

\author{
(Compiled and reviewed by Mary S. Dodgen)
}

\section{Overview}

\section{Purpose}

The purpose of environmental training presented in the GOCO school is to "produce" well-trained personnel who can make sound "environmental" decisions. Customers include personnel with "environmental-related" responsibilities, for example, engineers and first-line managers. Services include training, awareness, and opportunity to network.

\section{Description}

The DOE/Westinghouse School for Environmental Excellence is a unique, one-of-akind program that is designed to train Westinghouse and DOE employees in the rigors of environmental law and compliance. More than 200 students have attended the school in the first five sessions, and many have indicated that their job performances were enhanced.

Highly-placed DOE and Westinghouse managers have expressed satisfaction with the cost-effective program that meets a training need among the GOCOs. The addedvalue in the school's conduct is the building of a solid, environmental professional network at the "working level" because of the team-building, problem-solving, casestudying approach. Shared savings are expected to result from shared knowledge, experience, and experise that will benefit both DOE and Westinghouse. 


\section{Expected Benefits}

The school is expected to benefit Westinghouse and DOE as follows:

- provide increased environmental awareness to improve job performance

- provide regulatory knowledge of the consequences of noncompliance

- discover available resources

- provide a forum for sharing experiences across all GOCOs

- provide a common understanding of the environmental regulations

\section{Evaluation Results}

Students have said:

"The networking and exchange of experience was exceptional."

"The school, its content, students, and instructors, brought into perspective very rapidly the DOE GOCO big picture."

"The course outline was extremely well constructed in that: all major environmental regulations were covered; introductory technical information was provided to bring students up to necessary equivalency level; and activities were directed to enhance interaction between personnel from all involved institutions." 


\section{Chapter 12}

\section{Emergency Response, Environmental Occurrence Reporting, and Regulatory Notifications}

Chapter was compiled and reviewed by Carroll C. Zeigler. 


\section{Site Program Overview}

A number of environmental laws, regulations, and agreements require that records be maintained of spills, unpermitted releases, and occurrences (events, conditions, or concerns) that cause or have the potential to cause a degradation of the environment. In addition, emergency-response and regulatory notifications are required when cerain defined thresholds are exceeded. The Environmental Protection Department (EPD) provides around-the-clock coverage to assess environmental occurrences and make the necessary regulatory notifications.

The environmental occurrence response and notification program is a part of the sitewide occurrence-reporting system known as the Site Item Reportability and Issues Management System (SIRIM). SIRIM is the WSRC program that implements DOE Order $5000.3 \mathrm{~A}$ on occurrenc 3 reporting. Occurrences are reported, classified, entered into a DOE-wide database, and investigated. The reports document the facts of the occurrence, as well as corrective actions to prevent re-occurrence. 


\section{Policy}

The WSRC and DOE policy toward occurrence reporting is as follows:

- encourage a positive attitude toward reporting and handling spills, releases, and occurrences that have the potential to cause exposure to people or degrade the environment

- consistently report occurrences to ensure that both WSRC and DOE management are informed of occurrences that affect people and the environment

- notify regulatory agencies as scon as possible when notification thresholds are exceeded or when an occurrence may be of interest to a regulatory agency 


\section{Existing Conditions}

WSRC, EPD, and DOE-Environmental Compliance Division (ECD) have designated people, equipment, and procedures to handle both routine and emergency occurrences. EPD coordinates the environmental-occurrence program and provides training for EPD, DOE-ECD, and area environmental personnel. An EPD environmentaloccurrence (SIRIM) coordinator provides advice and assistance on handling environmental occurrences to site environmental-protection coordinators (SEPCs), area facility emergency coordinators (FECs), area environmental coordinators, and area environmental-occurrence coordinators. In addition, the EPD environmentaloccurrence coordinator issues guidance memorandums when new environmental regulations become effective and when changes occur in regulations or interpretations of regulations.

EPD administers the environmental-occurrence program through SEPCs. An SEPC is on-duty around-the-clock to assess occurrences, provide concurrence on classification, provide advice on cleanup, and notify regulatory agencies when required. The SEPC's duties rotate on a weekly basis hetween a number of EPD professional scientists and engineers (generally 12 to 14 ). The SEPCs receive performance-based training on procedures, reporting criteria, legal requirements, and basic radiation terminology. Trainees must past post-training examinations on each of the six training-program modules.

SEPCs are provided with a Site Environmental Protection Coordinator Handbook that contains procedures and regulations, as well as contact people in WSRC, DOE, and regulatory agencies.

Information on each environmental occurrence is recorded on a EPD Spill and Occurrence Reporting Form. The data on these forms are entered into a computer database for summary and reference purposes. 


\section{Objectives}

The objectives are to define SRS's responsibilities and actions to affirm that environmental-related occurrences (including spills and releases) are handled in an appropriate and timely manner and that notifications are made to WSRC management. DOE, and applicable federal, state, and local regulatory and emergency-response agencies. 


\section{Strategy}

The strategy provides the following resources to meet SRS policies and objectives:

- a trained staff to handle environmental events around-the-clock

- procedures, communications equipment, and information to optimize handling environmental occurrences

- advice and updates on new and changing regulations 
Included within the occurrence-reporting and regulatory notification requirements are several regulatory emergency-response programs. These programs include the following:

- Emergency Response (12-9)

- Regulatory Response required by the Emergency Planning and Community Rightto-Know Act (EPCRA), Comprehensive Environmental Response, Compensation and Recovery (CERCLA), and Resource Conservation and P.ecovery Act (RCRA) (12-13)

- National Contingency Plan (12-16) 


\title{
Emergency Response
}

\author{
(Compiled and reviewed by Carroll C. Zeigler)
}

\section{Site Program Overview}

Environmental protection is an integral part of SRS's emergency-response planning because spills or releas s of hazardous substances (including radionucrides) can spread offsite, causing expost re to people and degradation of the environment. The ability to respond to an unplanned release of a hazardous substance requires that the site have the capability to:

- rapidly detect and report the occurence

- rapidly assess the potential effects

- immediately notify responsible authorities

- institute monitoring and mitigation activities

To accomplish these objectives, SRS maintains real-time data-aquisition models to accurately predict plume movernent with time, and well thought out and rehearsed response plans.

Most aspects of the emergency-response program, such as response planning and drills, are beyond the scope of this Environmental Implementation Plan (EIP) section and are covered in DESP-89-121-1, Safety and Health Long Range Plan Savannah River Plant and Laboratory. This section principaliy covers the emergency-response activities that involve detection, notification, characterization, and definition of the extent and affect of a release.

SRS has monitoring and predictive , items to cietect and track releases of hazardous substances (including radion:-ilides) in near realtime. These systems frequently are reviewed and modified to improve their capabilities. The Remote Environmental Monitoring System (REMS) connects most process stack sensors to the meteorological laboratory in the Environmental Technology Section (ETS) of SRTC so that emission data can be used by the various models to predict plume movement and dispersion of contaminants into the environment. These models also receive realtime meteorological data from 10 instrumented towers and from the Nationa! Weather Service. Historical databases also are available for use. This system of predicting downwind and downriver concentrations of pollutants in the environment and doses of radiation to people is referred to as the Weather Information and Display (WIND) system.

An additional emergency-response iesource is the Tracking Radioactive Atmospheric Contamination (TRAC) mobile laboratory which can move rapidly to the location of a predicted plume and measure contaminant levels. A gamma-ray detection instrument array that can be mounted quickly onto a helicopter also is available. These monitoring systems also can be used to conduct research related to tracking and monitoring routine SRS releases. The research data are used to verify and update predictive models. 
Five-Year Outlook

The emergency-response program is expected to remain stable except for updates to SRS emergency-response procedures, and new DOE and regulatory agency requirements.

\section{Justification/Regulatory Requirements}

Emergency planning and the ability to respond to releases of oil, hazardous substances (including radionuclides), and extremely hazardous substances is required by a number of laws and regulations administered by EPA and SCDHEC, as well as DOE orders.

The two most significant drivers are Title III of the Superfund Amendments and Reauthorization Act of 1986 (SARA) and DOE Order 5500.3:

- SARA Tite III, also known as Emergency Planning and Community-Right-toKnow Act (EPCRA) (40 CFR 355), requires SRS to report the release of a hazardous substance ( 40 CFR 302 ) or extremely hazardous substance ( 40 CFR 355 ) in excess of a reportable quantity that is expected to have an offsite effect to the National Response Center, Local Emergency Planning Committees, and the State Emergency Planning Commission.

- DOE Order 5500.3, Reactor and Nonreactor Nuclear Facility Emergency Planning Preparedness and Response Program for Department of Energy Operations, was adopted Aug. 13, 1981. This order requires SRS to develop and improve monitoring and meteorological systems to detect, track and assess radiological or other effluent plumes.

\section{Organizational Responsibility Summary}

In the event of a release into the environment, the area emergency coordinator (AEC) or facility emergency coordinator (FEC) is responsible for notifying the Savannah River Site Operating Center (SRSOC). If the occurrence is environmental-related but not an emergency, SRSOC is responsible for notifying the site environmental protection coordinator (SEPC) of the release. In concurrence with the SEPC, the AEC or FEC is responsible for categorizing the release into one of three categories (unusual occurrence, off-normal occurrence, or non-routine occurrence) in accordance with sitewide procedures manual 1B (MRP 408). The AEC or FEC is responsible for mitigation and cleanup activities, SEPC for regulatory notifications, and SRSOC for communications.

In the event that the release exceeds or is expected to exceed emergency-action levels (EALs) defined for the facility, SRSOC is responsible for declaring an emergency and categorizing the occurrence as an alert, site-area emergency, or general emergency. An alent is the least serious emergency category, while the general emergency is the most serious. For emergencies, SRSOC is responsible for activating SRS emergencyresponse facilities and organizations. SEPC makes regulatory notifications and participates as a member of the Emergency Operating Facility during activation. 
If environmental sample collection and analysis are required, the Environmental Monitoring Section is responsible for such actions. The Technical Support Center is responsible for activating the TRAC vehicle when required.

The emergency duty officer (EDO) in SRSOC is responsible for promptly entering release data into the WIND system, evaluating plume movements and envirormental concentrations, and determining radiation dose. For emergencies, ETS is responsible for providing a WIND system specialist to relieve the EDO as soon as possible.

\section{Site Procedures and Documents}

- DOE Order 5000.3A, Occurrence Reporting and Processing of Operations Information

- SRS Management Requirements and Procedures Manual1B, MRP 4.07 - 4.09 Events, Conditions, and Concerns - Identification, Determination, and Issue Management

- Environmental Protection Department Manual Q-1-1-1, DPM-301, Spills and Environmental Occurrence Response and Notification Procedure

- WSRC-IM-92-21, SRS Site Environmental Protection Handbook

- DOE-ECD Procedure, Occurrence Response and Notification Procedure

- WSRC SRS Emergency Plan, Procedure Manual 6Q

- $\quad$ SRSOC Emergency Procedures Manual, 6Q15.4

- $\quad$ SRSOC Operating Procedures Manual, Q12

\section{Programs}

Departmental Emergency Response. Each PMT department has written procedures that require notifying SRSOC of all occurrences defined in MRP 4.08, as well as emergencies that exceed EAL tresholds.

ETS Meteorological System. A SRS meteorological system and computer database is maintained by ETS. ETS operates a system of nine onsite and one offsite instrumented towers to collect realtime meteorological data. Up to 125 data points are collected every 1.5 seconds and compiled using a quality-control algorithm. Data summaries are printed hourly to check instrumentation and assess local conditions. The data are stored to provide a permanent climatology record for SRS. In addition, meteorological data is received from the National Weather Service network. The meteorological system is used to support training exercises and is available for possible offsite emergencies. The large on-line database allows personnel to go back in time, as well as predict future conditions when assessing release consequences.

SRS Operations Center. The center maintains a 24-hour communications center and a staff capable of immediately initating a site-level response. The EDO performs/coordinates essential response functions until emergency-response facilities are activated. After activation, SRSOC staff provides support and assistance to responders and continues to perform required notifications. 


\section{Technical Support Programs}

Research/studies are conducted to improve SRS's ability to track releases and to determine their impact on human health and the environment. While these programs are directed primarily toward emergency response, they help to measure and determine the impact of routine emissions from SRS facilities.

Atmospheric Transport Studies is a basic research project in support of all DOE research and production programs aimed at increasing our understanding of the atmospheric transport and diffusion of environmental poliutants. This program ensures that SRS maintains state-of-the-art capabilities to predict transport and dispersion of pollutants into the environment and the resulting exposure to people offsite.

One-Year Road Map

The following actions are required to integrate the site emergency-response procedures with regulatory notification requirements:

- update EPD procedures and training material to reflect the integration of regulatory requirements with site emergency procedures

- continue to coordinate site emergency planning with regulatory notification requirements

Five-Year Road Map

The following actions are planned for the next five years:

- integrate EPCRA emergency-notification procedures and SRSOC emergency-notification procedures to reduce unnecessary duplication of efforts

- continue to conduct emergency exercises and enhance procedures based on lessons learned in the exercises 


\title{
Regulatory Response Required by EPCRA, CERCLA, and RCRA
}

\author{
(Compiled and reviewed by Carroll C. Zeigler)
}

Site Program Overview

SEPC is notified by SRSOC when a spill and other environmental-related occurrences are reported to SRSOC. SEPC then is responsible for notifying applicable regulatory agencies and local emergency-response organizations when reporting thresholds are exceeded. SEPC also responds and makes regulatory notifications when site emergencies occur that may affect the offsite population. The on-call DOE-ECD representative and EPD management also are notified of all occurrences.

Five-Year Outlook

EPCRA, CERCLA, and RCRA programs are expected to remain stable except for additional substances that are added periodically to the lists of substances with RQs or changes in hazardous-waste regulations. If unpermitted releases that are continuous in nature are discovered, continuous release notifications will be required under CERCLA.

A draft Federal Facilities Agreement (FFA) has been prepared. The FFA is an agreement between EPA-IV, DOE-SR, and SCDHEC that addresses how the site will implement CERCLAJEPCRA remediation programs. Some additional reporting is expected to be required when the FFA is signed by all agencies involved.

\section{Justification/Regulatory Requirements}

EPCRA requires immediate notification of the following agencies in the event that an unpermitted spill or release of a reportable quantity (RQ) or more of an extremely hazardous substance (40 CFR 355) or hazardous substance, including radionuclides (40 CFR 302) is expected to affect people offsite:

- National Response Center

- Local Emergency Planning Commissions (LEPCs) of affected areas

- State Emergency Planning Committees (SERCs) of affected areas

- Federal on-scene coordinator (DOE)

- Radiological control officer (EPA)-for radionuclide releases

The following agencies also are notified to maintain good working relations:

- South Carolina Department of Health and Environmental Control

- Georgia Department of Natural Resources (GDNR)

- Environmental Protection Agency Region IV (EPA-IV)

- Vogule Electric Generating Station 
After the above notifications are completed, the following SRS organizations are notified:

- DOE Environmental Compliance Division (ECD) on-call representative

- EPD management

CERCLA and RCRA also require regulatory notifications any time an unpermitted spill or release of a hazardous substance or hazardous waste occurs. Except for LEPC, SERC, and the Vogtle Electric Generating Station, all of the above notifications apply. LEPCs, SERCs, and Vogule Electric Generating Station only are notified when a spill or release is expected to cause an exposure to offsite people at specific locations.

\section{Organizational Responsibility Summary}

All WSRC organizations are responsible for reporting occurrences under criteria in Management Requirements and Procedures Manual section MRP 4.08. Generally, the custodial facility emergency coordinator notifies SRSOC. If the occurrence is environment-related, SRSOC notifies SEPC by "beeper" activation.

For environmental occurrences, SEPC confers with FEC to arrive at the applicable classification (emergency, unusual incident, off-normal incident, or non-routine occurrence). If emergency-response or regulatory notifications are required, the SEPC makes the applicable notifications in accordance with DPM-301 in the WSRC Q-1-1-1 Manual. After emergency and/or regulatory notifications are made, or if no such notifications are required, SEPC notifies the on-call DOE-ECD representatives and WSRC management.

\section{Site Procedures and Documents}

- DOE Order 5000.3A, Occurrence Reporting and Processing of Operations Information

- SRS Management Requirements and Procedures Manual 1B, MRP 4.07 - 4.09 Events, Conditions, and Concerns - Identification, Determination, and Issue Management

- Environmental Protection Department Manual Q-1-1-1, DPM-301, Spills and Environmental Occurrence Response and Notification Procedure

- WSRC-IM-92-21, SRS Site Environmental Protection Handbook

- DOE-ECD Procedure, Occurrence Response and Notification Procedure

\section{Programs}

Each operating organization (division/department) has procedures that define occurrence-response and notification requirements, as well as a staff to administer the program. 


\section{Technical Support Programs}

The EPD regulatory tracking specialist routinely reviews the National Register, state regulations, and other regulatory review documents for changes in regulations and/or new regulations that are relevant to occurrence reporting. The regulatory tracking specialist notifies the EPD occurrence-reporting coordinator of any such regulations that are discovered. The occurrence-reporting coordinator then prepares guidance memorandums that are sent to area environmental coordinators and area occurrencereporting coordinators.

One-Year Road Map

No additional actions are anticipated unless DOE and/or regulatory requirements change significantly, but the following actions are required each year to maintain the program:

- update SRS Site Environmental-Protection Coordinator Handbook to include organizational changes and add any new relevant information that is deemed necessary; data that is no longer relevant also may be removed

- update EPD procedures and training material to reflect changes in DOE or regulatory requirements

- obtain ESH\&QA Division Training approval of updated training

- select and train new SEPCs (SEPCs serve for a one-year period)

- provide training for DOE-ECD and area environmental coordinators when requested

- continue to prepare updated guidance as required

- procure cellular telephones to improve SEPC communication

Five-Year Road Map

The following is the five-year road map:

- update the SEPC training to meet all DOE Training Accreditation Program (TAP) standards (SRS implement of DOE standards change and are continuing to evolve)

- develop routine summaries of environmental occurrences and evaluate trends

- improve communication of summaries and trends to all relevant WSRC and DOE organizations 


\title{
National Contingency Plan
}

\author{
(Compiled and reviewed by Carroll C. Zeigler)
}

Site Program Overview

SEPC is notified by SRSOC when spills and other environmental related occurrences are reported to SRSOC. The SEPC then is responsible for notifying applicable regulatory agencies and local emergency-response organizations when reporting thresholds are exceeded. SEPC also responds and makes regulatory notifications when site emergencies occur that may affect the offsite population. The on-call DOE-ECD representative and EPD management are also are nintified of all occurrences.

Five-Year Outlook

EPCRA, CERCLA, and RCRA programs are expected to remain stable except for additional substances that periodically are added to the lists of substance with RQs or changes in hazardous-waste regulations.

\section{Justification/Regulatory Requirements}

The National Oil and Hazardous Substances Pollution Contingency Plan (NCP) was established under CERCLA to specify organizational structure and procedures for responding to discharges of oil and releases of hazardous substances, pollutants, and contaminants.

\section{Organizational Responsibility Summary}

All WSRC organizations are responsible for reporting any spill or release of oil, hazardous substance, pollutant, and/or contaminant. Small spills and releases that are less than the amount specified to meet the off-normal threshold in MRP 4.08 are classified as non-routine. Non-routine occurrences are not entered into the DOE
database. However, SEPC assesses these small spills and releases and records them on the EPD Spill and Environmental Occurrence Reporting Form. Spills or releases that meet or exceed the off-normal thresholds are handled in accordance with EPCRA/CERCLA/RCRA requirements.

When spills or releases occur, SEPC confers with the FEC to arrive at the applicable classification (Emergency, Unusual Incident, Off-Normal Incident, or Non-Routine Occurrence). If emergency-response or regulatory notifications are required, SEPC first makes the applicable notifications in accordance with DPM-301 in the WSRC Q-1-1-1 Manual. After emergency and/or regulatory notification are made, or if no such notifications are required, SEPC notifies the on-call DOE-ECD representatives and WSRC management. 
Site Procedures and Documents

- DOE Order 5000.3A, Occurrence Reporting and Processing of Operations Information

- SRS Management Requirements and Procedures Manual 1B, MRP 4.07 - 4.09 Events, Conditions, and Concerns - Identification, Determination, and Issue Management

- Environmental Protection Department Manual Q-1-1-1, DPM-301, Spills and Environmental Occurrence Response and Notification Procedure

- WSRC-IM-92-21, SRS Site Environmental Protection Handbook

- DOE-ECD Procedure, Occurrence Response and Notification Procedure

\section{Programs}

Each operating organization (division/department) has procedures that define spilland release-notification requirements, as well as a staff to administer the occurrencereporting program.

\section{Technical Support Programs}

The EPD CERCLA specialist supports the development and implementation of the NCP at SRS.

\section{One-Year Road Map}

In the next year, we plan to compare current WSRC reporting and notification procedures with the SRS NCP (currently in draft form) and integrate any additional NCP requirements into appropriate WSRC procedures.

Five-Year Road map

When the draft Federal Facilities Agreement under Section 120 or CERCLA and Sections 3008 (h) and 6001 of RCRA is finalized, we plan to update EPD procedures to comply with the agreement. 


\section{Chapter 13}

\section{Environmental Permitting}

Chapter is being developed. 


\section{Chapter 14}

\section{Environmental Compliance Tracking and Data Management}

Chapter was compiled and reviewed by Cheryl H. Story. 


\section{Site Program Overview}

Environmental projects, issues, and programs have become increasingly important to the Westinghouse Savannah River Company (WSRC) management and the Department of Energy (DOE). A compliance-tracking system has been developed to monitor environmental requirements and commitments because they have become incrasingly complex and numerous.

Professionals at the Savannah River Site (SRS) recognized the need to improve the Wisys environmental information is handled. One primary recommendation made by a study team, commissioned in 1985, called for developing site database applications to assist in managing environmental data. The study team generated a report entitled Information Systems. An Integrated Plan, which outlined recommendations for improving the acquisition, use, processing, transmission, and storage of information at the site. Management approved this document in the spring of 1985 and authorized allocating resources to implernent it.

An Environmental Data Management (EDM) steering committee was formed in Oresber 1987 to develop computer system solutions to environmental needs. The committee's main objective is to coordinate, within SRS divisions, the separate efforts that bave been or are being developed to meet regulatory requirements and specific programmatic goals. 


\section{Policy}

An overall tracking mechanism to monitor the progress of site environmental programs will he established so management can ensure that WSRC organizations meet regulatory compliance and DOE commitments. A database-management system is under development to enable easier access to site environmental data, as well as timely data analysis and report preparation.

Background

It is WSRC's policy to comply with all environmental laws, regulations, and DOE orders. WSRC also is committed to developing a sitewide database-management system for environmental programs. 


\section{Existing Conditions}

The EDM steering committee was formed in October 1987 to develop an integrated environmental-information system. Before the committee was established, individual departments and groups were taking those steps necessary to meet regulatory requirements and their own group objectives. There was not always time to develop standards, and in many cases, the environmental staff controlled environmental information.

As the number of environmental regulations increased and as individual database applications grew, the EDM steering committee began taking necessary steps to better manage environmental information.

In September 1988, the committee purchased a MicroVax 3500 and chose Oracle as the relational database standard. A plan was developed and implemented that addressed immediate data-management needs and that was compatible with other long-term environmental-data systems being developed for the site. This effort addressed applications including the National Pollutant Discharge Elimination System's (NPDES) discharge monitoring, well construction, SARA chemical information/inventory, and the Waste Information Tracking System. The MicroVax 3500 later was upgraded to a MicroVax 3800, and in October 1990, a Vax 6410 computer system was purchased. These systems serve as production systems for environmental activities accessible to site professionals via the site's local area network.

The nine major subject areas under the EDM umbrella are surface water, air, groundwater, ecology, solid/hazardous waste, audits/appraisals, chemical information/inventory, administration, and environmental education. These areas generally cover several aspects of the environmental activities which use or generate data that must be managed appropriately. 
Objectives

The following are the objectives that suppor developing a regulatory-compliance tracking system:

- monitor programs - monitor the progress of site environmental programs to ensure that regulatory and DOE commitments are met

- DOE orders - review, modify, and apply to particular situations, as needed, and accept all DOE environmental orders

- Environmental Database Management - develop an integrated environmentalinformation system to define data consistently, to allow data sharing among organizations, and to deliver an easy-to-use system to SRS professionals 


\section{Strategy}

The strategy for achieving the objectives of the Environmental Compliance Tracking and Data Management Program includes the following:

- review and verify status of all DOE-environmental orders

- initiate acceptance of all DOE-environmental orders

- maintain and improve EPD compliance-tracking system

- implement integrated system

- monitor and evaluate the integrated system

- consistently define data about environmental activities

- allow data sharing across organizational boundaries

- deliver easy-to-use system tools to SRS professionals

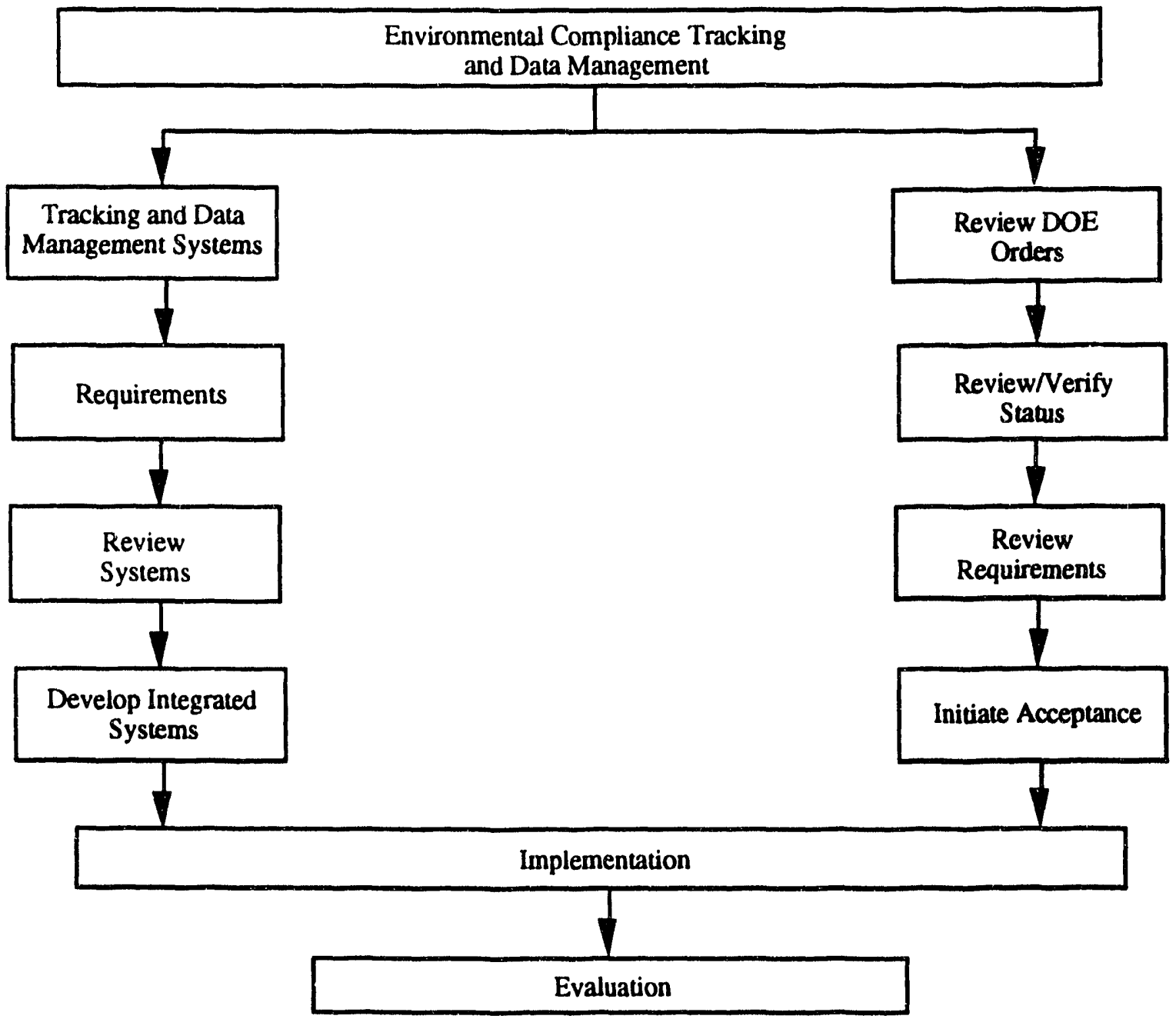

Figure 14-1. Environmental Compliance Tracking and Data Management Program Strategy 


\section{Implementation}

The SRS has implemented the following programs to meet the objectives of the Environmental Compliance Tracking and Data Management Program:

- Compliance/Commitment Tracking System (page 14-9)

- Review of DOE Orders (page 14-10)

- Data Management (see page 14-11) 


\title{
Compliance/Commitment Tracking System
}

\author{
(Compiled and reviewed by Tim R. Pfefferkorn)
}

Site Program Overview

Currenuly, there are a number of tracking systems for monitoring environmental compliance and commitments within WSRC and within the Environmental Protection Department (EPD). The site has implemented a new tracking system. Issues Management Processing Action and Commitment Tracking System (IMPACTS), to consolidate existing systems. During FY 92, EPD rolled some of its current tracking systems into this new system. Efforts to expand and enhance this coordinated tracking system/method will be continued in FY 93.

Justification

It is WSRC's policy to comply with all laws, regulations, and DOE orders. To ensure continued compliance, an improved management tool/method will be developed and implemented.

The current tracking system meets the Monitor Programs objectives.

\section{Organizational Responsibilities Summary}

EPD will be the leading organization with the responsibility to review and implement current environmental-tracking systems. These efforts will be coordinated with the Directives Management Section and the EPD Task Management Team.

\section{Site Procedures and Documents}

A sitewide commitment-management procedure, MRP 3.12, is located in procedure manual, WSRC-1B.

EPD Procedures DPM 505 and DPM 506 are located in EPD's Procedures Manual Q1-1-1.

\section{Programs}

EPD currently is using IMPACTS to track compliance and DOE commitments. An AVAX-based tracking system also is being used to track Environmental Audit and Appraisal findings. This system is called the Audit/Appraisal Tracking System (AATS).

There are plans to convert the AATS system into IMPACTS, thus, providing more consistency in the commitment-tracking program. These systems will be used to provide management and employees with reports to ensure timely closure of commitments and findings. 


\title{
Review of DOE Orders
}

\author{
(Compiled and reviewed by David L. Lester)
}

\section{Site Program Overview}

DOE establishes policies and guidelines for implementing various laws and programs through an order mechanism within the DOE complex. DOE orders apply to contractor-program implementation and facility operation. Those orders that affect the environment are referenced in various sections of this plan. Some DOE environmental orders are being revised due to changes in the laws.

EPD has reviewed DOE orders affecting the environment and developed DOE directives and compliance plans for DOE Orders 5400.1, 5400.3, 5400.4, 5400.5, 5440.1C, 5480.4, and 5482.1B.

Justification

DOE environmental orders set policies and guidelines for implementing applicable environmental laws and DOE programs. DOE orders apply to WSRC program implementation and facility operation.

The existing program to review and implement DOE orders meets DOE orders objectives.

\section{Organization Responsibilities Summary}

EPD maintains the lead responsibility for reviewing environmentally-related DOE orders and for implementing those orders. EPD coordinates with the General Counsel Office to review incorporating documentation on implementing orders.

\section{Site Procedures and Documents}

Program guidance is provided in WSRC-IM-91-66, Strategic Plan for Environmental Compliance at the Savannah River Site (SRS).

\section{Programs}

EPD is the leading organization for reviewing and implementing DOE environmental orders. A program flowchart is presented in WSRC-IM-91-66, Strategic Plan for Environmental Compliance at the Savannah River Site (SRS). 


\section{Data Management}

(Compiled and reviewed by Cheryl $H$. Story)

\section{Site Program Overview}

The goal is to develop an integrated environmental-information system for SRS. This extensive effort will require communication and coordination among several groups onsite. It is necessary for management to commit resources necessary to develop and maintain sitewide environmental systems.

Justification

It is WSRC's policy to achieve established environmental goals. An environmental data-management system will be developed and implemented to ensure these goals are attained.

The environmental data-management system will meet the chapter objectives.

\section{Organization Responsibilities Summary}

EPD will take the lead in developing and implementing the environmental datathariagement systein. These elforts will be coordinated through the Environmental Data Management Steering Committee.

\section{Site Procedures and Documents}

EDM is managed as a matrix organization, as described in the SRS Environmental Data Management Plan. EDM, WSRC-RP-91-179. Another document, Environmental Bases of the Savannah River Site 1990, lists environmental reference information (documents, files, papers, letters, etc.) which is available onsite.

\section{Programs}

The success of this project largely is dependent upon computer assistance from Computer Systems Development (CSD), Computer Projects (CP), Computer and Telecommunications Management (CTM), EDM Steering Committee members, and environmental custodians onsite. CSD will assume all software development and maintenance activities. CP will assist with system and network solutions, and CTM will provide operations support. Environmental and Health Protection will serve as the database administrator to ensure the integrity of data, and special-interest groups will be identified for the various topics to be addressed.

The EDM Steering Committee has identified nine environmental areas needing assistance with data management. They are administration, air, audit and quality assurance (QA), chemical information/inventory, ecology, environmental education, groundwater, solid/hazardous waste, and surface water. Identifying existing 
environmental databases, integrating them into a friendly environment, and developing new applications will take place as a result of this effort.

Site environmental monitoring is part of the Environmental Monitoring Section's (EMS) mission. It will be necessary to coordinate and communicate activities with EMS, as well as with other environmental custodians. EMS and most site organizations utilize Digital Equipment Corporation technology and have taken steps to comply with their own departmental goals. In many cases, this plan will address linking existing applications to centralize management.

Environmental professionals recognize that it is time to define standards and centralize the management of environmental data across the site. In today's regulatory and litigation climate, the site must have knowledge of significant issues as early as possible. The complexity of environmental regulations and reporting has reached the point where even teams of employees cannot easily keep up with the thousands of regulations and handle endless compliance requirements. 


\section{Chapter 15}

\section{Environmental Outreach}

Chapter was compiled and reviewed by Gail F. Jernigan. 


\section{Site Program Overview}

Before the site was constructed, a baseline environmental assessment was made by the University of Georgia and the University of South Carolina. Since 1951, the Savannah River Site (SRS) has written an annual environmental report that includes all environmental-monitoring data collected and analyzed during the previous year.

There are now, however, requirements in the Resource Conservation and Recovery Act (RCRA), the subsequent Hazardous and Solid Waste Amendments (HWSA) and corresponding South Carolina Hazardous Waste Management Regulations which require environmental outreach. In addition, the Comprehensive Environmental Response, Compensation, and Liability Act (CERCLA), as amended by the Superfund Amendments and Reauthorization Act (SARA), the National Environmental Policy Act and other environmental regulations have public-interaction requirements. The focus of this section is the environmental-outreach activities required by environmental regulations. Also addressed are other outreach activities that are required and encouraged by the Department of Energy (DOE). The Environmental Protection Department (EPD) has been working and will continue to work with the Public Relations Department and the Environmental Restoration Department to accomplish the objectives of the regulators and DOE. 


\section{Policy}

SRS's environmental-outreach policy is to make information available to the public regarding plant operations and activities to improve knowledge, awareness and support of neighboring communities, and to encourage public involvement in order to comply with applicable regulatory and DOE requirements and objectives.

\section{Background}

The operating contractor and DOE are committed to protecting public bealth, safety and the environment. These convictions are stated in DOE Order 5400.1, General Environmental Protection Program, in the revision of DOE Order 5480.14. CERCLA Program, and in SRS's Strategic Plan. In addition, the Secretary of Energy has made numerous public speeches reinforcing this claim. This also is mentioned in the annual Environmental Restoration and Waste Management Five-Year Plan, written and published by DOE. 


\section{Existing Conditions}

Since 1951, SRS has published an annual environmental-monitoring report. This report has been made available to the general public, the scientific community and the news media. In addition. SRS representatives meet with various regulators to exchange data and analyses to ensure accuracy. To improve this report's readability for the public, SRS representatives have met with a citizens advisory committee. This committee has made numerous suggestions for improving the report so that the public will have a better understanding of the site's environmental-monitoring activities.

SRS has developed an environmental-outreach program that offers a variety of informational sources to keep citizens involved and encourage them to participate in cleanup and waste-management activities. In developing the program, SRS representatives interviewed 85 South Carolina and Georgia citizens. These interviews formed the basis for the Public Involvement Plan (PJP). PIP is a working document that fulfills CERCLA's community-relations requirements. It also describes the publicinvolvement activities under the Resource Conservation and Recovery Act (RCRA) and the Nationa! Environmental Policy Act (NEPA), as well as other publicinvolvement opportunities related to other DOE environmental activities.

In December 1991, SRS held the first in a series of environmental forums. These forums are informal discussions between the public and SRS representatives on environmental and public health issues. Environmental forums have been held in Barnwell, Columbia, and Allendale, SC, and in Waynesboro, Augusta, and Savannah, GA. Topics for discussion at each forum were identified by local citizens.

Additional meetings, mandated by the law, have been held. Meetings and/or hearings have been held for NEPA and RCRA. Public meetings for the Site Specific Plan have been held annually in Aiken, SC, Columbia, SC, and Savannah, GA.

SRS offers group tours of the site and speakers for civic or church group meetings. Speakers have discussed a variety of SRS topics. including cleanup and waste management.

During PIP interviews. many people stated a preference for written materials about SRS activities. They requested the information be written simply and concisely. Every effort has been made to disseminate technical information in an understandable form. A mailing list has been developed consisting of peoplr interviewed for PIP; those who have attended SR I public meetings, tours and other functions; and other people suggested by the South Carolina Department of Health and Environmental Control (SCDHEC) and EPD.

SRS also has developed a newsletter, the Environmental Bulletin, to notify contiguous landowners, the media and nearby communities about proposed changes to its RCRA hazardous-waste permit application, as required by law. Major actions, public meetings and public comment periods have bee? announced through rress releases and ihe Exvironmenta! Bulletin. An expanded version of the newsletter is published once every quarter. Articles include current information on environmental restoration, waste management, and other environmental or ecological news. 
Other mechanisms used to inform the public include the local newspapers, listed by many to be the top source of information on SRS. Press releases and advertisements have been used extensively to inform the public about environmental activities at SRS. SRS also has advertised in several local newspapers, both as legal notices, as required by several environmental regulations, occasionally and as display ads. announcing an upcoming public meeting. Ads also are placed occasionally on AM and FM radio.

Fact sheets have been used to provide more specific information on cleanup or wastemanagement actions. These have been distributed through a site mailing list, at public meetings/hearings, on tours, and at briefings. 


\section{Objectives}

The objectives listed below are required to meet the environmental-outreach policy and to meet the intent of the Strategic Environmental Plan. The objectives are as follows:

- develop and conduct an environmental-outreach program to provide information about SRS operations and site environmental programs to the general public, the news media, and local and state agencies

- encourage public involvement in environmental decisions concerning site operations and activities, especially activities concerning cleanup and waste management 


\section{Strategy}

The following is the strategy for reaching the environmental-outreach program objectives:

- identify environmental-outreach planning needs with respect to all environmental regulations

- develop an environmental-outreach program

- implement the environmental-outreach program

- evaluate the environmental-outreach program to ensure that public information needs, involvement opportunities, and regulatory requirements are being met

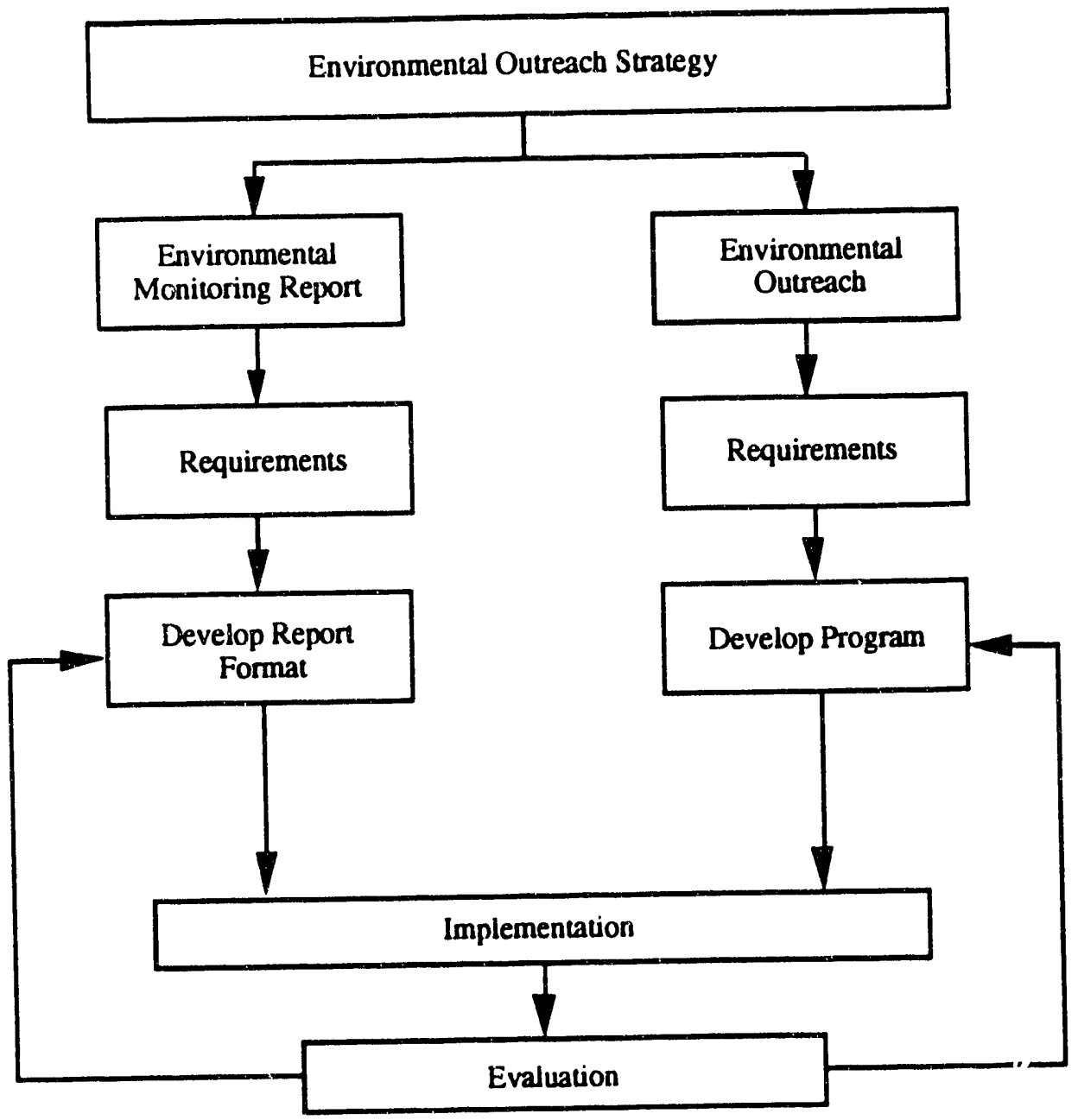

Figure 15-1. Environmental Outreach Strategy 


\section{Implementation}

The Savannah River Site has implemented the following programs to meet the objectives of environmental outreach:

- Savannah River Site Environmental Report (page 15-10)

- Environmental Outreach (page 15-11) 


\section{Annual Savannah River Site Environmental Report}

(Compiled and reviewed by Gail F. Jernigan)

The annual Savannah River Site Environmental Report shows the effects of site operations on the environment. The report contains annual onsite and offsite environmental data, information on radiological- and nonradiological-monitoring programs, and environmental regulatory compliance of the site. While the report is a DOE Order 5400.1 and 5484.1 requirement, it also is an informative tool for the general public, the scientific community, government agencies/officials, and the news media.

Justification

Publishing the annual environmental report is a requirement of DOE Order 5400.1 and DOE Order 5484.1.

This meets an outreach-program objective.

Organizational Responsibilities Summary

The Environmental Monitoring Section (EMS) is the lead organization for compiling and publishing the annual environmental report, and assists DOE-SR in distributing it.

Compliance Programs

EMS will continue to implement the annual environmental-monitoring report program requirements. 


\section{Environmental Outreach}

(Compiled and reviewed by Gail F. Jernigan)

PIP is the blueprint for environmental-outreach activities at SRS. PIP was written after interviewing 85 area citizens to get their views on how they wanted to receive environmental information about SRS. They also were asked what is the best way to get the public involved with environmental activities. The citizens said that they wanted different types of information, in varying amounts and at various frequencies.

The Environmental forums, begun in 1991, will continue as long as the public remains interested. SRS will visit places such as Aiken, Allendale, Hilton Head, Columbia and Barnwell, SC, and Augusta, Waynesboro and Savannah, GA. Plans are to visit each location at least once a year, or more often if the public wishes. Topics for discussion at each forum will be solicited from local organizations and community groups. After the groups recommend a list of topics, location, moderator, date and time, the Public Relations Department and EPD representatives decide on speakers and make final arrangements. The public is informed about each meeting through advertising, posters, letters, handouts, etc. SRS also encourages local organizations and community groups to spread the word about upcoming forums. Whenever possible, the forums also will be used to meet regulatory requirements that call for public meetings.

Legally-required meetings do not always fall within the schedule for the environmental forums. In those cases, additional meetings, required by law, will be held. The format may be as formal as a NEPA hearing or as informal as an SRS representative being available to answer questions. The site will continue to sponsor public meetings for the Site Specific Plan and the Environmental Restoration and Waste Management Five-Year Plan. SRS also will respond to requests for public meetings on specific issues.

Sometimes, topics for public discussion can be unusually complex. Workshops have been designed to allow citizens, who have special interests, an opportunity to engage in in-depth discussions with DOE and Westinghouse representatives.

As a result of public comments, a citizens review group will be formed to participate in the decision-making process on environmental restoration and waste management. Membership, purpose, and scope are to be determined by SRS personnel and the public. The membership should be balanced to include activists (both pro and antiSRS), government officials, medical professionals and university representatives. More information will be available after the group is formed and finalizes its charter.

SRS will continue to offer group tours of the site and speakers for group meetings. Speakers on a variety of topics, including cleanup and waste management, are available through the SRS Speakers Bureau.

CERCLA requires that an informational repository to be established at or near a CERCLA site. It should include site information, documents on cleanup activities and 
general information about CERCLA. The informational repositories for SRS will meet that CERCLA requirement. Copies of documents, such as the SRS Federal Facility Agreement, the SRS Public Involvement Plan, the DOE Environmental Restoration and Waste Management Five-Year Plan, and the SRS Site Specific Plan will be available. Copies of each cleanup and compliance document upon which the public has been invited to provide comment will be available, as will information materials, such as newsletters and fact sheets. The informational repositories will be located at the University of South Carolina libraries in Aiken and Columbia.

Another CERCLA requirement calls for an administrative record to be maintained and made available to the public. The Administrative Record is a legal file of documents upon which EPA and SCDHEC will base their selections of cleanup actions at SRS waste sites. Should a citizen sue to challenge a decision, the Administrative Record will form the basis for a judicial ruling.

The Environmental Bulletin will continue to be used to notify contiguous landowners, the media and nearby communities about proposed changes to its RCRA hazardouswaste permit application, as required by law. The Bulletin also will share information on topics such as cleanup progress, research, and upcoming public-involvement events.

In addition to the Environmental Bulletin, major actions, public meetings, and public comment periods will continue to be announced through press releases. SRS also advertises in several local papers, both as a legal notice, as required by several environmental regulations, and as display ads, announcing an upcoming public meetings. Fact sheets also will be used to provide more specific information and will continue to be distributed through a site mailing list, at public meetings or hearings, on tours, and at briefings. 


\section{Chapter 16}

\section{Environmental Appraisal and Surveillance Program}

Chapter was compiled and reviewed by Chike Amobi. 


\section{Site Program Overview}

\section{Introduction}

This section of the Environmental Implementation Plan (EIP) provides guidance to line and staff organizations who are responsible for meeting Department of Energy (DOE Order 5482.1B) and operating contractor auditing requirements. The words appraisal and surveillance are used generically in this section to cover the broad terms used to describe degrees of activity in which performance is evaluated against environmental requirements and potential problems that are identified.

The Environmental Appraisal Program does not include occupational health, industrial health, or safety activities. 


\section{Summary}

The Savannah River Site (SRS) environmental-appraisal/surveillance program is designed to monitor environmental performance and to ensure that regulatory requirements are met. The appraisal/surveillance program is a two-tiered system which consists of external and internal appraisals and surveillances. External appraisals/surveillances are conducted by organizations not reporting to SRS management. The internal appraisals/surveillances are conducted by site organizations referred to as organizations.

External appraisals include Environmental Protection Agency (EPA) and South Carolina Department of Health and Environmental Control (SCDHEC) regulatory appraisals, DOE-SR and DOE-HQ appraisals, and operating contractor reviews. These appraisals are the result of regulatory requirements, DOE orders, or operating contractor policies. The Environmental Protection Department (EPD) leads the coordination, planning, and scheduling support. The internal appraisal program consists of three types; management appraisals, program appraisals, and facility appraisals. All organizations developed and implemented a formal facility-appraisal program in February 1989. The first facility appraisal was completed during FY 89. To ensure consistency between departments, the SRS environmental appraisal procedure was completed in December 1988 and published in the Environmental Compliance Manual, $3 Q$, in 1991. EPD conducts both the management and program appraisals.

The management appraisal is an annual review of each organization's environmental program. The program appraisal is a detailed review of field conditions across the site for a single (or several closely related) regulatory program(s). The first management appraisal was completed in August 1988. Program appraisals are conducted in conjunction with DOE external appraisals so that all program areas are covered on a three-year cycle. All organizations developed and implemented a formal facility-appraisal program by December 1988. The first facility appraisal was completed in March 1989. To ensure consistency between departments, the SRS environmental appraisal and site appraisal procedures in the Environmental Compliance Manual were developed. 


\section{Policy}

The purpose of SRS's environmental-appraisal program is to monitor performance, determine compliance with applicable requirements, and ensure that environmental protection is maintained.

Background

The operating contractor is responsible for protecting human health, the environment, and other natural resources. At a minimum, this responsibility includes full compliance with applicable federal and state regulations, DOE orders, and operating contractor policy. Thus, site environmental goals must be linked closely to safety, quality, and production goals, and employees must be committed to protecting the environment.

To ensure compliance with regulatory requirements, an appraisal program, which is a self-assessment process, is an integral part of achieving environmental protection. 


\section{Existing Conditions}

At SRS, environmental compliance is a line management responsibility. A formal internal environmental-appraisal program has been developed, as required by DOE Order 5482.1B and operating contractor guidelines. SRS organizations conduct informal appraisals to verify that environmental regulations are being met.

EPD provides the lead, logistical support for external environmental appraisals and surveillances.

EPD's responsibilities include responding to pre-appraisal questionnaires, developing an appraisal schedule, coordinating the appraisal with custodians, and assembling responses to appraisal deficiencies.

EPD also performs some pre-appraisal inspections in preparation for an external environmental appraisal. These inspections are used as a part of the sitewide internal environmental-appraisal system. 


\section{Objectives}

The following are the Environmental Appraisal Program's objectives:

- external appraisals-provide technical and physical assistance to external agencies (DOE, SCDHEC, EPA, and others) during their appraisals of SRS

- These external appraisals should reflect that SRS's environmental program is well organized and effective in complying with environmental regulations and in meeting DOE and the operating contractor's objectives.

- Site Appraisal Program-implement a sitewide environmental-appraisal program to monitor environmental performance, as well as comply with federal and state environmental regulations and the operating contractor's requirements

- These site appraisals should reflect that SRS's environmental program is well organized and effective in complying with environmental regulations and in meeting DOE and the operating contractor's objectives.

- internal surveillance-monitor environmental practices to identify practices that could lead to non-compliance in the future

- correct adverse condition-identify, track, and correct conditions that potentially may cause adverse environmental impacts

- management appraisal-implement a management-appraisal program that will review annually how organizations run environmental programs 


\section{Strategy}

The sitewide strategy to achieve the objectives of the environmental-appraisal and surveillance programs include the following:

- identifying regulatory and other requirements

- defining appraisal and surveillance functions including:

- three appraisal tiers: facility, management, and program

- two appraisal types: external and internal -internal surveillances

- developing appraisal and surveillance systems and procedures

- implementing a sitewide internal-appraisal and surveillance program.

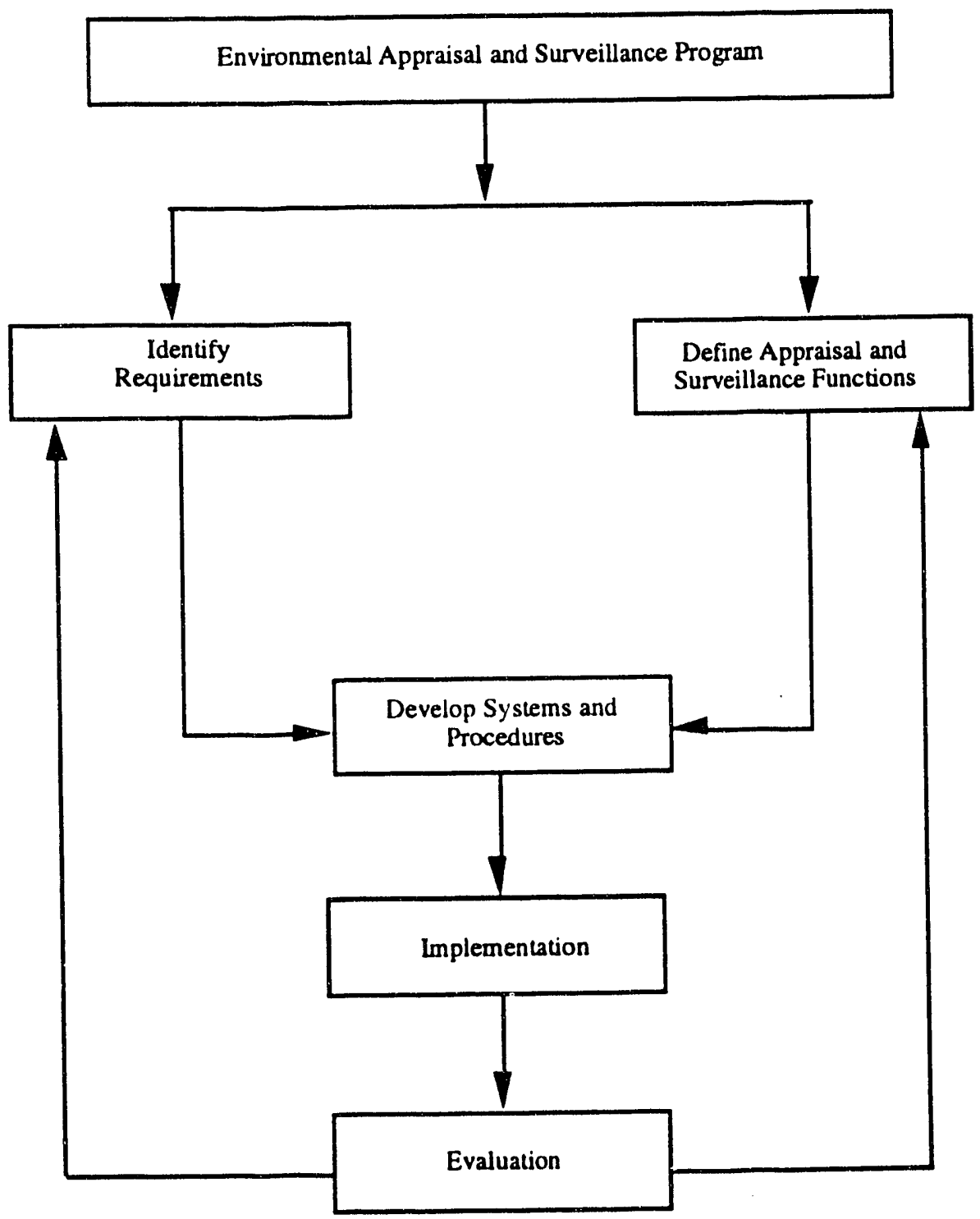

Figure 16-1. Environmental Appraisal and Surveillance Program Strategy 
Appraisal tiers and types related to appraising organizations are shown in Table 16.1. SRS organizations which potentially can impact the environment are identified in Table 16.2. Table 16.3 lists most of the regulatory programs and other requirements that apply to the site. Programmatic details are discussed in the implementation section.

Table 16.1. Environmental Appraisers

External Appraisals

Facility/Program

Management
Corps of Engineers
Congressional

\section{DOE-HQ/SR}

Operating Contractor Corporate

Environment Protection Agency

General Accounting Office

Inspector General

SC Department of Health and

Environmental Control

National Academy of Sciences

DOE-HQ/SR

Operating Contractor Corporate

\section{Internal Appraisals}

Operating Organization/Environmental Protection Department

Environmental Protection Department

Table 16.2. Organizations

Site organizations subject to internal environmental-appraisals requirements

\section{Organizations}

Central Services Works Engineering

Construction Management

Defense Waste Processing Facility

Environmental Monitoring

Laboratories

Power Operations

Reactor

Reactor Materials

Separations

Site Services Department

SRTC - Laboratory Operation and Engineering

SRTC - TNX Operations

SRTC - Equipment Engineering

Tritium

Waste Management \& Environmental Restoration 
Table 16.3. Applicable Environmental Regulatory Programs and Other Related Requirements for SRS (Generic List)

EPA - Environmental Protection Agency

RCRA

HSWA

Resource Conservation and Recovery Act

CERCLA

Hazardous and Solid Waste Amendments

(SUPERFUND)

CWA (WQA)

SCWA

CAA

NEPA

FIFRA

TSCA

SARA

Comprehensive Environmental Response Compensation and Liability Act

EPCRA

Clean Water Act

Safe Drinking Water Act

Clean Air Act

National Environmental Policy Act

Federal Insecticide Fungicide Rodenticide Act

Toxic Substances Control Act

Superfund Amendments and Reauthorization Act

Emergency Planning and Community Right to Know Act

DOT - Department of Transportation

HMTA Hazardous Materials Transportation Act

DOL - Department of Labor

OSHA Occupational Safety and Health Act

DOE - Department of Energy

DOE Orders

SCDHEC - South Carolina Department of Health and Environmental Control Industry Standards and Best Management Practices

State Regulations Implementing RCRA, CWA, CAA, SDWA requirements 


\section{Implementation}

The following programs have been implemented to meet the Environmental Appraisal and Surveillance Program objectives.

- External Appraisals (page 16-12)

- Internal Appraisals (page 16-14)

- External Surveillances (page 16-18)

- Internal Surveillances (page 16-20) 


\section{External Appraisals}

\section{(Compiled and reviewed by Chike Amobi)}

\section{Site Program Overview}

External appraisals are conducted onsite by organizations not reporting to SRS management. These include EPA and SCDHEC, DOE-SR and DOE-HQ, operating contractor corporate headquarters, and public interest groups. These appraisals are the result of regulatory requirements, DOE orders, or operating contractor policies. EPD is the lead department for coordinating, planning, and scheduling support. EPD will track deficiencies and follow-up activities. The organizations are responsible for the field aspects of these appraisals.

\section{Justification/Regulatory Requirements}

External appraisals are conducted by regulatory agencies, DOE-SR and DOE-HQ, and operating contractor corporate organizations. These appraisals are conducted as the result of regulatory requirements, DOE orders, and operating contractor environmental policies.

\section{Organizational Responsibilities}

With the exception of corporate appraisals, external facility appraisals are initiated through the Department of Energy-Environmental Division (DOE-ED). EPD is notified by DOE of scheduled appraisals and is requested to work with the appraising organization. This work involves scheduling, planning, and coordinating the appraisal with facility custodians and other site contractors.

EPD works with DOE-ED, the appraising organization, and the organization to define the appraisal's scope and objectives. Similar actions by EPD are required to coordinate corporate appraisals with the operating contractor's headquarter personnel.

EPD is responsible for coordinating the appraisal by informing custodians of appraisal requirements, compiling and forwarding pre-appraisal information, arranging for physical support needs (i.e., office space and transportation), making appropriate security arrangements, and scheduling safety orientation. A detailed appraisal schedule is developed with the custodians and appraisers to ensure that appropriate people are available. Where feasible, each audit team will be accompanied by a member of EPD, who may participate in the appraisal activities. Similar actions by EPD are required to coordinate corporate appraisals with the operating contractor's headquarter personnel.

EPD obtains any progress reports from the appraisals and distributes these to the appropriate personnel. These reports may identify potential deficiencies or may include requests for additional information or schedule changes. EPD schedules the exit briefing with the appraisal team and representatives of audited organizations. EPD obtains the draft appraisal report, dirtributes it to the custodians for review, and 
prepares the operating contractor's comments on the draft report to send to participants. When required, corrective-action reports are sent by EPD.

Custodians are responsible for coordinating the field aspects of the appraisal. They work with EPD to develop and implement the appraisal schedule. If unplanned schedule changes occur, EPD is notified. Custodians respond daily to progress report items. Custodians should attend the exit briefing to ensure that any concerns related to findings or observations are identified and discussed. Custodians review the draft appraisal report and notify EPD of any technical errors, inaccuracies, or deficiencies that should be challenged. Any necessary corrective action is completed by the custodians and written reports are sent to EPD. EPD will review and verify the status of any corrective action during annual management appraisals or during program appraisals. 


\title{
Internal Appraisals
}

\author{
(Compiled and reviewed by Chike Amobi,
}

\section{Site Program Overview}

An appraisal identifies items that could lead to noncompliances in the future. Appraisals reinforce the philosophy of best management practices. Internal appraisals are divided into facility, program, and management appraisals. Facility and program appraisals are conducted to verify field compliance with regulatory and corporate requirements, as well as to identify and correct conditions that might lead to adverse environmental impacts. Management appraisals are conducted to review the adequacy of administrative systems, operating procedures, and funding.

Internal appraisals are conducted by site organizations to monitor site environmental performance and to ensure compliance with regulatory requirements, DOE orders, and operating contractor environmental policies. The internal-appraisal program consists of facility appraisals, program appraisals, and management appraisals. All organizations had a formal facilities-appraisal program developed and implemented in February 1989. To ensure consistency between departments, an Environmental Compliance Manual $3 Q$ was completed in 1991. EPD is responsible for implementing management and program appraisals. The management appraisal consists of an annual management review of each organization's environmental program. The program appraisal is a detailed review of environmental compliance conditions across the site for a single (or several closely-related) regulatory program(s).

Justification

Internal appraisals are conducted by site organizations. These appraisals are conducted to monitor site environmental performance and to ensure compliance with regulatory requirements, DOE orders, and operating contractor environmental policies. The internal-appraisal program supports the site's appraisal program.

\section{Organizational Responsibilities}

All organizations have established an environmental-appraisal program which involves at least of one facility appraisal per year. Organizations, for the purpose of conducting appraisals, are designated in Table 16.2. Additional informal appraisals or informal inspections may be conducted by organizations to ensure that environmental perfornance is satisfactory. EPD will conduct an annual management appraisal of each organization to ensure compliance with regulations and verify effectiveness of each appraisal program. The annual management appraisal may include a field inspection. The program appraisals primarily are field inspections. They are scheduled and conducted so that in conjunction with external appraisals, all program areas are covered once every three years. 
The support department within each organization is not subject to routine environmental appraisals. However, appraisals may be conducted, if required due to special circumstances.

\title{
Criteria for Internal Appraisals
}

\begin{abstract}
Appraisals
An appraisal may cover a spectrum of activities to evaluate environmental performance. The first step in planning an appraisal is to determine the scope (degree and focus) of the activity. An appraisal may focus on one or more specific area of environmental concern.
\end{abstract}

\section{Appraisers}

A facility appraisal team consists of two or more members. One member must have one or more of the following credentials:

- a formal course in environmental auditing

- participated in at least two formal environmental audits or appraisals

- at least one year of experience as an environmental professional.

Another member must be a custodian from the operation being appraised. In order to enhance impartially, it is encouraged, but not required, to include one or more additional members from other site groups or people from the same organization who are not directly responsible for the program being appraised.

A management appraisal team must consist of three or more members. One member must be an EPD professional who has completed a formal course in environmental auditing. One member must be an environment professional, specializing in the environmental regulatory programs being surveyed.

A program appraisal team must consist of two or more members. The team leader must be an EPD environmental professional, specializing in the environmental regulatory program being surveyed.

\section{Standards}

The standard for site environmental appraisals is described in ECM-3Q procedures. The Environmental Appraisal Manual will be maintained by EPD. This manual will be based on operating contractor requirements and DOE orders, and will be compatible with the DOE Comprehensive Environmental Protection Appraisal Plan. 


\section{Followup}

The appraisal team should review applicable reports from previous appraisals and verify the status of any corrective actions. Deficiencies from previous appraisals should be considered when developing the scope of an appraisal.

\section{Environmental Appraisal Manual}

\section{Environmental Protection Department (EPD)}

EPD was the lead organization for developing the SRS Environmental Appraisal Manual. A task group which included SRS custodial departments developed the manual by December 1989. EPD has the responsibility to update the manual as needed.

Facility Appraisals

A summary of the requirements needed to develop and implement the internal appraisal program follows. Each organization will develop and implement a formal environmental appraisal program. Formal documented facility appraisals will be conducted at least annually.

Program Appraisals

\section{Environmental Protection Department (EPD)}

EPD will conduct program appraisals to review environmental regulatory compliance conditions for a single or several closely-related regulatory programs across the site. These program appraisals and the external appraisals will cover all regulatory programs on a three-year cycle or more often as needed. The Environmental Appraisal Manual will be the guide for conducting a program appraisal. The program appraisals will be conducted by at least one EPD environmental professional who may, upon request, be accompanied by an environmental representative from the organization being surveyed. 
OManagement Appraisals

\section{Environmental Protection Department (EPD)}

EPD will conduct yearly management appraisals of each organization. The focus of these appraisals will be management structure, organization, procedures, and resource allocations to carry out EIP objectives which include complying with applicable environmental requirements and regulations. The management appraisal also may include a facility inspection and informal discussions with personnel. The appraisals will be conducted by EPD. 


\section{External Surveillance}

\section{(Compiled and reviewed by Charles $R$. Dynarski)}

External surveillances are conducted by DOE-SR. These surveillances are designed to monitor environmental performance and to ensure regulatory requirements are met. EPD is the lead department for coordinating, planning, and scheduling support.

\section{Site Program Overview}

In October 1992, a new DOE-SR surveillance process was designed using the WesTip process. Plans are to begin implementing of the new process in January 1993 with full implementation by mid 1993.

DOE-SR and EPD will develop a draft three-month rolling surveillance schedule. The draft schedule will be distributed to all affected parties and to organizations such as safety and QA. The schedule is designed to help the operating line organizations schedule surveiliances, audits, and walk downs and to allow other groups to piggyback on other surveillances, thus, reducing the total surveillance schedule.

There will be an emphasis on conducting joint surveillances between WSRC, DOE, and other internal WSRC groups. In addition to the joint surveillances, EPD and DOE surveillances also will be conducted.

A surveillance exit briefing will be required to discuss the surveillance's observations, deficiencies, and method of disposition.

Corrective-action response, corrective-action verification, tracking, and close out of the surveillance will be similar to past practices.

The majority of the communications during the surveillance process will utilize the site's All in One system.

Justification

External surveillances are conducted by DOE-SR to monitor site environmental performance and to ensure compliance with regulatory requirements, DOE orders, and operating contractor environmental policies. The external-surveillance program supports the site appraisal program by verifying the completion of corrective-action responses. 


\section{Organizational Responsibilities}

All organizations are responsible for ensuring that personnel and facilities under their control comply with environmental requirements. Organizations conducting external surveillances are responsible for participating in the required surveillance activity, preparing and implementing the corrective-action response, and identifying points of contact for the surveillance.

While preparing the monthly surveillance schedule, organizations may request additional specific surveillances. Requested surveillances are added to the monthly schedule, and the results are reported to the organization requesting the surveillance. 


\section{Internal Surveillance}

\section{(Compiled and reviewed by Charles $R$. Dynarski)}

A surveillance is similar to an appraisal, but is not as formal, and has a narrower scope which identifies items that could lead to noncompliance in the future. Surveillances reinforce the philosophy of best management practices. Internal surveillances are divided into facility, program, and verification surveillances. Facility and program surveillances are conducted to verify field compliance with regulatory and corporate requirements. They also are conducted to identify and correct conditions that might lead to an adverse environmental impact, and to review the adequacy of administrative systems, operating procedures, and funding. Verification surveillances are conducted to review the idequacy of corrective actions identified by an EPD internal environmental appraisal deficiency.

\section{Site Program Overview}

Internal surveillances are conducted by EPD to monitor site environmental ierformance and to ensure compliance with regulatory requirements, DOE orders, and operating contractor environmental policies. The program consists of facility surveillances, program surveillances, and verification surveillances. The EPD Environmental Surveillance Plan includes the program areas to be surveyed during the year, and the frequency of the review. The EPD professional for each program area also is listed. A detailed surveillance schedule will be issued each month based on the plan.

Justification

Internal surveillances are conducted by EPD. These surveillances are conducted to monitor site environmental performance and to ensure compliance with regulatory requirements, DOE orders, and operating contractor environmental policies. The internal-surveillance program supports the site appraisal program by verifying completion of corrective-action responses.

\section{Organizational Responsibilities}

All organizations are responsible for ensuring that personnel and facilities under their control comply with environmental requirements. Organizations conducting internal surveillances are responsible for participating in the required surveillance activity, preparing and implementing corrective-action response, and identifying points of contact for the surveillance.

While preparing the monthly surveillance schedule, organizations may request additional specific surveillances. Requested surveillances are added to the monthly schedule and the results are reported to the organization requesting the surveillance. 


\section{Chapter 17}

\section{Quality Assurance Program}

Chapter was compiled and reviewed by Kenneth Lane. 


\section{Site Program Overview}

The Westinghouse Savannah River Company Quality Assurance (QA) program applicable to environmental activities is documented in the WSRC $1 Q$ and $3 Q$ manuals. It involves all planned and systematic actions necessary to provide confidence that a facility, structure, system, or component will perform satisfactorily and safely in service. The goal of the WSRC QA program is to ensure that: research and development projects, demonstrations, scientific investigations, production and datacollection activities are performed in a controlled manner; and that components, systems and processes are designed, developed, constructed, tested, operated, and maintained according to engineering standards, acceptable quality practices, and Technical Specifications/Operational Safety Requirements. The QA program ensures that the technical data used for environmental decisions, as well as ongoing performance evaluation's are valid, retrievable, and legally defensible.

\section{Five-Year Outlook}

WSRC's overall mission is placing an increased emphasis on environmental monitoring, waste management, and environmental restoration. Thus, the qualityassurance aspects of these programs are being evaluated to ensure that the corresponding quality programs meet or exceed customer requirements. Currently, a draft environmental quality-assurance procedure for the WSRC $1 Q$ Quality Assurance Manual is in the site review/approval process and is scheduled for issuance in FY 93. This procedure identifies the key QA program elements for environmental data activities, and when combined with the existing $1 Q$ program, it will satisfy requirements contained in the proposed ANSI Environmental Quality Assurance Program Standard (E-4) document.

DOE Order $5700.6 \mathrm{C}$, which specifies quality-assurance requirements, will result in a significant revision to the overall 1Q program. Of these changes, the new work control procedure's requirements may have the greatest impact in the environmental program area. This new program will require the systematic control of work quality and will direct division QA organizations' involvement in environmental work scope issues, previously not considered as quality-related. This will have a profound impact on the level of quality-assurance involvement in environmental activities such as sample collection, analyses, evaluations, and reporting results. According to the WSRC Implementation Plan for DOE Order 5700.6C, all required implementation actions will be completed by the end of FY 94 .

\section{Justification/Regulatory Requirements}

The WSRC Quality Assurance Program provides a description of the requirements, responsibilities, and controls necessary for the systematic implementation of the quality-assurance program requirements specified in DOE Orders $5700.6 \mathrm{C}$ and 5400.1 and the WSRC Quality Assurance Management Plan. The QA program requires that the control elements for quality control $(Q C)$ that will be applied to environmental 
activities be specified in quality-assurance requirements documents (QARD). The QARDs will contain or reference the quality-assurance elements established for an activity, group of activities, and a scientific investigation or project. It also describes how conformance with such requirements is to be assured for structures, systems, computer software, components, and that their operation commensurate with the scope, complexity, duration, and importance to satisfactory, safe performance; the potential impact on the environment, safety, and health; and requirements for reliability and continuity of operation.

\section{Organizational Responsibilities Summary}

The site quality-assurance organization and quality-assurance responsibilities are prescribed in the WSRC $1 Q$ Westinghouse Savannah River Company Quality Assurance Manual. The ESII\&QA Division Quality Assurance Department has the primary responsibility for the WSRC QA program. The Quality Management Council (QMC) is a site-level committee comprised of division-level QA managers that have the responsibility for providing consistency in QA program implementation. Individual cognizant quality functions (CQFs) are responsible for guiding/monitoring QA implementation in their assigned jurisdictions. Line management has the primary responsibility for implementing the WSRC QA program:

\section{Site Procedures and Documents}

The WSRC 1Q Westinghouse Savannah River Company Quality Assurance Manual $(U)$ provides the site-level program requirements for quality assurance. This manual is implemented at the division level by applicable division-level procedures. This manual is implemented further at the working-group level by applicable department and section-level procedures. In all cases, the preferred method for implementing $1 Q$ manual requirements is to have the working groups include the requirements into their work procedures, regardless of the level of those procedures.

\section{Programs}

The site quality-assurance program is prescribed by the WSRC $1 Q$ Westinghouse Savannah River Company Quality Assurance Manual.

Each WSRC division implements the $1 \mathrm{Q}$ manual through corresponding division, department, and section procedures. Each WSRC division has a corresponding CQF responsible for overseeing that division's QA program. This oversight is supported further by ESH\&QA-Quality Assurance Department's Quality Assurance Audits section which provides independent audit oversight for all QA programs.

In accordance with the WSRC $1 \mathrm{Q}$ manual, each CQF is responsible for determining which division/department/section activities affect quality and for providing independent assessment, verification, surveillance, or inspection of those activities.

\section{Technical Support Programs}


When requested by the supporting CQFs, technical support is provided hy WSRC. divisions or through the use of qualified subcontract personnel. This support can include technical specialists to assist in performing assessments, audits, or verification activities.

One-Year Road Map

ESH\&QA QAD currently is determining the scope and extent of environmental- related QA activities. These short-term activities include training in environmental auditing and surveillance, and in site environmental laws and regulations. Determining customer expectations for environmental QA programs and establishing communications channels are planned for the next year. This will be done in cooperation with the Enviromental Protection Department (EPD), the U.S. Environmental Protection Agency, and the South Carolina Department of Health and Environmental Control.

Following approval of QAP 2-9, "Quality Assurance Program Requirements for Environmental Data Activities", in early 1993, ESH\&QA QAD will establish an implementation date for the program sitewide and will monitor the procedure's implementation.

Five-Year Road Map

The primary direction for the site QA program is presented in detail in WSRC-RP-911236, A Strategic Plan for Quality Assurance at the Savannah River Site. Areas of emphasis include QA program training, DOE order compliance, self assessment. environmental QA activities, and increasing the scope of line and senior management in implementing the WSRC $1 Q$ program. 


\section{Chapter 18}

\section{Site Organizations}

Chapter was compiled and reviewed by Greg Peterson. 


\section{Department of Energy-Savannah River Field Office Organization}

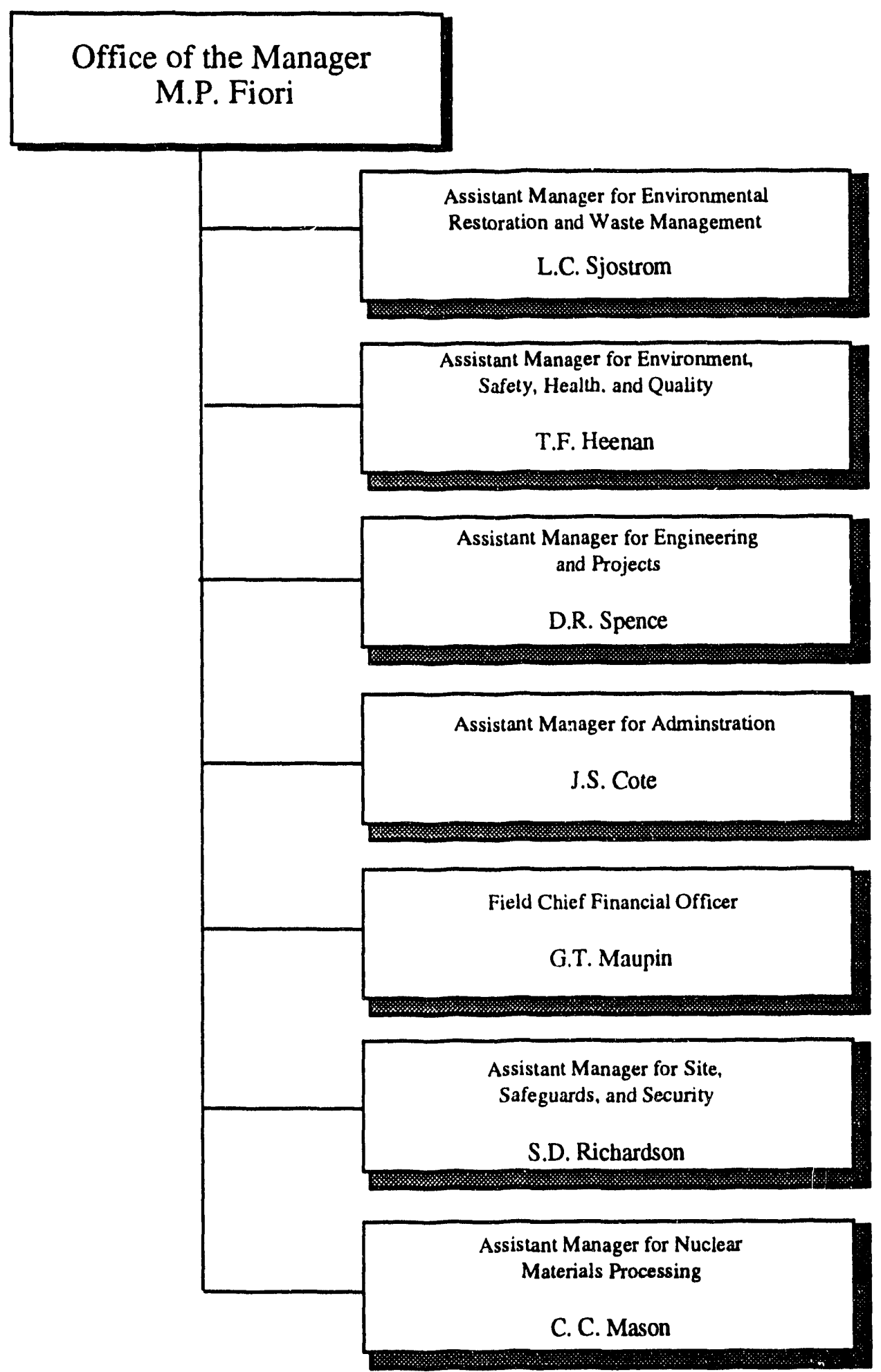




\section{DOE-SR ESH\&QA Organization}

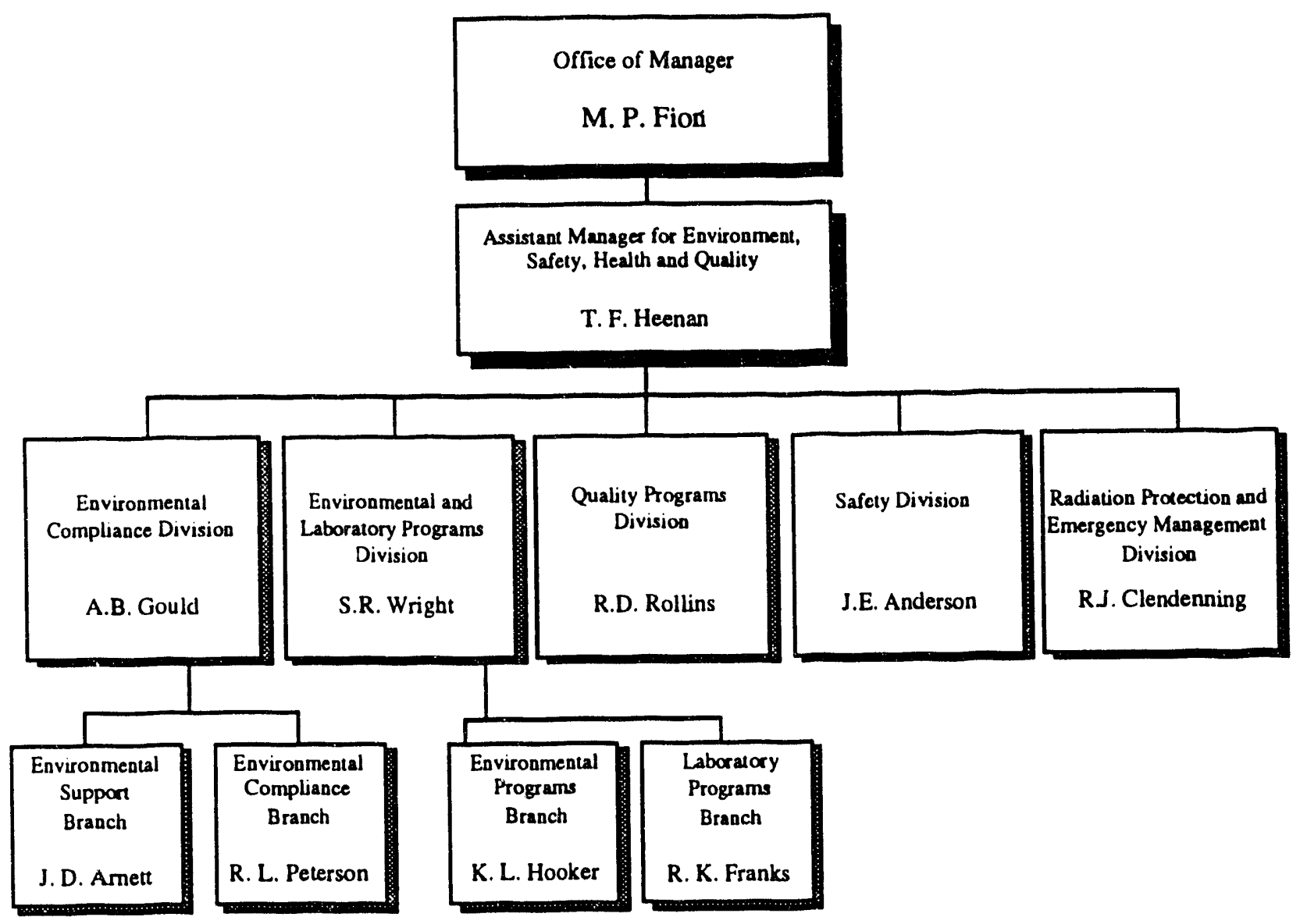




\section{Westinghouse Savannah River Company Organization}

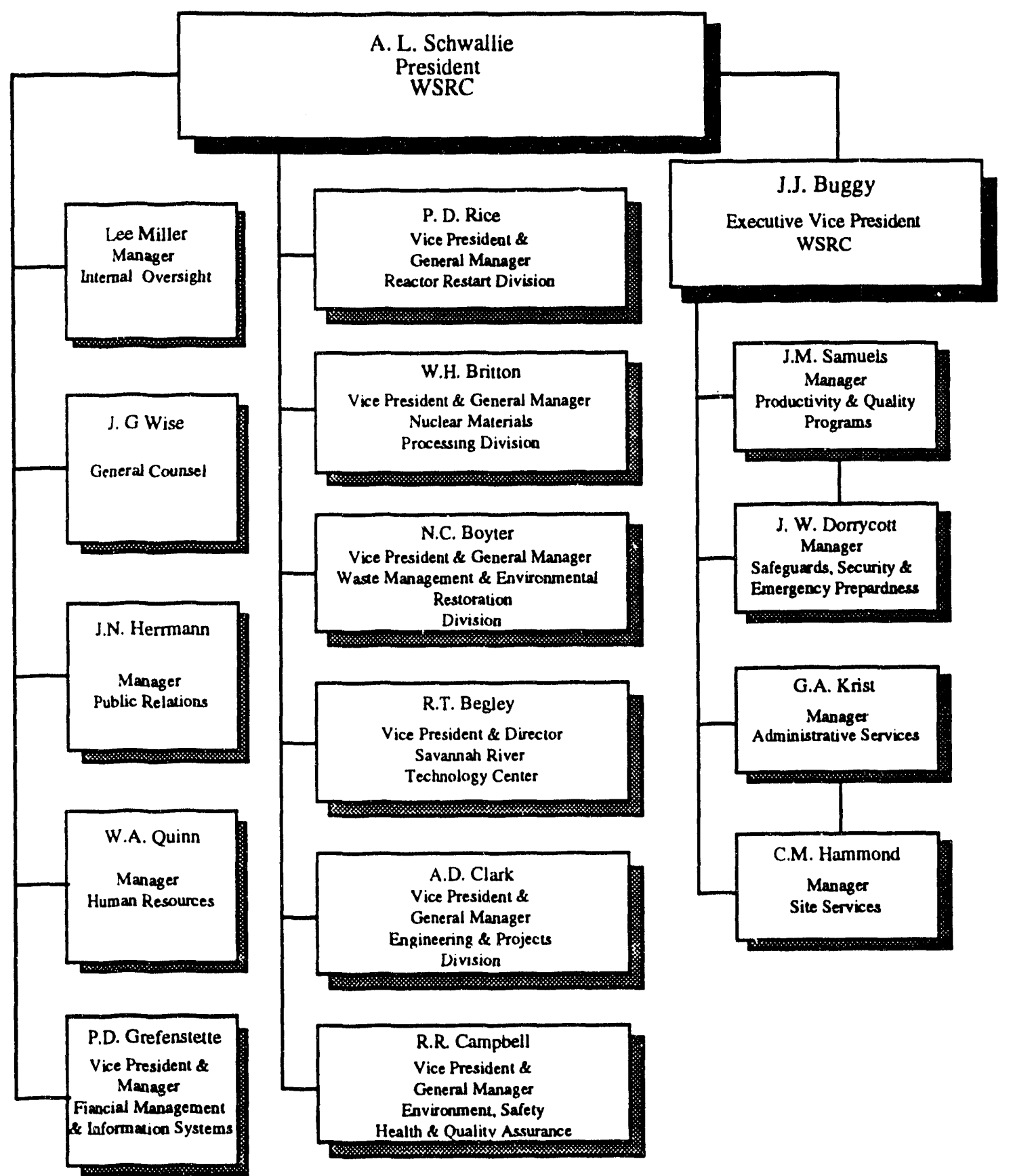




\section{WSRC Environmental Protection Department Organization}

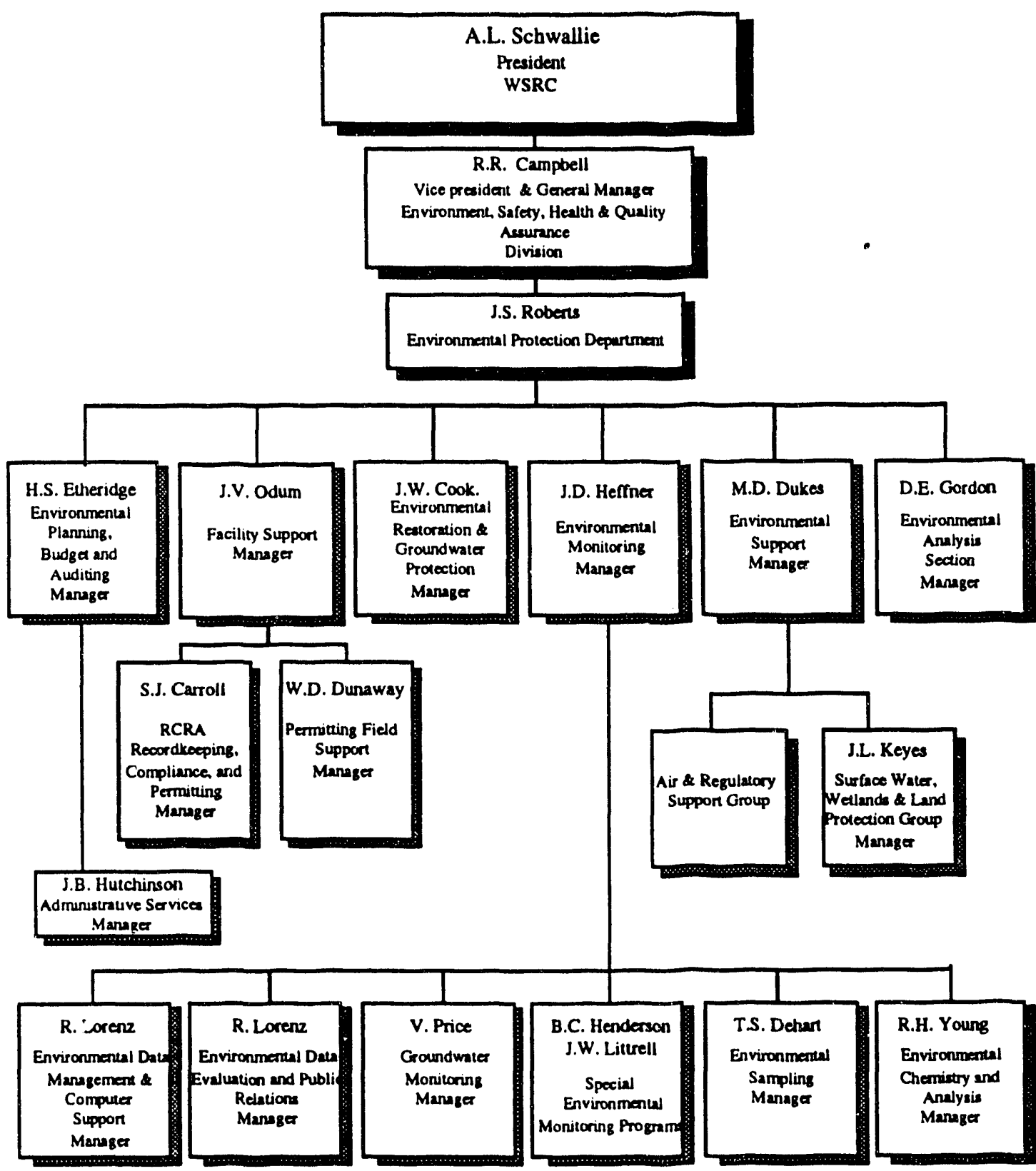




\section{Department of Energy-SR Organization and Responsibilities}

The U. S. Department of Energy-Savannah River (DOE-SR) Field Office is responsible for coordinating, planning, and directing the operations at SRS. DOE-SR oversees the day-to-day operations of SRS facilities, reviews operating policies and procedures, performs appraisals, and conducts audits.

DOE-SR directs the management and implementation of all environmental restoration (ER), waste-management (WM) corrective activities, and technology-development activities in the Site-Specific Plan (SSP). It reviews and checks the budget request for Congress to ensure that there is sufficient funding for SRS to meet its schedules and milestones. DOE-SR also reviews and approves all submittals related to environmental activities to agencies and organizations outside SRS.

Within DOE-SR, the ER, WM, corrective activities, and technology-development responsibilities for each organization include:

- The assistant manager for the Nuclear Materials Processing (AMNMP) organization has the primary responsibility for environmental compliance, operations, and management of SRS's nonreactor facilities.

- The assistant manager for the Environment, Safety, Health and Quality (AMESH\&Q) organization is responsible for directing, planning, and coordinating all SRS work related to environmental protection, health protection, safety, and quality assurance. In addition, AMESH\&Q provides independent oversight for environmental-protection, health-protection, safety, and qualityassurance activities in the SSP.

- The assistant manager for the Engiuzering and Projects (AMEP) organization is responsible for the design and construction of SRS facilities. AMEP also has the responsibility for project reporting, tracking, and coordinating environmental permits. It has the overall responsibility for implementing DOE orders relative to project management and engineering design.

- The director of the Manufacturing Division, who reports to the AMNMP, primarily is responsible for directing and managing the environmental compliance and operations of the Reactor Materials Facilities and the Tritium Facility.

- The assistant manager for ER and WM (AMERWM) has the primary responsibility for directing all work associated with ER and WM activities and implementing and managing the SSP. The AMERWM also is responsible for coordinating the planning, tracking, and reporting of activities for the SSP.

\section{AMERWM Responsibilities}

The AMERWM will ensure the implementation of the SSP by the following:

- providing technical oversight and direction to the contractor(s) for WM planning and operations

- reviewing and approving all ER/WM and technical-development reports and documents required by DOE-HQ or regulators

- coordinating the contractor(s) program/budget submission to DOE-HQ for ER/WM operations and technical-development activities 
- reviewing detailed procedures, policies, and practices established by the contractor for compliance with DOE policy and for the safe and environmentally soui.is operation of the facilities

- annually updating the WM plans for all WM activities at SRS

- requiring the contractor(s) to perform monthly budget and status reports on all WM/ER projects and technical-development activities

\section{Planring and Resource Office}

The Planning and Resource Office is responsible for providing crosscut support for the AMERWM organization in the areas of the FYP, budget coordination, roadmap development, planning and work control, and authorization. It also provides soordination and support for DOE-HQ initiatives, programmatic environmental impact staiement for ER/WM, and prioritization and reporting systems.

\section{Enviroumental Restoration Division}

The cirector of the Environmestal Restoration Division, reporting to the AMERWM, directs the effors of the Environmental Assessments and Closure and Technology brancbes. Responsibilities include planning, coordinating, and directing environmental programs for the Savannah River line and project activities, developing and implementing DOE-SR policies, and evaluating the contractor's work.

\section{Solid Waste Division}

The director of the Solid Waste Division, reporting to the AMERWM, plans, conrdinates, and directs the overall SRS low-level, transuranic (TRU), mixed, and hazardous WM programs and related technology-development prograrn. Other duties include providing technical oversight for DOE order compliance, environmental compliance and permits, and safety documentation and control mechanisms.

The principal areas of responsibility include:

- WM programs for low-level waste disposal, the Hazardous Waste/Mixed Waste Facility, Consolidated Incineration Facility, Sanitary Landfill Project, waste minimization, and the IRU Waste Storage and Processing Facility

- Research and technology-development activities in support of SRS ER/WM programs 


\section{Liquid Waste Division}

The director of the Liquid Waste Division, reporting to the AMERWM, provides resident and periodic onsite surveillance of the tank farms, waste evaporators, ITP, ESP, and ETF. Two branches, liquid waste operations and liquid-waste programs, report to the division. The principal areas of responsibility of the branches include:

- The Liquid Waste Operations branch oversees day-to-day operations (facility representatives), operational reviews, and DOE order compliance.

- The Liquid Waste Programs branch provides programmatic oversight for integrated scheduling, configuration management, work authorization control, environmental compliance and permits and safety documentation, and qualityassurance programs and controls mechanisms.

\section{Defense Waste Processing Division}

- The Director of the Defense Waste Processing Division (DWPD), reporting to the AMERWM, directs all activities for the Defense Waste Processing Facility (DWPF). The division is responsible for the safe operation and compliance of DWPF and ensures the program coordination efforts with DOE management and HQ for developing DWPF policies and programs. The following three branches report to DWPD:

- The Programs branch provides technical oversite and management for DWPF on startup criteria, fire and nuclear safety, planning and scheduling, and budget and project management.

- The Operations branch provides resident and periodic onsite surveillance, technical review, and oversite of day-to-day operations of DWPF and Saltstone.

- The Waste Compliance and Quality Assurance (QA) branch provides technical review and oversite of waste compliance and QA programs, which ensure that the DWPF product will be acceptable for placement in a federal repository when one becomes available. This branch also provides environmental-compliance oversite for DWPF operations.

\section{Environmental Compliance Division}

The director of the Environmental Compliance Division (ECD), reporting to the AMESH\&Q, oversees SRS compliance with federal and state environmental regulations, agreements, and DOE environmental orders and policies. The ECD also coordinates all federal and state environmental regulations, agreements, and permits associated with the SSP. 
ECD is composed of two branches: Environmental Support Branch and Environmental Compliance Branch.

- Environmental Support Branch

- Environmental Occurrence Reporting

- DWPF, Saltstone

- Waste Management (SWD \& LWD)

- Separations, WSI, and Support Management Forest Service

- Manufacturing and Tritium Facilities, Environmental Radiation

- Reactors, Labs

- ER, Decommissioning and Decontamination

- Environmental Compliance Branch

- CAA, SDWA, and FIFRA

- RCRA (hazardous waste permitting, nonhazardous waste, USTs, waste minimization)

- CCAR Coordinator, Annual Environmental Monitoring Report and Direct Order Compliance

- CWA, Environmental Monitoring, and TSCA

- RCRA (general/storage hazardous waste permitting)

- RCRA (treatment/disposal hazardous waste permitting, waste characterization and minimization), and LDR FFCA

- CERCLA (FFA and Public participation), RCRA (nonhazardous waste), ER closures and post-closures, and groundwater

- NESHAP, QA, Environmental Monitoring

ECD supports SRS operations and projects by reviewing, approving, and submitting documents related to environmental regulatory compliance (except NEPA), such as permit applications, monitoring reports, and project plans for environmental concerns.

ECD directs the development of engineering and scientific data related to regulatory permit requirements. The following seven general program areas are supported by ECD:

- Water Supply Program

- WM/ER Program

- Radiological Environmental Program

- Wastewater Management Program

- Air Program

- Environmental Emergency Response Program

- Audits and Appraisal Program 


\section{Environmental Laboratory Programs Division}

The Environmental and Laboratory Programs Divisions (E\&LPD), reporting to the AMESH\&Q, manage environmental studies and impact mitigation activities to support proposed and ongoing SRS projects; implement the National Environmental Policy Act (NEPA); provide advice and support to the manager of DOE-SR, and to other DOE-SR offices and divisions on implementing environmental requirements, environmental technology development, and natural resource management; and provides an overview of contractor quality performance of environmental requirements. This work covers the following four general areas: NEPA Implementation, Environmental Technology Development, Natural Resource Management, and Geoscience Management.

\section{Site and Waste Management Division}

The director of the Site and WM Projects Division (S\&WMPD), reporting to the AMEP, maintains an overview and directs the total WSRC design and construction effort at SRS. The director also is responsible for interim WM line item and expensefunded project management. S\&WMPD's responsibilities include reviewing projects to ensure that all environmental requirements are fulfilled, and appropriate permits are obtained. The S\&WMPD Project Management Manual directs staff to ensure that environmental considerations are part of the project plans.

\section{Office of Chief Counsel}

The Office of Chief Counsel (OCC) provides legal advice to the manager of DOE-SR, and in conjunction with ECD, it interprets envirot _tental laws and regulations as they apply to SRS.

\section{Program Support Division}

The director of the Program Support Division, reporting to the assistant manager for Administration (AMA), is responsible for the Issues Management Processing Action and Commitment Tracking System (IMPACTS).

IMPACTS is a database of information designed to support the tracking of evaluations, findings, issues, and commitments. This tracking and trending system is intended to facilitate the effective management and closure of issues and commitments onsite. The new computerized database replaces the old Recommendations and Finding Tracking System (RAFTS), which contained recommendations and findings from past inspections, appraisals, audits, and other compliance evaluations performed by DOE-SR, DOE-HQ, the General Accounting Office (GAO), and regulatory agencies such as EPA and SCDHEC. IMPACTS, like the old system, will contain evaluations of all SRS organizations. 


\section{SRS Contractor Organization and Responsibilities}

Each contractor is responsible for the safe, environmentally-sound maintenance and management of its designated facilities, specific facility upgrades, operational support, waste management, and monitoring of operations and effluents for environmental compliance. Facility or building managers are responsible for managing their facilities in a safe, environmentally-sound manner. SRS contractors include the following:

- The Savannah River Ecology Laboratory (SREL), operated by the University of Georgia, handles both basic and applied research designed to show how ecological entities (e.g., populations, terrestrial or aquatic systems, groundwater, etc.) function under both SRS-induced stresses and natural conditions.

- Wackenhut Services Incorporated (WSI) handles site security.

- The U. S. Forest Service (USFS) handles land management.

- Bechtel Savannah River Company handles onsite construction activities (design and construction management).

There are other contractors to DOE-SR performing primarily environmental-research activities: the U.S. Soil Conservation Service; U.S. Geological Survey; Academy of Natural Sciences of Philadelphia; the S. E. Forest Experiment Station (SEFES); and other researchers through the National Environmental Research Park (NERP) program.

- Westinghouse Savannah River Company (WSRC) is the managing and engineering contractor.

- Most waste operations activities, environmental-corrective and remedial actions, and decontamination and decommissioning (D\&D) of facilities, conducted at SRS are performed by or under contract to WSRC. WSRC has been assigned the responsibility to manage the high-level and solid wastes, implement the Environmental Restoration Program, and manage the site. WSRC ensures that environmental-design requirements are met and provides project support. WSRC also performs environmental research and development, provides an independent sitewide environmental-surveillance program, remediates assigned facilities, and applies waste-management technology to support operations and environmental restoration. WSRC is responsible for waste management and environmental compliance at its assigned facilities.

- The waste-management programs at SRS are extensive and comprehensive, covering all facets of site operations. The primary purpose of the wastemanagement programs is to manage, account for, and dispose of all types of DOE waste in a safe and environmentally sound manner.

Upon request by the DOE-SR, WSRC provides environmental support services, such as development of spill prevention, countermeasure, and control (SPCC) plans, to the other onsite contractors. Interaction with these contractors can be direct once a specific environmental issue has been defined and an agreement has been reached between the three parties (DOE-SR, operating contractor, and the other contractor). 


\section{WSRC Organization and Responsibility}

WSRC is organized into divisions and departments. The following is a brief description of each and its responsibilities. Waste-management activities are the responsibility of the Waste Management and Environmental Restoration Division. Additional discussion of environmental responsibilities can be found in Chapter 19.

Internal Oversight

Intemal Oversight provides aggressive, independent audits, evaluations, and appraisais of SRS programs and operations.

\section{Productivity and Quality Programs}

Productivity and Quality Programs concentrates on developing the total quality culture within WSRC and serves as a focal point for the company's productivity-improvement and cost-effectiveness initiations.

\section{Safeguards, Security and Emergency Preparedness}

Safeguards, Security and Emergency Preparedness ensures that critical safeguards and security functions are in place for material control, accountability, protecting sensitive and classified equipment, and for planning and training for the site's emergencyresponse activities.

\section{Administrative Services Division}

The Administrative Services Division consists of Training Integration; Planning, Support, and Analysis; Management Services; Procurement and Materials Management; and Strategic Programs.

\section{Site Services}

Site Services consists of the Transportation, Quality Assurance, Central Services Works Engineering, Site Utilities, Training, Operations Integration, Facilities and Services, Fire Protection, and Digital Control and Systems Departments.

\section{General Counsel Division}

The General Counsel Division provides legal advice to WSRC's management and interprets laws and contractual provisions to facilitate SRS's compliance with legal requirements.

\section{Public Relations Division}

Public Relations coordinates community-relations activities, including governmental communications and constituency building, community giving, and the visitor's program; manages a speakers' bureau and develops communications materials to 
support all media and public-information activities; develops and implements a community-relations plan, required by Superfund legislation and public-paricipation activities for Waste Management and Environmental Restoration; and coordinates proactive and reactive media and emergency-response activities.

\section{Human Resources Division}

Human Resources is a staff-support organization responsible for professional staffing, general employment, compensation administration, the design and administration of employee benefits, employee assistance programs, equal employment opportunity, employee communication, the administration of employee-relations policies and practices, and organizational and individual development and training.

\section{Financial Management and Information Systems Division}

The Financial Management and Information Systems Division's administrative operation supports the line organizations in achieving the site's mission. This organization includes Finance and Information Resource Management departments. These departments provide a variety of services associated with accounting, budgeting, financial management, administration of employee benefits, invoice management and processing, capital investment management, computer, and telecommunication support.

\section{Reactor Restart Division}

The Reactor Restart Division is responsible for the safe operation of $\mathrm{K}$ Reactor and the maintenance of $\mathrm{L}$ Reactor, which is in cold standby. The division will provide increased focus and directed effort toward accomplishing significant milestones such as the K-Reactor Cooling Tower outage, demonstration run, and resource-utilization plan.

\section{Engineering and Projects Division}

Engineering and Projects Division (E\&PD) provides construction liaison for projects for which it is responsible. For smaller projects, design is also provided by E\&PD. The division assists as necessary in all site tasks requiring new or modified facilities.

E\&PD will provide site activity support by implementing such programs as:

- full support to operations in restarting the reactors

- computer automation of the design and construction process, the projectmanagement system, and the work-management system

- a division quality-improvement plan

- execute a project-management system that meets the requirements of DOE Order 4700.1 to include configuration management, design reviews, and document controls

- meet established project completion schedules

- implementation of NQA-1, Quality Assurance Requirement for Nuclear Facilities 
- maintain and restore aging facilities

- develop training and procedures

\section{Nuclear Materials Processing Division}

Nuclear Materials Processing Division (NMPD) is responsible for Engineering, Separations, Training, Programs, Quality Assurance, Reactor Materials, and Tritium. The functions include executing of all engineering, technology, and regulatory activities with the division; executing of design authority for division operations, as delegated by the Engineering and Projects Division; and assuring that the division uniformly and consistently follows WSRC policies, practices, and procedures for engineering and technical activities.

Reactor Materials, Separations, and Tritium are responsible for waste control and management.

Reactor Materials (RM) - RM is responsible for providing fuel and targets to support SRS reactor operations. These activities must comply with federal and state environmental regulations, DOE orders and Tiger Team findings, and SRS wastemanagement goals. (The Tiger Team is an independent oversight group formed by the former Secretary of Energy, Admiral James D. Watkins, to assess the Environment, Safety, and Health programs at DOE facilities.)

The major activities associated with waste control and management needed to accomplish the RM mission are divided into the categories of air effluents, solid wastes, and wastewater effluents. The primary air effluent activities are replacing operations using chlorofluorocarbons (CFC), especially degreaser operations, and installing improved radioactive air emissions monitoring systems. The primary solid waste activities are the operation of the 313-M waste compactor; the excess chemical and material disposal program; the waste Filtration and Stabilization Facility (FIST) project; and the operation of two hazardous waste storage facilities: the Process Waste Interim Treatment/Storage Facility (IT/SF) and the Mixed Waste Storage Shed (MWSS). The primary wastewater activities are the Liquid Effluent Treatment Facility (LETF) operations, the wastewater effluent toxicity-reduction study, the M-Area process sewer repair and replacement program, and the M-Area storm sewer upgrade program.

Tritium - Tritium's responsibilities include identifying, handling, packaging, shortterm storing, and shipping job-control (low-level radioactive), mixed, and hazardous waste. Reducing the waste volumes of low-level, job-control waste by compaction is an important part of Tritium's waste-management program.

Waste minimization also is part of Tritium's waste-management activities. Material substitution, procedural control of material entering radiological-controlled areas, and revised work practices to eliminate using hazardous materials are all elements of Tritium's waste-minimization effort.

Separations - Separations' responsibilities consist of activities ranging from treatment, handling, and storage to disposal operations. Waste-management treatment activities 
in operating facilities include packaging and handling low-level, intermediate-level, and TRU waste.

\section{Waste Management and Environmental Restoration Division}

Waste Management and Environmental Restoration Division (WM\&ER) is divided into seven departments, four of which deal with waste management: the Defense Waste Processing Facility operations, High-Level Waste Programs, Environmental Restoration, Program Management, Operations Support, Quality Assurance, Engineering, and Solid Waste. The following four departments are responsible for waste control and management.

\section{Defense Waste Processing Facility}

DWPF immobilizes liquid high-level radioactive waste currently stored at SRS in borosilicate glass. This operation includes chemically treating two unique waste streams, mixing them with a ground borosilicate glass, and then heating the mixture in an electric melter to $1130^{\circ} \mathrm{C}$. The molten mixture then is poured into 10 -feet-tall, 2 feet in diameter stainless-steel canisters and allowed to harden. The canisters' outer surface then is decontaminated to Department of Transportation (DOT) standards, welded closed, and temporarily stored onsite for eventual transport to and disposal in a permanent, federal geological repository.

\section{High-Level Waste Programs}

High-Level Waste Programs manages high-level radioactive waste generated by routine and nonroutine operations of production and research facilities at SRS. The High-Level Waste Programs' facilities store and process this waste for feed to DWPF. Radioactive waste is categorized according to how it must be dealt with and managed according to standards established by Environmental Protection Agency (EPA) and DOE orders. HLW requires considerable shielding, is long-lived, and will be disposed of in a geologic repository.

\section{Solid-Waste Department}

The Solid Waste Department manages low-level waste (LLW). LLW normally is solid waste that is containerized according to its radioactivity and disposed of onsite. TRU waste generated onsite generally requires little shielding, is extremely long-lived, and will also be disposed of in a federal geologic repository. Hazardous waste is defined by several environmental laws and managed according to requirements established by EPA and states. Mixed waste is waste that contains both radioactive and hazardous components. It is managed to meet requirements for EPA, states, and DOE. Sanitary waste, which is neither radioactive nor hazardous, is managed according to established federal and state regulations (DOE 1989a). 
The strategy for achieving SRS waste-management objectives is the following:

- ensure there is a method to dispose of waste generated

- reduce/minimize waste generation

- recycle/reuse consumed waste in processes as much as practical

- segregate waste at point of generation such that uncontaminated waste or hazardous waste does not become radioactively contaminated

- segregate waste at the generating location for temporary storage in permitted facilities, as required

- incinerate to destroy hazardous waste and reduce waste volume

- treat waste to minimize mobility before final disposal

- ultimately dispose of newly generated wastes in monitored repositories

- maintain integrity of existing disposal sites to ensure performance objectives are met

\section{Environmental Restoration (ER)}

ER is responsible for all aspects of assessing and cleaning up sites and facilities that are no longer operating but are contaminated to various degrees with hazardous-, radioactive-, or mixed-waste materials. ER performs two sets of activities: remedial actions and decontamination and decommissioning (D\&D). The remedial action tasks encompass site characterization, analysis of cleanup alternatives, and selection of remedy; cleanup and site closure; and site compliance monitoring. D\&D is concemed with the safe caretaking of inactive nuclear facilities and either their decontamination or their complete dismantlement and removal.

\section{Savannah River Technology Center}

Savannah River Technology Center's (SRTC's) research and development activities center on supporting site waste-management production operations, solving production technical problems, and enhancing existing production processes. The emphasis is on developing and demonstrating technology for waste-management operations. The majority of these efforts are driven by numerous and diverse new production waste-management initiatives. This is accomplished by using engineeringscale facilities and laboratories.

SRTC is divided into five departments: the Waste Management \& Environmental Technology Department (WM\&ET), Nuclear Reactor Technology \& Scientific Computations Department (NRT\&SC), Equipment \& Materials Technology Department (E\&MT), Laboratory Operations \& Services Department (LO\&S) and Chemical Process Technology Department (CPT). There also is a consulting scientist to the division, as well as a Quality Section (QS). Dotted-lined sections to the division are Safety, Human Resources and Financial Resources.

WM\&ET is aligned closely with the Waste Management \& Environmental Restoration Division (WM\&ER). It also provides support for the various waste-treatment facilities around the site, including the Defense Waste Processing Facility (DWPF), the Effluent 
Treatment Facility, the Consolidated Facility, the Solid Waste Disposal Site, the Waste Tank Farm and the In-Tank Precipitation process.

NRT\&SC's main customer in its upgrade and operation of the K Reactor is the Reactor Restart Division. NRT\&SC also supports DWPF and WM\&ER.

E\&MT works in conjunction with many site functions, including Reactor Engineering, Reactor Materials and WM\&ER. E\&MT also is working on developing advanced equipment and metallurgical processes to meet the specifications of the future DOE reconfiguration "Complex 21."

Internally, LO\&S works to support the various SRTC research and development organizations. Onsite, the department's major customers are WM\&ER and DWPF.

CPT supports all the chemical process facilities onsite. Developing separations and tritium processes for Complex 21 also is a major department objective. For the purpose of further research and education. CPT is aligned closely with local Georgia and South Carolina universities.

Specific SRTC responsibilities include:

- developing new products and processes consistent with DOE objectives and policies

- improving existing processes and products

- providing basic technical information for equipment design and process operations

- providing and keeping up-to-date:

- technical safety requirements, operational safety requirements, or technical manuals that give the technical basis for plant processes

- technical standards that give the limits within which plant processes must be operated

- safety analysis reports that provide an evaluation of hazards associated with each operation and a basis for the technical safety requirements, operational safety requirements, or technical standards

- systems analyses that provide comprehensive assessments of system functions and processes

- hazard-assessment documents

- reviewing and approving test authorizations for nonroutine operations and operations outside the limits imposed by technical standards

- maintaining liaison on technical matters with DOE, other DOE contractors, and other laboratories

- operating experimental facilities

- maintaining the historical incident databank

- performing dose modeling and dose assessments

- providing technical assistance to Waste Management Operations when requested

- coordinating and carrying out advanced operational planning studies and maintaining liaison with other DOE planning groups 
- cooidinating environmental studies relating to SRS and maintaining liaison on environmental matters with DOE, other DOE contractors, other government agencies, and other environmental study groups

A further description of SRTC is provided to describe additional environmental activities.

SRTC's primary mission is technical research and development activities supporting SRS operations. There are three sections within SRTC that conduct environmental or environmentally-related research and development activities: Environmental Sciences (ESS), Environmental Technology (ETS), and Interim Waste Technology (IWTS). ESS conducts biological, ecological, and geologic studies and develops information to support NEPA activities, including review for technical accuracy; biological assessments, when required for compliance with the Endangered Species Act; 316 (a) and (b) studies to comply with the Clean Water Act (CWA); remote sensing activities in water-quality studies of various parts of the plant, including $L$ Lake and the Savannah River Swamp; and waste site characterization and closure activities. ETS assists in developing and using new technology for decreasing emissions into the environment, using meteorological techniques to predict plume or spill conditions, and operating the weather center. IWTS is responsible for researching and developing technology to reduce the volume of low-level and hazardous waste, and for developing techniques to safely dispose of waste and released substances. The sections maintain liaison with WSRC organizations, DOE-SR, other DOE contractors including SREL, and other laboratories. SRTC also operates the test facilities at TNX.

A further description of ESS is provided in the following subsections.

\section{Environmental Science Section}

\section{Organization}

ESS is in the Waste Management and Environmental Technology Department (WM\&ET) of SRTC. The section is divided into the Ecology and the Geotechnical groups. The section also has one advisory scientist, one project manager, and one QA coordinator. The Ecology Group comprises mainly of professionals with experience in biological sciences; the Geotechnical Group comprises of professionals with experience in geological sciences and engineering.

\section{Mission}

ESS's mission is to anticipate SRS environmental needs and provide/develop necessary technologies and information to ensure compliance with environmental regulations. 
Vision

ESS's vision is to be the recognized leader for ecological, geotechnical, and environmental-restoration issues effecting SRS.

This will be accomplished by the following:

- providing key technical input to policy decisions and environmental programs

- conducting needed research on environmental problems

- developing innovative environmental technologies

- developing, integrating, and automating environmental data

- establishing and maintaining state-of-the-art facilities needed to conduct programs

- maintaining an exceptional professional and managerial staff

- maintaining the support staff to facilitate efficient and effective communications and program administration

\section{Programs}

Through research and development initiatives and technical assistance, ESS strives to provide cost-effective, state-of-the-ant technologies to solve environmental of issues at SRS. These activities support both site operations and regulatory compliance programs. ESS staff maintains close interactions with national laboratory and university professionals in order to stay abreast of current technologies relevant to SRS programs. Major program areas are as follows:

- Clean Water Act and NPDES compliance programs

- environmental impact and site assessments/NEPA support

- environmental-restoration and RDDT\&E programs

- groundwater-remediation technologies developmen/demonstration

- environmental biotechnology developmen/demonstration

- remote sensing development and application

- geology, geochemistry, hydrology, and geophysics applications

- tectonics studies

- air/earth cycling of pollutants studies

The ESS significantly has reduced the amount of time required to produce, while continuously increasing the quality of, NEPA support documentation, as exemplified by the accelerated issuance of the 3-volume Environmental Information Document supporting the Reactor. Operation EIS. Expertise in aquatic ecology led to the Fish Kill Settlement Agreement, as well as a significantly reduced L-Lake/Steel Creek biological monitoring program. Major accomplishments also have been achieved in supporting the SRS seismic and groundwater programs. ESS contributions to ER and RDDT\&E programs have placed SRS in the lead in the integrated demonstration project, i.e., in situ air stripping using horizontal wells, and in situ bioremediation of groundwater and soils. ESS staff are well represented in peer-reviewed publications, patents, and invention disclosures. 


\section{Environment, Safety, Health, and Quality Assurance Division}

The Environmental, Safety, Health, and Quality Assurance (ESH\&QA) Division provides support in areas that are essential for the safe, secure, and responsible site operation. ESH\&QA is divided into the following organizations: Health Protection, Environmental Protection, Safety, Quality Assurance, Analytical Laboratories, Medical, and allocated ESH\&QA (administrative services).

The Environmental Protection Department's (EPD) Environmental Restoration/Groundwater Protection Section (ER/GW) within the ESH\&QA is responsible for coordinating all regulatory guidance for all environmental-restoration and groundwater-protection programs, all consent agreements, implementing the Federal Facility Agreement, and integrating all RCRA/CERCLA activities.

ESH\&QA's overall plan is described in its mission statement: "To provide guidance, independent critical assessment and necessary support to WSRC divisions in order to achieve the highest standards of safety, quality, environmental and health protection, safeguards, security, emergency preparedness and medical services."

A further description of the EPD is provided to describe additional environmental activities.

\section{Environmental Protection Department (EPD)}

EPD is the primary liaison with DOE-SR's Environmental Division (ED) for environmental matters involving the operating contractor at SRS. EPD personnel collect and review data from most SRS environmental projects, excluding nonregulatory matters. EPD coordinates all regulatory activities with ED, including permitting, reporting, and inspections, for all the other departments onsite. The EPD also has a number of other responsibilities which include: reviewing site use permit applications; providing guidance on Resource Conservation and Recovery Act (RCRA) and Comprehensive Environmental Response, Compensation, and Liability Act (CERCLA) activities; providing guidance in other media areas including air, surface water, and groundwater, coordinating and linking all groundwater activities and issues via the EPD site groundwater coordinator; overseeing monitoring, sampling, and analyzing groundwater and drinking water wells; coordinating streammanagement activities with DOE-SR, South Carolina Department of Health and Environmental Control (SCDHEC), SRTC, and SREL; coordinating the development of aquatic toxicity test guidelines with the SRTC; providing expertise on issues regarding polychlorinated biphenyls and coordinating their removal; coordinating other Toxic Substances Control Act (TSCA) activities including the review of Premanufacture Notifications; and overseeing training and providing specific training on permitting or spill prevention/control.

EPD also is responsible for ensuring that all projects undertaken at SRS comply with the National Environmental Policy Act (NEPA). A NEPA environmental evaluation checklist must be completed by a department custodian prior to initiating any activity that has a high potential for significant environmental, health, or safety impact regardless of cost, and prior to any process testing. The checklists provide key information to the custodian regarding emissions, what modifications are being made, 
spill potentials, impacts on wetlands or endangered species, the need for a site-use permit and other vital environmental information on the need for construction and operating permits. If additional documentation is required, EPD notifies the custodian and DOE-SR of the documentation level: required Memorandum-to-File (MTF), Environmental Assessment (EA), or Environmental Impact Statement (EIS). DOE-SR and COE-HQ must concur in their decision on the final appropriate level of NEPA documentation.

The Environmental Monitoring Section (EMS) is responsible for developing and operating a program for sampling and analyzing air, water, flora, and fauna from SRS environs for radioactive and nonradioactive pollutants. EMS also conducts programs for measuring and documenting environmental releases, and is responsible for evalyating environmental data to determine the effects of site operations on the offsite and onsite environment. These programs support site environmental-compliance requirements, including the DOE requirement to produce and publish an annual Environmental Monitoring Report. In performing these functions, this section ensure that the site remains a leader in addressing and assuring compliance with environmental guidelines and regulations.

EMS assists in fully meeting DOE orders, environmental regulations and WSRC policies. EMS has specific objectives to do the following:

- develop policies and conduct programs to ensure that both radiological and nonradiological monitoring of the environinent are conducted in a manner that is responsive to regulatory requirements and is technically valid

- establish annual site operating environmental radioactive release guides consistent with ALARA principles and track site performance with respect to the guide values established

- collect and analyze environmental samples to document radiological and nonradiological environmental levels associated with site operations

- publish the site Environmenial Report 


\section{Chapter 19}

\section{Environmental Reponsibility Summary}

Chapter was compiled and reviewed by Greg L. Peterson. 


\section{Site Program Overview}

\section{Summary}

The United States Department of Energy (DOE) and the managing contractor Westinghouse Savannah River Company (WSRC), are committed to operating the SRS in a manner that protects the public health and safety, and the environment. This philosophy is contained in DOE Order 5400.1, General Environmental Protection Program, the SRS Strategic Environmental Plan, and in the SRS Mission, Vision, and Principles.

Compliance with environmental regulations and U. S. Department of Energy orders relating to environmental protection is an important part of the SRS program. An overview of the strategy to reach our site goal of environmental excellence and compliance with new and existing environnental regulations and DOE orders is found in chapter two. Demonstrating environmental excellence is a high priority site initiative embodied in DOE and WSRC policy.

SRS is constantly striving to improve its standing as a leader in environmental protection activities. DOE-SR, WSRC, and the other SRS contractors are committed to environmental excellence and compliance. Through teamwork and proactive planning, a partnership for environmental excellence is formed to achieve our site vision for SRS to become: the recognized model for Environmental Excellence in the Department of Energy's Nuclear Weapons Complex.

\section{Chapter Overview}

In this chapter, a synopsis SRS environmental responsibilities are presented to provide an overview of the teamwork by SRS organizations in order to achieve environmental excellence and compliance. The chapter contains four sections:

The first section includes the Policy statement, DOE-SR, and SRS contactor responsibilities summarized from the Environmental Protection Implementation Plan.

The second section describes some of the SRS environmental committees, management, and communication networks which are in place to enhance teamwork by SRS organizations in order to achieve our site goal of environmental excellence and compliance.

The third section contains WSRC specific responsibilities from Management Policy 4.1, Environmental Assurance, from manual WSRC-1-01.

The fourth section includes the Environmental Program Responsibility Summary prepared by the Westinghouse Environmental Management Team. 


\section{Policy Statement}

On May 11, 1987, the Manager, U.S. Department of Energy-Savannah River Operations Office (DOE-SR), issued Announcement SR-87-31, a restatement of the DOE-SR Environment, Safety and Health (ES\&H) Protection Program Policy. This policy statement, which is periodically updated and reissued by the Manager, was distributed to all DOE-SR employees and contractors. In the Announcement, the Manager reaffirmed the DOE commitment to the ES\&H Program, specifically, that it is the policy of DOE-SR to assure protection of the environment, the safety, and health of the public, and government property against accidental loss and damage. With regard to the environment, it is also the policy to protect the natural resource value of soil, water, and biota on the Savannah River Site (SRS) consistent with the missions of the DOE; to assure compliance with applicable Executive orders, DOE policy statements and statutory requirements affecting federal facilities and operations; and to assure DOE ES\&H program execution for assigned programs and DOE-SR facilities and contractors.

In April of 1989, the Manager reinforced the spirit of this policy through the issuance of new Mission, Vision, and Principles statements. "The mission of the Savannah River Site is to serve the national security interest of the United States by safely producing nuclear materials while protecting the employee and public health and the environment." In addition, "the Savannah River Site Vision is to be the recognized model of excellence for the DOE nuclear weapons complex, valuing and involving the individual to continually improve operations, safety, health and environmental protection, quality, and customer satisfaction."

On January 12,1990, the Manager, DOE-SR, in concert with the Director, Special Projects Office. Savannah River Restart (SRSPO), issued Announcement SR-90-05, "SRS Environmental Protection Policy." This policy statement directs all SRS employees to "assure the incorporation of all Departmental and National environmental protection goals in the daily conduct of our business" and declares that "the SRS will continue to have and maintain a strong environmental protection program and be the front runner in DOE's commitment to excellence in environmental protection, waste management, wetland recovery, and pollution prevention awareness arenas." 


\section{Department of Energy-Savannah River (DOE-SR) Responsibilities}

The DOE-SR is responsible for implementing, managing, and overseeing the environmental activities at the SRS to meet objectives of DOE. The DOE-HQ bas assigned to DOE-SR the responsibility and authority for the management of national environmental objectives at the SRS. The DOE-SR prepares budget submittals necessary to meet environmental requirements. The DOE-SR also reviews and approves all submittals related to SRS environmental activities that are made to agencies and organizations outside of the SRS.

Environmental protection requirements at the SRS are established in Secretary of Energy notices, DOE orders, DOE-SR orders, executive orders, federal and state laws and regulations, and other commitments made by DOE. Such commitments are demonstrated in DOE and DOE-SR policies, the statements of the DOE-SR Mission, Vision, and Principles, environmental permits, environmental impact statements (EISs), or in compliance agreements.

The responsibility for the establishment and maintenance of an environmental protection program at SRS belongs to the DOE-SR line organizations. The Environmental Compliance Division (ECD) and Environmental and Laboratory Programs Division (E\&LPD) assists in the assurance of implementation of the SRS environmental protection program in the following ways:

- Provides oversight of contractor environmental protection programs and activities

- Provides advice to DOE-SR line organizations in their environmental protection programs and activities

- Provides liaison between SRS and environmental regulatory agencies

- Implements an environmental appraisal, audit, inspection, surveillance, and followup program to identify proficiencies and deficiencies in the SRS environmental protection programs and activities

- Provides line management of the natural resources management program and the Savannah River Ecology Laboratory

- Provides coordination and oversight of the environmental technology development program 


\section{Savannah River Site Contractor Responsibilities}

The DOE-SR contractors involved in ES\&H activities include the following:

- Westinghouse Savannah River Company (WSRC), the managing and engineering contractor

- Bechtel Savannah River, Inc.(BSRI), the contractor for construction activities;

- Savannah River Ecology Laboratory (SREL), operated by University of Georgia which handles both basic and applied research designed to show how ecological entities (e.g., populations, terrestrial or aquatic systems, groundwater) function under both SRS-induced or relaxed stresses and natural conditions;

- Wackenhut Services, Incorporated (WSI), which handles site security ;

- U.S. Forest Service (USFS)-Savannah River Forest Station (SRFS), which handles land management; and the

- U.S. Army Corps of Engineers (COE), which handles onsite construction activities (design and construction management)

Each contractor is responsible for the safe, environmentally sound maintenance and operation of its designated facilities, specific facility upgrades, operational support. waste, management, and monitoring of operations and effluents for environmental compliance. Facility or building managers have the responsibility to operate their facilities in a safe, environmentally sound manner.

Most waste operations activities, environmental corrective and remedial actions, and Decontamination and Decommissioning (D\&D) of facilities conducted at the SRS are performed by or under contract to WSRC. The balance of the waste operations activities are performed by WSI, SREL, USFS, and COE. These activities relate to waste minimization and pollution prevention awareness. WSRC has been assigned responsibility for management of the Waste Management Program, implementation of the Environmental Restoration (ER) Program, and management of the Site. The WSRC ensures environmental design requirements are met and provides project support. WSRC performs environmental research and development, provides an independent sitewide environmental surveillance program, remediates assigned facilities, and applies waste management technology to support operations and environmental restoration. Some of the specific contractor responsibilities for DOE Order 5400.1 requirements for WSRC are as follows:

WSRC

- Notification of Environmental Occurrences Responsibilities - Environmental Protection Department (EPD)

- Long Range Environmental Protection Plan Responsibility - EPD

- Annual Site Environmental Report Responsibility - Environmental Monitoring Section (EMS)

- OMB Circular A-106 Responsibility - EPD

- Groundwater Protection - EPD, EMS

- Waste Minimization Program Responsibility - WCAM

- Pollution Prevention Awareness Program Responsibility - EPD

- Environmental Monitoring Responsibilities - EMS 
- Quality Assurance Responsibility - Quality Assurance Department

- Laboratory Certification Responsibility - EMS

- DOE Laboratory Certification Responsibility - EMS

- Independent Data Verification Responsibility - EMS

\section{Environmental Management and Communications}

In order to achieve our site goal of environmental excellence and compliance, SRS contractors share a common vision:

". . the Savannah River Site Vision is to be the recognized model of excellence for the DOE nuclear weapons complex, valuing and involving the individual to continually improve operations, safety, health and environmental protection, quality, and customer satisfaction."

Some of the SRS environmental committees, management, and communication networks which are continually improving environmental protection are described below.

\section{Central Environmental Committee}

The Central Enviroumental Commuttee (CEC) provides WSRC Divisions and Departments and other SRS organizations an open forum to present and discuss environmental compliance related issues, questions, and concerns. The CEC provides the sharing of ideas, techniques, and plans to provide for the dissemination of vital information and the resolution of selected issues and concerns.

\section{Central Environmental Committee Executive Committee}

The Central Environmental Committee Executive Committee(CECEC) facilitates the flow of information to and from the CEC, in directing the CEC's efforts in evaluating vital issues, and in presenting the CEC's recommendations. Additional information on the CEC \& CECEC is found in WSRC Procedure Manual 3Q, Procedure 19.1.

\section{Natural Resources Coordinating Committee}

The Natural Resources Coordinating Committee (NRCC) was establisied in 1991 to enhance communication and understanding among the SRS organizations concerning natural resources management. The NRCC provides a forum for discussion of onsite natural resources issues and provides technical advice to DOE and all site users in order to effectively manage the natural resources of the SRS. 


\section{Westinghouse Environmental Management Team}

The WSRC Environmental Management Team (WEMT) provides improved communication, integration, strategic planning, and management of the WSRC Environmental Programs.

\section{Westinghouse Environmental Advisory Committee}

The Environmental Advisory Committee (EAC) provides independent strategic and programmatic guidance to WSRC management on intermediate and long-range environmental issues affecting SRS.

\section{WSRC Environmental Responsibilities}

Operations at SRS involve a variety of activities affected by legal and regulatory requirements. The responsibility for environmental compliance rests with the implementing line organizations. However, the legal and regulatory compliance is accomplished through a strategy that starts with the oversight group having the responsibility for defining what must be done in order to accomplish environmental compliance and for conveying this information to the line organizations.

The Environmental Protection Department (EPD) is the WSRC oversight group for environmental compliance. As described in chapter two, when new environmental laws and regulations are identified, EPD, General Counsel and site organizations define the environmental requirements based on site initiatives and interaction with DOE-SR, DOE-HQ, regulatory agencies, and other government-owned contractor operated sites. The new environmental requirements are conveyed to line organizations through a site Environmental Compliance Manual, 3Q. This information is also communicated at the monthly CEC meetings and through other environmental networks. 
An overview of this process is illustrated in figure 19-1.

\begin{tabular}{|c|c|c|c|}
\hline Environmental Regulations & Laws & Regulations & DOE Orders \\
\hline Requirements Definition & General Counsel & - EPD - & 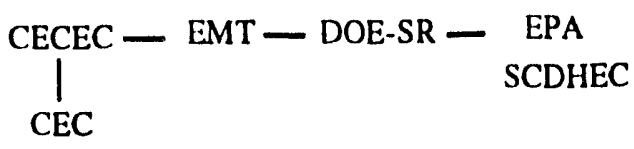 \\
\hline Process Definition & General Counsel & $\begin{array}{l}-\mathrm{EPD}- \\
\text { (3Q Procedures } \\
\text { Guidance Manuals) }\end{array}$ & $\left.\right|_{\mathrm{CEC}} ^{\mathrm{CECEC}-\mathrm{EMT}}$ \\
\hline Implementation & & $\begin{array}{c}\text { EPD } \\
\text { (Site Programs) }\end{array}$ & $\begin{array}{l}\text { CECEC } \\
\mid \\
\text { Line } \\
\text { Organizations }\end{array}$ \\
\hline Oversight & & $\overbrace{\text { (Appraisals }}^{\text {EPD }}$ & \\
\hline
\end{tabular}

Figure 19-1.

As an oversight group, EPD is responsible for coordinating the SRS environmentalappraisal/surveillance program which is designed to monitor environmental performance and to ensure that regulatory requirements are met. Other EPD responsibilities can be found in manual WSRC Q-1-1-1.

All WSRC divisions have environmental responsibilities listed in WSRC 1-01, Management Policy 4.1, WSRC Management Policy for Environmental Assurance. These responsibilities are summarized in the following paragraphs.

Westinghouse Savannah River Company Divisions/Departments are responsible for:

1. Ensuring that personnel and facilities under their control comply with established environmental requirements, including use of the appropriate WSRC Certification for Environmental Permits.

2. Establishing and maintaining accurate waste stream characterization data.

3. Incorporating waste minimization and waste control into all activities as appropriate.

4. Requesting the Environmental Protection Department to provide environmental impact analyses and National Environmental Policy Act (NEPA) review for facility modifications/projects, with oversight and reviews by General Counsel. 
5. Considering costs of final disposal and associated liabilities in the purchase of materials.

The Environmental Protection Department is responsible for:

1. Coordinating and overviewing the WSRC environmental protection program.

2. Establishing environmental standards in association with the General Counsel to ensure publication of appropriate procedures consistent with regulatory standards and this policy.

3. Implementing a system for disseminating environmental laws, regulations, and requirements.

4. Providing review, oversight, and reporting of activities in cooperation with General Counsel to ensure compliance with environmental requirements.

5. Representing the WSRC, in conjunction with General Counsel, in support of and/or on behalf of DOE in interactions with federal, state, and local agencies regarding environmental compliance and permits.

6. Coordinating efforts to anticipate, identify, and solve environmental problems, in conjunction with General Counsel, that affect WSRC-managed facilities.

7. Preparing and publishing the annual Savannah River Site Environmental Report. and all site wide federal and state environmental reports.

The Waste Management Department is responsible for:

1. Operation of site waste handling, storage, and disposal facilities.

2. Promotion and coordination of waste reduction activities for the site. This includes issuing and maintaining the Site Waste Minimization Plan.

3. Assisting each division/department in the implementation of an effective waste reduction program which complies with applicable federal and state laws, regulations, and DOE orders.

The Savannah Technology Center is responsible for:

1. Performing environmental research and development with applications to the Savannah River Site (SRS) and coordinating it with onsite and offsite organizations.

2. Performing analyses and special studies of site hydrogeology, hydrology, ecology, meteorology, and seismology in support of environmental regulatory and safety analysis requirements (permits, NEPA, compliance orders, safety analysis reports, etc.).

3. Developing and evaluating new technologies for environmental protection, restoration, and waste reduction.

4. Developing and providing emergency response technology and ultra-low-level radionuclide measurement technologies.

5. Developing the technology for monitoring releases from SRS facilities and for monitoring solid waste forms.

6. Concurring with NEPA documents, site use permits, test authorizations, etc. for their environmental implication. 
7. Developing and providing SRS environmental radionuclide and hazardous waste dosimetry transport models. Providing yearly environmental dosimetry impact of SRS operations.

The Engineering and Projects Division, in association with other divisions and where appropriate, is responsible for:

1. Performing facility design changes and projects necessary to implement nceded environmental improvements.

2. Developing and implementing all facility and equipment design modifications and projects in a manner that minimizes potential environmental impacts and complies with environmental requirements.

3. Defining and documenting waste quantity, characteristics, and disposal for all design changes/new facilities and incorporating waste minimization considerations in all designs.

4. Submitting the Environmental Evaluation Checklists to Environmental Protection Department, in conjunction with General Counsel, to identify possible enviroumental concerns.

5. Preparing environmental permit packages for submittal through the Environmental Protection Department.

General Counsel is responsible for reviewing Environmental Evaluation Checklist decisions made by the Environmental Protection Department and for consultation on all matters pertaining to environmental compliance that have legal implications. General Counsel responsibilities include:

1. Reviewing and providing interpretations of environmental laws and regulations.

2. Reviewing all applications for licenses, permits, and variances.

3. Preparing appeals from citations or other actions taken by regulatory agencies.

4. Representing Westinghouse Savannah River Company in administrative and court proceedings. 


\section{SRS Environmental Programs Responsibility Summary}

(Compiled by the Westinghouse Environmental Management Team)

Brogram

WSRC Contact:

\section{Environmental Monitoring}

J. Hetfiner

Environmental Sampling \& Analysis Program

T. DeHart

Monitoring Reports \& Notifications

Radiological Effluent Management Program

R. Lorenz

T. Jannik

Chemical Management, Pollution Prevention, and Other Compliance Programs

M. Dukes

Toxic Substance Control Act (TSCA) Program

Polychlorinated Biphenyl (PCB) Program

Federal Insecticide, Fungicide, \& Rodenticide Act (FIFRA)

Emergency Planning \& Community Right-to-Know Act (EPCRA)

Spill Prevention and Control Program

Drinking Water Program

National Environmental Policy Act (NEPA) Program

S. Glover

V. Osteen

S. Glover

S. Glover

P. Carroll

S. Smith

J. Mayer

Natural Resource Protection

\section{J. Koyes}

Land Use and Wildlife Protection:

Land Use Program

Endangered Species Program

C. Noah

Wildlife Programs

Wildlife Habitat Programs

Land Reclamation and Erosion Control Program

Cultural Resources Program

K. Dyer

K. Dyer

K. Dyer

D. Padgett

Surface Water and Wetlands Protection:

Surface Water Program

NPDES Wastewater

NPDES Stormwater Associated with Industrial Activity

K. Dyer

NPDES Stormwater Associated with Construction Activity

Erosion Control Program

Waste Water Treatment Facilities Program

Wetlands

K. Dyer

R. Weigel

J. Price

J. Price

D. Padgett

W. Payne

D. Padgett

\section{Groundwater and Hydrogeological Protection}

J. Cook

Groundwater Protection Program

Geology, Seismology, and Geotechnical (Hydrogeological Program)

P. Barnard

Groundwater Monitoring Program

L. Salomone

Water Conservation

Underground Storage Tank Program

P. Barnard

P. Barnard

R. Fanning 


\section{Waste Management and Disposal}

Waste Management and Disposal

Waste Minimization Program

Waste Handling, Treatment, \& Disposal Guidance

\section{Atmospheric Protection Programs}

Air Emissions Permitting Program

Air Emissions Inventory

Nonradioactive Emissions Management Programs

Asbestos Removal Control Program

Ozone Depleting Substances

Criteria Pollutants

Radioactive Emissions Management Program

Environmental Restoration Program

Environmental Restoration Program

\section{Employee Education}

Environment Awareness Program

Environmental Training Program

\section{J. Odum}

A. Guanlao

C. Thompson

A. Guanlao

J. Harris

c. Cook

T. Faugl

R. Wilson

R. Reynolds

C. Cook

B. Blunt

\section{J. Pope}

B. Wheat

J. Odum

P. West

P. Croll

Emergency Response, Environmental Occurrence Reporting, and Regulatory Notifications

M. Dukes

Emergency Response Program Regulatory Response Required by EPCRA, CERCLA, \& RCRA

C. Ziegler

C. Ziegler National Contingency Plan 


\title{
SRS Environmental Program Responsibility Summary Rev. 6, 2/19/93
}

\author{
Environmental Monitoring
}

Environmental Sampling and Analysis

The Environmental Monitoring Section's Sampling Group is responsible for the collection of samples in the various exposure pathways in and around SRS. These samples include such diverse media as air, water, soil, sediment, vegetation, milk, food, and wildlife. Sampling programs are balanced geographically in the vicinity of SRS, with onsite, plant perimeter, 25-mile-radius, and 100-mile-radius collection points. The sampling frequency and location of collected media is developed in the Environmental Monitoring Plan, and is determined in part by potential and historical release points and pathways. EMS also responds to nonroutine occurrences and releases with a sampling program specific to the nature. content, and pathway of the released activity.

EMS assumes responsibility for routine monitoring in the vicinity of and around the Savannah River Site. The majority of effluent and environmental measurements used to estimate annual offsite doses are made in the EMS Laboratories.

Other groups responsible for sampling programs include the Savannah River Ecology Laboratory (primarily streams, ponds, and Savannah River sampling), the Savannah River Technology Center (special studies, online effluent and environmental sampling), Health Protection Operation: (airborne and liquid effluent sampling), and the Power Department (drinking water sampling), as follows:

- Savannah River Technology Center - low-level counting, dosimetry of SRS operations, airborne and aqueous radionuclide effluent studies, activities to meet. environmental permits and other requirements, enhancement of emergency response capabilities.

- Savannah River Ecology Laboratory - independent environmental studies of SRS, surrounding streams and ponds, and the Savannah River.

- Health Protection Operations - analysis of effluent samples and maintenance of online monitoring equipment.

- Power Department - drinking water collection and analysis.

- Many radiological effluent and process samples are process by Analytical Laboratories because of their high activity levels. If measurements are below the detection limits of these labs and a numerical determination is needed, samples are frequently forwarded to EMS or SRTC for further counting.

\section{Monitoring Reports and Notifications}

EMS is responsible for compiling the Environmental Report, the Annual and Monthly Radioactive Release Reports, and the Effluent Information System and Onsite Discharge Inı: mation System EIS/ODIS repozi. Other reports, including a quarterly 
Drinking Water Report sent to water treatment plants and a Nonradiological Water Quality Report. are distributed to interested personnel. Special sampling surveys and unusual occurrences are also the subject of EMS monitering reports.

EPD has lead responsibility for notification of environmental occurrences at the SRS to appropriate officials. The EPD also has responsibility to ensure reporting requirements to EPA, DOE, and ther regulatory agencies are met within required time periods. Among others, thes reports include the Annual Compliance Report as part of the NESHAP program (40 CFR 61, Subpart H), and the Liquid Discharge Monitoring Report per the Clean Water Act.

\section{Radiological Effluent Management}

The various organizations and their responsibilities in Radiological Effluent Management are outlined in the WSRC-3Q procedure, "Radiological Effluent Monitoring, Reporting and ALARA Release Guides" (ECM 18.2). Organizations assuming program responsibility include WSRC Stnior Management, EMS, the Environmenta! Protection Department, Operating Departments/Facility-Line Management. Health Protection Operations, and the Environmental Technology Section of the Savannah River Technology Center. 


\section{Chemical Management, Pollution Prevention, and Other Compliance Programs}

\section{Toxic Substance Control Act (TSCA) Program}

The Environmental Protection Department EPD provides general site guidance for TSCA compliance. EPD's TSCA Coordinator is responsible for providing appropriate forms and submitting documentation for premanufacturing notification. The Industrial Hygiene Section coordinates the process of recording allegations that a chemical substance presents a substantial risk of injury to human health or the environment. EPD and the Medical department have responsibility for reviewing allegations and determining if they are significant and not a generally known risk to human health or the environment. Allegations are submitted to Corporate Westinghouse and may be reported to EPA if the corporate office determines the information reasonably supports the conclusion that a chemical substance presents a substantial risk and should be reported under Section 8(e).

\section{TSCA: Premanufacturing Notification Program (PMN)}

Any employee, group or department intending to manufacture or import a new chemical substance that is not excluded by an exemption and is for a "commercial purpose" must submit a PMN notice to the SRS TSCA Site Coordinator, EPD. The TSCA Site Coordinator will provide the appropriate EPA forms (to meet PMN compliance).

\section{Polychlorinated Biphenyl (PCB) Program}

EPD coordinates PCB activities for the site and consults with the operating and service organizations on $\mathrm{PCB}$ related issues. EPD prepares the annual PCB Inventory Report and interfaces with regulatory agencies on PCB matters. EPD consults with a PCB task force as part of a continuing effort to sample/analyze selected transformers onsite and re-verify that they contain no PCBs.

The Administrative Services Division, Materials Logistics and Inventory is responsible for: maintaining storage facilities in compliance with regulatory requirements; maintaining storage, inventory, and inspection records for the facility; ensuring proper packaging and labeling of PCB-containing material in the facility; obtaining a contract for offsite disposal of PCBs; and ensuring PCBs are shipped offsite within the time limitations set by regulations.

Waste Management Operations is responsible for: maintaining the storage facilities at Building 643-29E in compliance with regulatory requirements; maintaining storage, inventory and inspection records for Building 643-29E; and ensuring proper packaging and labeling of PCB-containing material in Building 643-29E.

Operating and service organizations are responsible for: determining, by coordinating a Health Protection (HP) survey, if the potential for occupational exposure to PCBs exists; instituting a program of personal monitoring to determine potential exposures if 
PCBs are in the area; notifying the HP Department and the EPD Site Environmental Protection Coordinator (SEPC) in the event of a spill; notifying area HP inspectors when working on PCB-containing equipment; identifying any PCB-containing materials in the area; ensuring proper labeling of PCB-containing materials; transporting $\mathrm{PCB}$-containing materials to the proper storage facilities; and ensuring that employees are trained in handling of PCBs and that training is documented.

\section{Federal Insecticide, Fungicide, and Rodenticide Act (FIFRA) Program}

The Pesticide Use Task Group (PUTG) is responsible for the analysis and standardization of current and new pesticide programs at SRS. The group responds to questions and communications concerning pesticide use at SRS and prepares statistical reports or responses concerning pesticide activities. The PUTG includes the EPD Pesticide Coordinator as Chairman, CSWE Pesticide Activity Supervisor, and a Health Protection Industrial Hygienist. Other members represent SRFS, SREL, SRTC, and DOE. This task group reports to the Natural Resources Coordinating Committee.

Prior to initiating a pesticide program the Program Originator, a representative of an SRS Department that needs a pesticide application, is responsible for preparing a formal written program plan for review and approval by the Pesticide Use Task Group.

The SRFS administers a separate SRS pesticide program including purchase, storage, issue, and applicatic::

\section{Emergency Planning and Community Right-to-Know Act (EPCRA) Program}

WSRC has general site wide responsibility for coordinating compliance activities under EPCRA. DOE SR is the point of contact with respect to emergency planning. Due to overlapping requirements with the OSHA Hazard Communication Standard, the Industrial Hygiene Section has responsibilities for Material Safety Data Sheet (MSDS) maintenance and sitewide inventory reporting per Section 312 Hazardous Chemical Reporting.

Section 313 Toxic Chemical Release Inventory Reporting, requires facilities to provide input to the annual report on toxic chemical releases to the State Emergency Response Commission and EPA. EPD is responsible for coordinating and submitting data generated by the various SRS organizations.

\section{Spill Prevention and Control Program}

Each SRS facility custodian is responsible for developing Best Management Practice (BMP)/Spill Prevention Control and Countermeasures (SPCC) plans for their area. They are also responsible for implementing the requirements of the BMP/ SPCC plans. Facility Custodians are responsible For containing spills in their respective areas. The Fire Department is responsible for spill cleanup in the general plant site. 
The EPD designated Site Emergency Protection Coordinator (SEPC) is responsible for site environmental protection advice concerning containment. mitigation, and cleanup of spills. The SEPC must concur with spill classification. The SEPC also notifies DOE and required outside regulatory authorities (SCDHEC, EPA, National Response Center, etc.). The SRS Fire Department and CSWE Response Teams have the responsibility to provide assistance for spill control and cleanup 24 hours a day as needed. The spill team leaders have the responsibility of maintaining trained units while drawing on the Safety Department and EPD for technical expertise.

Construction Management has resources and equipment to assist in spill cleanup. SRTC has an aqueous model to assist in determining the consequences of a spill at the SRS.

\section{Drinking Water Program}

Power Operations is responsible for all Drinking Water Facilities except for the DWPF facility, which is operated by DWPF. Power Operations and DWPF have supervisors and operators that are certified by the South Carolina Environmental Certification Board to operate domestic water facilities. EPD coordinates the sitewide program for operator certification. ESH\&QA Training is responsible for coordinating the training of certified operators. The EPD evaluates regulatory requirements and compliance issues, reviews projects, assists with facility permitting and provides assistance with regulatory agency facility audits and reporting. Site Services Engineering prepares a monthly Self-Monitoring Report which is submitted to the SCDHEC through EPD.

\section{National Environmental Policy Act (NEPA) Program}

EPD prepares and/or manages all appropriate NEPA documentation and recommendations, except EISs for transmittal to the DOE. A DOE contractor prepares EISs and provides other technical support for NEPA activities. EPD coordinates all SRS organization activities related to NEPA documentation for specific activities and train WSRC and other site organizations in the implementation of the NEPA process at SRS.

All organizations at SRS are required to complete an Environmental Evaluation Checklist (EEC) before any project is initiated. The project sponsor or EEC preparer is responsible for properly completing the checklist and providing any additional or follow-up information regarding the proposed action during the completion of the NEPA review and documentation process.

The Department NEPA Coordinators are responsible to ensuring implementation of NEPA provisions within their respective organizations. NEPA coordinators have been designated by all operating organizations and they have been trained. 


\section{Natural Resource Protection}

\section{Natural Resource Coordinating Committee (NRCC)}

The Natural Resources Coordinating Committee (NRCC) is a site-wide committee chaired by DOE-SR with membership made up of contractors on site. NRCC was established in 1991 to enhance communication and understanding among the SRS organizations concerning natural resources management. The NRCC provides a forum for discussion of onsite natural resources issues and provides technical advice to DOE and all site users in order to effectively manage the natural resources of the SRS.

\section{Land Use and Wildlife Protection}

\section{Land Use Program}

Land use management is administered by the DOE-SR and the onsite contractors including WSRC. The DOE-SR Site Use Coordination System governs the approval of land use not previously approved. Site contractors have land use management responsibilities in the approved areas under the guidelines established in the initial land use approval. WSRC custodial departments manage land use within the boundaries of the production areas and in cleared areas associated with various rights of way.

Natural resource management activities (e.g., forestry management) are conducted principally by the SRFS under an interagency agreement with DOE. SRS Natural Resources Management Plan (NRMP) approved for site use on February 15, 1991.

WSRC is responsible for a Land Use Planning Program, directed by an environmental land use coordinator in the Planning Support and Analysis Department. The Land Use Planning Program has two major responsibilities:

1. To develop a process to make Site decisions regarding zoning related issues and,

2. To identify and designate potential future SRS uses. The Coordinator reports to a high-level management steering committee and is supported by a technical committee comprised of mid-level managers from various site departments.

E\&PD supports the environmental land use coordinator by providing mapping services and land use data. E\&PD administers the site clearance and site use permit systems which approves and tracks all current and proposed SRS uses.

CSWE provides support to the Land and Timber Management Programs.

The Forest Manager, SRFS, is charged with managing the SRS Boundary Management Program and with management of the SRS secondary road program. Soil classification and mapping of the SRS was completed by the Soil Conservation Service (SCS). SCS and SRFS provide erosion and sedimentation control planning and services. 


\section{Endangered Species Program}

The SRFS administers the threatened and endangered species program at SRS as directed by the NRMP.

All organizations at SRS are required to complete an Environmental Evaluation Checklist (EEC) before any project is initiated. If an endangered species might be impacted, DOE-SR initiates contact with the Regional Field Station of the Fish \& Wildlife Service (FWS). If there is a potential for affecting endangered marine species, the regional office of the National Marine Fisheries Service (NMFS) is also contacted.

If an endangered species could potentially be affected, the DOE-SR will supervise the iniormation-gathering necessary for a biological assessment of the impact on the species.

Wildlife Programs

The Safeguards and Security Department, with support from the EPD. and CSWE, manages public hunts for deer and feral hogs at the SRS. Nuisance beaver are controlled under a contract with a local vendor that is funded, as necessary, by the SRFS and EMS, and administered by EPD with assistance from the SRFS. CSWE alerts SRFS to beaver and feral hog activity. SRTC, SREL, and Southeastern Forest Experiment Station of the U. S. Forest Service (SEFES) conduct environmental research as requested.

The Forest Manager, SRFS, is charged with planning and directing a fish and wildlife management program that includes all habitat and animal survey and manipulation activities including threatened, endangered and sensitive species under the administrative responsibility of the Environmental Division of DOE-SR.

\section{Wildlife Habitat Programs}

The major organizations conducting environmental research on the site are SRTC, SREL, and Southeastern Forest Experiment Station of the U. S. Forest Service (SEFES). The programs conducted by these organizations provide information essential to achieving environmental goals and for evaluating the effects of operating nuclear production facilities. The SRFS is responsible for forest management. Potential impacts on wildlife habitat from proposed new activities are identified in the planning stage by activity/sponsor. Potential impacts are assessed in a NEPA review and in a Site Use Permit review and mitigated as needed.

\section{Land Reclamation and Erosion Control Program}

The Forest Manager, SRFS, has the responsibility for planning and directing the soil resource program which deals with the non-point source impacts from natural resource management activities. The Soil Conservation Service (SCS) working jointly with the SRFS will provide onsite expert consultation and technical advice to the SRFS and other SRS contractors on specific problems related to the conservation of the SRS soil resource. The SRFS and SCS work will be under the administrative responsibility of 
the Environmental Division of DOE-SR. All new permitting activities are requested through EPD.

The SRFS Forest Manager is responsible for the water and air resource program which deals with the non-point source impacts from natural resource management activities. Program responsibilities include developing forest management activities which protect ground and surface waters and the air resource, and providing recommendations to WSRC and other site users, as directed by DOE, concerning impacts on water and air from nonforest operations.

Erosion control measures are the responsibility of Construction for construction projects, custodial departments for fenced areas, and CSWE for all areas outside the fences which are not controlled by other onsite contractors.

\section{Cultural Resources}

The cultural resources program is managed by the Savannah River Archaeological Research Program (SRARP) under the direction of DOE-SR. Cultural resources are managed under the terms of a Programmatic Memorandum of Agreement among DOE-SR, the South Carolina State Historic Preservation Officer, and the Advisory Council on Historic Preservation. SRARP is a coordinating land user and is thereby informed of potential land-disturbing activities. SRFS, EPD and E\&PD coordinate with SRARP for archaeological surveys of project areas. 


\title{
Surface Water and Wetland Protection
}

\author{
Surface Water Program
}

The Environmental Protection Department (EPD) is the lead organization for regulatory activities associated with surface waters, including thermal mitigation, and serves as the interface between other WSRC organizations and South Carolina Department of Health and Environmental Control (SCDHEC). National Pollutant Discharge Elimination System (NPDES) permits for new or modified discharges are prepared by the operating organizations with assistance from EPD, and submitted to regulatory agencies by EPD.

Routine monitoring of radiological and non-radiological constituents in surface waters is performed by EPD; most non-routine radiological, non-radiological, and biological sampling is performed by the Savannah River Technology Center (SRTC). Transport and predictions of impacts (radiological, non-radiological, biological) to surface waters are performed by SRTC. SRTC coordinates with Savannah River Ecology Laboratory (SREL), Savannah River Forest Service (SRFS), and Soil Conservation Service (SCS) as necessary to resolve surface water issues. SRTC is responsible for technical support of water quality and biotoxicity. The Aquatic Issues Task Group, chaired by SRTC, provides sitewide coordination and guidance on surface water issues. This committee reports to the Natural Resources Coordinating Committee (NRCC).

NPDES Wastewater

The NPDES permit is administered on a sitewide basis by Environmental Protection Department (EPD) Environmental Support Section (ESS). NPDES permits for new or modified discharges are prepared by the operating organizations with assistance from EPD, and submitted to regulatory agencies by EPD. The EPD provides support for permit application, modifications, and compliance. EPD and Power Operations are responsible for scheduling compliance sampling of outfalls as required by NPDES permits.

Operating organizations are responsible for minimizing and assessing their operational impacts on surface water and providing data for special studies. Each outfall has an assigned custodian who is responsible for ensuring that the outfall meets NPDES permit parameters. Outfall custodians are responsible for supplying the EPD with information needed for permitting support. The custodian conducts process control sampling and analysis.

\section{NPDES Stormwater Associated with Industrial Activity}

The NPDES stormwater Industrial General Permit is administered on a sitewide basis by EPD. EPD will provide guidance for stormwater discharges where Best Management Practices (BMPs) and/or Best Available Technology (BATs) are deemed necessary to meet water quality standards. BSRI Design Engineering will develop industrial facility specific Pollution Prevention Plans (PPPs). It is the facility 
custodian's responsibility to supply BSRI Design Engineering with all information requested for developing the PPP, ensuring its accuracy and the implementation of the plan. EPD will monitor the selected outfalls as required in the General Permit. Facility Custodians shall maintain the outfall for collection of representative samples, access to the outfall and safe sampling locations. Once monitoring data is accumulated, EPD will supply the data to facility custodians for the implementation of BMPs and/or BATs where necessary. EPD shall submit Discharge Monitoring Reports as required by the permit.

\section{NPDES Stormwater Associated with Construction Activity}

The NPDES stormwater Construction General Permit is administered on a sitewide basis by the EPD. Each outfall is the responsibility of one organization and is assigned to one individual. The facility custodian is responsible to ensure that PPPs are developed for land disturbances to mitigate/prevent erosion and sediment discharges. The facility custodian must submit a Notice of Intent (NOI) to EPD at least 30 working days prior to work start. EPD shall submit the NOI to SCDHEC. The facility custodian will ensure that all terms and conditions of the PPP and General Permit are carried out.

\section{Erosion Control Program}

Each Savannah River Site (SRS) area or facility custodian is responsible for controlling or minimizin' soil erusici. caused by stormwater runoff or heavy construction. The immediate reporting to SRFS of significant erosion in the contiguous vicinity of the area or facility is the responsibility of the facility custodian.

The SRFS conducts an annual road condition survey of all general use and secondary roads in addition to powerline and roads used in timber sales. The SRFS manages the construction of new secondary roads along with the maintenance of existing ones. Equipment, manpower, and materials to accomplish these tasks are provided by WSRC/CSWE. The SRFS prepares maintenance lists for road repairs or new roads for timber wood sales.

SRTC assists in developing long-term studies for addressing erosion control at the site. SRTC makes special studies on stream sediment transport to support stream/river transport model development, because many pollutants are transported by sediment particles.

Any erosion of the banks of the Savannah River that threatens SRS facilities, such as the river pump houses, is referred to the site office of the U.S. Army Corps of Engineers (COE) for site-specific action by the Charleston District CEO.

Sponsors for projects involving land disturbances of $1 / 2$ acre or more (includes $1 / 2$ acre or less if the slope is greater than $2 \%$ ) must have an approved erosion control plan before any earth disturbing activities began. If the project involves an area 2 acres or greater then the plan must also be submitted to SCLRCC for approval. 
EPD provides guidance to operating organizations in the development of sedimentation control plans.

\section{Waste Water Treatment Facilities Program}

Custodians of permitted wastewater treatment facilities are required to meet the permit limits for facility effluents and to operate the facilities in accordance with all NPDES permit conditions and State and Federal regulations. Each custodian of a permitted treatment facility (excluding oil/water separators and septic/drain fields) is required to have trained and licensed operators. Building custodians and project engineers are required to determine, in advance, the impact a large influx of operating or construction personnel would have on the local sanitary treatment system, and communicate with the Environmental Protection and Power Departments regarding such activity.

EPD helps custodians apply for permits and permit modifications, and provides guidance regarding general compliance and operational issues related to wastewater treatment and disposal. EPD facilitates the exchange of information between the regulatory groups and the SRS operating groups. EPD coordinates environmental surveillance of all Waste Water Treatment Plants (WWTPS) to ensure compliance with permits \& regulations. EPD is the sole contact with all regulatory authorities for all wastewater treatment activities.

Wetlands Program

EPD is the lead organization for wetlands regulatory activities and serves as the interface between other WSRC organizations and the U. S. Corps of Engineers (USCOE) on regulatory/compliance issues. EPD has administrative oversight responsibility for the Wetlands Protection Program. SRTC performs wetland evaluations and is the lead organization in WSRC for wetland mitigation/remediation activities. ER characterizes wetland impacts as part of the RFI/RI program. Operating organizations are responsible for ensuring their activities do not adversely impact wetlands and documenting this approach by completing the Environmental Evaluation Checklist. The Wetland Steering Committee, chaired by EPD, provides sitewide coordination and guidance for wetland issues and reports to the NRCC. EPD assists operating organizations in preparing a USCOE 404 Permit, prior to any dredging or filling of navigable streams or wetlands. 


\section{Groundwater Protection and Hydrogeological Program}

\section{Groundwater Protection Program}

Custodians of facilities that have affected or are likely to affect groundwater are responsible for assessment of the groundwater impact. This includes a significant effort to describe the site hydrogeology. These projects are performed by the ESS, EPD, EMS, custodial staff, and consultants. The primary custodian role lies with the Environmental Restoration Department (ERD).

EPD is responsible for coordinating all activities relating to the SRS groundwater protection program. The group coordinates the regulatory and reporting aspects of groundwater consumption, preservation, remediation, and contaminant monitoring activities. The group monitors the status of all ongoing groundwater projects, and maintains comprehensive documentation of project activities. Drilling and aquifer test projects require approval from the Manager of the EPD Environmental Restoration \& Groundwater Protection (ERGO). The Manager of the EPD ERGO interacts with all custodial departments and environmental coordinators, and works with or is a member of groundwater related task forces.

EPD reviews groundwater consumption activities to determine if site policies, objectives, and commitments are being met. EPD is responsible for coordinating all reporting activities relating to SRS groundwater consumption, e.g., EPD compiles and reports sitewide water use data. EPD supports custodial efforts with regulatory expertise.

\section{Geology, Seismology, and Geotechnical (Hydrogeological Program)}

All activities in the fields of geology, seismology and geotechnology at WSRC are integrated under the Site Chief Geotechnical Engineer who reports to the Site Chief Engineer (E\&PD). WSRC Operating Divisions (SSD, NMPD, WM\&ER, and RRD) have ultimate responsibility for accomplishing their assigned missions and will provide E\&PD, SRTC and ESH\&QA with clear and concise technical support requirements.

A Memorandum of Understanding was signed October 30, 1992 which describes the responsibilities.

ESH\&QA will provide environmental, safety, health and quality assurance support to all SRS organizations consistent with site policies. ESH\&QA will administer the sitewide drilling contract except for production well drilling. Construction Management's soil borings performed during foundation studies, road building, trenching, and other construction activities often provide useful hydrogeological information, such as the depth to water table. Piezometers and dewatering wells are often installed as part of the construction of large buildings. 
ESH\&QA will conduct groundwater and soil sampling and laboratory analyses for regulatory oversight programs and when requested by well custodians. EMS hydrologists and geologists administer subcontracts for geophysical logging, monitor well drilling, pump and aquifer tests, and coring projects. Technical staff help characterize site aquifers and assist in interpretation of groundwater flow directions. This organization if also responsible for research related to groundwater sampling and analysis. ESH\&QA will also provide the regulatory oversight, regulatory interpretation and guidance, and interface with the regulators for environmental protection activities. In its oversight role, the EPD may suggest projects to the SRTC or custodians, fund special studies, prepare policy and guidance statements, such as a water resource management plan, request acquisition of particular data, or conduct research of sitewide regulatory significance.

SRTC will conduct site-wide/regional hydrology, geology and seismology programs and technology development. SRTC will perform Geology, Seismology, Geotechnological (GSG) integrated technology demonstrations, perform groundwater model analysis and groundwater model code development and approve groundwater codes. SRTC will develop the GSG/Geographic Information System (GIS) data architecture as specified by the Chief Geotechnical Engineer. SRTC will determine SRS seismic hazards, perform seismology analyses, faulting investigations and maintain the seismic monitoring network. SRTC will perform risk analyses with guidance from ESH\&QA and WM\&ER to support environmental assessments.

E\&PD will define and interpret engineering codes, standards and practices for all GSG activities, manage a comprchensive GSG/GIS data base, and perform groundwater modeling with SRTC approved codes. E\&PD will provide field oversight of geotechnical, drilling and soil/foundation/remediation construction activities. E\&PD will perform GSG studies necessary to support construction/facility activities including geotechnical characterization, soil mechanics studies, static and dynamic foundation analysis, embankment and dam stability analyses, and provide geotechnical pre-conceptual studies.

E\&PD and SRTC will review geological, seismological and geotechnical reports before incorporation into regulatory documents or before such information is released as reports to the public. The Site Geotechnical Engineer will represent, or concur with representation of WSRC on all GSG matters in meetings and presentation with the DOE, the public, oversight boards and regulators.

\section{Groundwater Monitoring Program}

Operating organizations proposing hydrogeological related efforts must complete and submit to EPD a general program plan for hydrogeologic work at the SRS. Prior to commencing the project the EPD must approve the plan along with SRTC. The EPD is responsible for coordinating all activities relating to the quantity and quality of groundwater, including program completeness, consistency, uniformity, and progress, and for reviewing data and reports prior to transmittal to the regulatory agencies. 
Groundwater projects are carried out by the department with custodial responsibility for the geographical area where the project will occur. Most well drilling, soil boring and monitoring activities are centralized in EPD. The custodians are responsible for budgeting and planning groundwater projects, managing the projects, conducting data evaluation and preparing reports. EPD and SRTC support organizations that do have the expertise to conduct data evaluation and prepare reports. EPD administers most of the well drilling contracts. SRTC has an independent drilling program.

EPD is responsible for administering subcontracts for groundwater well drilling, sampling, and analysis. EPD assures that quality assurance and quality control requirements for sampling and analytical programs are met. Analytical results are transmitted directly to the appropriate custodian or through the EPD. The EPD maintains a computerized data base containing well construction records, well logs, cores, and analytical data.

EPD has established an extensive and comprehensive Groundwater Monitoring Program (GMP). The purpose of the GMP is to determine if any SRS facilities have influenced groundwater quality, and if they have, to quantify the influence. Facilities monitored include waste disposal sites, spill sites, chemical storage areas, process sewers, and certain process buildings.

Site Services Engineering is responsible for coordinating process and domestic water well construction, maintenance and abandonment activities.

ER is responsible for the Contaminated Groundwater Management Plan.

Water Conservation

Custodial departments have personnel responsible for reviewing their water use activities to ensure responsible use of water resources and to compile data for the quarterly Water Use Report submitted to the South Carolina Water Resource Commission. The personnel are also responsible for submitting appropriate water conservation information as required to the EPD.

The EPD is responsible for the technical and regulatory review of all activities affecting groundwater and site geology. The EPD provides the lead support for initiation of water conservation programs. The EPD will conduct periodic surveys of water use activities and provide recommendations for specific conservation programs. Additionally, the EPD will address water conservation in conjunction with related environmental audits and assessments in which they participate.

\section{Underground Storage Tank Program}

The Underground Storage Tank Committee is responsible for the SRS SMARTS (Specifications and Management Applications for Regulated Tank Systems) Program, WSRC-IM-90-90. 
EPD is responsible for communicating applicable hazardous waste and underground storage tank regulation requirements to the operating organizations. EPD is also the interface with the DOE and SCDHEC, including permit transmittals.

The operating organizations are responsible for identifying the new tank systems required to meet the facility needs and for acquiring the funding for tank design, construction, and installation. The custodian is responsible for providing the information required for the applicable permits. The custodians are responsible for the proper operation of the underground tanks. The custodians are also responsible for the development and imf'ementation of the regulatory required inventory systems. It is the responsibility of the operating organizations to determine which tanks need to be replaced or upgraded and to acquire the funding necessary to meet the requirements of the applicable regulations. All operating organizations are required to inventory and maintain records on all underground storage tanks containing hazardous materials, petroleum products, or hazardous waste. 


\section{Waste Management and Disposal}

\section{Waste Management and Disposal Program}

Waste Management has the primary responsibility for: selecting, constructing and operating waste disposal facilities with the exception of DWPF facilities. These activities must comply with applicable laws and regulations for the protection of the public, environment, and site workers and with applicable DOE orders and contractual provisions overseeing the quality assurance and control program (i.e., waste certification program) applicable to the Waste Management treatment, storage, or disposal (TSD) facility waste acceptance criteria. Waste Management is also responsible for off-site shipping of wastes.

Construction Management (CM) operates a SCDHEC-permitted landfill for construction and Cellulosic waste at Burma Road. In addition, CM operates a burn pit for SRS at Central Shops (N-Area).

The EPD is responsible for coordinating and organizing the permitting for the waste disposal facilities. The EPD is also responsible for reporting the status of waste disposal compliance to the DOE and SCDHEC.

The Custodial Departments are responsible for proper identification and packaging of wastes according to regulatory, DOE and Department of Transportation (DOT) requirements if applicable. Implementation of quality control and quality assurance functions is also part of the custodial responsibilities to provide assurance that the waste acceptance criteria for a TSD facility used by a generator are met.

The SRTC is responsible for research and development (R\&D) in support of waste characterization, treatment, storage, and disposal.

\section{Waste Minimization Program}

The Site has established a structure to ef.ectively support and implement waste reduction programs. WSRC has appointed the Vice President of Waste Management and Environmental Restoration as the senior management sponsor of the program to ensure that waste reduction receives proper management attention. A staff in Waste Management has been assigned responsibility for coordinating the development, promotion, implementation, and reporting of the Waste Minimization Program and activities. A central Waste Action Team with representatives from the major operations, service, and staff groups has been established to develop strategies for and coordinate implementation with waste minimization program activities. Each of the major facilities has assigned one or more waste coordinators to lead the implementation of waste reduction activities in their specific areas. Construction Management and Materials Logistics and Inventory supports this program.

The WSRC Waste Certification and Minimization (WCAM) Organization is responsible for the development of the overall waste minimization program. Specific responsibilities are to establish site waste minimization policy through the appropriate 
site managers, develop, issue, and update as necessary (annually as a minimum), the Site Waste Minimization Plan (SWMP), coordinate the development of site waste reduction goals, obtain management support for waste reduction activities and coordinate waste minimization/waste reduction/pollution prevention with DOE, including audits and award-fee activities.

Typical managerial responsibilities are to develop waste reduction goals and milestones and track progress.

Facility specific waste minimization plans shall be developed by each waste generating organization to address the strategy and program implementation to minimize waste.

Responsibilities of the Waste Action Team are to review and concur with Site Waste Minimization Plan and program objectives, develop site implementation strategies, coordinate and promote site waste minimization programs, promote employee awareness programs, promote employee training, identify opportunities for waste reduction including research program opportunities and facilitate technology and program information transfer.

EPD will provide regulatory review and program oversight, coordinate, prepare and submit of ficial reports due to regulatory agencies such as EPA and SCDHEC, interpret regulatory requirement and communicate necessary actions to SRS personnel and coordinate specific waste minimization projects as determined via the Waste Action Team.

SRTC will provide the necessary research and development support to departments on such topics as process modifications, product/material substitutions, and recycling technologies.

\section{Waste Handling, Treatment and Disposal Guidance}

Waste generator is a person in charge or a custodian of a facility whose activity or operation that produces a waste material, is responsible to characterize, manage, or dispose of according to EPA/SCDHEC environmental regulations.

SRTC provides research and developmental support for SRS waste processes, treatment and disposals. It also provide analytical support to plant personnel concerning radiometric screening of waste samples or materials prior to offsite shipments.

Waste Management coordinates offsite shipment of hazardous wastes for treatment and disposal. Operates and maintains hazardous and radioactive mixed waste storage facilities. Hazardous Material Transportation Coordinator provides regulatory guidance to plant personnel relative to DOT issues. Approves waste or material packaging, marking, labeling of containers, and placarding of vehicles prior to releasing an offsite shipment. Health Protection provides physical radiometric screening of packages or containers of samples or wastes prior to offsite shipments. 
EPD provides technical and regulatory support to plant personnel relative to environmental issues or regulations and guidance on waste handling, treatment, or disposal. EPD reviews and approves hazardous waste manifests and Land Disposal Restrictions (LDR) notifications or certifications forms for hazardous waste shipments. 


\section{Atmospheric Protection Programs}

\section{Air Emissions Permitting Program}

EPD is responsible for administrative oversight of air permitting. The EPD monitors site performance required by permits, assists custodians in preparing permit applications, transmits permit applications and regulatory reports to the SCDHEC, and is the operating contractor contact with the SCDHEC. EPD provides permiting support to custodial departments as needed.

Each facility custodian is responsible for completing an Environmental Evaluation Checklist and preparing required permit applications prior to any construction or facility modification. The custodians are responsible for ensuring that facilities are constructed and operated in accordance with permit requirements.

Custodial departments are responsible for submitting to the EPD information required for permit renewal or modification.

SRTC is responsible for conducting air modeling that may be required to support permit applications.

\section{Air Emissions Inventory}

The Savannah River Site (SRS) Air Emissions Inventory Program is conducted to maintain comprehensive inventory of radiological and non-radiological emission data.

EPD will be responsible for access authorization to the data base. Operations access will be limited to end user reporting tools.

Facilities and Services/Site Permitting Section will be responsible for maintaining the site mapping, and addressing building coordinate and shape/size issues developed during the data collection portion of the AEI.

Operating Organizations will be issued an Air Inventory Reporting System (AIRS) Users Guide and trained on the reporting tools available. Operating departments may desire to access the CADD portion of the AIRS system, if so, that department will be responsible for procuring a work station and the necessary training.

Information Systems Engineering will perform the requested enhancements to the AIRS data base and publish updates to the AIRS Users Guide reflecting changes made. 


\section{Nonradioactive Emissions Management Programs}

\section{Asbestos Removal Control Program}

Environmental Protection Department (EPD) is the organization responsible for environmental regulatory compliance concerning asbestos oversight for WSRC and serves as the interface between other WSRC organizations and SCDHEC. The EPD asbestos coordinator for WSRC is responsible for all interactions between WSRC and the Regulators (SCDHEC, EP A, and OSHA), pertaining to asbestos abatement project schedules at the SRS. Large NESHAP size projects are reported to SCDHEC on a project-by-project basis. Minor/small projects which involve less than 160 square feet or 260 linear feet are reported on a quarterly basis.

The EPD asbestos coordinator oversecs miedical records to ensure asbestos workers are medically fit for the job, maintains records on respirator fit tests, issues permits to perform asbestos abatement projects, coordinates training for supervisors and workers pertaining to asbestos, and maintains certification records.

The EPD asbestos coordinator issues permits for BSRI Construction Management and all WSRC organizations. BSRI Construction Management conducts large NESHAP size asbestos abatement projects and some smaller projects. WSRC operating personnel conduct minor/small abatement projects. The WSRC Medical Department oversees the medical records and Industrial Hygiene is responsible for all air sampling and clearance monitoriug.

The Industrial Hygiene Section monitors asbestos levels according to DPSOL 40-5-102 during all building renovations or demolitions involving asbestos and is responsible for OSHA compliance.

\section{Ozone Depleting Substances (ODS)}

Custodial departments are responsible for controlling ODS air emissions and for capturing \& recycling ODS before servicing or discarding ODS-containing refrigeration or fire-suppression equipment.

\section{Criteria Pollutants}

Operating departments are responsible for controlling air emissions from their facilities. Facilities must be operated such that all permit conditions are met. Programmatic regulatory support is provided by the EPD to achieve current and future regulatory requirements.

EPD has initiated an air emissions inventory program to identify and characterize all point and fugitive emission sources at the SRS.

SRTC is responsible for special studies and predictive air assessments. 


\section{Radioactive Emissions Management Program}

Operating departments are responsible for the radioactive air emissions from their facilities. Facilities must be operated to maintain radioactive emissions based on the ALARA principle and meet applicable Radiological Release Guides. Organizations such as Reactor Materials, Reactors and Separations set guides for their operating areas based on planned improvements, past performance and projected production rates. Site guides are set annually by a committee of operating representatives and EMS. Since radionuclide NESHAPS defines the entire SRS as a facility, the Environmental Support Section (ESS) monitors compliance with radionuclide NESHAP and prepares the annual NESHAP Report. ESS also monitors the progress of compliance with the NESHAPS Federal Facility Compliance Agreement (FFCA) and prepares monthly reports required by the FFCA.

EPD has initiated an air emissions inventory program to identify and characterize all point and fugitive emissions sources at the SRS, which includes both radioactive and nonradioactive emissions.

Annual site release guides for radionuclides are authorized by the Vice President, Environmental, Safety, Health and Quality Assurance (ESH\&QA) based on recommendations by the Site Release Practices ALARA Guides, and Monitoring Committee.

A Reactors ad hoc committee develops annual ALARA release guides based on production rates, production subcycles and fuel cycles.

The Separations Environmental Coordinator chairs the 200-Area release guide committee which develops annual radioactive release guides based on production rates, irradiation time and age of targets or fuel elements processed, and past experiences.

\section{Air Assessments Program}

The site maintains an extensive network of air monitoring stations to determine the concentrations of radioactive particles and gases in the air. SRTC conducts specific studies to characterize radioactive and non-radioactive particulate emissions and radioactive gases released to the atmosphere.

Environmental gamma radiation exposures from background scurces are also monitored to determine background radiation levels, seasonal variability and longterm trends.

EPD is responsible for preparing the annual SRS Environmental Report required by DOE Orders $5480.12,5484.1$ and 5400.1 for release to the public. The report, which covers all environmental media, is issued annually. The report describes the SRS environmental monitoring program, and reports and analyzes the data collected for the subject year. Air assessments of radionuclides are an integral part of this report. 
A system of nine onsite and one offsite instrumented towers to collect real-time meteorological data are operated by SRTC. SRTC conducts studies to assess air quality impacts of SRS operations and to understand pollutant transport and atmospheric dispersion. 


\section{Environmental Restoration Program}

\section{Environmental Restoration Program}

The Environmental Restoration (ER) Department is responsible for all aspects of assessment and cleanup of sites and facilities that are no longer a part of active operations but are contaminated with various quantities of hazardous, radioactive, or mixed waste materials. ER is responsible for remediation of contaminated groundwater and also for inactive waste sites which contain nonhazardous and nonradioactive material. ER performs two sets of activities: Remedial Actions and Decontamination and Decommissioning (D\&D). The Remedial Action tasks encompass (1) site characterization, analysis of cleanup alternatives, and selection of remedy; (2) cleanup and site closure; and (3) site compliance monitoring. D\&D is concerned with the safe caretaking of inactive nuclear and non-nuclear facilities, and either their decontamination or their complete dismantling and removal.

Subsurface environmental research at the SRS is primarily conducted by SRTC. EPD is the contact with the regulators in this Program area.

The Planning Integration Department has responsibility to oversee the coordination of transition planning with site mission, land use, and long-term plans. ER is responsible to provide the management expertise for transitional facilities which includes surveying \& maintaining surplus facilities awaiting disposition and program management for deactivation \& characterization. 


\section{Employee Education}

\section{Environment Awareness Program}

EPD is responsible for developing the site environmental awareness program.

Employee awareness and training activities to support the Waste Minimization Program are developed by the operating organizations.

EPD provides leadership and resources to support the activities of the Waste Action Team.

EPD coordinates Earth Day activities and Public Relations provides support.

Public Relations is responsible for public meetings, hearings, and press releases.

ESH\&QA Division Training provides documented, formal awareness training courses.

\section{Environmental Training Program}

Employee training is a responsibility of line management. Line management ensures that training is provided that meets the needs of their organization and employees.

ESH\&QA Division Training will assist line management in developing, instructing, maintaining, and documenting environmental training. ESH\&QA Division Training will develop training modules.

Specific issues relating directly to an area or facility, will be handled by the appropriate division training organization with oversight by ESH\&QA Division Training. All training activities will be coordinated by ESH\&QA Division Training. EPD will approve environmental training modules developed by ESH\&QA Division Training. 


\section{Emergency Response, Environmental Occurrence Reporting, and Regulatory Notifications}

\section{Emergency Response Program}

In the event a release to the environment, the Area Emergency Coordinator (AEC) or Facility Emergency Coordinator (FEC) is responsible for notifying the Savannah River Site Operations Center (SRSOC). If the occurrence is environmental-related and less severe than an Emergency, the SRSOC is responsible for notifying the Site Environmental Protection Coordinator (SEPC) of the release. In concurrence with the SEPC, the AEC or FEC is responsible for categorizing the release into one of 3 categories (Unusual Occurrence, Off-Normal Occurrence or Non-Routine Occurrence) in accordance with sitewide procedures Manual 1B (MRP 408). The AEC or FEC is responsible for mitigation and cleanup activities, the SEPC for regulatory notifications, and the SRSOC for communications.

In the event that the release exceeds or is expected to exceed Emergency Action Levels (EALs) defined for the facility, the SRSOC is responsible for declaring an Emergency and categorizing the occurrence as an Alert, Site Area Emergency, or General Emergency. An Alert is the less serious of the emergency categories and the General Emergency the most serious. For emergencies, the SRSOC is responsible for activating SRS emergency response facilities and organizations. The SEPC makes regulatory notifications and participates as a member of the Emergency Operating Facility during activation.

If environmental sample collection and analysis are required, the Environmental Monitoring Section is responsible for such action. The SRSOC is responsible for activating the TRAC vehicle when required.

The Emergency Duty Officer (EDO) in the SRSOC is responsibility for promptly entering release data into the WIND system and evaluating plume movements, environmental concentrations and determine radiation dose. For Emergencies, ETS is responsible for providing a WIND system specialist to relieve the EDO as soon as possible

\section{Regulatory Response Required by EPCRA, CERCLA, \& RCRA}

All WSRC organizations are responsible for reporting occurrences under criteria in Management Requirements and Procedures Manual section MRP 4.08. Generally the custodial Facility Emergency Coordinator notifies the SRSOC. If the occurrence is environmental-related, the SRSOC notifies the SEPC by "beeper" activation.

For environmental occurrences the SEPC confers with the FEC to arrive at the applicable classification (Emergency, Unusual Incident, Off-Normal Incident, or NonRoutine Occurrence). If emergency response or regulatory notifications are required, 
the SEPC makes the applicable notifications in accordance with DPM-301 in the WSRC Q-1-1-1 Manual. After emergency and/or regulatory notifications are made or, if no such notifications are required, the SEPC notifies the on-call DOE-ECD representatives and WSRC management.

\section{National Contingency Plan}

All WSRC organizations are responsible for reporting any spill or release of oil, hazardous substance, pollutant, and/or contaminant. Small spills and releases that are less than the amount specified to meet the Off-Normal threshold in MRP 4.08 are classified as Non-Routine. Non-Routine occurrences are not entered into the DOE database. However, the SEPC assesses these small spills and releases and records them on the EPD Spill and Environmental Occurrence Reporting Form. Spills or releases that meet or exceed the Off-Normal thresholds are handled in accordance with EPCRA/CERCLA/RCRA requirements.

When spills or releases occur the SEPC confers with the FEC to arrive at the applicable classification (Emergency, Unusual Incident, Off-Normal Incident, or NonRoutine Occurrence). If emergeticy response or regulatory notifications are required. the SEPC first makes the applicable notifications in accordance with DPM-301 in the WSRC Q-1-1-1 Manual. After energency and/or regulatory notifications are made or, if no such notifications are required, the SEPC notifies the on-call DOE-ECD representatives and WSRC management. 


\section{Chapter 20}

\section{Division Environmental Summary}

Chapter was compiled and reviewed by Greg Peterson. 


\section{Site Program Overview}

The United States Department of Energy (DOE) and the managing contractor Westinghouse Savannah River Company (WSRC), are committed to operating the SRS in a manner that protects the public health and safety, and the environment. This philosophy is contained in DOE Order 5400.1, General Environmental Protection Program, the SRS Strategic Environmental Plan, and in the SRS Mission, Vision, and Principles.

Compliance with environmental regulations and U. S. Department of Energy orders rclating to environmental protection is an important part of the SRS program. Demonstrating environmental excellence is a high priority site ini ative embodied in DOE and WSRC policy. SRS is constantly striving to improve its standing as a leader in environmental protection activities.

All activities at SRS are overseen by one or more regulators, such as South Carolina Department of Health and Environmental Control (SCDHEC) and the Environmental Protection Agency (EPA).

Over the past few years, the number of environmental regulations bas continued to increase. In chapter two the strategy to reach our site goal of environmental excellence and compliance with new and existing environmental regulations and DOE orders is described.

In this chapter, SRS environmental programs and plans from WSRC divisions/deparments are presented along with the environmental coordinator for each program. The objectives of this chapter are to enhance communication of existing or planned programs in order to do the following:

- identify activities required for meeting environmental needs

- identify needed resources and a schedule to accomplish those activities

- promote share-savings and consistency in those activities through teamwork,proactive planning, and a common vision

The consolidated environmental plans and initiatives of individual organizations and divisions form a long-range aavironmental-protection plan which fulfill the requirements of DOE Order 5400.1 , and provides SRS with a road map for the what. when, how, and why for environmental requirements.

This chapter of the EIP is designed to integrated with and complement the planning and budget process of WSRC individual departments and divisions, and with the SRS Site Development Plan. Detailed planning and financial information is provided in therr annual operating programs, five-year plans, and other documents (e.g.. Warte Management Progrnm Plan., ER \& WM Five Year Plan). 
In Chapter 20, Division/Department Environmental Summary, environmental plans are arranged by divisions in alphabetical order. For each department listed, the programs reported follow the order of EIP's table of contents. Table 20-1 is a matrix which indicates the programs reported for the following chapters by each department:

Chapter Title

5

Chemical Management, Pollution Prevention, and Other Compliance Programs

6

Natural Resource Protection (Land, Wildlife, \& Surface Water)

7

Groundwater Protection

8

Waste Management and Disposal

9

Atmospheric Protection Programs

10

Environmental Restoration 
Table 20-1. Environmental Plans Reported

Plans listed for EIP Programs from Departments chapters:

Division/Deparment

5

6

7

8

9

10

E \& PD

Construction Management

$\mathrm{X} \quad \mathrm{X}$

\section{ESH \& QA}

Analytical Laboratories

$X$

NMPD

Reactor Materials

Separations

$\mathrm{X} \quad \mathrm{X}$

$\mathrm{X} \quad \mathrm{X}$

$\mathrm{X} \quad \mathrm{X} \quad \mathrm{X}$

Tritium

$\mathrm{X} \quad \mathrm{X}$

$\mathrm{X} \quad \mathrm{X}$

X $\quad \mathrm{X} \quad \mathrm{X}$

RRD

Reactor (RES\&HWD)

$\mathrm{X} \quad \mathrm{X}$

$\mathrm{x}$

$\mathbf{x}$

$\mathrm{X}$

SRTC

Savannah River Technology Center

$\mathrm{X} \quad \mathrm{X}$

X $\quad \mathrm{X} \quad \mathrm{X}$

SSD

Central Services Works Engineering

Site Services Engineering

$\begin{array}{ll}\mathrm{X} & \mathrm{X} \\ \mathrm{X} & \mathrm{X}\end{array}$

$\mathrm{X}$

$\mathbf{X}$

$\mathrm{X}$

$\mathbf{X}$

WM \& ER

Defense Waste Processing Facility

Environmental Restoration

$\mathrm{x}-\mathrm{x}$

$\mathbf{X}$

$\mathbf{X}$

$\mathbf{X}$

$\mathrm{X} \quad \mathrm{X}$

$\mathrm{X}$

$\mathrm{X}$

$\mathrm{X}$

Waste Management

$\mathbf{X}$

$\mathrm{X}$

$\mathrm{X}$

$\mathrm{X}$

Note: Environmental plans from all deparments are not listed for this revision, but will be included during subsequent revisions. 


\section{Engineering \& Projects Division Environmental Summary}

Department

Construction Management(CM)

\section{Mission}

To provide our customers with Construction forces, methods, procedures, and programs that produce safe, high-quality, environmentally sound results that meet or exceed our customer's requirements and expectations; to exist only to serve our customer.

\section{Vision}

To achieve total customer satisfaction through cost-effective processes and efficient performance of every task, to maintain safety, to produce the desired quality, and to continuously improve.

\section{Lead Environmental Coordinator}

Joe Kato

Environmental challenges and issues from projected mission changes during next five years:

Construction Management will continue to strive to meet or exceed our customer's requirements and expectations and continue to serve as a center of technical excellence for Construction. 


\section{Natural Resource Protection, Surface Water \& Wetlands}

NPDES Outfalls

Program Coordinator

Joe Kato

Program Description

Construction Management (CM) has two outfalls, CS-002 in Central Shops and DW002 in S Area. CM plans to stop cleanup/industrial process effluent through the oil/water separator and subsequent discharges to DW-002 when a new facility is established in Central Shops. CM has submitted a project to obtain funding for this heavy equipment wash facility and oil/ water separator. $\mathrm{CM}$ has administratively closed the S-Area Batch Plant Pond (SCHEC permit \#10,955) and also the adjoining outfall DW-001. These outfalls are sampled by the EMS and analyzed for compliance parameters.

Organizational Responsibility

Maintain compliance with SCHDEC permit requirements, and perform routine maintenance at the outfalls on an as needed basis.

Major Milestones Accomplished in FY 92

\section{Major Milestones for FY 93}

CM has proposed a formal closure of the S-Area batch plant pond which would eliminate the adjoining outfall DW-001. CM plans on moving all steam cleaning operations to Central Shops. This would centralize all process effluent where it would enter a closed loop oil/water separator system and eliminate the need for waste water outfalls CS-002 and DW-002.

NPCES: S-Area Batch Plant Pond

\section{Program Coordinator}

Joe Kato 


\section{Program Description}

The concrete batch plant, installed and permitted to facilitate the batching of concrete for DWPF, has been demobilized. The effluent water from truck washing was clarified and its $\mathrm{pH}$ adjusted in the batch plant's treatment facility prior to release to onsite streams. This Batch Plant Pond is currently under review for formal closure.

\section{Major Milestones Accomplished in FY 92}

CM has submitted a formal closure plan to the WSRC-EPD. Representative samples of the sediment and pond liner have been taken by the Waste Analysis Group and analyzed by an offsite laboratory. Sample results have been submitted to EPD and closure guidance is pending.

\section{Major Milestones for FY 93}

CM plans to formally close the Batch Plant Pond and restore the area to its original condition. This would eliminate a waste water treatment facility permit and the associated NPDES outfall DW-001. 


\title{
Groundwater Protection
}

\section{Underground Storage Tanks (UST)}

\author{
Program Coordinator
}

Joe Kato

\section{Program Description}

CM plans to install four aboveground fuel storage tanks at Central Shops. The total tank capacity will be 40,000 gallons ( 30,000 diesel fuel, 10,000 gasoline). This is the first project on site to utilize a concrete encased carbon steel tank which meets the requirements of secondary containment. This system also incorporates a recirculating system for capturing hazardous vapors, thus minimizing the amount of VOCs, which would normally be released to the atmosphere.

\section{Major Milestones Accomplished in FY 92}

Four aboveground storage tanks have been delivered to the site in December 1992. This breakthrough design in fuel storage tanks has become the model for bulk fuel handling at SRS as WSRC plans to modify their bulk fuel handling system to match BSRI which will also provide compatibility. This project sets a new standard of excellence for the site and the environmental gains are expected to be widely publicized.

\section{Major Milestones for FY 93}

The expected construction completion date for aboveground fuel storage tanks is March 1993.

\section{Major Milestones for FY $94-98$}

$\mathrm{CM}$ plans to abandon the existing underground storage tanks located at $715-1 \mathrm{~N}$ in Cenural Shops. CM also, in conjunction with SRTC, will develop a plan to remediate the petroleum contaminated soil in all affected areas. 


\title{
Waste Management \& Disposal
}

\author{
Waste Minimization: Silver Rigcovery
}

\author{
Program Coordinator
}

Joe Kato

\section{Program Description}

The recovery system will reclaim silver from silver fixative that is generated through the film developing process. This will eliminate a hazardous waste stream and recover precious metals for transfer to the Department of Defense.

\section{Major Milestones for FY 93}

CM plans to install a silver recovery unit in Central Shops. CM is working in conjunction with the Power Department to assure all necessary permits are in place to discharge effluent into the sanitary sewer.

\section{Major Milestones for FI $94-98$}

CM plans to reclaim silver from a batch process and intends to eventually accept silver fixative form other WSRC entities and subcontractors.

\section{Waste Minimization: Wood Chipper}

\section{Program Coordinator}

Joe Kato

\section{Program Description}

CM has procured a wood chipper to aid in waste minimization efforts. It will minimize the number of controlled burns at the Central Shops Bum Pit and reduce the amount of land clearing debris entering the Burma Road Landfill. The chipper will also provide a disposal method for pressure treated lumber, creosote treated material and allow $\mathrm{CM}$ to crush and re-use asphait. 


\section{Major Milestones Accomplished in FY 92}

CM procured the wood chipper and it was delivered to SRS in December 1992. CM also began collecting the necessary data to prepare the required SCHEC Air permit needed to process pressure treated and cresote-treated wood products and asphalt.

\section{Major Milestones for FY 93}

$\mathrm{CM}$ will only chip regular excess/scrap wood and land clearing debris until the SCDHEC Air Quality Control permit is received. These chips will be used as mulch and for landscaping on site. After receiving the permit CM plans to also chip pressure treated excess/scrap lumber, creosote treated wood and spoil asphalt. $\mathrm{CM}$ is working in conjunction with the Power Department on using the creosote treated wood as fuel in the site powerhouses.

\section{Major Milestones for FX 94-98}

CM plans to accept permitted materials from other WSRC organizations and subcontractors, thereby minimizing landfill space, stockpiling and controlled burns sitewide.

\section{Waste Minimization: Lathe Coolant Recovery System}

Program Coordinator

Joe Kato

\section{Program Description}

$\mathrm{CM}$ has procured a lathe coolant recovery system which will recycle the coolant used in fabrication and machine shops where cutting, grinding or drilling takes place. Although the coolant is not hazardous, it is a liquid waste which currently cannot be disposed of on site. CM projects the recovery of the coolant to not only be a best management practice, but also a substantial waste disposal cost avoidance.

\section{Major Milestones Accomplished in FY 92}

The lathe coolant recovery system was procured in 1992. Procedures have been established and are in place on Lathe Coolant Recycling. 


\section{Major Milestones for FY 93}

CM plans to set up the recovery system and begin recycling activities in 1993.

\section{Major Milestones for FY 94-98}

CM could possibly accept used lathe coolant from CSWE and other works engineering departments which operate machinery.

Waste Minimization: Solvent Distillation Units

\section{Program Coordinator}

Joe Kato

\section{Program Description}

CM currently operates two solvent distillation units. These units recycle used solvent, mainly from painting activities, into a usable product through a heating/condensation process. Solvent was CM's largest waste stream and the distillation units allowed CM to minimize the hazardous waste by apprcximately $80 \%$.

\section{Major Milestones Accomplished in FY 92}

CM has received permits from SCDHEC to construct three additional units which will greatly increase the amount and types of solvent that can be reclaimed.

\section{Major Milestones for FY 93}

CM plans to expand the existing solvent recovery facility in order to operate the three additional solvent distillation units. A GPP Project has been submitted for approval to obtain the necessary funds.

\section{Major Milestones for FY 94-98}

With the operation of five distillation units, CM plans to accept used solvent from other site wide organizations in order to promote waste minimization throughout SRS. 


\section{Waste Management: H-Area Inert Waste Landfill}

Program Coordinator

Joe Kato

\section{Program Description}

The H-Area Inert Waste Landfill was established in 1984 and permitted by SCDHEC to accept inert construction material. Since that time the landfill has reached its maximum capacity and $\mathrm{CM}$ has administratively closed the area. The Burma Road Landfill has been established to arcept inert waste materials, and CM is developing a formal closure plan and trying to appropriate funding to close the H-Area Landfill.

Major Milestones Accomplished in FY 92

CM submitted a formal closure plan to the WSRC-EPD and a GPP project has been submitted to WSRC Financial Controls to obtain funding for the closure.

Major Milestones for FY 93

CM plans to begin formal closure of the H-Area Landfill and restore the area to its original condition. 


\section{Environmental, Safety, Health, \& Quality Assurance (ESH\&QA) Division Environmental Summary}

\section{Department}

Analytical Laboratories Department

\section{Mission}

The mission of Analytical Laboratories is to provide quality analytical services in support of site operations to allow Savannah River Site to comply with legal, regulatory, contractual, and corporate requirements.

\section{Vision}

The Analytical Laboratories vision is to be the recognized model of excellence for laboratories providing analytical services within the Department of Energy Complex and the Westinghouse Electric Corporation.

\section{Lead Environmental Coordinator}

Mark Kidd

\section{Environmental Challenges \& Issues from Projected Mission Changes during Next Five Years}

Some of the environmental challenges identified for Analytical Laboratories Department include the following:

- Changes in requirements from regulating agencies will impact the amount of documentation required for the data packages from the laboratory, as well as increasing quality assurance and review of the data packages. In addition, an increase in certified analyses is anticipated.

- Need to provide analytical support to site organizations' implementation of the waste acceptance criteria.

- Expand radiometric and chemical analyses for high alpha and beta gamma waste and materials.

- Increase analytical capability supporting environmental permitting compliance. 


\title{
Atmospheric Protection
}

\author{
Air Emissions
}

\author{
Program Coordinator
}

Mark Kidd

\section{Program Description}

Taking appropriate measures to ensure that new and existing facilities comply with current regulatory requirements.

\section{Organizational Responsibility}

Analytical Laboratories Department is responsible for the operation of 772-D, $772-F / 1 F / 4 F$ laboratory facilities.

\section{Major Milestones Accomplished in FY 92}

- Completed Air emission inventories for 772-D facility. Central Laboratories (772-F and 772-1F) currently conducting air emissions inventory.

- $772-4 \mathrm{~F}$ is being constructed under the October 1991 Federal Facilities Compliance Agreement for Radionuclide NESHAP. The 772-4F stack is an environmental and safety upgrade and will enable $772-\mathrm{F}$ laboratory facility to return from current limited operation to full operation.

\section{Major Milestones for FY 93}

- Hot tie-in and continuous operation of the $772-4 \mathrm{~F}$ stack. Anticipated to achieve hot tie-in Summer 1993.

- Participated with the Environmental Release Guides Committee and the ALARA Management Steering Committee to look at potential accidental airborne radioactive releases and means for minimizing risk or impact for $772-\mathrm{F}$ and 772-1F laboratory facilities. Committees are expected to develop an Airborne Release Prevention and Control Plan by 3/15/93.

\section{Major. Milestones for FY $\mathbf{9 4 . 9 8}$}

Restart of 772-F laboratory- Projected for December 1996. 


\section{Nuclear Materials Processing Divitment}

NMPD 300 Area Environmental, Safety, and Health

\section{Mission}

The mission of the NMPD 300-Area ES\&H Group is to direct Reactor Materials Department (RM) activities sucn that environmental regulations and requirements are met and sound environmental practices are promoted.

\section{Vision}

The vision of the NMPD 300-Area ES\&H Group is to set the standard of excellence at the Savannah River Site in the management of environmental activities and programs.

\section{Lead Environmental Coordinator}

F. R. Weitz 


\title{
Chemical Management, Pollution Prevention, and Other Compliance Programs
}

EPCRA, OSHA

\author{
Program Coordinator \\ Ming-Chau Wong
}

\section{Program Description}

The 300-Area Chemical Inventories Improvement Plan has been implemented. The M-Area Chemical Inventory System (MCIS) is in the RM support network to provide chemical information and assist chemical custodians to perform chemical inventory. The RM chemical custodian meetings are held monthly.

\section{Organizational Responsibility}

300 Area ES\&H assists the Reactor Materials Facilities in complying with EPCRA, and OSHA requirements. A computerized database (MCIS) to manage the RM chemicals was dev€loped. The database is maintained by facility and 300 Area ES\&H personnel. The program coordinator provides HAZCOM training to the RM chemical custodians and chemical coordinator.

\section{Major Milestones Accomplished in FY 92}

- The M-Area Chemical Inventory System (MCIS) was implemented. (12/1992)

- Annual Tier II Chemical Inventory report was completed and turned into Industrial Hygiene. (11/1992)

- The RM Chemical Custodian Meetings were held every month.

- The procedure SOP 300-182, Reactor Materials Chemical Inventory and MSDS Availability, was issued. (12/16/1992)

\section{Major Milestones for FY 93}

- The information of chemical ingredients, HAZCOM ratings, Blue Dot and other regulated chemical identifications will be added to The MCIS. (3/1993)

- A periodic RMQ surveillance of the Chemical Inventory program will be implemented beginning April 1993.

- A periodic performance indicator of the Chemical Inventory program will be initiated in May 1993.

\section{Major Milestones for FY $94-98$}

- Review and update MCIS database quarterly. 
Division Environmental Summary - Environmental, Safety, and Health Environmental Implementation Plan

- Review and update SOP 300-182 every 2 years. 


\title{
Chemical Management, Pollution Prevention, and Other Compliance Programs
}

\author{
National Environmental Policy Act
}

Program Coordinator

Steve Norford

\section{Program Description}

The Reactor Materials program is currently operating from the WSRC 3Q ECM 5.1 procedure and the WSRC Implementation Plan for NEPA in compliance with $10 \mathrm{CFR}$ 1021 and 40 CFR Parts 1500 - 1508. No area specific procedures have been developed. The Technical Review consideration/process implemented at the department level includes environmental review of modifications for Nuclear Safety (NS) and Critical Protection (CP) and Production Support (PS) and certain General Services (GS) systems.

\section{Organizational Responsibility}

The Reactor Materials Department NEPA coordinator is part of a sitewide team composed to implement the NEPA regulations.

Major Milestones/Accomplishments from Previous Year

- None

\section{Major Milestones for FY 93}

- Implement WSRC 3Q ECM 5.1 procedure when approved

- Provide support for Reactor Materials Operations, Maintenance, and Projects groups in complying with NEPA

- Re-assessment of required NEPA documentation of Project 2700 "Billet Handling"

- Complete Vendor Treatment Process and Storage Pad EA

\section{Major Milestones for FY $94-98$}

- Provide support for revision of NEPA documents every five (5) years in accordance with 10 CFR 1021.330

- Provide NEPA documentation for shutdown/standby activities 


\title{
Natural Resource Protection, Surface Water and Wetlands
}

\section{NPDES}

Program Coordinator

\author{
G. A. Diener
}

Program Description

Reactor Materials releases treated effluent from the Dilute Effluent Treatment Facility (DETF) to Outfall M-004 and on to Tims Branch via Outfall A-014. Each process batch is sampled by RM and analyzed by the 320-M Laboratory prior to the release to ensure compliance with NPDES permit limits. The Outalls M-004 and A-014 are sampled and analyzed weekly by the Environmental Monitoring (EM).

\section{Organizational Responsibility}

The 300-Area Environmental, Safety, and Health (ES\&H) is responsible for ensuring that the DETF and all its discharges are in compliance with the Clean Water Act.

\section{Major Milestones Accomplished in FY 92}

- Processed 172,000 gallons of supernate during FY 92

- Finished IT/SF Tank 8 supernate

- Submitted IT/SF Tank 7 treatability study to SCDHEC

- Chronic toxicity testing performed at Outfalls A-014 and M-004 to ensure no harm to the environment

- No Deficiencies found on 3560 Audit in M-Area

- Completed M-Area laboratory discharge characterization

- Performed non-destructive testing on all BMP tanks in M-Area

- Walked down all stormwater outfalls for Stormwater Permit

\section{Major Milestones for FY93}

- Process 200,000 gallons of supernate in FY93

- Relocated supernate transfer pump to IT/SF Tank 7 and SCDHEC approved operation on December 30, 1992

- Submitted NPDES permit renewal application for Outfalls A-014 and M-004 to EPD on November 12, 1992

- Negotiate new NPDES permit conditions and ensure compliance when issued by SCDHEC 
Environmental Implementation Plan Division Environmental Summary - Environmental, Safety, and Health

- Relocate A-014 (if required) to comply with new permit conditions (toxicity)

- Update BMP/SPC.C for M-Area (late FY93 or early FY94)

- Evaluate Liquid Effluent Treatment Facility (LETF) capacity to treat A-Area powerhouse wastewater

Major Milestones for FY94-98

- Complete processing of all Interim Treatmen/Storage Facility (IT/SF) supernate

- Submit wastewater permit modification to EPD for the M-Area Vendor Treatment Process

- Notify SCDHEC of closure of slurry hold tank area, once Chemical Treatment Facility (CTF) cleaned

- Submit NPDES permit renewal application

- Submit wastewater permit modification to treat A-Area powerhouse wastewater, if approved by Change Control Board

- Submit closure plan for the LETF, if necessary

- Develop Pollution Prevention Plan for M-Area 


\title{
Waste Management and Disposal
}

Waste Management

\author{
Program Coordinator
}

J. B. Pickett

\section{Program Description}

The Reactor Materials Waste Management Program includes the following objectives:

- Manage all hazardous wastes in total compliance with the regulatory requirements (State and Federal).

- Ensure that the RCRA treatment and storage facilities managed by the Reactor Materials Department are operated in full compliance with the regulatory requirements.

- Conduct the M-Area de-inventorying program such that the minimum amounts of hazardous wastes are generated during the lay-up program, by reuse and recycling of any suitable materials.

- Ensure that any hazardous wastes generated by a "shutdown" activity are anticipated, and are managed according to the hazardous waste regulations.

- Minimize the amount of any hazardous waste generated, especially the amounts of mixed waste.

- Minimize the amounts of radioactive/non-hazardous and sanitary wastes generated, in order to preserve the limited landfill capacities.

- Ensure that all wastes are categorized correctly and that the appropriate documentation is maintained.

\section{Major Milestones Accomplished in FY92}

Completed treatment of 172,000 gallons of supernate from the IT/SF

\section{Major Milestones for FY93}

- Treat 200,000 gallons supernate from the IT/SF

- Complete supernate transfer system relocation to Tank 7 from Tank 8

- Implement use of new type filter media (reusable belts) in the DETF

- Select subcontractor to treat and stabilize the sludge in the M-Area tanks

- Implement waste certification for the M-Area Low Level Waste \& Mixed Waste by $12 / 93$ 
Major Milestones for FY94-98

- Submit all necessary permits for Vendor Treatment Program by 6/30/94

- Start treatment of M-Area sludge within 180 days of permit approval (estimated 6/95)

- Complete treatment of M-Area sludge by subcontract within one year of start of treatment (estimated $6 / 90$ )

- Close all M-Area tanks by 6/97

Waste Minimization

\section{Program Coordinator}

\section{J. V. Burch}

\section{Program Description}

The Reactor Materials (RM) waste minimization program is a very aggressive program resulting in the reduction of all types of waste streams. SOP 300-168 (Waste Minimization in Reactor Materials $(U)$ ) is the programmatic document which outlines the waste minimization program for RM. As required by this procedure, RM issues annual reports summarizing waste minimization performance in M-Area and providing details on future efforts. The annual report fulfills the documentation and reporting requirements found in the RM procedure and the Department of Energy Savannah River Site Waste Minimization Plan Rev 4. The annual report, in conjunction with the waste minimization procedure, meets all of the site's requirements and guidance for facility-specific waste minimization programs and their maintenance.

The RM waste minimization program has made significant progress to reduce the amount of waste that is generated. Waste minimization considerations are included in procedures, job plans, and technical reviews whenever appropriate. In addition, Management Tours and Process Waste Assessments are continuously used to identify and evaluate opportunities for waste minimization. Cost-justified waste minimization opportunities are then implemented as the opportunities are identified.

RM has established programs for forecasting, tracking, and reporting waste generation and publishes the results in the WSRC Performance Indicator program. In addition, $R M$ issues its own internal performance indicator report on waste generation. RM uses these reports to identify areas in which waste minimization efforts can improve. 
Organizational Responsibility

The 300 Area Environmental, Safety and Health (300 Area ES\&H) group assumes direct responsibility for the reporting requirements associated with $R M$ waste minimization. This group tracks waste minimization in M-Area and ensures all environmental issues associated with waste minimization are resolved.

Along with the 300 Area ES\&H group, the RM Waste Coordinator plays a major role in waste minimization. The Waste Coordinator chairs the RM Waste Action Team (RM WAT) which is composed of various personnel from the RM operating facilities.

The RM WAT team members represent all appropriate RM groups including Production, Maintenance, HP, Analytical Laboratories, Quality, Program Integration, and Technical. Overall, the team's mission is to identify, evaluate, initiate, and monitor waste minimization activities, and the team also increases waste minimization awareness in the RM facilities. The RM WAT meets monthly to discuss ideas on waste minimization, to comply with site directives, to be the pro-active voice for waste issues, and to review information from the SRS WAT and Waste Coordinator meetings. Where appropriate, the RM WAT chairman is responsible for defining the applicable Consolidated Labor System (CLS) time codes that are used by personal for waste minimization activities.

\section{Major Milestones Accomplished in FY92}

- Found alternate uses for approximately $\mathbf{4 0 0 0} \mathrm{lbs}$ of excess chemicals which were stored in M-Area. Most of these chemicals were associated with the shutdown of the 313-M processes

- Treated 172,000 gallons of supernate at the Liquid Effluent Treatment Facility (LETF) in FY 92

- Decreased the amount of low level waste generated from FY 91 by 50 percent

\section{Major Milestones for FY93}

- Initiated a Process Waste Assessment (PWA) for the LETF

- Treat 200,000 gallons of supernate at the DETF to reduce Interim Treatment/Storage Facility (IT/SF) mixed waste volume

- Decrease annual generation of low level waste (LLW) by $20 \%$ as compared to LLW generation in FY 92 


\section{Major Milestones for FY94-98}

- Implement alternatives to Freon ${ }^{8} 113$ into full-scale use, as appropriate, or document results of testing for retrieval at a later date. Scheduled Completion Date - Dependent on Facility Operations Required for Shutdown

- Submit delisting petition to EPA for the Used Filter Paper Take Up Rolls (UFPTUR) to reclassifying the waste from mixed waste to low level waste. Scheduled Completion Date - 9/94

- Complete implementation of waste minimization into area procedures in FY94

- Initiate PWA activities for second RM facility (Building 321-M) in FY94 


\title{
Atmospheric Protection
}

\author{
Air Emissions
}

Program Coordinators

N. B. Chaddick and R. M. Benson

\section{Program Description}

Taking appropriate measures to ensure that new and existing facilities comply with current regulatory requirements.

\section{Organizational Responsibility}

The 300-Area Environmental, Safety and Health (ES \& H) Group is responsible for ensuring that all $\mathrm{M}$-Area facilities and all their discharges are in compliance with the Clean Air Act.

\section{Major Milestones Accomplished in FY92}

- Developed trending of environmental release data to determine the correlation of radioactive emissions with area production activities -Ongoing

- Provided environmental regulatory support for Project S-2972, Constant Air Monitoring, to upgrade Building 321-M Machining Room Stack sampling to an isokinetic system - Ongoing

- Upgraded sampling of the 321-M Billet Handling Stack to an isokinetic system $3 / 92$

- Completed SCDHEC Air Emissions Inventory for permitted and Freon emitting sources - 3/92

- Completed EPA Region IV NESHAP compliance inspection of twenty-five potential sources of radioactive airborne emissions - 6/92

- Completed source emissions testing on the Building 321-M Tube Cleaning Room and the 313-M Waste Compactor Stacks to proactively prepare for new CAA permit applications - 7/92

- Determined 321-M Machining Room Stack was out of compliance with NESHAP regulations based on new modelling techniques - 8/92. Negotiations with the EPA to revise the Site's NESHAP FFCA are continuing.

- Completed annual SCDHEC air compliance inspection on four M-Area permitted sources - 9/92

- Completed comprehensive Air Emissions Inventory with Radian Corporation $11 / 92$ 


\section{Major Milestones for FY93}

- Complete Action Plan for the prevention and control of airborne radioactive releases for the Environmental ALARA Management Steering Committee - 3/93

- Review the possibility of exempting the 320-M permitted diesel - 3/93

- Study and demonstrate the feasibility of suitable Freon TF alternatives - 5/93

- Submit to SCDHEC Air Emissions Inventory - 9/30/93

- Complete Project S-2972 and submit data to EPA - $12 / 93$

- Develop program to maintain current Air Emissions Inventory - 12/93

\section{Major Milestones for FY94-98}

- Implement the feasible, cost effective (less than $\$ 20,000$ ) Freon alternatives during the Operational Standby Mode - 9/94

- Implement Program Activities as production facilities shut-down, e. g. cap exhaust systems, revise permits, etc. - $12 / 97$ 


\section{Environmental Restoration Program}

\section{Environmental Restoration}

\section{Program Coordinator}

\section{G. A. Diener}

\section{Program Description}

Environmental Restoration (ER) has several remediation projects operating in the 3/700 Area. Currently, Reactor Materials is operating two Ground Water Air Strippers to treat groundwater contaminated with solvents; one at the Savannah River Technology Center (SRTC), A-1 air stripper; and one in M-Area. M-1 air stripper. Future ER projects include another SRTC air stripper, a southern sector air stripper, and four $\mathrm{A} / \mathrm{M}$ Area vadose zone treatment systems.

The M-1 air stripper discharges to Outfall M-005 and on to Tims Branch via Outfall A-014. The A-1 air stripper discharges to A-001A and on to Tims Branch via Outfall A-1.

\section{Organizational Responsibility}

$E R$ is responsible for ensuring that all remediation projects are in compliance with applicable federal and state regulations. The 300-Area ES\&H is responsible for the technical support until a new system engineer for ER is determined. the ES\&H is also providing project liaison between RM and ER on all future remediation projects.

\section{Major Milestones Accomplished in FY92}

- Provided technical support for M-1 and A-1 air stippers

- Provided project liaison for future ER projects

- No 3560 Audit findings

\section{Major Milestones for FY93}

- Provide technical support for M-I and A-1 air stippers

- Provide project liaison for future ER projects

Major Milestones for FY94-98

Provide project liaison for future ER projects 


\title{
Nuclear Materials Processing Division Environmental Summary
}

\section{Department}

Separations

\section{Mission}

To operate and maintain chemical processing facilities for the production of nuclear materials, primarily related to the defense and security of the country, while maintaining the highest standards of safety, employee treatment, quality, environmental safety and health, safeguards and security, and fiscal responsibility.

\section{Vision}

To be recognized by the U. S. Department of Energy and internal customers as the supplier of choice for quality products and services in compliance with regulations.

\section{Lead Environmental Coordinator}

\author{
W. M. Wierzbicki
}




\title{
Chemical Management, Pollution Prevention, and Other Compliance Programs
}

\author{
National Environmental Policy Act (NEPA)
}

Program Coordinator

Barbara M. Sly

\section{Program Description}

The Separations NEPA program is operating in accordance with the $3 Q$ ECM 5.1 procedure and the WSRC Implementation Plan for NEPA in compliance with $10 \mathrm{CFR}$ 1021 and 40 CFR Parts 1500-1508. No NMPD specific procedures have been developed. The Technical Review process implemented at the department level includes environmental review of modifications for NS and CP, and PS safety class systems..

Organizational Responsibility

The Separations Department NEPA Coordinator is part of a team composed of coordinators from across the site to implement the NEPA process.

\section{Major Milestones Accomplished in FY92}

- Designated Separations NEPA Coordinator

- Implemented NEPA Implementation Plan in H Area

- Assisted in the revision of site level NEPA implementing procedure 3Q ECM 5.1

- Supported development of EIS for the Upgrade Canyon Ixhaust System Project

\section{Major Milestones for FY93}

- Develop guidance procedures for full implementation of 3Q ECM 5.1

- Provide support for Separations Operations, Maintenance, and Projects groups in complying with NEPA

- Support review of final EIS for the Upgrade Canyon Exhaust System Project

\section{Major Milestones for FY94-98}

- Provide support for revision of NEPA documents every five (5) years in accordance with 10 CFR 1021.330

- Provide support for revision of NEPA documents every five (5) years in accordance with 10 CFR 1021.330 


\section{Chemical Management, Pollution Prevention, and other Compliance Programs}

Spill Prevention and Control (SPCC)

Program Coordinator

C. A. Bald

Program Description

The Separations Environmental Group is on call 24 hours a day to provide support and assistance to Separations in categorizing releases in accordance with the SIRIM system, SRS agreements with SCDHEC, and applicable environmental regulations. The Separations Environmental Group ensures the SEPC is notified, provides guidance to Operations for storage and disposal of clean up materials, and monitors trends of releases in the Separations area. An internal notification form is completed to collect required information and to document actions.

Operations personnel inspect all SPCC and BMP facilities by procedure on a weekly basis, and informally (no procedure) during rounds made on each shift. The Separations Environmental Group inspects the facilities semi-annually.

\section{Major Milestones Accomplished in FY92}

Initiated an on call system for Separations Program Environmental Group to provide a more reliable contact during environmental occurrences

\section{Major Milestones for FY93}

Update the SPCC and BMP plans to reflect changes since the last revision and to incorporate new regulations

Major Milestones for FY94-98

None identified. 


\title{
Natural Resource Protection, Surface Watter and Wetlands
}

\section{NPDES}

\author{
Program Coordinator
}

C. A. Bald

\section{Program Description}

NPDES permitted outfalls F-001, F-002, F-003, F-005, H-004, and H-012 are inspected daily and the $\mathrm{pH}$ is sampled for process control. Monthly compliance sampling and analysis is done by the EMS. All outfalls are inspected by the custodial organization on an informal basis to ensure outfall area is safe, clean, signs current and in place, quality of water appears good, and there is sufficient flow to obtain clean samples. Maintenance orders are in place for Construction to monthly cut weeds, clean pipe grating, clean litter, and perform other minor upkeep at four outfalls and will be in place for the remaining two outfalls in the near future.

Separations currently has one outfall covered under SCDHEC General Permit for Storm Water, which will be included in the site Pollution Prevention Plan.

\section{Organizational Responsibility}

None

\section{Major Milestones Accomplished in FY92}

- Installed a flow channeling device at outfall H-004 to ensure adequate samples can be taken.

- Completed a wastewater characterization survey to identify sources of toxic pollutant discharges to Separations outfalls.

- Received no non-compliances at any of the Separations seven permitted outfalls.

\section{Major Milestones for FY93}

- Complete updating the NPDES applications.

- Perform toxicity identification evaluations on outfalls which do not pass toxicity tests and which may be identified on upcoming permit through an EPD subcontract.

- Investigate feasibility of combining several outfalls to reduce sampling and analysis cost for the site. 
Major Milestones for FY94-98

Perform toxicity identification evaluations under EPD subcontract on remaining Separations outfalls which fail toxicity testing. 


\title{
Waste Management and Disposal
}

\author{
Waste Management
}

\author{
Program Coordinator
}

Gary T. Swisstack, (UST Program: C. A. Bald)

Program Description

Facility specific programs for handling RCRA hazardous waste are in place throughout Separations. The programs include facility specific training on hazardous waste and hazardous waste handling, waste snecific procedures which are reviewed by knowledgeable SPEG engineers, and quarterly inspections of all hazardous waste satellite and staging areas.

Separations currently owns no underground storage tanks.

\section{Organizational Responsibility}

The generator of hazardous waste is required to properly characterize their waste. If a new waste is generated in a Separations facility, the waste is sampled to determine if the waste is hazardous.

Each facility has a designated person or group of waste handlers who are trained in the proper handing and storage methods for hazardous waste. All inspections of satellite and staging area are conducted by these people.

\section{Major Milestones Accomplished in FY92}

- $\quad$ Received no hazardous waste handling or storage violations in 1992 . The 1992 SCDHEC Compliance Monitoring Evaluation resulted in no major findings against any Separations facility.

- Removed a 500 gallon underground storage tank from the ground. The tank had contained diesel fuel to heat an old office building, but had been taken out of service prior to 1969 . There were no releases from the tank but diesel fuel was present in the soil from previous spills that occurred when filling the tank. Dieselcontaminated soil was excavated and will be treated in a proposed bioremediation facility. Soil samples were analyzed for a number of constituents and information for the closure report was documented and will be submitted to SCDHEC in the near future. 
Major Milestones for FY93

- Develop a performance indicator for the length of time hazardous waste is stored in staging areas

- Move the 211-H staging area to a position closer into the 211-H facility.

Major Milestones for FY94-98

- Upgrade the storage areas as needed.

- Aggressively pursue product substitution to eliminate the generation of hazardous waste. 


\section{Waste Management and Disposal}

Waste Minimization

\section{Environmental Challenges \& Issues from Projected Mission Changes during Next Five Years}

Increased emphasis must be placed on Waste Minimization and Pollution Prevention due to the transition of facilities to the Environmental Restoration and Waste Management department within DOE Headquarters. Waste Minimization during D \& $\mathrm{D}$ will be a challenge for Separations facilities.

\section{Program Coordinator}

Ed F. Kay

\section{Program Description}

The Separations Program is similar to the SRS Waste Minimization Program. Facility Specific Waste Minimization Plans are the steps to waste minimization within the facilities. Waste Minimization within Separations is done on a prioritized basis, with the major waste streams receiving more of the priorities. Each facility has a waste minimization coordinator who runs the program within their facility. Separations has a program coordinator who ensures that each facility waste minimization coordinator receives the necessary information concerning waste minimization.

Separations has created the Separations Waste Minimization Team which is composed of the Separations Waste Minimization Coordinator and each facility Waste Minimization Coordinator. Resources to the team include management support, a construction representative and a SRTC Representative. The SWMT is tasked to address waste minimization problems within the Separations facilities and to facilitate the exchange of waste minimization information.

Waste Certification is an integral part of waste minimization. Through waste certification, Separations facilities will carefully characterize their waste, and certify that requirements met in the WSRC 1-S Manual, Waste Acceptance Criteria, are met.

\section{Organizational Responsibility}

The responsibility for the $\mathrm{F}$ and $\mathrm{H}$ Separations Waste Minimization Program lies within the SWMT. Each facility manager is responsible to see that waste minimization is accomplished within the respective facility. The Facility Waste Minimization Coordinator assists the facility manager is accomplishing the milestone and objectives set forth in the facility Specific Waste Minimization Plans. 


\section{Major Milestones Accomplished in FY92}

- Began Process Waste Assessment (. WA) program.

- Completed procedures to document the Waste Minimization program. (Section 5.10 of the S1-1 Manual, "Separations Program Administrative Procedures Manual.")

- Separations facilities reduced the amount of Low Level Solid Radioactive Waste by $20 \%$ during FY 92 from FY91 totals.

\section{Major Milestones for FY93}

- Reduce routine (i.e., non-D\&D) Low Level Solid Radioactive Waste in FY93 by $5 \%$.

- Implement a Waste Certification Program for all facilities that generate Low Level Solid Radioactive Waste and Mixed Waste by 12/93.

\section{Major Milestones for FY94-98}

- Complete Process Waste Assessments for waste streams which have a life cycle cost of over $\$ 500,000$ by the end of 1994 .

- Complete PWA for waste streams which have a life cycle cost of over $\$ 100,000$ by the end of 1998 . 


\section{Atmospheric Protection}

\section{Air Emissions}

\section{Program Coordinator}

\section{J. A. McLaughlin}

\section{Program Description}

The atmospheric protection program provides environmental support for operations and other activities involving the F\&H Area Separations facilities to ensure compliance with state and federal air regulations. It establishes and maintains programmatic regulatory compliance with the Clean Air Act (CAA).

\section{Organizational Responsibility}

The program coordinator organizes the acquisition and compilation of information to generate reports which must be submitted to EPD for demonstration of regulatory compliance. Each facility manager ensures that the coordinator receives all relevant information for the respective facility.

\section{Major Milestones Accomplished in FY92}

- Upgraded sampling at the 291-F (Project S-4441) and 291-H (Project S-4652) stacks to an isokinetic system

- Completed annual SCDHEC Air compliance inspection of F\&H Area Separations permitted sources

- Completed bi-annual Air Emissions Inventory for permitted sources

\section{Major Milestones for FY93}

- Complete Action Plan for the prevention and control of airborne radioactive releases for the Environmental ALARA Management Steering Committee

- Complete Air Emissions Inventory for facility operations through FY93

- Develop procedure for implementing 3Q ECM 4.7 to maintain Air Emissions Inventory for Separations

\section{Major Milestones for FY94-98}

Submit SCDHEC Air Quality Control permit renewal application in 1994 
l'rugram Coordinator

D. A. Gracy

\section{Program Description}

The 200 Area ES \& $\mathrm{H}$ Environmental Restoration Program was established to support 200 Area Operations departments in the transfer of selected facilities into the Site ER Program. It also provides support to ER in the early identification of environmental remediation projects that may be required in the future.

\section{Organizational Responsibility}

The primary responsibilities of Regulatory Programs in the Environmental Restoration Program are as $\mathrm{f}$ sllows:

- Assist in the compilation of data for the characterization of CERCLA waste units.

- Identify the requirements for the collection of additional information such as soil gas surveys, soil borings, well installations, and groundwater analysis.

\section{Major Milestones Accomplished in FY92}

- Replaced groundwater monitoring well FCA 9D with FCA 9DR

- Developed Program Plan for the installation of three new monitoring wells in $\mathrm{H}$ Area, HCA-5, -6, \& - 7.

- Developed Program Plan for the installation of seven new monitoring wells in FArea, FCA-1, $-4,-5,-11,-14,-15, \&-17$.

\section{Major Milestones for FY93}

- Install three new groundwater monitoring wells around H-Canyon and seven new wells around F-Canyon to improve overall understanding of the hydrogeological regime in the General Separations Area.

- Identify the areas of past contamination incidents which require Site Evaluations in 1993 to comply with the recently approved FFA.

- Determine, based upon existing data. what additional data will be required to adequately perform site evaluations in the General Separations Area.

- Coordinate the data collection process and assist in the performance of Site Evaluations. 


\section{Major Milestones for FY94-98}

- Identify the areas of past contamination incidents which require Site Evaluations in 1994-98 to comply with the recently approved FFA.

- Coordinate with Environmental Restoration in the design and development of remediation activities for the General Separations Area. 


\section{Employee Education}

Environmental Awareness

Program Coordinator

C. A. Bald

\section{Program Description}

The Separations Environmental Group participates on the site wide environmental awareness committee. An Environmental Awareness Day is held in F Area including pamphlets, posters, and displays to educate and inform employees of the environmental activities on site and the many environmental regulations.

\section{Major Milestones Accomplished in FY92}

Coordinated an Environmental Awareness Day by the Separations Environmental Group for F Area. The event was very well attended by personnel in the area.

\section{Major Milestones for FY93}

Coordinate Environmental Awareness activities similar to previous year.

\section{Major Milestones for FY94-98}

None identified. 
Nuclear Materials Processing Division Environmental Summary

\section{Department}

Tritium

Mission

To serve the national security interesis of the United States by safely supporting the needs of the Nuclear Weapons Complex while protecting the employee, public health, and the environment.

Vision

To provide only the highest quality product by each individual constantly improving his performance in a team effort to continue our vital role as guardian of the Nuclear Stockpile, the comerstone of our national defense.

\section{Lead Environmental Coordinator}

Paul Rowan

\section{Environmental Challenges \& Issues from Projected Mission Changes during Next Five Years}

- Startup and operation of building 233-H (RTF).

- Shutdown and decommisioning of some process operations in building $234-\mathrm{H}$ (tritium reservoir loading and unloading operations).

- Reduced nuclear weapon stockpile demand as a result of the "peace dividend".

- Consolidation of the Nuclear Weapons Complex with the potential for some programs to be transferred to the Tritium Facilities (SRS). 


\section{Chemical Management, Pollution Prevention, and Other Compliance Programs}

EPCRA, SPCC, BMP, PPP, NEPA

\section{Program Coordinators}

Paul Rowan, Brad Wilson, Craig Johnson and Kevin Sessions.

\section{Program Description}

Current and future Tritium Facilities(TF) operations require compliance with EPCRA, SPCC. BMP, PPP, and NEPA regulations.

\section{Organizational Respor sibility}

Tritium Environmental (200 Area ES\&H) assists the Tritium Facilities in complying with EPCRA, SPCC, BMP, PPP, and NEPA requirements. Environmental personnel assist with preparing documentation for these compliance programs. The TF Chemical Coordinator (Robert Rhodes - TSS) provides HAZCOM training to all TF personnel and maintains material safety data sheets (MSDS). The TF NEPA coordinator is Jill Sessions (Tritium Technology).

\section{Major Milestones Accomplished in FY92}

- Annual SARA Title III inventory completed on schedule.

- Annual Tier II Chemical Inventory

- HAZCOM training given to TF personncl.

- Spill control pallets procured for liquid wastes (RCRA and non-RCRA) stored outdoore.

- Environmental Evaluation Checklist (EEC) made available on TF electronic desktop. [NEPA]

\section{Major Milestones for FY93}

Tritium Facilities NEPA coordinator (Jill Sessions) appointed.

Major Milestones for FY94-98

Review and update TF contribution to SPCC and BMP plans 


\title{
Natural Resource Protection, Surface Water \& Wetlands
}

\section{NPDES}

\author{
Program Coordinator
}

Brad Wilson

\section{Program Description}

Tritium discharges once-through segregated process cooling water and other lowlevel, non-hazardous liquid effluents to tributaries of Upper Three Runs Creek (NPDES Outfall H-002) and Four Mile Creek (NPDES Outfall H-012). These liquid effluents are monitored by Tritium Operations twice a day for tritium concentration. EMS also measures tritium concentration on a weekly or every other week basis depending on the discharge point. Replacement Tritium Facility liquid effluents from their cooling tower and hold volume are also analyzed prior to discharge to site streams.

\section{Organizational Responsibility}

Tritium Environmental (200 Area ES\&H) is responsible for ensuring that the liquid discharges from the Tritium Facilities comply with the Clean Water Act (NPDES).

\section{Major Milestones Accomplished in FY92}

- Participated on the SRS Environmental Release Prevention Taskforce (ERPT). Developed action items for ensuring that liquid effluents are properiy monitored for tritium. All TF-specific action items resolved.

- Developed Tritium Facilities program for sampling the H-002 (HP-15) and H-012 (HP-50) outfalls for tritium concentration. Procedures developed for sampling, analysis, and response to high tritium concentrations.

- $\quad$ RTF erosion control project initiated. Modifications made to RTF sedimentation basin to reduce potential for solids going to the outfall.

- Stormwater discharge routes in the Tritium Facilities walked down. Stormwater discharge permit application made.

- SCDHEC 3560 audit of the NPDES H-002 and H-012 outfalls found no deficiencies.

\section{Major Milestones for FY93}

- Install continuous tritium monitors at the TF liquid effluent discharge points.

- Potentially relocate H-002 outfail or consolidate it with $\mathrm{H}-004$ outfail.

- Submitted NPDES permit renewal application for H-002 and H-012 outialls. 


\section{Major Milestones for FY94-98}

Toxicity testing of the H-002 and $\mathrm{H}-012$ outfalls with on-site screening to be determine applicability (potentially FY93). 


\title{
Waste Management \& Disposal
}

\author{
Waste Management
}

\section{Program Coordinators}

Brad Wilson and Craig Johnson

\section{Program Description}

The Tritium Facilities generate various forms of waste to include non-hazardous, hazardous, mixed, and sanitary wastes during normal operations. Procedures and plans have been developed and implemented to ensure environmental compliance, as well as, proper waste management and disposal practices.

\section{Organizational Responsibility}

Tritium Environmental (200 Area ES\&H) provides assistance to ensure Tritium Facilities compliance with applicable waste management regulations (e.g. RCRA). Tritium Environmental personnel also provide technical support and training for various TF waste management activities and disposal practices especially with regard to waste minimization and RCRA compliance.

\section{Major Milestones Accomplished in FY92}

- $\quad$ RCRA training developed and presented to appropriate personnel.

- Waste minimization training developed and presented to appropriate personnel.

- TF waste minimization plan reviewed and revised.

- Non-hazardous, low-level radioactive waste generation reduced 15 percent.

- Practice of reviewing operating procedures for waste minimization applicablity initiated.

- Waste minimization information presented in TF update newsletter.

- $4 \mathrm{HW} / \mathrm{MW}$ shipments made to Waste Management.

- All quarterly hazardous waste reports prepared and submitted on schedule.

- Provided a TF interface to the Hazardous Waste/Mixed Waste Treatment Facility project (Title I Design review).

- Supported SCDHEC RCRA CME audit preparation and followup.

- Developed schedule for implementation of a Waste Certification Program during FY93-94. 
Major Milestones for FY93

- Prepare for SCDHEC RCRA Compliance Monitoring Evaluation (CME).

- More RCRA and Waste Minimization Training

- Transfered expired/unused chemicals to Construction Sort Yard for use by other SRS work groups.

- Continue implementation of Waste Certification Program milestones.

\section{Major Milestones for FY94-98}

- TF low-level waste compactor installed.

- Complete Waste Certification Program implementation.

- Conduct follow-up PWA on low-level radioactive waste. 


\title{
Atmospheric Protection
}

\author{
Air Emissions
}

\section{Program Coordinator}

Paul Rowan

\section{Program Description}

Tritium Facilites operations emit tritium to the atmosphere from all TF processing buildings. These atmospheric effluents are sampled and monitored to ensure personnel protection, as well as, state and federal environmental regulatory compliance. Other non-radioactive emissions potentially include asbestos from equipment insulation, HCFCs/CFCs from HVAC systems and degreasing operations, and diesel generator exhaust from permitted sources in the TF.

\section{Organizational Responsibility}

Tritium Environmental (200 Area ES\&H) is responsible for ensuring that the Tritium Facilities complies with the Clean Air Act and any other state or federal regulation designed to protect the atmosphere.

\section{Major Milestones Accomplished in FY92}

- Provided environmental interface/support for Project S-3751, Improved Tritium Stack Samplers and Monitors.

- Asbestos abatement projects on HVAC equipment continues.

- Developed FPR for a project to install isokinetic sampling on the building 232-H, Line III stack.

- Assisted in preparation for the SCDHEC air compliance inspection of two TF permitted sources. Provide TF environmental interface during the inspection.

- Provided TF interface to EPA Region IV NESHAP compliance inspection of TF exhaust stacks.

\section{Major Milestones for FY93}

- Complete TF Air Emissions Inventory (EPD and Radian Corporation (subcontractor) assisting).

- Prepare schedule for implementation of HCFC/CFC phaseout in the TF. Determine appropriate substitute materials or actions.

- Provide TF interface and data for the Action Plan for the prevention and control of radioactive releases for the Environmental ALARA Management Steering Committee. 
- Continue asbestos abatement projects as necessary.

- Provide SCDHEC air emissions data for air compliance inspection.

- Complete Project S-3751, Improved Tritium Stack Samplers and Monitors. Evaluate stack monitoring capability and report results to EPA Region IV personnel.

\section{Major Milestones for FY94-98}

- Develop TF program for maintaining Air Emissions Inventory data.

- Revise air emissions data to reflect potential for reduced tritium emissions as a result of building $233-\mathrm{H}$ assuming all tritium loading and unloading operations. 


\title{
Environmental Restoration Program
}

\author{
Environmental Restoration
}

Program Coordinator

Paul Rowan

\section{Program Description}

Currenty, there are no active environmental restoration projects within the Tritium Facilities. However, preliminary work has been done on characterizing (describing) the abandoned, inactive $\mathrm{H}$-Area seepage basin header (18 inch vitrified clay pipe) located inside the Tritium Facilities fence. No future environmental restoration projects within the Tritium Facilities have been determined.

\section{Organizational Responsibility}

Environmental Restoration (ER) is responsible for any remediation projects on the SRS. Tritium Environmental (200 Area ES\&H) provides technical support and information to ER to aid in their assessments of any abandoned waste sites. EPD also provides assistance in assessment of these abandoned waste sites from a regulatory compliance standpoint.

Major Milestones Accomplished in FY92

- Repaired leaking abandoned seepage basin header during repair work on Tritium Facilities Entry Control Facility (ECF) vehicle trap. (Assistance by EPD and ER.)

- Made a preliminary characterization of the abandoned, inactive H-Area seepage basin header located inside the Tritium Facilities fence.

\section{Major Milestones for FY93}

- Formally document the characterization on the abandoned seepage basin inside the Tritium Facilities. Locate access points and potential sources of water inleakage.

\section{Major Milestones for FY94-98}

To be determined. Unknown at present time. 


\section{Reactor Division Environmental Summary}

\section{Department}

Reactor Environmental Stabilization and Heavy water Departments (RES\&HWD)

To provide environmental technical support, project oversight, and management of activities affecting or having the potential to affect the mission of the Reactor Division and the Savannah River Site, or the environmental quality of the site or surrounding community.

\section{Vision}

To establish and manage programs for improving environmental compliance and awareness within the Reactor Division and set the standard for proactive Division Environmental Compliance Programs.

\section{Lead Environmental Coordinator}

Peter D. Hanley, x7-7523. 


\title{
Chemical Management, Pollution Prevention, and Other Compliance Programs
}

\author{
National Environmental Policy Act (NEPA)
}

Program Coordinator

Sheri C. DeLattre, $\times 7-7416$

\section{Program Description}

This program ensure the NEPA process is adequately addressed by RD and that the EEC checklists are properiy completed and correct actions are taken. Also acts as the liaison between the site and $\mathrm{RD}$ in implementation of the Mitigation Action Plan for wetland management and restoration.

Major Milestones Accomplished in FY92

- Updated the Mitigation Action Plan (MAP)

Major Milestones for FY93

- Annual update MAP 


\title{
Natural Resource Protection, Surface Water and Wetlands
}

\section{NPDES}

\author{
Program Coordinator
}

Dan P. Skiff, x7-7355

\section{Program Description}

Water Compliance: The water compliance program involves Clean Water Act (CWA) compliance and grouno water activities. The CWA compliance includes NPDES outfall oversight, waste water treatment facility permit (retention basin liner and percolation drain field) and waste water treatment facility construction permit (Cooling Tower) oversight. Other ongoing projects include waste stream characterization, and outfall toxicity studies where needed.

\section{Major Milestones for FY93}

- Complete and submit update to Site BMP to include Cooling Tower to maintain compliance with construction permit \#16,785

- Complete and submit new form $2 \mathrm{C}$ on Cooling Tower discharge to maintain compliance with NPDES permit\#SC0044903

- Complete and submit revised outfall permit application package for NPDES permit \#SCO000175

- Implement site Stormwater Pollution Prevention Plan in Reactor Areas

- Complete review of Reactor Groundwater Monitoring Sampling program and submit for cost reduction

Major Milestones for FY94-98

- Complete and submit 2C application for K-018 outfall (5 year renewal) 


\section{Groundwater Protection}

\section{Underground Storage tanks}

\section{Program Coordinators}

Sheri C. DeLattre, $x 7-7416$.

\section{Program Description}

Soil Remediation: The soil compliance program involves above ground and underground storage tank management and removal. This program ensures appropriate actions are taken during the lifetime and disposal of tanks to fulfill state and federal requirements.

\section{Major Milestones for FY93}

- Asbestos removal from 412-D extraction towers and gas plant

- Removal of 108-K UST system

- Removal of petroleum contamination beneath 191/180-4K

- Removal of 108-4C AST and petroleum contamination

- Shipments of all RRD petroleum contaminated soil to D-Area bioremediation facility. 


\section{Atmospheric Protection}

Air Emissions

\section{Program Coordinator}

Ron J. Wood, $x 7-7347$

\section{Program Description}

Air Compliance: The air compliance program involves all aspects of air regulations. These include National Emission Standards for Hazardous Air Pollutants (NESHAP), Air Emission Inventories (AEI), and other Clean Air Act related initiatives. Under NESHAP the RD has to continuously monitor the $105-\mathrm{K}$ main stack and the main stacks of other reactor areas as they become operational for tritium and argon. The AEI programs are underway in the reactor areas.

Major Milestones Accomplished in FY92

- Hot Wire Anemometer Certification 9/92

- Air Emission Inventory - K-Area and portions of D-Area and Central Shops

Major Milestones for FY93

- Air Emission Inventory - L-Area, P-Area, C-Area, R-Area 


\title{
Waste Management and Disposal
}

\author{
Program Coordinator
}

David M. Nichols, $\times 7-7309$

\section{Program Description}

Waste and Materials: The waste and materials section covers all waste and materials related compliance issues in the $R D$. This function grouping includes RCRA, Waste Minimization, Land Disposal Restrictions, Waste Acceptance Criteria, SARA, Haz Com, Chemical Control program coordination, and lead tracking. This functional grouping deals with implementation of the Waste Acceptance Criteria and associated procedure and programmatic upgrades. Provide guidance and oversight as necessary for staging and satellite area management and RCRA issues. Waste minimization is addressed through coordination of a Process Waste Assessment and employee awareness. Coordination of the annual SARA Tier II and Title III reports.

\section{Major Milestones Accomplished in FY92}

- Completed the Process Waste Assessment for Low-Level Waste

\section{Major Milestones for FY93}

- Complete Waste Acceptance Criteria

- Complete WesTIP on Chemical Control and Implement recommendations 


\section{Waste Management and Disposal}

CERCLA

Program Coordinator

Barry L. Myers, $x 7-7327$

Program Description

Provide guidance for issues related to CERCLA, and environmental ALARA.

Major Milestones Accomplished in FY92

- Implementation of Ima Ware, an informative employee awareness bulletin via All-In-1. 


\title{
Waste Management and Environmental Restoration Division Environmental Summary
}

\author{
Department
}

SRTC Savannah River Technology Center Environmental Summary

\section{Mission}

The Savannah River Technology Center (SRTC) will support the current and future SRS Mission by providing the technical basis, understanding and advanced capabilities for safe, environmentally sound, high-quality, cost-effective, and continually improving operations.

Vision

To be highly valued by our customers as a technically excellent, innovative, effective, results-oriented, cost-conscious, technical laboratory that is an essential contributor to fulfilling the SRS Mission and is highly regarded by our employees as fostering an atmospt.ere of teamwork, safety, environmental stewardship, challenge and continual improvement.

\section{Environmental Challenges and Issues from Projected Mission Changes During the Next Five Years}

SRTC functions as an applied research and development center, providing technical support for all the major activities and operating facilities at the SRS. Currently the division provides this research and development for the site through the following major programs:

- providing technical support for chemical separation processes, tritium process development, reactor operations, and manufacture of fuel and target assemblies,

- developing computer codes for use in research and development.

- conducting safety analyses on reactor and nonreactor processing operations, and

- conducting research, process development, and technical support for the management of radioactive wastes and environmental issues.

As the site undergoes changes in its mission in future years, the SRTC mission will change to provide technical support, research and develor «nen'. on new site initiatives.

\section{Lead Environmental Coordinator}

Nancy V. Halverson 


\section{Chemical Management, Pollution Prevention, and Other Compliance Programs}

\section{Safe Drinking Water Act}

\section{Program Coordinator}

Power Department

\section{Organizational Responsibility}

Drinking water for SRTC facilities is completely the responsibility of the Power Department except at TNX. The TNX Domestic Water Facility is operated jointly by TNX Operations Section and Power. TNX Operations take water samples every shift to check $\mathrm{pH}$ and residual chlorine. If the readings are outside the appropriate range, Power is called to make the necessary chemical adjustments. Power also takes daily samples to check $\mathrm{pH}$ and residual chlorine and makes chemical adjustments based on their results.

\section{Major Milestones for FY93}

- Power will cake responsibility for operation and maintenance of the chemical addition shed associated with the quality of TNX domestic water.

- TNX will maintain responsibility for operation and maintenance of facility wells and valving. 


\title{
National Environmental Policy Act
}

\author{
Program Coordinator
}

Ann Y. Galbraith

\section{Program Description}

The WSRC NEPA implementation procedure (Environmental Compliance Manual 3Q. procedure 5.1 DRAFT) requires site departments to have Department NEPA coordinators. SRTC has a single Department NEPA coordinator to cover all SRTC departments. The Department Coordinator is responsible for ensuring implementation of NEPA provisions within SRTC. The Department Coordinator screens Environmental Evaluation Checklists to ensure the information is accurate and determine whether further review and analysis is required by the Environmental Protection Department.

Organizational Responsibility

The Department Coordinator reports to the Environmental Support Group.

\section{Major Milestones/Accomplishments from FY 92}

- Established a Departmental NEPA coordinator for SRTC. 


\title{
Natural Resource Protection, Surface Waters and Wetlands
}

\author{
Program Coordinators \\ Brian K. Culligan and Nancy L. Turner
}

\section{Program Descriptions}

SRTC releases treated and untreated effluent from Technical Area, TNX \& B-Area facilities. SRTC is custodian of seven NPDES outfalls and several unpermitted outfalls. The NPDES outfalls are sampled monthly for nonradioactive parameters. Two of the outfalls are sampled for radioactive constituents. Storm water permits have been submitted for nine outfalls.

SRTC also owns and operates four permitted wastewater treatment facilities. Two of these facilities release treated effluent through outfalls to site streams and on to the Savannah River. Each process batch is sampled by SRTC personnel and analyzed to ensure compliance with NPDES permit limits.

\section{Organizational Responsibility}

The TNX Operations Section and Laboratory Services Section are custodians of and operate the outfalls and wastewater treatment facilities. The Environmental Support Group provides oversight and guidance to ensure that SRTC facilities and activities remain in compliance with applicable regulations.

\section{Major Milestones/Accomplishments from FY 92}

- Chronic/acute toxicity testing performed on five SRTC outfalls to ensure no harm to the environment.

- Initiated laboratory discharge characterization.

- Performed nondestructive testing on low activity waste tank at 735-A to ensure that no leakage from the tank would reach surface waters of the state.

- Verified that sump around low activity waste tank at 735-A could hold contents of tank to ensure that no leakage from the tank would reach surface waters of the state.

- Established radiological outfall discharge criteria for rainwater in dike around 735-A low activity waste tank.

- Revised BMP plan.

- Reduced ALARA goal for A-001 outfall.

- No deficiencies found on the 3560 Audit.

- No deficiencies found on the SCDHEC Compliance Sampling Audit. 
- Walked down all stormwater outfalls for Stormwater Permit.

- Coordinated emergency treatment of diesel contaminated wastewater to ensure no NPDES deficiencies.

- Coordinated emergency treatment of ethylene glycol contaminated wastewater to ensure no NPDES violations.

\section{Major Milestones for FY 93}

- Submit NPDES permit renewal application.

- Negotiate new NPDES permit conditions and ensure compliance when issued by SCDHEC.

- Submit experimental treatment request to test treatment methods for removal of mercury from 607-17A waste neutralization facility.

- Complete wastewater discharge characterization.

- De-list NPDES Outfall X-011.

- Implement non-destructive testing program on all BMP/SPCC tanks at TNX.

- Update BMP/SPCC for TNX.

- Develop Pollution Prevention Plan for TNX in conjunction with Bechtel.

- Install Stormwater monitoring point for Outfall X-001.

\section{Major Milestones for FY 94-98}

- Submit waste water permit modification for 607-17A.

- Update BMP/SPCC annually or biannually

- Conduct Toxicity Identification Evaluation.

- Implement the Pollution Prevention Plan for TNX including the construction of the Contained Storage Pad. 


\section{Waste Management and Disposal}

Waste Management

\section{Program Coordinators}

Doris L. Simmons, Ann Y. Galbraith, Nancy L. Turner

\section{Program Description}

SRTC generates sanitary, low level, TRU, WIPP, hazardous and mixed waste. SRTC waste handling facilities include numerous hazardous waste satellite areas, hazardous waste 90-day staging areas, a waste assay facility, a low level waste storage yard, and a RCRA Treatment. Storage and Disposal (TSD) facility.

Organizational Responsibility

The TNX Operations Section operates the TNX staging area. The Laboratory Services section operates the waste assay facility, low-level waste storage yard and the RCRA TSD. Organizations generating hazardous and mixed waste are custodians of the satellite areas and some staging areas. The Environmental Support Group (ESG) provides guidance and oversight to ensure compliance with applicable regulations. The ESG also is responsible for the waste minimization program.

\section{Major Milestones/Accomplishments from FY 92}

- Began visually inspecting high and low activity waste storage tanks' (TSD facility) secondary containment and repairing minor cracking.

- Began conducting nondestructive integrity tests on the high and low activity waste storage tanks.

- Repaired broken trade waste line, resulting in significant decrease in water seeping into the low activity gallery.

- Implemented the new 3Q manual satellite area procedure.

- Issued the waste handling guidelines procedure in the SRTC Procedures Manual.

- No major findings from the SCDHEC CME audit.

- Maintained all RCRA training as required by the regulations.

- Performed waste characterizations on TNX waste streams.

- Submitted Quarterly Hazardous Waste Reports prior to EPD deadlines.

- Provided training to TNX personnel on segregation of nonhazardous materials. 


\section{Major Milestones for FY 93}

- Complete visual inspections of high and low activity waste storage tanks' (TSD facility) secondary containment and complete repairs of minor cracking.

- Complete conducting nondestructive integrity tests on the high and low activity waste storage tanks.

- Start decontamination of high and low activity waste storage tanks' (TSD facility) secondary containment.

- Revise blue dot procedure.

- Develop waste certification program for SRTC low level and mixed waste.

- Conduct self assessment on TRU waste.

- Implement new 3Q procedure on staging areas.

- Complete a process waste assessment for hazardous wastes.

- Evaluate TNX tank inventories and possible disposal methods.

- Evaluate TNX drum storage and possible disposal methods.

\section{Major Milestones for FY 94-98}

- Develop and implement waste certification programs for other waste categories.

- Implement waste certification program for SRTC low level and mixed waste $12 / 93$. 


\section{Waste Minimization}

\section{Program Coordinators}

Doris L. Simmons, Pauline D. Tu, Diane K. Singer

\section{Program Description}

SRTC's waste minimization plan is documented in the Savannah River Laboratory Procedures Manual, L1. procedure 6.12. The plan is approved by the SRTC Vice President to demonstrate SRTC's commitment to WSRC's goal of waste minimization. The program covers all types of wastes generated by current and future activities. The focus of the program is on waste reduction by source reduction, recycling and treatment. Program elements include waste inventories and characterization, developing baseline criteria, conducting research and development. conducting process waste assessments, and setting goals and milestones.

\section{Organizational Responsibility}

The Environmental Support Group of Laboratory Operations and Services is responsible for developing, managing, tracking and updating the waste minimization plan. All people using SRTC facilities are responsible for implementing the plan. The SRTC research organizations are responsible for conducting research and development in waste minimization techniques.

\section{Major Milestones/Accomplishrnents from FY 92}

- Conducted Process Waste Assessment on low level waste.

- Installed computer with a chemical database at chemical stores to determine if chemicals are already available in SRTC laboratories.

- Developed waste minimization checklist for work clearance permits.

- Reviewed/revised baseline criteria.

\section{Major Milestones for FY 93}

- Revise SRTC waste minimization plan.

- Provide general waste minimization training to SRTC personnel - 4/93.

- Conduct Process Waste Assessment on hazardous waste

- Issue report on Process Waste Assessment on low level waste - 12/92.

- Reduce generation of "routine waste" B-25 boxes by $15 \%$ 


\section{Major Milestones for FY 94-98}

- Issue report on Process Waste Assessment on hazardous waste - 12/93.

- Revise SRTC waste minimization plan annually.

- Conduct Process Waste Assessments on other waste categories. 


\section{Environmental Program}

Atmospheric Protection

Program Coordinators

Amy L. Fishburne and Nancy L. Turner

\section{Program Description}

The SRTC air emissions program covers radioactive and nonradioactive air emissions from the SRTC Technical Area, Lower 700 Area SRTC facilities, B-Area SRTC laboratories, and TNX. The program is comprised of physical monitoring and sampling of the highest risk emission sources and administrative controls for lesser emission sources. The program covers all activities necessary to ensure that new and existing facilities comply with current regulatory requirements.

\section{Organizational Responsibility}

A variety of SRTC and non-SRTC organizations play a part in the SRTC atmospheric protection program. The SRTC Environmental Support Group (ESG) is responsible for providing guidance and oversight to ensure that atmospheric discharges are in compliance with applicable regulations.

\section{Majur Milestones/Accomplishments from FY 92}

- The 773-A exhaust system and the 773-A, 735-A, and 776-A stack sampling systems were declared "priority systems" to ensure that programs are in place to operate and maintain these systems in a manner which provides maximum reliability.

- Filter paper hold-down devices were installed on the 5 major radiological stacks.

- Developed trending of environmental release data.

- Provided environmental regulatory and technical support for FY 95 project to upgrade 4 stacks with isokinetic sampling systems.

- Completed SCDHEC air emissions inventory for permitted sources.

- Completed annual SCDHEC air compliance inspection on permitted sources.

- Completed comprehensive air emissions inventory of TNX and lower 700 Area facilities.

- Initiated comprehensive air emissions inventory of Technical Area facilities.

- Load tested permitted diesel emergency generators to ensure compliance with opacity limits.

- Obtained the construction permit for the Offgas Component Test Facility. 


\section{Major Milestones for FY 93}

- Complete comprehensive air emissions inventory of Technical Area.

- Install new sample box at 735-A stack.

- Submit Functional performance Requirements document to DOE for stack upgrade project.

- Renegotiate Federal Facilities Compliance Agreement to incorporate SRTC stack upgrades.

- Complete Action Plan for the prevention and control of airborne radioactive releases for the Environmental ALARA Management Steering Committee.

- Review the possibility of exempting permitted diesel fuel generators.

- Develop program to maintain current air emissions inventory.

- Complete the compilation of the comprehensive Air Emission Inventory for calendar years ' 91 and ' 92 .

- Submit to SCDHEC the Air Emissions Inventory for permitted facilities.

\section{Major Milestones for FY $\mathbf{9 4 - 9 8}$}

- Conduct comprehensive air emissions inventories for 1992, 1993, 1994, 1995 , 1996 and 1997 emissions.

- Complete isokinetic sampling system upgrades to 4 Technical Area stacks. 


\section{Environmental Restoration}

\section{Environmental Restoration}

\section{Program Coordinator}

Nancy L. Turner and Ann Y. Galbraich

\section{Program Description}

Environmental Restoration (ER) has one closure project in process at the TNX facility and one adjacent to the Technical Area. The closure plan for the New TNX Seepage Basin and the work plan for the 904-A trench waste site are currently with SCDHEC for review. Future ER projects include further characterization and review of the Old TNX Burying Ground and the Old TNX Seepage Basin.

Environmental Sciences (ES) has several current and projected remediation projects for the TNX facility. Currently, TOS personnel are operating a trickle flow bioreactor to treat groundwater contaminated with volatiles. They are also supporting an in situ bioremediation project concerning the 678-T diesel spill. Future ES projects include two additional bioreactor units, an air stripper and a catalytic oxidation unit.

The trickle flow bioreactor discharges to the TNX Organic Removal Facility to Outfall X-014 and on to the Savannah River via Outfall X-008.

\section{Organizational Responsibility}

ER is responsible for ensuring that all closure projects are in compliance with applicable federal and state regulations. The Environmental Support Group of SRTC is responsible for oversight and support of the ES groundwater remediation program at TNX. Document preparation associated with the 904-A trench waste site is being managed by the Environmental Support Group rather than ER because the site is still an active facility. The Environmental Support Group will also provide project liaison between operations groups, ER, and ES on all future remediation efforts in SRTC facilities.

\section{Major Milestones/Accomplishments from FY 92}

- Gained SCDHEC operating approval for the trickle flow bioreactor.

- Submitted the work plan for the 904-A trench waste site to the EPA.

- Provided support for development of the closure plan for the New TNX Seepage Basin. 
- Installed an in situ bioremediation unit for experimental clean up of diesel contaminated soil.

- Provided project liaison for ER projects.

- No 3560 audit findings.

\section{Major Milestones for FY 93}

- Obtain a SCDHEC industrial wastewater operating permit for the trickle flow bioreactor.

- Coordinate permitting requirements for the mobile bioreactor unit.

- Provide project liaison for future ER projects.

- Continue work on the 904-A trench waste site according to approved schedules.

\section{Major Milestones for FY $\mathbf{9 4 . 9 8}$}

- Continue work on the 904-A trench waste site according to approved schedules.

- Coordinate permitting requirements for the TNX groundwater remediation unit (i.e. air stripper and catalytic oxidation units).

- Coordinate permitting requirements for the Fluidized Expanded Bed Eioreactor Unit. 


\title{
Site Services Division Environmental Summary
}

\section{Department}

Central Services Works Engineering (CSWE)

\author{
Mission
}

CSWE pledges to provide quality works engineering services and training in a way that meets our customers' needs while having no injuries, operating within budget constraints, and maintaining high morale so that process downtime is minimized, the environment is maintained or improved, and site commitments to DOE are satisfied.

\section{V:sion}

To be recognized by our internal customers as the best maintenance organization at SRS and to be recognized by DOE as the best in the DOE complex.

\section{Lead Environmental Coordinator}

\author{
Traci A. Richardson
}




\title{
Chemical Management, Pollution Prevention, and Other Compliance Programs
}

\section{Pesticide Program}

\section{Program Coordinator}

\author{
T.A. Richardson
}

Field Coordinator

T. McCormick

\section{Program Description}

CSWE has a 2-3 man crew (located in Central Shops) to apply approved pesticides to the roads, fields, and grounds. In general, two subsuntractors assist the CSWE crew in the application process. Most pesticides are applied between the months of MarchOctober. Excess pesticide material is stored in Building 709-N.

\section{Organizational Responsibility}

In conjunction with SRFS, CSWE is responsible for vegetation control involving SRS roads, fields, and grounds (i.e. substations, powerline right-of-ways, perimeter fence lines, roadways, etc). CSWE maintains STR (Subcontract Technical Representative) responsibilities for various pesticide contracts as well as two certified applicators within the department. Fire ant control is also available through this program.

\section{Major Milestones Accomplished in FY92}

CSWE assisted in establishment of the sitewide Pesticide Control Committee (PCC). This committee developes procedures, sets policy, and ensures compliance on a sitewide basis.

\section{Major Milestones for FY93}

Maintain vegetative control for approximately 250 acres turrugh use of CSWE certified applicators only (no subcontracts). Subcontracts will control the remaining areas. 


\section{Natural Resource Protection, Land Use \& Wildlife}

Petroleum Contaminated Soil Storage (PCS) and Bioremediation Facility

\section{Program Coordinator}

T.A. Richardson

Field Coordinator

J. Kirby

\section{Program Description}

In FY'93, CSWE will store non-hazardous and non-radioactive PCS material for SRS. The proposed storage facility will be located in D-area. CSWE will also operate the Bioremediation Facility which will serve to prepare the PCS for use as landfill cover or backfill material.

\section{Organizational Responsibility}

CSWE will serve as custodian of both the PCS Storage Area and the Bioremediation Facility. CSWE is responsible for establishing the Waste Acceptance Criteria for the facilities. CSWE will store the PCS in accordance with applicable SCDHEC requirements and operate the Bioremediation Facility according to its permit (with technical assistance from SRTC). The waste generator must properly characterize the PCS and adhere to the Waste Acceptance Criteria for storage of PCS.

\section{Major Milestones Accomplished in FY92}

Created PCS Task Team comprised of representatives from CSWE, EPD, WM, SSE, and Reactor. Task team developed draft Waste Acceptance Criteria.

\section{Major Milestones for FY93}

Construct Storage Area and Bioremediation Facility and initiate program. 


\title{
Natural Resource Protection, Land Use \& Wildlife
}

Creosote Wood Storage

\author{
Program Coordinator
}

T.A. Richardson

Field Coordinator

T. McCormick

\section{Program Description}

CSWE stores used creosote fence posts, guard rail posts, railroad ties, and powerpoles at Gunsite 12 per 3 Q6 SOP9-34043. A small number of these products are freereleased by HP for sale off-site. The majority of this wood, however, is stored for future use on-site at SRS (i.e. erosion control, construction projects, etc). Individuals interested in this material must contact CSWE.

\section{Organizational Responsibility}

CSWE is custodian of the Gunsite 12 Creosote Wood Storage Area. As custodian, CSWE is responsible for controlling access to Gunsite 12 and approving material to be stored at Gunsite 12. The wood generator is responsible for completing the Creosote Wood Data Sheet, obtaining HP surveys (as needed), contacting CSWE prior to wood delivery, and following the applicable CSWE procedure (3Q6 SOP9-34043).

\section{Major Milestones Accomplished in FY92}

Revised 3Q6 SOP9-34043.

\section{Major Milestones for FY93-96}

Work with Construction and Power to chip the creosote wood and use as a fuel additive in the D-area Powerhouse. 


\title{
Natural Resource Protection, Surface Water \& Wetlands
}

NPDES Outfalls

\author{
Program Coordinator
}

T.A. Richardson

Field Custodians

S.E. Smith (A005); E. McCalister (CS014); R.H. Moore (CY001)

\section{Program Description}

CSWE is custodian of 3 NPDES outfalls. The CS-014 and CY-001 outfalls receive stormwater runoff only. The A005 outfall receives stormwater from upper 700-area as well as discharge from the SREL duck ponds.

Organizational Responsibility

CSWE is responsible for maintaining compliance at these outfalls and operating each facility in accordance with the NPDES permit. Organizations contributing to the discharge at each of these outfalls are responsible for contacting the proper custodian prior to discharging to ensure that permit conditions will not be violated.

Major Milestones Accomplished in FY92

Issued request to SCDHEC to remove CS-014 and CY-001 outfalls from NPDES permit list.

\section{Major Milestones for FY93}

Consolidate A-005 (with various others) with the A-001 outfall. Pending SCDHEC approval, sampling will only be required at the A-001 outfall. 
Division Environmental Summary - Central Services Works Engineering Environmental Implementation Plan

\section{Groundwater Protection}

Removal of USTs

Program Coordinator

T.A. Richardson

Field Coordinator

J. Kirby

Program Description

CSWE removes abandoned Underground Storage Tanks (USTs) across the site. Services rendered include pumping product from the tank, properly venting the tank, excavating the tank, and backfilling. CSWE will provide assistance with soil sampling and tank disposal as needed.

Organizational Responsibility

CSWE is responsible for providing the equipment and personnel necessary for removing the USTs. The tank owner is responsible for notifying EPD prior to tank removal, submitting a work order to CSWE, disposing of any liquid removed, obtaining necessary soil samples, submitting closure reports to EPD, and disposing of the tank.

Major Milestones Accomplished in FY92

Removed 16 USTs for Reactor, Power, and DOE SRS-OC.

Major Milestones for FY93

Crush and dispose of approximately 25 USTs for CSWE, Power, and Reactor. 


\section{Waste Management \& Disposal}

Oil Filter Compacting

\section{Program Coordinator}

T.A. Richardson

Field Coordinator

R.M. Eberl

Program Description

CSWE's Tire and Lube Shop hot drains oil filters from the site's light vehicle/heavy equipment fleet. Once the filters are hot drained, they are compacted to 1/3 its original size. This program removes $80 \%$ more oil from the filter as opposed to gravity draining only.

Organizational Responsibility

CSWE is responsible for servicing the WSRC light vehicle/heavy equipment fleet. Compaction of oil filters removed during this servicing activity is the responsibility of CSWE's Tire and Lube Shop.

\section{Major Milestones Accomplished in FY92}

Compacted over 3,000 oil filters which saved 44 cubic feet of landfill space AND prevented approximately 950 gallons of oil from reaching the landfill through solid waste disposal.

\section{Major Milestones for FY93}

Incorporate oil filter heater into draining/compaction program to increase amount of oil removed prior to compaction. 


\title{
Site Services Division Environmental Summary
}

\author{
Department
}

Site Services Engineering (SSE)

\section{Mission}

To provide engineering design and technical support to our customers in a way that is value-added, environmentally responsible, and protects the health and safety of all employees.

\section{Vision}

To be recognized as the value-added leader in technical and engineering excellence in support of our customers' facilities and processes.

\section{Lead Environmental Coordinator}

\author{
Allen B. Edenfield
}




\title{
Chemical Management, Pollution Prevention, and other Compliance Programs
}

Domestic Water Systems

\author{
Program Coordinator
}

Robert D. Turner

\section{Program Description}

Verify site domestic water supplies meet all SCDHEC water quality standards. Meet SCDHEC commitments for implementing the sitewide cross connection control program. Comply with the SCDHEC lead and copper rule. Meet SCDHEC commitments for scheduled completion of domestic water upgrade projects. Provide technical support to the operation of the site well complex. including the formal closure of inactive production wells per SCDHEC requirements.

\section{Major Milestones Accomplished in FY92}

- Implemented sitewide cross connection control program.

- Initiated engineering study to evaluate options for consolidating sitewide domestic water systems.

- Completed system modifications and actions in 12 site domestic systems to provide enhanced pressure protection.

- All domestic water upgrade projects kept on schedule with SCDHEC commitment dates.

\section{Major Milestones for FY93}

- Analyze all site domestic water supplies for SCDHEC regulated contaminants.

- Complete cross connection inspection for $45 \%$ of total site facilities.

- Baseline sample all site domestic water systems for lead and copper.

- Issue Wells Management Plan.

- Abandon four inactive production wells.

\section{Major Milestones for FY94-98}

- Analyze all site domestic water supplies for SCDHEC regulated contaminants.

- Abandon inactive production wells.

- Complete sampling/analysis of the 14 domestic water supplies for lead and copper.

- Complete cross connection inspection for site facilities. 


\section{Natural Resource Protection, Surface Water \& Wetlands}

\section{Waste Treatment Facilities}

\section{Program Coordinator}

Ronda L. Huffines

\section{Program Description}

Provide an environmentally beneficial method of disposing sludge from all of the site sanitary wastewater treatment plants(SWTP). Provide guidance to the expansion/consolidation of SWTP. Provide technical guidance to the operation of SWTP in efficient and environmentally sound manner.

Major Milestones Accomplished in FY92

- Submittal of sludge application permit to SCDHEC.

- Developed baseline documents (FPR, FDC, CDR) and received DOE approval to proceed with Title I design for centralized SWTP.

\section{Major Milestones for FY93}

- Obtain SCDHEC permit for sludge application to forested areas.

- Start construction on 1.05 MGD centralized SWTP and collection system.

\section{Major Milestones for FY94-98}

Provide technical guidance for development of a complete process control and NPDES certified lab at the Central SWTP. 


\title{
Natural Resource Protection, Surface Water \& Wetlands
}

NPDES

\author{
Program Coordinator
}

Brian D. Silas

\section{Program Description}

Coordinate Site Services Division(SSD) preparation and follow-up for the 3560 audit. Provide technical support for the negotiation of the new NPDES permit. Participate on the Site Toxic Control Strategy Team.

Major Milestones Accomplished in FY92

- Supported 3560 audit--all SSD outfalls in compliance.

- Completed pilot SPCC/BMP investigation of SSD A-Area facilities to identify potential sources for release of chemicals and petrochemicals.

\section{Major Milestones for FY93}

- Support 3560 audit.

- Coordinate testing of SSD outfalls.

- Recommend actions needed to eliminate toxicity at SSD outfalls.

\section{Major.Milestones for FY94-98}

- Support NPDES permit negotiations:

- Support projects to eliminate toxicity at SSD outfalls. 


\section{Atmospheric Protection}

Air Emissions

Program Coordinator

Kevin R. Scaggs

\section{Program Description}

Provide technical support to Power Operations for meeting boiler emission compliance testing. Provide NESHAP stack airflow measurements for site's radionuclide emission points. Update EPD on changes to SSD facilities which may affect the air emissions inventory.

Major Milestones Accomplished in FY92

Developed and implemented procedure to provide NESHAP stack airflow measurements for site.

Major Milestones for FY93

- Compliance testing of boilers D-2, D-4, and H-2.

- NESHAP stack measurements for A, F, M, and H Areas.

- Review air emissions inventory data for SSD.

Major Milestones for FY94-98

- Compliance testing of boilers A-1, A-2, and D-3.

- Monitor SSD facilities for changes affecting air emissions inventory.

- NESHAP stack measurements. 


\section{Waste Management \& Disposal}

Waste Management

Program Coordinator

James H. Riggsbee

\section{Program Description}

Provide technical assistance to SSD for the management of RCRA hazardous waste. Provide technical support to Power Operations for the closure of underground storage tanks. Support SSD preparation and follow-up for the annual CME audit. Provide technical leadership to SSD departments required to prepare waste minimization plans per DOE Order 5400.1. Provide technical support to 723-F Laundry process waste assessment for low level waste.

\section{Major Milestones Accomplished in FY92}

- Developed and presented RCRA-awareness training for SSD departmental management.

- Supported SSD departments in preparation and follow-up to CME audit.

- Developed sampling/analysis program for 723-F Laundry effluent wastewater.

\section{Major Milestones for FY93}

- Provide assistance in Power Operations development of a corrective action plan for closure of 108-3P underground storage tank site.

- Provide technical support for CME audit.

- Support SSD departments preparing CY94 waste minimization plans.

- Support Laundry process waste assessment.

\section{Major Milestones for FY94-98}

- Support SSD departments in revision of waste minimization plants.

- Provide technical support for CME audits. 


\title{
Waste Management and Environmental Restoration Division Environmental Summary
}

\author{
Department
}

Defense Waste Processing Facility (DWPF)

\section{Mission}

To provide environmental support to our customers in a way that is value-added. environmentally responsible and protects the health and safety of all employees.

Vision

To be recognized as the value-added leader in environmental regulatory compliance matters in a way that lends excellence in support of our customers' facilities and processes.

\section{Lead Environmental Coordinator}

Kathy Z. Wolf 


\section{Chemical Management, Pollution Prevention, and other Compliance Programs}

Domestic Water Systems

Program Coordinator

Johnny R. Prica

Program Description

Verify the DWPF Domestic Water System meets all SCDHEC water standards. Comply with the EPA Lead and Copper Rule. Interface with the SRS Power Water Services Department towards meeting SCDHEC project commitments. Meet SCDHEC cross-zonnection control requirements. Develop and obtain SCDHEC Construction ar.j Operating domestic water permits.

\section{Major Milestones Accomplished in FY92}

- Participated in sitewide cross connection control surveys.

- Participated with Site Services Engineering in evaluating options for consolidating sitewide domestic water systems.

- Obtained SCDHEC permission to permanently tie-in the DWPF Back-up Well to the Primary domestic water system.

- Completed baseline sampling for lead and copper.

- Obtained a SCDHEC/EPD construction permit to tie-in the 221-S Portable Nitric Acid Safety Shower Eyewash.

Major Milestones for FY93

- Begin compliance sampling for lead and copper.

- Determine the feasibility of consolidating $\mathrm{H}$ and S Area domestic water systems.

- Obtain SCDHEC domestic water permits for new facilities as needed.

\section{Major Milestones for FY94-98}

- Analyze the DWPF system for all SCDHEC regulated contaminants.

- Facilitate successful turnover of the DWPF domestic water system to the sitewide Consolidated Domestic Water Facility. 


\title{
Chemical Management, Pollution Prevention, and other Compliance Programs
}

National Environmental Policy Act (NEPA)

\author{
Program Coordinator
}

Clarke A. Stanford

\section{Program Description}

The National Environmental Policy Act (NEPA) as specified in 10CFR Part 1021 and DOE Regulations establishes responsibilities and requirements for preparation and use of the Environmental Evaluation Checklist (EEC). The intent of the EEC is to ensure that proper Federal and State permits are identified and subsequently obtained.

\section{Major Milestones Accomplished in FY92}

- Identified and trained area NEPA coordinators to review, screen and file EEC's applicable to DWPF.

- Assisted in the revision of site level NEPA implementing procedure 3Q ECM 5.1 and provided guidance for compliance on several recent DWPF process modifications (e.g., late wash facilities, ammonia scrubbers mitigation, etc.)

\section{Major Milestones for FY93}

- Prepare instruction/guidance procedures for full implementation of 3Q ECM 5.1 procedure.

- Orient EEC preparers on applicable procedures and establish formal lines of communications.

\section{Major Milestones for FY94-98}

Document and maintain an effective screening, preparation and review of EEC's for all area work action requests. 


\title{
Natural Resource Protection, Surface Water \& Wetlands
}

\section{NPDES}

(Industrial Waste Water Treatment)

\author{
Program Coordinator
}

Bharat Damani

\section{Program Description}

Develop , organize, lead and coordinate the activities related to the construction and operational permit (application/approval) from SCDHEC on DWPF vitrification and chemical treatment facility.

\section{Major Milestones Accomplished in FY92}

- Obtained operating permit for the vitrification facility.

- Obtained operating permit for chemical treatment facility.

- Secure DHEC approval on cold chemical run Addendum to operating permit (above).

- Met the requirements of DOE HQ ORR checklists without significant findings.

\section{Major Milestones for FY93}

- Obtain DHEC approval on modifications to the construction permit for the tank farm and /or vitrification facility for the following:

- Hydrogen scrubber modification

- Inner area transfer line

- Late wash modification to the Auxiliary Pump Pits

- Obtain DHEC approval on the on-site or off-site treatment and disposal (POTW) facility for DWPF cold chemical runs aqueous recycle waste stream.

\section{Major Milestones for FY94-98}

- Secure DHEC permit to operate the vitrification facility for the following:

- The modified Inner Transfer Lines

- The modified hydrogen and scrubber systems

- The new late wash systems 


\title{
Natural Resource Protection, Surface Water \& Wetlands
}

NPDES

\author{
Program Coordinator
}

Bharat Damani

\section{Program Description}

Provide directions and guidance to the facility operators on the implementation of BMP, SPCC under CWA and SCDHEC effluent discharge limit and control of toxic pollutants in the waste water. This includes:

- preparing NPDES outfall permit renewal applications;

- providing the evidence on discharge compliance; and

- evaluating toxicity criteria for the non-routine discharges to meet SCDHEC toxic control strategy.

Major Milestones Accomplished in FY92

- Submitted NPDES permit application for the following:

- DW4 outfall; permit renewal

- DW5 storm water outfall; new permit

- Develop the justification for outfall meeting discharge of biocided water for SCDHEC criteria on toxic control strategy.

- Successfully met the criteria/requirements identified in the site and DOE Headquarters ORR checklists without significant findings for corrective action.

\section{Major Milestones for FY93}

- Negotiate with SCDHEC for higher discharge of biocide concentration in DWPF's waste water based on the vendor's test results and the site sponsored biological study.

- Implement pollution prevention plan for storm water permit.

\section{Major Milestones for FY94-98}

- Improve capacity of sedimentation basins

- Reduce erosion and sedimentation of the soil by implementing storm water management and erosion/sedimentation control plan. 


\section{Natural Resource Protection, Surface Water \& Wetlands}

Waste Treatment Facilities

\section{Program Coordinator}

Johnny R. Price

\section{Program Description}

Provide guidance and permitting assistance for bringing the S-Area Sanitary Treatment Facility Expansion Facility, and other permitted tie-ins on-line. Interface with Site Services Engineering and Power Water Services towards meeting future site project aims.

\section{Major Milestones Accomplished in FY92}

- Obtained SCDHEC Construction Permit (\#17,351-1W) for the S-Area Sanitary Expansion Facility Upgrade project.

- Obtained SCDHEC Construction permit (\#7475) for installing a lift station and line apperturances to the to the 704-49S Trailer Complex.

- Interfaced with Site Services Engineering to ensure DWPF is included in consolidation plans for the centralized SRS SWTP.

\section{Major Milestones for FY93}

- Continue to interface with Site Services Engineering to ensure DWPF is included in construction of the 1.05 MGD centralized SWTP and collection system.

- Start construction of the S-Area Sanitary Upgrade (project completion by 12/31/93).

- Start construction of the $704-49$ S trailer complex tie-in project by $3 / 31 / 93$.

\section{Major Milestones for FY94-98}

- Complete tie-in of 704-49S sanitary services to the S-Area SWTP.

- Complete tie-in of the S-Area Sanitary Treatment Plant Upgrade project.

- Complete tie-in of the DWPF Sanitary Wastewater Treatment Facility to the sitewide Consolidated SWTP. 


\section{Groundwater Protection}

\section{Underground Diesel Storage Tanks}

\section{Program Coordinator}

Bharat Damani

\section{Program Description}

Evaluate the existing underground storage tanks for meeting the regulatory compliance and provide recommendation and guidance to the facility operators for their implementation. This includes; 1) evaluating and implementing the SCDHEC and site requirements; 2) performing surveillance on the monitoring and operation requirements; 3 ) reviewing procedures and respond to ORR checklists.

\section{Major Milestones Accomplished in FY92}

- Successfully met DOE Headquarters ORR Checklists items

- Met SCDHEC compliance requirements on the operation and design of underground storage tanks.

\section{Major Milestones for FY93}

- Review the operation of cathodic protection systems and level detection system.

- Implement adequate record keeping requirements.

\section{Major Milestones for FY94-98}

Implementation of some of the upgrading requirements of SCDHEC's regulations which apply to DWPF. 


\section{Atmospheric Protection}

Air Emissions

\section{Program Coordinator}

Ron Reeves

\section{Program Description}

Provide regulatory guidance and oversight for all aspects of the CAA which are applicable to DWPF.

Major Milestones Accomplished in FY92

Completed a comprehensive air emissions inventory which identified and characterized over 1000 total points.

Major Milestones for FY93

Obtain SCDHEC air permits for $\mathrm{H} 2 / \mathrm{NH} 3$ modifications and the Late Wash Facility.

Major Milestones for FY94-98

- Modify DWPF radioactive sampling devices to comply with 40 CFR Part 60 , Appendix, Method 1.

- Provide benzene abatement necessary to comply with the 1990 CAA Amendments.

- Phase out usage of CFCs in AVC and cooling systems. 


\section{Waste Management \& Disposal}

\section{Z-Area Solid Industrial Waste Disposal}

\section{Program Coordinator}

Ron Reeves

\section{Program Description}

Dispose of the Saltstone Waste generated by the Z-Area Wastewater Treatment Facility.

Major Milestones Accomplished in FY92

Developed mechanism by which groundwater monitoring reports are submitted to SCDHEC in accordance to permit \#IWP 217.

\section{Major Milestones for FY93}

Obtain modification to permit IWP 217 to include changes incorporated during second generation vault design.

\section{Major Milestones for FY94-98}

Provide technical/regulatory support for a phased expansion of the Z-Area Industrial Waste Disposal Facility. 


\section{Waste Management \& Disposal}

RCRA and Waste Management

\section{Program Coordinator}

Tim Hagstrom

\section{Program Description}

Provide guidance and permitting assistance where required to insure compliance with and RCRA hazardous waste regulations as they apply to DWPF operations. This includes Hazardous waste permitting and Organic Waste Storage Tank permit compliance.

Major Milestones Accomplished in FY92

- Modified Organic Waste Storage Tank Part B application

- Modified site RCRA Part Q (Interim Status) application to include the Failed Equipment Storage Vaults.

- Maintained compliance with all hazardous waste staging and satellite areas.

- Produced Quarterly Hazardous Waste Reports and Hazardous Waste Minimization Reports.

- Minimized hazardous waste streams

- Provided emergency response assistance for several hazardous waste off-normal events.

\section{Major Milestones for FY93}

- Obtain RCRA Part A permit for the Failed Equipment Storage Vaults

- Minimize hazardous waste streams by reducing volume and/or toxicity

- Provide environmental oversight for startup of the Interim Waste Storage Facility

\section{Major Milestones for FY94-98}

Tie-in the Organic Waste Storage Tank to the CIF. 


\title{
Environmental Implementation Plan
}

\author{
Program Coordinator
}

Clarke A. Stantord

\section{Program Description}

The Environmental Implementation Plan (EIP) program is intended to communicate the current and future (5-year) environmental plans and initiatives from each organization and division that are designed to protect the environment and meet or exceed compliance with changingenvironmental requirements and laws.

Organizational Responsibility

Environment Protection Department coordinates the publishing of the Environmental Implementation Plan. DWPF and other site organizations review the site programs and provide their current and future (5-year) environmental plans and initiatives

\section{Major Milestones Accomplished in FY92}

- Assisted and interacted with EIP committee in development of current plan's format and procedure details.

- Assisted in preparing committee's status presentations to CEC.

- Obtained area approval and concurrence for implementing EIP.

\section{Major Milestones for FY93}

- Provide detail input for EIP summary report in 1 Q93.

- Support committee's objectives in future EIP updates during the calendar year.

\section{Major Milestones for FY94-98}

Continue providing details for all future EIP report updates that apply and relate to DWPF. 


\title{
Waste Management and Environmental Restoration Division Environmental Summary
}

\author{
Department
}

Environmental Restoration Department (ER)

\author{
Mission
}

To clean up inactive waste sites and decommission surplus facilities to ensure that the environment and the health and safety of people are protected.

\section{Vision}

To exceed the needs and expectations of our customers and become the standard of excellence for environmental restoration through the application of experience and leading technology by highly qualified and motivated professionals.

\section{Environmental Challenges \& Issues from Projected Mission \& Changes during Next Five Years}

- Establishing a balance between remediation efforts required and funding projected to be available.

- Achieving true integration of RCR $₫$ and CERCLA requirements.

- Meeting cleanup goals with existing technology. There is a need for technology development to address the spectrum of waste sites to be remediated.

\section{Lead Environmental Coordinators}

Beth Wheat and Mary Flora 


\section{Chemical Management, Pollution Prevention, and Other Compliance Programs}

National Environmental Policy Act (NEPA)

Program Coordinator

Beth Wheat

Program Description

ER is reponsible for maintainingg compliance with applicable regulations such as the Safe Drinking Water Act, TSCA and NEPA.

Major Milestones Accomplished in FY92

- Designation of a Department NEPA Coordinator to ensure ER compliance with NEPA.

- Supported development of a Supplement to the Groundwater Protection EIS to incorporate ER inactive waste units.

Major Milestones for FY93

Continue to support development of a Supplement to the Groundwater Protection EIS to incorporate ER inactive waste units 


\title{
Natural Resource Protection, Land Use \& Wildlife
}

Land Use

\author{
Program Coordinator \\ Mary Flora \\ Major Milestones Accomplished in FY92 \\ Participation on Land Use Planning Steering and Technical Committees
}

Major Milestones for FY93

Continued participation on Land Use Planning Steering and Technical Committees 


\section{Groundwater Protection}

Groundwater Protection

Program Coordinator

Mary Flora

\section{Program Description}

ER maintains a vast network of groundwater monitoring wells to assess impacts of inactive waste units on the groundwater.

\section{Major Milestones Accomplished in FY92}

- Negotiated with SCDHEC for sample minimization of groundwater monitoring wells to provide a program savings of $\$ 300,000$.

- Installation of additional groundwater monitoring wells at various waste units.

- Began use of cone penetrometer technology to enhance well placement and as a screening tool for determining extent of contamination.

Major Milestones for FY93

- Purchase new drilling rig for use in regulated areas.

- Completion of aquifer pumping tests to support the F and $H$ Areas Seepage Basins Groundwater Remediation Facilities.

Major Milestones for FY94-98

- Begin groundwater remediation at the $F$ and $H$ Seepage Basins

- Begin groundwater remediation at the Mixed Waste Management Facility. 


\section{Waste Management \& Disposal}

Waste Management

Program Coordinator

John Bradley

\section{Program Description}

ER is a generator of waste, primarily from investigating and closing inactive waste sites. ER practices waste minimization techniques according to the Waste Minimization Plan.

\section{Major Milestones Accomplished in FY92}

- Issued Environmental Restoration Waste Minimization Plan

- Development of Interim Investigation Derived Waste Management Plan

- Implement SRS investigation derived waste (IDW) management strategy

- Formation of Waste Coordination Task Team

\section{Major Milestones for FY93}

- Designate Waste Coordinator

- Negotiate with EPA and SCDHEC a regulatorily acceptable IDW Management Plan 


\section{Environmental Restoration}

\section{Environmental Restoration}

Program Coordinator

Jim Pope

\section{Program Description}

ER's mission is to clean up inactive waste sites and decommission surplus facilities to ensure that the environment and the health and safety of people are protected. ER is the custodian of the SRS RCRA/CERCLA waste units, and is responsible for the investigation, assessment and closure of the units.

Organizational Responsibility

ER is responsible for remediating inactive waste sites across the SRS.

Major Milestones Accomplished in FY92

- Closure of the Met Lab Basin according to a SCDHEC approved RCRA closure plan.

- Installation and startup of A-1 air stripper to remediate groundwater near SRTC.

- Treatment of almost 300 million gallons of contaminated groundwater in the $\mathbf{A} / \mathbf{M}$ Areas.

- Submittal of 12 RFIRI Workplans to the EPA and SCDHEC.

Major Milestones for FY93

- Closure of H \& P Acid/Caustic Basins

- Investigation of 5 RCRA/CERCLA waste units

- Continue groundwater remediation at AMM Areas

- Submit to SCDHEC Closure Plans for Sanitary Landfill and Low-Level Radioactive Waste Disposal Facility

- Submit to SCDHEC RCRA Post-Closure Care Part B Permit Applications for the Sanitary Landfill and the Mixed Waste Management Iacility. 


\section{Major Milestones for FY94-98}

- Closure of SRL and New TNX Seepage Basins and F \& K Acid/Caustic Basins

- Complete investigation and assessment activities at planned RFI/RI waste units.

- Begin closure of Sanitary Landfill and Low-Level Radioactive Waste Disposal Facility

- Begin groundwater remediation at the $\mathrm{F}$ and $\mathrm{H}$ Areas Seepage Basins. 

Division Environmental Summary

\author{
Department
}

Waste Management Regulatory Compliance (WM)

Mission

To provide regulatory support to operating facilities in Solid and Liquid Waste Management

\title{
Lead Environmental Coordinator
}

C. B. Stevens 


\title{
Chemical Management, Pollution Prevention, and other Compliance Programs
}

Emergency Planning and Community Right-to-Know Act (EPCRA)

\author{
Program Coordinator
}

K. N. Uzochuckwu

Program Description

Coordinate WM SARA III reporting. Participate onsite SARA III subcommittee.

Major Milestones Accomplished in FY93

- Submitted SARA III Usage Report

- Submit SARA III Toxic Chemical Release Report

Major Milestones for FY94-FY98

- Submit SARA III Usage Report

- Submit SARA III Toxic Chemical Release Report 


\section{Chemical Management, Pollution Prevention, and other Compliance Programs}

\section{National Environmental Policy Act (NEPA)}

\section{Program Coordinator}

Michael J. Hagenbarth

\section{Program Description}

The National Environmental Policy Act (NEPA) Compliance Program requires that all proposed activities to be conducted/located outside of a previously developed area have an Environmental Evaluation Checklist prepared and approved before the activity may begin.

\section{Major Milestones Accomplished in FY92}

On May 26, 1992, 10 CFR Part 1021 (57 FR 15122, "National Environmental Policy Act Implementing Procedures and Guidelines Revacation: Final Rule and Notice") was implemented. This final rule put DOE compliance with NEPA and related environmental impact assessment factors on a mandatory regulatory basis. At SRS and within WM, the result of this emphasis is a significant increase in the amount and quality of NEPA documentation, analysis, commitment tracking and mitigation evaluation.

\section{Major Milestones for FY93}

During 1993 SRS and WM will be issuing procedures to bring operations into compliance with 10CFR Part 1021. These procedures will include the creation of the new Department NEPA Coordinator position to oversee all NEPA compliance activities within each department. 


\section{Natural Resource Protection, Surface Water \& Wetlands}

NPDES: Clean Water Act

\section{Program Coordinator}

K. N. Uzochukwu

Program Description

Coordinate WM NPDES Program. Coordinate Waste Management (WM) preparation and follow-up for the 3560 SCDHEC audit. Provide technical support for the negotiation of the new NPDES permit. Participate on the Site Toxic Control Strategy Tram.

\section{Major Milestones for FY93}

- Support 3560 audit. Coordinate toxicity testing of WM outfalls.

- Coordinate routine sample analysis.

- Sunport wastewater permit modification efforts.

- Receive General Permit for stormwater.

- Implement the general permit Stormwater Pollution Prevention Plan.

Major Milestones for FY94-98

- Support NPDES permit negotiations.

- Support projects to eliminate toxicity at WM outfalls.

- Support 3560 audits.

- Support WM permit modifications. 


\section{Groundwater Protection}

Groundwater Protection

Program Coordinator

Beth DeWitt

\section{Program Description}

Verify all groundwater monitoring complies with facilities permits. Provide support for establishing sampling schedules for each well.

Major Milestones Accomplished in FY92

Began assessing the current groundwater program and recommendations for improvement.

Major Milestones for FY93

- Establish a program to ensure groundwater compliance.

- Establish a program to ensure adequate sampling schedules for each well.

Major Milestones for FY94-98

Continue to improve groundwater monitoring within Waste Management facilities. 


\title{
Atmospheric Protection
}

\author{
Air Emissions
}

\section{Program Coordinator}

David A. Broaden

\section{Program Description}

Provide technical support and coordination to Waste Management (WM) to ensure compliance with the Clean Air Act (CAA), SARA Title III, and SCDHEC Air Pollution Control Regulations and Standards.

\section{Major Milestones Accomplished in FY92}

- Provided technical sunport to WM for annual SCDHEC air emissions compliance inspections.

- Provided technical support to WM in the development of corrective action responses to deficiencies noted in the DOE-SR F/H Area WM Facilities Radiological Air Emissions Monitoring Environmental Appraisal Report.

- Provided technical support to WM in the development of corrective action responses to deficiencies noted in the EPA-IV SRS NESHAP's Inspection Report.

- Provided technical support to WM in the coordination of the Air Emissions Inventory (AEI) effort.

- Provided technical support to WM for SARA Title III reporting.

- Provided technical support to WM for annual NESPAP's reporting.

\section{Major Milestones for FY93}

- Provide technical support for DOE-SR/ECD Comprehensive Compliance Assurance Reviews (CCARS).

- Provide technical support for annual SCDHEC air emissions compliance inspection.

- Provide technical support for EPA-IV SRS NESHAP's inspection.

- Coordinate WM AEI effort.

- Provide technical support for SARA Title II reporting.

- Provide technical support for CAA and SCDHEC Bureau of Air Quality Control (BAQC) air permitting activities.

- Provide technical support for annual NESHAP's reporting. 


\section{Major Milestones for FY94-FY98}

- Provide technical support for DOE-SR/ECD Comprehensive Compliance Assurance Reviews (CCARS).

- Provide technical support for annual SCDHEC air emissions compliance inspection.

- Provide technical support for EPA-IV SRS NESHAP's inspection.

- Coordinate WM AEI effort.

- Provide technical support for SARA Tille II reporting.

- Provide technical support for CAA and SCDHEC Bureau of Air Quality Control (BAQC) air permitting activities.

- Provide technical support for annual NESHAP's reporting. 


\title{
Waste Management \& Disposal
}

Waste Management

\author{
Program Coordinator
}

Marcia Birk

\section{Program Description}

Provide technical assistance to WM facilities in proper classification and management of RCRA hazardous wastes. Provide assistance with preparation and follow-up of annual CME audit. Support WM facilities in daily compliance issues and activities.

\section{Major Milestones Accomplished in FY92}

- Assisted in revising RCRA training program for WM.

- Developed and coordinated implementation of RCRA records program in WM.

- Supported in preparation and follow-up with CME audit.

- Submitted Closure Plan to SCDHEC for solvent tanks S23-S30.

- Submitted renewal to RCRA Part B permit for HWSF.

- Submitted renewal to RCRA Pari B permit for MWSB.

\section{Major Milestones for FY93}

- Support project S.4790 to obtain new solvent tanks for RCRA waste.

- Support annual CME audit.

- Support sitewide program for chemical procurement and use.

- Complete draft RCRA Part B permit for TRU Waste Pads 6-17.

\section{Major Milestones for FY94-98}

- Support project S-4790 to obtain new solvent tanks for RCRA waste.

- Support annual CME audits.

- Support consolidated incineration facility project. 


\title{
Appendix 1
}

\section{Environmental Resources}

\author{
Central Environmental Committee (CEC)
}

The CEC provides Westinghouse Savannah River Company (WSRC) divisions and departments and other Savannah River Site (SRS) organizations an open forum to present and discuss environmental-compliance issues, questions, and concerns. The CEC provides the sharing of ideas, techniques, and plans to disseminate vital information and resolve selected issues and concerns. Additional information on the CEC is found in WSRC Environmental Procedure Manual $3 Q$, Procedure 19.1. The information contact is J. R. Brookshire.

\section{Central Environmental Committee Executive Committee (CECEC)}

The CECEC facilitates the flow of information to and from the CEC, by directing the CEC's efforts in evaluating vital issues, and by presenting the CEC's recommendations. CECEC sponsors various subcommittees to improve continually environmental programs. Additional information on the CECEC is found in WSRC Environmental Procedure Manual 3Q, Procedure 19.1. The information contact is J. R. Brookshire.

\section{Natural Resources Coordinating Committee (NRCC)}

The NRCC was established in 1991 to enhance communication and understanding among SRS organizations concerning natural-resources management. NRCC provides a forum to discuss onsite natural-resources issues and provides technical advice to the Department of Energy (DOE) and all Site users to manage effectively SRS's natural resources. NRCC members are intrasite representatives from different Site organizations with the DOE-SR member as the chairperson. The information contact is P. R. Jackson.

The following are some of the NRCC task groups:

- Aquatics Issues Task Group (AITG)

- Biodiversity Task Group

- Environmental \& Technical Research/Monitoring Task Group

- Geographic Information System (GIS) Task Group 
- Geoscience Task Group

- Pesticide Use Task Group (PUTG)

- Set-Aside Task Group

- Upper Three Runs Creek Task Group

- Wetlands Task Group

\section{Westinghouse Environmental Management Team (WEMT)}

The WEMT provides improved communication, integration, strategic planning, and management of the WSRC environmental programs.

Team members include ESH\&QA-EPD, SRTC-WM\&ET, WM\&ER-ER, E\&PD, GCO, and the CECEC. The team's mission is to ensure consistency in integrating and communicating SRS environmental programs. The information contact is J. R. Brookshire.

\section{Westinghouse Environmental Advisory Committee (EAC)}

The EAC provides independent strategic and programmatic guidance to WSRC management on intermediate and long-range environmental issues affecting SRS. The EAC has about seven members who are not WSRC employees. The committee inembers have a broad range of expertise related to environmental matters. The EAC reports to and advises the president of WSRC. The information contact is T. V. Crawford.

\section{Westinghouse Environmental Affairs Organization}

Westinghouse's Environmental Affairs Organization monitors changes in environmental laws and regulatory requirements, oversees Westinghouse facilities to ensure that they comply by developing corporate policies and procedures, and establishes programs to assist locations in environmental management. The information contact is S. Green.

\section{Waste Certification and Minimization (WCAM)}

The WCAM group coordinates the development, promotion, implementation, and reporting of sitewide waste-reduction activities. The information contact is C. P. Thompson.

Waste Action Team (WAT)

WAT has representatives from the major operations, services, and staff groups and was established to identify issues and develop strategies for implementing waste-minimization program activities. The information contact is E. F. Kay. 


\title{
Appendix 2
}

\section{Environmental Plans}

\author{
Best Management Practices Plan (BMP)
}

The BMP plan identifies SRS's actions and procedures to prevent or minimize potential releases of toxic or hazardous pollutants in significant anounts into surface waters. Sources identified in the plan include, but are not limited to, material storage areas, in-plant transfers, process and materials handling areas, loading and unloading operations, plant site runoff, and sludge and waste-disposal areas. The BMP plan is an integral part of SRS's National Pollutant Discharge Elimination System (NPDES) permit (WSRC-IM-90-49).

\section{DOE Environmental Restoration and Waste Management Five-Year Plan (FYP)}

The scope of this plan is to encompass three specific areas needed at all Department of Energy (DOE) operating facilities to bring air, water, and solid-waste discharges in compliance with state and federal regulations. These areas are Waste Management operations, inactive waste site cleanup, and corrective actions. The FYP describes the Environmental Restoration and Waste Management (ER/WM) planning process, communicates ER/WM's philosophy and overall strategy for achieving compliance and cleanup goals, summarizes multi-year program plans, and assesses progress made during the previous year. The FYP goal is to ensure that human health, safety, and environmental risks posed by the department's past, present, and future operations either are eliminated or reduced to safer levels by the year 2019 .

\section{Environmental Implementation Plan (EIP), WSRC-IM-93-17}

Chapter III of DOE Order 5400.1 requires that each field organization develop a long-range environmental-protection plan that defines specific environmental objectives and develops the means and schedules to attain objectives and complete programs and projects at each facility or group of facilities. The EIP is a long-range environmental-protection plan which describes the strategy for environmental compliance and excellence, site environmental-protection programs, management and support programs, environmental responsibilities, and environmental programs and plans submitted from SRS organizations. The person responsible for preparing the EIP in WSRC is the EPD's manager. 
EIP Action Plan

This action plan was developed by the EIP subcommittee. It recommended implementing three initiatives ( reflections, sectional revision, integrated planning ) in order for the EIP to become a continuous planning and improvement process that incorporates total quality and is integrated with other environmental and budgetary plans

\section{SRS Environmental Data Management Plan}

WSRC-RP-91-179 describes the EDM matrix organization.

\section{Environmental Monitoring Plan (EMP)}

The EMP is published by EMS and provides a comprehensive look at environmental-monitoring rationale and technical basis. Updated annuali $j$ and revised every three years, the EMP is the mechanism that communicates to DOE and the public the changes, additions, and enhancements in environmental monitoring.

\section{Natural Resources Management Plan}

This plan was developed by the U.S. Forest Service (USFS) for DOE-SR. The plan addresses complying with all federal and state environmental laws, implementing SRS's Fish and Wildlife Management Policy, protectiing the National Environmental Research Park setasides, and continuing forestry programs including reforestation, timber sales, and maintenance of forest soil stability.

\section{Pollution Abatement Plan}

This plan is submitted according to OMB Circular A-106 and is a listing of all projects needed to bring an agency's facilities into compliance with environmental laws and regulatory requirements. The repuit is a complete five-year plan and includes all projects expected to be placed into the pollution-abatement program during that perind. The person responsible for preparing the plan in WSRC is EPD's manager.

\section{Pollution Prevention Plan (PPP)}

SRS will develop a PPP by April 1, 1993, and implement it by October 1, 1993. The PPP is intended to facilitate a process for the Site to evaluates potential pollution sources and select and implement measures to prevent or control the discharge of pollutants in storm water runoff. The plan must include the following: designating or identifying of a pollution prevention team, identifying potential pollution sources, identifying pollution-prevention measures and controls, and creating a comprehensive Site compliance evaluation. 


\section{SRS Environmental Report}

This report provides the public and regulatory agencies an annual review of site monitoring results and compliance issues. The report includes the estimated offsite dose from SRS operations, discussions of environmental restoration and remediation, as well as other issues of community concern relating to conditions onsite (WSRC-TR-92-186).

\section{SRS Environmental Training Plan}

WSRC-RP-92-282, issued February 1992, is a documented framework for implementing and managing an integrated environmental-training system.

\section{Savannah River Site Development Plan (SDP)}

The SDP process identifies and defines current and future site missions, evaluates existing site conditions and regional influences, determines and quantifies facility requirements to accomplish site missions, formulates alternatives to satisfy facility requirements, evaluates and ranks the alternatives, and develops a plan to implement the preferred solution.

\section{Savannah River Site Strategic Plan}

A WSRC senior management team developed the strategic plan to provide a vision and a guide for the Site's future development. The strategic plan identifies management objectives and strategies to achieve this vision.

\section{Savannah River Site Waste-Minimization Plan}

The plan describes the Site's waste-minimization program and includes employee training, awareness, incentives and awards, as required by the Pollution-Prevention Awareness Program in DOE Order 5400.1, WER-SWM-92-0141 Revision 5 (11/92).

\section{Site Development and Facility Utilization Plan (SD\&FUP)}

This plan was derived from DOE Order 4300.1B. The SD\&FUP, which provides extensive information on natura' resources and the land-use approval process, primarily is concerned with facility planning.

\section{Site Specific Plan (SSP)}

SSP, (WSRC-RP-91-596), is produced annually to define sitewide Environmental Restoration and Waste Management activities identified by DOE's Environmental Restoration and Waste Management Five-Year Plan (FYP). 


\section{Spill Prevention Control and Countermeasures Plan (SPCC)}

The SPCC identifies SRS's procedures, methods, equipment, and other requirements to prevent the discharge of petroleum products from site facilities into or upon navigable waters of the United States (WSRC-IM-90-48).

Strategic Environmental Plan

The Strategic Environmental Plan, DPW-86-102, describes the philosophy, policy, and overall program direction of environmental programs for SRS operation and provides the basis for jeveloping the Environmental Implementation Plan (EIP).

\section{Strategic Plan for Environmental Compliance at the Savannah River Site (SRS)}

WSRC-IM-91-66 discusses implementing of programs and strategy to minimize the impact of new or changing environmental requirements and to ensure timely compliance with DOE orders and requirements.

\section{WSRC Airborne Release Prevention and Control Plan (ARP\&CP)}

ARP\&CP will document the characterization of SRS emissions, release potential, and control.

\section{WSRC Environmental Release Prevention and Control Plan (ERP\&CP)}

ERP\&CP documents options and alternatives for minimizing liquid releases and contains the characterization of SRS effluents, effluent release potential, and control.

\section{SRS Waste Management Program Plan}

The plan is an annual report on how Waste Management operations are conducted, which facilities are used to manage wastes, what forces change current Waste Management systems, and what the plans are for the next fiscal year. 


\section{Appendix 3}

\section{Environmental Documents and Procedures}

\section{Documents}

Environmental Bases of the Savannah River Site 1990

This document lists environmental-reference information (documents, files, papers, letters, etc.) available onsite.

\section{SRS Environmental Permitting "HOW" Manual}

WSRC-IM-91-69, the "HOW" manual originally was developed in May 1986 to provide guidance on the permitting process for obtaining environmental permits from regulatory agencies. The manual includes information on flow-sheets, time lines, specifications, and requirements for preparing permit applications. The manual has been used extensively by operating and designing organizations to minimize delays in obtaining permits and to prevent potential NOVs and noncompliances. The manual is being updated continually to ensure compliance with the permitting process.

\section{SRS Site Environmental Coordinators Protection Handbook}

WSRC-IM-92-21 is an information and guidance manual for environmental professionals involved with the SIRIM process and procedures.

\section{Guidelines for WSRC and DOE-SR Interaction with Environmental Regulatory Agencies}

This document's purpose is to guide and establish basic ground rules for devcloping a working understanding and partnership between WSRC and DOE-SR when interacting with environmental agencies (WSRC-RP-93-195). This document represents an update to the Implementation Plan for Establishing WSRC Lead with Environmental Regulatory Agencies.

Westinghouse Savannah River Company Quality Assurance Manual WSRC 1Q (U)

This manual provides the Site-level program requirements for quality assurance. This manual is implemented at the division level by applicable division-level procedures. 


\section{SRS Management Requirements and Procedures Manual $1 B$}

MRP 4.07 - 4.09, WSRC Management Requirements and Procedures, "Events, Conditions, and Concerns Determinations", is a level-one procedure that establishes a consistent reporting process sitewide for reportability determination for events, conditions, and concerns that may have safety, health, quality-assurance, security, operational, or environmental implications.

WSRC SRS Emergency Plan, Procedure Manual $6 Q$

\section{WSRC Management Policies, WSRC-1-01}

Management Policy 4.1 describes the policy and Site responsibilities for environmental assurance.

Savannah River Site Plan for Implementation of NEPA Procedures 10 CFR Part 1021

This plan provides a detailed strategy and process for implementing 10 CFR Part 1021 to fully comply with NEPA. This plan also defines DOE-SR and WSRC roles, responsibilities, and working arrangements to implement the NEPA process onsite (WSRC-RP-92-770).

\section{WSRC Department NEPA Coordinator Handbook}

This handbook/manual contains the materials and information used to train and qualify the designated Site department NEPA coordinators to enable them to function according to WSRC-RP-92-770.

\section{DOE Procedures Guide for NEPA Documentation for Savannah River Site}

This document encompasses general guidelines for implementing the DOE-SR NEPA process, including summaries of NEPA laws and DOE orders, descriptions of various lypes of NEPA documentation, EIS preparation activities and procedures, and checklists for each NEPA activity related to an EIS.

DOE Guide for NEPA Coordinators at Savannah River Sitc

This guide was prepared for the DOE NEPA coordinators as a tool to implement NEPA requirements at SRS. The guide provides an overview of NEPA and explains how DOE has integrated the NEPA process into its program. 
Polychlorinated Biphenyl (PCB) Management Manual for Savannah River Site (Draft)

This manual will be available in 1993.

\section{Radioactive Releases at the Savannah River Site}

All effluent data collected since Site startup is contained in this document. Releases are listed by radionuclide and by year.

\section{RFI/RI Program Plan}

This plan provides the framework for Site-specific investigations of RFI sites at SRS using a sitewide-consistent approach based on compliance with policies and procedures specific to the RFI program.

Specifications and Management Applications for Regulated Tank Systems, SRS "SMARTS" Program

WSRC-IM-90-90, the Specifications and Management Applications for Regulated Tank System (SMARTS) manual was developed originally as DPSP-85-1126 to assist in managing underground storage tanks (UST) at SRS. As EPA and SCDHEC changed UST regulations, SMARTS was updated. The manual was rewritten in 1991 and 1992 to include hazardous-waste management tank regulations, as well as UST regulations.

\section{SRS Waste Acceptance Criteria Manual}

WSRC-1S manual provides documentation of requirements applicable to transferring and receiving wastes for interim waste management, and solid and hazardous-waste operations.

\section{Waste Disposal Manual}

WSRC Waste Disposal Manual (WSRC-IM-90-138) guides SRS environmental personnel or waste generators in how to characterize, manage, store, treat, or dispose of waste according to all regulatory requirements, WSRC policies, and DOE orders. It also provides a summary of EPA and SCDHEC regulations applicable to determining hazardous waste, selecting compatible containers, managing the containerized waste in accumulation areas and storage facilities, and preparing for shipment to onsite storage facilities or offsite TSDFs. 


\section{Procedures}

Environmental Protection Department Manual Q-1-1-1

This manual defines EPD policies, practices, and procedures.

\section{Environmental Compliance Manual $3 Q$}

$E C M 3 Q^{\prime} s$ purpose is to provide guidance and detailed information concerning proper procedures and activities, as prescribed by federal, state, local laws and regulations, DOE orders, and WSRC policies.

WSRC-3Q1-1, Environmental Monitoring Section Administrative

WSRC-3Q1-2, Volume I, Environmental Monitoring Plan

The EMP is published by EMS and provides a comprehensive look at environmental-monitoring rationale and technical basis. Updated annually and revised every three years, the EMP is the mechanism that communicates to DOE and the public the changes, additions, and enhancements in environmental monitoring.

WSRC-3Q1-2, Volume III, Quality Assurance Procedures

This document contains procedures describing the EMS Quality Assurance Plan.

WSRC-3Q1-3. Environmental Sampling Procedures

This document contains procedures describing the EMS sampling programs.

WSRC-3Q1-4, Environmental Radiochemistry Procedures

WSRC-3Q1-5, Environmental Chemistry Water Quality Procedures

WSRC-3Q1-6, Environmental Counting Room Prccedures

This documents contain procedures describing the EMS laboratory programs. 
WSRC-3Q1-7, Environmental Data and Reporting Procedures

This document contains procedures describing the EMS monitoring reports.

Hydrogeological Data Collection Methods, Procedures, and Specifications

Procedure Manual 3Q5 gives the policies, processes, and procedures necessiary 10 collect environmental information related to subsurface sampling to comply with federal and state regulations and DOE orders. 


\section{Appendix 4}

\section{EIP Action Plan}

\section{Partnership In Environmental Excellence}

Submitted by the EIP subcommittee members

J. R. Brookshire, EPD

Steve Etheridge, EPD

Mark Kidd, Analytical Lahs

Ken Lane, EPD-QA LIA

Steve Mertz, WM

Sara Mundy, ROA

Greg Peterson, EPD

Barbara Sly, SEP

JoAnne Steingard, RMET

Beth Wheat, ER

Kathy Wolf, DWPF

Special support provided to the team: J. F. Jackson, GCO; C. P. Thompson, CECEC; T. V. Crawtord, SRTC; D. P. Ryan, DOE-SR

Spectal thanks to the CEC Executive Committee and EPD personnel for their support and participation. 


\section{Introduction}

During the last 10 months, the EIP subcommittee has met to identify customer expectations and expected benefits which are to be incorporated in the EIP's next revision. EIP customer expectations were requested by environmental professionals from the CECEC, DOE-SR, EPD, EIP subcommittee, and other SRS organizations. A list of their expectations is in Attachment 1. Also, customer expectations from the 1990 and 1991 EPD Management Appraisals, EPD Customer Service Action Plan, and EPD Customer Communications Plan were reviewed. The EIP Aclion Plan is designed to implement the above customer expectations by modifying the EIP revision process. The proposed revision process will challenge EPD environmental professionals and site environmental condinators to revise the EIP to develop program ownership and user value, so that this Site's master environmental planning document will become a continuous planning and improvement process that incorporates total quality and is integrated with other environmental and budgetary plans.

Based upon customer expectations, the EIP subcommittee recommends that IEPD cnvironmental professionals and site environmental coordinators support and focus improvement eflorts on the following EIP revision initiatives:

- rellections

- sectional revision

- integrated planning

A more detailed description of the initiatives is located in the attachments. The following is a brief description of the proposed initiatives.

\section{Reflections}

Rellections is a planned review of an environmental program by the EPD program owner/coordinator and facility environmental coordinators to develop joint program ownership and underslanding, and facililate planning which identifies areas for continuous improvement.

When changing environmental conditions (regulatory laws, site issues) are identified, communications with and early involvement by Site organizations in developing implementation plans and procedures will optimize resources and minimize the impact onsitc organizations. Also, a planned review of environmental programs by the EPD progran owner/coordinator and facility environmental coordinalors facilitates closcd-loop communications to assess the goals and performance of existing plans. While developing joint-program ownership and understanding, the rellections process iclentifies areas for continuous improvement.

Quarterly program reviews have been proposed for each program, but after the initial reflections, the review period should be evaluated by the EPD envirommental professional and facility environmental coordinators. 
Reflections is a four-step process :

1. EPD prolessionals initiate correspondence (brief form lefler) and shatre their awarencss of the changing conditions, which may or will impact lacis envirommental programs. Also, due letler reyuests customer ideats for comlimums improvement.

2. Site environmental coordinators respond with their perspectives and ideals.

3. EPD professionals compile responses and determine if a team mecting is needed.

4. If a meeting is not needed, a summary report is issued to members. If needed, an EPD professional schedules and chairs team meetings and distributes mecting minutes to record team decisions and paths forward.

Action Llem Description

1. initiate reflections process:

provide overview to program coordinators

incorporate reflections process for prograun review deternine appropriate review frequency with customers
Date

$10 / 92$

$11 / 92$

$02 / 93$

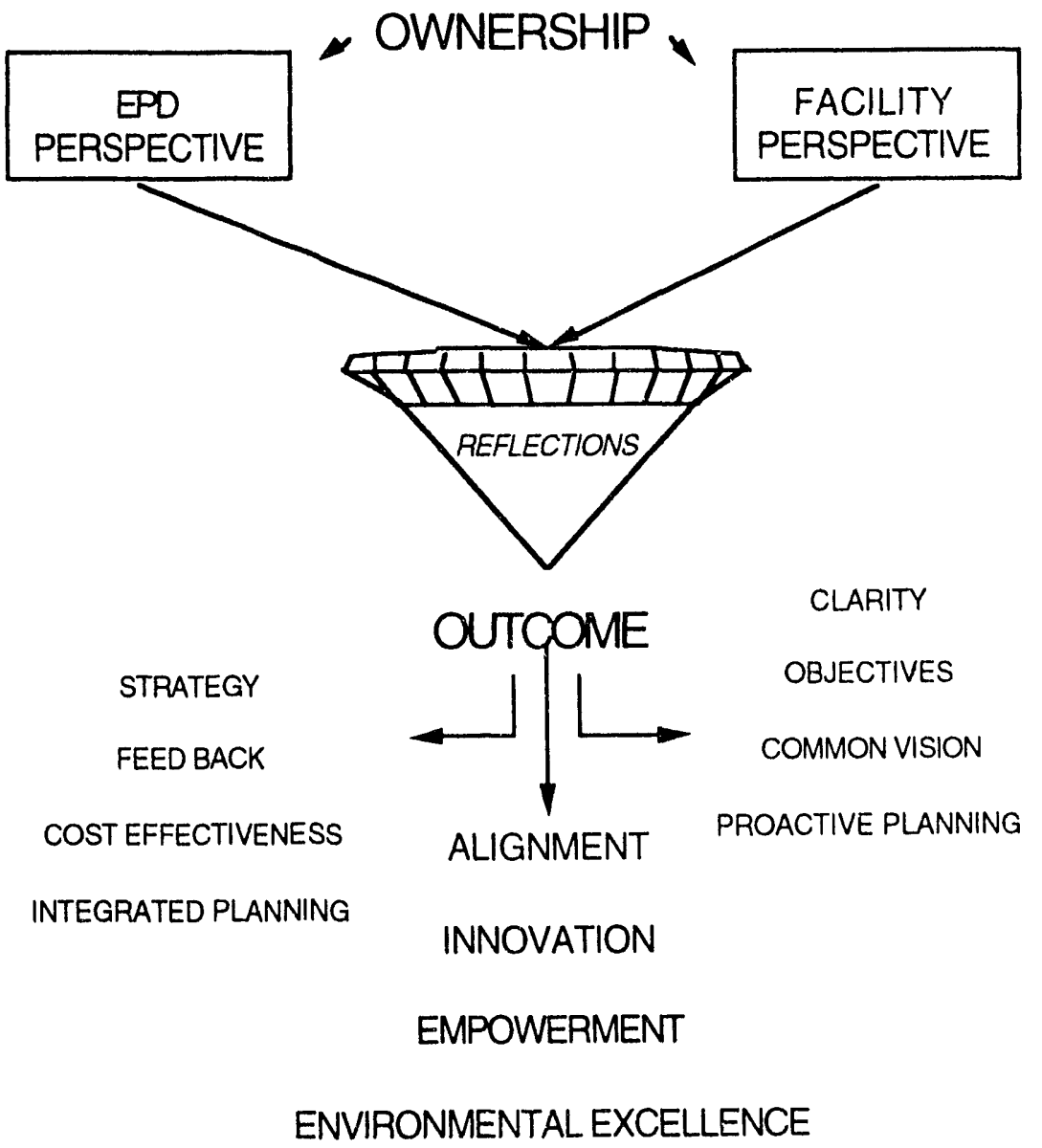




\section{Sectional Revision}

Sectional revisions will replace the annual revision of the entire EIP by updating different chapters throughout the year. Each chapter has several implementation programs that will need revision. This change is proposed to lessen the manpower impact for revisions and enable a more-concentrated and focused review of individual environmental programs by the environmental coordinators and EPD. This should encourage stakcholder participation and communication in assessing and devcloping revised goals, strategies, and objectives to meet identified environmental requirements and obligations. This also should improve the overall planning quality through increased program ownership. Note, since all environmental programs are reviewed quarterly during the reflections process, the program status is known by tean members which will reduce the overall effort required for the revision. Any changes to the site program are documented and distributed per controlled distribution. Although each chapter will have a scheduled revision month, the chapter cill he revised all allytince by the program owners

\section{Action Item Description}

2. determine schedule for revising EIP programs incorporate schedule for program revisions in EIP initiate sectional revision schedule
Dale

$11 / 92$

$12 / 92$

$04 / 93$

The revision process is initiated by the individual EIP program coordinators. Their naunes are listed in the front of each EIP program. The EIP program coordinators will review their existing prograns and make revisions as necessary. The revised text will be inclicated by sidebars to facilitate review by the envirommental coordinators. Copics of the revised programs will be distributed to the lead environmental coordinators for review and comments on or before the fifteenth of the scheduled month. Leal environmental coordinators' comments should be returned to the EIP prograun coordinator on or before the end of the scheduled month. The EIP program coordinators will resolve comments and send the final copy to the professional coordinating the EIP chapter review. Once the chapter review is completed, the chapter will be forwarded to the EIP coordinator. The EIP coordinator will have the text changes incorporated and have the chapter printed and returned to the EIP chapter reviewer. After final review is completed, the chapter will be printed and forwarded to document control for distribution. Document control will distribute revisions to the EIP on a quarterly basis.

NO'TE: Allhough each chapter has a scheduled revision month, the chapter can be revised at anytime by the program owners. 


\section{EIP Revision Flow Path}

EIP Program Coordinators $\quad$-.> Lead Environmental Coordinators $\quad$-.>

EIP Program Coordinators --> EIP Chapter Reviewer -->

EIP Coordinator --> Publications -->

EIP Cordinator --> EIP Chapter Reviewer -->

EIP Coordinator --> Publications --> Document Control -->

Quarterly Revisions to EIP

Integrated Planning

Integrated planning is a process that incorporates planning information identified in the EIP revision into other documents. Programs and projects required to meet environmental-compliance goals will need to be integrated into the financial planning documents. Information obtained from EIP environmental program selfassessments during reflections can be integrated into the annual environmental selfassessments for MRP 5.15. Existing detailed planning and guidance documents will be referenced to prevent duplication and ensure the accuracy of the information.

Action Item Description

3. propose list of documents to use EIP planning information delcrmine the type of input required and scheduled dates lor submitting information list infornation requirements and schedulc dates in EIP initiate schedule and obtain customer fecdhack after information has been shared; incorporate feedback
Date

$12 / 92$

$12 / 92$

$12 / 92$

$04 / 93$ 


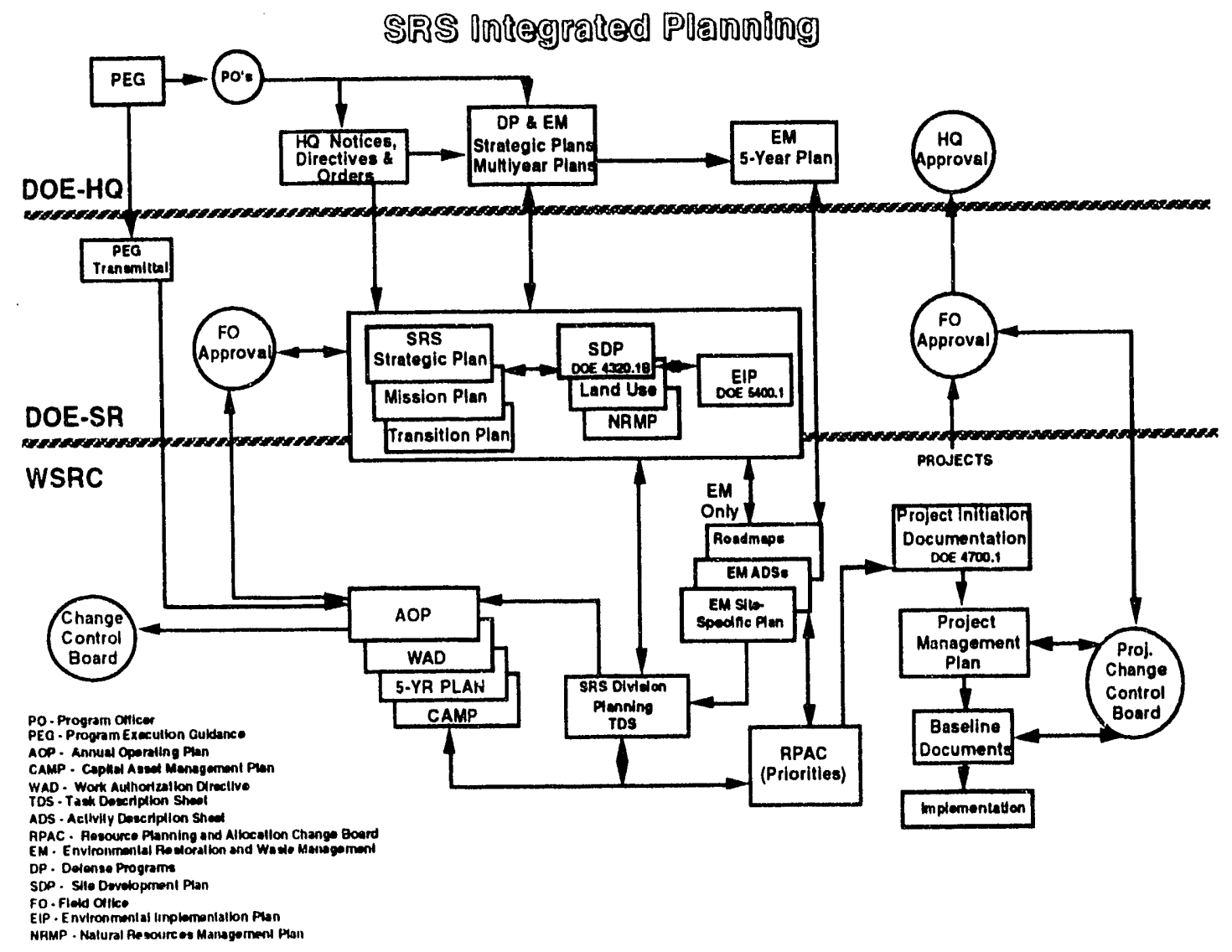

\section{Customer Expectations}

The EIP subcomınittee's proposed improvements to increase customer value to the existing EIP included customer expectations received from the CECEC, DOE-SR, EPD, and from other CEC environmental coordinations which represented various WSRC organizations and other SRS contractor organizations.

The major customer expectations are the following:

- document the process to revise the EIP, so that it is a dynamic environmental plamning process

- incsgrate EIP planning information into financial planning documents (Annual Operating Plan, Five-Year Budget Forecast) and into environmental selfassessinent plans

- include noleworthy practices and lessons learned from appraisals and surveillances, so environmental programs and compliance can be improved continuously

- incorporate the revised Table of Contents provided by CECEC and the EIP subcommitlec

- provide a summary of significant environmental information by departments/organizations

- adk! a road map 10 show fulure milestones for each program

- add an accomplishment section to the EIP to track progress/performance of milestones met during the previous year 
- reduce the volume of intormation reported by referencing existing plans, manuals, and documents (o) provide the reader a list whereto find more delailed information, i.e., (linancial information and manpower are to be removed and referenced to budget planning documents)

\section{Action Item Description Dalle}

4. incorporate customer expectations into the $1993 \mathrm{EIP} \quad 12 / 92$

5. publicize the publishing of the 1993 EIP $03 / 93$

6. initiate survey to determine if the $1993 \mathrm{EIP}$ met

customer expectations
$08 / 93$

\section{Summary}

The EIP subcommittce's mission statement, below, embodies the tean's goal for the EIP revision process:

The mission of the EIP subcommittee is to identify information that should be included in or excluded from the Environmental Implementation Plan. WSRC-IM-93-17, and to determine a systematic approach to obtain the information in a way that solicits and values the participation of CEC membership; optimizes the resource requirements for annual revisions; identifies and improves communicating of environmental requirements and obligations; publicizes environmental activities, plans, and information; forecasts environmental changes and upcoming regulatory developinents; meets or exceeds customer's expectations; and combines ideas and perspectives of CEC membership and EPD personnel, so that the EIP is the established, useful long-range operating plan for environmental activities at SRS.

The three proposed EIP revision initiatives, reflections, sectional revision, and integrated planning, will enable EPD environmental professionals and site environmental coordinators to fulfill this mission.

The EIP revision initiatives proposed are not a prescriptive, mandatory step-by-step instruction manual, but a flexible framework built on total quality initiatives that support and encourage EPD environmental professionals and site cnvironmentil coordinators 10 work in a partnership to develop joint-program ownership and understanding. It also should facilitate environmental planning to identify areas for continuous improvement. With this partnership, the EIP will become the site environmental-planning process that develops documents, communicates, and assesses implementation plans is to achieve the site environmental goal of excellence and compliance. Through this process, a road map will be developed for what, how, when, and why the site attains and maintains compliance with the numerous environmental requirements. Site efforts to incorporate the total quality elements into environmental planning and management will enable it to become more proactive in addressing environmental issues and will improve the coordination of site resources (1) respond effectively to new and revised environmental laws. Communication with Site organizations, departments, and committees is essential for making the revision process work. Through SRS efforts continually to improve environmental protection, based on the vision of "Partnership in Environmental Excellence", SRS will be the recognized Model of Environmental Excellence for the DOE Nuclear Weapons Complex. 


\section{EIP ACTION PLAN IMPLEMENTATION SCHEDULE}

September 1992

EPD

- agree with proposed EIP process (managers), identify EIP program owners

CEC

- obtain agreement with proposed EIP process (CECEC, LEAD ECs)

\section{October}

EPD

- EIP program announcement to CEC ( EIP Subcommittee)

- revicw and revise March 1992 draft EIP programs

CEC

- identify facility progran owners by Lead ECs

- EC facility program owners to identify their 1993 AOP environmental milestones, award fee items, corrective actions, noteworthy practices, and compliance deadlines

November - Reflections (all prograns)

\section{EPD \& CEC}

- EPD and facility program owners are to participate in the reflections process - - Based on the lead environmental coordinator's October list of facility contacts, EPD professionals will send the revised Site programs, along with the other reflection items to the facility contacts for review and revision.

- lacility program owners are to perform self-assessment of their prograuns

\section{December}

\section{EID \& CEC}

- deliver revised (CEC\&EPD) EIP tean prograuns w publicitions

- incorporate the revised Table of Contents into EIP 
- lead ECs to compile and approve division/department environmental summaries January 1993

- $\quad$ IIP in publications

February - Refleclions (all programs)

\section{EPI) \& CEC}

- EIP program assessments (review published programs in 1993 ElP draft FY 94 new initiatives and compliance commitments for PEG, input for 1993 annual environmental self-assessment)

- lead ECs to review and approve 1993 EIP draft

March

\section{EPD \& CEC}

- resolve comments and release 1993 EIP for controlled distribution

April 1993

\section{EPD \& CEC}

- begin EIP schedule for monthly program revicw and revision

May - Retlections (all prograns)

\section{EPD \& CEC}

- EIP schedule for monthly program review and revision (1994 additional initiatives for PEG/AOP/award fee, 1993 Program self-assessment feed for annual report)

June

\section{EIPI \& CEC}

- EIP schedule for monthly program review \& revision 
July

\section{EPD \& CEC}

- EIP schedule for monthly program review and revision

August - Reflections (all prograns)

\section{EPD \& CEC}

- EIP schedule for monthly program review and revision (1994 additional initiatives for AOP/award fee)

\section{CECEC}

- facility program owners, 1993 program self-assessments (performance) for 1994 draft EIP

- lead ECs compile and approve division/department envirommental summaries for 1994 draft EIP

- EPD management appraisal for 1993 EIP prograns

\section{September}

\section{EPD \& CEC}

- EIP process maintenance (customer revisions to EIP format, appendix information)

- lead ECs 10 review and approve the 1994 draft EIP facility section

\section{October}

\section{EPD \& CEC}

- EIP schedule for inonthly program review

\section{EPI)}

- 1994 (ball IIIP facility sections and EIP process maintenance revised sections (o) publications 
November - Rellections (all prograns)

\section{EPD \& CEC}

- EIP schedule for monthly program review and revision

- review and approve facility sections and EIP process maintenance sections in 1994 EIP draft

\section{December}

\section{EPD \& CEC}

- resolve comments and release 1994 EIP for controlled distribution

NOTE: Revised EIP programs are to be released for distribution within two months following the scheduled review and revision. 


\section{EIP Revision Schedule}

\begin{tabular}{|c|c|}
\hline Month & Chapter \\
\hline January & Waste Management and Disposal \\
\hline January & Environmental Responsibility Summary \\
\hline February & Environmental Restoration \\
\hline licbruary & Natural Resource Protection \\
\hline March & Strategic Plan for Environmental Compliance \\
\hline April & EIP Introduction \\
\hline April & Permitting \\
\hline May & Atmospheric Protection Program \\
\hline May & Site Organizations \\
\hline hunc & Environınental Compliance Tracking and Data Management \\
\hline July & Employee Education \\
\hline July & Environmental Appraisal and Surveillance Progran \\
\hline August & $\begin{array}{l}\text { Chemical Management, Pollution Prevention and Other } \\
\text { Compliance Programs }\end{array}$ \\
\hline September & Quality Assurance Prograun \\
\hline Oclober & Environmental Monitoring \\
\hline October & Appendix Information \\
\hline November & Executive Summary \\
\hline November & Groundwater Protection \\
\hline November & Division/Department Environmental Summary \\
\hline December & $\begin{array}{l}\text { Einergency Response, Environnental Oceurrence Reporting, } \\
\text { and Regulatory Notifications }\end{array}$ \\
\hline Decenber & Environmental Outreach \\
\hline
\end{tabular}



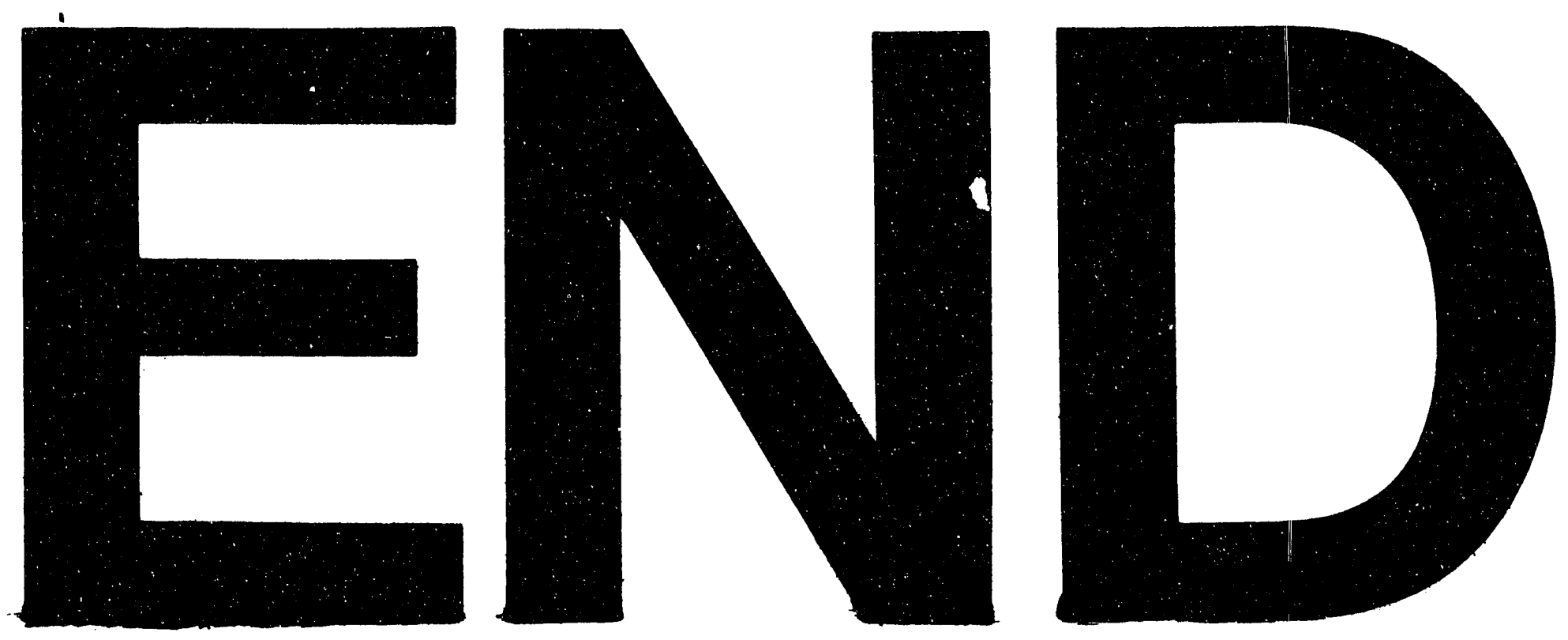

78

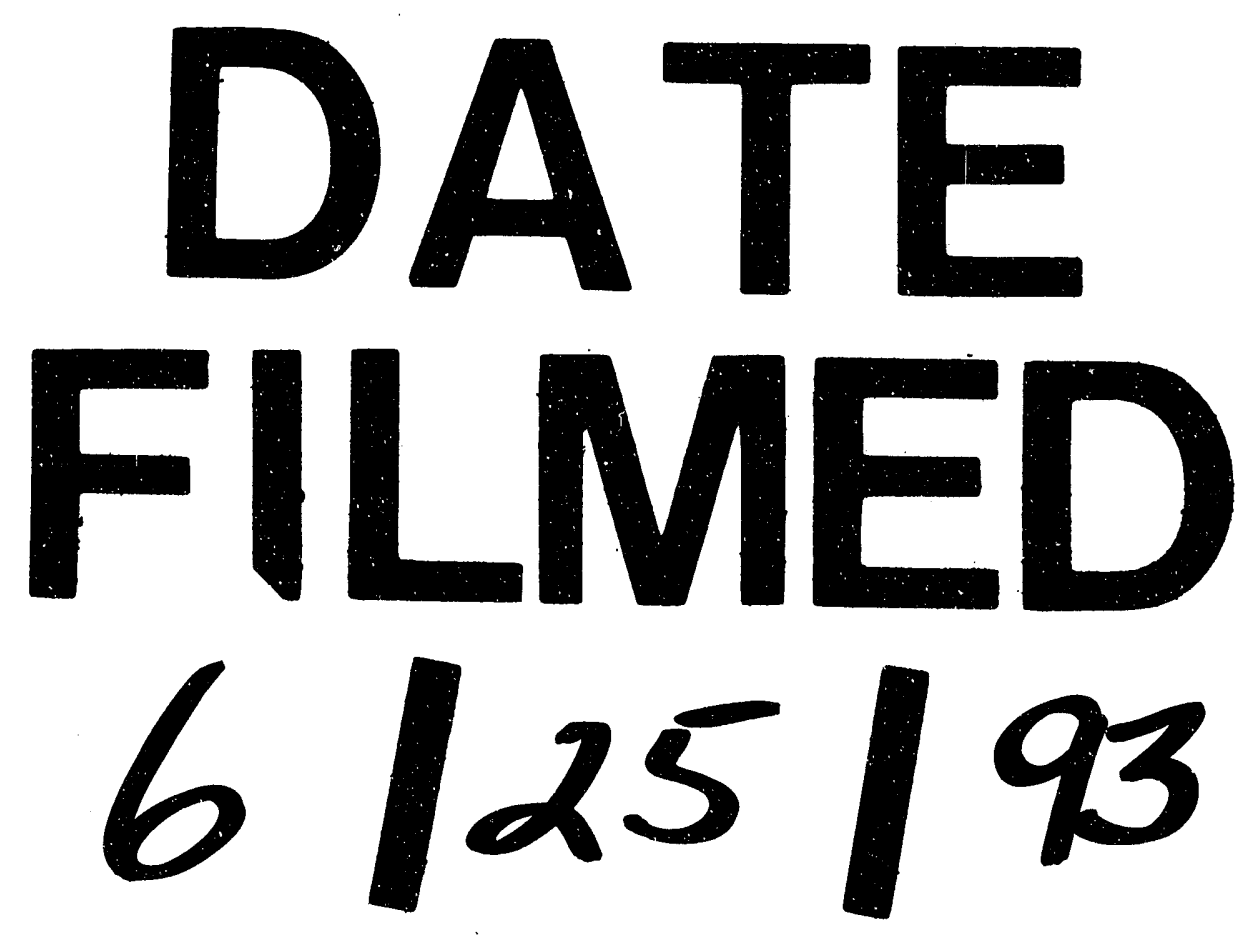


